\title{
Enhancing Vision in Nineteenth-Century Britain
}

\author{
Almond, Gemma
}

How to cite:

Almond, Gemma (2019) Enhancing Vision in Nineteenth-Century Britain. Doctoral thesis, Swansea University. http://cronfa.swan.ac.uk/Record/cronfa50630

Use policy:

This item is brought to you by Swansea University. Any person downloading material is agreeing to abide by the terms of the repository licence: copies of full text items may be used or reproduced in any format or medium, without prior permission for personal research or study, educational or non-commercial purposes only. The copyright for any work remains with the original author unless otherwise specified. The full-text must not be sold in any format or medium without the formal permission of the copyright holder. Permission for multiple reproductions should be obtained from the original author.

Authors are personally responsible for adhering to copyright and publisher restrictions when uploading content to the repository.

Please link to the metadata record in the Swansea University repository, Cronfa (link given in the citation reference above.)

http://www.swansea.ac.uk/library/researchsupport/ris-support/ 


\section{Enhancing Vision in Nineteenth-Century Britain}

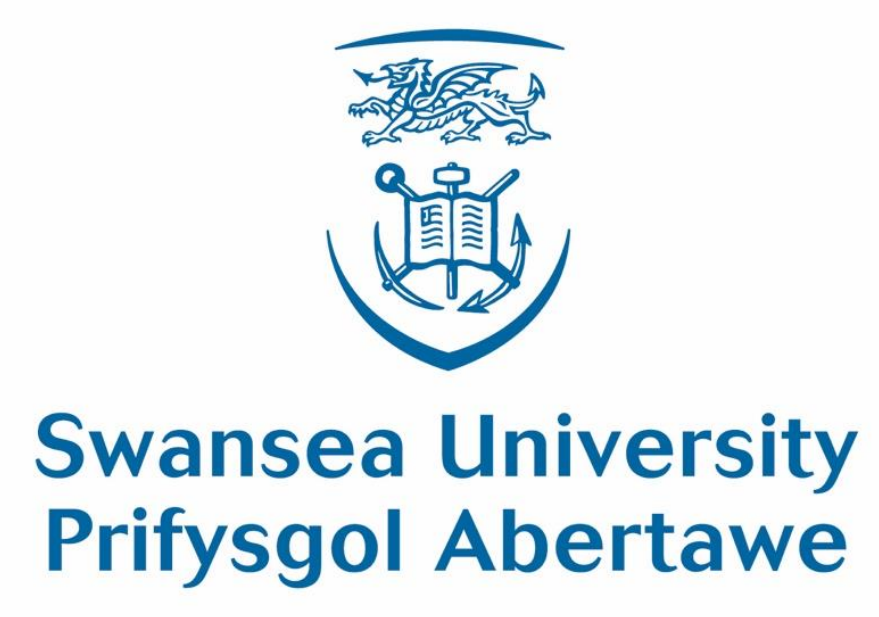

Gemma Almond

Submitted to Swansea University in fulfilment of the requirements for the Degree of Doctor of Philosophy

Swansea University 


\begin{abstract}
The measurement of vision and the use of vision aids changed dramatically across the nineteenth century. This thesis explores the retail, manufacture, design, and use of vision aids in this context. The overall argument is threefold. Firstly, that the advancement and professionalisation of medical knowledge of the eye led to the reconceptualization of how vision aids were used, tested and sold. Secondly, that changes in the manufacture and sale of vision aids led to greater numbers being produced, and these were better suited for more long-term wear. Thirdly, it argues that these two changes affected users of vision aids by improving their utility, as well as their accessibility. This is the first major study of nineteenth-century vision aids and how they were used, dispensed and sold. However, it also contributes to our understanding of the Victorian period. New demands were placed on vision and vision aids intersect a range of important areas of Victorian history, including urbanisation, industrialisation, rise of print and education. Additionally, it highlights how an assistive technology can be used to challenge conventional thinking about medicalisation, medical definitions, medical authority and measurement in the nineteenth century. Furthermore, because vision aids could be both fashionable and stigmatised, it provides new perspectives on the process of normalisation and our understanding of impairment in relation to commonality. It highlights scope for the study of minor impairments by showing how the experience of blindness, partial sight, and disability as a whole, cannot be seen as transhistorical. The Science Museum's Ophthalmology and Dunscombe collections have shaped this research. It reveals how objects can be used effectively alongside textual and visual evidence for the history of vision aids, as well as the history of medicine, retail, design, disability history, and the cultural perceptions that surround vision and its impairment.
\end{abstract}




\section{Declaration and Statements}

\section{DECLARATION}

This work has not previously been accepted in substance for any degree and is not being concurrently submitted in candidature for any degree.

Signed (candidate)

Date:

\section{STATEMENT 1}

This thesis is the result of my own investigations, except where otherwise stated.

Other sources are acknowledged by footnotes giving explicit references. A bibliography is appended.

Signed (candidate)

Date:

\section{STATEMENT 2}

I hereby give consent for my thesis, if accepted, to be available for photocopying and for inter-library loans after expiry of a bar on access approved by the Swansea University.

Signed (candidate)

Date: 


\section{Contents}

Acknowledgements

p. $\mathbf{v}$

List of Figures

p. vi

Introduction

p. 1

Chapter One: The 'Deterioration of Vision': The

p. 25

Nineteenth-Century Environment and Medicalisation

of the Eye

Chapter Two: Medical and Popular Responses to

p. 68

Sight Loss

Chapter Three: The Retail of Vision Aids, 1800-1850

p. 104

Chapter Four: Medicine and the Changing Methods of

p. 149

Vision Aid Sale, 1850-1900

Chapter Five: The Design and Manufacture of

p. 201

Nineteenth-Century Vision Aids

Chapter Six: Vision Aid Users in the Nineteenth

p. 258

Century

Conclusion

p. 314

Bibliography

p. 326 


\section{Acknowledgements}

First and foremost, I would like to thank my supervisor, Professor David Turner. Your support and guidance over the last 7 years has not only shaped my work and this thesis, it has shaped me as a person and an academic. Thank you for helping me to develop throughout my BA, MA and PhD and for all the time you have put aside to discuss ideas and provide encouragement. I would also like to thank my second supervisor at Swansea University, Professor Louise Miskell, for your helpful comments and advice throughout all stages of this thesis.

Secondly, I would like to thank Dr Tim Boon and Stewart Emmens at the Science Museum for their guidance, particularly in the early stages of this work. Your support enabled me to maximise the collections' potential as evidence in historical work and you gave me the confidence to undertake an ambitious plan to include them throughout my thesis. You have inspired me to use collections in my research, and your advice has been invaluable throughout.

Thirdly, I would like to thank Professor Graeme Gooday and Dr Adam Mosley for their comments in the examination of this thesis. It helped me to develop my work further and think about its broader contribution in new ways. Special thanks must also go to Adam for his time and guidance throughout the corrections stage.

I would also like to thank the following people for their advice and time. Firstly, Neil Handley, Curator at the College of Optometrists, for providing me with easy access to the College's library; the wide-range of sources available, alongside your expertise and discussion of ideas, has greatly enhanced my research. Thanks are also due to you for helping me gain access to Ron Cosens' broad collection of cartes de visite. It has been an invaluable resource, and I thank Ron Cosens for allowing me to include some in my thesis. Secondly, to Adrian Wilcher at the Science Museum for your time and flexibility in ensuring that I was able to gain regular access to the Dunscombe collection. Thirdly, to the staff at the Science Museum's Dana Research Centre and Library, and their off-site store at Wroughton, for all their help in providing me with access to their collections. Finally, to all those who worked at the various archives that I visited and were extremely accommodating in helping me to uncover a wide range of sources, and particularly: Boots Archives, Cambridge University Library, Carlisle Archive Centre, Devon Heritage Centre, Sheffield City Archives, Somerset Archives, Thackray Museum, University of Nottingham Archives, Manuscripts and Special Collections, and the West Sussex Record Office.

I would also like to acknowledge Samuel Brown at Swansea University for advising me on economics and the use of the retail price index. This allowed me to go away and apply it to my own work in chapter six, which greatly enhanced my findings. Secondly, the Postgraduate research communities at both the Science Museum and Swansea University, for all of your insights from our interdisciplinary discussions - and also for all the lunchbreaks and helping to keep me sane - thank you!

And last, but by no means least, thank you to my family and friends, and most especially my parents and sister, for your unconditional support and encouragement throughout. 


\section{List of Figures}

Figure 1.1. Science Museum's Dunscombe collection 1921-323/122, an example of a tinted pair of Double-D Spectacles.

Figure 2.1. Diagrams of the refractive errors of the eye, and their p. 90 correction by lenses in Thos Harris \& Son, A Brief Treatise on the Eyes.

Figure 2.2. Diagrams of the refractive errors of the eye, and their p. 90 correction by lenses in Francis West, A Familiar Treatise on the Human Eye.

Figure 3.1. Bar chart of the occupations of 88 traders associated with vision aid frames and cases in the Science Museum's collections, 18001850 .

Figure 3.2. Pie-chart of the location of 88 traders associated with vision aid frames and cases in the Science Museum collections, showing that the majority were London-based.

Figure 3.3. Science Museum Art collection, 1951-685/25, Trade Card of Dring \& Fage.

Figure 3.4. Science Museum Art collection, 1934-121/100, Trade Card of Thomas Rubergall.

Figure 3.5. Science Museum Art collection, 1934-121/2, Trade Card of J. Abraham.

Figure 3.6. Science Museum Art collection, 1948-397/16, Trade Card of C.W. Dixey \& Son.

Figure 3.7. Science Museum Art collection, 1951-687/29, Trade Card of Andrew Pritchard.

Figure 3.8. Science Museum Art collection, 1934-121/43, Trade Card of John Dunn.

Figure 3.9. Science Museum Art collection, 1951-685/50, Trade Card of A. Mackenzie.

Figure 3.10. Science Museum Art collection, 1948-397/44, Trade Card of S. Phillips.

Figure 3.11. Science Museum's Ophthalmology collection A600351, 'The Complete Sight Suiter: Or Book of Lenses' by John Thomas Hudson.

Figure 4.1. Photograph of the shopfront of Thomas \& Armstrong p. 190 Brother's Manchester Store. 
Figure 5.1 Bar-chart of the kinds of side-arms utilised in 709 pairs of p.205 spectacles dating from between c.1800 and c.1900 in the Science Museum's collections.

Figure 5.2. Science Museum Dunscombe collection 1921-323/137 and p. 206 1932-323/159, an example of transverse folding and extending spectacles dated to c. 1800 .

Figure 5.3. Science Museum's Dunscombe collection 1921-323/168 and p. 206 1921-323/200, examples of a turn-pin frame dated no later than 1820 and a straight frame dated between 1834 and 1913.

Figure 5.4. Science Museum's Dunscombe collection 1921-323/212, an example of coil-spring spectacles dated to 1893 .

Figure 5.5. Page from the catalogue of G.W. Proctor, showing the older straight and transverse folding spectacles styles, 1815.

Figure 5.6. Science Museum's Wellcome collection A681342, an example of straight spectacles similar to those depicted in Charles A. Long's Spectacles (1855).

Figure 5.7. Science Museum's Well collection, A681355 and A681346 and Science Museum's Dunscombe Collection 1921-323/209, examples of the ' $\mathrm{C}$ ' and ' $\mathrm{K}$ ' Bridge, and the newer 'crank' bridge.

Figure 5.8. Page from the catalogue of G.W. Proctor, showing nose spectacles.

Figure 5.9. Designs of pince-nez that were detailed in Walter Alden, The Human Eye; Its Use and Abuse (1866).

Figure 5.10. Designs of pince-nez detailed in Christopher Fenner, Vision: Its Optical Defects, and the Adaption of Spectacles (1875).

Figure 5.11. Bar-chart of the different kinds of materials utilised in 709 p. 215 pairs of spectacles dating from between c.1800 and c.1900 in the Science Museum's collections.

Figure 5.12. Bar-chart of the different kinds of materials utilised in the p. 216 frames of 261 eyeglasses dating from between c.1800 and c.1900 in the Science Museum's collections.

Figure 5.13. Science Museum's Wellcome collection A68247 and A681402, examples of frames with 'pebbles' stamped onto the side.

Figure 5.14. Science Museum's Wellcome collection A62297 and p. 211 Science Museum Dunscombe Collection 1921-323/207, examples of 'steel' and 'steel wire' spectacles.

Figure 5.15. Bar chart of the average weight (g) of 709 spectacles in the Science Museum's collections dating from between c.1800 and c.1900. 
They are arranged according to the design of their side-arms from the oldest (transverse folding) to the newest (coil spring) style of frame.

Figure 5.16. Bar chart of the average weight (g) of 201 older steel and tortoiseshell spectacles and 131 steel wire frames dating from between c.1800 and c.1900 in the Science Museum's Collections.

Figure 5.17. Science Museum's Wellcome collection A62431 and p. 234 A62416, examples of tortoiseshell spectacles with felt-like padding, and the serrated marks that can be found on the frames, most likely from previous material attachment.

Figure 5.18. Science Museum's Wellcome collection A62550 and A681374, examples of objects with material on the bridge and ring ends in the Science Museum's collections.

Figure 5.19. Science Museum's Wellcome Collection A681780, example of a straight wire frame with end attachment to increase comfort.

Figure 5.20. Bar chart of the kinds of plaquet materials utilised in 261 eyeglasses dating from between c. 1800 and c.1900 in the Science Museum's collections.

Figure 5.21. Table of the type of lens utilised in 709 spectacles and 261 eyeglasses dating from between c. 1800 and c. 1900 in the Science Museum's Dunscombe and Ophthalmology collections.

Figure 5.22. Front cover of the catalogue for Dunscombe's second p. 240 collection.

Figure 5.23. Cartes de visite from Ron Cosen's collection, showing p. 244 spectacle side-arms being attached into the wearer's hair.

Figure 5.24. Display of vision aids by men and women in cartes de p. 249 visite from Ron Cosens' collection.

Figure 5.25. Illustration of the latest 'Walking Dress' fashion, complete p. 250 with an eyeglass, in La Belle Assemblee (1823).

Figure 5.26. Science Museum's Dunscombe collection 2000-831/39 and Science Museum's Wellcome collection A682442, examples of a gold handfolder and brass spectacles with decorative features.

Figure 5.27. Use of rimless spectacles and eyeglasses in cartes de visite from Ron Cosens' collection.

Figure 6.1. Line graph plotting the upper and lower end prices (in pence and normalised to 1889 value) that were advertised by nineteenthcentury London and provincial retailers between 1829 and 1900. 
Figure 6.2. Line graph of the overall price in relation to frame material (in pence and normalised to the 1889 value) in nineteenth-century London and provincial advertisements from between 1829 and 1894.

Figure 6.3. Bar chart of the average price of different frame and lens materials (in pence and normalised to the 1889 value) in nineteenthcentury London and provincial advertisements from between 1829 and 1900.

Figure 6.4. Line graph of the price of spectacles by material of the lens (in pence and normalised to the 1889 value) in nineteenth-century London and provincial advertisements in nineteenth-century London and provincial advertisements from between 1837 and 1892 .

Figure 6.5. Bar chart of the difference in price of spectacles (in pence) in the account books of Robert Sadd and John Potter Dowell.

Figure 6.6. Line graph of the low end prices in nineteenth-century advertisements by location (in pence and normalised to the 1889 value) in nineteenth-century London and provincial advertisements from between 1829 and 1894 .

Figure 6.7. Upper end prices in nineteenth-century advertisements by (in pence and normalised to the 1889 value) in nineteenth-century London and provincial advertisements from between 1829 and 1894.

Figure 6.8. Science Museum Ophthalmology collection A62365, an example of a frame that has the bridge repaired.

Figure 6.9. Table of the average cost of different types of repair (in pence) from John Potter Dowell and Robert Sadd's account books.

Figure 6.10. Example of the cards that were distributed by the London Spectacle Mission Society.

Figure 6.11. Science Museum's Ophthalmology collection A62422, an example of a frame with a makeshift repair.

Figure 6.12. Photograph of a 'Little Grandma' (1889).

Figure 6.13. Photograph of a little girl wearing 'a cap and spectacles... with knitting needles' (1874).

Figure 6.14. Children photographed in Ron Cosens' collection of cartes de visite.

Figure 6.15. Adults, of a wide age range, photographed in Ron Cosens' collection of cartes de visite. 


\section{Introduction}

In 1840 a London optician, John Thomas Hudson, distributed a pamphlet that explored how the use of spectacles had grown. Hudson stated:

The use of Spectacles by persons of all ages has of late years become so prevalent - the advantages derived from their use so evident - the commerce produced by their manufacture so extensive - and the assistance rendered by the Optician so great, that no apology will be required from the writer in thus offering to the public, ample information relating to Spectacles and Spectacle Lenses. ${ }^{1}$

The increased use of spectacles was here placed in a broader context, which included greater awareness of the benefits of lenses and the expansion of spectacle commerce and manufacture. Hudson's early observations were not inaccurate. Indeed, the nineteenth century was a major period of transition in the use of vision aids and the measurement of vision. The diagnosis of refractive vision errors, development of diagnostic equipment, and the increasingly prominent role of medical practitioners from the mid-century changed the way that vision could, and would, be tested. Vision aids evolved from being a miscellaneous or optical item that was sold in a variety of retail locations to an increasingly sophisticated assistive device, which could be dispensed following a vision test performed by qualified personnel.

Moreover, the improved diagnosis of refractive vision errors demanded more sophisticated designs. Vision aids could be made on a larger scale, which increased both the functionality and availability of lenses as a treatment method for a greater proportion of people. The utility of lenses ultimately 'enhanced' people's visual capacity and allowed a number of newly diagnosed refractive conditions of the eye to be overcome.

Despite this, the changing nature of nineteenth-century vision aids and vision testing has not received close study or been properly acknowledged. This thesis is the outcome of an AHRC Collaborative Doctoral Partnership (hereafter CDP) project, whose aim was to assess what the Science Museum collections can reveal about the use of vision aids and the changing nature of vision testing in the

\footnotetext{
${ }^{1}$ J.T. Hudson, Useful Remarks upon Spectacles, Lenses, and Opera-Glasses; with Hints to Spectacle Wearers and others; being an epitome of practical and useful knowledge upon this popular and important subject (London: Joseph Thomas, 1840), p. 5.
} 
nineteenth century. Study of the Museum's Ophthalmology and Dunscombe collections have framed the project and shaped the five research questions that it has explored. Firstly, was vision important in the nineteenth century, and how and why did understandings of vision errors change? Secondly, what were the implications of this for vision aid use, and did they become a viable treatment method? Thirdly, how were vision aids sold, and was this affected by changes in medical thought across the century? Fourthly, how were vision aids designed, and to what extent was this influenced by function, as well as appearance? Finally, how did these changes affect the users of vision aids in the nineteenth century, and how accessible would they have been? Throughout the thesis the terms 'vision aids', 'spectacles' and 'eyeglasses' have been used. Many previous studies have used the term 'spectacles'. However, this can be misleading and does not reflect the variety of designs that existed in the nineteenth century. This thesis has primarily focused on two types of vision aid to answer these questions: eyeglasses, consisting of two lenses and a frame without side-arms, and spectacles, lenses with a frame not dissimilar to those in use today. 'Vision aids' have been used as the collective term for both 'spectacles' and 'eyeglasses'. However, the terms 'spectacles' and 'eyeglasses' have been used when referring to points particular to the specific design of vision aid, when this terminology has been used by contemporaries, or when quoting earlier scholarship.

The history of nineteenth-century vision aids has received little scholarly attention. Early twentieth-century research was motivated by a need to establish a comprehensive history of eyewear and fill in a number of gaps in that narrative. These studies did provide an overview of materials and designs and a sketch of how vision aids were distributed. However, there was a tendency for generalisation or speculation, due to a lack of substantial research or access to necessary evidence. ${ }^{2}$ More scholarly works, including Edward Rosen's research into the invention of eyeglasses and John Dreyfus' analysis of printing and spectacles, have focused on the early history of vision aid wear. ${ }^{3}$ In contrast, the history of nineteenth-century

\footnotetext{
${ }^{2}$ See, for example, Thomas H. Court and Moritz Von Rohr, 'On the Development of Spectacles in London from the End of the Seventeenth Century', Transactions of the Optical Society, 30.1 (19289), 1-21; C.W. Elson, Origin and Development of Spectacles (Worthing: Worthing Archaeological Society, 1935).

${ }^{3}$ E. Rosen, 'The Invention of Eyeglasses', Journal of the History of Medicine and Allied Sciences, 11.1 (1956), 13-46; Judith S. Neaman, 'The Mystery of the Ghent Bird and the Invention of
} 
vision aids has primarily been written by collectors. The key limitation of these accounts has been the prioritisation of the object, at the expense of context.

Moreover, collectors' interest in, and study of, their objects can also differ from that of the historian. Collectors often focus on factors that can affect the overall value, including perceptions of aesthetics, rarity, associations with significant manufacturers, owners, events, and provenances. Additionally, the collection of objects that might be especially valuable to the historian - for example objects bearing evidence of use or wear - are avoided in favour of more pristine examples.

Despite this, such works do contain important information about the manufacture, design and use of vision aids in nineteenth-century Britain. William Rosenthal's vast volume on Spectacles and Other Vision Aids is the most comprehensive. Rosenthal's study showed the potential for exploring people's acceptance of vision aids and how the history of vision aid design could be developed. However, Rosenthal's attempt to place the objects in a broader context was based on an earlier work by Richard Corson, which was limited in its scope and in the number of additional sources consulted. ${ }^{4}$ Other studies by collectors also explore the materials and styles of nineteenth-century vision aids. Certain designs such as folders with bow springs, the turnpin side frame and the sliding spectacle frames have been highlighted as popular, for example, by Hugh Orr and Derek C. Davidson. ${ }^{5}$ Despite this, the purpose of these publications was to provide an overview of the entire history of vision aids, and this limits their depth. Similarly, although a number of articles on the history of vision aids in the Ophthalmic Antiques Collectors Club News-Letter are informative, and draw on additional material such as trade literature, even considered collectively these only provide a few of the ingredients required to produce a full history of nineteenth-century vision aids. $^{6}$

Spectacles', Viator, 24 (1993), 189-214; John Dreyfus, 'The Invention of Spectacles and the Advent of Printing', The Library, 6.2 (1988), 93-106 (pp. 105-6).

${ }^{4}$ In some instances, the text was identical. See, for example, William Rosenthal, Spectacles and Other Vision Aids: A History and Guide to Collecting (San Francisco, CA, Norman, 1996), pp. 138-148; Richard Corson, Fashions in Eyeglasses, $3^{\text {rd }}$ edn (London: Peter Owen, 2011), pp. 85-90.

${ }^{5}$ Hugh Orr, Illustrated History of Early Antique Spectacles (London: The Author, 1985), pp. 38, 70, 84; Derek C. Davidson, Spectacles, Lorgnettes and Monocles (Buckinghamshire: Shire, 2002).

${ }^{6}$ For an overview of the information these provide see, for example, Ophthalmic Antiques Collectors Club Bulletin (East Chillington: The Club, 1982-1985), and The Newsletter: Ophthalmic Antiques 
The tendency of collectors' accounts to focus primarily on how surviving objects illustrate key changes in vision aid design has limited historical understanding, since such a focus fails to place these objects in their broader social, cultural and medical context, and pays little attention to the experiences of users. ${ }^{7}$ However, there have been some isolated attempts to situate spectacles and eyewear in relation to broader patterns of historical change. Kerry Segrave, for example, has recently researched medical literature, periodicals, and popular culture as part of her study of the social history of eyewear in America since 1900. Segrave shows how eyewear helped to inform our historical understanding of a range of different topics, including children, fashion and style, marketing, and gender. ${ }^{8}$ Neil Handley has also shown how eyewear can inform our understanding of gender, fashion and branding in twentieth-century Britain. ${ }^{9}$ For earlier periods, two historians have focused on spectacles as part of much broader studies of Victorian material culture and eighteenth-century steel devices. Asa Briggs has provided an outline of growing involvement of medicine and medical practitioners in the care of the eyes and use of spectacles in the nineteenth century, as well as the prevalence of spectacles in popular print and trade literature. ${ }^{10}$ Alun Withey has also shown the value of exploring the cultural perceptions, design, and marketing of spectacles as part of a broader history of technology and the body in the eighteenth century. ${ }^{11}$ Whilst their studies of spectacles have been limited to one chapter each, both Briggs and Withey highlight the potential of vision aids to inform other areas of historical research.

Studying spectacles and eyeglasses in their medical and cultural context provides an alternative approach to the history of vision aids. However, such an approach also highlights the ability of the study of vision aids to intersect a range of

International Collectors Club (East Chillington: The Club, 1985-present), available at the Science Museum's Library.

${ }^{7}$ An exception would be the online exhibitions by Neil Handley, curator of the College of Optometrists' museum. However, the format of this resource limits their scope: https://www.collegeoptometrists.org/the-college/museum/online-exhibitions.html [accessed 22 June 2018].

${ }^{8}$ Kerry Segrave, Vision Aids in America: A Social History of Eyewear and Sight Correction since 1900 (London: McFarland \& Company Inc., 2011), pp. 7-19 for pre-1900 and p. v for contents and list of chapters.

${ }^{9}$ Neil Handley, Cult Eyewear: The World's Enduring Classics (London: Merrell Publishers Ltd, 2011).

${ }^{10}$ Asa Briggs, Victorian Things (London: B.T. Batsford Ltd, 1998), pp. 103-141.

${ }^{11}$ Alun Withey, Self-Fashioning and Politeness in Eighteenth-century Britain: Refined Bodies

(Basingstoke: Palgrave Macmillan, 2016), pp. 91-112. 
additional areas of historical enquiry. Indeed, focused study of nineteenth-century vision aids is both enriched by, and contributes to, our understanding of the history of nineteenth-century society, medicine and disability. The history of prosthetics has expanded in recent years to incorporate consideration of a multitude of assistive devices, including hearing aids or amplifying technology, and dentures. ${ }^{12}$ These studies have highlighted the complexity of defining an object as a prosthesis, assistive technology or orthotic. Katherine Ott, for example, has categorised 'eyeglasses' as an orthotic that 'straddles' the boundaries of conventional prosthetics and assistive devices. Whilst prosthetics have received substantial historical attention, Ott has expressed the need to explore the social and cultural meanings of assistive devices and/or orthotics in order to further develop our understanding of the relationship between prosthetic technologies and the body. ${ }^{13}$ This thesis substantiates this claim and builds upon a range of themes that have been explored in the history of prosthetics more widely, including how developments in design entwined with the needs of people; the growth in mass-production of these devices; and their standardisation. ${ }^{14}$ Additionally, vision aids in the form of both spectacles and eyeglasses provide new perspectives on the relationship between technologies of the body and medicalisation, correction, stigma, normalcy and fashion in the nineteenth century.

The diagnosis of refractive vision errors, the adoption of lenses as a treatment method, and the involvement of medical practitioners from the mid-century suggests, in many ways, that vision became medicalised in the nineteenth century. The measurement and testing of vision was closely connected to the growth in ophthalmology as a medical speciality from the early nineteenth century. A number of historical studies have focused on the specialisation of medicine in the nineteenth century, and the position of ophthalmology at the forefront of a range of other

\footnotetext{
${ }^{12}$ See, for example, Rethinking Modern Prostheses in Anglo-American Commodity Cultures, ed. by Claire L. Jones (Manchester: Manchester University Press, 2017); Artificial Parts and Practical Lives: Modern Histories of Prosthetics, ed. by Katherine Ott, David Serlin and Stephen Mihm (New York: NYU Press, 2002).

${ }^{13}$ Katherine Ott, 'The Sum of Its Parts: An Introduction to Modern Histories of Prosthetics', in Artificial Parts and Practical Lives: Modern Histories of Prosthetics, ed. by Katherine Ott, David Serlin, and Stephen Mihm (New York: NYU Press, 2002), p. 7.

${ }^{14}$ See footnote 10 .
} 
disciplines, including obstetrics, paediatrics and orthopaedics. ${ }^{15}$ Traditionally, the history of ophthalmology has been explored internally from within the profession, and it was not until George Rosen's Specialisation of Medicine that more sociological models of specialisation were considered. ${ }^{16}$ More recent studies by historians have adopted Rosen's approach and placed the specialisation of ophthalmology in its wider social, economic, and political context. These have explored wider tensions in medicine more generally, and the growth of specialist institutions. ${ }^{17}$ Yet despite the history of ophthalmology having been studied as part of a broader interest in medical specialisation, little work has connected the advances in ophthalmology to the later nineteenth-century developments in optometry. ${ }^{18}$ Indeed, the history of optometry itself has remained more firmly within the profession and has received little recent attention from historians as part of their focus on nineteenth-century medical specialisation. ${ }^{19}$ It is clear, however, that ophthalmology, and the interest in the eye that this discipline helped to generate, influenced advances in determining, diagnosing and 'correcting' vision errors in the nineteenth century. A number of historians, for example, have concluded that the invention of the ophthalmoscope - which enabled practitioners to look inside a person's eye - was the most important development in this field in the period. ${ }^{20}$ However, how medical practitioners used the instrument to define new medical terms was equally important.

\footnotetext{
${ }^{15}$ See, for example, George Weisz, Divide and Conquer: A Comparative History of Medical Specialisation (New York: Oxford University Press, 2006); Lindsay Granshaw, "Fame and fortune by means of bricks and mortar': the Medical Profession and Specialist Hospitals in Britain, 18001948', in The Hospital in History, ed. by Lindsay Granshaw and Roy Porter (London: Routledge, 1989), pp. 199-220.

${ }^{16}$ George Rosen, The Specialisation of Medicine with Particular Reference to Ophthalmology (New York: Froben Press, 1944).

${ }^{17}$ See, for example, Luke Davidson, “'Identities Ascertained": British Ophthalmology in the First Half of the Nineteenth Century', Social History of Medicine, 9.3 (1996), 313-33.

${ }^{18}$ Connections between the development of ophthalmic instruments and vision testing have been made by Neil Handley, curator of the College of Optometrists' Museum: https://www.collegeoptometrists.org/the-college/museum/online-exhibitions/virtual-ophthalmic-instrument-gallery.html [accessed: 22 June 2018]. Equally, a connection was made in an article 'Nineteenth Century Spectacles' but only in the context of design: https://www.college-optometrists.org/thecollege/museum/online-exhibitions/virtual-spectacles-gallery/nineteenth-century-spectacles.html [accessed: 22 June 2018].

${ }_{19}$ An exception would be Diane D. Edwards, 'Optometry', in The History of Ophthalmology, ed. by Daniel M. Albert and Diane D. Edwards (Oxford: Blackwell Science, 1996), pp. 303-310.

${ }^{20}$ Wolfgang H. Vogel and Andreas Berke, Brief History of Vision and Ocular Medicine (Amsterdam: Wayenborgh Publishers, 2009), pp. 221-3; Mary Carpenter, Health, Medicine and Society in Victorian England (Santa Barbara CA: Praeger, 2009), pp. 143-4; Chris Otter, The Victorian Eye: A Political History of Light and Vision in Britain, 1800-1910 (Chicago; London: Chicago University Press, 2008), p. 38.
} 
The diagnosis of the refractive and accommodative state of the eye is a good example of the process of medicalisation described by Michel Foucault, namely because in this way medical practitioners created a problem that was not previously there. ${ }^{21}$ However, it does not fully explain the medicalisation of the eye in the nineteenth century or more recently scholarly treatment of the concept.

Medicalisation is about defining a mental or bodily condition or state as a medical pathology, regardless of whether it is seen as a problem by non-medical professionals. The medical pathology is then subject to the expertise of medical practitioners who are able to determine the medical solutions or treatment, regardless of whether a 'cure' is required or if the evidence of its medical nature is tenuous or dubious. Vision defects could be and were problems for those who suffered from them before they were fully recognised as such by medical practitioners. However, the creation of 'normal' vision and the way in which the eye was diagnosed was more fundamental to how contemporary understandings of the eye changed. The importance of definitions for understanding the concept of medicalisation has been noted by Peter Conrad. ${ }^{22}$ Conrad also shows how definitions are central to the process of medicalisation. Similarly, definitions, and diagnosis were central to medical practitioners' ophthalmological practice in the nineteenth century. The refractive state of the eye - such as 'myopia' or short-sightedness - became either a disease or dysfunction to be diagnosed according to changing medical understandings of health and pathology, precisely as a consequence of being named and defined. ${ }^{23}$ Thus the newly defined state of a person's eye became a 'vision error' or 'defect' that required a medical treatment or a cure.

Medicalisation has implications for how technologies of the body are distributed and accessed. Indeed, the treatment of vision by medical practitioners influenced how vision aids were dispensed and sold. Both Conrad and Robert A. Nye have discussed how medical authority was required for the growth and

\footnotetext{
${ }^{21}$ Michel Foucault, The Birth of the Clinic: An Archaeology of Medical Perception (New York: Vintage Books, 1975), pp. 33-4.

${ }^{22}$ For an overview see Peter Conrad, The Medicalisation of Society: On the Transformations of Human Conditions into Treatable Disorders (Baltimore: The John Hopkins University Press, 2007), pp. 3-4.

${ }^{23}$ Michel Foucault, The History of Sexuality, vol 1 (London: Penguin Books, 1990), p. 44.
} 
development of the medicalisation of society. ${ }^{24}$ Similarly, the growth of medical authority in the study of the eye influenced and started to control how vision aids were dispensed and, by implication, the extent to which vision aids were perceived as a medical object. Work on the sale and distribution of vision aids has been undertaken as part of broader histories of ophthalmology or optometry, but has principally produced very brief and generalised statements, based on too little engagement with the evidence. Andreas Vogel and Wolfgang Berke, for example, have suggested that there was a proliferation of oculists and street pedlars during the seventeenth and eighteenth centuries. ${ }^{25}$ Despite the lack of scholarly attention that has been given to vision aid dispensing, links between general medicine and optometry - for example that, in both, greater emphasis was being placed on closer examination and diagnosis, rather than relying on the patient's account - can be made. ${ }^{26}$ Furthermore, this study of vision aids draws on, and contributes to, understanding of three key areas of changing medical practice in the nineteenth century: professionalisation; quackery and regulation; and the development of medical institutions. ${ }^{27}$

The thesis assesses the extent to which medical practitioners were able to exercise their authority over, and medicalise, the diagnosis and dispensing of vision aids. In it, I highlight the importance of exploring advances in medical knowledge at both the elite and popular level to fully characterise this trend. Although it has long been recognised that developments in knowledge of the eye and refraction occurred, the extent to which they affected the average user has not previously been explored.

\footnotetext{
${ }^{24}$ Conrad, p. 9; Robert A. Nye, 'The Evolution of the Concept of Medicalization in the Late Twentieth Century', Journal of History of the Behavioural Sciences, 39.2 (2003), 115-129 (p. 122).

${ }^{25}$ Vogel and Berke, p. 213.

${ }^{26}$ See, for example, Carpenter, pp. 12-13.

${ }^{27}$ See, for example, Roy Porter, Health for Sale: Quackery in England, 1660-1850 (Manchester: Manchester University Press, 1989), pp. 222-235; Irvine Loudon, 'Medical Practitioners 1750-1850 and the Period of Medical Reform in Britain', in Medicine in Society, ed. by Andrew Wear (Cambridge: Cambridge University Press, 1992), pp. 219-247; Lindsay Granshaw, 'Fame and fortune by means of bricks and mortar': the Medical Profession and Specialist Hospitals in Britain, 1800 1948', in Medicine in Society, ed. by Andrew Wear (Cambridge: Cambridge University Press, 1992), pp. 199-220; Christopher Lawrence, Medicine in the Making of Modern Britain, 1790-1920 (London: Routledge, 1994); Keir Waddington, 'Mayhem and Medical Students: Image, Conduct, and Control in the Victorian and Edwardian London Teaching Hospital', Social History of Medicine, 15.1 (2002), 45-64; George Weisz, Divide and Conquer: A Comparative History of Medical Specialisation (Oxford: Oxford University Press, 2006); Michael Brown, 'Medicine, Reform and the 'end' of Charity in Early Nineteenth-Century England', English Historical Review, 124.511 (2009), 13531388; Michael Brown, Performing Medicine: Medical Culture and Identity in Provincial England, c.1760-1850 (Manchester: Manchester University Press, 2010).
} 
It cannot be presumed that these advances were automatically or immediately adopted in popular practice. Developments in visual acuity testing in the seventeenth century, for example, did not necessarily result in their general usage. ${ }^{28}$ Mary Carpenter is sceptical of the extent to which elite medical knowledge filtered into actual practice, and the speed with which it did so, and has argued that more research is required to assess what actually occurred. ${ }^{29}$ A number of chapters of the thesis have explored a range of popular and medical literature to analyse how medical ideas and methods of vision testing were distributed, and assess how they were received and adopted more widely.

The case of nineteenth-century vision aids provides a good example of the limits to medicalisation. Whilst medical practitioners helped to shape the way in which vision was tested and vision aids were dispensed and sold, they were unable to fully monopolise the practice by the start of the twentieth century. Medical and popular opinion could differ substantially. Additionally, medical practitioners were reliant on technology generated by others to treat the range of refractive vision errors that they diagnosed. The sale of vision aids therefore created a competing space between medical practitioners and the opticians who possessed the ability to manufacture eyeglasses and spectacles and had a different skillset. The nineteenth century was a crucial period for defining the role of medical practitioners in the dispensing of vision aids. Enhanced medical knowledge of the eye shaped new professional boundaries. However, it also led to the education and certification of opticians, and throughout the century vision aids could still be bought in a great variety of locations.

Developments in medicine also have a far reaching influence on the use of prosthetic technologies, especially for contemporary understandings of bodily capacity, bodily limitations and bodily 'norms'. ${ }^{30}$ This was particularly the case in the nineteenth century, when medical understandings of the body and health were being replaced by a more fixed and rigid concept of the 'normal'. ${ }^{31}$ The medical model of disability, which focuses on diagnosis and correction, highlights the

\footnotetext{
${ }^{28}$ Vogel and Berke, pp. 202-3.

${ }^{29}$ Carpenter, p. 144.

${ }^{30}$ Ott, p. 13.

${ }^{31}$ Foucault, The Birth of the Clinic, pp. 33-4.
} 
importance of normalcy in society. In this narrative, prosthetics are the solution which enables their user to conform. Lennard J. Davis has shown how social categories of 'normal' and 'deviant' were formed in the mid-nineteenth century. Davis argued that the body was increasingly measured against a scale of 'normalcy' that was based on statistics and commonality. ${ }^{32}$ In a similar fashion, the diagnosis of refractive vision errors both standardised and attempted to normalise vision in the mid-nineteenth century. The newly diagnosed conditions of myopia, hypermetropia and astigmatism were measured against the 'emmetropic' or normal eye from the 1850 s onwards. Whilst the emmetropic eye was 'perfectly formed', the ametropic eye was imperfect. ${ }^{33}$ The terms 'normal' and 'abnormal' became synonymous with 'emmetropic and 'ametropic' vision. ${ }^{34}$ In 1864, the seminal work on vision errors by Dutch ophthalmologist Fransicus Cornelis Donders cemented and stimulated the discussion of vision in this context. ${ }^{35}$ A straightforward reading of this process would suggest that vision aids subsequently became a device that was associated with the treatment of 'abnormality'. However, unlike prosthetics, vision aids could emphasise rather than mask physical difference. Additionally, the number of vision errors being diagnosed complicated the use of the terms 'normal' and 'abnormal'. Unlike prosthetics or other assistive devices, vision aids were also used merely as a fashionable accessory in the nineteenth century.

The study of nineteenth-century vision aids and the measurement of vision highlight how technology can both define and contest the categorisation of both normalcy and disability. Jaipreet Virdi and Coreen McGuire have explored how assistive hearing devices helped to standardise hearing capacity in the early twentieth century. ${ }^{36}$ Similarly, vision aids standardised visual capacity and the degree to which

\footnotetext{
${ }^{32}$ Lennard J. Davis, Enforcing Normalcy: Disability, Deafness, and the Body (London: Verso, 1995), pp. 24-26.

${ }^{3}$ See, for example, William Mackenzie, A Practical Treatise on the Diseases of the Eye, $4^{\text {th }}$ edn (London: A. and G.A. Spottiswoode, 1854), pp. 904, 924.

${ }^{34}$ See, for example, John Soelberg Wells, On Long, Short and Weak Sight and their Treatment by the Scientific Use of Spectacles (London: J.A. Churchill, 1862).

${ }^{35}$ F.C. Donders, On the Accommodation and Refraction of the Eye, with a Preliminary Essay on Physiological Dioptrics, trans William Daniel Moore (London: New Sydenham Society, 1864); for later use see, for example, Robert Brudenell Carter, Eyesight in Schools: A Paper Read Before the Association of Medical Officers of Schools on April 15 ${ }^{\text {th }}, 1885$ (London: Harrison and Sons, 1885), p. 8. N.B. both 'Cornelis' and 'Cornelius' are used in nineteenth-century medical texts. I have chosen to to use 'Cornelis' because it is the name used in the 1864 text.

${ }^{36}$ Jaipreet Virdi and Coreen McGuire, 'Phyllis M. Tookey Kerridge and the Science of Audiometric Standardisation in Britain', British Journal for the History of Science, 51.1 (2018), 123-146.
} 
vision should be 'corrected'. However, assistive hearing devices and vision aids also re-conceptualised what it meant to be 'deaf' and 'blind'. Whilst the history of blindness has been explored extensively, these works have not considered blindness as part of a broader spectrum of visual defects. As suggested by Christopher Woolgar, sensory experience is not transhistorical. ${ }^{37}$ This thesis shows that the experience of blindness and partial-sightedness changed in this period in response to the improved knowledge of the eye and use of lenses. It explores the relationship between vision aids and the classification of impairment to further highlight how the experiences of disability and impairment are dependent on the availability or utility of assistive technologies. However, it also shows how the broader social and cultural context can affect sensory experience. A number of studies have explored the importance of vision in nineteenth-century society. ${ }^{38}$ Chris Otter, for example, has argued that the environment and changing cultural practices of the Victorian period demanded an unprecedented use of vision and ocular capacity. ${ }^{39}$ As part of this, Otter predicted that the changes in medical knowledge and the importance of vision increased the value of vision aids. ${ }^{40}$ This thesis substantiates these conclusions. It shows how vision became standardised in response to medical knowledge and increased demand for 'normal' vision in the urban, workplace and school environment.

Changes in medical knowledge and the ability to treat a range of vision errors enhanced the visual capacity of an unprecedented number and range of users. This change in the use and effectiveness of lenses is not only important for the history of vision aids; it is important for our understandings of the medicalisation and/or normalisation of prosthetics and assistive devices. Contemporaries diagnosed and defined any difference in the refractive condition of the eye as an 'error', 'abnormality' or 'disease' that needed correcting, but regarding vision aids simply as tools for the 'correction' of ocular 'defects' is a limited approach. This thesis has opted for the term 'enhancing' vision in order to situate it away from the medical

\footnotetext{
${ }^{37}$ Christopher Michael Woolgar, The Senses in Late Medieval England (London: Yale University Press, 2006), p. 2.

${ }^{38}$ See, for example, Kate Flint, The Victorians and the Visual Imagination (Cambridge: Cambridge University Press, 2000); Martin Willis, Vision, Science and Literature, 1870-1920: Ocular Horizons (London: Pickering \& Chatto, 2011).

${ }^{39}$ Otter, pp. 22-61.

${ }^{40}$ Ibid., pp. 39-40.
} 
model of disability. The term enhancement signifies the newfound benefits of vision aid lenses for those that were short-sighted in this period; 'enhanced' vision enabled them to maintain work and engage in a range of activities. However, it also problematises the process of medicalisation and allows it to be fully assessed. Vision was not completely 'corrected' in the nineteenth century and nor were vision 'errors' solely seen as a pathology. Vision aids were not just medical objects. A vision aid was able to embody a range of cultural and social meanings that could be both fashionable and stigmatised.

The thesis draws upon the key themes that were acknowledged by Hudson at the outset of this Introduction to explore the measurement of vision and the use of vision aids in the nineteenth century: retail and distribution, design and manufacture, usage, and the role of opticians. Besides medicine and disability, study of vision aids provides new perspectives on various prominent areas of nineteenth-century historiography: the location of retail; the growing importance of professionalisation and reputation; mass production and the distribution of labour; urbanisation; faster transport methods; and the changing school and workplace environment. Pamphlets such as Hudson's were not uncommon, and nineteenth-century vision aids have been explored against a backdrop of greater cultural interest in the eye, vision, and the use of vision aids. Joanne Gooding argued that the design and manufacture of spectacles in the twentieth century were inextricably linked to wider developments in science and society. ${ }^{41}$ This thesis takes that proposition a step further and argues that the design and manufacture and the use and utility of vision aids were inextricably linked to developments in science, society, and medicine in the nineteenth century.

\section{Methodology}

Whilst the role of material culture in history still remains in its infancy, a number of recent studies have highlighted how objects can be a useful source and tool of analysis for a range of time periods, topics, and geographical locations. This research has shown how the study of objects has encouraged collaborations both in the

\footnotetext{
${ }^{41}$ Joanne Gooding, 'Rather Unspectacular: Design Choices in National Health Service Glasses', Science Museum Group Journal, 7 (2017) http://journal.sciencemuseum.ac.uk/browse/issue-07/ratherunspectacular/\#0 [accessed: 2 February 2018].
} 
discipline of history itself as well as a range of other disciplines or organisations, including the heritage industry and museums. My findings have been primarily based on the two most prominent collections of vision aids and vision testing equipment at the Science Museum: Henry Wellcome's collection of vision aids and testing equipment in the Ophthalmology collection and Matthew Dunscombe's collection of vision aids in the Optics collection. Having a museum collection as the primary source base for an historical study could affect the representativeness of findings and lead to a distortion in our understanding of the sale, use and perceptions of vision aids in the nineteenth century. Jim Bennett and Samuel Alberti, for example, have acknowledged that museum objects are 'not a straightforward record of the past'. ${ }^{42}$ Indeed, the character of a museum's holdings is both shaped by objects' original collectors and subsequently altered by later museum acquisitions or larger collections that they are placed in. My own research on the collecting contexts of the Wellcome and Dunscombe collections influenced my decision to include them. The two collections were chosen from the Science Museum's wider collection because of the way in which they were collected and the scope of their content, which helped to ensure that the findings would be representative.

Wellcome and Dunscombe's different collecting practices created two very different collections. To ensure representativeness, careful attention was paid to whether the collection covered the range of materials, side-arms, bridges and pincenez springs that existed across the nineteenth century. Both the Wellcome and Dunscombe collections reflect the key materials, changes in design, and locations of manufacture and/or retail of vision aids. The Wellcome collection of vision aids and testing equipment is by far the largest and contains nearly 5,000 objects. Henry Wellcome was a pharmaceutical entrepreneur with extensive resources who collected an array of miscellaneous items in the early twentieth century; a number of studies have explored the size, scope, and value of the broad collection that he amassed. ${ }^{43}$ Wellcome was interested in the everyday and this is reflected in the

\footnotetext{
${ }^{42}$ Quotation from Jim Bennett, 'Museums and the History of Science: Practitioner's Postscript', Isis, 96.4 (2005), 602-608 (p. 608); See also, Samuel J. Alberti, 'Objects and the Museum', Isis, 96.4 (2005), 559-571 (p. 562)

${ }^{43}$ Ghislaine M. Skinner, 'Sir Henry Wellcome’s Museum for the Science of History', Medical History, 30 (1986), 383-418; Frances Larson, 'The Things About Henry Wellcome', Journal of Material Culture, 15 (2010), 83-104; Ken Arnold and Danielle Olsen, 'Introduction', in Medicine
} 
surviving auction catalogues that were marked up by his collectors and acquisition records, which document his collecting of vision aids amongst many other items. ${ }^{44}$ His collecting practices were also influenced by the Pitt Rivers Museum and Darwin's ideas of evolution, which became prominent in the organisation of museum objects from the late nineteenth century. ${ }^{45}$ Wellcome acquired multiple sequences of similar or identical objects at different times to try to trace trends and complete an 'evolutionary' approach to history. This 'evolutionary' approach is evident in the number of similar objects that can be found in the Ophthalmology collection, something which has been invaluable for determining the development of design. ${ }^{46}$ In contrast, Matthew Dunscombe's collection of 289 spectacles and eyeglasses was based on a more calculated amassing of key examples of vision aids, mostly from the mid-nineteenth century onwards, to illustrate the developments in design.

Dunscombe was a nineteenth-century optician, and his original collection was more substantial before it was destroyed in a fire at an exhibition in $1908 .{ }^{47}$ Nevertheless, Dunscombe's surviving collection is a useful supplement to the volume of objects that were collected by Wellcome. Dunscombe's collection provides more examples of key design innovations, and frames made out of finer materials.

Collectively, the Wellcome and Dunscombe collections include the full range of vision aid designs and styles from the early, middle, and late nineteenth century. In particular, the Wellcome collections provide insight into the more 'everyday'

Man: The Forgotten Museum of Henry Wellcome, ed. by Ken Arnold and Danielle Olsen (London: The British Museum Press, 2011), pp. 29-50.

${ }^{44}$ These are currently uncatalogued but are available at the Wellcome Library. Catalogues for Stevens auction house were viewed for 2 March 1915; 13 April 1920; 2 September 1924; 21 and 22 August 1928; 21 September 1928; 14 October 1928; 23 October 1928; 26 and 27 March 1930; 16 and 17 September 1930; 7 November 1930; 5 August 1931; 20 and 21 October 1931; 20 and 21 September 1921; 20 and 21 October 1932; 16 April 1935; and catalogues for Glendining auction house for 29 July 1932; 29 October 1934; 14 January 1935.

${ }^{45}$ Arthur MacGregor, 'Exhibiting Evolutionism: Darwinism and pseudo-Darwinism in museum practice after 1859', Journal of the History of Collections, 21.1 (2009), 77-94

${ }^{46}$ For the wider value of the Wellcome Collection for the history of medicine, see In particular, see John Pickstone 'Objects of Modern Medicine' and John Mack, 'Medicine and Anthropology in Wellcome's Collection', in Medicine Man: The Forgotten Museum of Henry Wellcome, ed. by Ken Arnold and Danielle Olsen (London: The British Museum Press, 2011).

${ }^{47}$ Science Museum Technical File, T/1921-323: Catherine Gates, Matthew William Dunscombe: A Bristol Optician (1997), Derek C. Davidson, 'Matthew William Dunscombe the First Great Collector of Antique Spectacles', Ophthalmic Antiques Newsletter, 4, p. 51, and Margaret Mitchell, 'Optics and the Science Museum', The Optician, 21 September 1979, pp. 22-24. 
items that are often omitted from a museum collection. ${ }^{48}$ Other important collections, including the museum at the College of Optometrists, have been consulted to ensure that certain findings are representative. ${ }^{49}$ In total, over 1,000 spectacles and eyeglasses and 300 items of testing equipment have been weighed and closely studied for this project. The CDP scheme broadens the scope of object-work for the historian and allows the researcher to overcome a key methodological challenge: access to collections. ${ }^{50}$ As argued by Alison Hess and Hilary Geoghegan, long-term object-work as part of the CDP scheme can influence the way that research is undertaken. Hess and Geoghegan have explored how the relationship of an individual in an object-store can affect a person's experience with the objects, including the development of strong feelings of attachment and responsibility. ${ }^{51}$ But besides these affective consequences, the length of time that I spent studying these two Science Museum collections also influenced how I could use the objects as evidence. Consistent and long-term access enabled detailed object-study and the close comparison of objects across the two collections. The findings in this thesis show the value of jointly studying objects and additional textual sources to develop new perspectives on existing historical arguments and shape new lines of enquiry.

Objects are a new and increasingly used source in the histories of science, medicine and disability. Adam Mosley, for example, has attributed the rising profile of material culture in the history of science to a number of changes in the discipline, including the emergence of the history of museums; the historical work done by curators; changing interests in the history of science; and greater interpretation of museum exhibitions and catalogues. ${ }^{52}$ Whilst more work needs to be done to fully incorporate the use of objects as a source in the history of science, the value of an object for interpreting or re-interpreting the past has been acknowledged.

Additionally, in disability history the materiality of prostheses has become an object

\footnotetext{
${ }^{48}$ For a similar argument about the decisions to display broken scientific instruments see, Simon Schaffer, 'Easily Cracked: Scientific Instruments in States of Disrepair', Isis, 102 (2011), 707-717.

${ }^{49}$ My findings in the Science Museum's collections that straight tortoiseshell frames had uniform velvet-type material on the side-arms, for example, were tested and confirmed by looking at the College of Optometrists' Museum collection.

${ }^{50}$ Gerritsen and Riello, pp. 9-10.

${ }^{51}$ Alison Hess, Hilary Geoghegan, 'Object-love at the Science Museum: Cultural Geographies of Museum Storerooms', Cultural Geographies, 22.3 (2015), 445-465.

52 Adam Mosley, 'Introduction [to Special Issue "Objects, texts and images in the history of science"]', Studies in the History \& Philosophy of Science, 38 (2007), 289-301 (p. 291).
} 
of study. Indeed, Artificial Parts and Practical Lives brought a range of studies together to address the fact that prostheses had not been fully explored in material culture. ${ }^{53}$ As shown by Sophie Goggins, Tacye Phillipson and Alberti, prosthetics such as artificial limbs have long been collected and are an invaluable source. ${ }^{54}$ Museums are also more committed to displaying prostheses and ensuring that patient histories or agency are as dominant as the histories of clinicians and inventors in their exhibitions and galleries. ${ }^{55}$ The material forms of assistive technologies and orthotics have also been studied to explore users, consumption patterns and overall design. $^{56}$

As worn objects, vision aids are similar to the clothing and shoes treated in recent studies by Karen Harvey and Matthew McCormack. ${ }^{57}$ These studies have highlighted how material culture can be used to explore the wearing experience and social meanings of any given object. However, both McCormack and Harvey highlight the importance of texts in order to assess the object's significance. Indeed, Harvey in an earlier work defined 'material culture' against the study of 'object' or 'artefact' because it takes into account the physicality of an object and the range of contexts in which it acquires meaning. ${ }^{58}$ The role of both text and objects in the history of medicine and science is also evidenced in the edited collection, Things That Talk, by Lorraine Daston and a recent multi-authored study on a nineteenthcentury inhaler in the Science Museum Group Journal. ${ }^{59}$ Additional sources are a valuable tool for ensuring a museum collection's representativeness. Anne Gerritsen and Giorgio Riello, for example, have argued that the de-contextualisation of museum objects is not a limitation but a conceptual challenge that is able to be

\footnotetext{
${ }^{53}$ Artificial Parts and Practical Lives, passim.

${ }^{54}$ Sophie Goggins, Tacye Phillipson, Samuel J. M.M. Alberti, 'Prosthetic Limbs on Display: from maker to user', Science Museum Group Journal, 8 (2017) http://journal.sciencemuseum.ac.uk/browse/issue-08/prosthetic-limbs-on-display/\#reference-16 [accessed 28 March 2019]. 55 Ibid.

${ }^{56}$ See footnote 10 .

${ }^{57}$ Matthew McCormack, 'Boots, Material Culture and Georgian Masculinities', Social History, 42.4 (2017), 461-479; Karen Harvey, 'Men of Parts: Masculine Embodiment and the Male Leg in Eighteenth-Century England', Journal of British Studies, 54.4 (2015), 797-821.

${ }^{58}$ Karen Harvey, 'Introduction', in Material Culture: A Student's Guide to Approaching Alternative Sources, ed. by Karen Harvey (London: Routledge, 2009), p. 3.

${ }^{59}$ Barry Murnane, Darragh Murnane, Mark Sanders, Noel Snell, 'Great Ease and Simplicity of Action': Dr Nelson's Inhaler and the Origins of Modern Inhalation Therapy', Science Museum Group Journal, 8 (2017) http://journal.sciencemuseum.org.uk/browse/issue-08/dr-nelson-s-inhaler/ [accessed 28 March 2019].
} 
overcome by studying the object in its wider context. ${ }^{60}$ Notably, Daston has argued that objects 'talk' and do not simply 'repeat'. ${ }^{61}$ Mosley has also highlighted that objects and images are able to complete our historical understanding and do not simply reinforce it. ${ }^{62}$ Whilst text has often held primacy in our understanding and historical interpretation of the past, objects need not have a peripheral role and can provide a starting point for new research. Earlier approaches to material culture have been informed by anthropology and have tended towards object biography. ${ }^{63}$ However, objects also create new historical questions or angles of historical enquiry. ${ }^{64}$ In producing this thesis, close analysis of the inscriptions, materials, design and weight of vision aids has provided further evidence for the use, distribution and functionality of vision aids in the nineteenth century.

As an initial starting point for this study, I began by identifying relevant objects. This process involved surveying the objects, creating additional catalogue material, developing research questions, and performing some initial comparisons both within and between the Wellcome and Dunscombe collections. Relevant textual sources and images were then identified to help research the users and the retailers or manufacturers identified, or associated, with the objects. The medical and social contexts were also researched to support the material findings. Objects have not been used as a supplement to other sources in this work, but have appeared as evidence in their own right throughout. I could have researched the dispensing and design of vision aids, and the testing of vision, without objects, but my findings would then have been incomplete. I frequently returned to the objects to identify any further changes requiring investigation, including design features, the type of lens, and the weight of the frame and/or lens. But it was not a simple one-way process of identifying relevant objects and undertaking further research. The research process involved an iterative interchange of the information derived from textual, visual, and material sources, in order to build up the necessary picture of the context and

\footnotetext{
${ }^{60}$ Anne Gerritsen and Giorgio Riello, 'Introduction: Writing Material Culture History', in Writing Material Culture History, ed. by Anne Gerritsen and Giorgio Riello (London: Bloomsbury Academic, 2015), p. 9.

${ }^{61}$ Lorraine Daston, 'Introduction', in Things That Talk: Object Lessons From Art and Science, ed. by Lorraine Daston (New York: Zone Books, 2004), p. 11.

${ }^{62}$ Mosley, p. 291.

${ }^{63}$ See, for example, The Social Life of Things: Commodities in Cultural Perspectives, ed. by Arjun Appadurai (Cambridge: Cambridge University Press, 1995); Jones also discusses this, p. 17.

${ }^{64}$ Mosley, p. 291; Bennett, p. 606.
} 
develop conclusions based on all three forms of evidence. Objects and context are woven together throughout each of the chapters of this thesis. The Science Museum's collections - placed in context - have thus proved to be an invaluable source for exploring and communicating the social and medical history of vision measurement and vision aids in the nineteenth century.

The textual sources I have used include newspapers, periodicals, medical texts, opticians' texts, professional journals, patents, trade literature, business archives and correspondence. The visual sources can be broken down into photographs and satirical images. An exploration of these sources has allowed the history of nineteenth-century vision aids to be explored in depth, beyond gross changes in design, for the first time. The newspapers and periodicals were accessed in their digital form, and relevant information was identified using key-word searches. A number of historians have recently highlighted how the digitisation of the British press has allowed the potential of newspapers for exploring politics, culture and society to be fully realised. ${ }^{65}$ Key-word searching has been an invaluable search tool for the study of nineteenth-century vision aids and the measurement of vision. Key word searches have, for example, allowed the price and marketing of vision aids in contemporary advertisements to be explored in detail. ${ }^{66}$ However, methodological problems associated with key-word searches in digital sources have also been acknowledged by historians, including errors in the character recognition technology affecting the fidelity of the searchable data, and the possibility of missing significant findings due to poor word-choice or historical use of alternative terminologies. ${ }^{67}$ To minimise the problems associated with terminology, a range of key terms were used, including eyeglasses, spectacles, glasses, glasses and lenses, optician, oculist, hypermetropia, hypermetropic, myopia, and myopic. These terms were searched across all available publications between 1800 and 1900 in Gale

\footnotetext{
${ }^{65}$ Adrian Bingham, 'Review Article: The Digitisation of Newspaper Archives: Opportunities and Challenges for Historians', Twentieth Century British History, 21.2 (2010), 225-231 (pp. 225-226, 231) Stephen Vella, 'Newspapers', in Reading Primary Sources: The Interpretation of Texts from Nineteenth- and Twentieth-Century History, ed. by Miriam Dobson and Benjamin Ziemann (London: Routledge, 2009), p. 193; James Mussell, The Nineteenth-Century Press in the Digital Age (Basingstoke: Palgrave Macmillan, 2012), passim.

${ }^{66}$ See chapter six for further specific discussion on this, pp. 248-256.

${ }^{67}$ Bingham, pp. 229-230; Mussell, see particularly, pp. 61-67; Tim Hitchcock, 'Confronting the Digital, or how Academic History Writing Lost the Plot', Cultural and Social History, 10.1 (2013), 923 (pp. 12-14).
} 


\section{Cengage's $19^{\text {th }}$ Century British Library Newspapers and ProQuest's British}

Periodicals. The position as well as the content of the key word search result was analysed to ensure that it was not removed from its context or format on the page. ${ }^{68}$

Despite its limitations, key-word searching has also allowed the prevalence of vision aids and concerns about vision in nineteenth-century popular literature to be explored more thoroughly than was previously possible. Briggs' 1998 work on Victorian spectacles in printed material, for example, was limited to the discussion of one article. ${ }^{69}$ Digitisation permits searching of a much larger body of evidence to take place, but the range and representativeness of digital material needs to be taken into account. ${ }^{70}$ In order to ensure a broad coverage of the range of representations of visual aids in nineteenth-century print media, I explored 2,115 newspaper articles, items of correspondence, and reports in sports and news sections, and over 1,000 newspaper advertisements. Similarly, I considered 4,089 articles, reviews, 'general information' and correspondence as well as 2,818 advertisements in the periodicals. These texts were published in 65 different newspapers and 75 different periodicals, catering to readerships both inside and outside of London. As this was the first exploration of vision aids in digital sources, my purpose was to assess whether, and how, vision aids and vision testing were discussed in nineteenth-century popular media. This analysis of digital newspapers and periodicals has been able to show that, indeed, vision aids were extensively discussed in London and provincial publications. More recently, Stephen Vella has argued that cross-comparisons of multiple newspapers and periodicals should be undertaken in a single study. ${ }^{71}$ James Mussell has shown how digital sources can facilitate cross-comparison. ${ }^{72}$ This thesis has developed Briggs' analysis of printed material by demonstrating the usefulness of key-word searching for exploring multiple publications. The findings from the digital key-word searches show the volume as well as the content of discussion that was taking place, illuminating the wide-ranging social meanings of vision aids.

\footnotetext{
${ }^{68}$ The importance of exploring how an article looked, and where it was on the page, has been discussed extensively. See, in particular, Mussell, pp. 28-68; Bingham, p. 230; Vella, pp. 199-200. ${ }^{69}$ Briggs, p. 105.

${ }^{70}$ See, for example, Bingham, p. 229; Rosalind Crone and Katie Halsey, 'On collecting, cataloguing and collating the evidence of reading: the 'RED movement' and its implications for digital scholarship', in History in the Digital Age, ed. by Toni Weller (London: Routledge, 2013), p. 102.

${ }^{71}$ Vella, p. 200.

${ }^{72}$ Mussell, p. 58.
} 
Future study could analyse these findings further to assess how material varied depending on the readership of these publications. However, for the purpose of this study, the findings from key-word searches were used to ascertain where this discussion predominated within the newspaper and periodical, and whether vision aids were being discussed in London and provincial popular media. The exploration of London and provincial newspapers in this way has allowed the variety of contexts in which vision aids were discussed to be explored, and made it possible to tease out the different social meanings associated with their use.

A number of medical texts, optical texts, and medical trade catalogues have also been explored in both digital and physical form. Coupled with The Optician and the British Medical Journal, these have allowed contemporary understandings and theories of different kinds of professional to be explored. The journals have provided invaluable information on current designs, the public use or abuse of vision aids and vision testing, and the tensions or debates surrounding professional control and boundaries. The Science Museum's library also acted as an invaluable source for patents and a wide range of trade literature, including trade cards and directories. Recent studies have used patent specifications to explore the design of artificial limbs and assistive hearing devices. ${ }^{73}$ Patents have been used similarly in this study to explore the design and retail of vision aids in the nineteenth century in greater depth. Finally, a range of business archives and correspondence have been explored through archival research in a number of locations: London, Cambridge, Somerset, Carlisle, Leeds, Nottingham, Chichester, and Sheffield. The range of business archives and correspondence allowed the retail, marketing, distribution and use of vision aids to be researched, as well as ensuring that the findings were not unduly London-centric. Photographs are a unique addition to this source base; they were primarily obtained from a private collection of cartes de visite that has been amassed by Ron Cosens. ${ }^{74}$ Previous studies of vision aids - including those by Rosenthal, Vincent Ilardi, and Gerard L'E. Turner - have all highlighted the potential value of imagery and art for exploring how vision aids were designed and used. ${ }^{75}$ Ron

\footnotetext{
${ }^{73}$ Jones, p. 17.

${ }^{74}$ See Ron Cosens' collection for more information, http://www.cartedevisite.co.uk/ [accessed: 22 June 2018].

${ }^{75}$ Vincent Ilardi, Renaissance Vision from Spectacles to Telescopes (Philadelphia: American Philosophical Society, 2007), p. ix, Appendix III, pp. 261-338; 359-368; Gerard L'E. Turner,
} 
Cosens' collection also illustrates the broadening users of vision aids and is a useful supplement to the satirical images in contemporary newspapers and periodicals.

\section{Chapter Outline}

The thesis is separated into six chapters, which cover a range of topics associated with the testing of vision and use of vision aids. Chapters one and two draw upon objects, medical texts, newspapers and periodicals to explore changing medical ideas about vision and vision aids and how these were distributed more widely. The first chapter explores the value attributed to vision and the corresponding concern about its fallibility in the nineteenth century. It has been split into three parts to show how vision became increasingly measured against a newly standardised 'normal', the emmetropic eye. The first section explores how vision and the new demands that were being placed on the eye were discussed in contemporary literature. The second and third sections show how vision was increasingly measured and analysed in the school and workplace environments. This first chapter argues that vision was increasingly medicalised in the nineteenth century, and the discipline of ophthalmology brought it under the authority of medical practitioners.

The second chapter builds on the findings of chapter one to show how the medicalisation of vision pathologised the refractive condition of the eye as something 'erroneous' that required 'correction'. The chapter is split into two sections to highlight how medical perceptions of vision aids changed, and how they were distributed, across the century. The first section highlights a shift in opinion from the mid-century, when the advantages of lenses and the use of vision testing became part of the general medical consensus. The second section explores how medical ideas were distributed amongst the general public. It argues that medical practitioners had to compete with opticians and popular claims about eyesight and vision aids in contemporary newspapers, periodicals, and popular texts.

'Spectacles over Seven Hundred Years', in A Spectacle of Spectacles: Exhibition Catalogue, ed. by Wolf Winkler (Leipzig: Edition Leipzig, 1988), p. 14; Rosenthal, p. 359. 
Chapters three and four explore how changing medical ideas of the eye, vision testing, and vision aids affected the retail and dispensing of vision aids, drawing on the advertisements of vision aid retailers in newspapers and periodicals, trade literature, professional journals, and the objects in the Science Museum's collections. The third chapter explores how the retail of vision aids broadened in the first half of the century. It argues that the sale of vision aids developed alongside wider developments in the history of retail. Chapter three also shows how considering the location of sale is insightful for exploring the methods and expectations of vision aid dispensing. Criticism of vision aid sale focused on issues identified in wider retail and not on the vision testing methods of dispensers. Whilst the concept of accuracy was important, it shows that 'trial and error' on the part of the customer, in order to find a lens that suited them best, allowed the sale of vision aids to exist in a variety of retail and street locations.

Chapter three shows that, in the first half of the nineteenth century, vision aids could be categorised equally as scientific instruments, fancy goods, or miscellaneous sundries. Chapter four assesses how medical involvement affected the dispensing of spectacles and eyeglasses in the second half of the nineteenth century. It assesses to what extent vision aids became medical objects, and highlights through reference to ophthalmic institutions and medical knowledge - how the retail of vision aids from the 1830s followed broader trends in medical specialisation and professionalisation. However, it also highlights how the development of objective sight technologies in the second half of the period changed the language and advertised skillsets of vision aid retailers in the second half of the nineteenth century. Through exploring The Optician and the British Medical Journal it shows how the medical profession and the wider retail trade were forced to co-operate, and how professional boundaries became a contested topic of debate in the 1890s. It highlights that the medicalisation of the retail trade was not complete by the end of the nineteenth century because vision aids were still dispensed in a variety of locations. However, medical ideas had transformed expectations of how spectacles and eyeglasses were sold, namely by making the incorporation of a vision test seem essential. The knowledge, authority and skillset required to manage a transaction in which a vision aid changed hands now lay with the dispenser, as opposed to the customer. 
Chapter five assesses the changing design of vision aids in the nineteenth century. It draws extensively upon the Science Museum collections to assess and track how the design of two types of vision aids - spectacles and eyeglasses evolved across the century. It is split into two sections to assess why this change occurred. The first section uses objects, patents, medical texts, opticians' texts, and The Optician to show how changing manufacture and the choice of materials created a frame that was more uniform and intended for large-scale manufacture. The second section draws upon the same sources, as well as contemporary photographs, to explore how the function of vision aids altered frame design. This section is separated into discussion of three topics: comfort, length of use, and the appearance of the frame. It assesses how a desire to create a comfortable frame that could be worn for longer periods, and for a more diverse range of activities, created a lighter and more secure device. Finally, it shows how the frame was not just altered by functional considerations. The importance of appearance led to the development of bold, decorative designs as well as invisible, discrete frames. It argues that, whether from a desire for a more functional or a more elegant frame, nineteenth-century design responded to the broadening functions that vision aids were expected to serve.

The final chapter focuses on vision aid users. It explores the prices advertised in nineteenth-century newspapers and periodicals to assess the affordability of vision aids in greater depth. This analysis is supplemented with evidence from the objects, opticians' account books, catalogues, and the correspondence of a London charity, in order to argue that the perception of vision aids changed from an association with the upper-classes, to being considered objects to which the poor should have access as a basic right. The second section draws upon medical case accounts, opticians' accounts, and correspondence from the 1890s. These sources are used to assess the overall utility of vision aids in the nineteenth century, and how they transformed the lives of their users. It shows that the relationship between utility and usability was not straightforward, but that improvements in the design and the measurement of vision increased the value of vision aids for prospective users. The last section draws upon contemporary newspapers, periodicals, photographs, opticians' texts and medical texts to assess how much can be known about users of vision aids in the nineteenth century. In the absence of statistical data, it explores contemporary 
stigma, perceptions, and commentary to assess the age, gender and number of users. It argues that, in response to the developments that have been discussed in the previous chapters, the range of expected users of vision aids expanded in this period. Vision aids were expected to be accessible and functional for a broader cross-section of society, even if this was not achieved in reality.

The thesis as a whole provides a more comprehensive study of nineteenthcentury vision aids by placing them in the medical and social context of the period for the first time. The medical context, which is discussed in chapters one and two, is essential for understanding how the retail, design, and use of vision aids evolved. Exploring the social context through contemporary literature provides greater insight into how vision aids were perceived and used, as well as how medical ideas were distributed in the nineteenth century. Whilst objects still form a considerable part of this work, additional sources have enabled vision aids to be explored in greater depth. When placed in their medical and social context, nineteenth-century vision aids are not just of interest to museum curators or amateur collectors. This thesis shows how study of vision aids speaks to the broader histories of medicine, retail, design, manufacture, fashion, prosthetics and disability. In doing so, it provides a unique perspective on the relationship between technology, medicine and impairment in the nineteenth century. 


\section{Chapter One}

\section{The 'Deterioration of Vision': The Nineteenth-Century Environment and Medicalisation of the Eye}

Vision was valued in nineteenth-century Britain and permeated both popular and medical thought. In popular culture, optics, optical illusions and ocular inventions, such as the kaleidoscope, meant that a fascination with vision entered the domestic sphere. ${ }^{1}$ Ophthalmologists drew upon a variety of epistemological, theological and literary sources to achieve their specialist status and justify their study of the eye. These sources form part of a wide historical context, which considered the eye to be designed with unparalleled perfection. In particular, the medical profession described the eye as the 'quintessential organ', both in healthy and morbid states, because of its 'perfect' design and ability to provide a 'window' to the diseased body. ${ }^{2}$ However, increased study of the eye also meant that its vulnerability was exposed and anxiety about its deterioration began to develop in this period.

This chapter explores the value attributed to vision and the corresponding concern over its fallibility. In this context, it highlights how vision became increasingly measured against a newly standardised 'normal': the emmetropic eye. The chapter is split into three parts. The first considers how vision was discussed in medical and popular literature, and how the nineteenth-century environment both affected and placed new demands on the eye. The second and third sections then explore the measurement of vision in schools and the workplace. The relationship between eyesight and education are treated prior to discussions of vision in the workplace, because I argue that workplace examination further developed the importance for systematic, accurate vision testing. Urbanisation, leisure, education and work were part of the changing landscape of nineteenth-century society. This chapter explores how these changes led to the measurement and development of 'normal' vision as the idealised state. However, it also shows that vision was

\footnotetext{
${ }^{1}$ Kate Flint, The Victorians and the Visual Imagination (Cambridge: Cambridge University Press, 2000), pp. 1, 4, 5; Martin Willis, Vision, Science and Literature, 1870-1920: Ocular Horizons (London: Pickering \& Chatto, 2011), pp. 4, 165-6.

2 Luke Davidson, "Identities Ascertained": British Ophthalmology in the First Half of the Nineteenth Century', Social History of Medicine, 9.3 (1996), 313-33 (pp. 324-328).
} 
increasingly problematized and, in a number of contexts, abnormal vision was becoming less tolerated. In response to concerns about the nation's visual acuity, this chapter argues that vision was medicalised in the nineteenth century and brought within the authority of medical practitioners.

\section{Vision and the Nineteenth-Century Environment}

Vision has often been perceived as superior to the other senses. More recently, this position has been critiqued, and phrases such as the 'crisis in ocularcentrism' have been coined to emphasise the danger of monosensory studies. ${ }^{3}$ The importance of vision could be challenged on various levels throughout the past by looking at the experiences of sensory loss and, in particular, multiple sensory loss. ${ }^{4}$ However, vision was valued in the nineteenth century and exploring how it was celebrated is important for understanding how the medical profession developed ophthalmology as a subspecialty, and how this influenced the measurement of vision and the use of vision aids. ${ }^{5}$ In his 2006 study Christopher Woolgar did not consider sensory experience to be transhistorical. Woolgar concluded that it was 'not a study of biological universals but of the cultural attitudes that constitute and accompany perception' and, therefore, the experience of each sense - smell, touch, sound, taste and sight - would have been conceived differently at different periods. ${ }^{6}$ Consequently, celebration of the eye and vision throughout the past has been based on a variety of reasons, which were dependent on the cultural context. Woolgar dated the pre-eminence of sight in the west to antiquity and early Christianity, whereby the eye was associated with strength and the element of fire. However, eighteenth-century Enlightenment theory and investigation had a decisive influence on the perception of vision and the eye. ${ }^{7}$ Enlightenment theorists, such as Locke and Molyneux, discussed sensory perception and its relationship to the acquisition of knowledge and education. These discussions led to comparisons between loss of

\footnotetext{
${ }^{3}$ See, for example, Martin Jay, 'The Rise of Hermeneutics and the Crisis of Ocularcentrism', Poetics Today, 9.2 (1988), 307-326.

${ }^{4}$ Graeme Gooday and Karen Sayer, Managing the Experiences of Hearing Loss in Britain, $1830-1930$ (Basingstoke: Palgrave Macmillan, 2017), pp. 48-49.

5 Davidson, "'Identities Ascertained", pp. 313-33.

${ }^{6}$ Christopher Michael Woolgar, The Senses in Late Medieval England (New Haven; London: Yale University Press, 2006), p. 1.

${ }^{7}$ Ibid., pp. 146-7.
} 
sight, hearing, touch, taste and smell, and their contribution to intelligence, as well as investigations of those with sensory impairments. Vision was considered integral to the acquisition of knowledge, something which helped galvanise its position as the superior sense. ${ }^{8}$ Locke had considered the physiology of vision, but chose to separate his arguments from it. Yet from the eighteenth and especially in the nineteenth centuries, sensory perception became increasingly rooted in physiology. In the nineteenth century, contemporaries sought to define sensation, a physiological process, and perception, a psychological one. ${ }^{9}$ Consequently, in Victorian culture, the eye and vision were celebrated due to studies both in its role in acquiring knowledge (i.e. perception), and its perfection in design and function (i.e. sensation).

Discussion of the primacy of vision and the 'hierarchy of senses' did not remain in the circles of philosophers and the medical elite in nineteenth-century Britain. The importance of vision proliferated in popular print through contributions from medical and non-medical professionals. In 1856, in keeping with enlightenment thought, an article in The North British Review declared that 'of all the Five Senses... by which we acquire our knowledge of the external world, the form, the colour, and the properties of matter, the sight is the most important'. ${ }^{10}$ Two years later 'A CHAPTER ON EYES' stated that not 'the mechanism of the ear, nor the organism of taste, of smell, or of touch, is so full of interest'. ${ }^{11}$ Succinctly summarised at the end of the nineteenth century, contemporaries considered the eye as 'supereminently, amongst the organ of sense, the one which ministers to the intellectual operations. It deals almost exclusively with matters of experience and comparison'. ${ }^{12}$ In these studies, vision was positioned at the top of this hierarchal order because it was considered necessary for functioning in the nineteenth-century world. In 1839 the leading West Midlands ophthalmologist Richard Middlemore, for example, considered inflammatory diseases of the eye to be important and 'more

\footnotetext{
${ }^{8}$ V. Soderfeldt, R. Verstraete, 'From Comparison to Indices: A Disabling Perspective on the History of Happiness', Health, Culture and Society, 5.1 (2013), 249-264 (pp. 251-2); M. Morgan, Molyneux's Question: Vision, Touch and the Philosophy of Perception (Cambridge: Cambridge University Press, 1977), pp. 7-11, 17; Darrin M. McMahon, Happiness: A History (New York: Grove Press, 2006), pp. 178-9.

${ }^{9}$ Chris Otter, The Victorian Eye: A Political History of Light and Vision in Britain, 1800-1910 (Chicago: University of Chicago Press, 2008), pp. 24-8.

${ }^{10}$ The North British Review, November 1856, p. 145.

${ }^{11}$ Chambers's Journal of Popular Literature, Science and Arts, 11 December 1858, p. 378.

${ }^{12}$ The Edinburgh Review, October 1881, p. 543.
} 
important indeed than are the frequent results of inflammation of other parts, whose functions are, nevertheless, essential to the persistence of life'. ${ }^{13}$ In 1885 an American ophthalmologist, David F. Lincoln, took this a step further. Rather than being simply superior to vital organs, the eye and vision was associated with 'all the pleasures and duties of life'. ${ }^{14}$

However, alongside celebrations of the eye's importance was a preoccupation with its fallibility. Woolgar has stated that, parallel to a historical celebration of the eye's perfection and design, there has been a long-recognised consideration that the eye was especially vulnerable to disease. ${ }^{15}$ Martin Willis has also argued that ophthalmology and an increased study of the eye in the nineteenth century, led to better knowledge on potential eye diseases and weaknesses. These studies were not confined to the medical elite, and emerged in broader culture through public lectures and popular texts. Consequently, Willis has argued that focus on aberrations of the eye by ophthalmologists in the public sphere led to a culture of anxiety over vision and visual acuity. ${ }^{16}$ Eighteenth-century enlightenment thought investigated sensory impairments with a view of determining the more superior senses, but also the corresponding effects of their loss. A key debate, for example, was between the comparative advantages or disadvantages of being deaf and blind. ${ }^{17}$ Whilst these studies considered vision to be more important, individual experiences could be varied and, for some who were blind and deaf in the nineteenth century, deafness could be considered a 'deeper and more complex' 'problem'. ${ }^{18}$ Despite this, vision often appeared at the forefront of comparative sensory loss in this period. In 1856, for example, it was stated that 'nor does the superiority of sight to the other four senses seem less striking, when we consider what would have been the consequences

\footnotetext{
${ }^{13}$ Richard Middlemore, Introductory Lecture on the Anatomy, Physiology and Diseases of the Eye, Delivered at the Birmingham Royal School of Medicine and Surgery, 4 October 1839 (London: S. Longman, Orme, Brown, Green and Longmans, undated), p. 5; D.C. Lloyd-Owen, 'British masters of Ophthalmology Series: II - Richard Middlemore (1804-1891),The British Journal of Ophthalmology, 1 February 1920, pp. 49-53 http://bjo.bmj.com/content/bjophthalmol/4/2/48.full.pdf [accessed: 18 April 2018].

${ }^{14}$ David F. Lincoln, School and Industrial Hygiene (Philadelphia: P. Blakiston, 1885), p. 53.

${ }^{15}$ Woolgar, pp. 178-9, 184.

${ }^{16}$ Willis, p. 174.

${ }^{17}$ Soderfeldt and Verstraete, pp. 252-3; Morgan, see for example, pp. 7-11, 17-40.

${ }^{18}$ Gooday and Sayer, p. 49.
} 
had we been limited to one... it is difficult to imagine the condition of a world where space is impervious to light, or man insensible to its impressions' ${ }^{19}$

David Turner has proposed in his study of disability and emotion that 'hierarchies of the senses produced hierarchies of impairment' ${ }^{20}$ Contemporaries, perhaps not taking into account individual experience, argued that there were more severe consequences for those whose vision became impaired or marred. In 1888 The Edinburgh Review, for example, drew upon the history of comparative sensory loss to declare:

...it is better to preserve the eye in its highest natural vigour... and to avoid those risks and diseases that necessitate operations and lead to impairment of its powers. There is a wide difference between defective hearing and defective sight, as far, that is, as the enjoyment of life is concerned. ${ }^{21}$

Earlier in the century, a review of a medical text in a popular magazine also stated that 'to lose or to injure one's sight is drawing a veil over all the glories and almost all the comforts of this life'. ${ }^{22}$ This review discussed both partial and total loss of sight in this context. However, it was not only a loss of enjoyment that was considered and eye defects could be conceptualised as a 'disease' that could restrict the 'sufferer'. ${ }^{23}$

The status of vision and concern over its fallibility helped to justify intervention by the medical elite. Medical practitioners used this discourse to successfully create the first medical speciality that was not associated with quackery: ophthalmology. ${ }^{24}$ An international community of ophthalmologists were established during the latter half of the nineteenth century, and an Ophthalmological Society was set up in the UK in $1880 .^{25}$ In 1881 the president of the Ophthalmology Section at the British Medical Association reflected on the International Congress of Ophthalmology and how the position of the discipline had changed:

\footnotetext{
${ }^{19}$ The North British Review, November 1856, p. 146.

${ }^{20}$ David M. Turner, 'Disability History and the History of Emotions: Reflections on EighteenthCentury Britain', Asclepio, 68.2, http://dx.doi.org/10.3989/asclepio.2016.18 [accessed 2 June 2018].

${ }^{21}$ The Edinburgh Review, October 1888, p. 146.

${ }^{22}$ The Metropolitan Magazine, September 1835, p. 10.

${ }^{23}$ Aberdeen Weekly Journal, 18 February 1885.

${ }^{24}$ Davidson, 'Identities Ascertained', pp. 331-2; Otter, p. 34; Mary Carpenter, Health, medicine and society in Victorian England (Santa Barbara CA: Praeger, 2009), p. 144.

${ }^{25}$ Gooday and Sayer, p. 51.
} 
Our branch of practice... stood in a sort of isolation...To-day we are obviously one among many members of the entire medical commonalty, and our work is admitted to be of the highest value, not only for its own sake, but for the beneficial influence which its aims and methods exercise over the whole field of medicine. ${ }^{26}$

Alongside the establishment of ophthalmology as a discipline, the invention of the ophthalmoscope in 1851 by Hermann von Helmholtz enabled the user to see inside the eye for the first time. The ophthalmoscope acted as a diagnostic tool for disease. However, it also allowed the refractive condition of the eye to be observed and fully understood. ${ }^{27}$ As part of this development, a number of medical texts proliferated in the second half of the nineteenth century. Significantly, many of these texts were aimed at the public, and stressed the importance of looking after, and understanding, the eye. In 1833 a review of one suggested that 'the value of the hints and cautions in the chapter on preserving the sight \&c. is so very great, and they should be engraven on the palms of the hands of all such individuals'. ${ }^{28}$ This concern can be seen as part of the increased measurement of the eye. For the first time, the ophthalmoscope and newly invented eyesight test charts had identified the 'normal' visual range and the range of vision errors that existed. ${ }^{29}$

Medical practitioners were not only emphasising the importance of maintaining eyesight, but were also alarmed by the increasing number of vision defects being recorded. Comment on the fallibility of vision accelerated in the late nineteenth-century popular press. In 1884 an article in The Morning Post reflected on the contemporary fear that future generations could become blind:

The culture of the eyes and efforts to improve the faculty of seeing must become matters of attentive consideration and practice, unless the deterioration is to continue and future generations are to grope about the world purblind. ${ }^{30}$

These fears can be seen as part of a wider culture of anxiety surrounding the health of the eye in nineteenth-century society. ${ }^{31}$ Focus on the eye and vision was part of an important medical and popular concern: the deterioration of eyesight, which

\footnotetext{
${ }^{26}$ William Bowman, 'An Address Delivered at the Opening of the Section of Ophthalmology', British Medical Journal, 13 August 1881, pp. 277-279.

${ }^{27}$ See, for example, Wolfgang H. Vogel and Andreas Berke, Brief History of Vision and Ocular Medicine (Amsterdam: Wayenborgh Publishers, 2009), pp. 221-3; See also, for example, Daniel M. Albert, 'Ocular Refraction and the Development of Spectacles', in The History of Ophthalmology, ed. by Daniel M. Albert and Diane D. Edwards (Oxford: Blackwell Science, 1996), p. 109.

${ }^{28}$ The New Monthly Magazine and Literary Journal, May 1833, p. 102.

${ }^{29}$ See pp. 77-81 for more discussion on the value of ophthalmoscope and its role in vision testing.

${ }^{30}$ The Morning Post, 18 September 1884.

${ }^{31}$ Otter, pp. 42-5; Gooday and Sayer, p. 50.
} 
existed alongside discussion of the diseases and vulnerability of the eye. At the end of the nineteenth century, an article entitled 'TEST YOUR SIGHT' commented on the increasing frequency with which vision was being measured and the prevailing perception that there was an unprecedented attention and need for care. ${ }^{32}$ A number of extracts from the texts of medical practitioners were published in London and provincial newspapers. In 1880, for example, The Morning Post reviewed a recent publication on vision and the eye by Robert Brudenell Carter, a prominent ophthalmologist, in relation to the 'prevalence of defective or impaired vision in the present day'. ${ }^{33}$ Focus on the state of people's vision in popular print was presented as a national, as well as a medical, concern. In 1883 The Leeds Mercury reported on the Health and Education Department and the view that 'our nation is becoming prone, so much so that every ophthalmologist is constantly treating cases of myopia' ${ }^{34}$ Other newspapers also used medical authorities to comment on this, and in 1889 The Pall Mall Gazette had a grabbing headline, 'The Increase of Short Sight'. ${ }^{35}$ Alongside these extracts whole public and medical lectures were also transcribed. These lectures reported on the advancing numbers of vision defects; presented the concern as a public issue; and, in some instances, called for and encouraged further studies in ophthalmology in light of these findings. ${ }^{36}$

Concerns about the potential consequences that were believed to arise from this increase in vision defects were emphasised through medical discussion. In 1883 an extract from the Medical Times and published by two newspapers posited:

We shall become an island full of round-backed, blear-eyed book worms, poor of heart and small of soul, instead of a nation of men and women, strong of limb, graceful in movement, nimble-handed, quick-sighted, clear-headed, tender and true - a nation as we would all wish the English to become. ${ }^{37}$

Here, deterioration of vision was described as a pressing problem that would have nation-wide effects on health. Whilst this concern was presented largely through the voice and opinion of the medical elite, popular columns and articles also asked the

\footnotetext{
${ }^{32}$ The Wesleyan-Methodist Magazine, February 1895, pp. 96-8.

${ }^{33}$ The Morning Post, 12 February 1880.

${ }^{34}$ The Leeds Mercury, 5 October 1883.

${ }^{35}$ The Pall Mall Gazette, 16 July 1889.

${ }^{36}$ See, for example, 'Notes on Current Science', The Wesleyan-Methodist Magazine, March 1885, pp. 219-220; Trewman's Exeter Flying Post or Plymouth and Cornish Advertiser, 18 June 1892; The Belfast News-Letter, 27 October 1896.

${ }^{37}$ The Morning Post, 12 October 1883; 'Educational Over-Pressure', The Star, 16 October 1883.
} 
same questions and provide evidence that medical opinion was reaching a wider audience. In 1889 an article in the Illustrated London News also questioned 'To what are we coming? ... Now we are informed by men of science that the eyes used so effectively by our forefathers will not suffice for us, and that there is a prospect of England becoming purblind' ${ }^{38}$ This article considered schooling, heredity and the nineteenth-century physical environment to be potential factors in this acceleration.

The 'deterioration of vision' that characterised late nineteenth-century writing was believed to derive from two main causes: individual accountability and changes in the environment. This concern can be placed in the wider context of Victorians' preoccupation with health. Karen Bourrier and Bruce Haley have shown how changes in the nineteenth-century environment, such as urbanisation and industrialisation, were affecting contemporary notions of vitality and masculinity, as well as the physical and mental state of healthiness. ${ }^{39}$ In particular, Haley has highlighted how a range of diseases were diagnosed in the nineteenth century. However, Haley also has shown that the Victorian public were exposed to a range of 'new' conditions, without any established or effective treatment plan for curing them. ${ }^{40}$ The deterioration of vision presented a similar problem. 'Myopia' was frequently acquainted with 'disease', but there was little awareness of what was causing it or how to manage it. ${ }^{41}$ In 1896 the medical elite's primary concern was posed through a simple question in the popular column 'Table Talk' from The Leeds Mercury: 'How is it that at present everybody one knows has suddenly become short-sighted ${ }^{\prime 42}$ In answering this question, medical professionals emphasised the need to care for vision and could identify problems on an individual level. ${ }^{43}$ 'Carelessness', for example, was a term frequently used by general public

\footnotetext{
38 'With Spectacles on Nose', Illustrated London News, 12 January 1889, p. 56.

${ }^{39}$ Karen Bourrier, The Measure of Manliness: Disability and Masculinity in the Mid-Victorian Novel (Ann Arbor: University of Michigan Press, 2015), pp. 2-3, 9-12; Bruce Haley, The Healthy Body and Victorian Culture (London: Harvard University Press, 1978), pp. 3-5.

${ }^{40}$ Haley, pp. 5-6.

${ }^{41}$ Robert Brudenell Carter, Eyesight in Schools: A Paper Read Before the Association of Medical Officers of Schools on April 15 $5^{\text {th }}, 1885$ (London: Harrison and Sons, 1885), p. 13; Edward G. Loring, Is the Human Eye Changing its Form Under the Influence of Modern Education (Publisher not identified, 1878), p. 22; Robert Farquharson, School Hygiene and Diseases Incidental to School Life (London: Smith, Elder, 1885), p. 363; See also examples in popular print: The Leisure Hour, January 1889, p. 64; The Pall Mall Gazette, 16 July 1889.

${ }^{42}$ The Leeds Mercury, 4 April 1896.

${ }^{43}$ Willis, pp. 180-181; for comment on this in contemporary newspapers see, for example, The Standard, 21 December 1881, p. 5; The Yorkshire Herald, and the York Herald, 21 January 1892.
} 
commentators to describe people's attitude to their own vision. ${ }^{44}$ Similarly, a review of Carter's work by The Academy in the second half of the nineteenth century claimed that 'it is a very singular fact that the human race collectively troubles itself but little about its eyesight' ${ }^{45}$ However, some individuals were blamed when the responsibility lay either with the state or beyond their control. ${ }^{46}$

The problem of vision was predominantly situated in the nineteenth-century environment and broader changes in leisure. Contemporaries studied the urban environment and its effect on vision, in a similar manner to other public health concerns such as hygiene and water supply. ${ }^{47}$ Rosemarie Garland-Thomson has argued that the twenty-first century, due to the visual demands of a built environment, cemented vision's position at the top of the hierarchy of the senses. ${ }^{48}$ Whilst the eye was already revered and considered the 'quintessential organ' in the nineteenth century, an environment that demanded visual acuity and the primacy of vision was also being developed. Otter has proposed that the development of cities, street signs, house numbers and street lamps demanded an unprecedented level of visual acuity in Victorian Britain. However, Flint has argued that this increased visual culture, led to discussion of the built environment in relation to bodily health, physical and mental limits, and eyestrain. Collectively, Otter and Flint have suggested that greater comment on eye strength, as seen in this chapter, was based on the increased importance of vision in the environment of nineteenth-century society, and the development of new popular practices that subjected it to strain. ${ }^{49}$

In 1892 an article entitled 'Some Social Changes in Fifty Years' connected improvements in urban life with deteriorating eyesight. It argued that the 'inestimable benefits' of improved lighting and attractiveness of shop fronts and thoroughfares must be set against 'the increase of spectacle-wearers and other

\footnotetext{
${ }^{44}$ Richard Hengist Horne, 'Eyes and Eyeglasses: A Friendly Treatise', Fraser's Magazine, December 1876, p. 709; 'The Care of the Eyes', Bow Bells: A Magazine of General Literature and Art for Family Reading, 1 March 1877, p. 208.

${ }^{45}$ The Academy, 3 July 1880 , p. 7.

${ }^{46}$ Willis, p. 181.

${ }^{47}$ For a brief discussion of this see, for example, Haley, p. 9.

${ }^{48}$ Rosemarie Garland-Thomson, Staring: How We Look (Oxford: Oxford University Press, 2009), p. 26.

${ }^{49}$ Otter, pp. 52-54, 61; Flint, p. 8.
} 
indications of a decidedly lower sight average' ${ }^{50}$ Attention was drawn to this relationship between urban living and vision by the ophthalmologist James Ware in the early nineteenth century. Ware stated that 'myopia was more prevalent among inhabitants of cities and towns, or those who applied eyes upon smaller objects... than it was among the inhabitants of the country, where the application of the eyes was less'. ${ }^{51}$ Medical practitioners, therefore, perceived that the closer proximity of buildings and signage in cities prevented inhabitants from exercising their full ocular range. By the end of the nineteenth century, the medical elite referred to a phenomenon that they termed 'urban myopia' and discussed short sight in relation to the built environment. In 1885 an extract from the Medical Times that appeared in a two newspapers had the headline 'URBAN MYOPIA' and discussed 'a form of myopia to which dwellers in populous places are particularly subject' ${ }^{52}$ This view was corroborated in a medical lecture that occurred in the same month, and later by more popular comment in the Illustrated London News. ${ }^{53}$

However, it was not just the development of towns; the products of civilisation were also referred to as part of a commentary on social change. A variety of protective vision aids developed in response to changing pastimes and transport methods in the nineteenth century, and as part of wider medical knowledge on the need to guard the eye from wind, dust or bright light. ${ }^{54}$ In 1890 an advertisement from Thomas Harris \& Son highlighted that there were frames suited to a range of protective functions, as well as physical activities:

THOS HARRIS and SON'S SPECTACLES for BICYCLISTS THOS HARRIS and SON, SPECTACLES for CYCLISTS THOS HARRIS and SON, SPECTACLES for LAWN TENNIS THOS HARRIS and SON, SPECTACLES for BILLIARDS THOS HARRIS and SON, SPECTACLES for SHOOTING THOS HARRIS and SON, SPECTACLES for CRICKET THOS HARRIS and SON, SPECTACLES, from 3s THOS HARRIS and SON, SPECTACLES for PROTECTION from SUN THOS HARRIS and SON, SPECTACLES for PROTECTION from DUST THOS HARRIS and SON, SPECTACLES for PROTECTION from WIND

\footnotetext{
${ }^{50}$ The Nineteenth Century: A Monthly Review, March 1892, p. 465.

${ }^{51}$ Loring, p. 7.

${ }^{52}$ Liverpool Mercury, 14 February 1885; Hampshire Telegraph and Sussex Chronicle, 21 February 1885.

${ }^{53}$ Aberdeen Weekly Journal, 18 February 1885; Illustrated London News, 12 January 1889, p. 56.

${ }^{54}$ Frames changing in relation to the environment or views on ocular health are also discussed by Alun Withey, Self-Fashioning and Politeness in Eighteenth-century Britain: Refined Bodies (Basingstoke: Palgrave Macmillan, 2016), p. 107 and William Rosenthal, Spectacles and Other Vision Aids: A History and Guide to Collecting (San Francisco, CA, Norman, 1996), p. 294.
} 


\section{THOS. HARRIS AND SON, OPTICIANS, 32 GRACECHURCH-STREET. ${ }^{55}$}

Contemporary commentators also commented on the 'several' or 'infinite number' of frames that had been developed across the nineteenth century to protect the eye. ${ }^{56}$ These frames, particularly the early Double D-spectacles which were designed to provide protection when travelling, have been discussed and explored in a number of previous works and can be seen in Figure 1.1. ${ }^{57}$

Figure 1.1. Science Museum's Dunscombe collection 1921-323/122, an example of a tinted pair of Double-D Spectacles.

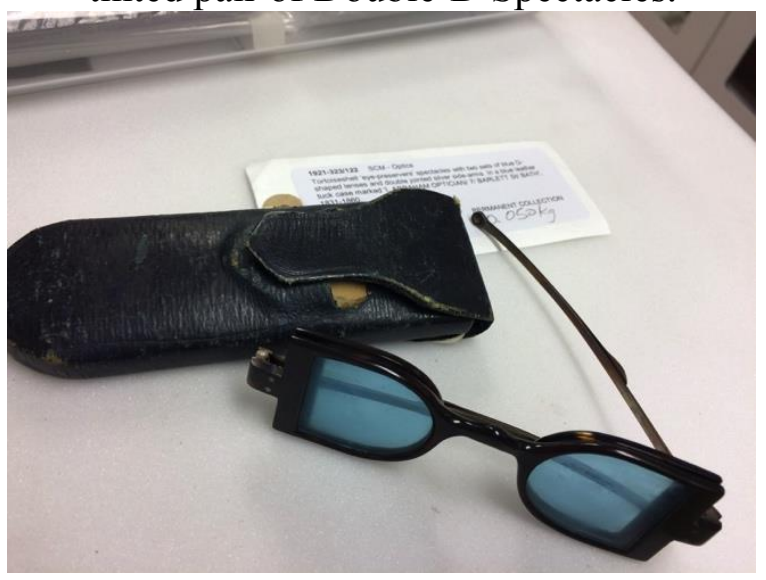

Patents abound in the nineteenth century for the type of protective spectacles mentioned in Harris \& Son's advertisement - protecting against bright light and environmental hazards, including dust and fumes - and the manufacture of tinted lenses for a range of functions. ${ }^{58}$

\footnotetext{
${ }^{55}$ Daily News, 13 September 1890.

${ }^{56}$ See, for example, Horne, Fraser's Magazine, December 1876, p. 719; William White Cooper, On Near Sight, Aged Sight, Impaired Vision and the Means of Assisting Sight, $2^{\text {nd }}$ edn (London: John Churchill, 1853), p. 327.

${ }^{57}$ Rosenthal, pp. 284-9, Withey, p. 107; Derek C. Davidson, Spectacles, Lorgnettes and Monocles (Buckinghamshire: Shire, 2002), pp. 30-2; 'Development of Spectacles: $1^{\text {st }}$ half of the Nineteenth Century', Ophthalmic Antiques International Collectors Club Newsletter, No. 16 (1986), 4; Neil Handley, Cult Eyewear: The World's Enduring Classics (London: Merrell Publishers Ltd, 2011), p. 16.

${ }^{58}$ See, for example, Protection Against Light: Patent Number 471, 22 February 1871; Patent Number 237, 18 January 1877; Patent Number 4760, 17 Mach 1891; Protection from the Environment: Patent Number 55, 7 January 1865; Patenet Number 2438, 8 October 1860; Patent Number 3116, 5 November 1867; Patent Number 3056, 22 November 1870; Patent Number 2393, 10 August 1872; Patent Nmber 1852, 22 May 1873; Patenet Number 998, 18 March 1875; Patent Number 3701, 25 October 1875; Patent Number 5086, 18 March 1884; Patent Number 11,443, 18 June 1892; Patent Number 23,095, 3 December 1895; Patent Number 16,799, 15 July 1897; Patent Number 24, 832, 26 October 1897; Patent Number 18, 363, 26 August 1898; Patent Number 21, 347, 25 October 1899. Tinted lenses: Patent Number 2699, 31 October 1863; Patent Number 647, 27 March 1858; Patent Number 3678, 3 December 1868; Patent Number 1772, 6 July 1871; Patent Number 1570, 22 May 1872; Patent Number 857, 9 March 1874; Patent Number 4572, 3 December
} 
These frames provide an explicit example of contemporary desires to protect the eye against changes in the nineteenth-century environment, and how vision aids could be used in response to these concerns. The majority of tinted spectacles and eyeglasses in the Museum's collection served a solely protective function and did not have a prescription. ${ }^{59}$ In particular, newspaper advertisements and medical practitioners highlighted how tinted lenses could be used for therapeutic purposes. ${ }^{60}$ This concept continued across the century, and the medical trade catalogues by James Woolley Sons \& Co. in 1894 and 1896 placed tinted spectacles separate from vision aids in the section on 'Sick Room Appliances' ${ }^{61}$ However, tinted lenses were also developed to protect against certain environments. ${ }^{62}$ The use of tinted lenses can be seen as part of a newfound importance to protect the eyes, in response to a range of changing transport methods and pastimes. Advertisements, for example, acknowledged the ability of tinted lenses to protect against weather conditions when outside or travelling, and stated that they were used particularly in the 'sunny and dusty season'. ${ }^{63}$ Medical practitioners also discussed the increased demand for this form of lens during summer. Both Charles A. Long and Joel Soelberg Wells in the mid-century proposed the perceived benefit of wearing neutral tint to prevent 'dazzling' at the sea-side or other 'watering places and towns of fashionable resorts

1877; Patent Number 973, 7 March 1881; Patent Number 3676, 27 July 1883; Patent Number 6252, 22 March 1899.

${ }^{59}$ This conclusion has been drawn from an analysis of 132 of spectacles and eyeglasses with a tinted lens in the Science Museum's Ophthalmology and Dunscombe collections.

${ }^{60}$ See, for example, medical texts: Charles A. Long, Spectacles: When to Wear and How to Use Them: Addressed to Those who Value Their Sight, $2^{\text {nd }}$ edn (London: Bland and Long, 1856), pp. 1920; Joel Soelberg Wells, Short and Weak Sight and Their Treatment by the Scientific Use of Spectacles (London: J.A. Churchill, 1862), pp. 71-2; Walter Alden, The Human Eye; its Use and Abuse: A popular Treatise on Near and Impaired Sight, and the Methods of Preservation by the Proper Use of Spectacles (Cincinnati: The Author, 1866), pp. 100, 120; and also newspaper advertisements that consider them for 'sensitive eyes' or those 'labouring under nervous debility': Aberdeen Weekly Journal, 21 April 1878; 3 July 1878; Hampshire Advertiser \& Salisbury Guardian Royal Yacht Club Gazette, Southampton Town and Country Herald, Isle of Wight, Winchester Chronicle, and General Reporter, 20 May 1837; 27 May 1837; 17 June 1837; 29 July 1837

${ }^{61}$ James Woolley Sons \& Co., Catalogue of Surgeons' Instruments and Medical Appliances (1894), p. 347 and (1896), p. 480.

${ }^{62}$ Thos Harris \& Son, A Brief Treatise on the Eyes, Defects of Vision, and the Means of Remedying the Same by the Use of Proper Spectacles, Also Rules for judging when Spectacles are necessary, and Directions for selecting them (London: Onwhyn, 1839), p. 28; John Browning, Our Eyes and How to Preserve Them from Infancy to Old Age. With Special Information About Spectacles, $7^{\text {th }}$ edn (London: Chatto \& Windus, 1887), pp. 104-6.

${ }^{63}$ See, for example, The Ipswich Journal, 3 June 1854 or The Blackburn Standard, 13 January 1836; 20 January 1836. 
such as Brighton, Cheltenham'. ${ }^{64}$ Similarly, in the 1890s The Optician suggested that 'holiday-seekers especially patronise these sunshades' and noted that:

The holiday season brings with it a demand for the goggles and coloured eyeglasses so much in vogue with pleasure seekers, especially those who patronise seaside resorts. ${ }^{65}$

Besides their use at seaside resorts, the London optician John Browning proposed that protective vision aids were designed parallel to wider developments in transportation. In 1887 Browning advised that tinted folders should be worn by those who 'ride, drive, or cycle' in bright light for protection, particularly on the chalk roads in 'the South of London, and in Kent generally'. ${ }^{66}$

Sedentary pursuits as part of the urban environment were also a cause for concern, and a number of preventative measures were discussed to help protect the eye. However, rather than necessitating the use of protective vision aids, the development in print and increased use of close-work also highlighted the refractive capacity of a person's eyes. In 1898 an article entitled 'The Vaunts of Modern Progress' suggested that there was a growth in defective eyesight, and a number of 'new nervous diseases, exclusively consequence of the present conditions of civilised life'. ${ }^{67}$ Alongside the enclosed streets of cities and towns, attention was drawn to a more sedentary lifestyle in the form of education, and the proliferation of print, which caused an increase in reading for leisure. In 1885 an article had stated that people now desired to read beyond school life and as a result 'a painfully significant sight may be seen any day on London streets', in which 'through dense jostling crowds, in jammed omnibuses, in dimly-lighted underground railwaycarriages, you may see men of all conditions with a book in hand, trying to read, risking their eyesight'. ${ }^{68}$ Specifically, the article considered the written language to be threatening the position of the spoken language. This argument is similar to later criticism on the primacy of vision in city environments that created a social passivity whereby people look, rather than communicate. ${ }^{69}$

\footnotetext{
${ }^{64}$ Long, p. 20; Wells, pp. 71-2.

${ }^{65}$ The Optician, 4 June 1891, p. 160; 7 July 1892, p. 279.

${ }^{66}$ Browning, pp. 104-6.

${ }^{67}$ The Scottish Review, July 1898, pp. 103-104.

${ }^{68}$ The Nineteenth Century: A Monthly Review, March 1885, p. 497.

${ }^{69}$ See, for example, George Simnel and Christoph Asendorph quoted in Otter, pp. 23-4.
} 
The opinion that written material could subordinate the spoken word was not unfounded. Both medical and non-medical professionals commented on the increasing amount of printed material in the nineteenth century. One contemporary, for example, argued that 'the art of printing has added a tenfold value to this organ... it may emphatically be called the reading age' ${ }^{70}$ However, beyond the general spread of the book, there was also detailed attention given to poor printing standards and the small type in newspapers and popular print. Quicker and more efficient communication was achieved by the removal of the Stamp Duty in 1855, the Paper Duty in 1861, and innovations in technology and transport. This, in turn, caused the sales and production of popular print to increase dramatically in the latter half of the century. ${ }^{71}$ Whilst the effect of these developments on readership numbers is difficult to determine, O’Malley and Solely calculated that newspaper circulation rose by 600 per cent between 1856 and $1881 .^{72}$ In 1876 Richard Hengist Horne, in his 'Friendly Treatise' on eyeglasses argued against 'youthful readers of the cheap editions of sensational novels... faded ink, upon bad paper of uneven surface' ${ }^{73}$ Similar to Reynolds' description of reading as the 'fashion of the day', Horne concluded that people now passed 'the greater part of their lives in reading or writing'. ${ }^{74}$

It was the 'artificial' nature of sedentary pursuits such as reading or writing that was thought to adversely affect vision. In 1885 Carter, for example, concluded that 'myopia appears to be a malformation, artificially created in the first instance' ${ }^{75}$ To emphasise this point, comparisons were made between animals and 'savages' across the century by medical authorities. In December of 1890 , for example, an experiment into the effects of captivity on animals' eyes that had been discussed at a recent meeting of the Paris Academy of Medicine was frequently reported. ${ }^{76}$ In 1890 the Aberdeen Weekly Journal also quoted a medical lecture, which stated that 'shortsightedness was not a natural state of the eye, because it was unknown among

\footnotetext{
${ }^{70}$ The Monthly Review, July 1842, p. 297.

${ }^{71}$ Denise Bates, Historical Research Using British Newspapers (Barnsley: Pen and Sword History, 2016), pp. 5-6; Mick Temple, The British Press (Maidenhead: Open University Press, 2008), pp. 15, 18 .

72 Cited in Kevin Williams, Read All About It!: A History of the British Newspaper (London: Routledge, 2010), p. 5.

${ }^{73}$ The Monthly Review, July 1842, p. 298; Horne, Fraser's Magazine, December 1876, p. 706.

${ }^{74}$ Ibid., p. 706; The Monthly Review, July 1842, p. 297.

${ }^{75}$ Carter, p. 12.

${ }^{76}$ Manchester Times, 26 December 1890; The Belfast News-Letter, 30 December 1890; The Star, 30 December 1890; The Yorkshire Herald, and the York Herald, 30 December 1890.
} 
savages and never found in animals. It was clearly an accompaniment of civilisation'. ${ }^{77}$ Medical professionals investigated the effects of race and environmental conditions on vision, and the aborigines of Bengal, 'a large number of Hindoos' and 'negroes' became the focus of certain studies. ${ }^{78}$ As early as 1884 , Simeon Snell, ophthalmologist and former President of the British Medical Association, had concluded 'Savages are, of course, noted for their wonderful range of vision'. ${ }^{79}$ Conclusions such as this were used to support contemporary opinion that deteriorating vision was an accompaniment of urban environments and modern leisure pursuits, which were specific characteristics of the western world.

Whilst eye conditions such as myopia could be seen as a product of civilisation, there were concerns about their transmission. In 1885 Carter, for instance, stated that although artificially created in the first instance it was 'liable, like all other artificial malformations to be handed to offspring, ${ }^{80}$ Concerns about the hereditary nature of vision can be seen as part of a wider anxiety to ensure the health of the future population in the nineteenth century, which encompassed studies such as eugenics and national or parental health. ${ }^{81}$ In 1883 vision was included as part of a broader lecture on 'Heredity' at the opening of medical classes at Aberdeen University. ${ }^{82}$ From the later nineteenth century the tendency towards short sight was reported in newspapers to be 'undeniably hereditary'. ${ }^{83}$ This was also reflected in articles and correspondence in the British Medical Journal in the $1880 \mathrm{~s} .{ }^{84}$ However, in 1887 Loring stated that 'hereditary influence alone could never, at this late date, so increase the amount of myopia as to change the existing standard, or normal eye, to a near-sighted eye'. ${ }^{85}$ In 1890 an article on 'Heredity' in The Morning Post also

\footnotetext{
${ }^{77}$ Aberdeen Weekly Journal, 27 January 1890.

${ }^{78}$ Loring, p. 13; Simeon Snell, Influences of School Life on Eyesight (London: Wyman \& Sons, 1884), p. 6.

${ }^{79}$ Snell, Influences of School Life on Eyesight, p. 6; 'Obituary: Simeon Snell, F.R.C.S.Edin, D.Sc. Sheffield', British Medical Journal, 24 April 1909, pp. 1031-1033.

${ }^{80}$ Carter, p. 12.

${ }^{81}$ See, for example, David M. Turner, Disability in Eighteenth Century England (London: Routledge, 2012), p. 50; Joanne Bailey, Parenting in England, 1760-1830 (Oxford: Oxford University Press, 2012), pp. 100-2.

${ }^{82}$ Aberdeen Weekly Journal, 25 October 1883.

${ }^{83}$ The Pall Mall Gazette, 16 July 1889; The Leeds Mercury, 5 October 1883.

${ }^{84}$ See, for example, Henry Hadlow, 'Short Sight Amongst the Boys of Greenwich Hospital School', British Medical Journal, 19 May 1883, pp. 952-954; W.W. Ireland, 'Eyesight and the Education Act', British Medical Journal, 26 January 1889, p. 213.

${ }^{85}$ Loring, p. 7.
} 
concluded that the majority of people were shortsighted because of their lifestyles, and not as a result of inheritance. ${ }^{86}$ Vision can be located in an interesting dimension of contemporary eugenic discussions, because civilisation itself was seen to be the primary cause of this transmittable, degenerative trait. Medical professionals and information available in the public domain argued that there were two contributable factors to short sight. As proposed by Carter, the increase, in myopia at least, lay heavily in the conditions of life as well as a hereditary predisposition to vision defects. $^{87}$

Alongside generating the use of protective vision aids, the changes in the nineteenth-century environment exposed and encouraged discussion of the population's visual acuity. Two specific areas of the nineteenth century-environment received increasing attention in the discussion of vision and its deterioration: schools and the workplace. Both underwent numerous investigations by medical professionals, and were prominent in newspapers and periodicals. Following the Education Act in 1870, education and work would have been the two dominant areas of nineteenth-century life for the majority of people. Whilst the deterioration of vision in association with cities and towns has primarily involved discussions of myopia, education and work have been studied to explore the range of vision defects that were discussed; the extent to which they can be seen as causal factors; and how they can be used as examples to propose that eyesight underwent unprecedented measurement and became medicalised by the late-nineteenth century.

\section{Eyesight and Education}

Contemporaries often correlated vision defects with the environment of schools. Moreover, the school, following the 1870 Education Act, became an important part of medical practitioners' wider concern with 'civilisation'. Steps to make elementary education compulsory led to debates over its long-term effect on children's vision. In 1887 Dr Arthur Newsholme who wrote extensively on issues of public health, for example, stated that short-sight 'may be acquired, and it is chiefly during school-life

\footnotetext{
${ }^{86}$ The Morning Post, 5 May 1890.

${ }^{87}$ Carter, p. 12.
} 
that this occurs' ${ }^{88}$ In a broader context, children were considered representative of the future nation's health, and their health was considered paramount for the wellbeing of British society. ${ }^{89}$ Ensuring that vision was protected in the young was equally important; it was integral to attempts to curb both the fears and reality of deterioration.

The association between education and defective eyesight became a topic of international importance amongst medical practitioners during the nineteenth century, and this filtered down into popular texts, namely newspapers and periodicals. Richard Meckel has illustrated the value of studying medical journals alongside medical texts, in his study of the American school environment. ${ }^{90}$ However, in Britain, research has only focused on medical journals and school hygiene books. ${ }^{91}$ Furthermore, no study of eyesight and education in a British or American context has looked beyond the medical profession. As a result, this section studies a broader range of medical journals and school hygiene texts, and explores how these issues were presented in nineteenth-century newspapers and periodicals. Their discussion of education and eyesight followed a similar pattern to contemporary focus on vision as a whole: concern about a rise in defects; the role of environmental conditions; and the perceived negative effects that these vision errors could have. This section explores these, and analyses how measurement of vision in the school environment became increasingly part of the discussion and role of medical practitioners.

International studies on schools and visual acuity can be found across the nineteenth century in British popular print. However, Meckel has proposed that American studies accelerated in the last quarter of the nineteenth century, and the British press supports this trend. ${ }^{92}$ General references to the number of countries undertaking various studies on eyesight were made. In the 1880 s, for example, the

\footnotetext{
${ }^{88}$ Arthur Newsholme, School Hygiene: The Laws of Health in Relation to School Life (London: Swan Sonnenschein, Lowrey, 1887), p. 109; Review of John M. Eyler, Sir Arthur Newsholme and State Medicine, 1885-1935 (Cambridge: Cambridge University Press, 1997) by Christopher Hamlin, Bulletin of the History of Medicine, 72.3 (1998), 564-566.

${ }^{89}$ Bailey, pp. 100-2.

${ }^{90}$ Richard A. Meckel, Classroom and Clinic: Urban Schools and the Protection and Promotion of Child Health, 1870-1930 (New Brunswick: Rutgers University Press, 2013), pp. 23-30.

${ }^{91}$ Otter, pp. 43-5.

${ }^{92}$ Meckel, p. 27.
} 
Birmingham Daily Post and The Morning Post stated that examinations had occurred in Germany, Russia and America. ${ }^{93}$ Information on specific studies can also be found alongside these general references, and the results of particular studies seem to have attracted public attention. The examinations of Cohn from Breslau, which provided the groundwork for future investigations, were repeatedly published in the $1880 \mathrm{~s} .{ }^{94}$ A physician at Tübingen who explored the living and sanitary conditions of children, and located a relationship between weight and eyesight, was also reported extensively in both provincial and municipal newspapers throughout $1881 .^{95}$ Interest in studies on Germany in particular may be because, due to their early adoption of universal education, they were considered to have the worst eyesight in the Western world. In 1882 The Graphic stated that shortsightedness among children in school 'had long been a trouble in Germany', and others considered the German type and poor printing techniques. ${ }^{96}$ However, findings were also reported from studies in France and America. ${ }^{97}$ In particular, detail was given of these two countries' methods to halt the acceleration of vision defects in schools in the $1880 \mathrm{~s} .^{98}$ Significantly, whilst the reports on these new initiatives were written as the events occurred, studies by those such as Cohn were carried out in the 1860s and did not receive comment in British newspapers and journals until the later nineteenth century.

The delayed reporting on investigations into eyesight in the popular press could reflect the delayed uptake of the matter by British medical practitioners, and its

\footnotetext{
${ }^{93}$ The Morning Post, 18 September 1884; Birmingham Daily Post, 17 September 1884. Other examples can be found in The Huddersfield Daily Chronicle from 19 September 1884 and 20 September 1884.

${ }^{94}$ The Morning Post, 14 May 1881; The Leeds Mercury, 11 September 1888; The Leeds Mercury, 22 September 1888; Saturday Review of Politics, Literature, Science and Art, 15 May 1880, pp. 637-8; later examples include, The Practical Teacher, September 1900, p. 124.

${ }^{95}$ The Ipswich Journal, 16 August 1881; Birmingham Daily Post, 18 August 1881; The Leeds Mercury, 20 August 1881; The Belfast News-Letter, 20 August 1881; Liverpool Mercury etc, 18 August 1881; The Morning Post, 18 August 1881, p. 7; The Dundee Courier \& Argus, 18 August 1881; The Dundee Courier \& Argus and Northern Warder, 19 August 1881, p. 6; The Graphic, 10 September 1881.

${ }^{96}$ The Graphic, 3 June 1882. For general comment on increase in short sight and criticism of print see, for example, The Morning Post, 18 August 1881; The Morning Post, 29 August 1881; The Graphic, 10 September 1881.

${ }^{97}$ See, for example, Bentley's Miscellany, July 1867, p. 594; Book-Lore, November 1885, p. 182; The Practical Teacher, September 1900, p. 125.

${ }^{98}$ The Leisure Hour, September 1882, p. 576 and further mention of it in The Graphic, 3 June 1882; Other commissions and committees could be discussed such as one in Ohio in Chambers's Journal of Popular Literature, Science and Arts, 30 October 1880, p. 702 and a further one in France, The Royal Cornwall Gazette, Falmouth Packet, Cornish Weekly News \& General Advertiser, 8 July 1888, p. 2.
} 
relationship to the introduction of the Education Act in 1870. The late interest in education and eyesight by the British medical profession has also been shown in Meckel's study of American medical journals and texts, which date at least a decade or more earlier than significant attention to the subject in Britain. ${ }^{99}$ By the $1880 \mathrm{~s}$, British medical authorities began to comment on eyesight in schools, but also on the lack of a comparable study of short sight in Britain. The medical elite both requested and emphasised the necessity of specific studies in British schools and the state of British children's eyes. Although a British ophthalmologist, James Ware, was credited with pioneering the study of vision and education in the early nineteenth century, little had been done since then. ${ }^{100}$

A proliferation of articles on the subject in publications such as the British Medical Journal, and a variety of medical texts and lectures appeared from the 1880s. These drew comparisons with international studies and provided new statistics on the relationship between education and eyesight in children. This can be seen in articles in the British Medical Journal with such titles as 'Short Sight Amongst the Boys of Greenwich Hospital School', and an 'Abstract of a Report on the Vision of Children Attending London Elementary Schools'. ${ }^{101}$ In 1889 correspondence in the British Medical Journal also featured the topic of 'Eyesight and the Education Act'. ${ }^{102}$ Texts especially devoted to the subject began to be published from 1880, such as Priestley Smith's Short Sight in Relation to Education and Simeon Snell's Influence of School Life on Eyesight. ${ }^{103}$ Others by those such as Robert Brudenell Carter were also written and a landmark work on the school environment, by German Ophthalmologist Richard Liebreich, was translated into

\footnotetext{
${ }^{99}$ Meckel, pp. 23-30.

${ }^{100}$ Priestley Smith, Short Sight in Relation to Education (Birmingham: The Midland Educational Company, 1880), p. 13; Snell, Influences of School Life on Eyesight, p. 5; Loring, p. 7; See also comment for this in late nineteenth century periodicals: The Morning Post, 18 September 1884, p. 4; The Practical Teacher, September 1900, p. 124.

${ }^{101}$ Hadlow, pp. 952-954; Arnold Lawson, 'Abstract of a Report on the Vision of Children Attending London Elementary Schools', British Medical Journal, 18 June 1898, pp. 1614-1617; other examples, such as a discussion on 'The Vision of School Children' can also be found, 14 January 1899, pp. 77 78.

102 Ireland, 'Eyesight and the Education Act', p. 213.

${ }^{103}$ Priestley Smith, Short Sight in Relation to Education (Birmingham: The Midland Educational Company, 1880); Simeon Snell, Influences of School Life on Eyesight (Wyman \& Sons, 1884). Priestley Smith was a prominent Birmingham ophthalmologist, and later Emeritus Professor of Ophthalmology at the University of Birmingham, 'Obituary: Priestly Smith', The British Journal of Ophthalmology, 17.7 (1933), 442-445.
} 
English. ${ }^{104}$ This interest in some instances evolved into wider studies on the hygiene of schools and education, and considered broad themes such as physical education, ventilation, and mental health. ${ }^{105}$

British newspapers and periodicals provided information on specialised works and also commented on further investigations that attempted to fill the gap in British statistics. Current studies, for example, were reviewed and Carter's books, governmental reports and papers were particularly prominent in the1880s and 1890s. ${ }^{106}$ Likewise, other works, for example by Snell and Smith, were reviewed in popular form. ${ }^{107}$ The prominent position of the medical elite in popular discussion of this issue can also be gleaned through other means. Reports on lectures reveal interest in localised studies that were undertaken by medical practitioners. In $1890 \mathrm{a}$ paper that was reported in the Aberdeen Weekly Journal, for instance, read some notes from an investigation into children attending Aberdeen public schools. ${ }^{108}$ In 1899 another report on eyesight from schools in the local area, which had been requested by the Government, appeared in the Leicester Chronicle. ${ }^{109}$

Carter at the outset of his study declared: 'nothing is farther from my own wish than to play the part of an alarmist'. ${ }^{110}$ However, this may not have been the approach chosen by newspapers and periodicals in the late-nineteenth century, which emphasised the numbers of shortsighted children and had a certain tendency to use emotive language. In 1815, for example, an extract from an oculist's text on The Art of preserving the Sight described children as 'the poor martyrs... cooked up at home... until the little ones driven beyond their powers, can no longer support it

\footnotetext{
${ }^{104}$ Richard Liebreich, School Life in Its Influence on Sight and Figure: Two Lectures (London: J. \& A. Churchill, 1878); Robert Brudenell Carter, Eyesight in Schools: A Paper Read Before the Association of Medical Officers of Schools on April 15 $5^{\text {th }}, 1885$ (London: Harrison and Sons, 1885). ${ }^{105}$ Robert Farquharson, School Hygiene and Diseases Incidental to School Life (London: Smith, Elder, 1885); Arthur Newsholme, School Hygiene: The Laws of Health in Relation to School Life (London: Swan Sonnenschein, Lowrey, 1887).

${ }^{106}$ See, for example, Saturday Review of Politics, Literature, Science and Art, 15 May 1880, pp. 6378; The Academy, 3 July 1880, p. 7; Book-Lore, November 1885, p. 182; The Standard, 17 July 1896; The Bristol Mercury and Daily Post, 17 July 1896; Saturday Review of Politics, Literature, Science and Art, 18 July 1896, pp. 57-8; The Derby Mercury, 22 July 1896.

${ }^{107}$ The Athenaeum, 24 October 1896, pp. 567-8.

${ }_{108}$ Aberdeen Weekly Journal, 27 January 1890.

${ }^{109}$ Leicester Chronicle and the Leicestershire Mercury, 11 November 1899.

${ }^{110}$ Carter, p. 4.
} 
without complaining of their eyes'. ${ }^{111}$ These popular texts were perhaps prone to exaggeration. In 1885 Carter, for example, criticised a newspaper that had reported on one of his previous studies and distorted the evidence to scaremonger. ${ }^{112}$ However, they also acted as an invaluable source for large quantities of referenced information and whole extracts of lectures or texts were frequently reported in newspapers and periodicals. ${ }^{113}$ As early as 1814, James Ware's discussion of strain and pressure in schools was quoted along with the text's adjoining appendix. ${ }^{114}$ In a bid to encourage change, medical professionals also wrote explicitly for a pedagogical audience. In 1900 Arthur Newsholme, for example, wrote a column to be included in multiple editions of The Practical Teacher. ${ }^{115}$ The information provided in The Practical Teacher attempted to educate teachers on broader medical ideas. In discussion of homework, for example, the same information was presented in both the journal and the medical texts, because the same author had written them. ${ }^{116}$ However, this also highlights how the boundaries between readerships and different types of texts are not so clear-cut or easy to demarcate. It would be too simplistic to conclude that the general public read popular texts, or that medical texts were only consulted by a medical audience. Carter for instance suggested that his text on vision and eyesight could potentially be read by a wider, less educated, audience. $^{117}$

Jamie L. Bronstein has used the proliferation of newspapers articles on workplace accidents in the nineteenth century as evidence that readers focused intensely on this issue. ${ }^{118}$ The large quantities of information in both medical and popular texts suggest that the fear and anxiety about nineteenth-century education, and its association with the deterioration of eyesight, was both a medical and a public concern. The negative conditions of schools in popular and medical discussion were both material, in terms of desk and lighting, and practical, in terms

\footnotetext{
${ }^{111}$ The ArtThe Critical Review, or Annals of Literature, February 1815, p. 167.

${ }^{112}$ Carter, pp.4-5.

${ }^{113}$ See, for example, Aberdeen Weekly Journal, 27 January 1890; Leicester Chronicle and the Leicestershire Mercury, 11 November 1899.

${ }^{114}$ The Literary Panorama, January 1814, p. 985-993.

${ }^{115}$ See, for example, The Practical Teacher, August 1900, pp. 66-8; The Practical Teacher, September 1900, pp. 122-24.

${ }^{116}$ The Practical Teacher, September 1900, p. 124.

${ }^{117}$ Carter, p. 5.

118 Jamie L. Bronstein, Caught in the Machinery: Workplace Accidents and Injured Workers in Nineteenth-Century Britain (Stanford: Stanford University Press, 2008), p. 3.
} 
of type and length of study. ${ }^{119}$ These conditions can be broken down into four sections or themes that were found in the medical texts and journals: pressure, builtenvironment, homework, and physical education. In the British Medical Journal at the end of the nineteenth century, the Surgeon-Oculist to Queen Victoria, Arnold Lawson, stated that 'defective vision, especially as regards myopia, is frequently said to be on the increase, owing to the strain of the present system of higher education'. ${ }^{120}$ Children were considered vulnerable to the effects of education because of their age, which meant that the eye was not yet strong enough to cope with the strain. ${ }^{121}$ However, whilst strain was considered important, the school environment was thought to have an equally detrimental effect on the physical health of the eye. The majority of conclusions drawn up in a wide examination of vision in British schools proposed that deterioration of vision was as a result of school buildings. ${ }^{122}$ Wider international studies in the 1870 s and 1880 s- such as by the American ophthalmologists Edward Loring and D.F. Lincoln - also supported these British findings. These studies suggested that whilst current education was overworking its students, it was not study itself that was causing vision defects, but the environment in which children studied. ${ }^{123}$

In 1885 a text on British school hygiene was motivated by the lack of research, and the author's acknowledgment of its importance. ${ }^{124}$ This gap motivated the study of the school and home environment in a variety of British medical journals, texts, and hygiene manuals across the 1880s. In 1885 Carter, for example, argued that the environment of schools needed to be controlled because how the eyes were used in childhood would have a subsequent effect on their later development and functionality. ${ }^{125}$ As part of these concerns, the construction of schools could be studied meticulously and factors such as the dimensions of the building to maximise

\footnotetext{
${ }^{119}$ Otter, p. 44.

${ }^{120}$ Lawson, p. 1614; 'Obituary: Sir Arnold Lawson', British Journal of Ophthalmology, 31.4 (1947), 251-253.

${ }^{121}$ Loring, pp. 23-5.

${ }^{122}$ See, for example, Smith, pp. 32-3; Snell, Influences of School Life on Eyesight, pp. 5-12.

${ }^{123}$ Lincoln, pp. 45-78.

${ }^{124}$ Robert Farquharson, School Hygiene and Diseases Incidental to School Life (London: Smith, Elde \& Co., 1885), pp. 5-7.

${ }^{125}$ Carter, p. 3. However, in this text, he also questioned whether the influence of environment on eyesight was as 'real' as others have made out.
} 
light and the health of the eye were held to be significant. ${ }^{126}$ Additionally, beyond more broad hygiene manuals, Liebreich's translated work was a specific study of the design and construction of desks and seats. ${ }^{127}$ The home environment was scrutinised as part of wider studies on the conditions of schools and education, and many medical practitioners condemned the adoption of homework due to poor lighting and desk conditions. ${ }^{128}$ In 1884 Snell, for example, stated that 'the deleterious influence of home-lessons on the visual organs can hardly be questioned' ${ }^{129}$ However, homework was also criticised by medical contemporaries as particularly burdensome because it interrupted hours of 'ease' or 'play'. 130

In discussion of both the home and school environment, there was an emphasis on the need for exercise and the general physical health of children. ${ }^{131}$ Consideration of vision defects and the environment of schools can be placed in the broader context of discussion on children's health. As early as 1815 , for example, the school environment was criticised because of its sedentary nature, and a lack of exercise. ${ }^{132}$ In these discussions, vision defects were particularly alarming to the medical elite because they were believed to be rooted in the broader condition of the body and were associated with physical weakness and poor mental aptitude. ${ }^{133}$ However, they were also thought to alter a child's physical appearance, and myopia was believed to cause children to 'stoop' and become 'quiet' and 'pale'. ${ }^{134}$ This reference to pallor was part of a wider association between shortsightedness and unhealthiness in medical texts. The myopic eye for instance was not believed to be a 'strong' eye, and this was continually emphasised. ${ }^{135}$ Moreover, short sight was frequently placed in direct relation to the body's constitution in the 1870s and 1880s:

A sound physique - a healthy vigorous condition of the body generally - is antagonistic to the working of almost every morbid process, and even in the case of short sight... I will

\footnotetext{
${ }^{126}$ Newsholme, pp. iii-iv.

${ }^{127}$ Liebriech, School Life in Its Influence on Sight and Figure: Two Lectures.

${ }^{128}$ Smith, p. 22.

${ }^{129}$ Snell, Influences of School Life on Eyesight, p. 14.

${ }^{130}$ Ibid., p. 14; Newsholme, p. 66.

${ }^{131}$ Whilst there were no specific works relating to the relationship between physical education and vision, it was discussed as part of broader attempts to improve the school environment and prevent eyestrain. See, for example, Snell, Influences of School Life on Eyesight, pp. 15-16.

${ }^{132}$ The Critical Review, or Annals of Literature, February 1815, p. 171.

${ }^{133}$ See, for example, Lawson, p. 1615; Newsholme, p. 111; and popular discussion of this in Trewman's Exeter Flying Post or Plymouth and Cornish Advertiser, 18 June 1892.

${ }^{134}$ Smith, p. 12; Use of 'round-shouldered' is also mentioned in The Leeds Mercury, 22 February 1890 .

${ }^{135}$ See, for example, Lincoln, pp. 49, 54; Farquharson, p. 363; Carter, pp. 11-12.
} 
merely point out in passing that an impaired physique brings with it, amongst other evils, an impaired resistance to the active causes of short-sight. ${ }^{136}$

Alongside this description of 'impaired physique', was a range of other terminology that implied physical weakness, such as 'delicate'. ${ }^{137}$ Meckel has shown that this association was made by American ophthalmologists based on the systemic view of the body, which continued to be influential in medicine. ${ }^{138}$ This was also apparent in the writings of British ophthalmologists and medical practitioners, and can be most explicitly seen in their discussions of the relationship between vision defects and scoliosis. $^{139}$

Like wider changes in the nineteenth-century environment, the artificial conditions of compulsory education were thought to be causing and also highlighting vision defects in children. In 1896, an article from The Morning Post argued that: 'there is an obvious difficulty in apportioning such an increase between a more general recognition of defective eyesight among children and a growth of the defect itself'. ${ }^{140}$ The Morning Post proposed that the acceleration in vision defects reported amongst children in the nineteenth century may have been because of increased attention to the issue rather than an increase in actual numbers. Indeed, the proliferation of discussion on eye defects highlighted the issue, and encouraged standardisation.

Otter has argued that investigations into the environment and practice of education in schools attempted to 'normalise' the projected visual development of children. ${ }^{141}$ The development of ophthalmology, and the invention of the

\footnotetext{
${ }^{136}$ Smith, pp. 20-1; See also, Carter, p. 13; Loring, p. 22; Farquharson, p. 363; See also examples in popular print: The Leisure Hour, January 1889, p. 64; The Pall Mall Gazette, 16 July 1889. Loring also discussed the wider international consequences of the deterioration of eyesight in children, p. 2. ${ }^{137}$ Quoted in a review on 'Lectures on the Recent Progress of the Theory of Vision by Professor Helmholtz and Eyesight Good and Bad by Robert Brudenell Carter', The Edinburgh Review, October 1881, p. 539.

${ }_{138}^{138}$ Meckel, pp. 29-30.

${ }^{139}$ This point was first raised in Liebreich's seminal work, which was published in 1878. However, it appeared with frequency in medical and popular texts in the last two decades of the nineteenth century: Snell, Influences of School Life on Eyesight, p. 7; Farquharson, p. 23; Newsholme, p. 15. Hadlow, p. 953; Birmingham Daily Post, 11 January 1882; The Morning Post, 2 August 1883; the latter is also printed in Liverpool Mercury, 2 August 1883; Cheshire Observer, 21 June 1884; The Practical Teacher, September 1900, p. 124.

${ }^{140}$ The Morning Post, 16 July 1896.

${ }^{141}$ Otter, p. 43.
} 
ophthalmoscope in the mid-century, helped diagnose a range of refractive vision errors for the first time. However, these studies, and the development of eye charts and testing techniques, also meant that children's vision was increasingly measured against a newly formed standard: the emmetropic eye, which was also considered to be the 'normal' eye. ${ }^{142}$ In 1881 The Standard praised Francis Cornelis Donders because he had invented a vision testing methodology that allowed for complete accuracy, and 'to tell exactly how much, or how little, it differs from the normal'. ${ }^{143}$ Other medical works emphasised the scientific and empirical quality of their methodologies and research. ${ }^{144}$ This can be seen as part of a wider nineteenthcentury fascination with the 'norm', the average, and statistics. ${ }^{145}$ As Lennard J. Davis has detailed, terms such as 'normal' or 'normalcy' entered the English language in the middle of the nineteenth century. Davis has located their origin in the symbiotic relationship between the study of statistics and eugenics, which sought or believed that the population could be 'normed' or standardised. This in turn had complications for those they termed 'deviations', which were increasingly seen to contribute to national disease and concerns of national health. ${ }^{146}$

Meckel has suggested that investigations into American schools and education pathologised conditions and created a host of 'norms' and 'school diseases'. ${ }^{147}$ In Britain a similar emphasis was placed on measuring the eye through better parental awareness and more thorough testing in the late nineteenth century. This is a key argument made by medical practitioners, such as Robert Farquharson and Carter in the 1880s. Farquharson requested that parents should be educated on

\footnotetext{
${ }^{142}$ Use of the term 'normal' or 'abnormal' is referred to in all the medical texts: Carter, pp. 8-9; Newsholme, pp. 105-8; Loring, pp. 1, 5, 7; Farquharson, p. 357; Lincoln, p. 49; Smith, p. 9; Liebreich, pp. 6-7; Snell, Influences of School Life on Eyesight, p. 4; For information on the adoption of the new standards, please see chapter two, pp. 72-6.

${ }^{143}$ The Standard, 21 December 1881, p. 5; This process was not only occurring in the study of vision defects in children, but also encompassed wider issues such as feeble-mindedness see, for example, 'Elementary Education of Defective and Epileptic Children', British Medical Journal, 28 October 1899, pp.1027-1028; for more information on Donders, see pp. 72-6.

${ }^{144}$ Meckel commented on this in reference to Lincoln, pp. 26-7. For a British example see Carter, pp. 4-5 and his discussion on the errors of other investigations, pp. 13-36.

${ }^{145}$ Martha Stoddard-Holmes, Fictions of Affliction: Physical Disability in Victorian Culture (Ann Arbor: University of Michigan Press, 2004), pp.7, 27; Lennard J. Davis, The Disability Studies Reader, $4^{\text {th }}$ edn (London: Routledge, 2013), pp. 1-12.

${ }^{146}$ Lennard J. Davis, Enforcing Normalcy: disability, deafness and the body (London; New York: Verso, 1995), see particularly pp. 23-41.

${ }^{147}$ Meckel, pp. 25-6; See also, for example, the title of Newsholme's text.
} 
the issue and that they be assigned responsibility for their children to be tested. ${ }^{148}$ Carter also focused on the responsibility of the schools and the state to ensure children's eyes were tested prior to the outset of education. ${ }^{149}$ In both arguments the importance of testing was emphasised. This concern filtered into newspapers and periodicals for the remainder of the century. In 1892 an extract from The Yorkshire Herald, for example, provided popular advice and suggested that parents with visual defects had an enhanced responsibility to get their children tested. It concluded that 'the remedy for all this is thorough and careful and regular periodical examination'. ${ }^{150}$ There was a corresponding emphasis on the importance of testing in periodicals from the $1880 \mathrm{~s} .{ }^{151}$

However, whilst certain medical professionals argued that steps were being made, concern about the extent and effectiveness of these initiatives was reflected in the British Medical Journal throughout the 1880s and 1890s. As late as 1898, discussion on the improvement of school education, continued to call for three steps that revolved around improved, more regular, vision testing. ${ }^{152}$ A key issue presented in The Standard was whether schools should offer the service of vision testing for children, and when their vision should be tested. Correspondence in 1888, for example, proposed that examinations of 'these poor little sufferers' should be carried out prior to entering school. ${ }^{153}$ However, earlier correspondence in 1881 suggested that it was a 'duty' to ensure each child was examined throughout their school life. Despite this, the article also stated that this is 'unfortunately... exactly what we never do. ${ }^{154}$ Indeed, articles in popular literature emphasised the need to improve teachers and parental knowledge. In 1885, for example, it was suggested that 'there would be a manifest advantage' in teachers being fully acquainted with pupils' vision capabilities. ${ }^{155}$ As previously shown, The Practical Teacher provided certain articles for teachers that placed particular focus on how to detect vision defects. ${ }^{156}$

\footnotetext{
${ }^{148}$ Farquharson, pp. 6-7, 367-8.

${ }^{149}$ Carter, pp. 35-6.

${ }^{150}$ The Yorkshire Herald, and the York Herald, 21 January 1892.

${ }^{151}$ See, for example, The Wesleyan-Methodist Magazine, March 1885, p. 220; The Leisure Hour, January 1889, p. 64.

${ }^{152}$ Lawson, pp. 1614-1617; whereas, Ireland, p. 213, for example, claimed that steps had been made.

${ }^{153}$ The Standard, 20 December 1888.

${ }^{154}$ The Standard, 21 December 1881.

${ }^{155}$ Book-Lore, November 1885, p. 182.

${ }^{156}$ The Practical Teacher, 1900, pp. 66-8; The Practical Teacher, September 1900, pp. 122-24.
} 
Otter has proposed that, although slow and uneven, the adoption of vision testing was 'discernible' by the end of the nineteenth century. ${ }^{157}$ The adoption of vision testing in the later nineteenth century was also increasingly being highlighted as important in newspapers and periodicals. It is impossible to truly ascertain from the newspapers, periodicals and medical texts the number of children who would have attended opticians. However, the emphasis placed on children's vision defects, and their standardisation against a national average, can be ascertained. The use of terms such as 'normal' to describe children's eyesight in Britain was not met without criticism. In 1899 D. Love, for example, argued that ophthalmic surgeons were erroneous because they were 'adopting an arbitrary standard, and calling it the normal for children's eyes... Nature has no fixed standard. Here normal is a variety'. ${ }^{158}$ Central to Love's criticism was the adoption of an artificial 'standard' by medical practitioners, which in turn led to the diagnosis of 'normal' and 'abnormal' vision. Peter Conrad, in his 2007 study on the medicalisation of society, posed a question that can be applied to the investigations into vision errors by the nineteenthcentury medical elite: 'does it mean there's a new epidemic of medical problems or that medicine is better able to identify and treat already existing problems? ${ }^{159}$ Or, in other words, was children's eyesight deteriorating or was it the measurement of vision, the demand or prevalence of these tests, and the environment in which children were placed that led to more frequent diagnosis of visual impairment. Medical practitioners commented extensively on the conditions of schools. However, to better answer this question it is fruitful to draw upon another nineteenth-century environment in which this process also occurred.

\footnotetext{
${ }^{157}$ Otter, p. 44.

${ }^{158}$ D. Love, 'The Vision of School Children', British Medical Journal, 25 March 1899, p. 763.

${ }^{159}$ Peter Conrad, The Medicalisation of Society: On the Transformation of Human Conditions into Treatable Disorders (Baltimore: John Hopkins University Press, 2007), p. 3.
} 


\section{Vision and the Workplace}

Occupational environments became an issue of public concern in the nineteenth century. The advent of industrialisation and the factory system created new working and social conditions, which increasingly became subject to contemporary criticism. The mid-nineteenth century, galvanised by attempts since the late-eighteenth century, saw a wealth of legislation that sought to impose greater regulation on the industrial workplace. ${ }^{160}$ Equally, the social conditions that stemmed from industrialisation helped coin the 'Condition of England' question by Thomas Carlyle in 1839, which criticised class disparity and the poor domestic and working conditions of the lower classes. ${ }^{161}$ These criticisms took into account unemployment, child labour, poverty and factory conditions, which also filtered into a sub-genre of nineteenth-century literature written by authors such as Charles Dickens, Elizabeth Gaskell and Benjamin Disraeli. ${ }^{162}$ Social commentary, legislation and the establishment and enforcement of factory inspectors following the Factory Act of 1833 placed the workplace under greater scrutiny. In this context, aspects such as industrial accidents and worker's health became areas of concern.

Bronstein has suggested that the increase in workplace accidents led to greater information and discussion on the work environment in written form, such as in the press and governmental studies. ${ }^{163}$ However, concerns about vision in the workplace extended beyond industrial accidents; it formed part of a wider interest in the effects of over-use or strain on the eyes. Otter, for example, has argued that each trade had a certain level of visual demand that could have a permanent effect on the individual's eye, body or health. ${ }^{164}$ Similar to the discussion of schools in the nineteenth-century press, the proportion of studies focusing on the environment and

\footnotetext{
${ }^{160}$ For a brief overview see Wilson J. Hoffman, 'Factories', in Victorian Britain: An Encyclopaedia ed. by Sally Mitchell (Oxon: Routledge, 2011), pp. 280-281; Dennis J. Mitchell, 'Factory Acts', in Victorian Britain: An Encyclopaedia ed. by Sally Mitchell (Oxon: Routledge, 2011), p. 282.

${ }^{161}$ Michael Levin, The Condition of England Question: Carlyle, Mill, Engels (Basingstoke: Macmillan Press, 1998), see especially pp. 6-32, 42-46; John Morrow, Thomas Carlyle (London: Hambledon Continuum, 2006), pp. 75-104.

162 James G. Nelson, 'The Victorian Social Problem Novel', A Companion to the Victorian Novel, ed. by William Baker and Kenneth Womack (Westport: Greenwood Press, 2002), pp. 189-209 but especially 189-193; Mine Özyurt Kiliç, Maggie Gee: Writing the Condition-of-England Novel (London: Bloomsbury, 2013), pp. 5-14.

${ }^{163}$ Bronstein, p. 3.

${ }^{164}$ Otter, p. 45.
} 
conditions of the workplace reflected contemporary interests. ${ }^{165}$ Whilst Bronstein has shown that a 'health and safety' concept was not yet in place, these sources reveal that there was concern over the eye and vision, and there were some attempts to reduce occupational hazards. At the close of the nineteenth century, Arlidge conducted an innovative, and extensive, assessment of different occupations, and the affect that they could have on the health of employees. ${ }^{166}$ However, Arlidge drew some of his findings from earlier investigations, which had been published throughout the century in both popular and medical outlets. These studies considered the effects of occupations on the health and vision of the eye; suggested preventative methods; and measured the eye in an unprecedented manner to determine visual acuity standards for certain work environments.

The nineteenth-century work environment could be a dangerous one. Industrial accidents were commented on as a source of eye injury and could indeed damage an individual's visual range. In 1835 an article in the Chambers's Edinburgh Journal declared that the eyes were exposed 'to many injurious influences' and these could leave 'the organs either destroyed, or so greatly impaired' that they could no longer serve for the active employments of life. ${ }^{167}$ It associated eye injuries with occupations that involved the chipping or breaking of hard materials, such as stone or iron. In 1858 'A Plea for the Eyes', which was published in the mid-century, listed a variety of industrial occupations that were prone to damage the eye because of foreign particles. The article concluded that all workers subject to 'chips, splinters, dust, grit, or fluff would do well to look about them for eye-protectors... spectacles of wire-gauze might often be used with advantage'. ${ }^{168}$ Two years later an investigation into the 'Effects of Arts, Trades and Professions, and of Civic States and Habits of Health and Longevity', proposed that the danger of flying particles in certain occupations necessitated the appropriate use of protective goggles. ${ }^{169}$ The industrial environment increased the likelihood of eye injury and created a demand

\footnotetext{
${ }^{165}$ Bronstein, p. 3.

${ }^{166}$ J.T. Arlidge, The Hygiene Diseases and Mortality of Occupations (London: Perceval, 1892). Although Arlidge acknowledged the international study of occupational health and hygiene, particularly in France and Germany, this was the first treatise of its kind to have been produced in Britain since the work of Charles Turner Thackrail in 1831, pp. 1-12.

${ }^{167}$ Chambers'sEdinburgh Journal, 10 January 1835, p. 394.

168 'A Plea for the Eyes', Chambers's Journal of Popular Literature, Science and Arts, 5 June 1858, pp. 357-8.

${ }^{169}$ The Edinburgh Review, January 1860, p. 4.
} 
for a new form of eyewear. However, its adoption into the nineteenth-century workplace can be questioned. Snell for instance suggested a difficulty in getting workmen, as opposed to employers, to adopt the use of protective eye measures in the iron and steel industries, and continued to call for a more thorough implementation at the end of the nineteenth century. ${ }^{170}$

Although the eye was subject to accident in the workplace, the effect of a broader range of trades on the health of the eye was more subtle. In 1894 an article entitled 'The Victims of Industry' described the 'highly injurious' effects of fine work and poor lighting conditions, which suggested that certain occupations demanded the same use of the eyes as education. ${ }^{171}$ Bronstein has argued that certain industries could have a slower, deleterious effect on general health. ${ }^{172}$ Contemporaries, alongside physical damage to the eyes, were also concerned with the gradual deterioration of vision that occurred in the workplace due to environmental conditions. In 1856 The North British Review directly associated an individual's refractive capability with the visual demands of their occupation. It concluded that 'shortsight is more frequent in artisans who require to have their work brought close... and in literary men... whilst shepherds, sailors, and labourers in the field, have their sight lengthened by their profession'. ${ }^{173}$

The condition and strength of a person's eyesight was placed in direct relation to their work environment, and how the eyes were used for certain occupations was a primary concern. This can be divided into two sources of eyestrain: over-work and close work. ${ }^{174}$ However, greater emphasis was placed on the effects of close work across the century. In 1843, for example, an article on short sight was published in a number of provincial newspapers. It concluded that employments, which required prolonged work on minute objects, were 'more apt' to

\footnotetext{
${ }^{170}$ Simeon Snell, On the Prevention of Eye Accidents Occurring in Trades: An Address Delivered at the Opening of the Section of Ophthalmology at the Annual Meeting of the British Medical Association at Portsmouth, August, 1899 (London: John Bale, 1899), p. 27.

171 'The Victims of Industry', Westminster Review, January 1894, pp. 425-6.

${ }^{172}$ Bronstein, p. 17.

${ }^{173}$ The North British Review, November 1856, pp. 181-2.

${ }^{174}$ See, for example, a lecture at the Royal Dublin Society in the Freeman's Journal and Daily Commercial Advertiser, 19 March 1887.
} 
turn those employed near-sighted. ${ }^{175}$ The nineteenth-century popular press revealed that specific investigations were being made into occupations and the effects of close work from early in the century. In 1838 a repeating column in The Saturday Magazine, for example, discussed the effects of close work on vision, and twice stated that the over-use of magnifying lenses could have negative consequences. ${ }^{176}$ This was not an isolated opinion in the mid-nineteenth century, and in 1850 an article in The Quarterly Review concluded 'all who use a single glass, and always apply it to the same side - especially artisans who, like watchmakers pass hours in this position - are in a particular manner exposed to the defect' ${ }^{177}$

Similar to discussions of schools, the manner of employment was analysed alongside the conditions that employees worked in. Bronstein has argued that 'for all but the sedentary and skilled professions, each task had its own danger and drawback' ${ }^{178}$ However, certain sedentary or skilled occupations could have a detrimental effect on the health of the eye and vision. Close work in poor lighting conditions was considered particularly dangerous. In 1869 the fine work that was undertaken by printers in artificial lighting, for example, was topical. ${ }^{179}$ Although in 1896 an article, 'Working in the Dark', concluded that darkness provided the eyes with rest, most commentary across the century criticised poor lighting and dark working conditions. ${ }^{180}$ In 1838 The Saturday Magazine, for example, argued against the use of poor natural light, shades or artificial light by those engaged in minute work. ${ }^{181}$ In these instances there was an attempt to associate eye defects and conditions with certain occupations, and determine ways to avoid these. In 1872 this approach was made explicit at the International Oculist Meeting where statistics were given on the number of cataract cases that occurred in a variety of different

\footnotetext{
${ }^{175}$ The Bury and Norwich Post, and East Anglican, 4 January 1843; The Essex Standard and General Advertiser for the Eastern Counties, 6 January 1843; The Manchester Times and Gazette, 7 January 1843. This was also mentioned later in the century see, for example, E. H. Turnpin, 'The Uses of the Senses in Art', Musical Standard, 14 February 1885, p. 105.

176 'Employments Which Injure the Eyesight', No. IV, The Saturday Magazine, 9 June 1838, pp. 222-

3; 'Employments Which Injure the Eyesight', No. V, The Saturday Magazine, 16 June 1838, p. 230.

${ }^{177}$ The Quarterly Review, June 1850, p. 56.

${ }^{178}$ Bronstein, p. 17.

${ }^{179}$ The Leeds Mercury, 3 June 1869; Western Mail, 5 June 1869; The Newcastle Courant, 17 December 1869.

${ }^{180}$ Chambers's Journal of Popular Literature, Science and Art, 5 December 1896, pp. 771-773.

181 'Employments Which Injure the Eyesight', No. III, The Saturday Magazine, 28 April 1838, pp. 158-9.
} 
occupations. ${ }^{182}$ Arlidge at the end of the century adopted this methodology and discussed the effect of different occupations on the eyes, such as teaching, lace making, watch making and engraving. ${ }^{183}$ Arlidge covered three specific areas of close work that received particular attention in the nineteenth century, and can be used to illustrate this point: literary professions, needlework, and artisans.

Like accidents in the workplace, close work in literary professions placed the eye or vision at risk, and created a new demand for vision aids. As early as 1814, James Ware made a connection between the high percentages of shortsightedness at a university level and prolonged education. Ware concluded that 'study too long continued... without necessary intervals, may render hopeless of cure that incipient disorder' ${ }^{184}$ Additionally, in the mid-century, a whole medical text was devoted to how students in extended education should use their eyes. ${ }^{185}$ Links to poor eyesight were not just made to university study; literary pursuits in general were associated with defective vision. A review of a medical text on vision in 1821, and its later edition in 1833 , recommended that the work was particularly important to 'our own craft... as well as to barristers, clergymen, and indeed to all whose employments are literary'. ${ }^{186}$ Needlework, for similar reasons, demanded close work and received extensive attention across the nineteenth century. In 1858 the 'Committee on Industrial Pathology on Trade which Effect the Eyes', referred to the surgeon of St Mary's Hospital, Mr White Cooper, who had responded to the committee's queries. Cooper broke down the problems of needlework into four kinds that have been mentioned already in the chapter: over-work, excess of light, deficiency of light, and badly applied light. ${ }^{187}$ In fact, premature failure of sight in women was already being linked to their employment in fine sewing earlier in the century. ${ }^{188}$

\footnotetext{
182 'International Oculist Meeting', Glasgow Herald, 3 August 1872.

${ }^{183}$ Arlidge, pp. 114, 193-4, 208-9, 365-8.

${ }^{184}$ The Literary Panorama, January 1814, p. 985.

185 This text was detailed in The Monthly Review, July 1842, pp. 297-312.

${ }^{186}$ Blackwood's Edinburgh Magazine, September 1821, p. 229; The New Monthly Magazine and Literary Journal, May 1833, pp. 101-2.

187 'A Plea for the Eyes', Chambers's Journal of Popular Literature, Science and Arts, 5 June 1858, pp. 357-60.

${ }^{188}$ The Literary Gazette: A Weekly Journal of Literature, Science and the Fine Arts, 22 May 1824, pp. 323-4.
} 
Artisans were often placed alongside seamstresses or dressmakers because of the similarities in work environment. In particular, the bending over a desk to carry out work was considered injurious for lacemakers, watchmakers, and engravers collectively. ${ }^{189}$ However, rather than solely emphasising the dangers and bad effects of these employments, there was also a considerable proportion of individuals who proposed watchmakers and engravers had good eyesight. In the 1880s Carter was a particularly strong advocate against the idea that watchmakers had poor eyesight from habitual use of lenses and closework, a claim that had been frequently printed in newspapers and periodicals in the early $1880 \mathrm{~s} .{ }^{190}$ Arlidge also argued that not all occupations that required closework were damaging to the eyes. Whilst Arlidge concluded that employments such as lace making, artificial flower making, and hosiery manufacture caused poor eyesight, he also proposed that watchmakers, jewellers and engravers had good eyesight. ${ }^{191}$ To support his argument, Arlidge drew upon the work of Mr Lloyd Owen, senior surgeon to the Birmingham Eye Hospital, who had concluded that for jewellers and watchmakers 'close work even when regular and persistent, does but little, if any harm, to normal eyes'. ${ }^{192}$

Other medical investigations have provided statistics to suggest that vision was not always marred by jobs that involved close work. In 1878 American ophthalmologist Edward Loring, for example, drew on both his own work and international studies to conclude that watchmakers and silversmiths did not suffer any injurious effects as a result of their work. ${ }^{193}$ Likewise, in 1891 an article in The North-Eastern Daily Gazette referred to studies by a German ophthalmologist, which revealed similar results: 'examining the eyes of seventy-five watchmakers [he] found that scarcely five per cent of the number were affected with shortsightedness'. ${ }^{194}$ Loring had based his findings on age, and proposed that fine work was less damaging on the eye than at school because the eye would have become strong

\footnotetext{
189 'Eyes and Eyeglasses: A Friendly Treatise', Fraser's Magazine, December 1876, pp. 706-7.

${ }^{190}$ See, for example, Saturday Review of Politics, Literature, Science and Art, 15 May 1880, pp. $637-$

8; The Edinburgh Review, October 1881, p. 535.

${ }^{191}$ Arlidge, for occupations that affect eyesight: artificial flower making, p. 231, lace making, p. $365-$

8, hosiery, p. 409; watch-making, jewelers, and engraving discussed between pp. 193-209.

${ }^{192}$ Arlidge, pp. 199-200; this is also supported in a study that was reported in the Nottinghamshire Guardian, 29 April 1887.

${ }^{193}$ Loring, p. 24.

${ }^{194}$ The North-Eastern Daily Gazette, 11 March 1891.
} 
enough to withstand the strain. ${ }^{195}$ In contrast, Arlidge referred to the findings of a senior surgeon at the Birmingham Eye Hospital who, together with his colleagues, saw an average of 20,000 cases per annum. Here, it was stated that close work was not harmful to those with normal eyes, because it affected only those with latent or manifest refractive errors. In other words: 'it is not the work but the unfitness of the eyes for the work which is to blame'. ${ }^{196}$ These studies reveal that the effects of close work and the work environment did not necessarily cause vision defects, or demand the use of eyewear. However, they have shown that close work could have an effect on the health of the eye and vision and create a new demand for vision aids. Whilst no consensus can be reached on the numbers of people affected by the conditions of their work, it can be concluded that, as was the case for schools, the work environment underwent significant investigation and discussion. This, in turn, caused an unprecedented attempt to measure the conditions of the workplace and the physical condition of the individual workers.

In 1887 Irish ophthalmologist, Dr Arthur Benson, based the suitability of a person for different professions on the condition of their eyesight:

Before deciding on a profession, employment, trade, or form of labour to which any young person should be put it would be very advisable to weight with due care the question of his sight, and the probable influence of the employment on his eyes. ${ }^{197}$

Benson proposed that for those with more severe degrees of myopia, or short sight, 'a country life with agricultural work was alone suitable'. ${ }^{198}$ As has been seen, broad investigations were being made into different occupations and their effects on the health of the eye and visual acuity across the nineteenth century. Yet, from the later nineteenth century, there was a similar emphasis from medical authorities on the need for more thorough vision testing in the workplace. This can be seen as part of a wider interest in workers' bodies in industrialising countries. Steve Sturdy has argued that contemporaries saw labour as integral to the growth of national economies, and therefore the health of workers and their suitability for certain jobs

\footnotetext{
${ }^{195}$ Loring, see particularly pp. 21-5.

${ }^{196}$ Arlidge, p. 199.

${ }^{197}$ From a lecture to the Royal Dublin Society on the over-use of the eyes, Freeman's Journal and Daily Commercial Advertiser, 19 March 1887.

${ }^{198}$ Ibid; Dr Arthur Benson was an original member of the Ophthalmological Society for the United Kingdom, for an overview of his career see: 'The Late Dr Arthur H. Benson', British Medical Journal, 23 November 1912, p. 1502.
} 
meant workers' bodies became crucial to the success of production. ${ }^{199}$ More recently, Sarah F. Rose has shown how mechanisation and the concept of efficiency led to the measurement, exclusion and scrutiny of bodies in certain workplace environments. ${ }^{200}$ For the study of vision and the eye, certain occupations demanded a standardised level of visual acuity that could be measured and would determine an individual's fitness for the work required. ${ }^{201}$

The testing and measurement of worker's bodies was increasing in the nineteenth century to maximise efficiency. ${ }^{202}$ Articles which detailed the physical and visual qualifications required for admission to the medical and wider military services, for example, began to appear in the British Medical Journal from the 1880 s. $^{203}$ These articles can be seen as the culmination of work undertaken by medical practitioners in the nineteenth century to cement themselves as authoritative experts in matters of occupational health. ${ }^{204}$ As to be expected, physical requirements for the army and related military services were heavily discussed and there was a popular fascination with soldiers being allowed to wear spectacles in different countries. ${ }^{205}$ Beyond popular discussion, however, medical authorities became increasingly more involved and vision testing featured prominently in medical journals. In 1885 Surgeon-General T. Longmore in his Optical Manual, for example, argued that the development of long-range firing caused vision to have a more vital military role and, therefore, more complex examination was required. ${ }^{206}$ Longmore provided a guide for a more complex eye examination, which in turn

\footnotetext{
${ }^{199}$ Steve Sturdy, 'The Industrial Body', Companion to Medicine in the Twentieth Century, ed. by Roger Cooter and John Pickstone (London: Routledge, 2003), pp. 218-221.

${ }^{200}$ Sarah F. Rose, No Right to be Idle: The Invention of Disability, 1840s-1930s (Chapel Hill: The University of North Carolina Press, 2017), passim.

${ }^{201}$ Otter also considered vision testing in the army and train driving, p. 45.

${ }^{202}$ Sturdy, pp. 220-223.

${ }^{203}$ See, for example, 'Military and Naval Medical Services', British Medical Journal, 12 November 1881, pp. 798-99; 'The Public Services: The Naval and Military Medical Services', British Medical Journal, 2 September 1893, pp. 544-545.

${ }^{204}$ Sturdy, p. 219.

205 See, for example, Daily News, 9 February 1863; The Leeds Mercury, 10 February 1863; The Dundee Courier \& Argus, 23 March 1863; The Dundee Courier \& Argus, 18 June 1877; The Leeds Mercury, 11 July 1877; The Huddersfield Daily Chronicle, 17 December 1877; The Belfast NewsLetter, 27 July 1893; The Essex County Standard West Suffolk Gazette, and Eastern Counties Advertiser, 24 February 1894; The Dundee Courier \& Argus, 6 October 1894; The Yorkshire Herald, and the York Herald, 2 February 1899.

${ }^{206}$ T. Longmore, The Optical Manual: or, Handbook of Instructions for the Guidance of Surgeons in Testing the Range and Quality of Vision of Recruits and Others Seeking Employment in the Military Services of Great Britain (London: HMSO, 1885), pp. iii-iv.
} 
provided more sophisticated rules and measurements required for physical qualification. These new rules and regulations were set out for both medical officers and those on the front line. In 1895 Kenneth Macleod discussed the physical examinations required for employment in Government, and related services, and the decisive new role of medical authorities. Macleod concluded that vision testing and visual requirements for occupations had 'become an important part of medical practice, constituting boards and committees acting under rules and regulations'. 207

Beyond the civil services, the medical profession increasingly performed 'gate-keeping' roles to judge a person's fitness for employment. Anne Digby has discussed this in relation to medical policing by general practitioners to ensure a person met certain height, weight, and visual requirements for occupations within organisations such as the Post Office. ${ }^{208}$ In 1881 E. Warlomont, a Belgian medical practitioner, writing in the British Medical Journal considered the 'concomitant examination of the refraction and of the acuteness of sight' to be 'indispensable' for those employed on the railroad and in the army. ${ }^{209}$ Systematic vision and physical testing of railway workers and those who worked at sea became a particular issue of contention for medical authorities in the later nineteenth century. Medical practitioners increasingly emphasised the need for accurate examinations that should be undertaken by those in the profession, and this can be seen explicitly in the British Medical Journal in the last two decades of the century.

The study of railway and naval signalling had been undertaken since the midcentury and was discussed in the popular press. In the $1850 \mathrm{~s}$, periodicals referenced early medical works on colourblindness and signalling. In 1856 a review of $\mathrm{Dr}$ Wilson's pioneering work on this area, for example, concluded that the 'public are under deep obligations to Dr Wilson for having taken up this subject'. ${ }^{210}$ By the end of the nineteenth century the prevalence of these discussions in popular literature was commented on: 'we have heard so much lately about colour-blindness... and the

\footnotetext{
${ }^{207}$ Kenneth Macleod, 'Remarks on the Physical Requirements of the Public Services', British Medical Journal, 11 May 1895, pp. 1021-1025, quote taken from p. 1021.

208 Anne Digby, The Evolution of British General Practice, 1850-1948 (Oxford: Oxford University Press, 1999), p. 247.

${ }^{209}$ E. Warlomont, 'On the Use of Optometers for the Examination of Soldiers and Workmen Employed on the Railroad', British Medical Journal, 5 March 1881, pp. 333-336, on p. 336.

${ }^{210}$ The North British Review, February 1856, p. 350.
} 
knowledge of this visual deficiency leads the authorities to test very severely the candidates for railways and naval services'. ${ }^{211}$ However, the British medical authorities contested the thoroughness and effectiveness of vision testing, both for general visual acuity and colour blindness. In 1890 Thomas Bickerton, Oculist of the Liverpool Royal Infirmary, condemned the Board of Trade and continued to do so in 1895 for their failure to provide proper regulations on the matter. ${ }^{212}$ A number of individuals writing in the British Medical Journal document the history of the British Medical Association (BMA) in this area of concern. Bickerton, and those who responded to his condemnation of the Board of Trade in the 1890s, contrasted the Board's inaction with the attempts of medical practitioners to secure proper regulation. ${ }^{213}$ Additionally, in 1891 an earlier annual meeting of the BMA discussed the international state of affairs, identifying nations which had more advanced modes of testing. ${ }^{214}$ The opinion that Britain lagged behind other parts of the world was corroborated in 1897 by William Beaumont, Surgeon to the Bath Eye Infirmary, when he discussed reasons for Britain's seeming slowness to incorporate standardised vision testing. ${ }^{215}$ The medical authorities in all these instances recommended that more sophisticated, systematic testing to be carried out by fully qualified individuals in the rail and marine services.

The perceived importance of vision testing for overall public safety meant that these recommendations did not fall short of reaching more popular outlets. In 1892 the Trewman's Advertiser published a paper read by the President-Elect of the South Western Branch of the BMA and condemned the allowance of partially sighted railway drivers. ${ }^{216}$ However, the importance of vision testing in the railway

\footnotetext{
${ }^{211}$ The Wesleyan-Methodist Magazine, February 1895, p. 97.

212 'Defective Eyesight in Railway Servants and Seamen: Deputation to the President of the Board of Trade', British Medical Journal, 9 February 1895, pp. 315-316; For information on Bickerton's position see Thomas H. Bickerton, Colour Blindness and Defective Eyesight in Officers and Sailors of the Mercantile Marine: A Criticism of the Board of Trade Tests (Edinburgh: James Thin, 1890).

${ }^{213}$ See, for example, 'Defective Eyesight in Railway Servants and Seamen', pp. 315-316; 'Colour Blindness and Defective Eyesight in the Personnel of the Mercantile Marine', British Medical Journal, 18 May 1895, pp. 1112-1113; 'The Eyesight of Seamen: Colour Blindness and Defective Sight in the Mercantile Marines', British Medical Journal, 30 January 1897, pp. 292-293; 'The Eyesight of Seamen: Colour Blindness and Defective Sight in the Mercantile Marines', British Medical Journal, 27 February 1897, pp. 537-8.

214 'A Discussion on the Vision of Railway Servants', British Medical Journal, 9 August 1891, pp. 466-470.

${ }^{215}$ W.M. Beaumont, 'Continental and British Vision Tests for Railway Servants: A Comparison', British Medical Journal, 16 October 1897, pp. 1085-6.

${ }^{216}$ Trewman's Exeter Flying Post or Plymouth and Cornish Advertiser, 18 June 1892.
} 
and marine professions was not solely printed as a view held by the medical authorities. In 1876 Horne's 'friendly treatise' on 'Eyes and Eyeglasses' concluded that for 'railway officers and servants, it is obvious that they should pass a preliminary examination'. ${ }^{217}$ Horne based this reasoning on the number of lives and property that were dependent on the conduct of employees in this profession. Two letters of correspondence in 1875 and 1882 also voice their opinion on the need for more thorough examination of railway drivers and present it as a public issue. A letter to the Medical Times and Gazette was published in The Morning Post, and argued that railway companies needed to have the eyesight of all their employees tested by fully qualified professionals for the satisfaction or peace of mind of railway travellers. ${ }^{218}$ Additionally, a public correspondent to the Daily News considered the importance of colour differentiation and the ability to determine railway signals. The correspondent referred to a recent collision at Canonbury and concluded that there 'has long been an uneasy suspicion in the public mind that engine-drivers do occasionally run through danger signals'. ${ }^{219}$ Those that voiced their opinion also referred to medical texts on the subject of marine and sailor's eyesight, such as a review of the reports made by Bickerton in 1887 and 1888. The review especially commended, and endorsed the necessity of, expert examination and commented that 'it surely is not too much to ask that a man upon whom avoidance of the calamity of a collision at sea may almost entirely depend should be examined as to his capability of distinguishing red from green' ${ }^{220}$ In these instances, collisions and the safety of the public were used to emphasise the importance of vision testing. As summarised in The Academy in 1881, the subject of ship and railway-train vision testing was 'not only of scientific interest, but of much practical importance'. ${ }^{221}$ The popular press presented the issue as a matter of 'health and safety', as it did demands for better protection of workers in a variety of trades in this period. However, more unusually, these considerations focused on the welfare of employees and third parties.

With health and safety of the public and employees in mind, medical authorities criticised the methods of late nineteenth-century vision testing. These

\footnotetext{
${ }^{217}$ Horne, Fraser's Magazine, December 1876, p. 711.

${ }^{218}$ The Morning Post, 18 December 1875.

${ }^{219}$ Daily News, 6 January 1882.

${ }^{220}$ Saturday Review of Politics, Literature, Science and Art, June 1889, pp. 804-5.

221 'Science Notes', The Academy, 23 July 1881, pp. 74-5.
} 
reports drew upon statistics from railway and marine companies, and case studies from their own experience, to encourage reform. In 1891 a group of medical practitioners, as part of 'A Discussion of the Vision of Railway Servants' in the British Medical Journal, identified the deficiencies of the current system. ${ }^{222}$ Part of their criticism explored the inadequacy of the testing methods adopted by seven companies in Scotland, which together operated 3,058 miles of railway. ${ }^{223}$ Other studies drew upon specific cases of failure in the 1890s to prove the urgency for reform in both the railway and marine services. ${ }^{224}$ The effect that late disqualification from service had on employees' welfare, as well as health and safety, were at the centre of these criticisms. Two cases studies, for example, revealed that men in their mid-thirties could pass a range of earlier vision tests but fail a more rigorous examination and be disqualified for the services that they trained for. ${ }^{225}$ Further evidence of individuals slipping through the examination process also appeared in the discussion of two men from the railroad profession who had managed to pass five previous vision tests. ${ }^{226}$ Correspondence in the British Medical Journal from 1898 concluded that insufficient vision testing failed the railway companies, safety of the travellers, and the livelihoods of the men involved. ${ }^{227}$

Whilst medical practitioners argued that systematic vision testing had not been established in the railroad and sea professions, some steps had been made, and particularly at sea. In 1899 correspondence in the British Medical Journal, for example, highlighted that all pilots and employees from the Honourable Trinity Corporation underwent careful examination. ${ }^{228}$ Similarly, the Cunard Line had brought attention to the issue from as early as 1876 , following the observation by the on-board surgeon for the Cunard crack passenger steam, Russia, that one of the lookout men had defective vision. Through correspondence between the surgeon and the Captain of the Company, it was concluded that all men should have their

\footnotetext{
222 'A Discussion on the Vision of Railway Servants', pp. 466-470.

${ }^{223}$ Ibid., pp. 468-70.

${ }^{224}$ Ibid., pp. 465-6.

${ }^{225}$ J.B. Lawford, The Visual Tests for Railway Servants and Mariners', British Medical Journal, 23 March 1895, p. 641.

${ }^{226}$ Henry G. Terry, 'Railway Servants' Eyesight: Two Cases of 'Hard Lines', British Medical Journal, 25 July 1896, p. 234.

${ }^{227}$ S. Johnson Taylor, 'The Vision of Railway Officials', British Medical Journal, 26 March 1898, pp. $815-816$

${ }^{228}$ James Godding, 'The Eyesight of Pilots', British Medical Journal, 30 September 1899, p. 883.
} 
eyesight examined and it was argued that this correspondence 'seems... to have done the Cunard Company great credit'. ${ }^{229}$ In 1895 the President of the Board of Trade at the Deputation also drew attention to the fact that 'great lines had set a good example; the Cunard, the White Star etc., were subjecting their men to very careful tests'. ${ }^{230}$ As proposed here, the White Star Company, like the Cunard Line and the Honourable Trinity Company, had adopted periodic testing for all men employed. ${ }^{231}$ It is clear from the level of discussion on the matter by the medical profession in the 1890 s that these attempts were not deemed satisfactory, and they only covered a minority in the sea-faring professions. However, the uncertainty about whether these new testing methods were fully implemented does not detract from the level of emphasis on vision testing in medical and popular literature for these two professions. They reflect a growing demand for a measurable standard of vision as a requirement for working in certain occupations, which was able to both qualify and disqualify a worker from such employment.

The railway and marine professions show how improvements in technology, such as the invention of coloured signal lighting and faster locomotives, created a new environment. This environment required the eyes to be used in new ways and served to highlight vision defects. Additionally, the conditions of the wider work place created new demands for eyewear to protect or maintain a person's eyesight at a level required to maximise workers' efficiency. These work environments both highlighted employees' visual acuity, and generated attempts to measure this against a 'standard' in a similar manner to the environment and vision testing in schools. Technological advance was not isolated to the workplace. Greater knowledge of the eye and vision defects influenced the desire for greater sophistication and accuracy of eyesight testing in certain occupations. ${ }^{232}$ In turn, the changing environments of work and vision testing, and the new demands they placed on their employees, both measured and had the potential to disqualify individuals from the workplace.

\footnotetext{
229 'Colour Blindness and Defective Eyesight in the Personell of the Mercantile Marine, pp. 11121113.

230 'Defective Eyesight in Railway Servants and Seamen: Deputation to the President of the Board of Trade', p. 316.

231 'The Eyesight of Seamen: Colour Blindness and Defective Sight in the Mercantile Marines', British Medical Journal, 6 February 1897, pp. 343-344.

${ }^{232}$ Such as the Loiseau optometer proposed by Warlomont, pp. 333-336.
} 


\section{Conclusion}

Vision was celebrated and valued across the nineteenth century as the superior sense. However, concerns about its fallibility existed alongside this celebration.

Ophthalmology and the measurement of the eye did much to increase knowledge on eye disease and weaknesses. As has been shown in this chapter, these studies in many ways increased anxiety and concern about the deterioration of vision, which could be criticised at an individual level. Yet the condition of the nation's vision was also considered to be heavily rooted in the developments of nineteenth-century society. Increased urban life in the forms of towns and cities, and people's leisure or the environment in which they worked became subjected to investigation and comment. At all stages of life, in both education and work, individuals were considered vulnerable to the effect of their occupational demands. This highlighted people's vision defects and also created a new requirement for protective eyewear.

Rooted in the environment, and also its potential hereditary nature, the quality of people's vision was presented as a national concern, and associated with wider issues of general health. These medical concerns were repeatedly published in popular literature through reviews of medical texts, lengthy quotes or lectures, and extracts from medical texts and opinions. This focus on the subject in newspapers and periodicals has been used to show a wider, popular interest in the issue. Moreover, vision testing for sea and railway workers became a public as well as a medical concern because it was a matter of safety. The increased presence of medical practitioners and their opinions in more popular sources can be seen as part of the widening authority and visibility of the medical profession in the nineteenth century. ${ }^{233}$ This authority allowed medical opinion on eyesight and deterioration to hold weight, and justified their increased intervention into aspects of people's lives through, for example, advice on lifestyle or leisure choice. At the root of this discussion was a justification of the involvement of the medical profession in sight testing, regulation, and devising standards.

${ }^{233}$ Christopher Lawrence, Medicine in the Making of Modern Britain (London: Routledge, 1994), pp. 55-77; Digby, particularly emphasised on pp. 1, 99, 230, 247. 
Peter Conrad has explained medicalisation as a problem 'defined in medical terms, described using medical language, understood through the adoption of a medical framework, and treated with medical intervention'. ${ }^{234}$ These processes were reflected in the work of ophthalmologists and related medical practitioners in the nineteenth century, and particularly towards its close. In turn, this increased medical involvement raised the demand for testing and diagnosing conditions with greater accuracy. However, one of Conrad's primary concerns about widespread medicalisation was its ability to transform what could be seen as human difference, into pathology. ${ }^{235}$ This was also a concern at the end of the nineteenth century, and there was criticism about ophthalmologists' 'arbitrary' measurements of vision against a norm when 'normal is a variety'. ${ }^{236}$ The increased authority of medical practitioners in these matters did much to encourage discussion of vision defects and physical standards in popular as well as medical discourses. As part of this, attitudes to individuals with vision defects in certain work environments became less tolerant, and on the railroad and in shipping individuals were excluded for the first time. In many ways this narrative can be situated in the wider theory of disability studies, which argues that people with 'non-standard bodies' were increasingly rejected from the industrial workforce. ${ }^{237}$ In particular, parallels can be drawn to Rose's study on disability and employment in late-nineteenth and early twentieth century America, where workers bodies were increasingly defined in the context of both efficiency and capacity. ${ }^{238}$ These similarities highlight the importance of exploring the full spectrum of physical difference for building upon our understandings of the experience of disability. Beyond blindness, more minor vision defects and partial sightedness, had a significant effect on a person's employability in the changing work and economic market, and provide a different perspective on exclusion in the nineteenth-century workplace.

\footnotetext{
${ }^{234}$ Conrad, p. 5.

${ }^{235}$ Ibid. pp. 8, 148.

${ }^{236}$ Love, p. 763.

${ }^{237}$ David M. Turner and Daniel Blackie, Disability in the Industrial Revolution: Physical Impairment in British Coalmining, 1780-1880 (Manchester: Manchester University Press, 2018), pp. 5-7, 201203; Michael Oliver and Colin Barnes, The New Politics of Disablement (Basingstoke: Palgrave Macmillan, 2012), pp. 52-73; Davis, Enforcing Normalcy, pp. 86-90.

${ }^{238}$ For an overview of this argument see Rose, pp. 11-12, 223, and for discussion about how this process was not universal see Rose pp. 12, 228.
} 
However, vision defects also offer a unique case-study for exploring the relationship between capacity, worker's efficiency and the measurement of bodies in the nineteenth-century industrial workforce. Increased vision testing and the ability to measure the eye also led to improvements in the treatment and measurement of vision defects, and this had the ability to expand and not restrict many individuals' career opportunities. This chapter poses as many questions as it answers, and these questions are explored and answered in the remainder of this thesis: how vision was tested in these environments; how medical intervention altered the measurement and testing of visual defects; and how these influenced the dispensing, design and use of vision aids. In particular, this chapter has shown that discussion by medical practitioners, in a variety of publications, appears predominantly in the $1880 \mathrm{~s}$ and 1890s. Consequently, the remaining chapters explore the testing of vision and adoption of vision aids prior to these discussions, and how the intervention and discussions of medical practitioners influenced these in the latter two decades of the century. Whilst we cannot determine how 'real' the deterioration of vision may have been, due to absence of complete medical statistics, the study of vision aids or eyewear has not been previously placed in this context. Consequently, the effect or usage of eyewear against a backdrop of increased medical intervention and concern over the deterioration of vision has not been considered. The nineteenth-century environment demanded new levels of visual acuity, and in turn made the measurement of vision a more pressing concern. Additionally, the pathologisation of vision defects meant that errors of refraction were increasingly presented as a 'problem' that could be 'corrected'. Vision aids became a viable solution to this 'problem', and the growing intervention of medical practitioners would ultimately influence and control how these would be used to both test and treat vision by the end of the century. 


\section{Chapter Two}

\section{Medical And Popular Responses To Sight Loss}

There are individuals who when they see young people with glasses say, 'The race is deteriorating; blindness is increasing.' They ought to say 'how sensible are the parents of this generation; how careful they are to promote the welfare of their children'. '

In 1890 Phyllis Browne, in her column 'Chats with Housekeepers', in The Newcastle Weekly Courant proposed that an increase in vision aid use should be considered positively. Browne argued that the use of 'glasses' amongst children should be seen as a sign of conscientious parenting, and greater awareness of vision and its appropriate care. As part of this, Browne claimed a direct correlation between awareness and the use of vision aids. The previous chapter showed that the nineteenth-century environment placed new demands on the eye, and medical practitioners became increasingly prominent in the discussion of vision testing and the deterioration of vision. This chapter explores the effect that this had on the use of vision aids as a form of treatment. Whilst both the value and deterioration of vision in this period have been studied previously, little attention has been given to whether vision aids were used as a primary treatment method for vision defects. William Rosenthal, for example, has explored the denunciation of the monocle by the medical profession, but did not do the same for other eyewear designs. ${ }^{2}$ Similarly, Richard Corson has provided only a broad cross-centuries overview of the medical elite's slow acceptance of 'spectacles' as a means of treatment. ${ }^{3}$ However, the value of vision, the creation of ophthalmology, and the changing environment influenced medical perceptions of vision aids. Chris Otter has proposed that these factors would have influenced the importance of spectacles during this period, and this chapter explores whether this was the case in both the popular and medical perspective. ${ }^{4}$

\footnotetext{
${ }^{1}$ The Newcastle Weekly Courant, 5 July 1890.

${ }^{2}$ William Rosenthal, Spectacles and Other Vision Aids: A History and Guide to Collecting (San Francisco: Norman, 1996), pp. 233-235.

${ }^{3}$ Richard Corson, Fashions in Eyeglasses, $3^{\text {rd }}$ edn (London: Peter Owen, 2011), pp. 26-7.

${ }^{4}$ Chris Otter, The Victorian Eye: A Political History of Light and Vision in Britain, 1800-1910

(Chicago; London: Chicago University Press, 2008), p. 40.
} 
This chapter assesses contemporary opinions on how vision defects could be best treated, and what medical and popular advice was available for the preservation of eyesight and use of eyewear. The chapter is split into two parts. The first explores the changing medical perspectives on sight loss and vision testing, which charts the growing acceptance of vision aids as the best solution in medical thought and professional practice. For this discussion, it focuses specifically on 'spectacles', because this was the predominant style of frame that was referred to in discussions of lenses as an effective treatment method for vision errors. In particular, medical practitioners increasingly discussed the utility of spectacles and how to care for or preserve eyesight. Margaret Mitchell has commented that 'it is a strange fact that the medical profession despised the use of spectacles right up to the end of the nineteenth century'. ${ }^{5}$ This statement could be questioned for its present-centredness. Whilst not every member of the medical profession wholly accepted the use of spectacles, study of a number of nineteenth-century medical and popular texts suggests that Mitchell's conclusion is too harsh and definitive. The medical profession did not provide a unified view of spectacles and the opinion that spectacles were valuable can be traced back into the eighteenth century whilst the opinion that spectacles were not valuable can be traced into the twentieth. ${ }^{6}$ From the outset this suggests that attitudes towards spectacles were divided, and this would remain the case for much of the nineteenth century. Yet a shift in opinion is evident, particularly from the mid-nineteenth century, whereby the advantages of spectacle usage, and adoption of vision testing, became part of the general medical consensus.

The second part discusses how these ideas were transmitted via newspapers, popular medical texts, and other sources, looking in particular at how users sought and received advice on vision testing and vision aids as a whole. It studies this in the context of the growth in medical authority in the nineteenth century that was discussed in the previous chapter. Chapter one highlighted medical practitioners' increased professional monopoly over the treatment of bodily ailments and their role

\footnotetext{
${ }^{5}$ Margaret Mitchell, History of the British Optical Association, 1895-1978 (London: British Optical Association, 1982), p. 21.

${ }^{6}$ See, for example, Benjamin Martin, Essay on Visual Glasses (London: The Author, 1756); Bernarr Adolphus MacFadden, Strong Eyes: How Weak Eyes May Be Strengthened and Spectacles Discarded (New York: Physical Culture Publishing Co., 1903).
} 
in 'gate-keeping' employees' fitness for certain professions. ${ }^{7}$ However, this chapter argues that medical practitioners were not the only group of people offering advice on vision and eyesight, and information was also circulated by opticians and miscellaneous individuals in newspapers, periodicals and popular texts. Opticians, with a background in scientific optics and the manufacture of lenses, produced a range of texts that competed with the popular works that were produced by medical practitioners. 'Optical' or 'scientific' texts in this chapter refer to the texts that were produced by these men and included a range of information on the use of lenses and vision aids, as well as information on the anatomy of the eye. 'Medical' texts contained similar information. However, this term is used to describe texts authored by those with a medical degree. The 'popular' texts that were produced by both medical practitioners and opticians have been defined by audience; these works specifically state that they were intended for a broader audience in their prefaces or introductions.

\section{Medical Perspectives on Spectacles}

When it came to the 'correction' of the eye and treatment of vision in the nineteenth century, prevention was often better than cure. Moreover, medical practitioners and ophthalmologists were quick to point out the superiority of the 'emmetropic', or normal, eye and therefore considered ocular care to be of particular importance. As a result, a lot of attention was given to care of the eye and preservation of vision in popular medical and scientific texts. ${ }^{8}$ These texts were quick to point out methods

\footnotetext{
${ }^{7}$ Anne Digby, The Evolution of British General Practice, 1850-1948 (Oxford: Oxford University Press, 1999), p. 247.

${ }^{8}$ See Medical: Georg Beer, The Art of Preserving the Sight Unimpaired to an Extreme Old Age; and of Re-establishing and Strengthening it When it Becomes Weak (London: Henry Colburn, 1815); Alfred Smee, Vision in Health and Disease: the Value of Glasses for its Restoration and the Mischief Caused by their Abuse: Being the Substance of Lectures Delivered at the Central London Ophthalmic Hospital (London: Horn, Thornwaite and Wood, 1847); John Soelberg Wells, On Long, Short and Weak Sight and their Treatment by the Scientific Use of Spectacles (London: J.A. Churchill, 1862); Robert Brudenell Carter, Eyesight: Good and Bad: A Treatise on the Exercise and Preservation of Vision, $2^{\text {nd }}$ edn (London: Macmillan, 1880); George Black, Eyesight and How to Care for It (London: Ward, Lock, 1888); Scientific or optical: J.T. Hudson, Spectaclaenia, $10^{\text {th }}$ edn (London: Simpkin and Marshall, 1834); Walter Alden, The Human Eye; its Use and Abuse: A popular Treatise on Near and Impaired Sight, and the Methods of Preservation by the Proper Use of Spectacles (Cincinnati: The Author, 1866); Charles A. Long, Spectacles: When to Wear and How to Use Them: Addressed to Those who Value Their Sight, $2^{\text {nd }}$ edn (London: Bland and Long, 1855); John Browning, Our Eyes and How to Preserve Them from Infancy to Old Age. With Special Information About Spectacles, $7^{\text {th }}$ edn (London: Chatto \& Windus, 1887); Henry Laurance, The Eye in Health and Disease: With Hints
} 
that should be adopted to abate the acceleration of vision defects. They advised on a range of topics such as the appropriate position of reading, ocular hygiene, and the importance of physical health or observing moving imagery. Advice on how to preserve ocular health can be seen across the century, which suggests that methods used to care for the eyes remained important regardless of medical opinion towards spectacles. However, this section explores how medical opinion changed across the century. Whilst care of the eyes remained a primary priority for medical practitioners, the use of lenses as a treatment method became integrated into medical theory and practice from the mid-century.

Opticians and medical practitioners discussed the utility of spectacles, as a treatment method to correct vision defects across the eighteenth and nineteenth centuries. However, medical opinion was not always unanimously in favour of the use of spectacles, and they were not considered the only solution to vision defects. There is no straightforward narrative to be written when exploring medical perspectives of vision aids and vision testing. Despite this, a general trend can be ascertained. In the eighteenth century, medical practitioners, as part of general medical works and family health guides, acknowledged the value of spectacles and advised those who might require them to consult with an optician. However, by the first half of the nineteenth century a shift can be seen, and spectacles were primarily discussed by ophthalmologists in more specialised works, which could favour therapeutic methods and express caution towards the adoption of lenses. Finally, by the latter half of the nineteenth century, with the invention of the ophthalmoscope and the diagnosis of refractive and accommodative vision errors, spectacles continued to be discussed by ophthalmologists but opinions were more favourable. I argue that changing medical perspectives towards spectacles were influenced by the need to develop a reputable medical discipline concerned with the eye in the first half of the nineteenth century, and the growing knowledge of vision and vision defects from the mid-century onwards.

Eighteenth-century texts that discussed spectacles existed in two primary forms: optical and medical. Optical texts and medical dictionaries explained the 
basic principles of lenses for the treatment of two known vision defects, which were referred to as 'presbytae' and 'myopia'. This information was distributed in medical texts as part of more general medical works, medical dictionaries, and family health guides. ${ }^{9}$ Spectacles were discussed as a 'remedy' for what they described as an 'infirmity' and people were 'relieved' by their usage. ${ }^{10}$ As a result, in both optical and medical texts, they appeared as an acknowledged treatment method and were obtained from the optician. However, by the late eighteenth century, increased medical specialism in the eye and vision appeared in contemporary discussion of spectacles. In 1793 Dr William Rowley, member of the Royal College of Physicians and physician to the St Marylebone Infirmary, produced a text on the eyes and eyelids as part of a multivolume treatise on the 'Rational Practice of Physic'. ${ }^{11}$ Rowley argued that spectacles 'were necessary to rectify defects of vision' if they originated from 'peculiarity in the figure of the eye, or advanced age'. ${ }^{12}$ However, he also suggested that "people should be cautious in the choice of glasses, and not use them unless absolutely necessary'. ${ }^{13}$ Rowley's treatise was the outcome of twenty years work on the eye in response to the 'defective' methods of treating its diseases, as well as the 'pretensions of itinerant oculists, and the neglect of regular practitioners'. ${ }^{14}$ Rowley's discussion of 'Spectacles and other Glasses' highlighted the place of vision aids in an emerging discipline of ophthalmology, and was driven by concerns surrounding professionalism and quality of practice.

\footnotetext{
${ }^{9}$ See, for example, Robert James, M.D., A Medicinal Dictionary, including physic, surgery, anatomy, chymistry and botany (London: T. Osborne, 1743-5), digital page 96; William Lewis, M.B. F.R.S., Medical Essays and Observations, published by a society in Edinburgh, containing meterology, mineral waters, material medica and pharmacy, animal oeconomy, vol I (London, 1746), p. 387; William Emerson, The Elements of Optics. In Four Books (London: J. Nourse, 1768), p. 156; Joseph Harris, A Treatise of Optics: Containing Elements of the Science, In Two Books (London, 1775), pp. 147-50; Erasmus Middleton, The New Complete Dictionary of Arts and Sciences (London, 1778), p. 256; Addison Smith, Visus Illustratus; or, the sight rendered clear and indistinct (London, 1783), passim; William Nicholson, An Introduction to Natural Philosophy, vol I (London: J. Johnson, 1790), pp. 333-4; George Motherby, A New Medical Dictionary; Or, General Repository of Physic (London: J.Johnson, 1791), p. 528; F.M. Willich M.D., Lectures on Diet and Regimen: Being a systematic inquiry into the most rational means of preserving health and prolonging life (London: A. Strahan, 1800), pp. 652-8.

${ }^{10}$ The Family Guide to Health, or a General Practice of Physic (London, 1767), p. 33; Malcolm Flemyng M.D., An Introduction to Physiology, being a course of lectures upon the most important Parts of the Animal Oeconomy (London, 1759), p. 336.

${ }^{11}$ William Rowley, A Treatise on One Hundred and Eighteen Principle Diseases of the Eyes and Eyelids (London: J Wingrave, 1790); William Rowley, Dr Rowley's Rational Practice of Physic, in Four Volumes, vol III (London, 1793)

${ }^{12}$ Rowley, A Treatise on One Hundred and Eighteen Principle Diseases of the Eyes and Eyelids, pp. 353-4; Rowley, Rational Practice of Physic, p. 397.

13 Ibid.

${ }^{14}$ Rowley, A Treatise on One Hundred and Eighteen Principle Diseases of the Eyes and Eyelids, pp iii-iv.; Rowley, Rational Practice of Physic, pp. i-ii.
} 
Professionalism, the emergence of ophthalmology, and the process of establishing a role for ophthalmologists all help to explain attitudes towards the use of spectacles in the early nineteenth century. Throughout the first half of the century, caution towards vision aids in general continued to be emphasised and the use of therapeutic methods, which could be undertaken by ophthalmologists, were being explored. Spectacles were not always decisively dismissed, but extreme care was advised for their usage and there was more favour towards strengthening the eye. In 1815 Georg Beer, an Austrian ophthalmologist who helped found the discipline of ophthalmology, for example, cautioned against their use and ability to worsen vision in a translation of his work. ${ }^{15}$ Beer believed that the misuse of spectacles could cause blindness in the short-sighted, and concluded that he did not 'entirely forbid the use of glasses... because I know it will be attended to; but let them use only one glass at a time... and, let them, as much as possible, do without it'. ${ }^{16}$ Likewise in 1839 , William Clay Wallace, an American oculist whose work was recommended by prominent British men, argued that 'spectacles should be delayed as long as possible' and warned that 'permanent injury to the eyes is often caused'. ${ }^{17}$ In both of these instances, the authors' key argument was spectacles weaken rather than aid vision in the longer term.

This is not to say that favourable opinions of spectacles cannot be found in the earlier part of the century. In 1847, Alfred Smee, a lecturer and Surgeon to the Central London Ophthalmic Hospital, proposed that spectacles should be 'at once employed' to avoid strain when signs of diminishing vision were evident. ${ }^{18}$ Smee's opinion was based on the idea that, rather than strengthening the eye independently of spectacles, lenses should be adopted to prevent overwork of the organ. However, this theory did not stray too far from earlier thought, and Smee acknowledged the damage that spectacles could cause in terms of weakening the eye. In particular,

\footnotetext{
${ }^{15}$ Beer, p. 206; D.M. Albert, F.C. Blodi, 'George Joseph Beer: A Review of His Life and Contributions', in History of Ophthalmology 1. Academiae Ophthalmologicae Internationalis, vol 1 (Dordrecht: Springer, 1988), pp. 79-103.

${ }^{16}$ Beer, p. 206.

${ }^{17}$ William Clay Wallace, Wonders of Vision: A Treatise on the Eye (New York: Samuel Colman, 1839), pp. 69-70. Although Wallace was American, his opinions would have been known by the British medical profession through the eighth meeting of the British Association for the Advancement of Science, and as evidenced by the London British and Foreign Medical Review.

${ }^{18}$ Smee, p. 44.
} 
Smee criticised the adoption of lenses that were too strong and their detrimental effects. In his published lectures, he argued that 'very great mischief' was caused by lenses that were too strong, and that eye injury from the wrong use of spectacles in general should not be underestimated. ${ }^{19}$ This view was widely held in the nineteenth century as a whole, and the majority of medical practitioners admitted the negative effects of wearing too strong lenses, and the potential risks of adopting glasses. Indeed, even in the latter half of the century when medical opinion became more favourable, medical practitioners would acknowledge the damage, 'mischief', or seriousness of concave or convex lenses when used wrongly. ${ }^{20}$

Lenses were not the only solution in the early nineteenth century and several ophthalmologists explored a variety of treatment options in a bid to ascertain the most effective treatment method. Wallace, for example, in his criticism of spectacles proposed an alternative in the form of medicinal and therapeutic treatments. Wallace's treatment methods ranged from 'application of cologne-water', the invigoration of health 'by exercise in the open air', and control of diet. Yet those who were short-sighted in adolescence could also be treated with 'four or six leeches... applied to each temple every week, or every two weeks' ${ }^{21}$ Wallace, as an oculist, discussed and approached the treatment of vision defects in a similar manner to the range of eye diseases that he explored. Similarly, in 1854 William Mackenzie, a surgeon and lecturer based in Glasgow and one of the founding fathers of British ophthalmology, described a case where a short-sighted person, eventually treated with spectacles, was subjected to leeching, purgatives, and blisters in an attempt to remedy their vision. ${ }^{22}$ Mackenzie did criticise this treatment and could promote the use of spectacles to remedy myopia and presbyopia. However, he also explored the value of exercising the eye when a person had myopia and suggested that concave

\footnotetext{
${ }^{19}$ Ibid., pp. $45,47$.

${ }^{20}$ F.C. Donders, On the Accommodation and Refraction of the Eye, with a Preliminary Essay on Physiological Dioptrics, trans William Daniel Moore (London: New Sydenham Society, 1864), p. 102; This opinion was supported by many, see, for example, Friedrich Horner, On Spectacles: Their History and Uses (London: Balliere, Tindall \& Cox, 1887), p. 26; Christopher Smith Fenner, Vision: Its Optical Defects, and the Adaption of Spectacles (London: Lindsay \& Blakiston, 1875), p. 175; Browning, p. 71.

${ }^{21}$ Wallace, pp. 69-71.

${ }^{22}$ William Mackenzie, A Practical Treatise on the Diseases of the Eye, $4^{\text {th }}$ edn (London: A. and G.A. Spottiswoode, 1854), p. 910; 'William Mackenzie Medal', British Journal of Ophthalmology, 12.12 (1928), 648-649.
} 
lenses could 'aggravate' vision. ${ }^{23}$ Additionally, Mackenzie advocated a variety of possible therapeutic treatments for a condition of the eyes known as 'asthenopia'. 'Asthenopia' could cause a person discomfort or a range of physical symptoms when they over-used their eyes. Mackenzie suggested tonics, diet, sedatives, stimulants, spirituous and aromatic vapours, and even 'cauterisation of the urethra', in order to help alleviate symptoms and seek a cure. In instances where these were unsuccessful, Mackenzie advised emigration to Australia, because such a change enabled the patient to undertake 'pastoral pursuits' and reduced strain on their vision. ${ }^{24}$

The desire to adopt therapeutic methods could be based on the need for ophthalmologists to justify their role, and develop remedies that they could adopt themselves. Mackenzie, for example, highlighted how the use of lenses was not part of the ophthalmologist's training and the patient would need to attend an optician's shop. ${ }^{25}$ However, Mackenzie was not dismissive of spectacles as a whole, and his reasoning was primarily based on clinical experience and the use of therapeutic methods to treat a range of eye diseases and conditions that were presented in his vast treatise. As a result, the inclination to avoid the use of lenses in certain cases can also be explained by the constraints on medical knowledge and training in ophthalmology at the time. 'Asthenopia', which was discussed by Mackenzie, is a good example for this, because effective treatment by lenses was dependent on being able to examine the eye in greater depth to ascertain the cause of the problem. Without the technology to achieve this, lenses could not be accurately 'suited' - a technical term used to describe a lens that was appropriate strength and able to 'correct' a person's vision - and therapeutic methods, which were observed to have helped, were adopted.

In 1864 the seminal work of the Dutch ophthalmologist Franciscus Cornelis Donders, On the Anomalies of Accommodation and Refraction of the Eye, caused a decisive shift in medical opinion towards the adoption of spectacles, because it drew upon the advances in testing technologies to enhance knowledge of refractive vision errors. Donders declared that therapeutic treatments were for hygiene purposes only

\footnotetext{
${ }^{23}$ Mackenzie, p. 912.

${ }^{24}$ Ibid., pp. 987-990; Cauterisation of the urethra and surrounding areas was considered a possible cure because asthenopia in some cases was linked to masturbation.

${ }^{25}$ Ibid., p. 915.
} 
and were not preventative cures, and this attitude was integral to approaches to vision testing from the mid-century. ${ }^{26}$ Ophthalmology, and the subsequent interest in the eye, had influenced the nineteenth-century advance in diagnosing and attempting to 'correct' vision errors. In May 1888 at the 'Presentation of the Charter of the Donders Foundation', Donders reflected on the importance of Hermann von Helmholtz's invention of the ophthalmoscope in 1851 for his work. ${ }^{27}$ The importance of the ophthalmoscope lay in the one decisive outcome of ophthalmoscopy: the ability to see inside the eye. Eighteenth and early nineteenthcentury opticians and medical practitioners understood the principles of optics, and how alterations in the shape of the eye could affect the way light refracted onto the retina. ${ }^{28}$ However, the ophthalmoscope was able to shine light into the eye, and this allowed practitioners to observe the interior of the organ and determine refractive vision errors for the first time. Whilst it was invented by Helmholtz in 1851, a number of valuable versions of the device were soon acknowledged by ophthalmologists. In both England and America, the ophthalmoscope was described as 'indispensable' by both general medical practitioners and specialised medical practitioners for understanding refractive errors and diseases of the eye. ${ }^{29}$

Historical studies have considered the ophthalmoscope to be integral to the development of more precise knowledge of the eye. Wolfgang H. Vogel and Andreas Berke in their brief overview of the history of vision and ocular medicine, for example, have concluded that the invention of the ophthalmoscope was the most important advancement of the nineteenth century. ${ }^{30}$ However, more precise

\footnotetext{
${ }^{26}$ Donders, pp. 194-6.

${ }^{27}$ Ibid., p. 278.

${ }^{28}$ See footnotes 8 and 9 .

${ }^{29}$ See, for example, American: John Phillips, Ophthalmic Surgery and Treatment: With Advice on the Use and Abuse of Spectacles (London: W.B. Keen \& Co., 1869), p. vi; English: Carter, Eyesight Good and Bad, p. 52; For how it was adopted in practice, please see: https://www.collegeoptometrists.org/the-college/museum/online-exhibitions/virtual-ophthalmic-instrumentgallery/ophthalmoscopes.html [accessed: 6 May 2018]; and for examples of how ophthalmoscopes were used by ophthalmologists for testing vision in practice, see: E. Landolt, A Manual Examination of the Eyes (London: Tindall \& Cox, 1879), pp. 261-269, 270-273; A. Stanford Morton, Refraction of the Eye: It's Diagnosis and the Correction of its Errors (London: H.K. Lewis, 1881), pp. 40-43; James Thorington, Refraction and How to Refract. Including Sections on Optics, Retinoscopy, the Fitting of Spectacles and Eye-glasses, etc (London: Rebman Ltd, 1900), pp. 87-100.

${ }^{30}$ Wolfgang H. Vogel and Andreas Berke, Brief History of Vision and Ocular Medicine (Amsterdam: Wayenborgh Publishers, 2009), pp. 221-3; See also, for example, Daniel M. Albert, 'Ocular Refraction and the Development of Spectacles', in The History of Ophthalmology, ed. by Daniel M. Albert and Diane D. Edwards (Oxford: Blackwell Science, 1996), p. 109.
} 
knowledge of the eye was also important for the adoption of lenses as a treatment method amongst medical practitioners. Donders' seminal work in 1864 showed how the ophthalmoscope enabled refractive vision errors to be diagnosed and fully understood for the first time, indicating the speed with which it was adopted into certain ophthalmologists' practice. In particular, contemporaries highlighted Donders' ability to explicitly write down and explain the various vision defects in the eye, and separate refractive from accommodative errors in simple terms. ${ }^{31}$ The range of known refractive vision errors expanded from 'myopia', 'presbytae' and early knowledge on astigmatism to the refractive vision errors - myopia, hypermetropia, and astigmatism - and the accommodative vision error, presbyopia. ${ }^{32}$ In particular, Donders was able to prove and explain that both hypermetropia and presbyopia appeared similar and led to 'long sight', but that they came from two separate causes. $^{33}$

Internationally, ophthalmologists considered Donders and the ophthalmoscope to be important because of the newfound ability to be 'accurate' or 'scientific'. In 1887 Friedrich Horner, Swiss Ophthalmologist and Professor at the University of Zurich, suggested that previous examinations had been 'mere suggestions and guesses unsupported by proofs and not duly followed up, or stated in such an unintelligible manner that they could only be properly understood after Donders'. ${ }^{34}$ Similarly, in 1899 D.B. Roosa, Professor Emeritus of the Eye at the New York Post-Graduate Medical School and Surgeon to the Manhattan Eye and Ear Hospital, adopted a similar opinion and argued that Donders 'famous work' established spectacles, 'corrective' lenses, and the diagnosis of vision errors on 'scientific principles'. ${ }^{35}$ Both Roosa and Horner considered the ophthalmoscope, and Donders' work with it, to have advanced vision testing and spectacle provision to a discipline that was centred on scientific knowledge rather than mere speculation. Whilst treatment of vision defects by lenses had been used for centuries, how they

\footnotetext{
${ }^{31}$ See, for example, Landolt, p. 17; Horner, p. 6; D.B. Roosa, Defective Eyesight: The Principles of its Relief by Glasses (London: Macmillan, 1899), p. 29.

${ }^{32}$ For Donders' separation of the two, see pp. 93-4, and his discussion of hypermetropia from p. 105 onwards.

33 'Guest Editorial: Hypermetropia or Hyperopia?', Ophthalmic \& Physiological Optics, 35 (2015), 27.

${ }^{34}$ Horner, pp. 9-10.

${ }^{35}$ Roosa, pp. 11-12, 14.
} 
actually worked had been little understood. ${ }^{36}$ This increased understanding of vision defects was quickly distributed amongst ophthalmologists, and the progress that had been made in the 'correction' of vision defects across the nineteenth century was frequently reflected upon. ${ }^{37}$

The influence of a greater understanding of refractive vision errors, and vision testing, caused spectacles to become a more viable remedy. The most illustrative result of Donders' work and the use of the ophthalmoscope on the adoption of spectacles as a treatment method can be seen in his work on the condition of asthenopia. Donders concluded that asthenopia was not incurable and could be caused by the refractive error hypermetropia, which he diagnosed for the first time in $1858 .{ }^{38}$ In most cases, Donders understanding of hypermetropia eliminated asthenopia and transformed a fatiguing condition that could be life limiting, into a curable and measurable one by the use of spectacles. Moreover, Donders explored William Mackenzie's discussion of asthenopia and suggested that he had not used the correct strength of lenses. ${ }^{39}$ Ultimately, Donders' questioned why previous examinations had not discovered the connection and concluded that 'it is a great satisfaction to be able to say that asthenopia need now no longer be an inconvenience to any one'. ${ }^{40}$ The quick transmission of Donders' ideas can be seen in the early work of John Soelberg Wells, Ophthalmic Surgeon and Lecturer on Ophthalmic Surgery to the Middlesex Hospital. In 1862 Wells discussed the relationship between hypermetropia and asthenopia, and strongly urged the 'necessity of the hypermetropic person wearing glasses always' ${ }^{41}$ Similarly, in 1885 the column, 'Notes on Current Science', in a British periodical argued that Donders reduced the suffering of those with the condition immeasurably. ${ }^{42}$ A more popular

\footnotetext{
${ }^{36}$ See, for example, Roosa, p. 29; Vogel and Berke, pp. 239-40.

${ }^{37}$ Landolt, pp. 14-16; A. Maitland Ramsey, On the Rise of Modern Ophthalmology (Privately Printed: Ballantyne Press, 1900), pp. 5-6, 14-16, 19-20; Anderson Critchett, 'Chart for Measuring the Field of Vision', British Medical Journal, 1 January 1881, p. 9; C.H. Vilas, Spectacles; and How to Choose Them (Chicago: Duncan Brothers, 1881), pp. 17-19; Horner, pp. 5-10; A. Fournet, Medical Spectacles and the Royal London Hospital: Bloomfield Street, Moorfields, E.C. (London: A. Fournet, 1894), p. 4. 38 'Guest Editorial: Hypermetropia or Hyperopia?', Ophthalmic \& Physiological Optics, 35 (2015), 27.

${ }^{39}$ Donders, p. 124

${ }^{40}$ Ibid.

${ }^{41}$ Wells, pp. 99-100.

42 'Notes on Current Science', The Wesleyan-Methodist Magazine, March 1885, p. 219.
} 
British medical work from 1889 also argued that Donders' ability to explain the 'true cause' of asthenopia helped to transform the lives of those in 'hopeless conditions'. 43

Donders defined a refractive condition, disproved earlier theories, and proved the use of spectacles as an effective treatment. The success of Donders' treatment of asthenopia was based on the adoption of new technologies and a more thorough examination. Alongside the invention of the ophthalmoscope in 1851, the invention of the test chart by Herman Snellen in 1862 allowed vision defects to be measurable for the first time. This was considered important by both British and American ophthalmologists for its ability to determine the degree of someone's visual acuity with 'exactness' ${ }^{44}$ Indeed, it was argued that the invention of test-types in itself 'virtually solved the problem of measuring and registering vision'. ${ }^{45}$ The method adopted by Donders in the mid-century incorporated test-types, trial lenses and the ophthalmoscope to determine a person's visual acuity. In 1862 Wells described Donders' method of examination in detail and argued that it enabled the degree of error to be 'easily determined'. ${ }^{46}$ However, across the second half of the century a number of other testing methods - such as retinoscopy - and equipment - such as viscometers, optometers and ophthalmometers - were developed. Alongside this, the adoption of a universal lens measurement, the dioptre, in 1875 allowed vision defects to be measured with greater precision. In medical texts, for example, arbitrary methods of lens measurement for only spherical concave and convex lenses appeared in $1860 .{ }^{47}$ However, by 1900 , a description of a trial case contained concave and convex spherical and cylindrical lenses, of a standardised quantity and measurement. ${ }^{48}$ Medical practitioners increasingly developed and discussed more complex methods for diagnosing and determining the refractive condition of a person's eye. Medical practitioners were not only able to recognise a greater number of vision errors and alleviate conditions such as asthenopia, but were able to observe the benefits of lenses and adapt them with greater speed and precision.

\footnotetext{
${ }^{43}$ Black, pp. 75-6.

${ }^{44}$ Carter, Eyesight Good and Bad, p. 59.

${ }^{45}$ Roosa, p. 3. A good description of nineteenth-century test types for near and distant vision can be found in Stanford, pp. 16-17.

${ }^{46}$ Wells, pp. 40-44.

${ }^{47}$ For an overview of how lenses were measured in the nineteenth century, see Vilas, pp. 51-53.

48 Thorington, p. 45.
} 
The ability to determine refractive and accommodative vision errors, and measure them with greater precision, was important for the adoption of lenses as a corrective treatment by medical practitioners. In particular, it allowed lenses to be suited with a degree of accuracy necessary for enhancing vision whilst ensuring that vision was not damaged. As a result, lenses were better adapted and became a more conceivable solution. The efficacy of this method by the second half of the nineteenth century is best reflected in the terminology used to describe the state of a person's eyes both prior to, and after, the use of lenses. In particular, lenses were able to re-classify what it meant to be 'blind' in the nineteenth century and how it was conceptualised by those who were partially sighted. Similar parallels can be drawn between the invention and adoption of new technologies and the classification of hearing loss in the early twentieth century. Coreen McGuire, for example, has explored how telephony affected descriptions of hearing loss in the early twentieth century. McGuire argued that improvements in technology caused the terminology used to describe a person's level of hearing to change from 'extremely deaf' to 'hard of hearing', despite the overall level of hearing remaining unchanged. ${ }^{49}$

The adoption of spectacles in the nineteenth century enabled patients to reconsider the condition and state of their vision. Mackenzie, for example, offered a bleak prognosis and regarded certain conditions of the eye that would be later treated by lenses as 'incurable'. ${ }^{50}$ However, patients could also take this a step further and consider themselves 'blind' prior to the use of spectacles. A number of medical case accounts in the second half of the nineteenth century document people, who thought they were 'blind', being able to see again with the use of spectacles. In 1866 Walter Alden, an American optician who drew upon the work of British ophthalmologists, referred to the case 'of a master of a printing office, who became blind'. Despite being 'blind' and only 'capable of perceiving the light so as to find his way into the streets' he 'ultimately recovered sight' with the use of lenses over a period of a few years. ${ }^{51}$ Similarly, a boy aged ' 16 or 17 ' was supposed 'blind' by both his parents and friends but had 'a new world opened to him' by the use of glasses, which

\footnotetext{
${ }^{49}$ Coreen McGuire, 'Inventing amplified telephony: the co-creation of aural technology and disability' in Rethinking modern prostheses in Anglo-American commodity cultures, 1820-1939, ed. by Claire Jones (Manchester: Manchester University Press, 2017), p. 84.

${ }^{50}$ Mackenzie, p. 986.

${ }^{51}$ Alden, pp. 24-5.
} 
improved his vision until it was 'restored to him as perfectly as could be desired' ${ }^{52}$ Moreover, Alden concluded that those suffering from hypermetropia - a refractive condition caused by the focus of the eye extending beyond the retina - 'often neglect the true and only remedy, and wander on in darkness'. ${ }^{53}$ A decade earlier in 1853, ophthalmologist William White Cooper, who was based at the North London Eye Institution and later St Mary's Hospital, provided two similar cases. Whilst Anne Spencer aged 23 was 'supposed blind' and Miss H aged 14, 'had never seen' in one eye, they were both restored through the use of spectacles and 'suitable' lenses. ${ }^{54}$

The case accounts that were used to help support the use of spectacles in treatment practice at Moorfield Eye Hospital in the last decade of the nineteenth century also revealed that patients considered themselves to be blind. These cases are also useful for showing how the adoption of lenses as a treatment for more complex vision errors was being debated and explored at the century's close. The personal accounts that were sent to Moorfields Eye Hospital could have had an intended purpose, namely to help support the optician who provided these patients with spectacles, and also to encourage the use of lenses in treatment practice. ${ }^{55}$ However, these accounts reveal contemporary perceptions of the potential permanency of a range of refractive vision errors and eye conditions. Equally, they also show that individuals still considered themselves 'blind' when they had a range of conditions that could be restored by the use of lenses. In 1899 and 1900, for example, Thomas Roskilley wrote on behalf of his daughter, and described how she had experienced 'thirteen years of blindness' in her right eye, and was told it 'was useless to call there anymore'. ${ }^{56}$ Similarly, parents of a number of children suffering from potential 'blindness' were told that their sight would 'never improve', or would not respond to other forms of treatment. ${ }^{57}$

\footnotetext{
${ }^{52}$ Ibid., p. 59.

${ }^{53}$ Ibid., p. 56.

${ }^{54}$ Sir William White Cooper, On Near Sight, Aged Sight, Impaired Vision and the Means of Assisting Sight, $2^{\text {nd }}$ edn (London: John Churchill, 1853), pp. 6-7.

${ }_{55}$ The patients here had complex vision errors, which had not responded to previous treatment methods.

${ }^{56}$ London Metropolitan Archive, A/KE/B/01/04/004: 'Complaint that there was little profit in supplying spectacles' charities', letters dated 22 May 1899 and 17 May 1900.

${ }^{57}$ Ibid., letters dated 23 May 1899 and 18 May 1900.
} 
As shown in the cases from the middle and end of the nineteenth century, patients who considered themselves 'blind' had their vision restored by the appropriate use of lenses. Consequently, the state of being 'blind' was being reconceptualised, something which highlights how the degrees and meaning of blindness should not be seen as transhistorical. ${ }^{58}$ Prior to the improved testing of vision in the mid-century, individuals could think that they were 'blind' and suffer a number of negative consequences as a result of this, such as difficulties with work. ${ }^{59}$ However, the appropriate use of lenses transformed a person's visual capabilities. Increased understanding of lenses, and their ability to measure and test vision, was helping to re-classify what was considered 'blind', the permanency or curative nature of certain 'blindness', and what it was to be partially sighted in the nineteenth century. Yet, in contrast to advances in telephony, the terminology used by patients or practitioners to describe the effects of spectacles reveals how effective lenses could be as an assistive technology. Whilst McGuire has shown how Harris transformed from being 'extremely deaf' to 'hard of hearing' in the early twentieth century, a number of 'blind' patients by the mid-nineteenth century had 'recovered sight' or vision 'as perfectly as could be desired.${ }^{60}$ Importantly, however, the overall utility of lenses was not solely dependent on improvements in technology. The effective use of spectacles needs to be seen as part of a complex process that encompassed an improvement in examination, diagnostic technologies, and understanding of the eye. This is highlighted in instances where lenses were not appropriately adapted to the sight. In $1899 \mathrm{~W}$. Rudland, for example, was told that he was incurable and had lenses that were 'useless', before being fitted with a pair that enabled him 'to read and write as well as any other person' ${ }^{61}$

Enhanced knowledge of how lenses could be adapted, and growing evidence of their utility, meant that the use of lenses was more decisively encouraged and came to be seen as a necessity in the latter half of the century. Medicinal advice did not necessarily stop. In 1889 Charles Bell Taylor, surgeon to the Nottingham and Midland Eye Infirmary, for example, advocated leeches to the temple, darkness, and

\footnotetext{
${ }^{58}$ See, for example, Christopher Michael Woolgar, The Senses in Late Medieval England (New Haven; London: Yale University Press, 2006), p. 1.

${ }^{59}$ McGuire, p. 84.

${ }^{60}$ Ibid; Alden, p. 59; Cooper, pp. 6-7.

${ }^{61}$ London Metropolitan Archive, A/KE/B/01/04/004: 'Complaint that there was little profit in supplying spectacles' charities', letter dated 8 June 1899.
} 
tonics in severe cases of myopia. ${ }^{62}$ Yet recommendation by medical practitioners of other remedies was primarily used to aid eye inflammation or disease, not to solve refractive errors or vision defects. In contrast, the necessity of acquiring spectacles, as the only method of treatment, when the first symptoms of vision defects arose was emphasised. Even earlier the work of the American oculist and optician John Phillips', which was published in London in 1869, argued that spectacles should be used 'at once'. Phillips suggested that 'as a general rule, spectacles always act beneficially when they afford just so much assistance to the eye in its attempt at adjustment as enables it without fatigue'. ${ }^{63}$ The risks and dangers of incorrect lenses were still discussed. However, as suggested by Phillips, the spectacles that afforded 'just so much assistance' as necessary were beneficial, and the increased knowledge of vision defects helped to ensure that this was the case. The strength of a lens that would provide 'just so much assistance' was still being debated by medical practitioners in publications such as the British Medical Journal in the last decade of the nineteenth century. ${ }^{64}$ Despite this, the debate revealed that, while their strength was contested, the medical practitioners involved were unanimous on the overall benefit of lenses. Indeed, in 1899 it was proposed that popular and medical prejudices towards spectacles had 'passed away'. ${ }^{65}$ Based on current medical knowledge and technological advance, the use of lenses had become accepted into medical practice as a means to correct refractive and accommodative vision errors.

Negative opinions on spectacles in the later nineteenth century still existed, and there was some disfavour towards their adoption. In correspondence to the British Medical Journal in 1889, W.W. Ireland continued to propound the need for strengthening the eye, and cautioned against the use of spectacles as the absolute solution for cases of myopia. As part of this, Ireland argued that children's vision in particular should be exercised and they should habitually view longer distances. ${ }^{66}$ Similarly, in 1899 D. Love also cautioned against the general assumption that spectacles were the only solution, and discussed the potential 'evil' that this could

\footnotetext{
${ }^{62}$ Charles Bell Taylor, How to Select Spectacles in Cases of Long, Short, and Weak Sight, $2^{\text {nd }}$ edn (London: Cassell, 1889), p. 14.

${ }^{63}$ Alden, p. 27; Phillips, p. 22.

${ }^{64}$ See, for example, 'A Discussion on the Causes, Prevention, and Treatment of Myopia', British Medical Journal, 27 September 1890, pp. 723-728.

${ }^{65}$ Roosa, pp. 30-31.

${ }^{66}$ W.W. Ireland, 'Eyesight and the Education Act', British Medical Journal, 26 January 1889, p. 213.
} 
cause, particularly in the unquestioning use of glasses by the young. ${ }^{67}$ As previously discussed, medicinal alternatives offered by medical practitioners in the later nineteenth century were primarily for eye hygiene and poor eye health, not for simple refractive or accommodative errors. Whilst there was some consideration given to the treatment of myopia by operation in the 1890 s, and as early as 1840 , earlier therapeutic treatments for myopia were uncommon. ${ }^{68}$ Alternatives to spectacles tended to be isolated to other ocular defects and diseases, or as supplements to spectacles to avoid eyestrain, such as the typewriter and contraptions that could enable a person 'to write without using [their] eyes' ${ }^{69}$ Like spectacles, new technological inventions such as the typewriter were designed to reduce eyestrain, but they were no longer thought to replace them.

By the end of the nineteenth century, spectacles had become cemented in medical practice to such an extent that in 1904 The Lancet produced a mocking title 'The Last Days of Spectacles' to dismiss an unviable alternative remedy that had recently been advertised. ${ }^{70}$ Spectacles, as a corrective vision aid, were increasingly referred to as the remedy for refractive and accommodative errors. As shown in the discussions of 'blindness', lenses, when accurate, greatly alleviated a person's suffering from visual defects. Yet they were not seen as the perfect solution. In the second half of the century, discussion of the disadvantages and harm of spectacles was more focused on how they were worn. In 1889 Horner concluded that 'spectacles, like medicines, may sometimes prove to be poisons'. ${ }^{71}$ Similarly, opticians and medical practitioners alike were concerned about the number of glasses

\footnotetext{
${ }^{67}$ D. Love, 'The Vision of School Children', British Medical Journal, 25 March 1899, p. 763.

${ }^{68}$ See 'Division of the Recti Muscles in Myopia', The Lancet, 36.923 (1841), 239-40; 'A Discussion on the Causes, Prevention, and Treatment of myopia', pp. 723-728; J.R. Wolfe, 'Extraction of the Transparent Crystalline Lenses in Cases of Strong Myopia', British Medical Journal, 6 February 1892, p. 305; Kenneth Scott, 'Removal of the Transparent Lens from the Eye in High Degrees of Myopia', The Lancet, 24 September 1898, pp. 805-6; Robert Brudenell Carter, 'A Case of Operation for Extreme Myopia', The Lancet, 14 January 1899, pp. 87-88; F. Richardson Cross, 'The Operative Treatment of Eyes Exhibiting High Degrees of Myopia', The Lancet, 1 July 1899, pp. 17-22; W. Adams Frost, 'The Optical Effect of Removal of the Lens in Myopia', The Lancet, 15 July 1899, p.155; Adolph Bronner, 'The Removal of the Lens in Cases of High Myopia', The Lancet, 18 November 1899, pp. 1358-1359.

${ }^{69}$ See, for example, 'tenotomy' operations for weak rectus eye muscles that were discussed in Wells, pp. 55-8; Donders, pp. 192-4; Fenner, p. 246. For discussion of supplementary aids to spectacles see Carter, Eyesight Good and Bad, pp. 231-8 and Vilas, pp. 145-153.

70 'The Last Days of Spectacles', The Lancet, 8 October 1904, p. 1034.

${ }^{71}$ Horner, p. 26.
} 
worn incorrectly. ${ }^{72}$ As a result, educating the public on the nature of spectacle usage and vision defects was stressed as equally important in medical discussion of their utility. Whilst spectacles were a viable treatment method, they were a solution that relied on the ability to adapt them to the sight and the assurance that the user would wear them appropriately.

\section{Challenges to Medical Authority and the Distribution of Ideas in Popular Print}

Benarr Macfadden, an American who wrote for a public audience, rejected spectacles in a text on the eye and vision at the start of the twentieth century. ${ }^{73}$ Although not a medical professional, Macfadden produced a number of popular texts on physical exercise and health in the first half of the twentieth century. In 1903 Macfadden argued that glasses 'crippled' the eyes and proposed exercise and constitutional treatments as alternative remedies. ${ }^{74}$ Written at a point when vision aids had become accepted in the writings of both British and American medical practitioners, Macfadden's work raises questions about who could write on spectacles and vision aids, how medical ideas were distributed in lay texts, and whether medical and popular opinion differed. Information on vision aids appeared in British newspapers, periodicals and medical texts aimed at a popular readership. Medical monopoly has generally been seen to increase over the nineteenth century, especially after the Medical Act of 1858. Despite this, medical authority seems less straightforward for vision aids and care of the eyesight. As Anne Digby has suggested, 'self-help' ideologies continued parallel to the growing profile of, and confidence in, the medical profession. ${ }^{75}$ For eye care and vision aids these ideologies emerged in the form of popular texts, advice, and medical practitioners' continued discussion of erroneous beliefs on eyesight and vision aids on the part of the general public. However, information on vision aids was also provided by a range of nonmedically qualified individuals, allowing both medical and popular knowledge to circulate. In particular, opticians - who made and sold lenses and a range of optical and scientific equipment - wrote popular texts and were part of discussions on vision

\footnotetext{
${ }^{72}$ Browning, pp. 41, 46, 60.

${ }^{73}$ MacFadden, pp. 23, 37, 41, 45.

${ }^{74}$ Ibid., p. 41.

${ }^{75}$ Digby, pp. 35, 99-100, 230.
} 
and the use of vision aids in newspapers and periodicals. The section explores this, and assesses whether the increasingly favourable opinions of spectacles amongst ophthalmologists and medical practitioners affected how vision aids were discussed and perceived in texts aimed at the general public. It argues that the 'medicalisation' of vision and lenses that has been explored in the first two chapters only partly explains the use and adoption of vision aids in the nineteenth century.

In response to concerns about the preservation of vision, and the potential harm of spectacles when worn wrongly, the medical profession attempted to explain why people wore spectacles, and how they should be worn, through popular texts. Although it is not possible to know who read these books, it is clear that medical practitioners intended them to reach beyond a scientific or medical audience. In 1815 Beer, for example, stated that his use of language might 'displease the more scientific reader' but would be 'the most useful and the most requisite for whom I wish to serve, I mean for the MANY! ${ }^{76}$ As part of this, Beer targeted the 'simplest' reader. Other texts also highlighted simplicity using such vocabulary as 'easy', 'clear', and 'untechnical'. ${ }^{77}$ Medical practitioners devoted a large proportion of their popular works to supplying advice and information on spectacle usage. Many of the medical texts that dealt with the care and preservation of eyesight, discussed the education of the general public in these topics. As summarised in the mid-century by Alden and Wells, 'the proper and scientific choice of spectacles is, indeed, of great importance to the public'. ${ }^{78}$

Influence of these medical ideas in newspapers and periodicals can be seen in the attention that was given to the eye and preservation of vision in the popular press. In particular, information on vision defects was provided as part of an overview of the anatomy of the eye. During the 1830s, two articles in London and Scottish periodicals attempted to explain the nature of vision defects in simple terms. An article from 1836 entitled 'Popular Information on Science - the human eye', discussed vision and the causes of long and short-sightedness, alongside the 'decay'

\footnotetext{
${ }^{76}$ Beer, p. xiv.

${ }^{77}$ See, for example, Smee, preface; Wells, pp. v-vi; Black, p. v; R.E. Dudgeon, The Human Eye; Its Optical Construction Popularly Explained (London: Harwicke \& Bogue, 1878), p. vi.

${ }^{78}$ Alden, p. 26; Wells, p. 111.
} 
of sight in old age. ${ }^{79}$ Similarly, in 1838 a column on 'employments which injure the eyesight' had a feature on near and long-sightedness, which contained information on the age that presbyopia could begin, as well as the anatomy and causes of various visual defects. ${ }^{80}$ In the second half of the century, popular articles contained similar information. An article from 1880 headed 'Familiar talks about physiology', for example, discussed the relationship between the shape of the eyeball and vision defects, and some of the symptoms of these defects. ${ }^{81}$ Others also published findings from recent papers or lectures. In 1885 a 'Notes on Current Science' section of The Wesleyan-Methodist Magazine considered a recent paper, which discussed the theories and medical opinions on vision defects of those such as Donders and a prominent English ophthalmologist, Robert Brudenell Carter. ${ }^{82}$ Large attendances at lectures on related topics were also commented on in late nineteenth-century newspapers. There was a widespread public interest in many branches of science in this period, and particularly in the periodical press. ${ }^{83}$ The number of articles and reports of 'an extremely large audience', 'a very large attendance', and 'numerous attendance' at public lectures suggests that a general interest in the physiology and anatomy of the eye existed within this broader context. ${ }^{84}$

Reviews of popular medical texts do suggest that the authors' simple language was beneficial and received well. ${ }^{85}$ They also indicate that these works could reach a wide and varied readership. Beer's work, for example, was described as 'familiarly written' and also 'professedly popular'. ${ }^{86}$ Similarly, medical practitioners could draw upon earlier versions of their work to highlight the influence

${ }^{79}$ Chambers's Edinburgh Journal, 13 February 1836, pp. 18-19.

${ }^{80}$ The Saturday Magazine, 9 June 1838, pp. 222-3.

${ }^{81}$ After Work, November 1880, pp. 196-9.

${ }^{82}$ The Wesleyan-Methodist Magazine, March 1885, pp. 219-220.

${ }^{83}$ See, for example, Sally Shuttleworth and Geoffrey Cantor, 'Introduction', in Science Serialized: Representations of the Sciences in Nineteenth-Century Periodicals, ed. by Sally Shuttleworth and Geoffrey Cantor (London: The MIT Press, 2004), pp. 2, 4; Gregory Tate, 'Researching Science and Periodicals: Satire and Scientific Jargon in Punch', in Researching the Nineteenth-Century Periodical Press: Case Studies, ed. by Alexis Easley, Andrew King, John Morton (London: Routledge, 2018), p. 161.

${ }^{84}$ See, for example, The Morning Post, 8 February 1872; Freeman's Journal and Daily Commercial Advertiser, 6 April 1883; Aberdeen Weekly Journal, 21 June 1886; Belfast News-Letter, 31 January 1895; Freeman's Journal and Daily Commercial Advertiser, 2 March 1895; Belfast News-letter, 27 October 1896.

${ }^{85}$ The Gentleman's Magazine and Historical Chronicle, December 1819, p. 614; The Academy, 3 July 1880, p. 7; The Graphic, 17 November 1883.

${ }^{86}$ The Critical Review, or, Annals of Literature, May 1814, p. 555; Monthly Review, or, Literary Journal, November 1814, pp. 324-5. 
of early favourable opinions on the later production of more popular texts. In 1862 Wells, for example, highlighted how the 'favourable reception' of his work, as part of a series of papers in the Medical Times and Gazette, had motivated him to produce a text that was both 'easy and practical' in form. ${ }^{87}$ A number of pseudonyms were used when giving advice on the care of vision in popular texts, such as 'A Medical Man'. ${ }^{88}$ A pseudonym such as 'Medical Man' raises questions about the importance of a medical affiliation when giving advice to the public. In the first place, it highlights that they did not necessarily need to be specialists in the eye, because 'medicine', 'M.D', or 'doctor' were emphasised in all these instances. However, it also raises questions about whether these terms could be adopted by those beyond the medical sphere.

The statements of medical practitioners and extracts from their writings and lectures were numerous and suggest that the medical profession had gained some monopoly over the discussion of vision. However, the success of the medical profession in distributing knowledge on lenses and eye defects was not certain. Advice on the use of lenses as a treatment method was also coming from completely outside the medical profession, and was reproduced in popular columns and advice sections in many newspapers and periodicals. These most particularly suggest that there was popular interest on the eye at this time. Yet they also suggest that medical authority was not absolute. As Digby has stated, medical self-help manuals prevailed across the nineteenth century, and self-diagnosis or self-treatment would have been the first resort for many. ${ }^{89}$ Individuals could have turned to popular medical texts or extracts from these texts in periodicals and newspapers to obtain medical information on their own accord. However, popular advice was also present in newspapers, periodicals and popular texts, and this suggests that people could see and engage with advice that did not necessarily come from those within, or associated with, the medical profession.

Medical practitioners were not the only group of individuals to produce popular works on vision aids and vision testing. Across the nineteenth century, a

\footnotetext{
${ }^{87}$ Wells, p. iv.

${ }^{88}$ See, for example, Leeds Mercury, 4 October 1884.

${ }^{89}$ Digby, p. 99.
} 
number of texts were also produced by opticians. The similarities between medical and optical texts are striking; both kinds of text provided information on two key areas that will be explored in turn: an explanation of vision defects and the practicalities of spectacle wear. In order to explain how lenses work, medical practitioners and opticians used the same language. ${ }^{90}$ However, opticians - without a medical degree and with a background in the scientific use of lenses and optics also wrote on the anatomy of the eye and nature of vision defects to educate the public. In 1888 Henry Laurance - an optician with shops in London, Manchester, Birmingham and Glasgow - explicitly stated the defects of vision that required spectacles and how spectacles should be worn in each instance, dependent on the distance of work carried out. ${ }^{91}$ These optical texts used drawings and diagrams to aid understanding of how certain defects affected vision, and how lenses could correct them. The diagrams included in books by London opticians Thos. Harris \& Son in 1839 and Francis West in 1827, for example, included visual information on the refractive properties of various states of the eye, and how it could be 'corrected' by lenses, at the start of their text, opposite the title page. ${ }^{92}$

\footnotetext{
${ }^{90}$ See, for example, Alden, pp. 31-45; Carter, Eyesight Good and Bad, pp. 77-177.

${ }^{91}$ Laurance, pp. 14-25.

92 Thos Harris \& Son, A Brief Treatise on the Eyes, Defects of Vision, and the Means of Remedying the Same by the Use of Proper Spectacles, Also Rules for judging when Spectacles are necessary, and Directions for selecting them (London: Onwhyn, 1839); Francis West, A Familiar Treatise on the Human Eye: Containing Practical Rules that will Enable all to Judge what Spectacles are Best Calculated to Preserve their Eyes to Extreme Old Age, $2^{\text {nd }}$ edn (London: W. Ackrill, 1827).
} 
Figure 2.1. Diagrams of the refractive errors of the eye, and their correction by lenses in Thos Harris \& Son, A Brief Treatise on the Eyes. ${ }^{93}$

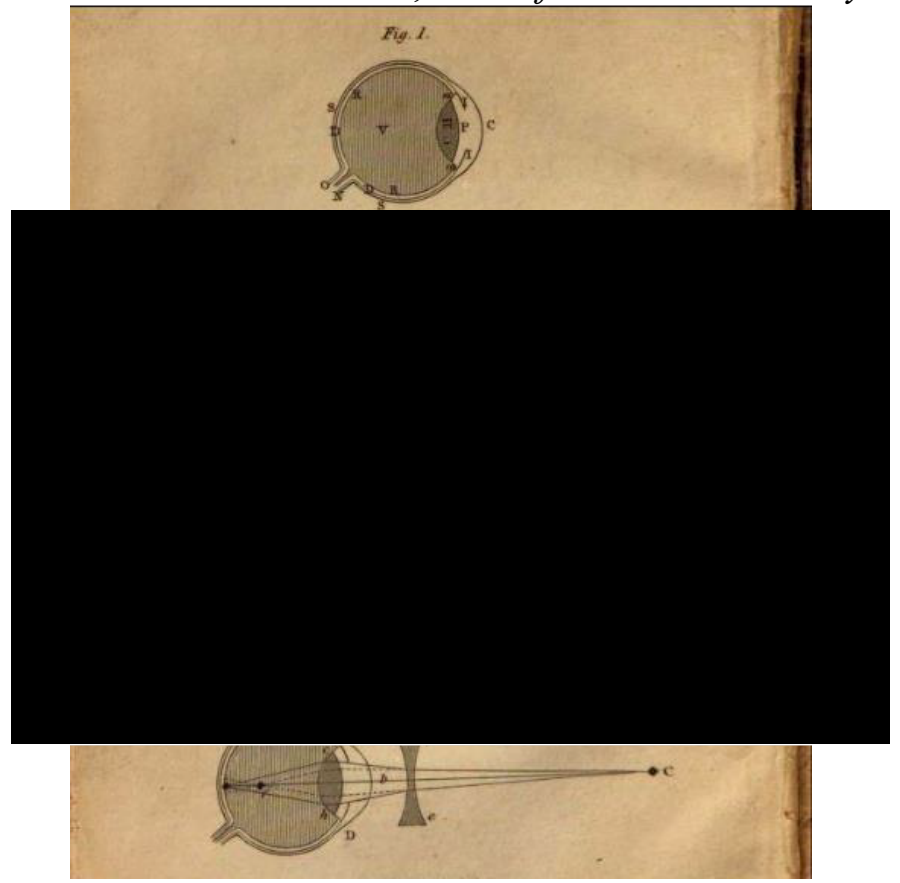

Figure 2.2. Diagrams of the refractive errors of the eye, and their correction by lenses in Francis West, $A$ Familiar Treatise on the Human Eye. ${ }^{94}$

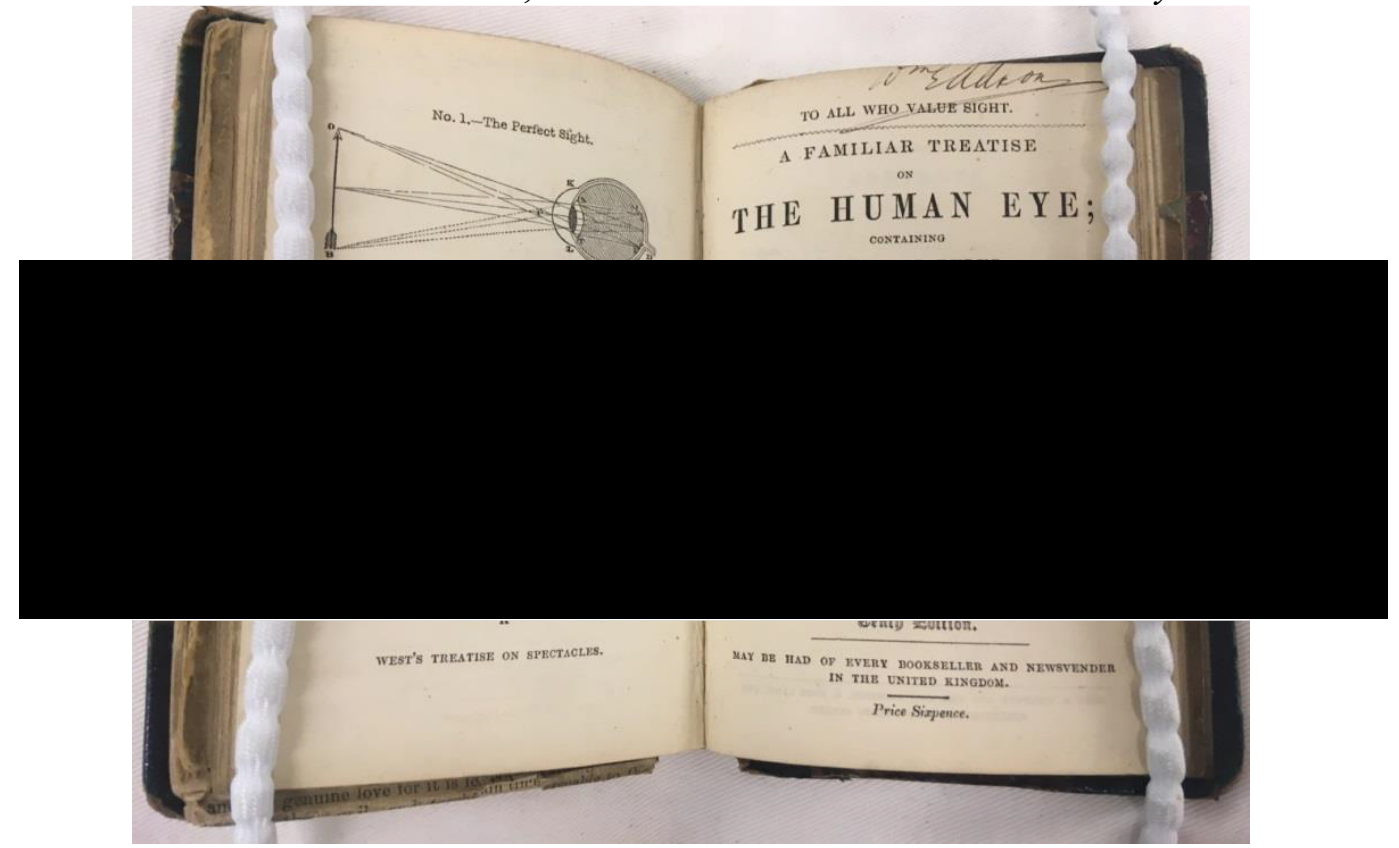

\footnotetext{
${ }^{93}$ Harris \& Son, frontpage.

${ }^{94}$ Francis West, A Familiar Treatise on the Human Eye: Containing Practical Rules that will Enable all to Judge what Spectacles are Best Calculated to Preserve their Eyes to Extreme Old Age, $10^{\text {th }}$ edn (London: W. Ackrill, [1843?]), frontpage. The diagrams were clearer in the tenth edition, and therefore were chosen in lieu of the $2^{\text {nd }}$ edition that has been used in this chapter.
} 
Besides explanations of refractive and accommodative vision errors, advice was also given on a variety of matters associated with the selection and wear of lenses. Medical practitioners and opticians discussed the symptoms and times when vision should be tested and lenses should be used to avoid strain. Indeed, advice on how to detect these symptoms remained prominent in popular medical texts across the century, and was distributed by medical practitioners in periodicals. ${ }^{95}$ However, advice on when to wear vision aids also featured in short pamphlets that were produced by opticians for the general public. A pamphlet from Laurance stated that for presbyopic persons who required convex lenses 'the first indication of failing sight is a difficulty in reading by artificial light... the proper time for taking to spectacles is found when it is impossible to read with facility at the natural distance'. ${ }^{96}$ Concise and simple advice was an indicative feature of these pamphlets as can be seen in the formats adopted by opticians William Baxter from Leeds and J. Gray Keith from Glasgow. In 1889 Keith provided the reader with ten indications of when spectacles were required:

1. When we are obliged to remove small objects to a considerable distance...

2. If we find it necessary to use more light than formerly...

3. If, in looking at, and attentively considering a near object, or in threading a needle, it becomes confused...

4. When the letters of a book run one into the other...

5. If the eyes are so fatigued with a little exercise that we are obliged to shut them from time to time...

6. When there is redness and itching of the conjunctiva, some intolerance of light, and stiffness of the globe of the eye...

7. When by the formation of a red zone of small, straight, parallel vessels arranged round the circumference of the cornea and terminating abruptly near its edge, the redness after a time extending to the conjunctiva, the Iris loses its brilliancy and becomes muddy.

8. When you perceive the formation of a blue zone of variable width around the cornea, followed by the protrusion of small dark blue tumours, varying in size and situation.

9. When distant objects are not clearly seen.

10. When small print is held closer than 12 inches in order to be clearly seen. ${ }^{97}$

In contrast, in 1898 Baxter provided a descriptive indication for failing eyesight in presbyopia, and questioned the reader on general symptoms of vision defects:

\footnotetext{
${ }^{95}$ A review of Carter's Eyesight Good and Bad, for example, which detailed how spectacles worked, the treatment of vision defects, and measurement of lens strength appeared in The Edinburgh Review, October 1881, pp. 516-546. See also, further examples from earlier in the century: Operative, 27 January 1839; The London Saturday Journal, 12 September 1840, p. 126.

${ }^{96}$ Laurance, pp. 12-15.

${ }^{97}$ J. Gray Keith, Facts Relating to Spectacles: How, When, Where and Why to Wear Them, with Rules for the Preservation of the Sight, and Cautions as to how Thousands Ruin their Sight, or are Rendered Blind, also Several Important Discoveries (Glasgow: David Bryce \& Son, 1889), p. 6.
} 
Do your eyes water? Do they pain? Does print blur? Do things appear double or mixed up? Do you have headache? Does everything turn dark before the eyes? Do you feel Drowsy? Do your eyes feel a drawing in? Do your eyes turn? Neglected eyesight grows constantly worse. ${ }^{98}$

In the pamphlets produced by opticians, and the popular medical texts produced by ophthalmologists and medical practitioners, the necessity of seeking immediate advice and having recourse to spectacles was emphasised. Both medical practitioners and opticians provided lengthy sections on the lenses that were best, and how to ensure that the frames were positioned correctly. ${ }^{99}$ As a result, both medical practitioners and opticians were encouraging the public in the adoption, and appropriate use, of vision aids. The information that originated outside the medical profession could compete with the distribution of popular medical texts. In $1835 \mathrm{a}$ London optician, John Harrison Curtis, reported that his text had a wide readership and had sold ' 4000 copies... in a short time'. ${ }^{100}$ Similarly, Charles A. Long thanked the public for buying his text in later editions of his work. In 1855, for example, Long's preface included the statement: 'the Author expresses his gratification at the favourable reception experienced by the first issue'. ${ }^{101}$ Long also included opinions from the press of his first edition, and whilst these two methods do not provide proof of a wide readership, the reviews from the popular press covered a wide geographical area. ${ }^{102}$ Although not medically qualified, some opticians could hold prominent positions or claim substantial knowledge in optics and vision testing. In 1898 Keith, for example, was a lecturer on Science at Queen's College and Assistant Optician to the Royal Family, whilst William Baxter had obtained one of the early qualifications for sight-testing opticians. ${ }^{103}$

Both medical practitioners and opticians presented their work on the nature of vision defects, and the appropriate use of vision aids, as authoritative against the backdrop of a wider range of information available to the public. Information on

\footnotetext{
${ }^{98}$ Baxter, pp. 6-7.

${ }^{99}$ For advice on lenses see, for example, Alden, pp. 108-111; Browning, p. 93; Baxter, p. 10; Horner, p. 26; Black, pp. 102-3. For advice on fit of the frame see, for example, Alden, pp. 106-109; Carter, Eyesight Good and Bad, pp. 247-254.

${ }^{100}$ Monthly Magazine, or British Register, September 1835, p. 315.

${ }^{101}$ Long, preface.

${ }^{102}$ Long included reviews from The Banker's Circular; Ipswich Express; Hampshire Advertiser; Newcastle Guardian; Bedford Times; Sheffield and Rotherham Independent; Salisbury and Winchester Journal; The Western Times; Nottingham Review; Sussex Advertiser.

${ }^{103}$ Keith, preface and Baxter, preface.
} 
vision and spectacles circulated in popular texts, newspapers and periodicals in the nineteenth century. By the 1860s, an article in Bow Bells under the title of 'SPECTACLES' concluded that 'spectacles are so well known, and their purposes so well understood that it seems unnecessary for us to attempt any lengthened description of them or their uses'. ${ }^{104}$ Beyond information provided on vision testing, the history of spectacles and where they were invented was printed in columns such as 'Facts and Fancies' and 'Table Talk' in the latter half of the century. ${ }^{105}$ Yet, despite the fact that they were 'well known', the Bow Bells article explained 'it may not, however, be amiss for us to give...the optical philosophy of the subject' and went on to describe how spectacles were best used or adopted. ${ }^{106}$ Similarly, in 1815 Beer provided a lengthy account of when to acquire spectacles 'because it happens that no person knows precisely the time when spectacles become necessary'. ${ }^{107}$ Thus, the choice of topics in Beer's treatise was motivated by the perception of a deficiency in public knowledge, something which became a growing concern for both opticians and medical practitioners.

The existence of medical monopoly during the nineteenth century can be questioned in light of the range of facts and information that can be found in various publications authored by those who did not practice medicine or optics. Indeed, it would be anachronistic to assume that the medical profession would be a person's first point of call for health issues in this period. As previously noted, Digby has shown that self-treatment or the acquisition of advice from individuals other than medical practitioners was often preferred, at least initially. ${ }^{108}$ Advice columns in newspapers and periodicals show that people in the nineteenth century did not necessarily obtain medical opinion when they were initially concerned about their vision. Much of the correspondence focused on the utility of spectacles and when a person should visit an optician or ophthalmologist. In 1863, for example, The

\footnotetext{
${ }^{104}$ Bow Bells: A Magazine of General Literature and Art for Family Reading, 22 March 1865, p. 181.

${ }^{105}$ Once a Week, 20 May 1871, p. 504; Standard, West Suffolk Gazette, and Eastern Counties' Advertiser, 21 February 1891, p. 2; See also further columns that distributed facts on spectacles and their invention: Bow Bells: A Magazine of General Literature and Art for Family Reading, 16 November 1894; The Lancaster Gazette and General Advertiser for Lancashire, Westmorland and Yorkshire, 20 February 1892; Chambers' Journal of Popular Literature, Science and Arts, 15 August 1896, pp. 525-7.

${ }^{106}$ Bow Bells: A Magazine of General Literature and Art for Family Reading, 22 March 1865, p. 181.

${ }^{107}$ Beer, p. 130.

${ }^{108}$ Digby, p. 99.
} 
London Reader responded to 'I.R.' with the answer that 'the only remedy for failing eyesight is wearing spectacles. Consult an optician'. ${ }^{109}$ Likewise, in 1890 Bow Bells received a question from a person in Salford: 'I am very near-sighted. What can I do besides wearing spectacles to improve my eyesight?'110 'The Answers to Correspondents' sections of Bow Bells magazine and The Weekly Standard and Express show that people described their symptoms and asked whether they required spectacles. In 1867, for example, it was recommended that 'you must consult a respectable optician who will very soon tell you whether you require spectacles'. ${ }^{111}$ Later in the century and by 1899, 'M.H.B.' was advised with the following: 'yes, you must have the eyes examined by a good oculist, and get fitted with suitable glasses'. ${ }^{112}$ These instances show that people were unsure of how to combat deteriorating vision, who to consult, the utility of spectacles, or whether there were alternatives to spectacle wear. Concern over the matter was reflected in people titling themselves 'anxious country reader', or 'worried Dick' ${ }^{113}$ However, they also show that vision aids were being suggested by anonymous advisors in popular print, and the public were advised to visit opticians as well as medical practitioners.

Beyond advice columns, a range of information or suggestions for care of the eyesight and use of spectacles appeared in popular literature from miscellaneous sources. In 1839 an article from The London Saturday Journal, headed 'Information on Spectacles', quoted information on spectacle design and how to detect poor quality from a 'lively tract' on Spectacle Secrets. ${ }^{114}$ Similarly, in 1876, the English poet and critic Richard Hengist Horne wrote a lengthy account on spectacles in 'Eyes and Eyeglasses: A Friendly Review'. Horne admitted that he was 'not an optician, or an oculist in any professional sense' and that he did 'not deal in spectacles. Neither have I any relations or friends in that way'. ${ }^{115}$ Despite this, he provided advice and information on the different shapes of lenses, the different

\footnotetext{
${ }^{109}$ The London Reader: of Literature, Science, Art, and General Information, 31 October 1863, p. 800.

${ }^{110}$ Bow Bells: A Magazine of General Literature and Art for Family Reading, 10 January 1890, p. 42.

${ }^{111}$ Bow Bells: A Magazine of General Literature and Art for Family Reading, 16 October 1867, p. 275.

${ }^{112}$ The Weekly Standard and Express, 15 July 1899.

${ }^{113}$ Reynold's Miscellany of Romance, General Literature, Science and Art, 18 July 1857, p. 399; The London Reader: of Literature, Science, Art and General Information, 12 October 1889, p. 600.

${ }^{114}$ The London Saturday Journal, 16 February 1839, pp. 110-111.

115 'Eyes and Eyeglasses: A Friendly Treatise by Richard Hengist Horne', Fraser's Magazine, December 1876, p. 701.
} 
designs of spectacles, and when spectacles should be used both indoors and outdoors. ${ }^{116}$ In contrast, individuals in texts could also claim medical knowledge and distribute advice. William Kitchiner, for example, styled himself with a medical degree from Glasgow and wrote two texts relating to spectacles, vision and optics, which were frequently reprinted in the $1810 \mathrm{~s}$ and $1820 \mathrm{~s} .{ }^{117}$ Kitchiner did have a keen interest in optics, but he was neither a practicing optician nor ophthalmologist and yet he produced a text strikingly similar to the ones authored by members of those professions. ${ }^{118}$ The approach of Horne and Kitchiner highlights the complex nature of assessing the dissemination of knowledge on vision aids and eyesight in the nineteenth century. Whilst both Horne and opticians challenge the extent of medical authority over vision testing and the dispensing of spectacles, Kitchiner provides an early example of someone claiming medical credentials in order to discuss the topic.

Alongside competition with opticians and the popular press, medical monopoly and public understanding was also challenged by the complexity of refractive or accommodative vision errors and the function of lenses. Moreover, ophthalmologists and medical practitioners acknowledged that their attempts to make the subject accessible and engage with the public were not wholly successful. In medical and popular works it was suggested that the general public did not always respect expert opinion and retained their own beliefs, or that the subject was too complicated for them. In 1888, George Black, a practitioner with a medical degree from Edinburgh, considered the topic of eye defects and vision, for those outside of the medical profession, a 'practically sealed book'. ${ }^{119}$ Similarly, in 1895 a review of the latest book by Simeon Snell, an ophthalmologist and former President of the British Medical Association, argued that the subject of vision was 'rather a difficult one to treat of in a popular way... some knowledge of the structure and functions of the eye is necessary'. ${ }^{120}$ Across the century, the technicality of the subject also

\footnotetext{
${ }^{116}$ Ibid., pp. 701, 719.

${ }^{117}$ W. Kitchiner, Practical Observations on Telescopes, Opera-Glasses and Spectacles, $3{ }^{\text {rd }}$ edn (London: S. Bagster, 1818); W. Kitchiner, The Economy of the Eyes: Precepts for the Improvement and Preservation of Sight (London: Hurst Robinson \& Co., 1824); Anita McConnell, 'William Kitchiner', Oxford Dictionary of National Biography https://doi.org/10.1093/ref:odnb/15690 [accessed: 15 March 2018].

${ }^{118}$ Kitchiner, Economy of the Eyes, was very similar to texts produced by medical practitioners and opticians in the 1820 s and 1830 s.

${ }^{119}$ Black, p. 10.

${ }^{120}$ Glasgow Herald, 26 September 1895.
} 
presented itself in the form of satire, and jokes were made on the use of scientific language. In 1877 a joke from Punch, for example, was printed in The Star:

Oculist Evidence: 'Ignatieff a humbug?' Let Liebreich make reply;

'Say, doctor, had the general not something in his eye?'121

Similarly, in two other instances, the inability to understand the term 'myopia' and other technical language was subjected to satire in 1863 and 1894:

'Young man', said the surgeon, looking me straight in the eye, 'you have got the myopia'. 'Yes, Sir', said I, 'and good ones, too - a little Binniger, with a drop of Stoughton makes an excellent eye opener of a morning'. 'And there seems to be an amaurotic tendency of the right eye, accompanied with ophthalmia'. 'Show', says I. 'And that white sort on the left eye betokens a cataract'. 'I guess you mean in the ear', says I, 'cause I went in swimming this mornin', and I got an all fired big bubble in my left ear', and here I jumped up two or three times on my left foot, but to no purpose. ${ }^{122}$

\section{A LANKISHER ENCYLOPAEDIA - BY TIM O’ DICK O’ BOBS -}

MYOPIA - This rum sort o' word has summat to do wi' short sect, as far as th' meanin' gooas; aw nobbut mention id to worn yo' nod to injure yo'r minds oen. Iv yo' ged a bit o'dust in theoero god id sawt as soon as yo' cos-tek every keer on 'em for ther's no doctor can do 'em ony good, an' no spectacles to remedy th' evil. (To be Kontinid.) ${ }^{123}$

These instances suggest that the term myopia was sufficiently well understood to be turned into a joke. However, they highlight that the term was situated amongst a broader range of complex technical jargon, which both alienated and separated popular and elite understanding. ${ }^{124}$ These technical terms were frequently used alongside simpler ones across the century. The Manchester Times in 1882 and The Royal Cornwall Gazette in 1883, for example, described myopia as 'doctor for short sightedness'. ${ }^{125}$ Likewise, even at the close of the nineteenth century, the use of short-sighted and long-sighted were described as terms used by 'ordinary persons' whilst the technical terms were considered to disguise themselves from 'comprehension of the ordinary intellect'. ${ }^{126}$

\footnotetext{
121 'Jokes of the Period', The Star, 31 March 1877.

${ }^{122}$ Belfast News-Letter, 11 November 1863.

${ }^{123}$ The Weekly Standard and Express, 1 December 1894.

${ }^{124}$ This argument has also been made by Gregory Tate in his exploration of technical jargon in Punch. For an overview of his argument see Tate, p. 173.

${ }^{125}$ Manchester Times, 16 December 1882; The Royal Cornwall Gazette Falmouth Packet, Cornish Weekly News, \& General Advertiser, 5 January 1883.

${ }^{126}$ The Yorkshire Herald and the York Herald, 5 August 1899.
} 
In 1894 the technical nature of the subject was corroborated in a patient's account when their ability to know and use the term 'myopia' surprised the medical practitioner:

He asks what is the matter with me? On receiving as reply 'myopia I think' he looks at me in such a way that I infer first, that the patients there are seldom or never able to name their own ailment; and second, that nothing seriously wrong with my organs of sight is perceptible at first glance. ${ }^{127}$

This account reveals that a practitioner did not perceive knowledge of myopia to be common. However, it also suggests that the subject was not completely inaccessible and some members of the public could adopt this terminology. Moreover, the jokes and other texts previously discussed reveal that medical information could be successfully geared towards, and understood by, the general public. The majority of medical texts that claimed to be written for the general audience used technical terms alongside simpler, more colloquial terms. Practitioners and opticians adopted this method either by using brackets, such as 'myope (short-sighted person)' or referring to the scientific terms as technical versions of common ones, as in 'short-sight called technically myopia'. ${ }^{28}$

Besides emphasising the importance of public knowledge and offering advice, medical practitioners were critical, highlighting areas in which they believed popular belief and opinion to be deficient. The broad period over which these criticisms occurred suggest that medical practitioners were not wholly successful, and did not monopolise or prevent popular beliefs from being followed or circulated. Their comments suggest that, despite their efforts to educate about vision and lenses, members of the public had little knowledge of how to appropriately wear or use vision aids. Beer at the start of the century, for example, described popular opinion as 'warped', and claimed that this had 'given rise to that pernicious plan of many opticians, to prepare spectacles for every age, which they of course dispose of to the ignorant'. ${ }^{129}$ 'Erroneous beliefs', such as wearing the wrong strength of lenses, were also criticised across the century by medical practitioners. ${ }^{130}$ However, criticism could also be directed at the difference between the views of experts and the public

\footnotetext{
${ }^{127}$ Aberdeen Weekly Journal, 14 December 1894; 19 December 1894.

${ }^{128}$ See, for example, Alden, pp. 18, 31; Fenner, p. 287; Browning, p. 29; Taylor, pp. 4, 5, 6, 62.

${ }^{129}$ Beer, p. 131.

${ }^{130}$ Mackenzie, p. 915; Lack of knowledge on appropriate fit of frames also discussed by Smee, p. 48; Carter, p. 255; And being unaware of vision defects discussed by Wells, p. 84.
} 
over the use and benefits of vision aids. As early as 1775, Joseph Harris highlighted that prevalent popular opinion could differ to what was advised by opticians and medical practitioners. ${ }^{131}$

Criticism of public conduct calls into question how much was known about vision testing and vision aids, and whether the public accessed information provided by medical practitioners and opticians. However, it can also be seen as part of medical practitioners' attempts to reassert authority and draw a distinction between popular and medical understanding. Medical practitioners often referred to erroneous beliefs in the general public as a 'popular idea', or 'common error into which people fall' ${ }^{132}$ Across the century, a range of popular beliefs were consistently referred to as a 'common mistake' or 'erroneous notion', highlighting the desire of ophthalmologists to dismiss the claims of the public to possess knowledge of their subject. In particular, the increasing approval of vision aids as a corrective treatment method on the part of medical practitioners was not necessarily shared by members of the public. In 1866, for example, Alden wrote that 'many people entertain a prejudice against wearing spectacles'. ${ }^{133}$ An individual's decision to wear or avoid vision aids could be based on aesthetic as opposed to medical reasons. The use of vision aids for fashion, for example, could appear as the subject of jokes, and in 1864 Donders argued that some people wanted to wear spectacles when they were not required. ${ }^{134}$ However, the choice to not wear vision aids could also be based on a more genuine fear or 'common notion' that vision aids were 'injurious to the eyes'. ${ }^{135}$ American and British medical practitioners such as John Phillips in 1869 and Robert Brudenell Carter in 1880 suggest that the general public came to accept vision aids more slowly, and considered them harmful for longer, than was true of members of the medical profession. ${ }^{136}$ As late as 1899 Roosa argued that whilst disfavour of vision aids had disappeared from the ophthalmological community, there continued in many other quarters 'to this day... a prejudice against the use of

\footnotetext{
${ }^{131}$ Harris, p. 148.

${ }^{132}$ Wells, p. 34; Phillips, pp. 10-11; Fenner, p. 237.

${ }^{133}$ Alden, pp. 56-7.

${ }^{134}$ Donders, p. 151; For jokes see, for example, Berrow's Worcester Journal, 17 December 1859.

135 Phillips, p. 22.

${ }^{136}$ Ibid., Carter, Eyesight Good and Bad, pp. 78-9.
} 
corrective lenses even when it is shown that vision without them is not nearly up to the normal standard'. 137

Despite the proliferation of advice in this area, the 'public' were continually criticised or described as being unaware of vision defects, and having a lack of knowledge of when to wear vision aids and how to ensure they fitted correctly. In terms of knowing when to wear spectacles, for example, Beer, in 1815, described 'most men' as 'deficient'. ${ }^{138}$ Similarly, in 1869 Phillips stated that one of the most frequent questions he received was: 'Do you think, sir, that spectacles will be of use to me?'139 As suggested by the advice columns at the outset of this section, there was also a lack of awareness about defective vision as a whole. In 1880 Carter argued that people's impressions were 'untrustworthy, and nothing is more common than for people who never had half vision in their lives to represent that they have always been remarkable' ${ }^{140}$ Whilst this statement could have been intended to assert the 'trustworthy' nature of Carter's own knowledge, it does also indicate a lack of public knowledge about when vision aids were required and suggests that there was both an elite and popular level of understanding.

Opticians also criticised public conduct and popular levels of knowledge, doing so in order to assert a similar level of authority to medical practitioners and challenge their position as experts on the 'correction' of vision. In 1877 London optician, John Browning, concluded that it was 'such a pity that people think they know anything about their eyes'. ${ }^{141}$ In particular, Browning also considered people unable to determine when to wear vision aids and suggested that 'no attention is generally paid to a pair of spectacles fitting the face' and that it was necessary to give instructions 'over such a simple matter'. ${ }^{142}$ Likewise, in 1898 Baxter argued that the general public 'foolishly think' that they understand something about the proper selection and adoption of 'spectacles'. ${ }^{143}$ However, besides opticians and medical practitioners, many other miscellaneous individuals were also quick to criticise

\footnotetext{
${ }^{137}$ Roosa, pp. 56-7.

${ }^{138}$ Beer, pp. 129-30.

${ }^{139}$ Phillips, p. 11.

${ }^{140}$ Carter, Eyesight Good and Bad, p. 59.

${ }^{141}$ Browning, p. 101.

${ }^{142}$ Browning, pp. 39, 96.

${ }^{143}$ Baxter, p. 3,
} 
erroneous popular opinion. In 1818, for example, Kitchiner described the prevalence of 'a very general vulgar error that near-sighted persons who use concaves, as they get older become less short-sighted'. ${ }^{144}$ Kitchiner, in claiming that he was a medical man, may have also wanted to assert his authority. However, the article by Richard Hengist Horne in 1876, who had no connection with either profession, suggests that public conduct could be criticised when there was no personal or vested interested. Horne, for example, argued that he produced this treatment of eyes and eyeglasses so that his readers would be "sufficiently "facted up", 145

Discussion of popular levels of knowledge suggests that the public were slower to understand the value and use of lenses as a treatment method. However, whilst the public's knowledge was often considered deficient, medical practitioners also had to compete against information being circulated by opticians. Despite this, both opticians and medical practitioners also suggested that knowledge was improving by the later nineteenth century. Browning, for example, recognised the existence of 'a large minority' of people who were anxious to ensure that they were wearing the correct lenses, and were concerned with the health of their eyesight. ${ }^{146}$ Likewise, a medical practitioner in the 1880 s and an optician in the 1890 s proposed that people were now better educated about the strength of lenses that were best for the eye. ${ }^{147}$ Scientific medical terms were also used in other contexts by the later nineteenth century. Whilst 'short-sight' was used in a variety of contexts across the century, and an instance of 'political myopia' can be found in 1869, the term did not become prominent until the late $1880 \mathrm{~s}$. This could suggest that a more general knowledge of the word's meaning was becoming established; so too does the fact that newspaper articles began to use the term metaphorically in the $1890 \mathrm{~s}$ in reference to 'spiritual myopia' or 'mental myopia'. ${ }^{148}$ Despite this, there is not enough evidence to draw firm conclusions about the public knowledge of vision defects and vision testing, and the evidence that does exist can appear contradictory.

\footnotetext{
${ }^{144}$ Kitchiner, Practical Observations, p. 64.

${ }^{145}$ Richard Hengist Horne, Fraser's Magazine, December 1876, p. 720.

${ }^{146}$ Browning, p. 101.

${ }^{147}$ Black, p. 103; Baxter, p. 4.

${ }^{148}$ Examiner, 3 June 1865; Glasgow Herald, December 10 1889; The North-Eastern Daily Gazette, 11 February 1890; The Sheffield \& Rotherham Independent 12 February 1890; The Royal Cornwall Gazette Falmouth Packet, Cornish Weekly News \& General Advertiser, 15 February 1894; The Sheffield \& Rotherham Independent, 21 March 1896; Lloyd's Weekly Newspaper, 26 April 1896; Glasgow Herald, 20 July 1896; The Morning Post, 13 April 1898.
} 
However, it is clear that the public could adopt their own ideas, and drew upon advice from opticians as well as medical practitioners. The discussion of the matter in America in 1881 by C.H. Vilas, Professor of Diseases of the Eye and Ear in the Hahnemann Medical College and Hospital in Chicago, perhaps best summarises the situation that also existed in Britain:

From early childhood nearly all have been familiar with the fact that spectacles, or lenses as the oculists call them, have been worn as aids to sight; but nearly all grow up with somewhat confused notions regarding their functions. Indeed, it will not be far out of the way to say that a large proportion know almost nothing of their uses beyond that they help the aged and the short-sighted. $^{149}$

Whilst the glimpses into popular knowledge are small, they reveal that it could be severely erroneous. Medical practitioners had not fully monopolised knowledge on vision and the use of lenses by the later nineteenth century. Despite their attempts to assert their authority, opticians adopted similar techniques and old myths or beliefs persisted.

\section{Conclusion}

This chapter has explored medical and popular perspectives on the use of vision aids in the nineteenth century. The value of spectacles was acknowledged by medical practitioners prior to the nineteenth century. However, opinions shifted across the nineteenth century in response to the establishment of the discipline of ophthalmology, and the subsequent development of knowledge of the eye and vision. Advances in diagnostic technologies in the middle of the century gave rise to greater awareness of the refractive and accommodative conditions of the eye. Beginning with Donders, this led to enhanced knowledge of how to diagnose errors and test vision to remedy them. In particular, the number of known defects of vision expanded in this period and they were measured with greater accuracy and precision. Opticians' ability to suit the sight correctly with lenses meant that vision aids were increasingly seen as the correct solution to these problems. This was reflected in terminology used to describe partial sightedness and the restorative properties of spectacles. However, these discussions also highlighted that it was not simply the use of lenses, but how they were adapted and suited to the sight, that was important

${ }^{149}$ C.H. Vilas, Spectacles; and How to Choose Them (Chicago: Duncan Brothers, 1881), p. 21. 
for ensuring their efficacy and shifting opinions about them in the nineteenth century.

Whilst medical opinion of spectacles and the use of lenses became more favourable, medical authority was neither certain nor necessarily achievable. This chapter has shown that medical monopoly was challenged by the continuance of selfhelp ideologies, and the prominence of popular advice in newspapers, periodicals, and opticians' texts. Importantly, the overall ability of physicians to 'medicalise' vision problems was compromised by the activities of opticians across the century. As a result, the use of lenses and vision aids was not necessarily discussed in a medical context or dominated by medical practitioners in popular print. Furthermore, whilst the use of vision aids was encouraged by both medical practitioners and opticians in popular texts, the authoritative nature of their work existed against a backdrop of alternative information and deficiency in public knowledge. Popular acceptance of vision aids could be affected by slower understanding of their benefits, and the belief that they were injurious. However, complaints about public knowledge can also be seen as a method used by both medical practitioners and opticians to assert their knowledge and differentiate popular from elite level of understanding. Despite this, by the 1880 s and 1890s medical practitioners and opticians suggested that understanding of the benefits and use of vision aids had improved. In fact, both medical practitioners and the general public had a better understanding of vision defects and the benefits of vision aids by the end of the period.

The changing opinions of lenses and the use of vision aids can be placed in the wider context of reputation and the medical profession, and medical specialties, in the nineteenth century. However, it was not simply a matter of professional control. Early ophthalmologists based their opinions of lenses on clinical case observations. Prior to the invention of the ophthalmoscope, the use of therapeutic treatments were discussed because these methods were observed to have noticeable benefits. As a result, attitudes towards vision aids across the century can be seen to have been related to both wider advances in knowledge and the need to justify the discipline of ophthalmology. The introduction of the ophthalmoscope in the latter half of the century altered attitudes because it meant ophthalmologists could more readily adopt lenses in their practice on the basis of observable evidence. Whilst 
medical authority was important, most especially in the second half of the nineteenth century, chapters three and four show that discussions about professional control do not appear until the last two decades of the nineteenth century and they were not the primary motive for establishing favourable opinions of lenses. Concerns about professional control appeared after medical opinion changed and were fixed on how vision aids were dispensed and sold, and whether opticians had the appropriate skillsets. Consequently, this chapter highlights that the medicalisation of refractive vision errors and the use of vision errors was not complete by the end of the nineteenth century and popular beliefs remained prominent and opticians continued to possess considerable authority. However, the advances in medical opinion and favour towards the use and adoption of lenses would have a great influence on the relationship between medical practitioners and opticians, and how vision aids would be both sold and used. 


\section{Chapter Three}

\section{The Retail of Vision Aids, 1800-1850}

The sale and retail of vision aids has been considered in many general works on the history of spectacles. In these, the typical narrative documents the early trade of spectacles as part of the guild system, which was heavily controlled by the Spectacle Makers' Company through the adoption of fines and premise inspections. From the Company's establishment in 1629 , these works have traced a decline in regulation by the end of the eighteenth century and concluded that it predominantly focused on the administration of its charities, and not spectacle making. ${ }^{1}$ Richard Champness has suggested that, whilst the optical trade was thriving, the ability of the Spectacle Makers' Company to control it had considerably waned. ${ }^{2}$ By the nineteenth century, these studies propose, the sale of spectacles had become increasingly unregulated but consisted broadly of two primary methods of distribution: via itinerant pedlars on the street, and through opticians' shops. ${ }^{3}$ However, no substantial research has explored the locations where vision aids could be bought in the nineteenth century or the extent to which they were available beyond the optician's store. Additionally, how they were sold has not been the focus of previous studies, and this has limited their scope. Many of the comments are, for example, generalised or qualified with

\footnotetext{
${ }^{1}$ See, for example, John Dreyfus, 'The Invention of Spectacles and the Advent of Printing', The Library, 6.2 (1998), 93-106 (pp. 101-2); Hugh Orr, Illustrated History of Early Antique Spectacles (London: The Author, 1985), p. 7; Richard Corson, Fashions in Eyeglasses, $3^{\text {rd }}$ edn (London: Peter Owen, 2011), pp. 51-2; Carl Barck, The History of Spectacles, Originally Delivered as a Lecture Before the Academy of Science (Reprinted from the Open Court for April, 1907), p. 15; Margaret Mitchell, History of the British Optical Association, 1895-1978 (London: British Optical Association, 1982), pp. 11, 13, 19; Vincent Ilardi, Renaissance Vision from Spectacles to Telescopes (Philadelphia: American Philosophical Society, 2007), p. 138; Thomas H. Court and Moritz von Rohr, 'On the Development of Spectacles in London from the End of the Seventeenth Century', Transactions of the Optical Society, 30.1 (1928-9), 1-21 (p. 3); William Rosenthal, Spectacles and Other Vision Aids: A History and Guide to Collecting (San Francisco, CA: Norman, 1996), p. 41; Hugh Barty-King, Eyes Right: The Story of Dollond and Aitchison, Opticians, 1750-1985 (London: Quiller P, 1985), pp. 53, 69; B. Michael Andressen, Spectacles From Utility Article to Cult Object (Stuttgart: Arnoldsche, 1998), p. 15.

${ }^{2}$ Richard Champness, A Short History of the Worshipful Company of Spectacle Makers up to the Beginning of the Twentieth Century (London: Apothecaries Hall, 1952), pp. 8-9.

${ }^{3}$ An optician at this time did not specialise in vision testing or spectacles, but was a retailer in a range of optical and scientific instruments.
} 
hedging terms such as 'probably' and, as a result, suggest that further research is required to substantiate their conclusions. ${ }^{4}$

This chapter shows that the retail of vision aids expanded in the first half of the nineteenth century, and that a variety of sources can be used to explore how they were sold. The sale of vision aids during this period mirrored wider developments in the history of retail and broadly encompassed a range of increasingly specialised shop premises - including opticians, jewellers, and watchmakers - as well as more miscellaneous spaces, which included the street in both the metropolis and provincial town, and the early nineteenth-century bazaar. It argues that the location of sale can be used to explore how vision aids were sold. In particular, it highlights that the sale of vision aids differed little in the shop and in the street, and in municipal and provincial areas. In this instance, 'provincial' is used to describe areas that traded in vision aids outside of London. The existence of spectacles and eyeglasses in the stock of a range of sellers, and alongside several products, is significant for exploring both how they were categorised in the nineteenth century and their overall importance to individual trades. By the twentieth century, vision aids had become a more 'medical object' and were dispensed in close association with a medically qualified ophthalmologist. However, in the first half of the nineteenth century, their existence across a variety of trades placed them in a liminal position between scientific instrument, decorative item, and quotidian device.

This chapter uses evidence from eighty-eight instrument makers associated with objects in the Science Museum's collection, contemporary accounts and letters, trade literature, advertisements, and popular literature to assess both the position of vision aids in these trades, and how they were sold. The chapter argues firstly, the sale of vision aids was affected by broader trends in retail practice and appeared as an adjunct to a variety of trades. Secondly, it proposes that this was because they were dispensed without an eyesight test, and sold in a similar manner, regardless of trade or location. Criticism of vision aid sale in the first half of the nineteenth century focused on issues that were identified in retail as a whole - for example the reputation of shop owners or itinerant pedlars on the street - rather than how a

\footnotetext{
${ }^{4}$ See, for example, the use of 'probably' by C.W. Elson, Origin and Development of Spectacles (Worthing: Worthing Archaeological Society, 1935), p. 13.
} 
customer chose a suitable lens. Whether on the street or in the optician's store, vision aids were dispensed by trial and error, the customer trying out a range of frames to find one that suited best; this method was advocated by both opticians and medical practitioners at this time. In the absence of objective methods, and with the accepted consensus that subjective methods were the most 'accurate', authority lay with the customer and the retailer only needed a sufficient range of stock. Consequently, the knowledge of the dispenser in 1850 differed substantially from that possessed in the second half of the period, following the invention and implementation of diagnostic techniques and the vision test. It was therefore possible for the retail of vision aids to exist in a variety of locations, and amongst the stock of a diverse range of traders, between 1800 and 1850 .

\section{The Location of Vision Aid Sale}

The history of retail in the first half of the nineteenth century has received less attention than that of either the eighteenth century, which witnessed the so-called birth of consumerism, or the later nineteenth century, studies of which have tended to focus on the effects of industrialisation and urbanisation. However, historians have argued that the factors to which the growth or change of retail have been ascribed in the two periods surrounding 1800-1850 also existed at this time: population expansion, urbanisation, change in income or overall expenditure, and the invention of new technologies. ${ }^{5}$ In particular, more recent historical works have questioned the growth and prominence of shop premises, and have highlighted that a variety of forms of retail 'beyond the shop' existed. This type of sale included hawkers on the street, periodical fairs, and purpose-built halls, such as bazaars, and these both thrived and helped to support the growth in consumer demand that would have not been initially accommodated by the rise in shop premises. ${ }^{6}$ Additionally, these studies have highlighted that the boundaries between, for example, street sale

\footnotetext{
5 Ian Mitchell, 'Retailing Innovation and Urban Markets, c.1800-1850', in Retailing Beyond the Shop, c. 1400-1900, ed. by Laura Ugolini and John Benson (Bradford: Emerald Group Publishing Ltd, 2010), p. 288.

${ }^{6}$ Retailing Beyond the Shop, c. 1400-1900, ed. by Laura Ugolini and John Benson (Bradford: Emerald Group Publishing Ltd, 2010).
} 
and shop retail were not clear, and individuals could both own shops and peddle their goods in the streets. ${ }^{7}$

An analysis of the objects in the Science Museum's collections, and supplementary sources, supports the current consensus of historians of retail about this period. The sale of vision aids in the nineteenth century could occur in shop premises - including those of opticians, scientific instrument makers, jewellers, watchmakers, and sundry good traders - but also remained a prominent street practice, and inhabited more miscellaneous spaces of trade such as the swag shop or bazaar. Historical scholarship on retail has also shown that geography and spatial differences are important considerations. ${ }^{8}$ An analysis of the shop and non-shop retail of vision aids, however, shows that there was an overlap between practices in London and the provinces. This section explores three categories: street sellers; scientific instrument makers; and the miscellaneous market - which included jewellers, engravers, and a range of sundry traders - to assess the position of spectacles in these trades in both London and the provinces, and the effect that this could have on how they were categorised and perceived by contemporaries. It argues that vision aids were often stocked as an additional, and potentially lucrative, item. However, while Henry Mayhew in his discussion of street sellers categorised spectacles as part of articles of 'miscellaneous manufacture', an exploration of the shop-retail of spectacles in the first half of the nineteenth century reveals that they could also logically be fitted into the categories of a scientific instrument and decorative or 'fancy' good, and were not only perceived as quotidian devices.

Perhaps the most striking aspect of the Science Museum's collections is the level of anonymity that surrounds the objects themselves. The majority of spectacles, eyeglasses and other forms of vision aid within the collections carry no information about where they were made, sold, and bought. Yet rather than being considered without significance, or merely unfortunate, this anonymity can perhaps be seen as evidence of a method of spectacle sale that has also left very little trace: the

\footnotetext{
${ }^{7}$ John Benson and Laura Ugolini, 'Beyond the Shop: Problems and Possibilities', in Retailing Beyond the Shop, c. 1400-1900, ed. by Laura Ugolini and John Benson (Bradford: Emerald Group Publishing Ltd, 2010), p. 259.

${ }^{8}$ Jon Stobart, Andrew Hann, Victoria Morgan, Spaces of Consumption: Leisure and Shopping in the English Town, c.1680-1830 (London: Routledge, 2007), show the benefits of a comparative study of different locations.
} 
dispensing of cheaply made spectacles on the street. John Benson and Laura Ugolini have highlighted the difficulties of assessing both the extent and form of street selling in this period because of the lack of documentation. However, they have argued that the inability to quantify the full extent of street sale does not lessen its importance or mean that shops were necessarily the dominant form of supply. ${ }^{9}$ The street has long been considered an important location for the sale of vision aids in historical work. ${ }^{10}$ Moreover, although anecdotal, the descriptions of street vendors by contemporaries provide the most vivid accounts of traders associated with spectacle sale in the first half of the nineteenth century.

Street selling was multifarious, and remained a popular practice in the nineteenth century. ${ }^{11}$ A.D. Morrison-Low, for example, has argued that for scientific instruments as a whole, the method of hawking via itinerant pedlars could be found into the middle of the nineteenth century. ${ }^{12}$ Equally, whilst the peddling of vision aids has often been discussed in a rural context, this practice can be found to exist in both the city as well as the country. ${ }^{13}$ In 1851 Henry Mayhew documented the variety of sellers and performers that could be found on the streets of London in his account of London Labour and the London Poor. In particular, Mayhew divided these into six distinct types: street sellers, street buyers, street finders, street performers, street artisans and street labourers. ${ }^{14}$ In this work, Mayhew also alluded to the number of items that the pedlars could sell, and the conditions in which they sold them. In his description of the practice as a whole he concluded:

Those who obtain their living in the streets of the metropolis are a very large and varied class; indeed, the means resorted to in order to 'pick up a crust', as the people call it, in the public thoroughfares (and such in many instances it literally is) are so multifarious that the mind is long baffled. ${ }^{15}$

\footnotetext{
${ }^{9}$ Benson and Ugolini, 'Beyond the Shop: Problems and Possibilities', pp. 258-9; David Alexander, Retailing in England During the Industrial Revolution (London: The Athlone Press, 1970), also discussed the potential problems of quantifying street selling, pp. 61-5.

${ }^{10}$ See, for example: Corson, p. 52; Elson, p. 13; Barck, p. 15.

${ }^{11}$ Benson and Ugolini, 'Beyond the Shop: Problems and Possibilities', pp. 257-9; Alexander, p. 65.

${ }^{12}$ A.D. Morrison-Low, Making Scientific Instruments in the Industrial Revolution (Aldershot: Ashgate, 2007), pp. 205-6.

${ }^{13}$ See, for example, Corson, p. 66; Elson who discussed it in the context of 'villages', p. 13; and Orr who discussed pedlars travelling from 'town to town', p. 7.

${ }^{14}$ Henry Mayhew, London Labour and the London Poor, A Cyclopaedia of the Condition and Earnings or Those that Will Work, Those that Cannot Work, and Those that Will Not Work, vol 1 (London: Griffin, Bohn and Company, 1851), p. 3.

${ }^{15}$ Ibid.
} 
The 'multifarious' nature of the items sold by street sellers at this time is evident in Mayhew's breakdown of the types of objects that could be purchased. The category of goods sold by street sellers was separated into eight sections that ranged from fish to the fine arts, and spectacles could be found amongst the section entitled 'manufactured articles'. Spectacles were situated in the ambiguous class of 'miscellaneous articles of manufacture' alongside a variety of other items, such as 'cigars, pipes, snuff-boxes, combs... sponges, wash-leather, paper-hangings...[and] pin-cushions'. ${ }^{16}$

The condition of both street sellers and street sale, and the position of spectacles amongst a range of other quotidian items, highlights their potential to be lucrative. Whilst Mayhew suggested that the number of street sellers dispensing spectacles was diminishing, he provided a vivid account that suggested many of these people used the sale of spectacles as a means to survive and earn a living:

There are sometimes 100 men, the half of whom are Jews and Irishmen in equal proportion now selling spectacles and eyeglasses... Some of these traders are feeble from age, accident, continued sickness or constitution and represent that they must carry on a 'light trade', being incapable of hard work, even if they could get it. ${ }^{17}$

Furthermore, Mayhew proposed that spectacle sellers did not necessarily 'confine themselves' to the sale of spectacles, and would sell anything that they thought was profitable. ${ }^{18}$ This suggests that, although the profitability of spectacle-selling could fluctuate, it was lucrative at certain times. In his estimations of the numbers of those selling spectacles on the street, Mayhew allowed for 'breaks in regular spectacle selling' but concluded that there were about thirty-five men who vended them daily and earned a profit of $10 \mathrm{~s}$ each week. ${ }^{19}$ This account of individuals of limited means, vending what they could for profit, provides an interesting perspective on the possible motives of individuals entering the trade and the position of vision aids in the retail market.

Whilst Mayhew's account is notable for its descriptive vividness, it only provides fragmentary evidence on the practice of street sellers in a single location and may not be representative of the practice as a whole, or its extent. However,

\footnotetext{
${ }^{16}$ Ibid., pp. 3, 323-4.

${ }^{17}$ Ibid., pp. 444-5.

${ }^{18}$ Ibid., p. 445.

${ }^{19}$ Ibid., pp. 445, 490.
} 
warnings against this practice proliferated in advertisements of other spectacle sellers, and more widely in contemporary accounts. These provide greater insight into the geographical spread and the putative conduct of street sellers both in and outside the capital. Cautions against street sellers appeared in a range of provincial newspapers, including Leeds, York, Dublin, and Preston. ${ }^{20}$ Whilst the criticism of other spectacle sellers could have been part of a trader's method to market their own products, it does seem that the overall quality of vision aids varied at this time. Similarly, medical as well as optical texts emphasised the widespread nature of the practice and suggested, for example, that 'thousands' had had their eyes ruined through the purchase of spectacles from street sellers. ${ }^{21}$ As we have seen, these texts could reach a wider audience through publication in a variety of popular literature. In 1838, for example, George Cox's Spectacle Secrets appeared in two periodicals to 'expose' the widespread nature of fraud and the sale of substandard goods. ${ }^{22}$ Whilst his statements were more than likely exaggerated, the key point is that the street sale of spectacles was significant enough to be talked about in a variety of contemporary literature. Equally, although rural areas have often been associated with the sale of spectacles by itinerant pedlars, it is clear through the accounts of Henry Mayhew, and London-based periodicals, that the sale of spectacles by itinerant pedlars continued as part of the wider practice of street sale in the metropolis, as well as provincial areas, in the mid-nineteenth century.

Warnings against street sellers also highlight the inability to clearly demarcate between shop and 'beyond the shop' retail in the nineteenth century. This is illustrated well in an undated circular within the Science Museum's collections from a travelling optician, Mr Issacs, which addressed the 'Inhabitants of This House' on his 'Assortment of Spectacles'. Although Mr Isaacs explicitly stated that

\footnotetext{
${ }^{20}$ See, for example, Leeds Mercury, 1 August 1829; Freeman's Journal and Daily Commercial Advertiser, 19 November 1842; 25 November 1842; 3 December 1842; The York Herald and General Advertiser, 21 October 1843; The Preston Guardian 3 August 1844; 5 October 1844; 16 November 1844; 18 January 1845; 1 March 1845; 22 March 1845; 12 April 1845.

${ }^{21}$ Thos Harris \& Son, A Brief Treatise on the Eyes, Defects of Vision, and the Means of Remedying the Same by the Use of Improper Spectacles (London: Onwhyn, 1839), p. 32, See also Georg Beer, The Art of Preserving the Sight Unimpaired to an Extreme Old Age; and of Re-establishing and Strengthening it When it is Become Weak (London: Henry Colborn, 1815), p. xiv; W. Kitchiner, The Economy of the Eyes: Precepts for the Improvement and Preservation of Sight (London: Hurst Robinson \& Co., 1824), p. 7; and its criticism can also be found in a popular text on spectacles by Andrew Ross, On the Use and Abuse of Spectacles (London: R. Kinder, 1840), p. 1.

${ }^{22}$ The Athenaeum, 1 December 1838, p. 855; Tait's Edinburgh Magazine, December 1838, pp. 803-4.
} 
he was not a 'pretender', his position as a retailer was not straightforward because he was both travelling and advertised a permanent address. ${ }^{23}$ While Benson and Ugolini have argued that there was not a straightforward hierarchy and shop premises were not necessarily superior to street sale, Isaacs' choice to reference a permanent address could have been influenced by the importance of reputation and having a reputable premise in the nineteenth century. ${ }^{24}$ Alongside the street, the sale of vision aids existed and was advertised as part of the activity of a variety of traders with shop premises. Like street selling, the sale of vision aids in a variety of shops reached into the provinces.

Throughout its history, the spectacle trade has often been associated with opticians. Richard Champness has summed up this association in his conclusion that 'the spectacle maker of 1630' had 'evolved into the optician of 1750 '. ${ }^{25}$ Opticians were not vision testing specialists in the early nineteenth century, and the term instead denoted a specialisation in the making of optical lenses and instruments such as the telescope and microscope. By the eighteenth century, London had arguably become the centre for the scientific instrument trade; B. Michael Andressen has referred to 'monster opticians' in his reflection on the strength of the optical trade at this time. ${ }^{26}$ The scientific instrument trade and what exactly constituted a 'scientific instrument' has been treated extensively by historians. ${ }^{27}$ This section uses the categories that were devised by contemporaries to classify items according to the instrument's function: mathematical, philosophical, and optical. ${ }^{28}$ Importantly, these categories often overlapped and those who sold vision aids did not always specialise in optical instruments and stocked a range of mathematical and philosophical devices. ${ }^{29}$ The names of individuals involved in these trades can be found on a limited number of frames and cases within the Science Museum's collections. Their identities can be explored through trade literature and advertisements to explore the

\footnotetext{
${ }^{23}$ Science Museum Art collection, 1948-397/31, dated 1801-1900.

${ }^{24}$ Benson and Ugolini, 'Beyond the Shop: Problems and Possibilities', p. 266.

${ }^{25}$ Champness, p. 9.

${ }^{26}$ Andressen, p. 15; Morrison-Low, p. 2.

${ }^{27}$ See, for example, Lisa Taub, 'Reengaging with Instruments', Isis, 102.4 (2011), 689-696; Jim Bennett, 'Presidential address: Knowing and Doing in the Sixteenth Century: what were instruments for?', British Journal for the History of Science, 36.2 (2003), 129-150.

${ }^{28}$ Morrison-Low, p. 23.

${ }^{29}$ Gloria Clifton, Directory of British Scientific Instrument Makers 1550-1851 (London: Zwemmer, 1995), p. xiii.
} 
'opticians' of the early nineteenth century, their location individuals were identified, and the place of vision aids in their trade.

Eighty-eight individuals were recorded following a search of trade directory records for names that associated with a spectacle frame or spectacle case within the Science Museum's collections. Of these, standalone opticians were the largest number: as shown in Figure 3.1, thirty-three individuals were described as 'opticians' in trade directories:

Figure 3.1. Bar chart of the occupations of 88 traders associated with vision aid frames and cases in the Science Museum's collections, $1800-1850 .{ }^{30}$

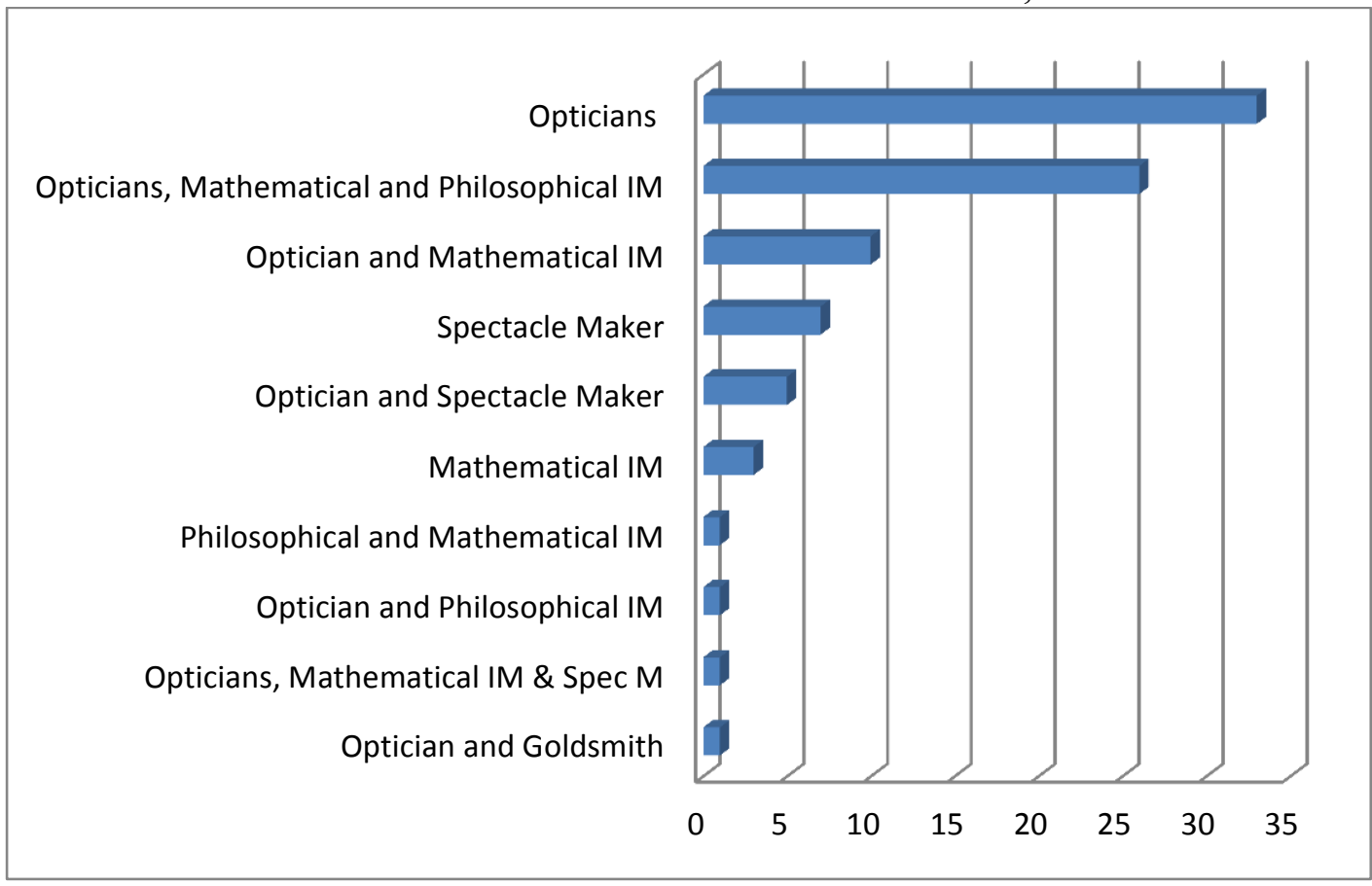

However, as can be seen, there were significant numbers of other kinds of retailer who can also be connected to a frame, or case, and these outnumbered the total number of standalone 'opticians'. As a result, the position of the optician in the wider scientific instrument trade needs to be considered when exploring the retail of vision aids in the first half of the nineteenth century. Whilst there were a few individuals who specialised as 'spectacle makers', the additional trades were predominantly associated with scientific instruments and include philosophical and

\footnotetext{
${ }^{30}$ These findings have been compiled from the trade directory findings of project SIMON that are detailed in Gloria Clifton's Directory of British Scientific Instrument Makers 1550-1851. 'IM' is an abbreviation of instrument maker.
} 
mathematical instrument making. Unsurprisingly, vision aids could therefore be stocked alongside a variety of other items and this was reflected in some of the other objects in the Museum's collections. Eight of the individuals associated with vision aids in the Science Museum can also be identified with several other devices in its holding, including microscopes, hygrometers, kaleidoscopes, telescopes, and saccharometers. $^{31}$

The use of shop premises for the retail of vision aids extended into the provinces, as well as the metropolis, and vision aids could appear both insignificant and central to their trade. The location of the instrument trade, beyond London, has been the focus of some study in recent years. A.D. Morrison-Low's work has confirmed Gloria Clifton's speculation that the provinces had a more significant body of instrument makers than previously recognised. ${ }^{32}$ Morrison-Low has argued that, by 1851, provincial instrument makers were confident enough to appear in the Great Exhibition and, in some instances, they were able to compete against London makers. ${ }^{33}$ Despite this, objects associated with the scientific instrument trade often have a signature associated with London. Whilst the objects themselves are a rich source for information on makers, suppliers, and the manufacturing processes of scientific instruments, the material evidence can lead the incautious to suppose that the scientific instrument trade was predominantly London-based. ${ }^{34}$ Figure 3.2 shows, for example, that provincial examples of frames or cases exist within the Science Museum's collections for the first half of the nineteenth century, but the overwhelming majority originated in London.

\footnotetext{
${ }^{31}$ These instrument makers and/or businesses are: Dudley Adams; A. Abraham; Blunt \& Son; John Braham; Thomas Rubergall; Dixey; W. Harris and Robert Brettell Bate. Most of the additional objects in the collections are identifiable online, searching by maker's name, at: https://collection.sciencemuseum.org.uk/ [accessed: 20 September 2018]

${ }^{32}$ Morrison-Low, p. 133; Clifton, pp. xii and xiv.

${ }^{33}$ Morrison-Low, p. 133.

${ }^{34}$ Ibid, p. 285.
} 
Figure 3.2. Pie-chart of the location of 88 traders associated with vision aid frames and cases in the Science Museum collections, showing that the majority were London-based. ${ }^{35}$

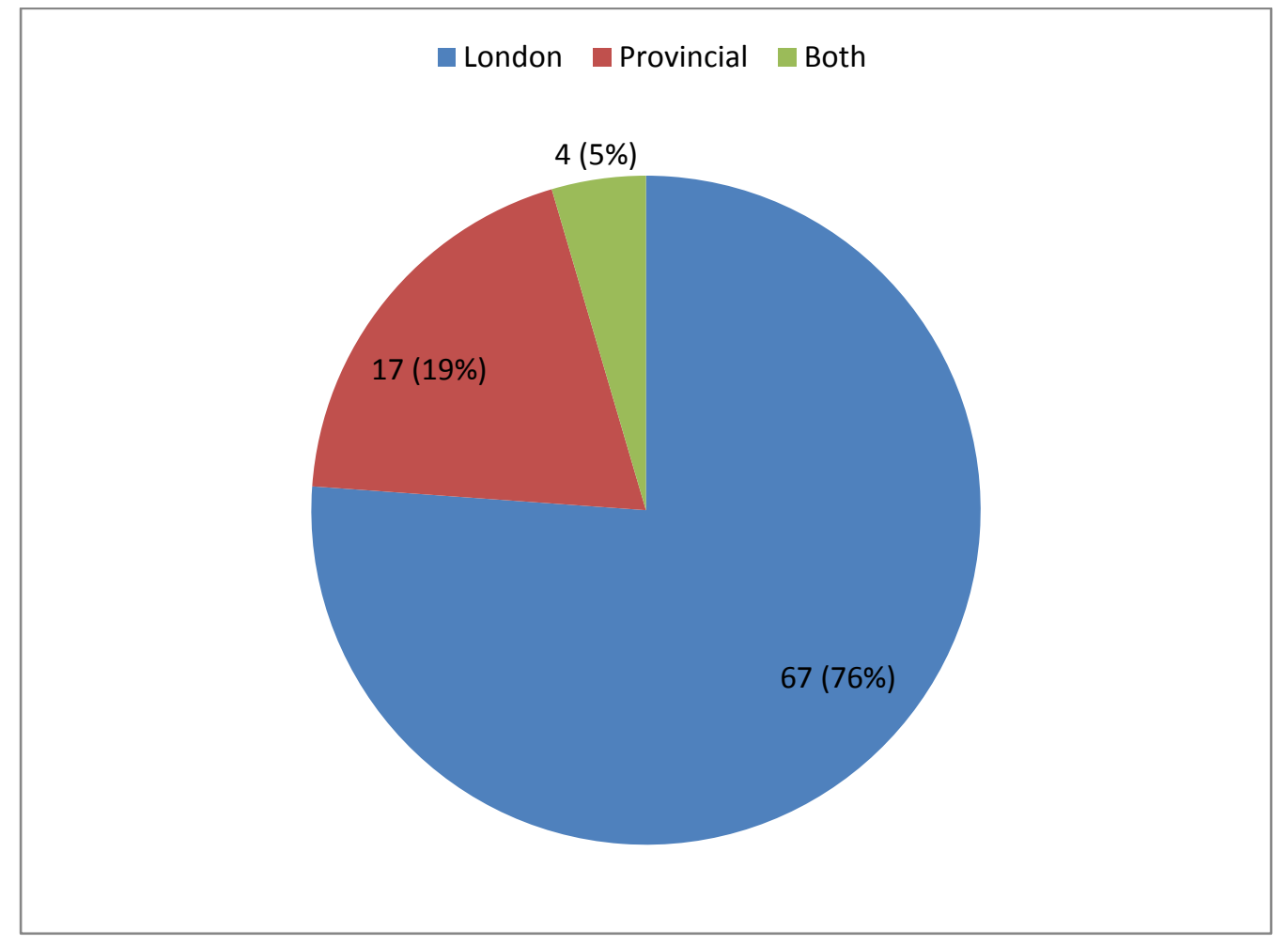

However, whilst the material evidence is more London-centric, the study of a wider range of additional sources highlights that there was a significant, and growing, body of instrument makers in the provinces. Evidence of vision aids being sold by provincial scientific instrument traders can be found in nineteenth-century newspaper advertisements, and these also make clear that opticians, both in and outside of London, travelled to increase their market range. ${ }^{36}$

The location of opticians and scientific instrument makers that sold vision aids follows wider trends in retail during this period. Jon Stobart, Andrew Hann and Victoria Morgan, for example, in their study of five English counties, have documented a growth in specialised shops in commercial towns and argued that by

\footnotetext{
${ }^{35}$ Percentages calculated from the location of 88 traders. For further information on the source of this data, please see Figure 3.1 and reference 30.

${ }^{36}$ See, for example, John Solomon of Bristol in the Southampton Herald, 28 January 1832; 12 August 1837; Hampshire Advertiser \& Salisbury Guardian Royal Yacht Club Gazette, 12 August 1837; Berrow's Worcester Journal, 27 April 1848. Also see M. \& N. Gluckstein of East London in The Essex Standard and General Advertiser for the Eastern Counties, weekly between 24 May 1850 and 14 June 1850 and The Bury and Norwich Post and Suffolk Herald, weekly between 29 May 1850 and 19 June 1850.
} 
1830 the majority of towns had a diverse number of retailers and services, and these included both luxury and non-luxury items. ${ }^{37}$ A key word search of the online British Library Newspapers shows opticians' premises were advertised across a wide geographical area. Although not yet comprehensive, this resource suggests that provincial opticians could be found in a range of towns in Ireland and North Wales, as well as in the North and South of England. Traders with a fixed address in the same locality as the advertising publication were named in the Liverpool Mercury, The York Herald, and General Advertiser, Newcastle Courant, The Preston Guardian, The Preston Chronicle, Hampshire Advertiser \& Salisbury Guardian, Caledonian Mercury, North Wales Chronicle and Freeman's Journal and Daily Commercial Advertiser. In the Liverpool Mercury in 1835, for example, B. Salom a 'manufacturing optician' of 16 Slater Street, advertised his testimonials and education. Similarly, in 1837 a York optician, T. Cooke, thanked his customers for their 'liberal support' and advertised his stock 'made to order on the shortest notice'. ${ }^{38}$

Opticians, with either a London or provincial address, also travelled outside their localities to extend the sale of vision aids further. As previously shown by the circular of Mr Isaacs, opticians could have both a permanent address and adopt a method of door-to-door sale. ${ }^{39}$ Opticians also advertised their ability to travel to those that were unable to visit the shop premises. In 1837, Chamberlain, 'manufacturer of the Eye-preserving spectacles' of 37 Broad-street, Bloomsbury, advertised his ability to attend his customers 'at their own residence within ten miles of London' in a London newspaper. ${ }^{40}$ However, advertisements in other newspapers suggested that - in marked contrast to the method of street sale - opticians could travel further than a 10 mile radius and occupy business premises in a number of towns on a temporary basis. From the traces that have been left in nineteenth-century newspapers, it is clear that a travelling optician could cover a variety of locations and counties during the course of a year. Although these individuals advertised fixed

\footnotetext{
${ }^{37}$ Stobart, Hann, Morgan, pp. 35-7.

${ }^{38}$ Liverpool Mercury, 17 July 1835; The York Herald and General Advertiser, 26 August 1837.

${ }^{39}$ For another example of this see: Science Museum Art collection, 1948-397/14, dated 1815-1899.

${ }^{40}$ The London Dispatch and People's Political and Social Reformer, 27 January 1837; This is also stated in his earlier advertisements in the same newspaper for 8 October 1837; 22 October 1837; 19 November 1837; 26 November 1837; 24 December 1837; 25 March 1838; 29 July 1838; and 9 December 1838 .
} 
addresses in the locations that they visited, parallels can be drawn between travelling opticians. Shop-trade of this kind had an ambiguous position between temporary and permanent residence. Additionally, the newspaper evidence reveals that vision aids were retailed from the premises of a range of provincial scientific instrument makers and shop owners in a number of localities.

Vision aids could be bought from a travelling optician both in and outside of London and the variety of locations of this activity that were advertised reflect the widespread nature of this practice. ${ }^{41}$ Typically, the sellers arrived in a certain area for a fixed number of days and published in the local newspaper to bring public attention to their presence. Advertisements from Messrs Davis and Sons, based in St James Street in London and 3 Mulberry Street in Liverpool, illustrate the extent to which opticians could travel at this time. Between 1837 and 1840, the firm advertised in at least six different publications, on at least twelve occasions, that its representatives were available to local residents 'for a few days' or 'a short time' in places as far afield as North Wales, Bradford, Derby, Preston, and Blackburn. ${ }^{42}$ Similarly, other opticians travelled on a more regular basis to towns in their local region. ${ }^{43}$ In 1850 M \& N. Gluckstein, opticians of 24 Turner Street in East London, visited Ipswich every Friday, and 'effected several cures'; he also repeatedly advertised his presence in Bury St Edmunds. ${ }^{44}$

These advertisements could suggest that the boundary between street sellers and opticians in a shop premises was a thin one. Similar to pedlars, the credibility or reputation of travelling opticians with a fixed address might have been questionable. Advertisements for them frequently adopted techniques that were open to criticism or suspicion, such as using the phrase 'licensed hawker', or claiming a 'new'

\footnotetext{
${ }^{41}$ See, for example, The York Herald and General Advertiser, 3 March 1827; Belfast News-Letter, 4 August 1835; Hampshire Advertiser \& Salisbury Guardian Royal Yacht Club Gazette, 16 September 1837; Belfast News-Letter, 19 October 1841; 2 October 1841; The Cornwall Royal Gazette, Falmouth Packet and Plymouth Journal, 23 January 1846; Berrow's Worcester Journal, 27 April 1848.

${ }^{42}$ North Wales Chronicle, 15 August 1837; 22 August 1837; The Bradford Observer, 4 January 1838; 11 January 1838; Derby Mercury, 15 January 1840; 22 January 1840; 29 January 1840; 5 February 1840; North Wales Chronicle, 23 June 1840; Preston Chronicle, 10 October 1840; The Blackburn Standard, 11 November 1840; 18 November 1840.

${ }^{43}$ See, for example, another Liverpool-based optician who advertised their temporary residence in Blackburn: The Blackburn Standard, 13 January 1836; 20 January 1836.

${ }^{44}$ The Essex Standard and General Advertiser for the Eastern Counties, weekly between 24 May 1850 and 14 June 1850 and The Bury and Norwich Post and Suffolk Herald, weekly between 29 May 1850 and 19 June 1850.
} 
invention. However, the case of an individual in Gloria Clifton's study of scientific instrument makers who advertised their residency in different locations suggests something else. John Solomon, an optician and spectacle maker from Bristol between 1836 and 1848, advertised in the Berrow's Worcester Journal, the Hampshire Advertiser \& Salisbury Guardian, and the Southampton Herald during the 1830s and 1840s. ${ }^{45}$ Significantly, Solomon also used the term 'licensed hawker' and highlighted his 'improved glasses'. This suggests that, whilst the wording of the advertisement could be considered fraudulent, it could be adopted by more reputable opticians. However, travelling opticians sought to separate themselves from street sellers and suspicion, through emphasising their permanent address and the business address that they currently resided at. Solomon, for example, highlighted his 'London and Bristol Optical Establishment', and his patronage from individuals in London, Brighton, Bristol, Bath, Cheltenham and Worcester. ${ }^{46}$

Travelling opticians could peddle in a similar manner to street sellers, and Benson and Ugolini have found that a hierarchy of general retail was not straightforward from the consumer perspective in this period. However, amongst retailers of vision aids, the use of fixed addresses and royal patronage or iconography was adopted by opticians to bolster their reputation or separate themselves from those who sold on the street. As well as simply revealing a trader's location, the advertisements are significant because of the different techniques for attracting custom and securing a reputation that they display in their language and content. Trade cards provide a useful supplement to these advertisements and trade directory records. Michael Crawford and Morrison-Low have argued that trade cards can reveal a lot about the scientific instrument industry. ${ }^{47}$ For the study of sellers of vision aids, the trade literature - including trade cards, trade catalogues and exhibition lists - is fruitful and helps place the instrument makers represented by the Science Museum's collections in a wider context.

\footnotetext{
${ }^{45}$ Clifton, p. 258; Southampton Herald, 28 January 1832; 12 August 1837; Hampshire Advertiser \& Salisbury Guardian Royal Yacht Club Gazette, 12 August 1837; Berrow's Worcester Journal, 27 April 1848.

${ }^{46}$ Hampshire Advertiser \& Salisbury Guardian, 12 August 1837.

${ }^{47}$ Michael A. Crawforth, 'Evidence from Trade Cards for the Scientific Instrument Industry', Annals of Science, 42.5 (1985), 453-544; Morrison-Low, pp. 11, 226
} 
Many trade cards of the late eighteenth and early nineteenth-century optician were visually striking and their imagery in these provides an insight into how opticians marketed and sold their products. A number of trade cards, as can be seen in Figures 3.3 to 3.6 below, adopted the use of the royal crest. Helen Berry has argued that crests of a highly visible nature were used to show the quality of goods, and contributed to the 'democratisation of luxury', because individuals could obtain products that were associated with elite society. ${ }^{48}$ Similarly, in opticians' trade cards, reference to the monarch, members of the royal family, and high-status organisations were often included. This phenomenon can be placed in the wider context of respectability and reputation in nineteenth-century retail and nineteenth-century society more generally. ${ }^{49}$ Like the advertisement of a permanent address, the use of a royal crest or 'high society' connections bolstered the authority of an optician as a vendor of vision aids and presumably helped them to market their products.

Trades cards allow us to explore royal connection and patronage, however, they also reveal the diversity of the scientific instrument maker's trade in this period, and the position of vision aids within it. The position and marketing of vision aids can be placed in the wider context of 'polite commerce' that was established in the eighteenth century. Berry and Jon Stobart have argued that advertisements could help link tradesmen and the growing middling class with the social elite. However, Stobart has also proposed that the diverse range of goods found in advertisements from the eighteenth century can be seen as to represent the world of growing commercialism, as well as the trader's attempt to present the reader with a 'cornucopia'. ${ }^{50}$ Opticians and scientific instrument makers' advertisements included a range of goods in the first half of the nineteenth century. As a result, they can be seen as part of wider trends in retail. However, the uniformity of goods depicted reveals that these traders specialised in a specific range of products. Vision aids were sold alongside a variety of mathematical, optical and philosophical apparatus, and there was a great level of diversity of goods for both the standalone 'optician' and

\footnotetext{
${ }^{48}$ Helen Berry, 'Polite Consumption: Shopping in Eighteenth-Century England', Transactions of the Royal Historical Society, 12 (2002), 375-394 (particularly pp. 383-4, 393-4).

${ }^{49}$ See, for example, John Benson, 'Drink, Death and Bankruptcy: Retailing and Respectability in Late Victorian and Edwardian England', Midland History, 32.1 (2007), 128-140.

${ }^{50}$ Berry, pp. 383-4, 393-4; Jon Stobart, 'Selling (Through) Politeness: Advertising Provincial Shops in Eighteenth-Century England', Cultural and Social History, 5.3 (2008), 309-328.
} 
the 'optician and scientific instrument maker'. In each, the position of vision aids could vary from being a small, almost insignificant item, to the primary selling point.

In the absence of any significant additional evidence about the businesses that supplied the vision aids in the collection, trade cards and trade catalogues, where available, are an invaluable source for ascertaining the position of vision aids in the wider trade of the scientific instrument maker. ${ }^{51}$ As well as sometimes feature the royal crest, eighteenth-century trade cards could be highly decorative, and this remained the case into the early nineteenth century. In Figure 3.3, a trade card by London opticians Dring \& Fage, which the Science Museum have dated to between 1804 and 1844, clearly detailed the variety of instruments they sold.

Figure 3.3. Science Museum Art collection, 1951-685/25, Trade Card of Dring \& Fage.

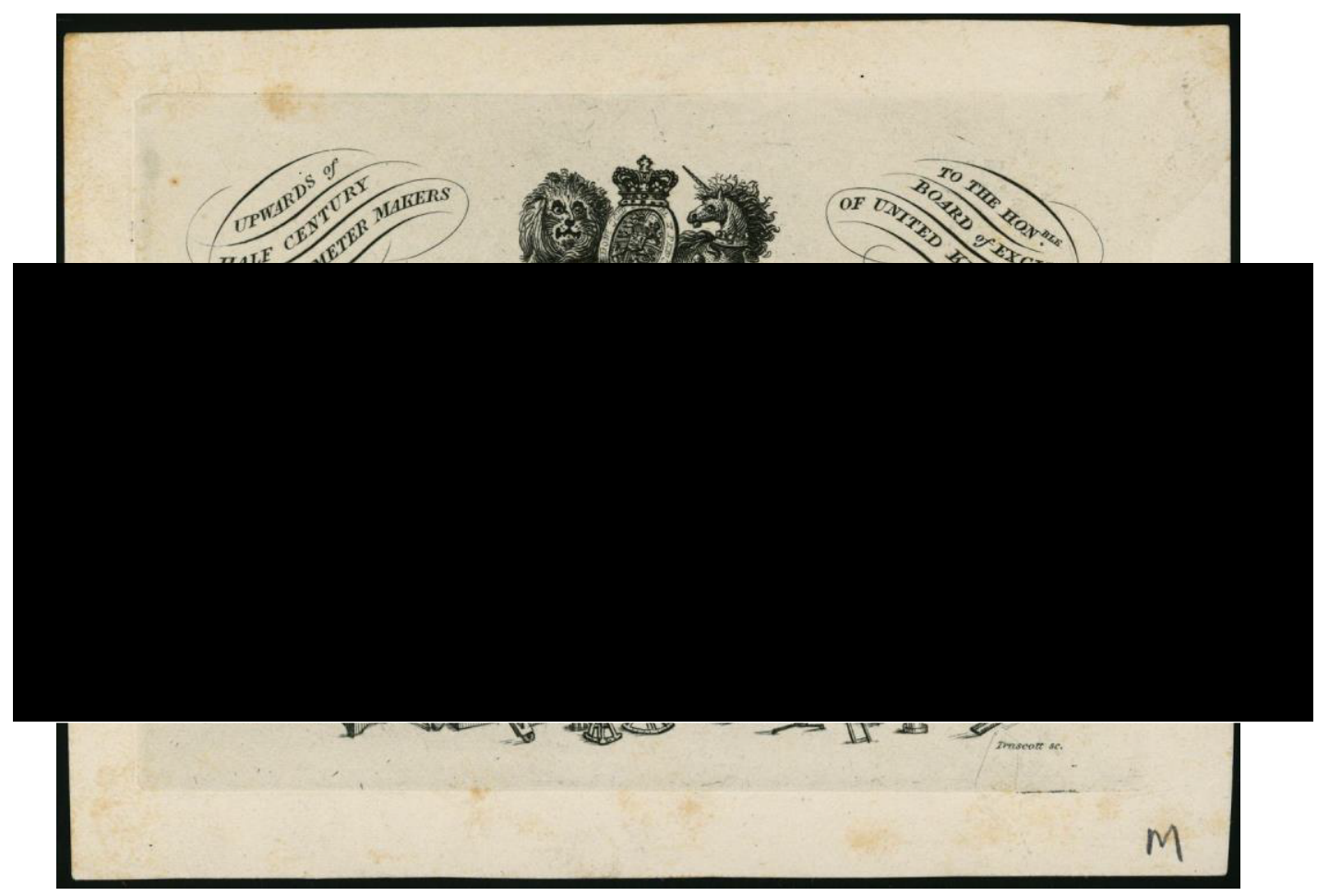

The adoption of imagery, crests, and elaborate backgrounds positions these traders in the wider context of polite commerce, and was a tool to help bolster the firm's

\footnotetext{
${ }^{51}$ This argument was originally made in Robert S. Whipple, 'John Yarwell, or the Story of a Trade Card', Annals of Science, 7 (1951), 62-69 (p. 63); and further emphasized by Joshua Nall and Liba Taub, 'Selling by the Book: British Scientific Trade Literature After 1800', How Scientific Instruments Changed Hands, ed. by Alison D. Morrison-Low, Sara J Sechner, Paolo Brenni (Leiden: Brill, 2016), pp. 21-2.
} 
reputation. ${ }^{52}$ However, the cards are also useful for exploring what items were sold. Besides Dring and Fage, many early nineteenth-century London instrument makers adopted this technique of depicting the objects they sold. In Figure 3.4 a trade card for Thomas Rubergall dating from between 1802 and 1854 illustrated the diversity of his trade as an 'Optician' and 'Mathematical \& Philosophical Instrument Maker', through its inclusion of a globe, telescope, and sextant.

Figure 3.4. Science Museum Art collection, 1934-121/100, Trade Card of Thomas Rubergall.

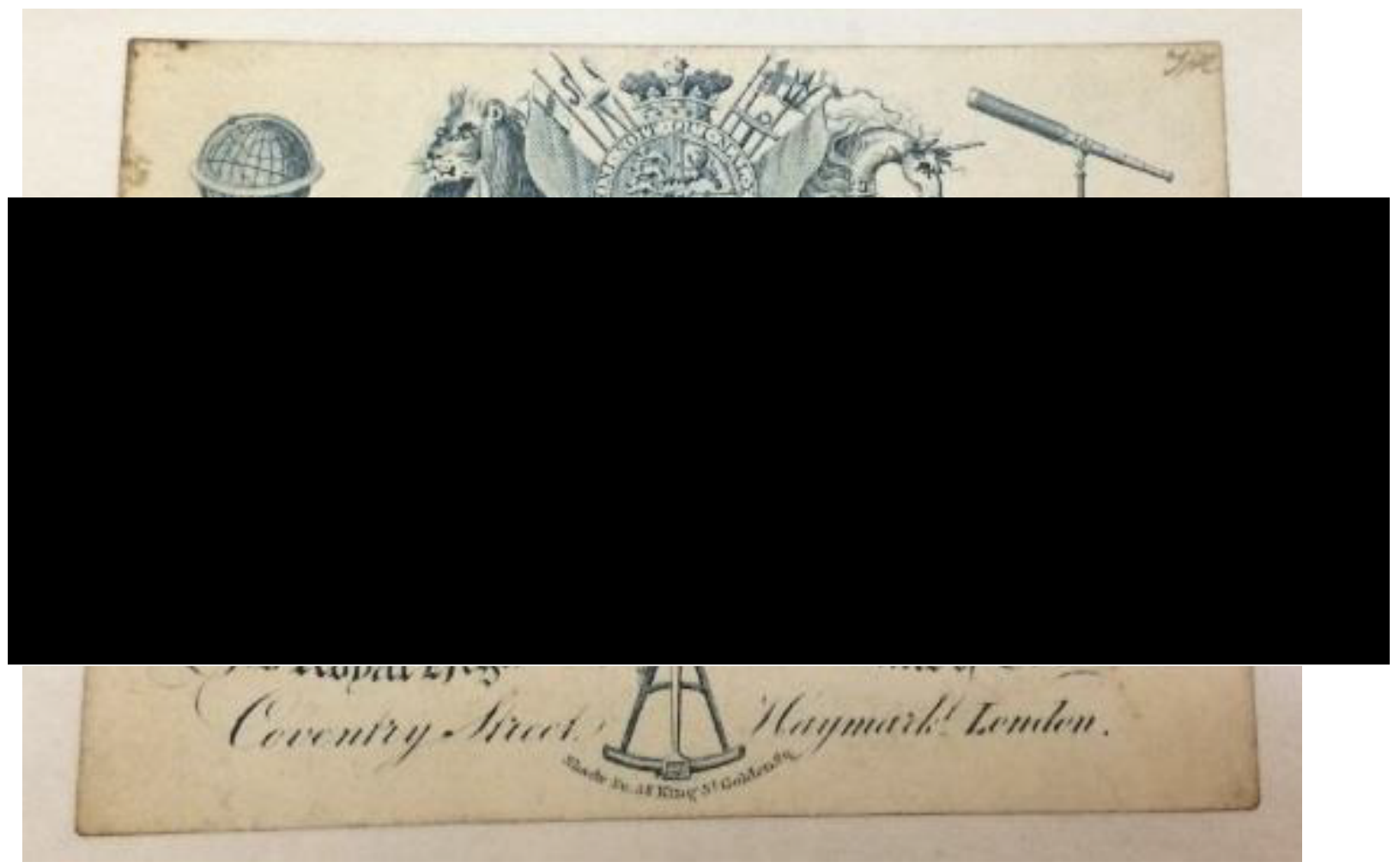

Such designs were also used outside of London. Figure 3.5 shows a trade card from 1837 by J. Abraham, 'Optician' and 'Mathematical Instrument Maker' from Bath, which illustrates some of his instruments in use, alongside spectacles in a flip-top case, and a lorgnette on the floor.

Figure 3.5. Science Museum Art collection, 1934-121/2, Trade Card of J. Abraham.

${ }^{52}$ Stobart, p. 314. 


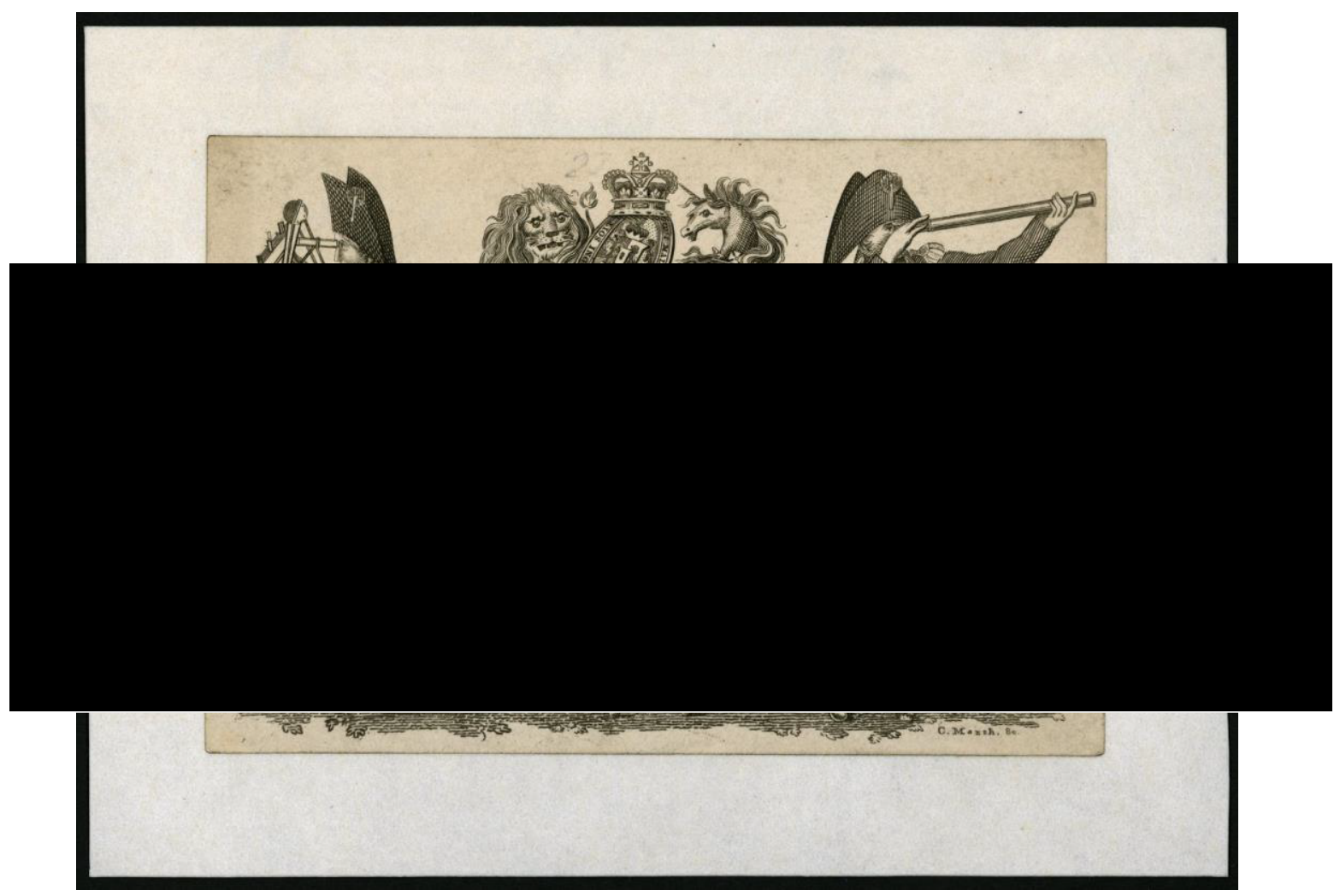

Opticians utilised text to reveal the range and diversity of their products.

Figure 3.6, for example, shows a large card from London optician and mathematical instrument maker C.W. Dixey, dated to between 1838 and 1862, which lists an extensive number of items underneath a series of subheadings: telescopes, mathematical instruments, drawing instruments, surveying instruments, newly invented portable microscopes and lamp \& candle screens, alongside their spectacles, improved eye protectors, and improved double opera glasses. 
Figure 3.6. Science Museum Art collection, 1948-397/16, Trade Card of C.W. Dixey \& Son.

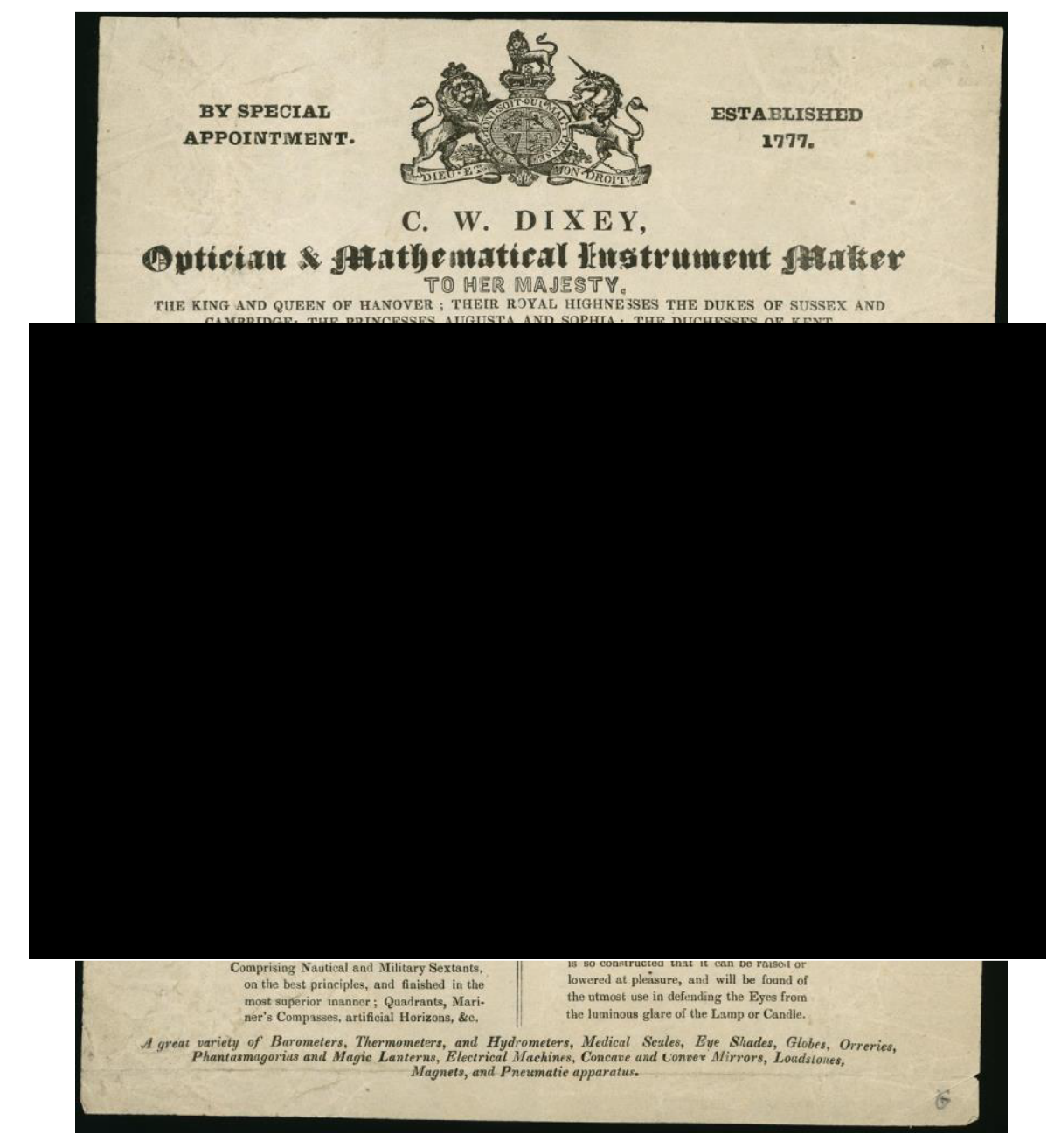

Trade cards indicate that the variety of objects that can still be found in the Museum's collections associated with a single instrument maker, such as Robert Brettell Bate, was perhaps not unusual for the time. Extensive lists of instruments for sale can also be seen in the trade cards from the late eighteenth and early nineteenth centuries of instrument makers John Snart and Edward Nairne. ${ }^{53}$ Given the extent of their range, it is unlikely that all of these items would have been kept in the stock of the instrument maker at all times, or manufactured by them. ${ }^{54}$ However, similarly extensive stock ranges appear consistently in the trade card collection and advertisements from the first half of the nineteenth century. In particular, auction advertisements from newspapers and periodicals in the mid-century reveal that the stock at the time of an opticians' death, retirement, or bankruptcy was varied. In the

\footnotetext{
${ }^{53}$ Science Museum Art collection, 1934-121/110, dated 1805-1827 and 1934-118, dated 1748-1806.

${ }^{54}$ For further discussion of this see, for example, Morrison-Low, p. 221.
} 
Leeds Mercury in February 1850, for example, the 'Stock-in Trade of an Optician' included:

...upwards of 300 pairs of spectacles, several gross of cases, pocket glasses, telescopes, and multiplying glasses; dials, magnets, galvanic apparatus and plates; magic lanterns with glasses, thirteen barometers (unfinished), thermometer frames, a large quantity of lenses and glasses with a variety of other articles partly finished. ${ }^{55}$

A diverse range of products were also stocked by retailers who were more specialised or focused more heavily on a single area of the instrument trade.

Although they are not represented in the collection, an 1815 catalogue of $\mathrm{G} \& \mathrm{~W}$. Proctor, 'Opticians' with branches in Sheffield and Birmingham, is a rare surviving example of trade literature from a specialist, which details the instruments they manufactured and sold. ${ }^{56}$ Whilst all the instruments in the catalogue were optical, they covered a wide range, including: spectacles, reading glasses, opera glasses, common telescopes, achromatic telescopes, diagonal mirrors, magic lanterns, and microscopes. A drawing was provided for each of these items, alongside a breakdown of their materials and prices. ${ }^{57}$ However, although such items were not included in the catalogue itself, the frontpage that they also manufactured 'mathematical and philosophical instruments', and the last page included an advertisement of the 'Lamphus', an alternative light source to candles. In a similar manner, an individual with a more specialised trade name, such as 'Optician and Spectacle Manufacturer', could also sell a wider range of instruments, not limited to the optical category. Significantly, a trade card in Figure 3.7 dating from between 1838 and 1854 for Andrew Pritchard, a London 'Optician and Spectacle Manufacturer', still included 'barometers, hygrometers and thermometers' in the list of instruments that he sold.

${ }^{55}$ Leeds Mercury, 20 July 1850; See also a similar example in The Athenaeum, 19 September 1853, p. 355.

${ }^{56}$ Morrison-Low also described it as a 'pattern-book', p. 171.

${ }^{57}$ Sheffield City Archives, Bradbury Record 293: G.W. and Proctor, Opticians and Manufacturers (Sheffield: C.W. Thompson, 1815). 
Figure 3.7. Science Museum Art collection, 1951-687/29, Trade Card of Andrew Pritchard.

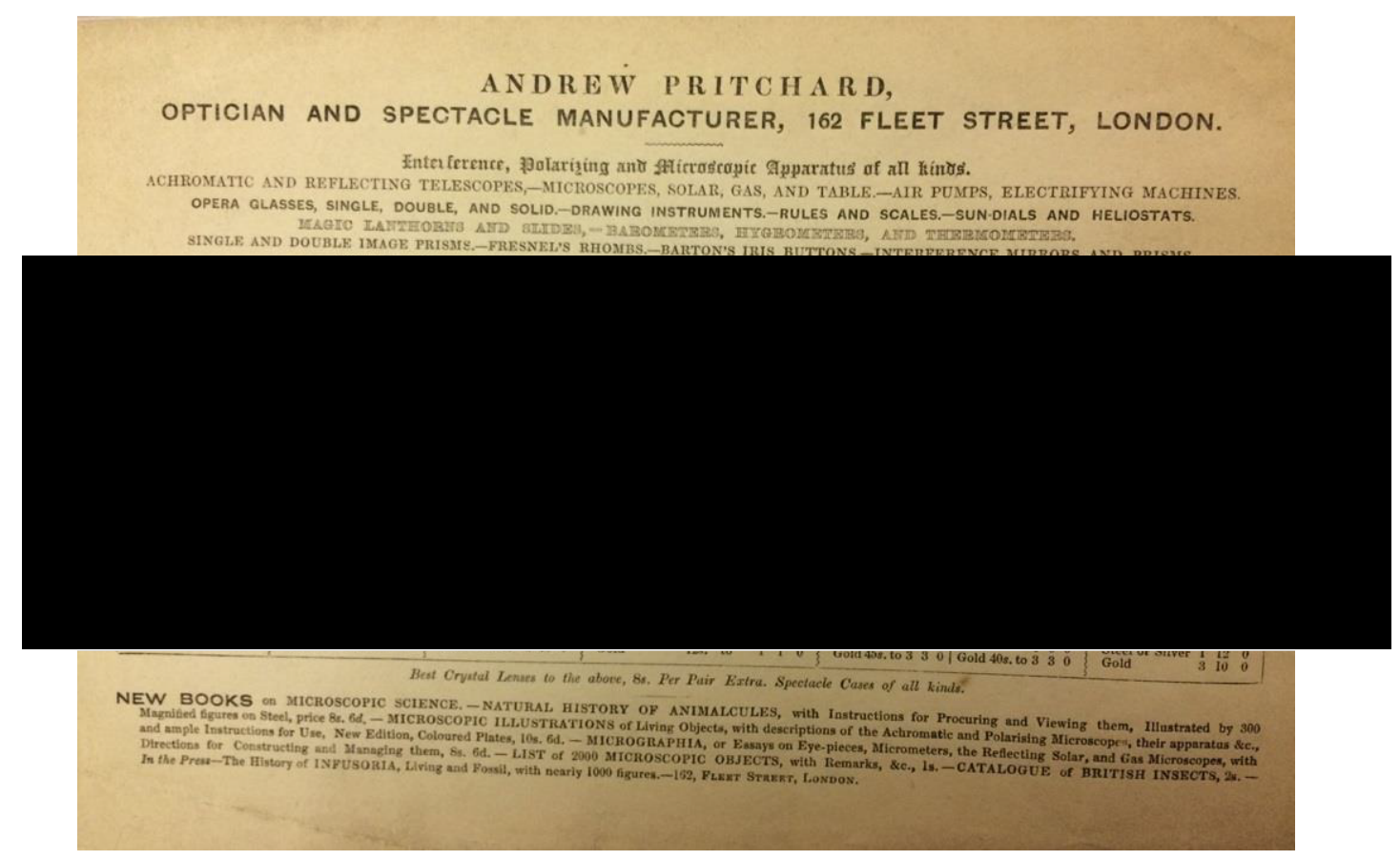

However, Pritchard's trade card was equally striking because vision aids were given particular prominence on it, via an image of each frame design that he sold. This is unsurprising considering Pritchard described himself as a 'spectacle maker', but in other cases the place and position of vision aids in trade cards regardless of trade name - varied substantially, regardless of trade name. In particular, vision aids could appear insignificant amidst the variety of other items listed in advertisements. In the trade cards shown in Figures 3.3 to 3.5, for example, spectacles are either not prominent or not shown at all. Similarly, the position or size of the text describing these devices could vary depending upon the position of vision aids in the wider trade of the seller. A trade card (Figure 3.8) dating between 1832 and 1842 by John Dunn of Edinburgh, for example, added that he sold a 'variety of spectacles, telescopes \&c' in small writing. The spectacles in Figure 3.8 appear to be more of an adjunct to the philosophical and chemical apparatus, and the surveying and drawing instruments, which were available at Dunn's 50 North Hanover Street store. 
Figure 3.8. Science Museum Art collection, 1934-121/43, Trade Card of John Dunn.

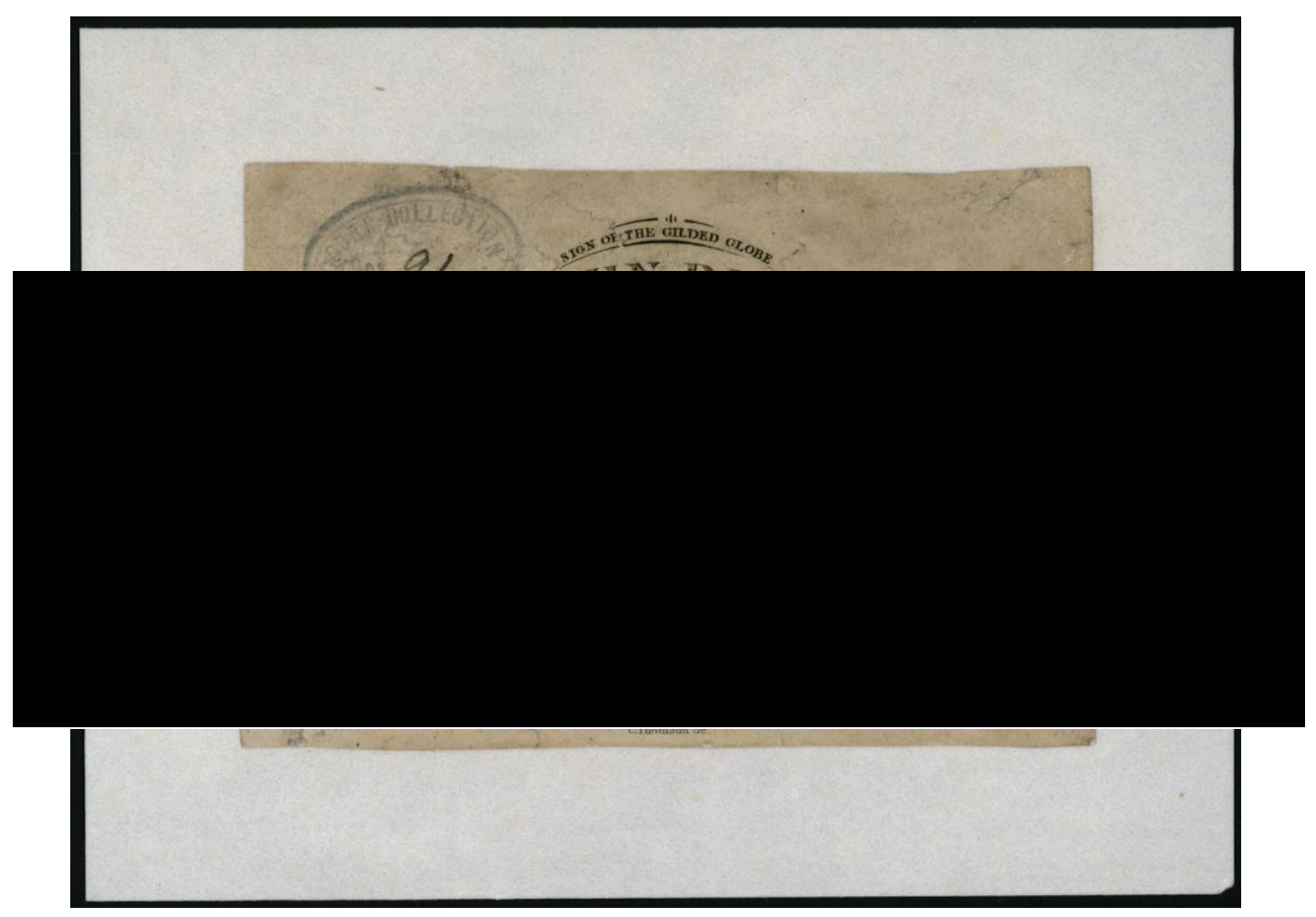

Spectacles and telescopes mentioned in Dunn's advertisement seem likely to have been the more 'everyday' or quotidian items that were sold alongside the philosophical and chemical apparatus. Moreover, Morrison-Low has noted, in the late eighteenth and early nineteenth centuries, spectacles were part of the instrument maker's 'domestic' market and the 'bread and butter' of their income. ${ }^{58}$ The broad potential usership of spectacles might partly explain why they appear amongst the stock of the early nineteenth-century instrument maker, because they would have enjoyed more universal appeal than specialised scientific instruments. Moreover, the difference in cost of the two was substantial; spectacles were the much more affordable item. ${ }^{59}$ The importance of vision aids to the opticians' trade is best illustrated in retailer's iconography. Before the advent of street numbers, opticians could be frequently found at the 'sign of the royal spectacles', or 'the two pairs of

\footnotetext{
${ }^{58}$ Morrison-Low, p. 108.

${ }^{59}$ Please see chapter six on users for a more extensive analysis on the cost of vision aids in this period, pp. 243-266.
} 
golden spectacles'. ${ }^{60}$ In the Museum's collection of illustrated trade cards as a whole, spectacles and eyeglasses appear as a visible symbol for the optician, both for those who specialised in optical manufacturers, and those who produced mathematical and philosophical goods. ${ }^{61}$ In Figure 3.9, for example, a trade card that has been dated between 1816 and 1822 includes an illustration of the shop premises of $\mathrm{A}$.

Mackenzie. Mackenzie, although an optical, mathematical and philosophical instrument maker, continued to use the image of spectacles above the door and in the shop windows.

Figure 3.9 Science Museum Art collection, 1951-685/50, Trade Card of A. Mackenzie.

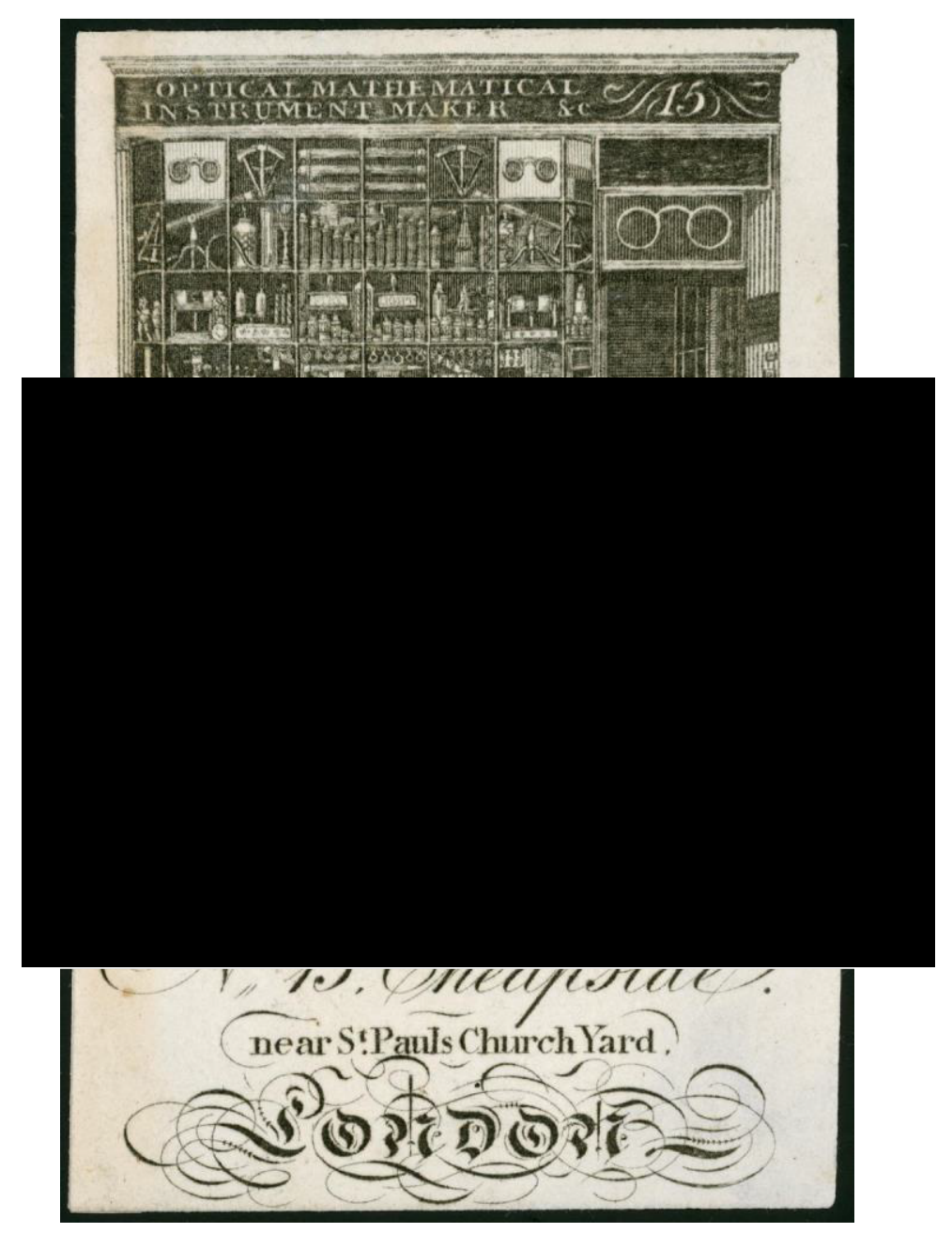

\footnotetext{
${ }^{60}$ For examples of this on eighteenth-century trades cards, see Science Museum Art collection,1951685/49, dated 1776-1784; 1934-122/21, undated; 1934-97/2; 1934-106, dated 1706-1756; 1934-110, dated $1745-1772$.

${ }^{61}$ See, for example, Science Museum Art collection, 1934-121/131, dated 1812 and 1951-685/18, undated.
} 
However, beyond their use as iconography, vision aids could appear as the main selling point in nineteenth-century trade cards and form a prominent and marketable aspect of the instrument makers' trade. In the 1820s a trade card of William Dowling, a London 'working optician', for example, highlighted the importance of vision aids to his trade. Dowling used two columns to extensively discuss the types of vision aids he had available, and the care he took to suit them to a person's eyes. ${ }^{62}$ Moreover, in contrast to the trade card of John Dunn in Figure 3.8, a number of trade cards in the Science Museum's collections focus on the provision of spectacles, and include other available instruments in a smaller font. In the mid1830s J. R. \& H. Stebbing from Southampton, for example, detailed in a large typeface their 'Spectacles, Reading and Eye Glasses' ${ }^{63}$ In Figure 3.10 a more explicit example can be seen in a trade card by a London 'practical optician' that has been dated between 1840 and 1844. S. Phillips, included a large image of spectacles and a price list, but only a short statement: 'N.B - Barometers and Thermometers made and repaired'.

${ }^{62}$ Science Museum Art collection,1934-98, dated 1822-1830. The technical term 'suit' is explained in chapter two, p. 72.

${ }^{63}$ Science Museum Art collection, 1934-397/56, dated 1834-1837. 
Figure 3.10. Science Museum Art collection, 1948-397/44, Trade Card of S. Phillips.

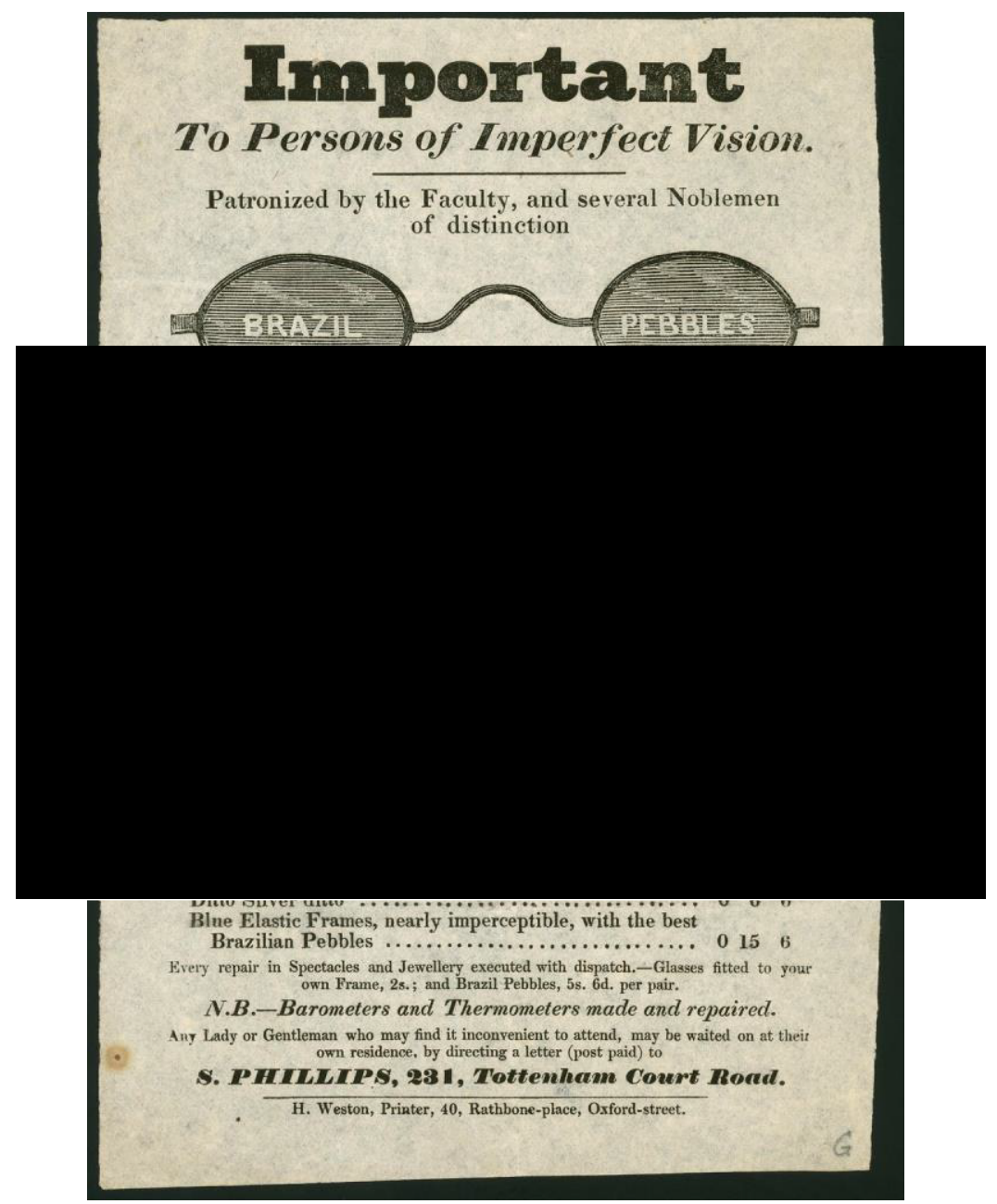

The findings in these trade cards are corroborated by a key-word search in the British Library Newspapers archive. Whereas in 1837 York optician Thomas Cooke advertised a whole range of instruments that could be made to order, an optician publishing in the Hampshire Advertiser in the same year emphasised the importance of his vision aids and 'bohemian crystal glass' ${ }^{64}$ A similar emphasis occurs in an advertisement for practical and mechanical opticians in the North Wales Chronicle in the 1840 s, which discussed 'A New Discovery for the Eyes', and focused on the properties of their lenses, and their knowledge of the 'imperfections of sight' ${ }^{65}$ Such advertisements suggest an increasing specialisation in the manufacture of vision aids; indeed, Morrison-Low has suggested that by the mid-nineteenth century this had become a separate enterprise, distinct from the instrument trade. The evidence for

\footnotetext{
${ }^{64}$ The York Herald, and General Advertiser, 26 August 1837; Hampshire Advertiser \& Salisbury Guardian, 20 May 1837; 27 May 1837; 17 June 1837; 29 July 1837.

${ }^{65}$ North Wales Chronicle, weekly between 7 May 1844 and18 June 1844.
} 
this lies in trade directory records; the evolution of Thomas Askey's profession, for example - from an 'optician' in 1815, an 'optician and spectacle maker' in 1830 to a 'spectacle maker' by 1850 - illustrates this. ${ }^{66}$

Specialisation in the retailing of vision aids is evident. Trade cards and newspaper advertisements show that vision aids still remained an important part of the scientific instrument maker's retail trade. Despite the mention of vision aids in many of their advertisements, these traders did not solely specialise in the sale of vision aids, and continued to describe themselves as 'mathematical instrument makers and general manufacturers' and 'optical, mathematical and nautical instrument makers'. ${ }^{67}$ The significant changes in the manufacture of spectacles and eyeglasses from the early nineteenth century onwards are acknowledged in the chapter on design. ${ }^{68}$ However, for the retail of vision aids the move away from the scientific instrument trade seems to have occurred much later, and, as is discussed in the fourth chapter, they continued to be purchased from opticians alongside a whole range of other products in the closing decades of the nineteenth century. ${ }^{69}$ Whilst some opticians chose to market their vision aids more extensively, the majority continued to be sold as part of a wide variety of stock. In summary, therefore, trade literature and advertisements for early nineteenth-century opticians reveal that vision aids were part of the broader scientific instrument trade, which occupied a range of temporary and fixed business premises in both London and the provinces.

The shop-setting beyond the scientific instrument trade also offered a wide range of opportunities for the sale of vision aids in the nineteenth century. Spectacles or eyeglasses could be found in the stock of a variety of other traders, both in and outside London. Benjamin West, a London 'Goldsmith and Optician', was active in 1828 , and his name can be found inscribed onto the handle of a wooden lorgnette in the Museum's Ophthalmology collections. ${ }^{70}$ Although only a single example, this object indicates that an alternative market for spectacles existed in the early

\footnotetext{
${ }^{66}$ Morrison-Low, p. 273.

${ }^{67}$ Ibid.

${ }^{68}$ See chapter five, pp. 189-99 for an overview.

${ }^{69}$ See chapter four, pp. 172-184.

${ }^{70}$ Science Museum's Ophthalmology collection, object number A680673.
} 
nineteenth century. Just as they could appear as the 'bread and butter' of the opticians' trade, spectacles could be found in the stock of 'toy' retailers and considered an 'impulse buy'. ${ }^{71}$ Moreover, vision aids appeared amongst a vast assortment of miscellaneous fancy and quotidian commodities in the nineteenth century. The evidence of newspaper advertisements, trade catalogues, and account books show that both spectacle and eyeglasses were part of the jewellers, watchmakers, and sundry trades between 1800 and 1850 .

The account books of Robert Sadd, an 'Optician and Jeweller' from Cambridge, reveal the close connection between the jewellery trade and vision aids in the first half of the nineteenth century. The purchase of vision aids, or parts of vision aids, were studied for five sample years between 1837 until 1851. This study showed that eyeglasses, as well as spectacles and spectacle cases, were not the primary form of income for the business but were purchased consistently throughout the year. ${ }^{72}$ Many examples of individuals who styled themselves as jewellers and opticians, and could have also dealt in spectacles and eyeglasses, can be found in contemporary newspapers. In 1846, for example, The Bristol Mercury included the advertisement of Thomas Sale 'Jeweller \& Optician' who had a stock of 'several hundred pairs of spectacles, eyeglasses \&c.' alongside a variety of other items. ${ }^{73}$ In these businesses, spectacles or eyeglasses were not situated beside other scientific instruments, but could be found alongside watches, brooches, locket glasses and musical-boxes.

Thomas Sale and Robert Sadd included the title of 'optician' in their trade names. However, other traders could style themselves solely as jewellers or engravers and continue to include spectacles and eyeglasses amongst their stock. A number of advertisements indicated that spectacles could be part of a jewellery, watchmaker and fancy goods trade, selling a range of products similar in its diversity to that retailed by scientific instrument makers. In the 1840s, James Wales, a Jeweller and Watchmaker, for example, included 'spectacles and eyeglasses' in the

\footnotetext{
${ }^{71}$ Alun Withey, Self-Fashioning and Politeness in Eighteenth-century Britain: Refined Bodies (Basingstoke: Palgrave Macmillan, 2016), p. 102.

${ }^{72}$ Cambridge University Library, GBR/0012/Ms Add.5781-5783: Account books of Robert Sadd, Optician and Jeweller, for the years 1837, 1839, 1847, 1849, and 1851.

${ }^{73}$ The Bristol Mercury, 21 March 1846.
} 
same sentence as 'silver and plated goods... parasols and umbrellas'. ${ }^{74}$ Similarly, in 1850 M. Cohnert, 'Jeweller, Watchmaker \& Importer of Fancy Goods' advertised his 'spectacles, optical instruments, gold lockets \& eyeglasses' as part of a broad range of ideal 'Christmas presents \& New Year's gifts'. ${ }^{75}$ Jewellers, watch- and clockmakers, both within and outside London, included spectacles and eyeglasses amongst their stock. The stock-list of the late William Strange, watch and clockmaker from the early 1850s is a particularly useful source alongside these advertisements. The stock-list, which was accumulated at his death, showed that spectacles and eyeglasses formed a small part of a variety of other goods, including: combs and brushes, bronzed goods, gold rings, watches, clocks, clock movements, new plated silver, and walking sticks. ${ }^{76}$

However, beyond the premises of the 'jeweller and optician', or the 'jeweller, watchmaker and engraver', spectacles can also be found amongst the range of sundries retailed by other kinds of tradesmen. This phenomenon occurred in both the city and the provincial town. An early 'Tradesman's Account and Memoranda Book' by Samuel Brookes, a Cutler and Stationer from Wellington in Somerset, shows that spectacles were bought by customers who purchased a variety of sundries at different points throughout the year $1800 .^{77}$ However, vision aids could be found in more miscellaneous spaces, such as the early nineteenth-century bazaar, which occupied large purpose-built buildings that let retail counters out daily. ${ }^{78}$ In 1835 The Bristol Mercury, for example, included spectacles amongst a variety of miscellaneous goods sold within 'Levy's Bristol Bazaar and General Furnishing Depot' ${ }^{79}$ In this instance, vision aids appeared alongside chess pieces, fenders, fancy cabinet work, and inkstands. Spectacles were not only to be found amongst a miscellaneous group of items in the provinces. In London itself, Henry Mayhew in his London Labour and the London Poor, had categorised spectacles amongst the street sellers' 'miscellaneous manufactured articles', alongside many items similar to those to be

\footnotetext{
${ }^{74}$ Leeds Mercury, advertised between April 1840 and June 1841.

${ }^{75}$ Caledonian Mercury, 18 December 1845; for another example see The Bristol Mercury, 20 April 1850.

${ }^{76}$ The National Archives, J/90/834: Catalogue of the 'late' William Strange, Watch and Clock-Maker.

${ }^{77}$ Somerset Heritage Centre, DD/X/RCH/1: Tradesmans's Account and Memoranda Book of Samuel Brookes, Cutler and Stationer, 1797. Whilst the instances were not numerous in this account book, the trade in all other items was not large across the year as a whole.

${ }^{78}$ For more information on bazaars, see Mitchell, 'Retailing Innovation', pp. 291-2, 296.

${ }^{79}$ The Bristol Mercury, 12 September 1835.
} 
found in 'Levy's Bristol Bazaar and General Furnishing Depot'. ${ }^{80}$ Mayhew also described the availability of these items in more ambiguous 'swag shops' and 'cheap shops'. His listing of the typical stock of these businesses shows that they included spectacles, in a variety of materials and with a range of lenses, alongside a miscellaneous assortment of scientific instruments and fancy goods. ${ }^{81}$

The existence of vision aids alongside a range of fancy goods, such as jewellery and watches, and in a range of shop or 'beyond the shop' spaces, raises questions about their function. ${ }^{82}$ Throughout the first half of the nineteenth century, vision aids were not a medical device, but might appear as a scientific instrument or a potentially more decorative or 'fancy' device, as well as a more quotidian sundry item. However, significantly for this chapter, the description of Henry Mayhew's 'swag shops' and the existence of travelling opticians also highlights the similarities between shop premises and sellers on the street. Likewise, the ambiguous status of jewellers or engravers as 'opticians' demonstrates how study of the location at which vision aids were retailed can illuminate how they were sold. The place of spectacles and eyeglasses amongst a vast array of products, and in a variety of different markets, perhaps says something about both the demand for them and their value to retailers as profitable goods. However, it arguably reveals more about the expectations of spectacle sale. The existence of a diverse number of traders in the retail of vision aids raises questions about what knowledge or technical expertise was required in order to dispense them in the first half of the nineteenth century.

\section{The Dispensing of Vision Aids}

The location of vision aids in a range of shop premises, miscellaneous trading spaces, and the street, calls into question whether they were dispensed with any knowledge of the eye or an eyesight test. As has been seen, some opticians wished to separate themselves from street sellers through the use of royal crests, or by highlighting a business address. However, criticism of, and attempts to distance

\footnotetext{
${ }^{80}$ Mayhew, pp. 323-4.

${ }^{81}$ Ibid., p. 335.

82 The phrase 'beyond the shop' has been taken from, Retailing Beyond the Shop, c. 1400-1900, ed. by Laura Ugolini and John Benson (Bradford: Emerald Group Publishing Ltd, 2010).
} 
themselves from, street sellers tended to focus on the use of persuasive rhetoric or the quality of the products, and not on their methods of dispensing. As a result, the complaints about practices on the street were not specific to the sale of vision aid; the same concerns were expressed by other retailers with business premises about the street peddlers who competed with them. This section explores how vision aids were sold in these different locations. It argues that dispensing was primarily a retail transaction in this period, and was driven by the autonomy of the customer, who could choose their own frame and lens. To do this, this section firstly explores the criticism that was directed at vision aid dispensing practices in the first half of the nineteenth century, and discusses how this was driven by broader concerns in retail and not considerations of the medical knowledge or expertise of the retailer.

Secondly, it assesses why this was the case. I shall argue that, whether on the street or in the shop of the optician, vision aids were dispensed by a process of "trial and error', which involved the trying out of lenses to find those that suited purchasers best. Vision aids existed amongst a diverse range of traders because expertise lay with the customer, and not the retailer, who only needed to provide a sufficient range of stock.

In 1831 a letter written by Emma Botham Alderson- sister to a prolific nineteenth-century Quaker writer Mary Howitt - provided a striking description of an encounter with a spectacle hawker, remarking that:

He proved to be the most truly...worthiest old man I ever met or hope to meet...really philosophical, he talked of the laws of light $\&$ colours $\&$ the formation of the human eye most beautifully and yet so quaintly, that I could hardly refrain laughing at times \& yet I listened in astonishment and pleasure. ${ }^{83}$

Although complimentary, Alderson alluded to the apparent misconceptions that could be held of street vendors at this time, and she reflected on how her opinions of the street vendor changed during this single encounter. She suggested that his 'coarse features \& mean appearance' transformed into what she would later describe as a 'poor disguised wayfarer' with 'noble intellect'. Equally, whilst she did not state whether she purchased anything from the hawker, Alderson suggested that inviting him in for a cup of coffee was unusual for the time. She recounted that the "poor fellow' had stated that he would 'often think of thy kind loving behaviour, some I

\footnotetext{
${ }^{83}$ University of Nottingham Archives, Manuscripts \& Special Collections, HT/7/1/30: Letter from Emma Botham Alderson to her sister Mary Howitt, 26 October 1931.
} 
meet with don't \& deaden me, and make me go on my way rejoicing, ${ }^{84}$ This account raises a number of points about the perception and conduct of street sellers at this time: the suspicion that was directed towards them, the persuasive rhetoric that they could have employed to encourage a sale, and the extent to which the dispensing of vision aids was medical in nature.

Whilst the records are by no means complete, the phenomenon of street sellers was frequently discussed by contemporaries in the first half of the nineteenth century, and these shed light on the account provided in Alderson's letter. The methods that street sellers adopted were often looked upon unfavourably and raised concern amongst other traders. However, rather than focusing on the way vision aids were actually dispensed, they tended to address concerns that were common to retailers of a wider variety of goods or raise doubts about the activity of medical quacks. In particular, street sellers were considered to coerce their customers and falsely claim new inventions. A common strategy adopted by opticians in contemporary advertisements, therefore was to warn their potential customers against 'pretenders'. In 1829 Messrs G and E. Davies, opticians advertising in the Leeds Mercury, cautioned the public 'against a set of itinerant pedlars who travel the country in all directions' with various forms of spectacles and lenses of 'unheard of properties' ${ }^{85}$ Additionally, other opticians often highlighted their lack of connection to any other individual of the same name. In 1842, E. Solomons, an optician advertising in an Irish newspaper, cautioned his customers against "parties who assume his name, and travel from town to town, vending spectacles calculated to injure the sight to a frightful extent' ${ }^{86}$ Solomons' caution was not simply an advertising ploy; a week later a former employee, having been dismissed from service, assumed the name of 'H.C. Solomon' and was advertising in local newspapers using the same testimonials as his previous employer. ${ }^{87}$ Four years later,

\footnotetext{
${ }^{84}$ Ibid.

${ }^{85}$ Leeds Mercury, 1 August 1829.

${ }^{86}$ Freeman's Journal and Daily Commercial Advertiser, 19 November 1842; 25 November 1842; 3 December 1842.

${ }^{87}$ Freeman's Journal and Daily Commercial Advertiser, 19 December 1842.
} 
it appears, the same individual was continuing to advertise in a different locality and E. Solomons was forced to instigate criminal proceedings against him. ${ }^{88}$

Whilst these advertisements cannot detail the conduct of itinerant pedlars directly, they do suggest that street sellers were viewed with suspicion, and could falsely claim an association with certain inventions or traders. This distrust amongst retailers of different kinds was not isolated to vision aid dispensing at this time; as Benson and Ugolini have demonstrated the reputation of street sellers as a whole was often dubious. Benson and Ugolini also highlight the difficulty of assessing the conduct of street sellers through the eyes of their critics. ${ }^{89}$ However, Alderson's letter revealed that, although the attitudes towards street sellers were complex and could change in a single encounter, a more negative stereotype of street sellers could be held by contemporary customers. A similar stereotyping of spectacle pedlars in more popular culture is also found in the account of a street vendor in a provincial periodical. Here, the persuasive methods of street sellers on one of the town's streets are described in aggressive terms, as 'thrusting their wares on the walking public'. 90 That they used aggressive techniques to sell their goods is corroborated in the account of Henry Mayhew in London Labour and London Poor. Mayhew recorded a conversation with a spectacle street seller who concluded that their practice was almost a matter of coercion:

I think it's more in the way of persuasion... Why, I've persuade people, when I was in the trade and doing well at it - for that always gives you good spirits - I've persuaded them in spite of their eyes that they wanted glasses. I knew a man who used to brag that he could talk people blind and they bought. ${ }^{91}$

The methods adopted by street sellers can be connected to the wider issue of persuasion in medical quackery, and the dispensing of medical goods through the use of advertising and sales pitches. Indeed, the ability of street sellers to 'talk people blind', is not dissimilar to that of medical quacks of this period who could 'out-argue illness. 92

\footnotetext{
${ }^{88}$ Freeman's Journal Daily Commercial Advertiser, 8 January 1846; 17 January 1846; 3 March 1846; 28 April 1846. What is interesting in this latter case, however, is the change in the spelling of the individual's name in the news stories from 'Henry Cohen' to 'Henry Cowan'.

${ }^{89}$ Benson and Ugolini, 'Beyond the Shop: Problems and Possibilities', pp. 260-262.

${ }^{90}$ Bradshaw's Manchester Journal, 7 August 1841, pp. 355-7.

${ }^{91}$ Mayhew, p. 444.

92 Roy Porter, Health for Sale: Quackery in England, 1660-1850 (Manchester: Manchester University Press, 1989), pp. 94-6.
} 
Concern was also expressed about those working from established premises with criticism often levelled at the remarks they made in popular periodicals. The claims of retailers highlight how the perception of problems of honesty and overall conduct were not isolated to street sellers, and further illustrate the difficulty of ascertaining whether there was a hierarchy of retailers in this period. ${ }^{93}$ In 1839 an advert for 'West's Improved Stanhope Lens' claimed that 'several unprincipled traders have been styling themselves OPTICIANS', suggesting that the use of titled professions in nineteenth-century advertisements was unregulated. ${ }^{94}$ This has been shown to be the case in studies of medical advertising by Hannah Barker and Lisa Forman Cody, which have demonstrated that 'quacks' adopted persuasive techniques to sell their wares under limited regulation. ${ }^{95}$ The criticism of advertisements' use of persuasion can be found in correspondence in popular literature. In 1843, for example, 'one who is not to be duped by quackery' discussed how the 'system of puffing extortion so generally and successfully' adopted by a number of spectacle dispensers was a 'daily practice' ${ }^{96}$ By the middle of the century, the moral responsibility of the public press in relation to the representation of those dispensing vision aids was being questioned. Indeed, in 1839 in a medical lecture on the eye it was argued that the press should cease to 'pollute their pages and prostitute their pens' with the advertisements of empirics. ${ }^{97}$

Criticism towards the dispensing of vision aids in this period, when it was directed at both the street vendor and the 'unprincipled' optician, was not specific to this trade. In contrast, concerns over the legitimacy of street sellers and opticians, and how they advertised, were shared across retail more generally, and with the dispensing of medical remedies, devices and products in particular. Far from being solely focused on knowledge of the eye and the testing of vision, contemporaries

\footnotetext{
${ }^{93}$ Benson and Ugolini, 'Beyond the Shop: Problems and Possibilities', p. 266.

${ }^{94}$ The Athenaeum, 15 June 1839.

${ }^{95}$ Lisa Forman Cody, "No Cure, No Money', or the Invisible Hand of Quackery: the Language of Commerce, Credit and Cash in Eighteenth-Century Advertisements', Studies in Eighteenth-Century Culture, 28 (1999), 103-30; Hannah Barker, 'Medical Advertising and Trust in Late Georgian England', Urban History, 36.3 (2009), 379-98.

${ }^{96}$ The York Herald and General Advertiser, 21 October 1843.

${ }^{97}$ Richard Middlemore, Introductory lecture on the Anatomy, Physiology, and Diseases of the Eye, Delivered at the Birmingham Royal School of Medicine and Surgery, 4 October 1839 (London: S. Longman, Orme, Brown, Green and Longmans), pp. 17-18.
} 
were largely concerned about the quality of the product and the truthfulness of the seller. The street seller in Emma Botham Alderson's account mentioned at the outset of this section did discuss 'the formation of the human eye'. Likewise, a number of opticians' texts and advertisements in this period claim anatomical knowledge and parallels can therefore be drawn with medical quackery. However, strikingly, the anatomical or medical knowledge of retailers was not the primary concern of those who criticised the nature of vision aid dispensing in this period. Indeed, opticians and not medical practitioners were more likely to express concerns. ${ }^{98}$ This suggests that the sale of vision aids was similar to other retail transactions, and the way that vision aids were dispensed differed between the street seller and the, perhaps more credible, optician.

A box labelled 'The Complete Sight Suiter: Or Book of Lenses by John Thomas Hudson', and dated to 1854, can be found amongst the test spectacles in the Science Museum's Ophthalmology collection. ${ }^{99}$ The box, shown in Figure 3.11, contains ten cardboard-framed lenses, each marked with 'J.T. Hudson, Optician, London' on one side. However, on the other side is printed 'prices 10/6, 12/3, 1/6: The complete Sight Suiter, sold by all booksellers', which suggests that this kit was intended to be purchased and used by the general public for self-testing, and was not necessarily intended for vision aid dispensers. Each lens was marked with their focal length in English inches, and they are labelled 48, 36, 24, 18, 16, 12, 9, 8, 7, and 6.

Figure 3.11. Science Museum's Ophthalmology collection A600351, 'The Complete Sight Suiter: Or Book of Lenses' by John Thomas Hudson.

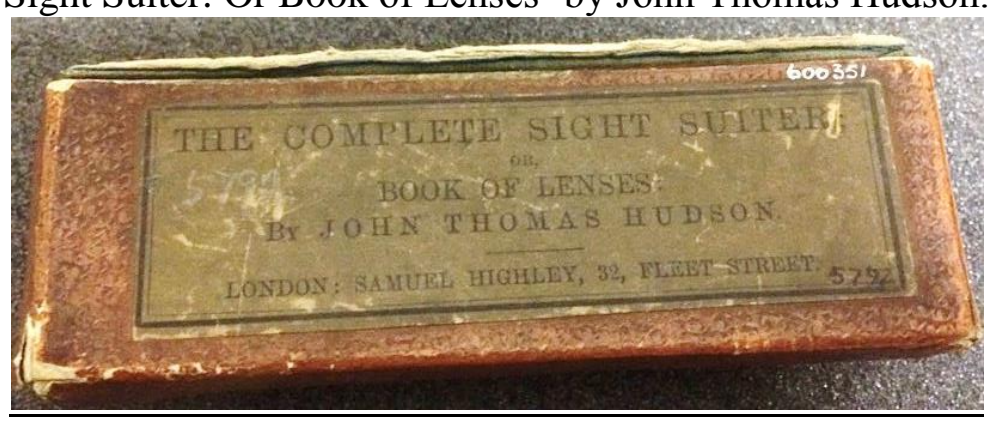

\footnotetext{
${ }^{98}$ Although some evidence of medical practitioners can be found in this period. See, for example, Beer, p. xiv; Kitchiner, The Economy of the Eyes, p. 7.

${ }^{99}$ Science Museum Ophthalmology collection, A600351.
} 
The object allows nineteenth century vision testing and vision aid dispensing to be explored in terms of: how many different focal lengths were available; the existence of self-testing devices in places such as bookshops; and the importance or existence of vision testing in the first half of the nineteenth century. The device suggests that obtaining a vision aid relied upon the trial and error of the customer; it only allowed them a choice of ten lenses to find the pair that suited them best. For John Thomas Hudson, a 'complete' sight suiter was a subjective method that relied on the customer and involved self-testing.

The type of criticism retailers faced, and the presence of spectacles and eyeglasses amongst the stock of a wide range of retailers, suggest that the dispenser did not necessarily require knowledge of the eye, optics, or lens grinding. John Thomas Hudson styled himself as an 'Optician and Spectacle Maker to many eminent Opticians', and wrote two texts for the general public between 1830 and 1840, which advised on how to use and select spectacles. ${ }^{100}$ Hudson argued that the fit of the frame was important, and half an hour should be put aside to ensure that they were correct. ${ }^{101}$ Despite this, Hudson concluded that 'no optician however great his natural genius, or acquired skill, can be half so good a judge of all these matters, as the intelligent wearer himself' ${ }^{102}$ These texts suggest that Hudson did have some knowledge of how to test vision and the function of spectacles. However, Hudson believed that the customer should choose their own lens, and produced a product that would enable them to have total autonomy. This raises questions about perceptions of the best way to dispense vision aids, and suit the individual's eyesight in the first half of the nineteenth century. Hudson, whose profession and publications make him a credible authority on this point, suggested that accuracy was obtained through selftesting; his product could have been adopted by a range of individuals, customers and retailers alike.

Most work on how vision aids were dispensed or sold has been written as part of the broader history of optometry. These studies tend to document the early

\footnotetext{
${ }^{100}$ Science Museum Art collection, 1948-397/29, dated 1831-1838; A 'J.T. Hudson' wrote, Spectalaenia; or the sight restored, assisted and preserved by the use of spectacles (London: Simpkin and Marshall, 1833) and Useful Remarks upon Spectacle, Lenses and Opera-Glasses; with Hints to Spectacle Wearers (London: Joseph Thomas, 1840).

${ }^{101}$ Hudson, Spectalaenia, p. 29.

102 Ibid.; Hudson, Useful Remarks on Spectacles, p. 28.
} 
tradition of 'trial and error', whilst looking at a few particularly novel ways in which certain individuals tried to create objective methods. ${ }^{103}$ Margaret Mitchell in her history of the British Optical Association concluded that 'before 1880 the hawker's tray and the empirical advice of the optician was the best service that could be offered'. ${ }^{104}$ Mitchell suggested that there was little difference between the methods of those dispensing on the street and the techniques of the optician. Moreover, the early nineteenth century is generally believed to have been a period of little change, because advancement relied on more sophisticated testing and diagnostic equipment that was invented from the mid-century onwards. ${ }^{105}$ The existence of Hudson's 'Complete Sight Suiter' challenges this consensus. This testing-kit may seem arbitrary to a modern user, but Hudson perceived it to be the best method of dispensing because he judged that the user was in the best position to decide which lenses suited their eyes. The exact nature of the 'trial and error' process of dispensing lenses has not been previously explored in the literature. Equally, whether the more novel 'objective' methods reached mainstream practice has not been ascertained. This could be because of the lack of clear evidence concerning the practices adopted by traders in this period. However, this topic can be studied through an amalgamation of a variety of fragmentary accounts to be found in business archives, advertising and popular literature and, more rarely, advice manuals written by opticians and members of the medical profession. An exploration of these sources suggests that subjective methods predominated in this period. However, whilst the greatest degree of change took place in the latter half of the century, there was already an expectation in the first half that the dispensing of vision aids should be accurate.

Although the cost of vision aids is discussed in chapter six, it is helpful to note here that the accounts of street vendors present the initial sale of spectacles and eyeglasses as a bartering transaction. ${ }^{106}$ In 1841 the Bradshaw's Manchester Journal described what seemed to be a process of bartering between a 'country man' and an

\footnotetext{
${ }^{103}$ See, for example, Wolfgang H. Vogel and Andreas Berke, Brief History of Vision and Ocular Medicine (Amsterdam: Wayenborgh Publishers, 2009), pp. 202-239; Daniel M. Albert, 'Ocular Refraction and the Development of Spectacles', in The History of Ophthalmology, ed. by Daniel M. Albert and Diane D. Edwards (Cambridge, Mass; Oxford: Blackwell Science, 1996), pp. 108-119.

${ }^{104}$ Mitchell, History of the British Optical Association, p. 19.

105 Rosenthal, pp. 308, 311; Barck, p. 20.

${ }^{106}$ See chapter six, pp. 243-266.
} 
'open air vender': after 'wrangling over the price of a pair of green spectacles', and 'a bargain being struck', the country man 'proceeded on his way'. ${ }^{107}$ Similarly, Henry Mayhew's account of London street sellers also detailed the haggling that took place during the purchase of spectacles. Significantly, the street seller in Mayhew's account was an 'optician by trade', and out of work. In the street seller's own description of supplying spectacles he stated that he had 'known customers to try my glasses one after another', suggesting both customer authority over their choice of glasses and the method of trial and error. ${ }^{108}$ This method of trial and error, as both the primary and best measure, is documented in a variety of popular literature produced during the first half of the nineteenth century. In 1850, for example, one newspaper article advised that 'the selection should be made by trials in the shop of the optician, and the lowest power taken which shows the work for which they intended at the ordinary distance'. ${ }^{109}$ This account differs little in the method it describes from that detailed in a much earlier account of 1800. An extract from 'Lectures on Diet and Regimen' by A.F.M. Willich, M.D. in The Critical Review advised that, when an individual could not attend an optician in the first instance, they could follow the subsequent instructions:

\begin{abstract}
A short-sighted person, who wishes for a proper concave or magnifying glass, may take the exact focus, or point of vision, by presenting the smallest print very close to the eye, and gradually removing it... When he has accurately ascertained the focus, after frequent trials, let him employ another person to take the measure of this distance, with a flip of paper, in the nicest possible manner. An optician on receiving this measure, and being informed at what distance the glasses are intended to be used, will be able to judge in a certain degree, what glasses are necessary. ${ }^{110}$
\end{abstract}

Opticians often provided a service that enabled customers to obtain vision aids from a distance. Written accounts and advice on how vision could be tested through this postal correspondence reveal the expectations of customers and retailers and the methods of sale used in the early nineteenth century. In 1839 Thomas Harris \& Son, for example, stated in their Brief Treatise on the Eyes that they could prescribe spectacles to those who were unable to attend in person. The optician stated that he only required the following information: whether the person had previously worn spectacles, and for how long; the distance they could see best; and

\footnotetext{
${ }^{107}$ Bradshaw's Manchester Journal, 7 August 1841, pp. 355-7.

${ }^{108}$ Mayhew, p. 444.

109 Trewman's Exeter Flying Post or Plymouth and Cornish Advertiser, 1 August 1850.

${ }^{110}$ The Critical Review, Or Annals of Literature, November 1800, pp. 299-300.
} 
the intended purpose. Harris \& Son argued that this method had 'succeeded in giving satisfaction', but noted that trial boxes of spectacles could also be lent if desired. ${ }^{111}$ Similarly, in 1840, Hudson claimed that customers in the country could have a number of pairs sent for a trial period in order for them to 'judge accurately' the vision aid required. ${ }^{112}$ Similar suggestions were also made by opticians in their advertising to potential customers in the country. In 1837 Chamberlain, for example, suggested that customers further than ten miles away could be 'suited either by sending the glass last used...or by stating the distance they can read common type, specifying the length of time they have used spectacles'. ${ }^{113}$ In the 1830s E. Solomons offered the same service and required the same information. Solomons' advertisement proposed that by 'stating particulars of defect of sight' customers could have trial glasses forwarded to them for inspection. ${ }^{114}$ In the absence of a detailed account of how an optician tested a person's sight between 1800 and 1850 , these advertisements are useful for ascertaining some of the finer details of dispensing. They show that the lenses customers had previously used, the length of wear, the distance at which they could read certain print, and the intended purpose, were commonly asked questions and considerations.

The use of the trial and error method can also be found in publications that offered advice. In January 1839 an extract from a treatise by the London optician Francis West in the Operative, for example, provided insight into the testing methods of opticians. West stated that vision testing relied on a book of small print and a selection of spectacles:

A part of the furniture of an optician's shop is a book of rather small print, which is presented to those who come to choose spectacles, and such glasses are very properly recommended as will enable the person to read it at the same distance and with the same ease that he could before his eyes were impaired. ${ }^{115}$

\footnotetext{
${ }^{111}$ Harris \& Son, p. 26.

${ }^{112}$ Hudson, Useful Remarks upon Spectacles, pp. 23-4, 28, 32.

${ }^{113}$ The London Dispatch and People's Political and Social Reformer, 8 October 1837; 22 October 1837; 19 November 1837; 26 November 1837; 24 December 1837; 25 March 1838; 29 July 1838; 9 December 1838; 27 January 1839; and he also advertised this statement prolifically in a variety of periodicals in the period 1838-1840, including the Examiner, Figaro in London, The Athenaeum, and The Musical World.

${ }^{114}$ E. Solomons: Freeman's Journal and Daily Commercial Advertiser, regularly (almost weekly) between 14 January 1843 and 17 June 1843; Mr Abraham: Hampshire Advertiser \& Salisbury Guardian Royal Yacht Club Gazette, Southampton Town and Country Herald, Isle of Wight, Winchester Chronicle, and General Reporter, 20 May 1837; 27 May 1837; 17 June 1837; 29 July 1837.

${ }^{115}$ Operative, 27 January 1839.
} 
The customer would have made their choice of lens from a narrow selection, which was based on the measurement of focal lengths in inches that was detailed on the lenses of Hudson's 'complete sight suiter'. ${ }^{116}$ Works on the history of optometry and spectacles have focused on the well-documented evolution of focal length measurements in contemporary accounts from one based on age to the inch system. ${ }^{117}$ The flaws in this system have been well discussed. They included the lack of sufficient differentiations to suit an individual's sight, and also the lack of standardisation across opticians and lens-grinders. Specifically, the numbers could differ depending on where the vision aid was purchased; contemporaries themselves commented on this numbering system, and the problems that this caused. ${ }^{118}$ The difference in strength between each lens was greater than in the later system of dioptrics, and perhaps more readily discernible. However, in the absence of any popular objective techniques, dispensers relied on the judgement of the customer to determine the lens power. As noted in the 1840s, this presented a number of problems because the use of a lens too strong or weak could have a damaging effect. $^{119}$

Accuracy in dispensing came to be seen as important in this period because of the risks associated with the use of incorrect or inaccurate lenses, and early attempts were made to improve the testing process. As a result, the first half of the nineteenth century should not be completely dismissed as a time of haphazard sale. In the previously mentioned advertisement of B. Salom in the Liverpool Mercury,

\footnotetext{
${ }^{116}$ As shown on Hudson's sight suiter, for convex lenses the English inch system was typically: 48, $36,24,18,16,12,9,8,7,6$ for weak to moderate strength, and he discusses these in Useful Remarks Upon Spectacles, p. 23. Concave lenses, however, were described as 'more arbitrary' by T. Wharton Jones, and there was less standardisation, Defects of Sight and Hearing, Their Nature, Causes, prevention and General Management (London: John Churchill and Sons, 1866), pp. 56-7. ${ }_{117}^{1}$ Ilardi, p. 24; Rosenthal, p. 32; Barck, pp. 16-18; Mitchell, History of the British Optical Association, pp. 19-21.

${ }^{118}$ See, for example, Hudson's comment on this in, Spectaclaenia, p. 9; and for an overview of the nineteenth-century development see Robert Brudenell Carter, Eyesight Good and Bad: A Treatise on the Exercise and Preservation of Vision, $2^{\text {nd }}$ edn (London: Macmillan, 1880), pp. $42-46$ and C.H. Vilas, Spectacles and How to Choose Them (Chicago: Duncan Brothers, 1881), pp. 51-53; A few examples of this form of numbering can also be found in the account books of Robert Sadd, Cambridge University Library, GBR/0012/Ms Add.5781-5783. Equally, the lack of standardisation can also be found in the material evidence that survives in the Science Museum's collections. The Ophthalmology collection has a variety of test spectacles, and the numbering on the lenses themselves varied. Whilst the number 1 could mean the weakest concave lens for some of the examples, it could also represent the strongest concave lens in others.

${ }^{119}$ See, for example, Alfred Smee, Vision in Health and Disease: the Value of Glasses for its Restoration and the Mischief Caused by their Abuse (London: Horn, Thornthwaite and Wood, 1847), pp. 37-8.
} 
Salom devoted a considerable proportion of the advertisement to his newly invented instrument called the 'Optician's Guide'. ${ }^{120}$ Although Salom argued that 'the dealer in Optics' rarely 'studied the nature and physiology of the eye', he emphasised his own training under a variety of talented and eminent gentlemen'. ${ }^{121}$ Salom argued that this instrument was able to ascertain the focus of each individual's sight, and remove 'all doubt... so as to preclude the least shade of error' ${ }^{122}$ Similarly, the use of other measuring equipment to ensure an accurate fit of both the frame and lenses also began to be discussed in the first half of the nineteenth century outside of the optician's trade. In 1837 at the seventh meeting of the British Association for the Advancement of Science in Liverpool, the importance of a correctly fitting frame was suggested in a paper 'On Measuring the Eyes for suiting them with Spectacles'. ${ }^{123}$ Here, it was argued that the width of the eyes differed between people and, therefore, it should be properly measured. Likewise, an examination of the eye, by means of a card of 'twenty-four, equidistant, radial lines' to ascertain the longest and shortest focus of the eye, was recommended before any attempt to select spectacles was made. ${ }^{124}$

By the mid-century, concerns over the testing of vision and the dispensing of vision aids were of growing interest to medical practitioners. In 1847 Alfred Smee F.R.C.S., in lectures delivered at the Central London Ophthalmic Hospital, discussed two instruments for measurement of both the face and vision. Smee's 'visometer' measured the face and visual axes so that the 'centres of vision may be learnt to onehundredth of an inch without error'. Smee's 'optometer' was similar to Salom's 'Optician's Guide' and consisted of a graduated scale to obtain a person's point of distinct vision. ${ }^{125}$ Smee did not invent the optometer. However, he adapted this design and argued that the optical properties or defects of the eye could be ascertained with it. Smee also proposed that it should 'invariably' be used by the optician before any spectacles were sold or chosen by the 'applicant'. ${ }^{126}$ As early as

\footnotetext{
${ }^{120}$ Liverpool Mercury, 17 July 1835.

${ }^{121}$ Ibid.

122 Ibid.

${ }^{123}$ The Literary Gazette: A Weekly Journal of Literature, Science, and the Fine Arts, 7 November 1837, pp. 643-644.

124 Ibid.

${ }^{125}$ Smee, pp. 37-8.

${ }^{126}$ Ibid., pp. 40-42.
} 
1855, the London optician Charles A. Long praised Smee's 'optometer' and described the trial and error method of dispensing vision aids as the 'old plan' of a bygone era:

The selection of spectacles and eye-glasses requires the greatest care and attention, and should not be performed hurriedly... The old plan of trying on a number of glasses is most injurious as the eye becoming fatigued refuses to perform its functions properly... We are indebted to Alfred Smee...the use of the Optometer, an instrument invented by that gentleman... enables the optician to determine at a glance, and without fatigue to the eyes of the applicant, the exact amount of correction that requires to be given to the sight. ${ }^{127}$

These instruments formed part of discussions about the potential elimination of 'error' when dispensing vision aids; their design helped to ensure that the lenses that were suited would be 'exact'. However, the extent to which these new inventions, and the calls for 'scientific' accuracy to which they were the response, filtered into the everyday practices of retailers is difficult to ascertain and has not been previously explored. As this chapter has shown, vision aids could be bought in a variety of locations. The ledger books of Robert Sadd, Jeweller and Optician, whilst not indicating the direct methods of sale, suggest that people were buying their spectacles as they would purchase any other items. The accounts between 1837 and 1851 record the purchase of spectacles alongside other items in the same transaction, and there were only a few notings of the individual's prescription to suggest that there was any recording of a person's eyesight for later consultations. ${ }^{128}$ Two letters sent to the London optician C.W. Dixey suggest that, at the more extreme end, some of his more genteel clientele corresponded through their servants and had erroneous beliefs about how the strength of a person's lenses was ascertained. A letter from Lord Stamford in February 1843 suggested that spectacles could be dispensed without any examination at all, and that his age was the significant detail that would determine the selection of the lenses:

Lord Stamford encloses Messrs Dixey his Evening Spectacles which do not now magnify sufficiently to read small print in the Morning. He therefore wishes to send him a Pair of Morning spectacles to magnify more, and a Pair of Evening spectacles great magnifiers in different coloured cases. Lord S is now in the Seventy Eight year of his age. ${ }^{129}$

\footnotetext{
${ }^{127}$ Charles A. Long, Spectacles: When to Wear and How to Use Them: Addressed to Those Who Value Their Sight (London: Bland and Long, 1855), pp. 23-5.

${ }^{128}$ Cambridge University Library, GBR/0012/Ms Add.5781-5783: Account books of Robert Sadd, Optician and Jeweller, for the years 1837, 1839, 1847, 1849, and 1851.

${ }^{129}$ The original letters were destroyed in the Second World War. The surviving journal article that details the destroyed scrapbook were published in C.W. Dixey \& Son, A Short History, 1777-1977 (Newport: Mullock \& Sons, 1977), p. 29.
} 
Likewise, another letter from $18^{\text {th }}$ May 1852 suggested that a pair of spectacles could be chosen, without examination, and was based on the distance at which he held his face from his plate at meal times:

Lord Buckinghamshire will thank Mr Dixie to send him down to Sidmouth a pair of spectacles such as he thinks will suit a youth of 16 years of age who has never worn any but is so short sighted as to be obliged to hold his face close to his plate when he takes his meals. They are wanted for one of Lord B's Sons. ${ }^{130}$

These letters propose that the public were not necessarily aware of the advances in, or discussions on, the examination of the eye and vision testing that had taken place by the middle of the century. However, the information provided was also very similar to the information requested by opticians when individuals ordered from a distance. As a result, these letters offer an interesting insight into the customer's perspective, and the persistence of traditional practices at the mid-century.

Despite the growing development of objective instruments, the autonomy of the customer and the process of trial and error were also discussed in relation to the idea of accuracy. In 1827 the optician Francis West argued that 'no rule can be laid down for the short sight', and therefore the optician must 'depend on the observation of the Short Sighted themselves, who, by trying Glasses of different degrees of concavity, will soon find out'. ${ }^{131}$ Correspondingly, William Kitchiner, a prolific writer with a keen interest in optics, showed how new diagnostic equipment or techniques could be acknowledged, but not adopted. ${ }^{132}$ Writing in the $1820 \mathrm{~s}$, Kitchiner argued that an earlier version of the optometer was 'ingenious' for those who required spectacles and resided at a distance. However, despite this, Kitchiner maintained that the most 'accurate, and more satisfactory' plan for choosing spectacles remained in the optician's shop by means of trial and error. ${ }^{133}$ Indeed, in 1840 London opticians Thomas Harris \& Son, argued that 'the near sighted themselves are the best qualified to determine with what kind of glasses they can see most clearly'. ${ }^{134}$ Medical practitioners could acknowledge advances in the ability to

\footnotetext{
${ }^{130}$ Ibid.

${ }^{131}$ Francis West, A Familiar Treatise on the Human Eye: Containing Practical Rules that will Enable all to Judge what Spectacles are Best Calculated to Preserve their Eyes to Extreme Old Age (London: W. Ackrill, 1827), p. 36.

${ }^{132}$ For more information on Kitchiner see: Anita McConnell, 'William Kitchiner', Oxford Dictionary of National Biography https://doi.org/10.1093/ref:odnb/15690 [accessed: 15 March 2018].

${ }^{133}$ Kitchiner, The Economy of the Eyes, p. 225.

${ }^{134}$ Harris \& Son, p. 25.
} 
measure the eye or face but continue to prefer the older method of trial and error. One of the founding fathers of British ophthalmology, William Mackenzie, for example expressed the same opinion as Kitchiner in the fourth edition of his treatise, published in 1854. Mackenzie stated that for ascertaining glasses for short sight, the 'surest plan is to try a series of them, at an optician's shop', and the optometer was useful solely for those residing at a distance. ${ }^{135}$

The comments by both opticians and medical practitioners suggest that new technologies were not immediately adopted, and the older methods of spectacle dispensing continued to persist in opticians' shops as they did on the street. However, they also show that the method of trial and error, which predominated in the first half of the nineteenth century, should not be considered simply as a form of haphazard sale. As Mackenzie's argument revealed, the optician's preference for trial and error, as opposed to the optometer, was based on his aspiration to achieve the same kind of 'accurate' and 'surest' choice of lens for his customers as others sought through the new technology. Consequently, in a period where the use of 'trial and error' was considered by many to be the most scientific method, and prior to the complete development of objective sight tests, a retailer of vision aids did not need specific knowledge of vision testing or the eye; authority lay with the customer, and the retailer only needed a sufficient range of stock for them to try. It was this fact that allowed vision aids to be sold in a wide variety of locations, and by a diverse range of tradesmen.

\section{Conclusion}

This chapter has used the objects in the Science Museum's collections, contextualised by trade literature, advertisements, and contemporary accounts, letters and popular literature, to explore the sale and retail of vision aids in the first half of the nineteenth century. The sale of vision aids occurred in a number of locations and followed broader trends in retail in this period. Vision aids could be found consistently in the stock and trade of opticians and scientific instrument makers; they

\footnotetext{
${ }^{135}$ William MacKenzie, A Practical Treatise on the Diseases of the Eye, $4^{\text {th }}$ edn (London: A. and G.A. Spottiswoode, 1854), pp. 915-6; For information on Mackenzie see: 'William Mackenzie Medal', British Journal of Ophthalmology, 12.12 (1928), 648-649.
} 
were also sold on the street and in a variety of other retail premises. The ability to find vision aids alongside jewellery, scientific instruments, and miscellaneous sundries reflects the lack of regulation that has been emphasised in broad histories of spectacles and earlier work on the Spectacle Makers Company. Their availability not only in London, but also other major cities and provincial towns, also suggests that this wide-ranging market of vision aids was not as geographically restricted as previously proposed. Alun Withey has argued that corrective bodily devices, including spectacles, occupied a liminal position in the trade in scientific instruments and toys in the eighteenth century. ${ }^{136}$ This chapter has developed this by showing that vision aids could be found in the markets of the scientific instrument trade, the jewellery, watch, and engraver's trade, as well as the more miscellaneous sundry trade, in the first half of the nineteenth century.

Given the various locations and trades through which vision aids could be bought, the chapter has argued that there were different standards in the retail, sale, and dispensing of vision aids. ${ }^{137}$ The complicated nature of the vision aid market makes it difficult for the historian to assess what made a seller reputable at this time. Criticisms of street sale, travelling opticians, and the 'self-styled' optician abounded, but were not unlike those levelled at retailers more generally at this time. However, the location of vision aid sale, and the criticisms directed towards it, also reveals much about how these devices were dispensed and sold. As has been shown, trial and error methods seemed to persist into the mid-nineteenth century. Although some advances were made, it is clear that new inventions, such as the optometer, were not quickly adopted by practising opticians. Yet I have also shown, by looking more closely at the language used in contemporaries' arguments, that the continued use of the trial and error method was also based on a desire for accuracy. Vision aids could still be dispensed subjectively between 1800 and 1850, but opticians and medical practitioners alike agreed on the importance of avoiding error.

The growing involvement of the medical profession in eye examinations can be seen in Alfred Smee's discussion of spectacles, and the testing of vision, as part

\footnotetext{
${ }^{136}$ Withey, p. 7.

${ }^{137}$ The effect this had on the quality of these products, and the typical customers for these markets is explored in chapter six, pp. 243-266.
} 
of a lecture series at the London Ophthalmic Hospital. However, an exploration of Mackenzie's treatise showed that medical practitioners continued to advise individuals to visit an optician's shop to obtain spectacles. The invention of the ophthalmoscope, and a closer involvement of the medical profession, was required to develop more objective testing methods and the dispensing of vision aids in a more medical context. The following chapter argues that the medical profession had a pivotal role in shaping the way in which opticians perceived their role, as well as the regulation and dispensing of vision aids as a whole. However, for the period 18001850 , the regulation or specialisation of vision aid dispensing was not so straightforward. The selling of vision aids followed broader trends in retail, and they were distributed via a diverse range of traders, as a scientific instrument, fancy or decorative product, and a quotidian, miscellaneous device. 


\section{Chapter Four}

\section{Medicine and The Changing Methods Of Vision Aid Sale, 1850-1900}

A case containing a pair of straight spectacles in the Science Museum's

Ophthalmology collections was inscribed with 'Priest \& Ashmore, Ophthalmic Optician, Sheffield'. ${ }^{1}$ Priest \& Ashmore's trade directory entries changed from manufacturing opticians in 1833 , to manufacturing opticians, makers of ophthalmological instruments, and the adoption of 'oculists' prescription work' as a specialty in $1901 .^{2}$ This alteration raises many questions about the relationship between vision aid dispensers, the scientific instrument trade and the medical profession in the nineteenth century. Priest \& Ashmore was not the only business to highlight a medical connection. L.J. Troulan \& Son, for example, also chose the term 'oculistic opticians' for their leather frogmouth case. ${ }^{3}$ Additionally, the trade directory entries of opticians from the collection included Alfred Steward 'the only Manufacturing Ophthalmic Optician in Leicestershire' and Charles Coppock as an 'oculistic optician'. 4 The use of 'oculist' and 'ophthalmic' in the trade directory entries, and on the spectacle cases, suggests that by the 1890s some opticians were using terminology to align themselves to, or suggest a relationship with, the medical profession. Alun Withey has placed spectacles in a liminal position between the medical marketplace and scientific instruments in the eighteenth century. ${ }^{5}$ The previous chapter highlighted how vision aids were dispensed by peddlers on the street and by retailers in shop premises in the first half of the nineteenth century. It

\footnotetext{
${ }^{1}$ Science Museum's Ophthalmology collection, A49646.

${ }^{2}$ History and General Directory of the Borough of Sheffield with Rotherham, Chesterfield, and all The Villages and Hamlets (1833), p. 149; General Directory of Sheffield (1849), p. 177; Gazetteer and General Directory of Sheffield (1852), p. 181; General and Commercial Directory and Topography of the Borough of Sheffield (1862), pp. 47, 149; White's General and Commercial Directory of Sheffield (1879), pp. 809, 397; Kelly's Directory of West Riding of Yorkshire (1881), p. 1950; White's Directory of Sheffield \& Rotherham (1901), p. 5930.

${ }^{3}$ Science Museum's Ophthalmology collection, A682408; This case is undated, however, L.J Troulan appear as an optician at 11 Higher Union Street in Kelly's Directory of Devon (1889), p. 588.

${ }^{4}$ Science Museum's Ophthalmology collection, A681995; Deacon's Leicestershire, Rutland \& Northamptonshire Court Guide and County Blue Book (1890), unpaginated, digital page 543; Science Museum's Ophthalmology collection, A681449; Post Office London Directory [part 3: Commerical and Professional Directory] (1895) p. 1022; Post Office London Directory [Part 3: Commercial and Professional Directory] (1899), p. 1022.

${ }^{5}$ Alun Withey, Self-Fashioning and Politeness in Eighteenth-century Britain: Refined Bodies (Basingstoke: Palgrave Macmillan, 2016), p. 7.
} 
also showed that vision aids were sold alongside a variety of scientific instruments and miscellaneous items during the period1800-1850. However, it did not consider an optician's education, the medical marketplace, or the role of the medical profession.

This chapter looks at the second half of the nineteenth century to assess how far spectacles can be seen as a 'medical' object. Medical advertising and the medical marketplace have been used by historians to explore the diversity of medical care and the role of consumerism from the seventeenth to the end of the nineteenth centuries. ${ }^{6}$ Corrective technologies as well as proprietary medicines have been researched in this context, and Lilaine Hilaire-Perez and Christelle Rabier have directly compared spectacles to eighteenth-century steel trusses. ${ }^{7}$ Despite this, Alun Withey and David Turner have questioned how far corrective devices can be seen as 'medical' objects. ${ }^{8}$ This chapter assesses whether vision aid dispensing became more closely aligned to medicine in the nineteenth century. However, it also explores this in the context of professionalisation. Both opticians and medical practitioners were attempting to establish reputable professions in a society that increasingly associated the 'profession' with status, as well as an organising principle that could replace older concepts such as entrepreneurship and class. ${ }^{9}$ The previous chapter explored the diversity of vision aid sale and highlighted the unregulated nature of dispensing between 1800 and 1850. This chapter assesses how both opticians and medical

\footnotetext{
${ }^{6}$ See, for example, Michael Brown, 'Medicine, Quackery and the Free Market' : The "War" Against Morison's Pills and the Construction of the Medical Profession, c.1830-c.1850', in Medicine and the Market in England and its Colonies, c.1450-c.1850, ed. by Mark S.R. Jenner and Patrick Wallis (London: Palgrave Macmillan, 2007), pp. 238-261; Michael Brown, 'Medicine, Reform, and the 'End' of Charity in Early Nineteenth-Century England', The English Historical Review, 124.511 (2009), 1353-1388; Michael Brown, Performing Medicine: Medical Culture and Identity in Provincial England, c. 1760-1850 (Manchester: Manchester University Press, 2010), p. 5; Roy Porter, Health for Sale: Quackery in England, 1660-1850 (Manchester: Manchester University Press, 1989), pp. 222-235; Lisa Forman Cody, 'No Cure, No Money', or the Invisible Hand of Quackery: the Language of Commerce, Credit and Cash in Eighteenth-Century Advertisements', Studies in Eighteenth-Century Culture, 28 (1999), 103-30; Hannah Barker, 'Medical Advertising and Trust in Late Georgian England', Urban History, 36.3 (2009), 379-98; Louise Curth Hill, 'Medical Advertising in the Popular Press: Almanacs and the Growth of Proprietary Medicines', in From Physick to Pharmacology: Five Hundred Years of British Drug Retailing (Aldershot: Ashgate, 2006), 29-48.

${ }^{7}$ Liliane Hilaire-Perez and Christelle Rabier, 'Self-Machinery?' Steel Trusses and the Management of Ruptures in eighteenth-century Europe', Technology and Culture, 54 (2013), 460-502 (p. 490 ).

${ }^{8}$ David Turner and Alun Withey, 'Technologies of the Body: Polite Consumption and the Correction of Deformity in Eighteenth-Century England', History: The Journal of the Historical Association, 99.338 (2014), 775-796 (pp. 786-7).

${ }^{9}$ See, for example, an overview of this in Harold Perkin, The Rise of Professional Society (London: Routledge, 2002), pp. 1-16.
} 
practitioners used professional values and medical knowledge to address the problems of regulation in the latter half of the century. Similar to the medical profession's response to 'quacks' and charlatans that purported newfound means of medical cures, both opticians and medical practitioners increasingly sought professional integrity to control the way in which spectacles were dispensed.

The chapter is split into three parts. The first considers how opticians attempted to align themselves to a medical profession and medical institutions that were becoming increasingly more involved in the sale and dispensing of vision aids. The second uses The Optician and the British Medical Journal to consider the debates that arose from the medical profession's increasing involvement in vision aid dispensing. It shows how opticians attempted to reform their role and establish their own profession in the 1890s. The final section explores the effect of these developments on wider dispensing practices. I argue that opticians and medical practitioners were increasingly forced to cooperate. As part of this, opticians sought a cohesive body, standardised education, and certification to obtain professional dignity. I also argue that medical ideas changed the expectations for, and practice of, the retail and dispensing of vision aids. By the end of the nineteenth century, the idea that appropriate vision testing was required could be found both amongst opticians and medical practitioners, and in the advertisements of miscellaneous traders. However, this process was by no means complete by the start of the twentieth century and vision aids were not solely conceived as medical objects; tensions between medical practitioners and opticians continued to exist and quackery persisted.

\section{The Advertised Skillset of the Optician and the Role of Medical practitioners in the Retail of Vision Aids, 1850-1900}

The testimonials, patronage and style of advertisements for retailers of vision aids allow the relationship between dispensing practices and the medical profession to be explored. The origin of this affiliation and the form it took aids our understanding of opticians' roles and the medical profession from the mid-nineteenth century. An advertisement from 1842 by E. Solomons, a London optician and 'Patentee of Spectacles' in the Science Museum's Ophthalmology collection, stated that 'the 
instruments of his manufacture have been patronised by most of the Nobility of the united kingdom, the following are a few names; it would require too much space to publish them all'. ${ }^{10}$ Solomons' advertisement listed these individuals under the subcategories of the royal family, marquises, earls, countesses, viscounts, lords, admirals, generals, major-generals and lieutenant generals. ${ }^{11}$ However, the advertisement also stated that Solomons had 'been favoured by the chief medical practitioners of Europe'. ${ }^{12}$ In a corresponding manner, between 1838 and 1840 a London optician advertised that he was 'patronised by the nobility, clergy, and the principals of the British Museum' and had been 'strongly recommended by most distinguished members of the Colleges of Physicians and Surgeons' ${ }^{13}$ Both advertisements suggest that retailers drew upon traditional forms of patronage and adopted the language of 'polite commerce'. ${ }^{14}$ However, they also show that testimonies were used to align themselves with the medical profession.

Hannah Barker has argued that medical or scientific testimonials in medical advertising of this period were not as important as branding. Moreover, endorsements only occurred in 18-28\% of Barker's sample of medical advertisements in northern newspapers from 1760 to $1820 .{ }^{15}$ Yet in the advertisements of vision aids, the medical profession were consistently referred to from the 1830s. For corrective body technologies as whole - which includes devices for the correction or concealment of physical difference such as trusses - HilairePerez and Rabier have argued that individuals frequently advertised as 'doctors', or stated their strong connection to medical professionals. ${ }^{16}$ This section explores how retailers of vision aids adopted medical terminology or physiological knowledge to obtain the approval of a medical profession that had begun to pay increasing

\footnotetext{
${ }^{10}$ Freeman's Journal and Daily Commercial Advertiser, 19 November 1842.

${ }^{11}$ Ibid.

${ }^{12}$ Ibid.

${ }^{13}$ This statement appeared in a variety of Chamberlain's advertisements for the period 1838-1840: Examiner, between 15 April 1838, p. 239 and 13 June 1840, p. 487; The London Dispatch and People's Political and Social Reformer, 27 January 1839; Figaro in London, 11 February 1839, p. 47; The Athenaeum, between 30 November 1839, p. 911 and 12 December 1840, p. 999; The Musical World, between 14 May 1840, p. 312 and 23 July 1840, p. 63.

${ }^{14}$ See, also, previous chapter and A.D. Morrison-Low, Making Scientific Instruments in the Industrial Revolution (Aldershot: Ashgate, 2007), pp. 215-216; John Stobart, Andrew Hann, Victoria Morgan, Spaces of Consumption: Leisure and Shopping in the English Town, c.1680-1830 (London: Routledge, 2007), pp. 36-37.

${ }^{15}$ Barker, p. 390.

${ }^{16}$ Hilaire-Perez and Rabier, p. 483.
} 
attention to the testing of vision, and use of vision aids. As discussed in the previous chapter, there were a range of retailers dispensing vision aids by the $1850 \mathrm{~s}$. However, opticians' advertisements, the changing methods of vision testing, and medical trade literature show how the advertising discourse became increasingly medical in tone, and moved towards knowledge of the body, as well as scientific or lens grinding skill. Whether vision aids can be seen as 'medical' objects on the basis of this is open to question. Turner and Withey in their study of corrective body technologies in eighteenth-century England have showed that, whilst suppliers referred to members of the 'medical faculty', the relationship of these individuals and the products they sold to the medical profession was not straightforward. ${ }^{17}$ This section assesses how far, and to what extent, opticians attempted to position themselves alongside medical practitioners in the second half of the nineteenth century. It argues that, unlike sellers of corrective body technologies, opticians claimed both optical skill and medical knowledge by the end of the nineteenth century. Overall, it highlights that the retail and marketing of vision aids responded to wider changes in ophthalmology and the testing of vision, which were discussed in chapters one and two.

Medical advertising is evident from the seventeenth century - first in almanacs and later in newspapers - and had become widespread from the eighteenth century as the press expanded. ${ }^{18}$ Barker, for example, has suggested that the sale of medicine and related services increased dramatically in a sample of northern newspapers between the period 1760 and $1830 .{ }^{19}$ In the nineteenth century opticians advertised vision aids and adopted a range of techniques to market their products in both London and provincial newspapers. Whilst studies of the medical marketplace have tended to focus on proprietary medicines, a few works have considered the role of corrective body technologies in this period, and their place in this market. Vision aids were part of the broader retail of corrective body technologies, and advertisements for these products drew upon their association with the medical profession as well as the language of new science. ${ }^{20}$ However, references to medical practitioners in the advertisements of vision aids did not follow broader trends in the

\footnotetext{
${ }^{17}$ Turner and Withey, pp. 786-7.

${ }^{18}$ Cody, pp. 105-7; Hill, p. 37.

${ }^{19}$ Barker, p. 384.

${ }^{20}$ Turner and Withey, pp. 776, 783-4.
} 
retail of corrective body technologies from the late eighteenth century. Testimonials by medical practitioners do not appear until the early nineteenth century and their inclusion responded to the growing involvement of the medical profession in vision testing that was discussed in chapter two. ${ }^{21}$

In the first half of the nineteenth century, early references to medicine highlighted how the retailer was 'favoured', 'recommended' or 'patronised' by medical practitioners. ${ }^{22}$ The authenticity of these statements could be questioned. However, it was a growing trend amongst opticians, and the increasingly specific nature of medical testimonials ran parallel to the growing discipline of ophthalmology. ${ }^{23}$ Knowledge of refractive vision errors and the increasing number of ophthalmic institutions had a direct effect on the language used by opticians to attract customers. Beyond the use of testimonies, a shift in the skills of the trader can be seen in nineteenth-century advertisements: anatomical and physiological knowledge replaced earlier emphasis on length of practice and practical experience. Claiming the ability to 'preserve' the sight or care for the eyes was not necessarily new. Eighteenth- and early nineteenth-century trade cards and advertisements, for example, included claims that retailers could 'suit the sight' and prevent damage. ${ }^{24}$ However, in these instances the advertiser did not claim that they had anatomical or physiological knowledge. In contrast, by the 1830s retailers' began to advertise anatomical and physiological expertise, which went beyond the quality or construction of the frame and lens of vision aids that were sold. ${ }^{25}$ In 1835 , for example, an optician claimed to have a superior skillset because it 'rarely occurs that a Dealer in Optics has studied the nature and physiology of the eye' ${ }^{26}$ Additionally, the advertisement of pamphlets or lectures became a chosen method adopted by

\footnotetext{
${ }^{21}$ See chapter two, pp. 72-80.

${ }^{22}$ See, for example, Preston Chronicle, 10 October 1840; The Blackburn Standard, 11 November 1840; 18 November 1840; Freeman's Journal and Daily Commercial Advertiser, 19 November 1842; and the advertisements of Chamberlain advertisements for the period 1838-1840 in the Examiner between 15 April 1838 and 13 June 1840, p. 487; The London Dispatch and People's Political and Social Reformer, 27 January 1839; Figaro in London, 11 February 1839, p. 47; The Athenaeum, between 30 November 1839 and 12 December 1840, p. 999; and The Musical World, between 14 May 1840, p. 312 and 23 July 1840, p. 63.

${ }^{23}$ See, for example, Liverpool Mercury, 17 July 1835.

${ }^{24}$ See, for example, Science Museum Art Collection, eighteenth century examples: 1934-97/2; 1934121/43; 1951-687/19; 1951-687/41; and an early nineteenth century example: 1934-98.

${ }^{25}$ For an early example of this, see Hampshire Advertiser \& Salisbury Guardian Royal Yacht Club Gazette, Southampton Town and County Herald, Isle of Wight Journal, Winchester Chronicle, and General Reporter, 12 August 1837.

${ }^{26}$ Liverpool Mercury, 17 July 1835.
} 
opticians to proclaim medical knowledge to the potential customer. ${ }^{27}$ These advertisements highlighted lengthy periods of study, or 'paying attention' to the anatomy and physiology of the eye and vision. ${ }^{28}$

Whilst eighteenth-century and early nineteenth-century advertisements had focused primarily on the quality of lens and construction of the frame, anatomical knowledge as well as optical skill had become important features of the mid nineteenth-century optician's business. In 1853 William Ackland, a London-based optician, philosophical and photographic instrument maker, advertised 'his medical knowledge as a Licentiate of the Apothecaries' Company, his theoretical knowledge as a mathematician, and his practice as a working optician'. ${ }^{29}$ Likewise, in the $1880 \mathrm{~s}$, Henry Laurance - an optician whose business encompassed branches in Birmingham, London, Manchester, and Glasgow - produced pamphlets and advertised prolifically. However, Laurance had taken Ackland's statement a step further by describing himself as an 'oculist optician' and arguing that 'spectacles can only be perfectly adjusted by those having a thorough knowledge of the anatomy of the eye combined with optical experience'. ${ }^{30}$

The emphasis on anatomical and physiological knowledge in opticians' advertisements developed alongside the growing knowledge of refractive vision errors in the discipline of ophthalmology. Whilst focus on anatomical knowledge can be found in the $1830 \mathrm{~s}$, the number of vision testing technologies expanded from the mid-century. By the second half of the nineteenth century, opticians' advertisement went beyond the basic claim of an association with medical personnel or institutions that can be seen in the advertisements of medical devices such as trusses in the eighteenth century; they claimed medical knowledge and a close relationship with medical practitioners. ${ }^{31}$ The addition of anatomical knowledge, as well as quality of construction, can be seen as part of wider changes in the diagnosis and testing for

\footnotetext{
${ }^{27}$ See, for example, Arnold's Magazine of the Fine Arts, and Journal of Literature and Science, May 1834, p. 10; The Preston Guardian etc, between 3 August 1844 and 12 April 1845.

${ }^{28}$ See, for example, Hampshire Advertiser \& Salisbury Guardian Royal Yacht Club Gazette, Southampton Town and Country Herald, Isle of Wight, Winchester Chronicle, and General Reporter, between 20 May 1837 and 29 July 1837.

${ }^{29}$ The Athenaeum, between 4 June 1853, p. 665 and 16 July 1853, p. 842.

${ }^{30}$ See The Academy, between 17 March 1883, p. 5 and 20 October 1883, p. 7; Saturday Review of Politics, Literature, Science and Art, 7 April 1883, p. 454.

${ }^{31}$ Turner and Withey, p. 786.
} 
vision errors, which had a direct effect on expectations for how and where vision aids should be sold in the second half of the century.

Chapter three argued that accuracy was considered important when dispensing vision aids in the first half of the nineteenth century. This was also reflected in the advertisements of opticians in this period; whilst vision aid dispensing in the first half of the century was primarily a matter of trial and error, 'accuracy' and 'precision' were still part of the optician's and spectacle dispenser's vocabulary. In 1837 a London optician and spectacle manufacture, H. Adams, discussed how his spectacles could be 'brought exactly opposite to the pupil of the eye'. ${ }^{32}$ Similarly, towards the mid-century, London 'Oculist's Optician' N.

Whitehouse argued that his spectacles were 'acutely suited to every defect of vision'. ${ }^{33}$ Terminology such as 'carefully', 'accurately', and 'correctly' can be found in a number of advertisements for the period, which suggest that this remained an important requirement across the century. ${ }^{34}$ However, the meaning of 'scientific' and 'accurate' altered significantly in the latter half of the century in response to the degree of accuracy obtainable. The technical equipment dating from the nineteenth century in the Science Museum's Ophthalmology collections is striking. ${ }^{35}$ Objects held there include trial lenses, trial frames, ophthalmoscopes, optometers, and eyesight testing charts for short and long sight, and astigmatism. The objects in the collection show how diagnostic technologies developed from simple test spectacles that could be placed in the pocket, to a range of diverse and increasingly sophisticated equipment to test vision. ${ }^{36}$ The trial lens cases in large engraved wooden boxes are an especially interesting group of objects. ${ }^{37}$ Their size suggests a lack of portability when compared to the small test spectacles, and raises a number of questions about the space in which vision testing took place, and whether more standardised testing rooms were being adopted.

\footnotetext{
${ }^{32}$ Examiner, between 8 October 1837, p. 654 and 18 March 1838, p. 174.

${ }^{33}$ Lloyd's Weekly London Newspaper, 11 February 1844.

${ }^{34}$ See, for example, Caledonian Mercury, 30 April 1855; Caledonian Mercury, 6 May 1857; Glasgow Herald, 27 November 1872.

${ }^{35}$ For further information on sight testing technologies see chapter two, pp. 72-76.

${ }^{36}$ For test spectacles see, for example, Science Museum Ophthalmology collection, object numbers: A69554, A69555, A141039, A141040, A141041, A141042, A141043, A141045, A180949, A680956, A680957, A681084, A681085, A681086.

${ }^{37}$ For trial lenses see, for example, Science Museum Ophthalmology collection, object numbers: A51021, A680575, A606433, A680641, A635437, A680494, A680882.
} 
The growth in objective testing technologies led to a competing space for the sale of vision aids in the form of the hospital, as well as a new demand for standardised eyesight testing rooms and the expectation that an examination would be carried out by the dispenser. Whilst vision aids were described as being 'scientifically adapted' in the first half of the nineteenth century, Manchester optician A. Franks discussed having spectacles 'scientifically tested' and adapted in a specific 'eyesight testing room' in $1890 .{ }^{38}$ Similar to wider developments in medical diagnostic techniques during the nineteenth century, eyesight-testing technologies changed and became more complex. Mary Carpenter has highlighted how the use of equipment such as the stethoscope and thermometer increased medical authority, and caused patients to become increasingly passive in the diagnosis of illness. ${ }^{39}$ The use of vision testing technologies also shifted authority to the dispenser, and therefore the knowledge required of spectacle retailers went beyond aspects of construction and sale. The effect that these transformations could have on the expectations of how vision aids should be sold can be seen in popular and medical accounts. In 1890 Phyllis Browne in her column 'Chats with Housekeepers' in the Newcastle Weekly Courant criticised previous methods and argued that 'nothing can be more foolish than for a person to go into a shop, 'try on' a few spectacles, and then purchase the pair through which they can see best' ${ }^{40}$

In 1899 the American ophthalmologist D. B. Roosa proposed that changes in vision testing were due to the involvement of the medical profession, and stated that:

The haphazard and insufficient methods of the opticians were replaced by exact and scientific measurement of the refraction and accommodation of the eye, by skilled men who could distinguish between incipient or advanced inflammatory or other morbid changes constituting disease, and purely optical conditions. ${ }^{41}$

Roosa's conclusion was not new: in 1862 a British Ophthalmic Surgeon, Joel Soelberg Wells, had argued that methods adopted by opticians were generally

\footnotetext{
${ }^{38}$ Manchester Times, between 7 June 1890 and 22 August 1890.

${ }^{39}$ Mary Carpenter, Health, Medicine and Society in Victorian England (Santa Barbara, CA: Praegar, 2009), pp. 2, 4-5, 12.

${ }^{40}$ The Newcastle Weekly Courant, 5 July 1890.

${ }^{41}$ D.B. Roosa, Defective Eyesight: The Principles of its Relief by Glasses (London: Macmillan, 1899), p. 12.
} 
'haphazard' and 'empirical', when they could be 'scientific' and 'skilful'. ${ }^{42}$ Wells' and Roosa's conclusion was well founded. Increased use of controls for subjective examination and new methodologies in medicals texts predominated in the latter half of the century. As part of this, the method of trial and error was becoming standardised through a growing consensus in favour of a universal lens measurement, an increasingly controlled testing environment and the use of equipment to determine a person's vision and visual acuity. ${ }^{43}$ Ophthalmologists and medical practitioners also considered the possibility of objective measures and the incorporation into their practice of a variety of equipment, such as viscometers, optometers, ophthalmometers, and ophthalmoscopes. In 1864, for example,

Franciscus Cornelis Donders pinned the development of the objective examination of the eye on the ophthalmoscope that was used in examinations from the mid-century onwards. $^{44}$

Whilst medical practitioners did not dismiss the utility of trial lenses and testtypes for determining simple vision errors, they were increasingly developing more complex methods for vision errors to be obtained objectively. This allowed practitioners to diagnose a greater number of conditions, such as astigmatism and hypermetropia, with greater speed and precision. ${ }^{45}$ In 1884 Henry Juler explored 'the Best Methods of Diagnosing and Correcting the Errors of Refraction' in the British Medical Journal. ${ }^{46}$ Juler concluded that trial glasses were 'perfectly safe' and useful if vision could be immediately improved to the $6 / 6$ standard (the modern day 20/20). ${ }^{47}$ However, Juler also explored the potential problems that arose from being reliant on the patient, and therefore argued that using objective methods would save great time and trouble. ${ }^{48}$ Juler, in his analysis of objective examinations, argued that the shadow-test, or retinoscopy, was the best for determining the most complex

\footnotetext{
${ }^{42}$ John Soelberg Wells, On Long, Short and Weak Sight and their Treatment by the Scientific Use of Spectacles (London: J.A. Churchill, 1862), p. 111.

${ }^{43}$ See chapter two, pp. 72-6 for more information on changes in vision testing.

${ }^{44}$ F.C. Donders, On the Accommodation and Refraction of the Eye, with a Preliminary Essay on Physiological Dioptrics, trans William Daniel Moore (London: New Sydenham Society, 1864), p. 59. ${ }^{45}$ See, for example, 'A New Instrument for Estimating Astigmatism', The York Herald, 27 August 1880.

${ }^{46}$ Henry Juler, 'On the Best Methods of Diagnosing and Correcting the Errors of Refraction', British Medical Journal, 27 December 1884, pp. 1274-1275.

${ }^{47}$ Ibid., p. 1274.

${ }^{48}$ Ibid.
} 
errors of refraction. ${ }^{49}$ For Juler, this method was superior because it eliminated any reliance on the patient. The subjectivity of tests was increasingly considered by a variety of medical writers and ophthalmologists. In 1881 A. Stanford Morton, for example, had advocated the method of 'Keratoscopy' because the refractive error could be obtained 'quite independently of the patient'. ${ }^{50}$ In a later edition from 1886 Morton also discussed the 'exceedingly useful' method of Retinoscopy, because it placed him 'in complete independence'. 51

By the 1890s knowledge on the physiology and anatomy of the eye, use of testing equipment, and an understanding of optics were considered necessary for the 'scientific' sale of vision aids. These requirements were increasingly controlled and drawn up by the medical profession, which created a new and competing location for the testing of vision and the acquisition of vision aids in the latter half of the century. Spectacle dispensing had previously been considered 'beneath' the attention of the medical man or oculist. In 1845 William White Cooper, who was later appointed surgeon-oculist for Queen Victoria, concluded that the acquisition of vision aids was a separate sphere to that of medical practitioners and 'as a general rule it is considered sufficient when a person complains of being near-sighted to recommend him to pay a visit to an optician'. ${ }^{52}$ Yet the development of ophthalmology and sight testing technologies, and the growing acceptance of vision aids discussed in chapter two, meant that vision testing and dispensing were increasingly undertaken by medical practitioners. ${ }^{53}$ An account in the 1890 s from the Aberdeen Weekly Journal detailed an individual having their vision examined with the ophthalmoscope and trial lenses. Entitled 'The Ophthalmic Institution and What I Saw There (By a Patient)', the writer described his experience of consulting an 'eye doctor' for his short sight. The account detailed a vision test by means of a card with 'printed letters of several dimensions', 'a sort of dummy pair of spectacles' and 'lenses of various powers'. ${ }^{54}$ The account provides an interesting insight into the testing of vision in the

\footnotetext{
${ }^{49}$ Ibid., p. 1275.

${ }^{50}$ A. Stanford Morton, Refraction of the Eye: It's Diagnosis and the Correction of its Errors: with Chapter on Keratoscopy (London: H.K. Lewis, 1881), p. 27.

${ }^{51}$ Morton, p. 27; A. Stanford Morton, Refraction of the Eye: It's Diagnosis and the Correction of its Errors: with Chapter on Keratoscopy, $3^{\text {rd }}$ edn (London: H.K. Lewis, 1886), p. 62.

${ }^{52}$ William White Cooper, 'On Myopia and Presbyopia', Provincial Medical Surgical Journal, 23 July 1845 , p. 470.

${ }^{53}$ See chapter two, pp. 72-80.

${ }^{54}$ Aberdeen Weekly Journal, 14 December 1894, and was reprinted on the 19 December 1894.
} 
hospital setting during the 1890s; it described how an individual was tested one eye at a time with lenses from 'a well-supplied' trial case.

Despite the value of detailed individual accounts, they are limited in number. Medical trade catalogues are enlightening for exploring the scale of vision testing by the medical profession because of their greater scope. The medical trade catalogues, coupled with the discussions of vision testing and technical equipment in medical texts, suggest that the medical profession were becoming increasingly more involved in the supply and distribution of vision aids. Claire Jones in her study of the Thackray Museum's medical trade catalogues between 1870 and 1914 has argued that the catalogue was one of the key methods of advertising aimed at medical practitioners during this period. The publication of medical trade catalogues expanded dramatically, and circulation figures had reached 30,000 in $1914 .{ }^{55}$ Whilst it is more difficult to ascertain who received the catalogues, they are significant for showing doctors' interaction with traders of instruments and material goods. ${ }^{56}$ Fiftyfive catalogues, which included vision testing equipment and/or spectacles, were found in a key-word search of 'ophthalmology' in the Thackray Museum's collection. The catalogues' extensive lists and illustrations highlight the expansion of diagnostic equipment by the end of the nineteenth century. London-based James Weiss \& Son, for example, had an ophthalmoscope and a trial lens case section as early as 1863 , but gradually expanded their range between 1889 and $1898 .^{57}$ Similarly, Mayer, Meltzer \& Jackson of London and Leeds increased the variety of diagnostic equipment that they supplied. In 1885 and 1890, for example, their catalogues included trial lenses, ophthalmoscopes, and a trial frame. ${ }^{58}$ However, by 1900 a broader range of test lenses and a large range of testing equipment, along with illustrations were provided. ${ }^{59}$ London-based Down Bros, between 1885 and 1901 also increased the range of available equipment in their 'Catalogue of Surgical Instruments and Appliances'. This growth showed a much greater variety of trial

\footnotetext{
${ }^{55}$ Claire L. Jones, The Medical Trade Catalogue in Britain, 1870-1914 (London: Pickering and Chatto, 2013), pp. 1, 16, 26.

${ }_{56}$ Jones, pp. 5, 106.

${ }^{57}$ James Weiss \& Son, A Catalogue of Surgical Instruments, Apparatus, Appliances etc, 1863; Illustrated Catalogue and Price List of Surgical Instruments, 1889; A Catalogue of Ophthalmic Instruments and Appliances, 1898.

${ }^{58}$ Mayer, Meltzer \& Jackson, A Catalogue of Surgical Instruments and Appliances, 1885; Catalogue of Surgical Instruments and Appliances 1890.

${ }^{59}$ Mayer, Meltzer \& Jackson, Illustrated Catalogue of Surgical Instruments, 1900.
} 
lenses, ophthalmoscopes and test charts by $1901 .^{60}$ Indeed, consecutive runs of catalogues for individual companies, such as Mayer, Meltzer \& Jackson and the Downs Bros, illustrate the development in vision testing equipment in medical trade catalogues of the period.

Catalogues for other companies, based both in and outside of London, included spectacles and other forms of vision aid by the end of the nineteenth century. These catalogues also provided an alternative system of ordering spectacles, which enabled medical practitioners to bypass other retailers. In 1904, for example, London-based surgical instrument makers, Arnold \& Sons, listed an extensive number of spectacles in their catalogue. ${ }^{61}$ From the 1890 s firms in Newcastle, London and Manchester advertised spectacles and vision aids. In 1897 Brady \& Martin of Newcastle included spectacles in their catalogues for a variety of surgical, physical, physiological and scientific apparatus. ${ }^{62}$ In the same year S. Maw \& Son of London, in their 'Quarterly Price Current', also included spectacles and eyeglasses, and James Woolley Sons \& Co of Manchester began to supply spectacles from $1898 .^{63}$ These catalogues are particularly useful for their comments about the medical profession's role in the dispensing of spectacles. Brady \& Martin in 1897, for example, described the increasing desire of medical practitioners to have complete control of vision testing and the supply of vision aids:

The careful selection of spectacles...is now universally recognised. Most Medical Practitioners will prefer to order the particular spectacles required by their patients, and we have at the service of those who do not possess them, a series of trial sights for loan. ${ }^{64}$

\footnotetext{
${ }^{60}$ Down Bros, A Catalogue of Surgical Instruments and Appliances, 1885; A Catalogue of Surgical Instruments and Appliances, 1887; A Catalogue of Surgical Instruments and Appliances, 1889; A Catalogue of Surgical Instruments and Appliances, 1892; A Catalogue of Surgical Instruments and Appliances, 1894; A Catalogue of Surgical Instruments and Appliances, 1896; A Catalogue of Surgical Instruments 1897; A Catalogue of Surgical Instruments and Appliances, 1900; A Catalogue of Surgical Instruments and Appliances, also of Aseptic Hospital Furniture, 1901.

${ }^{61}$ Arnold \& Sons, Catalogue of Surgical Instruments and Appliances, 1904, pp. 1311-1320.

${ }^{62}$ Illustrated Catalogue of Instruments, Appliances, and Fittings used in Surgery \& Medicine, 1897.

${ }^{63} \mathrm{~S}$ Maw \& Son, A Quarterly Price Current of Surgeon's Instruments and Appliances 1870; A Quarterly Price Current of Surgeon's Instruments and Appliances 1881; A Quarterly Price Current of Surgeon's Instruments and Appliances, 1882; A Quarterly Price Current of Surgeon's Instruments and Appliances, 1891; A Quarterly Price Current of Surgeon's Instruments and Appliances, 1897; James Woolley Sons \& Co, Catalogue of Surgeons' Instruments and Medical Appliances, 1894; Catalogue of Surgeons' Instruments and Medical Appliances, 1896; Catalogue of Surgeons' Instruments and Medical Appliances, 1898; Catalogue of Surgeons' Instruments and Medical Appliances, 1903.

${ }^{64}$ Brady \& Martin, Illustrated Catalogue of Instruments, Appliances, and Fittings Used in Surgery \& Medicine, 1897, p. 225.
} 
S. Maw \& Son and James Woolley Sons \& Co. also supplied a system of prescription, and Woolley Sons \& Co. argued in 1898 that they included spectacles 'in response to numerous enquiries' for the 'arrangement to supply above to prescription only, and in three days from receipt of order' ${ }^{65}$

The companies that sold vision testing equipment and vision aids in the nineteenth century covered a wide geographical area, including London, Newcastle, Manchester, Leeds and Birmingham. However, their trade could have reached beyond this because companies by the 1880 s increasingly focused on postal distribution to expand their market beyond their locality. ${ }^{66}$ This practice of ordering spectacles or other vision aids through a medical trade catalogue can be traced to the 1880s outside of London. In 1887, for example, Surgical Instrument and Medical Appliance manufacturers, Reynolds \& Branson of Leeds had a whole section on spectacles and stated that they 'devote special attention to the prescription of Surgeon Oculists, all glasses being carefully tested previously to dispatch'. ${ }^{67}$ In 1903 the company advertised that 'printed forms for ordering spectacles' were 'supplied free to prescribers' and that there was a 'medical discount off spectacles and eyeglasses'. ${ }^{68}$ The extensive number of spectacles and eyeglasses for the years 1885 and 1891 were also striking in the Illustrated Catalogue of Surgical Instruments and Appliances by Birmingham firm Mappin \& Co. ${ }^{69}$

In medical trade catalogues vision aids were often categorised as a medical appliance, and were advertised alongside eye instruments and ophthalmic equipment. Indeed, by the $1880 \mathrm{~s}$, vision aids were increasingly being conceived as a medical object that was both supplied and used by medical practitioners. The language used in advertisements by opticians in the latter half of the century show the effect of medical involvement on the broader retail and marketing of vision aids. Affiliation

\footnotetext{
${ }^{65}$ S. Maw Son \& Thompson, stated 'oculists prescriptions carefully and accurately made up', in their A Quarterly Price Current of Surgeon's Instruments and Appliances, 1897, p. 8; James Woolley Sons \& Co., Catalogue of Surgeons' Instruments and Appliances, 1898, p. 130.

66 Jones, p. 105.

${ }^{67}$ Reynolds \& Branson, Handy Guide to Surgical Instruments and Medical Appliances, Physical and Physiological Apparatus, Microscopes, Spectacles, Artificial Eyes, 1887, p. 237-241.

${ }^{68}$ Reynolds \& Branson, Monthly Catalogue, 1903, p. 107.

${ }^{69}$ Mappin \& Co, Illustrated Catalogue of Surgical Instruments and Appliances, Manufactured and Imported, 1885, pp. 57-60; Illustrated Catalogue of Surgical Instruments and Appliances, 1891, pp. 66-71.
} 
with medical institutions can be found from the late 1830s, and it was claimed in advertisements that they were 'Opticians (By Appointment) to the Eye Infirmary' or 'Opticians to the Principal Ophthalmic Institutions' in a number of locations, such as Newcastle, Derby and North Wales in 1839 and $1840 .^{70}$ Despite this, they were the exception rather than the rule, and the advertisement of opticians as suppliers to ophthalmic institutions occurred with greater frequency from the 1860s. In 1866 the optician James Simonton of 69 and 70 Grafton-Street in Dublin claimed that his glasses were being used in 'all London Ophthalmic Hospitals'. ${ }^{71}$ However, opticians more commonly aligned themselves to specialised medical institutions through phrases such as 'optician to' or 'supplier of'. In 1869, for example, A. Alexander stated that he was optician to 'The West of England Eye Infirmary' in the Trewman's Exeter Flying Post. ${ }^{72}$ In 1897 and 1900 an 'optician by appointment to the Chester Infirmary', J.D. Siddall, also advertised in The Cheshire Observer and North Wales Chronicle. $^{73}$

Opticians also advertised that they used the new instruments and equipment being discussed by medical practitioners and distributed in the medical trade catalogues. From the mid-century, the optometer, which enabled a person's vision to be measured more objectively, proliferated in opticians' advertisements. In particular, Smee's Optometer was frequently cited and described as ensuring that 'the exact focal distance' was recorded 'accurately' in the advertisements of Londonbased opticians and scientific instrument makers Bland and Long in 1840 and between 1852 and $1853 .^{74}$ In 1852 London opticians and scientific instrument makers, Horne, Thornthwaite and Wood, also argued that the use of the optometer was 'the only true and correct mode of adapting spectacles to suit the sight'. ${ }^{75}$ Outside of London, newspapers contained further mention of Smee's optometer, as

\footnotetext{
${ }^{70}$ Newcastle Courant, 21 June 1839; Derby Mercury, weekly between 15 January 1840 and 5 February 1840; North Wales Chronicle, [Bangor] 23 June 1840.

${ }^{71}$ Freeman's Journal and Daily Commercial Advertiser, 19 January 1866.

72 A. Alexander: Trewman's Exeter Flying Post or Plymouth and Cornish Advertiser, 1 September 1869; Cheshire Observer, 16 January 1897; 8 May 1897; 22 May 1897; 28 August 1897; 11 September 1897; 9 October 1897; 23 October 1897.

73 J.D. Siddall: North Wales Chronicle, 3 November 1900; 10 November 1900.

${ }^{74}$ Theatrical Journal, February 1840, p. 84; March 1840, p. 108; The Critic, between 16 August 1852, p. 413 and 15 February 1853, p. 106; The Athenaeum, between 18 September 1852, p. 1023 and 5 March 1853, p. 274; For information on Smee's Optometer, see chapter three and the discussion of its slower acceptance by medical practitioners pp. 136-7.

${ }^{75}$ The Critic, 1 July 1852 , p. 335.
} 
can be seen in the advertisement of James Simonton of Dublin. ${ }^{76}$ Additionally, improvements and adaptions to the optometer were recorded across the second half of the century in a wide variety of provincial newspapers. In the 1870 s a Glasgowbased optician, James Brown, for example, stated that his spectacles and eyeglasses were 'fitted by the Improved Optometer'. 77

Besides the optometer, advertisers mentioned the use of additional diagnostic equipment to measure a person's vision. In 1871 F. New \& Co. from Southampton stated in The Hampshire Advertiser that their 'finest worked flint glasses' would be 'accurately tested by Spherical Trial Lenses'. ${ }^{78}$ Advertisements that focused on both the accuracy of vision testing, and the quality of construction, suggest that opticians, both in and outside London, considered it important to state that they had knowledge of the anatomy of the eye, used testing equipment, and understood the principles of optics. In particular, opticians' advertisements from the 1870s began to mention separate vision testing rooms in a variety of locations, including Ireland, Liverpool, Manchester, Sheffield, Cheshire, and the North East. ${ }^{79}$ These advertisements suggest that more opticians were offering standardised conditions for their vision tests. In 1895, an advertisement of the optician 'Wood, Late Abraham', in the Liverpool Mercury, detailed the firm's change in location and the opening of 'new eye-testing rooms ${ }^{80}$ The reason for their newly acquired premises was because 'persons having their sight tested have to sit about $16 \mathrm{ft}$ from the test-types, much space is needed, especially when several sights are tested at one time'. ${ }^{81}$ Wood did advertise his optical skill and the ability to watch how a piece of glass 'is ground and shaped to the exact curve' in his store. ${ }^{82}$ However, his advertisement revealed an acute awareness for vision testing to be carried out in a controlled environment.

\footnotetext{
${ }^{76}$ Freeman 's Journal and Daily Commercial Advertiser, 19 January 1866.

${ }^{77}$ Glasgow Herald, 26 July 1871; 3 August 1871; similar phraseology can also be seen in advertisements in the same newspaper for earlier in the year: between 3 February 1871 and 3 March 1871. See also, for example, an advertisement by Harry Watts: Aberdeen Weekly Journal, between 14 November 1890 and 2 December 1890.

${ }^{78}$ The Hampshire Advertiser, between 18 March 1871 and 10 June 1871.

${ }^{79}$ See, for example, Freeman's Journal and Daily Commercial Advertiser, 9 June 1875; 16 June 1875; 18 June 1875; 19 June 1875; Liverpool Mercury, 18 April 1895; Manchester Times, between 7 June 1890 and 22 August 1890; Cheshire Observer, between 16 January 1897 and 23 October 1897; The Sheffield \& Rotherham Independent, between 7 January 1899 and 6 July 1899; The NorthEastern Daily Gazette, between 7 March 1900 and 15 May 1900.

${ }^{80}$ Liverpool Mercury, 18 April 1895.

${ }^{81}$ Ibid

${ }^{82}$ Ibid.
} 
By the 1890s, opticians both in and outside of London highlighted their knowledge of the physiology and anatomy of the eye and use of testing equipment, as well as optical skill for the dispensing of vision aids. This transformation occurred alongside the growing involvement of medical practitioners in vision testing and the distribution of vision aids; as vision testing became more complicated so too did the necessary skills of the dispenser. Whilst retailers of vision aids did not position themselves as practitioners, by the later nineteenth century they had become increasingly aligned to the medical profession. Similar to the titles used on spectacle cases in the Science Museum's Ophthalmology collection, advertisements from 'ophthalmic' opticians began to appear amongst vision aid dispensers at the close of the century. These advertisements both suggest and claim a close connection with the medical profession that was not claimed by makers of corrective body technologies. ${ }^{83}$ Viewing spectacles solely as a medical object would be too simplistic, because vision aids were still marketed on grounds of scientific or optical accuracy. However, opticians by the 1880s and 1890s were increasingly forced to co-operate and establish a relationship with a medical profession that conceived vision aids as a medical object that was produced for, and supplied by, them.

\section{Opticians and the Medical Profession: Reform and Tension in the 1890s}

A case of trial lenses made by C.W. Dixey, and owned by British ophthalmic surgeon, Sir Anderson Critchett, can be found in the Science Museum's Ophthalmology collection. ${ }^{84}$ The case raises many questions about the relationship between ophthalmologists and opticians, how they co-operated or delineated their roles, and whether opticians began to function as manufacturers and suppliers of technical equipment for medical practitioners by the end of the century. As early as 1862, John Soelberg Wells had suggested the adoption of this plan, which he claimed was already in use on the continent, and by 'several ophthalmologists' in England:

\footnotetext{
${ }^{83}$ See, for example, The Hampshire Advertiser, 7 October 1893.

${ }^{84}$ Science Museum Ophthalmology collection, A635437; For more information on Critchett see his obituary in the British Medical Journal, 14 February 1895, p. 338.
} 
The medical man himself selects the proper glass from his spectacle box (which contains concave and convex glasses, corresponding number[s] being kept by the optician); the focal distance of the required glass is written on a slip of paper, which is taken to the optician who supplies the patient with the spectacles prescribed thereon. Thus we are sure that the patient is furnished with proper glasses. ${ }^{85}$

Likewise, advertisements from the 1870 s began to state that they devoted 'most careful attention to the correct making up of oculist's prescriptions to the accurate measure of lenses'. ${ }^{86}$ As shown by the cases in the Science Museum's Ophthalmology collection at the outset of this chapter, a growing body of opticians were increasingly using more specialised terms such as 'ophthalmic' or 'oculistic' opticians by the $1890 \mathrm{~s}$. The $1890 \mathrm{~s}$ in particular revealed increasing tensions between opticians and the medical profession in the matter of vision aid dispensing. Growing interest of the medical profession can be explained through their interest in the eye, and the development of vision testing technologies as previously shown. However, medical practitioners were also aware of the commercial prospects of vision aids, and aspired to obtain autonomy and professionalise dispensing practices. In a similar manner, opticians became increasingly conscious of their status as a profession and attempted to reform their public image and skillset. These changes can be part of the increasing status of a 'profession' at the end of the nineteenth century, and the broader move towards a professional society. ${ }^{87}$

Whilst advertisements and medical trade literature are informative, they are not able to document the practical relationship between opticians and the medical profession in any great detail. As a result, this section uses the The Optician and the British Medical Journal to explore the changing status of the optician and their relationship to medical practitioners. These two publications are useful because they had both emerged as the public voice of their respective professions. In the 1890s, articles in the The Optician divided the role of the optician into 'two orders'. These two orders were categorised as 'retail' and 'wholesale', and by the later nineteenth century there were a number of wholesale houses making large numbers of spectacles and distributing them amongst retailers. This section only focuses on the first order of optician, the 'retail', because they became the most prominent in the

\footnotetext{
${ }^{85}$ Wells, pp. 111-112.

${ }^{86}$ See, for example, Derby Mercury, between 12 December 1877 and 19 June 1878.

${ }^{87}$ Perkin, pp. xxii-xxiii, and 1-16.
} 
journal. ${ }^{88}$ Firstly, it argues that retail opticians attempted to reform their role and establish a professional community through education and certification. Secondly, it argues that a working relationship with the medical profession became both possible and necessary. As part of this, it shows that the debates surrounding this working relationship were primarily concerned with the issues of professionalisation and commercialisation. Despite this, this section also proposes that contentions over professional or ethical boundaries cannot fully explain the debates that emerged. In contrast, it argues that contemporary knowledge of the eye, and the changing methods of vision testing, were fundamental and key to transforming expectations of the optician's role. Similar to the argument made by Geoffrey Stuart Taylor and Malcolm Nicolson in their article on the emergence of orthodontics, the development of knowledge or technology, and stronger claims for distinctive skill, had a significant role in the creation of specialities and professional identities for both opticians and medical practitioners involved in vision testing. ${ }^{89}$

Launched on $2^{\text {nd }}$ April 1891, The Optician called for greater knowledge and a more standardised, cohesive community. The journal argued that 'the consequent returns for this are fairly manifest, and the day will be welcomed by all when the covert sneer contained in the epitaph 'Shoptician' shall have been, once and for all, wiped out'. ${ }^{90}$ The journal was suggesting that opticians desired to distance themselves from 'shopticians', vendors without vision testing skill, and establish themselves as a body of expert vendors of vision aids following standardised practices. It was a nationwide journal with a wide reach; that it did indeed reflect a desire to educate opticians and reform their role can be seen in some of the early correspondence it published..$^{91}$ Michael Brown and Ian Burney have highlighted the centrality of professional periodicals, in particular The Lancet, in the campaign for medical reform. ${ }^{92}$ Parallels can be drawn between the centrality of The Lancet in the

\footnotetext{
${ }^{88}$ Wholesalers are discussed in chapter five in the context of manufacture and design, see pp. 206212.

${ }^{89}$ Geoffrey Stuart Taylor and Malcolm Nicolson, 'The Emergence of Orthodontics as a Speciality in Britain: The Role of the British Society for the Study of Orthodontics', Medical History, 51 (2007), 379-398.

${ }^{90}$ The Optician, 2 April 1891, p. 2.

${ }^{91}$ See, for example, The Optician, 9 April 1891, p. 30.

92 Ian A. Burney, 'Medicine in the Age of Reform', in Rethinking the Age of Reform: Britain 17801850 , ed. by Arthur Burns and Joanna Innes (Cambridge: Cambridge University Press, 2003), pp. 163-4; Brown, 'Medicine, Reform and the 'End' of Charity', pp. 1379-1380.
} 
creation of a 'medical profession' and the role of The Optician in creating a 'profession' of vision-aid dispensers. The Optician enabled opticians to achieve a more cohesive professional community and implement educational reform. The journal provided a space for the discussion of concerns and information that helped to encourage the dissemination of knowledge and the idea of professional unity in local provincial areas and in London. ${ }^{93}$

The journal sought to reform the optician's role and uphold professional dignity through the establishment of local societies, education and certification. Michael Brown, in his discussion of medical unity, has highlighted the importance of local medical societies in creating an ideology of professional community. These created an 'imagined community', which had not previously existed between city and regional practitioners. ${ }^{94}$ Opticians similarly attempted to establish a wider community through the development of local societies in the $1890 \mathrm{~s} .{ }^{95}$ This desire was similar to concerns about professionalism in a range of disciplines, and amongst a variety of retailers, in the nineteenth century. ${ }^{96}$ However, parallels can also be drawn between opticians and the emerging medical profession through their concern for education, societies, and a drive for certification and control to separate the unqualified. Keir Waddington, for example, in his study of the education of London medical practitioners showed that both the concept of 'profession' and the use of

\footnotetext{
${ }^{93}$ Brown also discussed this in relation to the medical profession in 'Medicine, Reform and the 'End' of Charity', pp. 1380-2; For discussion on the intention of a nation-wide optical society to disseminate knowledge see: The Optician, 11 May 1899, p. 322; see also discussions on the need for an Optical Society, The Optician, 18 August 1898, p. 698; 4 May 1899, p. 292.

${ }^{94}$ Brown, Performing Medicine, pp. 194-5; See, for example, discussion of the previous lack of unity in correspondence in The Optician, 11 May 1899; Keir Waddington also discussed the importance of in-house journals for establishing community in London Medical schools, 'Mayhem and Medical Students: Image, Conduct, and Control in the Victorian and Edwardian London Teaching Hospital', Social History of Medicine, 15.1 (2002), 45-64 (p. 56); These discussions are based on Benedict Anderson, Imagined Communities: Reflections on the Origin and Spread of Nationalism (London: Verso, 2006).

${ }^{95}$ See, for example, information on the meetings and proceedings of the Manchester Optical Society and the West Riding Optical Society in The Optician, 1 December 1898, 13 October 1899, 5 January 1900; and also the election of regional based representatives for the London-based Optical Society: The Optician, 18 May 1899; 15 June 1899; 29 June 1899; 6 July 1899; 13 July 1899; 24 November 1899; 2 March 1899.

${ }^{96}$ See, for example, Philippa Levine's discussion of professionalisation in relation to historical practice, The Amateur and the Professional: Antiquarians, Historians and Archaeologists in Victorian England, 1838-1886 (Cambridge: Cambridge University Press, 2002). And discussion of retailers and reputability: John Benson, 'Drink, Death and Bankruptcy: Retailing and Respectability in Late Victorian and Edwardian England', Midland History, 32.1 (2007), 128-140; John Stobart, Andrew Hann, Victoria Morgan, Spaces of Consumption: Leisure and Shopping in the English Town, c.16801830 (London: Routledge, 2007).
} 
examinations became more prominent in the late nineteenth century. ${ }^{97}$ A number of opticians writing in the journal also sought a cohesive body with a standard level of knowledge that would be credible and ensure a relationship with ophthalmologists and medical institutions. Correspondence from an oculist as early as June 1891discussed the varying standards of dispensing that reforming opticians were confronted with. ${ }^{98}$ Opticians acknowledged this discrepancy and a response to this letter suggests that a group of opticians had attempted to distance themselves from those who simply vended their wares:

There are Opticians and Opticians, and there is just as much difference between a spectacle dealer and a first-class Optician as there is between a dabbler in oculistic matters and a qualified surgeon oculist. ${ }^{99}$

Ivan Waddington and Irvine Loudon argued that a centralised system of education, and distinctions between the qualified and unqualified were necessary for establishing a medical professional community. ${ }^{100}$ Similarly, The Optician developed a strong emphasis on education, examination, control, and certification, which would form the basis of debates and arguments between the trade and medical profession into the twentieth century. ${ }^{101}$ Appropriate training was highlighted as a primary concern in the journal's introduction, and it continued to document opportunities for classes and courses across the 1890s. The journal highlighted how education and the training of opticians included both practical apprenticeship training, as well as the need to study contemporary medical theories on the eye and the testing of vision. Through the inclusion of extracts from medical texts, and debates in the medical press, it sought to inform its readers on both medical and optical knowledge. ${ }^{102}$ Education was perceived to be important because an optician's

\footnotetext{
${ }^{97}$ Waddington, 'Mayhem and Medical Students', pp. 50, 63; See also for more general studies: H. Perkin, The Rise of Professional Society: England since 1880 (London: Routledge, 2002); J.P.C. Roach, Public Examinations in England, 1850-1900 (Cambridge: Cambridge University Press, 1971). ${ }^{98}$ The Optician, June 1891, p. 207. Journal, 301.6754 (1990), 690; Irvine Loudon, 'Medical Practitioners 1750-1850, and the Period of Medical Reform in Britain' in Medicine in Society, ed. by Andrew Wear (Cambridge: Cambridge University Press, 1992), p. 230.

${ }^{101}$ Rosemary Stevens, Medicine and the Public Interest: A History of Specialisation (Berkley; Los Angeles; London: University of California Press, 1998), pp. 98-102; G.V. Larkin, 'Professional Autonomy and the Ophthalmic Optician', Sociology of Health and Illness, 3.1 (1981), 15-30.

${ }^{102}$ See, for example, articles on technical equipment: 'The Ophthalmoscope' on 8 October 1891, 13 July 1893 and 28 April 1898, or information on the Ophthalmometer on 23 September 1897, 31 March 1898, 19 May 1898, 2 June 1898, 9 June 1898 and 16 June 1898; Extracts from prominent ophthalmologists: Landolt 'The Movements of the Eyes', 12 May 1892; Dr Brudenell Carter,
} 
knowledge was considered fundamental for obtaining professional integrity. In 1898, for example, it was argued that 'knowledge, indeed, and power have come to the Optician, and the whole profession has been invested with a new dignity'. ${ }^{103}$

The availability of education and the need for a professional body were intimately linked to examination and the desire to standardise an optician's expected knowledge. Certification in particular was thought to be integral for distinguishing the 'shoptician' from the 'optician'. The need for both a registered institution and certification became the focus of a number of articles and correspondence. ${ }^{104}$ The motivations behind an institute were twofold: to improve the optician's standing in the eyes of medical practitioners, and to help differentiate reputable traders from the quack. As early as 1891 calls for certification emphasised that it 'would raise the industry to a far higher level, and a Fellow of the Royal College of Opticians would be an individual whom it would be impossible for oculists to ignore or defame'. ${ }^{105}$ To defend the plausibility of this claim, parallels were drawn with the regulations that could be found in the practices of pharmacy and dentistry. Discussing this under a column headed 'Responsibility' in 1896, the journal stated that:

Our drug contemporary [British and Colonial Druggist] twits Opticians upon the fact that they are not compulsorily trained and examined. And the criticism certainly involves a 'home truth' which we would frankly recognise. The moral is, simply, let there be statutory requirements whereto Opticians may conform. ${ }^{106}$

The article highlights that advocates of professionalisation in the trade understood the role of a formal education system in separating the qualified from the

\footnotetext{
'Neglect of the Culture of the Eyes', 22 February 1894 and 'The Eyesight of Children', 17 March 1898; 31 March 1898 and 5 May 1898; Simeon Snell, 'The Influence of Certain Occupations on Eyesight', 10 January 1895; For examples of information on medical theories, see: 24 September 1891; 26 November 1891; 28 January 1892; 25 August 1892; 8 September 1892; 1 December 1892; 11 August 1893; 16 March 1893; 31 March 1893; 8 March 1894; 24 August 1893; 16 August 1894; 16 May 1895; 23 May 1895; 27 June 1895; 18 July 1895; 26 December 1895; 16 April 1896; 6 August 1896; 13 August 1896; 2 April 1897; 8 July 1897; 5 August 1897; 29 September 1898; 13 July 1899; 17 September 1899; 29 September 1899; For discussion or extracts from the medical press: See, for example, The Lancet mentioned 6 August 1891, 21 June 1894; The Glasgow Medical Journal, 21 January 1892; British Medical Journal, 29 December 1892, 23 February 1899.

${ }^{103}$ The Optician, 17 July 1898 , p. 526.

${ }^{104}$ See, for example, The Optician, 20 August 1891, p. 325; correspondence and calls for an institution peaked at various intervals across the 1890s, and was particularly numerous between 1893 and 1894. See, for example, correspondence on 'Chartered Institute for Opticians', 21 September 1893, 28 September 1893, 5 October 1893, 12 October 1893, 19 October 1893, 26 October 1893, 2 November 1893, 16 November 1893, 30 November 1893. And also further mention 15 February 1894, p. 200 and 4 April 1894, p. 138.

${ }^{104}$ The Optician, 16 April 1896, p. 78.

105 The Optician, 13 August 1891, p. 310.

${ }^{106}$ The Optician, 16 April 1896, p. 78.
} 
unqualified. ${ }^{107}$ The need to regulate the trade was intimately connected to expectations of how vision aids should be dispensed. Indeed, criticism of 'spectacle vendors' primarily focused on how they sold their products. ${ }^{108}$ In 1891 , for example, one correspondent summarised succinctly that 'A spectacle vendor is not an optician'. ${ }^{109}$ Additionally, in 1892 a correspondent under the name of 'insider' criticised those who sold 'instruments as they would firewood, and without any greater knowledge of the goods than they would need to hawk salt'. ${ }^{110}$ Rather than being 'vended', there was a growing argument that vision aids should only be sold by those who could assess the quality of the product, and test vision to ensure an accurate fit.

Early forms of certification were implemented in the 1890s through the establishment of examinations by the British Optical Association (hereafter BOA) in 1897 and the Spectacle Maker's Company (hereafter SMC) in 1898. The Optician provides an interesting perspective on these organisations because it became an unofficial mouthpiece for both. ${ }^{111}$ The meetings, decisions, and progress made by both the SMC and the BOA were documented and debated in the journal frequently. ${ }^{112}$ The volume of correspondence and articles about them, as well as the advertisement of their examinations, suggests that there was a keen interest in the development of these institutions. Both the advent of examination and attempts to improve education highlight a fundamental shift in the expected knowledge of an optician dispensing vision aids. In particular, the publication of the examination syllabuses and papers became a regular feature and reveal the institutions' approach and focus. Mitchell has argued that the BOA favoured the interests of opticians who specialised in vision testing, while the SMC perhaps fostered the interests of oculists

\footnotetext{
${ }^{107}$ This is similar to arguments in the medical profession: Waddington, 'The Movement Towards the Professionalisation of Medicine', p. 690; Loudon, p. 230.

${ }^{108}$ For an example of criticism on the quality of products, see The Optician, 6 April 1894, p. 12.

${ }^{109}$ The Optician, 10 September 1891, p. 382.

${ }^{110}$ The Optician, 18 August 1892, p. 374.

${ }^{111}$ For discussion of its independence see, for example, The Optician, 4 August 1898, p. 638.

${ }^{112}$ For information on the Spectacle Makers Company see The Optician, 23 December 1897; 13 January 1898; 27 January 1898; 10 March 1898; 14 July 1898; 1 June 1899; 28 July 1899; 10 November 1899; 29 December 1899; and for the British Optical Association see The Optician, 7 March 1895; 28 November 1895; 30 June 1898; 7 July 1898; 14 July 1898; 2 March 1899; 13 July 1899; 17 November 1899.
} 
by limiting an optician's skillset. ${ }^{113}$ However, the examination papers show that, regardless of their differing perspectives on vision testing, the SMC and BOA required the optician to have knowledge on optics, the principles of vision testing, the practicalities of measuring frames to the face, and also the ability to establish working relationships with the medical profession through reading and following prescriptions. $^{114}$

\section{Discussions of the BOA and SMC further show how certification was} intended to promote professionalization as much as education. In $1895 \mathrm{~W}$. Heath \& Son, for example, argued that the BOA was beneficial because it was able to raise the status of the optician. ${ }^{115}$ The Optician also argued that the main objective of the SMC was to be able to certificate the 'reputable' and 'capable' opticians. ${ }^{116}$ The importance of certification was to provide 'integrity', and the journal concluded in 1898 that this would allow the industry to be 'raised to the status of Profession'. ${ }^{117}$ The effect that these examinations had is difficult to ascertain. However, the journal's editors argued that examination entries were increasing, and attendance was national in scope. ${ }^{118}$ This advance was not without conflict. Negative correspondence about both institutions continued to be published until the end of the decade, and there was also comment on people failing and being unable to meet the standards that the examinations set. ${ }^{119}$ Additionally, in 1899 The Optician reported that they were disappointed with the inadequate number of examination candidates. ${ }^{120}$ However, as argued by the secretary of the BOA, these organisations,

\footnotetext{
${ }^{113}$ Margaret Mitchell, History of the British Optical Association, 1895-1978 (London: British Optical Association, 1982), p. 61; This is also similar to Lionel Laurance's claim that 'every optician will want to belong to the SMC and every refractionist should desire to belong to the BOA' in The Optician, 17 March 1898, p. 631.

${ }^{114}$ Examination papers were further published on the 8 June 1899, 29 June 1899, 21 July 1899, 1 December 1899, and 8 December 1899.

${ }^{115}$ The Optician, 19 December 1892, p. 182.

${ }^{116}$ The Optician, 10 February 1898, p. 472.

${ }^{117}$ The Optician, 24 March 1898, p. 640.

${ }^{118}$ The Optician, 9 March 1899, pp. 793-4; Equally a breakdown of those that passed the SMC examination showed that only fifty of the candidates lived in London, and seventy-six could be found in the provinces, with eleven towns having produced more than one diploma by March 1899, The Optician, 30 March 1899, p. 37.

${ }^{119}$ For criticisms of the BOA see, for example, The Optician, 30 April 1896; 7 May 1896; 12 November 1896; 11 March 1897; 25 March 1897; 1 April 1897; 22 April 1897; 29 April 1897; 13 May 1897; 18 December 1897; Equally, for the SMC, see 10 November 1899, and 26 January 1900. For comments on people failing the SMC Diploma, see The Optician, 3 November 1899, p. 292.

${ }^{120}$ The Optician, 29 September 1899, p. 34.
} 
although slow, were 'not asleep' but 'sowing seed that will bring forth fruit'. ${ }^{121}$ Like the medical profession's 'imagined community', opticians were creating an ideology and expected level of knowledge, even if it was not yet fully established in practice. $^{122}$

Institutional histories for both the BOA and SMC exist. Richard Champness, for example, has argued that the 1890s was 'the great awakening!' for the SMC and the 'court at long last awoke to its responsibilities'. ${ }^{123}$ Similarly, Mitchell has argued that by 1900 the aims of the BOA were well-established. In her analysis, Mitchell has highlighted a transformation from a collection of 'shop-keepers' to a 'professional body'. ${ }^{124}$ However, these works did not consider trends in nineteenthcentury retail or focus specifically on the relationship between the trade and the medical profession. Opticians who identified themselves as 'first-rate' were battling for recognition from a medical profession that was increasingly concerned about the regulation of vision aid dispensing practices. Although opticians did not perhaps have the bounded character of the medical profession at this time, they increasingly sought to distinguish themselves from the 'unqualified'. In doing so, they highlighted a fundamental shift in the way opticians were expected to dispense vision aids and position themselves alongside medical practitioners. Moreover, it was against the backdrop of particularly contentious relations with the medical profession that the BOA was set up. ${ }^{125}$ John Browning, for example, highlighted that the founding of the BOA occurred only when medical practitioners began to encroach and attempt to control the role of opticians in the dispensing of vision aids. ${ }^{126}$ Certification as a whole was considered in The Optician as an opportunity to ensure competency and improve relationships with the medical profession; establishing a working relationship with the medical profession and the registration of opticians was 'the great end to be achieved'. ${ }^{127}$

\footnotetext{
${ }^{121}$ The Optician, 23 December 1897, p. 348.

${ }^{122}$ Brown, Performing Medicine, pp. 194-5.

${ }^{123}$ Richard Champness, A Short History of the Worshipful Company of Spectacle Makers up to the Beginning of the Twentieth Century (London: Apothecaries Hall, 1952), p. 10.

${ }^{124}$ Mitchell, p. 45.

125 See, 'Organising a British Optical Association', The Optician, pp. 365-6.

${ }^{126}$ The Optician, 18 March 1897, p. 339.

${ }^{127}$ The Optician, 29 April 1897, p. 110.
} 
In their attempts to achieve a system of qualification and become a recognised body, opticians sought the approval of the medical profession. At the same time the medical profession were also forced to accept that they were reliant on the optician's skillset. Debates that persisted into the turn of the twentieth century were generated in the 1890s and centred on the establishment of appropriate boundaries and the difficulties of defining roles that would allow the two bodies to amicably co-exist. Both the optician and the medical profession saw the education of all vision aid dispensers as a benefit. In August 1893 The Optician reported on Dr Williamson's address to the British Medical Association, which complemented the journal and its plans to improve training. However, tensions were clearly evident, with the journal arguing that:

We do not even despair of obtaining the proper medical co-operation to enable us to start training classes... If, however, Dr Williamson really recognises the importance of qualifying opticians... why does he not induce his colleagues to place proper facilities in their way? ${ }^{128}$

Mitchell has proposed that the BOA was neither universally nor initially welcomed and certainly medical opponents were quick to state their disapproval. ${ }^{129}$ The Optician recorded in 1892 that early attempts of the SMC in the 'direction of technical education' fell through because advice was taken from oculists who were 'adverse to the best interests of the industry'. ${ }^{130}$ Heated debates on both sides can be seen in the last ten years of the nineteenth century, particularly in the correspondence section of the journal, over the methodologies of vision testing and who would have monopoly over them. The debate can be separated into three key strands: discussion about the nature of each profession's role; the problems of commercialism and practical ethics; and, finally, how the two bodies might co-operate and establish a role that was determined by two increasingly defined skillsets.

Conflict primarily centred on the discussion of professional 'boundaries'. In particular, emphasis was placed on medical practitioners' belief that opticians would be unable to recognise disease and refer patients on when appropriate.

Correspondence in December 1895 from an individual who signed himself as 'M.R.C.S.', or a Member of the Royal College of Surgeons, questioned the capabilities of the optician by stating that:

\footnotetext{
${ }^{128}$ The Optician, 7 August 1893, p. 782.

${ }^{129}$ Mitchell, p. 31.

${ }^{130}$ The Optician, 10 March 1892, pp. 385-6.
} 
Sir - I am amused, from time to time, with a glance at your interesting little paper, with which I am favoured by my Optician. In your serious efforts to prove the degeneracy of the medical profession, you occasionally touch some vulnerable or 'sore' spots. Yet the fact remains that the Optician who is a really capable refractionist is almost entirely a creature of your fine imagination. ${ }^{131}$

In January 1894 a London 'Surgeon Oculist' also argued that the approaches to education were both beneficial and problematic because 'a little knowledge is a dangerous thing'. ${ }^{132}$ The 'Surgeon Oculist' justified this argument on the grounds that, unless opticians obtained a medical degree, they were not capable of detecting the fine border-line often separating disease and errors of refraction.

Opticians considered this debate to be a matter of 'professional jealousy'. ${ }^{133}$ One optician in 1896, for example, proclaimed in strong terms that the surgeon oculist had 'sounded the trumpet of hostility' and this hostility was seen as a barrier to the proper advancement and establishment of the optician's role. ${ }^{134}$ However, the conduct of opticians also featured in the British Medical Journal with increasing frequency from the 1890s. Medical practitioners considered the role of the 'shoptician' to be the most appropriate. An 1886 review of a text written by the London optician John Browning argued that much of the information was incorrect and it should have been called 'Where to Buy Spectacles' rather than 'How to Use Our Eyes'. ${ }^{135}$ Medical practitioners justified these claims by situating them within broader concerns about the quality of care. In 1895, for example, it was proposed that opticians had a damaging effect because they were 'so little qualified to judge of the fitness of things' ${ }^{136}$ To support this point, the journal was often quick to include correspondence from individuals who wrote in to show examples of opticians making a mistake. ${ }^{137}$ In discussing these mistakes, the correspondents suggested that the 'optician has not the requisite knowledge to enable him to deal fully with the subject of sight'. ${ }^{138}$ As argued on the 24 June 1899, 'the proper function of an

\footnotetext{
${ }^{131}$ The Optician, 26 December 1895, p. 199.

${ }^{132}$ The Optician, 4 January 1894, p. 142; this debate continued throughout the month. See, for example, The Optician, 18 January 1894, p. 152.

${ }^{133}$ The Optician, 18 January 1894, p. 152.

${ }^{134}$ Ibid; The Optician, 22 October 1896, p. 79.

${ }^{135}$ British Medical Journal, 9 October 1886, p. 682.

${ }^{136}$ British Medical Journal, 14 December 1895, p. 1511.

137 This could include errors opticians made when handling prescriptions, or when opticians failed to refer to a an ophthalmologist when required. See, for example, British Medical Journal, 30 April 1904, p. 1050; 12 July 1902, p. 156.

${ }^{138}$ British Medical Journal, 25 June 1904, p. 1517.
} 
optician is to make spectacles for the public according to directions received in the prescription of a properly qualified medical man'. ${ }^{139}$

The fundamental difference, besides the problem of professional boundaries, lay in medical ethics and professional practice. Opticians were presented as lying or posing as medical practitioners, and publishing 'false' advertising became an underlying issue in the British Medical Journal. ${ }^{140}$ In particular, there was a dislike of opticians using the letters 'F.S.M.C.' or 'B.O.A.' when they passed the SMC or BOA examinations because these initials could be used to suggest to an ignorant public that they had received some kind of medical training. ${ }^{141}$ In this correspondence the medical profession perceived the optician to be 'poaching' on their 'preserves'. Indeed, whilst medical practitioners were concerned with their own monetary gains and potential loss of patients, they were particularly preoccupied with the problems of advertising, false advertising and commercialism in the optician's trade. Moreover, The Optician continued to focus on 'business stimulants' and 'how to pick up trade' across the 1890s. ${ }^{142}$ In 1895, for example, under the heading 'Profession or Trade' highlighted the prejudices that surrounded commercialism by stating that there was a:

survival of the old-fashioned and now very obsolete prejudice against these classes of the community which are engaged in trade - a prejudice against the manufacture and sale of goods, as being less dignified, or (in some obscure manner) less respectable than the vending of professional advice. ${ }^{143}$

The commercial nature of the optician's trade was continually criticised at the start of the twentieth century. These criticisms meant that co-operation between the 'oculist and optician' was considered to be a 'utopian dream' that depended on the optician knowing his/her place. ${ }^{144}$ Rosemary Stevens and G.V. Larkin have studied the relationship between the two bodies in nineteenth and twentieth-century America and twentieth-century Britain. They have argued that the debates between medical practitioners and opticians reveal both the ethics and boundaries that

\footnotetext{
${ }^{139}$ British Medical Journal, 24 June 1899, p. 1547.

${ }^{140}$ See, for example, British Medical Journal, 27 September 1902, p. 1003.

${ }^{141}$ British Medical Journal, 24 June 1899, p. 1547.

${ }^{142}$ See for example, The Optician, 1 October 1891, p. 2; 3 December 1896, pp. 147-8; 7 October 1897, p. 147.

${ }^{143}$ The Optician, 6 June 1895, p. 119.

${ }^{144}$ British Medical Journal, 1 August 1903, p. 278; There were a small minority of female opticians by the 1890 s, although correspondence in The Optician also highlights tensions about their ability to sit the SMC's examinations, 16 February 1899, p. 722.
} 
surrounded the practice of medicine. ${ }^{145}$ Indeed, comment on other countries' conduct and tougher regulations in the British Medical Journal show that it was as much about how medicine was practiced, as it was about opticians themselves. ${ }^{146}$ In Britain itself a correspondent summarised: 'of all medical impositions on the public that of the shopkeeper deciding upon glasses is probably the most pernicious'. ${ }^{147}$ However, parallels can be drawn to Taylor and Nicolson's argument for the emergence of orthodontics. Taylor and Nicolson suggested that changes in technique and knowledge were just as important as the market considerations - including professionalisation and commercial gain - that have been discussed. ${ }^{148}$ Similarly, in 1904 the Medico-Political Committee of the British Medical Association 'carefully considered the diploma scheme of the SMC in which sight-testing is now included', and recommended that the Association 'should express its disapproval [of it]... as being fraught with special risk to the public'. ${ }^{149}$ The Medico-Political Committee focused on provision of care and the interests of medical practitioners. However, the decision was driven by the inclusion of vision testing. It highlights how the incorporation of vision testing into vision aid dispensing was equally important in the debates about occupational control and professional dignity. ${ }^{150}$

The dispensing of vision aids is an unusual case in comparison to corrective body devices or other assistive technologies because of the volume that were required and a need to understand both optics and medicine. ${ }^{151}$ Medical practitioners did not arguably have the capacity, or the manufacturing skills, to gain complete monopoly of vision aid dispensing. The quantity and manufacturing skills required helps to explain the co-operation that existed alongside the hostility of the $1890 \mathrm{~s} .{ }^{152}$ In 1894, for example, a London Surgeon-Oculist argued that they would 'welcome'

\footnotetext{
${ }^{145}$ Stevens, pp. 98-102; Larkin, pp. 18-19.

${ }^{146}$ See, for example, the British Medical Journal's discussion of France on 23 January 1892, p. 203; and America, 1 July 1899, p. 21.

${ }^{147}$ British Medical Journal, 28 May 1904, p. 1288.

${ }^{148}$ Geoffrey Stuart Taylor and Malcolm Nicolson, 'The Emergence of Orthodontics as a Speciality in Britain: The Role of the British Society for the Study of Orthodontics', Medical History, 51 (2007), 379-398.

${ }^{149}$ British Medical Journal, 16 July 1904, p. 36.

${ }^{150}$ Larkin discussed the continued presence of this in the twentieth century, pp. 15-28.

${ }^{151}$ Larkin also makes this point in his analysis of the relationship between opticians and ophthalmologists in the first half of the twentieth century, pp. 19-20.

${ }^{152}$ See, for example, the statement made by the Master of the Spectacle Makers Company, which acknowledged the skill of medical practitioners but argued that at least half of British population, which numbered 45million, would require glasses at some points in their lives: British Medical Journal, 11 March 1899, p. 632.
} 
the assistance of opticians if they kept 'within their proper sphere'. ${ }^{153}$ The need for co-operation between opticians and the medical profession highlights how professional boundaries were being conceptualised in relation to the two increasingly specialised skillsets that were emerging in the sale of vision aids. In 1886 in the British Medical Journal it was argued that 'the optician must not test for spectacles no more than fly', but that the oculist, too, 'could no more make a pair of spectacles than fly'. ${ }^{154}$ This was also supported in The Optician in 1895, which argued that 'our science of geometrical optics is entirely distinct from... the basis of a doctor's training' and it should therefore 'rank entirely distinct from, but coequal' to the medical profession. ${ }^{155}$ Moreover, while medical practitioners attempted to assume a superior position, opticians and even medical practitioners were quick to point out the lack of optical training that appeared in the medical curriculum. ${ }^{156}$ The acknowledged difference in skillsets could be used to establish distinct professional roles in favourable terms. In 1894, for example, The Lancet was quoted in The Optician because it had discussed how the practical optician was more experienced than the average medically trained practitioner. The Optician considered these remarks 'a step forward' in medical opinion, and by 1899 commented that 'it is a relief to turn attention to the assistance and support... from many able members of the medical profession' for the SMC. ${ }^{157}$

The extent of co-operation between opticians and the medical profession is not easy to deduce. However, between 1875 and 1903 the British Medical Journal provides evidence for working partnerships in the development and improvement of sight testing technologies. Although the dynamic of the relationship could be uneven - as can be seen in the account of a Newcastle optician, Mr Robson, who produced a new optometer 'under the supervision' of a medical man - opticians in the Science Museum's collections designed, and produced, new sight testing technologies for medical practitioners. ${ }^{158}$ At the extreme end, Mr Percy Dunn, F.R.C.S., Ophthalmic

\footnotetext{
${ }^{153}$ The Optician, 25 January 1894, p. 171.

${ }^{154}$ British Medical Journal, 21 April 1898, p. 211.

${ }^{155}$ The Optician, 7 February 1895, p. 294; This point is also made by Larkin, p. 18.

${ }^{156}$ See, for example, The Optician, 31 January 1895, p. 280; and this was acknowledged in an address to the section of ophthalmology at the meeting of the British Medical Association in 1896, which was quoted in The Optician, 30 April 1896, pp. 91-2.

${ }^{157}$ The Optician, 14 May 1896, p. 120; 11 May 1899, p. 326.

${ }^{158}$ See, for example, British Medical Journal, 15 July 1882, p. 9; 6 February 1886; 23 July 1898, 23

December 1899, 9 May 1903, p. 1092.
} 
Surgeon to the West London Hospital, stated that he was 'much indebted for the skill and care' undertaken by F. Davidson, of 140 Great Portland Street. ${ }^{159}$ Besides the interchange of ideas for sight-testing technologies, there is evidence that opticians did establish connections with the ophthalmic institutions that appeared so frequently in their advertisements. The cashbook subscriptions of the West of England Eye Infirmary show that regular payments were made to Pickard and Curry - and later Curry and Paxton from October 1889 - for the supply of spectacles between 1885 and $1895 .{ }^{160}$ Similarly, in 1904 London optician James Aitchison argued in the British Medical Journal that a lot of the medical profession's dislike for opticians was based on ignorance, but 'many opticians will bear me out when I say that it is a matter of everyday occurrence for doctors to send patients to the opticians to be fitted with glasses' ${ }^{161}$ The following month this was supported by further correspondence, which argued that it would surprise certain medical practitioners if they knew that 'a number of medical men' sent their patients to opticians 'with complete satisfaction'. ${ }^{162}$

A spectacle case from James Aitchison, a prominent figure in the British Medical Journal and The Optician, is one of many preserved in the Science Museum's Ophthalmology collection. A set of letters exchanged by Aitchison and Dr Lindsay Johnson between 1898 and 1900 survives in the Boots' Archives. Johnson was an overt supporter of opticians' education: in 1900 Johnson wrote in a letter to Aitchison that he was 'desirous of doing my little mile towards helping the English optical trade'. ${ }^{163}$ The correspondence between these two men provides a unique insight into the working relationship between an optician and a medical practitioner. Johnson thanked Aitchison regularly for the patients that he received, and also sent these patients back to obtain spectacles. However, the letters showed that Aitchison could prescribe glasses and send them to Johnson to double check, and Johnson could ask Aitchison to try and get a better prescription for the patient.

\footnotetext{
${ }^{159}$ British Medical Journal, 10 January 1903, p. 88; Science Museum's Ophthalmology collection: A681267.

${ }^{160}$ Devon Heritage Centre, 1299F/0/HA/19: West of England Eye Infirmary, Cashbook of Subscriptions, 1885-1895.

${ }^{161}$ British Medical Journal, 14 May 1904, p. 1170.

${ }_{162}$ British Medical Journal, 4 June 1904, p. 1345.

${ }^{163}$ Boots Archives, DA15/43: Collection of Letters from Lindsay Johnson to James Aitchison, 18981906.
} 
In a letter from 7 June 1898, for example, Johnson discussed a patient's eyesight and stated 'I cannot get her vision better than $20 / 40$ to $20 / 5$ R \& L... I wish you to see if you can improve her sight'. ${ }^{164}$ This relationship between the two men may have been an unusual one. In 1903, for example, Johnson stated that his support for opticians had resulted in four years of 'continual criticism' from his 'medical colleagues'. ${ }^{165}$ However, the letters do show that an optician and a medical practitioner could work alongside each other in a manner that suited both parties ethically and financially.

The letters and published material that survives also show how these two individuals conceptualised their roles, and adopted a positive working relationship. Aitchison's correspondence highlights his awareness of the negative implications that false advertising and commercialism could have on the medical profession's opinion of opticians. Three letters between 1901 and 1902 document Aitchison's apprehension about Johnson's position and wider medical opinion because an optician had advertised that he could test the sight after receiving the SMC diploma:

This statement now publishing is so directly in opposition to the assurances which we gave to the oculists who were consulted in the beginning that I am afraid if it goes unchallenged will get you into serious trouble if brought before the medical societies. ${ }^{166}$

However, the two individuals also highlight how they favourably delineated their role based on two distinct skillsets. In 1903 a letter from Johnson published in the British Medical Journal explicitly advocated the benefits of co-operation, and saw 'no possible solution except to recognise frankly the traditional right of the opticians'. ${ }^{167}$ As the correspondence with Aitchison revealed, the 'traditional right of the optician' could be respected through a system of prescription and open dialogue between both parties. Additionally, the trade directory entries for Aitchison are revealing. They show that in 1895 he was listed as an 'oculist optician' but by 1899 had dropped the title of 'oculist' and was described solely as an 'optician'. ${ }^{168}$ By 1904, Aitchison was situating himself in the British Medical Journal firmly away

\footnotetext{
164 Ibid.

165 British Medical Journal, 11 July 1903, pp. 109-110.

${ }^{166}$ Boots Archives, DA15/43: Collection of Letters from Lindsay Johnson to James Aitchison, 18981906.

${ }^{167}$ British Medical Journal, 11 July 1903, pp. 109-110.

${ }^{168}$ Post Office London Trades Directory (1895) [Part 3: Commercial \& Professional Trade Directory], p. 771; Post Office London Directory (1899) [Part 3: Commercial \& Professional Trade Directory], p. 853.
} 
from any association with medicine, and highlighting the increasing development and acknowledgement of specialised skillsets that would help to distinguish the two roles. $^{169}$

This chapter has shown that, across the century, a number of opticians emphasised either sight testing knowledge or a medical connection. In 1904, for example, a retailer described himself as an 'old-fashioned fellow' in The Optician because he was happy to supply spectacles that had been prescribed by an oculist. ${ }^{170}$ However, a number of opticians remained unwilling to proclaim or advocate an association with sight testing by the century's close. This reluctance was based on the individual optician's skill, or lack of it. In 1895 a correspondent writing into The Optician argued that the trade would be wiped out if sight testing was made a requirement, and he was 'quite content to let the oculist do the hard work and fill the prescription myself (or rather let my manufacturer do it for me)'. ${ }^{171}$ Indeed, opticians' reluctance to adopt vision testing by the century's close was based on the increasing sophistication of both vision testing and the task of fitting vision aids to the face. In 1896 one prominent London optician, W. A. Dixey, argued in The Lancet that 'the great increase during the last thirty years in the knowledge of ocular refraction and the therapeutic use of spectacles has lifted the whole matter into the professional sphere'. ${ }^{172}$ However, he also proposed that it would take time to implement these changes and they could 'look forward hopefully to a time when people will go as naturally to a practitioner for advice on eye and sight troubles as they do now for defects of hearing, ${ }^{173}$ A week later, in justifying his claims in The Optician, Dixey argued that 'there is absolutely no doubt in my mind that a large part of what may be called a medical training is not only useful but necessary to the right practice of ophthalmometry, or the prescription of spectacles' ${ }^{174}$

Integral to Dixey's argument was the advancement in sight testing, which he thought had gone beyond the capabilities of the 'traditional' optician. Dixey explained the role of the optician in response to the changing ways that vision aids

\footnotetext{
${ }^{169}$ British Medical Journal, 14 May 1904, p. 1170

${ }^{170}$ The Optician, 11 October 1894, p. 65.

${ }^{171}$ The Optician, 28 February 1895, p. 337.

${ }^{172}$ Cited in The Optician, 4 June 1896, p. 164.

173 Ibid.

${ }^{174}$ The Optician, 11 June 1896, p. 178.
} 
were sold; vision needed to be tested and knowledge on the eye had advanced. Indeed, in 1904 Dixey argued in the British Medical Journal that sight-testing had 'acquired new meaning' and was beyond the competency of a tradesman. ${ }^{175}$ This argument was not supported by all opticians. There were still divisions about the appropriate role of the optician and whether opticians should test the sight. The SMC, for example, still pushed for, and eventually included, sight testing in their diploma in 1904. ${ }^{176}$ However, Dixey’s arguments suggest that the changing practices of vision aid dispensing were equal to the debates that centred on powerdynamics and professionalisation. Indeed, conflict between medical practitioners and opticians was not isolated to the financial or commercial opportunities that predominated in the twentieth century. ${ }^{177}$ Debates in the later nineteenth century were affected by a growth in specialised knowledge that can also be seen in the emergence of orthodontics in the early twentieth century. ${ }^{178}$ As Dixey has shown, the necessary requirements for spectacle dispensing now involved a sophisticated vision test, which went beyond the opticians' traditional role as a scientific instrument maker. As argued by H.L. Taylor in 1898, 'the sale of spectacles is a very different thing from the vending of articles of food or clothing, for it is tacitly understood between seller and purchaser that the former possesses a certain amount of skill' ${ }^{179}$ Taylor then argued that 'where spectacles are sold without a certain amount of skill or knowledge of visual defects and technical skill, something in the nature of fraud is committed'. ${ }^{180}$ By 1899 it was argued that spectacle dispensing and the study of optics had also considerably changed and become more sophisticated from the "mere buying and selling of optical goods', to one of optical study, optical teaching and 'scholastic optics'. 181

In 1899 the methods of choosing vision aids that had predominated in the first half of the century were considered 'out-of-date'. ${ }^{182}$ The conflicts that would

\footnotetext{
${ }^{175}$ British Medical Journal, 23 June 1904, p. 203.

${ }^{176}$ Champness, p. 10.

${ }^{177}$ Ibid., pp. 17, 21, 25.

${ }^{178}$ Geoffrey Stuart Taylor and Malcolm Nicolson, 'The Emergence of Orthodontics as a Speciality in Britain: The Role of the British Society for the Study of Orthodontics', Medical History, 51 (2007), 379-398.

${ }^{179}$ The Optician, 28 December 1898, p. 436.

${ }^{180}$ Ibid., italics my own.

${ }^{181}$ The Optician, 1 June 1899, pp. 424-425.

${ }^{182}$ The Optician, 3 November 1899, p. 312.
} 
continue into the twentieth century centred on issues of professional autonomy, knowledge on the body and eye, and what it was to 'practice' medicine. ${ }^{183}$ However, for the nineteenth century, the fundamental and underlying issue was that they were at the forefront of change, and this change had caused a significant transformation in the expectation of how vision aids should, and could, be dispensed. Regardless of whether it was undertaken by a medical man or the optician, it was acknowledged that the dispensing of vision aids required a vision test. However, these expectations were not necessarily shared by all vision aid dispensers. In 1904 Aitchison argued that the biggest problem came from a difference in opinion with 'chemists, jewellers, and those who call themselves optologists, who sell spectacles as a side to businesses which are not generally optical' ${ }^{184}$ Whilst the appropriate roles of medical practitioners and opticians were being debated in the 1890 s, both bodies were still attempting to regulate and standardise the optical profession and the dispensing of vision aids. Mitchell has shown that the council of the BOA estimated that alongside 600 certificated opticians, there were 20,000 non-certified practitioners claiming to be opticians in 1904. ${ }^{185}$ Exploring these traders, and how they operated, highlights both the limits and success of medical practitioners' and opticians' attempts to regulate vision aid dispensing in the second half of the nineteenth century.

\section{The Effect of Medicine and Vision Testing on the Wider Retail Trade, 1850- 1900}

In 1877 an advertisement in The Bristol Mercury announced that Bristol was 'THE BEST PLACE, Indeed! For What? Why for EVERYTHING GOOD' ${ }^{186}$ The advertisement listed gold spectacles and eyeglasses, steel spectacles and 'real Brazilian pebbles' for half the usual price. ${ }^{187}$ Opticians and medical practitioners were striving to reform against the sale of spectacles and vision aids in a wideranging and competitive miscellaneous market. Similar to the first half of the century, this retail continued to exist in both shop premises and the street. Cambridge's charity organisation records contain a range of documents relating to a

\footnotetext{
${ }^{183}$ Larkin, pp. 15-28.

${ }^{184}$ British Medical Journal, 14 May 1904, p. 1170.

${ }^{185}$ Mitchell, p. 62.

${ }^{186}$ The Bristol Mercury, 16 June 1877; 23 June 1877; 7 July 1877; 14 July 1877; 21 July 1877.

${ }^{187}$ Ibid.
} 
German migrant, Wilhelm Bauman. The correspondence described a man of 'destitute' means trying to obtain employment between 1884 and 1886. Bauman had been deaf fifteen months and believed that he could 'make $1 / 6$ per day' by hawking spectacles. The correspondence records show that he was a respectable man and a previous employer had 'felt for him'. They also discuss the difficulty of his position, as well as the medical opinion that his deafness was deemed incurable. Bauman was eventually 'given the 13/- for spectacles', and a pair of new boots, before being secured passage back to Germany. ${ }^{188}$ Whilst Bauman ended up travelling back to Germany, he believed that he could have been saved from destitution by selling spectacles on the street. Bauman's belief raises a number of questions about the success of regulating vision aid dispensing in the 1880s and 1890s. For medical practitioners and reforming opticians, the dispensing of vision aids began to include a vision test, which altered the practice considerably from the earlier method of 'trial and error'. However, these changes cannot be applied to the whole of vision aid dispensing and were not adopted by all traders in the second half of the nineteenth century.

This section explores how the debates between medical practitioners and opticians influenced the way vision aids were advertised and sold in the wider market. It analyses the discussions of street hawking and the advertisements of a range of traders to show that the fringes of vision aid retail did respond to some of the changes in vision testing. However, it assesses the full potential for this by studying the cases of Thomas Armstrong and Brother of Manchester, the existence of automatic sight testing machines in the 1890 s, and the continued practice of vision testing through postal correspondence. It highlights the complexity of studying 'opticians' in this period by comparing reforming opticians with a number of traders who tagged the title of optician to their trade name. I argue that changes in the ways that vision aids were marketed and sold by a variety of traders may not have affected a proportion of the population by the close of the century. In the second half of the century, vision aids were sold on the street and were found amongst the stock of retailers that advertised toys, scientific instruments and miscellaneous goods. A

\footnotetext{
${ }^{188}$ Cambridgeshire Archives, K1350/1/892: Wilhelm Bauman aged 51, moulder. Requests stock of spectacles for hawking. Passage paid to return to Germany, 1884-1886.
} 
vision aid was not necessarily sold via the testing equipment and methodologies that were being established and the method of trial and error was still adopted.

The sale of vision aids by peddlers on the street is evident across the second half of the nineteenth century. Comment on this form of quackery shows how concerns about vision aid dispensing shifted from a focus on the quality of product, to the methods of dispensing and the vision test. Moreover, criticism of the 'quack' continued to predominate in late nineteenth-century medical texts and The Optician in the 1890s. It highlights that caution about, and criticism of, quackery was used to justify calls for regulation and intervention by those who considered their dispensing practices to be superior. In 1892 The Optician, for example, commented that:

The peripatetic Optician seems to have been very rampant of late. We have reported several instances where purchasers of spectacles have been swindled by these prowling adventurers. ${ }^{189}$

In the same year, the journal also proposed that George Cox's commentary on quackery in the first half of the nineteenth century, discussed in the previous chapter, was still applicable. ${ }^{190}$ However, responses to quackery differed in the second half of the century. Fraud was increasingly exposed, policed or regulated, and traders could face prosecution. ${ }^{191}$ The British Medical Journal as early as 1859 and The Optician in the 1890 s commented on individuals being sued or ending up in court for selling vision aids under 'false pretences' in areas such as Hastings, Lancashire and Royton. ${ }^{192}$ Cases in the 1890 s, for example, included instances where a spectacle hawker had obtained thirty shillings for spectacles that were worth only a shilling, or secured $£ 4$ for spectacles that were 'soon to be found of no value whatever'. ${ }^{193}$ Implicit in these arguments was the cheapness of the product and quality of goods, and this became a chargeable offence. In 1892, for example, a 'hawker of spectacles' in Jedburgh was charged because he had dispensed pairs that were considered to be 'inferior quality'. 194

\footnotetext{
${ }^{189}$ The Optician, 11 February 1892, p. 322.

190 The Optician, 11 August 1892, p. 334; for discussion of George Cox's Spectacle Secrets see chapter three, pp. 103-4.

${ }^{191}$ For an example of a report on numerous frauds in Manchester see The Optician, 8 December 1892, p. 196.

${ }^{192}$ British Medical Journal, 18 June 1859, p. 495; The Optician, 12 April 1894, p. 28; 11 November 1897, p. 240; 12 January 1900, p. 620.

${ }^{193}$ The Optician, 25 February 1898, p. 366; 24 August 1893, p. 798.

${ }^{194}$ The Optician, 24 November 1892, p. 166.
} 
Criticism was increasingly directed at how vision aids were sold. In 1898 H.L. Taylor, for example, wrote a column on quackery for The Optician. It claimed that the trade was putting its 'house into order' but that the advance in vision aid dispensing techniques had increased concerns about quackery. ${ }^{195}$ Taylor argued that the biggest problem was quacks posing as medical practitioners and adopting the use of testing equipment; ' armed generally with a cheap sliding optometer it is easy to imagine the harm such a person can do' ${ }^{196}$ In his column a week later, Taylor suggested that the 'general form of the quack nuisance in the larger towns may be styled 'The Professor'. 'The Professor' would adopt the language of the qualified; claim to be a 'specialist' on eyesight; and often 'spread' his 'fame by means of photographs representing him standing in dramatic attitude by a trial case, the contents most ostentatiously displayed'. ${ }^{197}$ Taylor was most concerned with how vision was tested. However, his statements also suggest that a variety of traders were aware of broader changes in the way that vision aids were being dispensed. The case of 'The Professor' highlights that retailers were aware of the involvement of medical practitioners, and adopted certain titles and methods regardless of whether they were qualified. In 1894 a very elaborate account of fraud in Halifax in The Optician involved the charging of 'Dr Yates', at Oldham Police Court who called upon the house of Mrs Mary Ann Howlett and pretended to be associated with the medical man, 'Dr Little of the Manchester Royal Infirmary'. ${ }^{198}$

In 1898 Taylor proposed that the solution to quackery was to adopt America's stricter regulation. ${ }^{199}$ Opticians and medical practitioners were battling against a growing body of individuals who were increasingly aware of shifts in vision aid dispensing, and highlighted these in their attempts to trick the public. However, criticisms were not just directed at those who travelled and hawked spectacles. In 1894 The Optician argued that 'this trade is not confined to hawkers, but is also encouraged by respectable tradesman who ought to know better'. ${ }^{200}$ Opticians' attempts to reform themselves, and medical practitioners' complaints

\footnotetext{
${ }^{195}$ The Optician, 8 December 1898, p. 436.

${ }^{196}$ Ibid.

${ }^{197}$ The Optician, 15 December 1898, p. 464.

198 The Optician, 26 April 1894, p. 50.

${ }^{199}$ The Optician, 22 December 1898, p. 478.

${ }^{200}$ The Optician, 6 April 1894, p. 12.
} 
about the conduct of spectacle selling, existed against a persistent backdrop of adhoc sale by retailers. The wider practices of spectacle sale in the nineteenth century, and how these were affected by broader changes in spectacle dispensing is limited by the number of sources that survive. However, advertisements, trade directory records, contemporary comment, and the Science Museum's collections allow the broader retail of vision aids to be studied in greater depth.

Although the standalone optician was dominant in the Science Museum's collection findings, the variety of sellers for vision aids continued to be diverse in the latter half of the nineteenth century. The category of 'optician' that has been discussed in this chapter was an ambiguous term by the second half of the century. In the previous section I argued that a number of opticians were not associated with or involved in professional reform and the testing of vision. Moreover, the 'optician' continued to be a term used by a retailer who sold a variety of scientific instruments and may not have claimed any medical knowledge or dispensed vision aids. Despite this, The Optician worried about the sale of vision aids in other trades, and this was a particular concern as the publication was becoming established. In April 1891, for example, they argued that 'chemists and druggists are encroaching'. ${ }^{201}$ Additionally, in June 1891 it was proposed that 'on a recent provincial tour we found that in many cases the local chemists, stationers, and even the drapers were filching business that by right belonged to the Optician'. ${ }^{202}$ By 1896 the journal concluded that 'so long as proper legal recognition...[is] deferred, incompetent pretenders to the art of spectacle-prescribing will abound and multiply among almost every class of tradesman'. 203

Newspaper advertisements highlight the reality of the perceived problem and show that spectacles and eyeglasses persisted in the trade stock of a variety of retailers. The Hampshire Advertiser in 1880/1 and The Yorkshire Herald and York Herald in 1895, for example, included advertisements from two 'Stationer \& Opticians' who stocked spectacles and eyeglasses by Henry Laurance. ${ }^{204}$ This

\footnotetext{
${ }^{201}$ The Optician, 16 April 1891, p. 39.

20211 June 1891 , p. 166.

${ }^{203}$ The Optician, 16 April 1896, p. 64.

${ }^{204}$ The Hampshire Advertiser, between 8 May 1880 and 12 March 1881; and The Yorkshire Herald and the York Herald, 19 January 1895; 14 December 1895.
} 
advertisement reveals that a Stationer could adopt the title of 'optician' in order to show that they sold vision aids. Besides being employed by the 'Stationer', the term 'Optician' was also used by retailers in trades as diverse as 'fancy goods'. ${ }^{205}$ The 'Agents' for Henry Laurance's spectacles illustrate the common categories of traders adopting this practice in the latter half of the nineteenth century: jewellers, cutlers, and chemists frequently claimed to be opticians throughout the $1870 \mathrm{~s}, 1880 \mathrm{~s}$ and 1890 s. $^{206}$ The existence of vision aids in these trades is reflective of the materials that were used in manufacture and their perceived function in the later nineteenth century. However, it also raises questions about how and whether the role of the 'Optician' and the meaning of the term was being reconceptualised.

Jewellers and watchmakers became especially prominent in other advertisements of vision aids. In 1898 The Optician reported on a speech delivered by Mr Thomas Field to members of the National Retail Jewellers Association in Bath. Field argued that 'some 15,000 jewellers and watchmakers' had the 'bulk' of the optical trade, and the totality of sales of spectacles and eyeglasses. ${ }^{207}$ The number of advertisements in London and provincial periodicals and newspapers supports the high numbers documented by Field. The advertisements also highlight the similarities that can be drawn between retailers, regardless of location and time period. Continuity is evident, for example, in the advertisements of a 'Silversmith and Optician' at 'High-street on Gravesend' in 1852 and a 'Goldsmith and Optician' in the Northern Echo in the 1890s. ${ }^{208}$ A variety of other traders in provincial newspapers advertised as jewellers, watchmakers and opticians. The newspaper advertisements covered a wide geographical area, including Bristol, Ipswich, Liverpool, Preston, Lancaster, Huddersfield, Aberdeen, Isle of Wight, North Wales,

\footnotetext{
${ }^{205}$ See, for example, The Sheffield \& Rotherham Independent, 4 January 1868; 11 January 1868; 15 February 1868; 29 February 1868.

${ }^{206}$ Jewellers and opticians: Aberdeen Weekly Journal, 3 July 1878; Isle of Wight Observer, weekly between 10 April 1880 and 16 October 1880; The Star, between 5 May 1881 and 19 July 1881; The North-Eastern Daily Gazette, 3 July 1895; 20 November 1895; 28 December 1895; Cutler and Optician: Trewman's Exeter Flying Post or Plymouth and Cornish Advertiser, weekly between 12 January 1895 and 28 December 1895; The York Herald, between 3 August 1878 and 11 November 1878; Chemist Optician: The Hampshire Advertiser, weekly between 8 May 1880 and 12 March 1881; The Wrexham Advertiser, and North Wales News, 26 March 1887; 24 December 1887; Aberdeen Weekly Journal, regularly between 1 January 1890 and 17 December 1890; and weekly between 2 January 1895 and 13 November 1895.

${ }^{207}$ The Optician, 1 September 1898, p. 756.

${ }^{208}$ The Critic, 15 March 1852, p. 163; and see also the Examiner, weekly between 4 April 1863 and 9 May 1863; Northern Echo, regularly between 27 September 1895 and 14 October 1895.
} 
and Cardiff between 1853 and $1891 .{ }^{209}$ In all of these advertisements, the trader identified themselves as 'opticians'. These advertisements highlight a shift in the perceived role of the 'optician' and the term could be used to signify an individual who dispensed spectacles and eyeglasses, and not necessarily optical instruments. There were also a large number of instances where vision aids continued to be placed as part of the 'fancy good' or toy trade. Here, the trader did not readily identify themselves as an 'optician', and this persisted into the 1890 s and early 1900 s. $^{210}$

Despite attempts to reform the trade in the 1890 s, advertisements show that there could be very little difference or shift in the types of retailers that advertised vision aids, and the sort of goods that they were sold alongside. 'Spectacles \& eyeglasses' often appeared as part of a long list of miscellaneous items. The advertisements show that claims about the transformation in vision testing, as well as the effectiveness of the 1890s reform, need to be treated cautiously. However, these advertisements also show how changes in vision aid dispensing were reaching the fringes of the spectacle market. Just as hawkers of spectacles were claiming their use of technical equipment, Alfred W. Butt in 1895 - although a 'watchmaker, jeweller, and silversmith'- advertised that 'special attention' was given to spectacles and eyeglasses and that 'Oculist's prescriptions' were 'carefully adhered to'. ${ }^{211}$ In 1898 it was also argued that jewellers needed to take the examinations that were being discussed in The Optician to secure their position as vision aid dispensers. ${ }^{212}$

\footnotetext{
${ }^{209}$ See, for example, The Bristol Mercury, 22 October 1853; Cheshire Observer and Chester, Birkenhead, Crewe and North Wales Times, 22 December 1866; Liverpool Mercury, 5 November 1869; Liverpool Mercury, weekly between 22 December 1869 and 17 January 1870; Isle of Wight Observer, 12 February 1870; Ipswich Journal, 3 December 1870; The Royal Cornwall Gazette, Falmouth Packet and General Advertiser, 20 September 1873; 11 October 1873; 25 October 1873; 8 November 1873; Isle of Wight Observer, weekly between 3 April 1875 and 22 April 1876; Aberdeen Weekly Journal, 28 November 1877; and weekly between 27 December 1877 and 1 January 1878; Derby Mercury, between 12 December 1877 and 19 June 1878; Nottinghamshire Guardian, weekly between 10 January 1879 and 31 January 1879; Western Mail, 4 November 1882; The Huddersfield Chronicle and West Yorkshire Advertiser, 23 December 1882; Ipswich Journal, 16 May 1885; North Wales Chronicle, 23 October 1886 and 16 July 1887; The Preston Guardian, between 30 June 1888 and 5 December 1891; The Lancaster Gazette and General Advertiser for Lancashire, Westmorland and Yorkshire, 4 January 1890; Aberdeen Weekly Journal, weekly between 14 November 1890 and 29 December 1890.

${ }^{210}$ See, for example, The Wrexham Advertiser, Denbighshire, Flintshire, Cheshire, Shropshire, Merionethshire and North Wales Register, 16 August 1873; The Royal Cornwall Gazette, Falmouth Packet, and General Advertiser, 31 January 1874; 21 March 1874; The Star, 23 June 1900; Northern Echo, 22 June 1895; 24 June 1895; 26 June 1895.

${ }^{211}$ The Wrexham Advertiser, and North Wales News, between 23 February 1895 and 7 September 1895. ${ }^{212}$ Ibid.
} 
A closer alignment to the medical profession by miscellaneous traders could be more subtle. Lindsey and Sons, for example, advertised as 'Surgical Instrument Makers, Cutlers and Opticians' in the Jackson's Oxford Journal in 1888 and the Trewman's Exeter Flying Post or Plymouth and Cornish Advertiser in $1895 .^{213}$ Whilst this does not outright suggest that their vision aids were sold to members of the medical profession, miscellaneous traders could claim an association with surgeons or the medical profession through their role as instrument makers. This alignment was not complete. Two businesses in the Science Museum's Ophthalmology collection, Thomas Armstrong and Bother of Manchester, and the Automatic Sight Testing Company of London illustrate the varying nature of spectacle retail in the second half of the nineteenth century. The two businesses propose that changes in vision aid dispensing from 1850, and the arguments in The Optician and British Medical Journal in the 1890s, were filtered down and ignored.

A photograph of Thomas Armstrong and Brother's Manchester store from 1898, in Figure 4.1, shows the staff and shop premises of their prominent local business.

Figure 4.1. Photograph of the shopfront of Thomas \& Armstrong Brother's

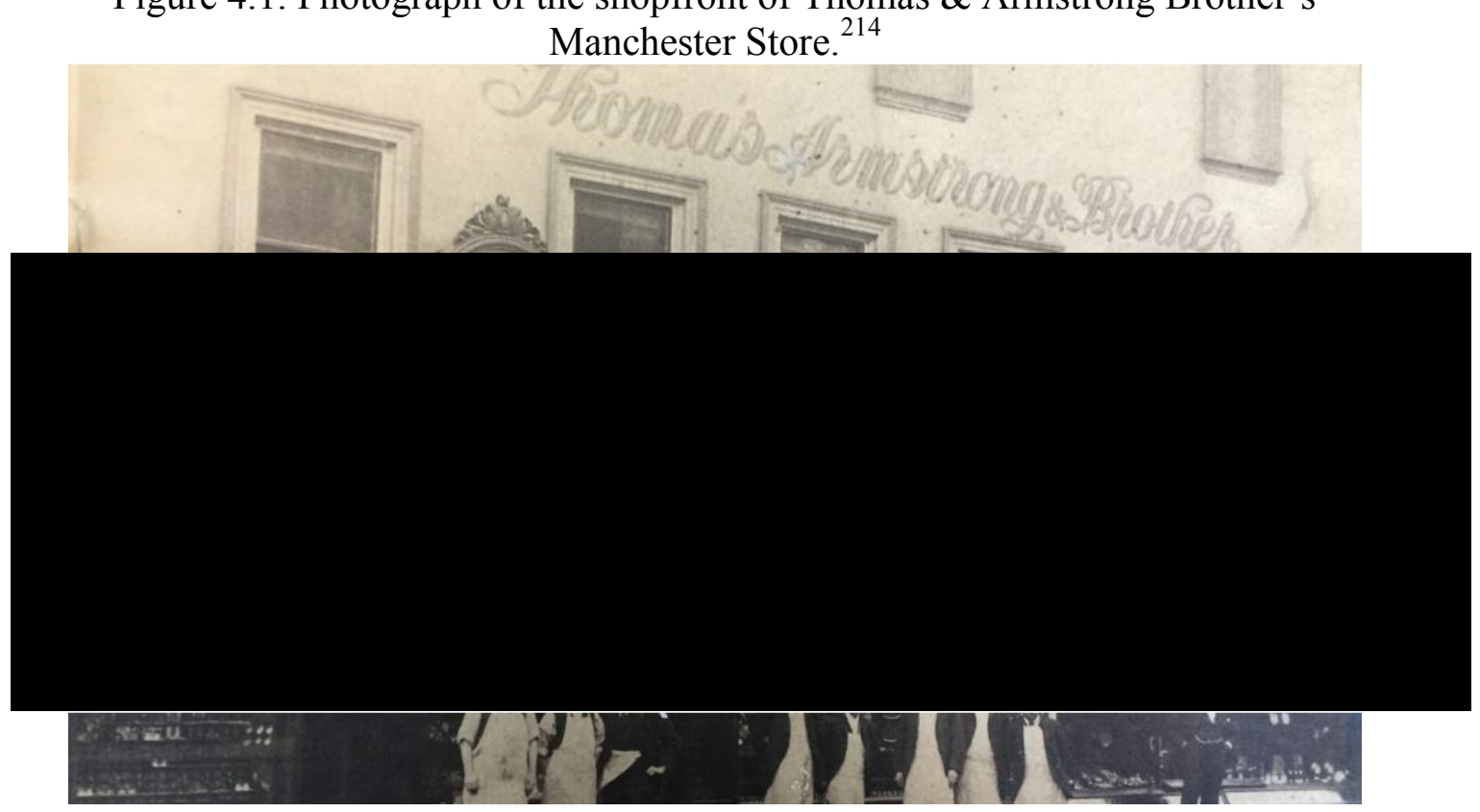

${ }^{213}$ Jackson's Oxford Journal, between 22 September 1888 and 12 January 1889; Trewman's Exeter Flying Post or Plymouth and Cornish Advertiser, between 12 January 1895 and 28 December 1895. ${ }^{214}$ Boots Archives, DA25/8, 1898e: Photograph of Thomas Armstrong and Brother store, Manchester 
The names and position of the staff members were provided on the reverse of the photograph and can be broken down into: 1 jeweller, 3 spectacle makers, 2 watch makers, 2 clockmakers, and a care-taker. ${ }^{215}$ Yet the photograph also depicted their shop sign, which stated that they were 'Opticians to the Royal Eye Hospital', as well as 'watch and clock manufacturers, jewellers and silversmiths'. Armstrong and Brother advertised frequently in the latter half of the nineteenth century in the Manchester Times, as well as The City Jackdaw and British Architect. ${ }^{216}$ These advertisements stated that they had been 'established since 1825 ' and were 'opticians to the Royal Eye Hospital'. The firm's entries in Manchester trade directories stated that they were 'opticians by appointment to the Eye Hospital' as well as 'watch and clock manufacturers and importers, jewellers, silversmiths... mathematical \& philosophical instrument makers'. ${ }^{217}$ Whilst this statement could tell us very little beyond the fact that they claimed an association with the medical profession, the relationship of the business with their medical counterparts could have been a positive one. A diary entry of Edward M. Wrench, a Derbyshire surgeon, in the University of Nottingham Archives, for example, detailed that he took 'Kirlee' to Dr Little of Manchester who prescribed him with spectacles. On the prescription ticket dated from 11 June 1883, and enclosed in the diary, Thomas Armstrong and Brother were asked to 'supply Master Wrench, D plane glass... S +24 pebble'. ${ }^{218}$ It suggests that Armstrong and Brother were engaged in prescription work and had a working relationship with the medical practitioners, which had been claimed in their advertisements.

Advertisements and the account books of an optician and jeweller in Carlisle help to assess whether there was any interaction between various retailers who

\footnotetext{
${ }^{215}$ A range of objects can also be found in the Science Museum's collections made by the company: compound coil spring glasses, A680289, opera glasses A680282 and A680290, and a set of Jaeger test-types: A625220, A625221, A625222, A65223, A625224, A625225.

${ }^{216}$ See, for example, The City Jackdaw, weekly between 21 September 1877 and 23 November 1877 and 1 February 1878 and 31 January 1879; British Architect, weekly between 22 August 1879 and 17 September 1880; Manchester Times, frequently between 16 January 1875 and 5 October 1900. ${ }^{217}$ Slater's Directory of Manchester \& Salford (1879), p. 10; Slater's Directory of Manchester \& Salford (1883), p. 10; Slater's Directory of Manchester \& Salford (1895), p. 16. They were also in bold text as a principal firm.

${ }^{218}$ University of Nottingham Archives, Manuscript and Special Collections, Wr/D/28: Diaries of Edward M. Wrench, 1856-1912, 1883 p. 93 and Wr/D/28/4: Notes. Originally found enclosed in Wr D 28, inside front cover.
} 
dispensed vision aids and the medical profession. Those who dispensed vision aids from a variety of trades adopted similar techniques to standalone opticians by claiming an association with medical institutions. In the 1870 s and $1880 \mathrm{~s}$, for example, cutler and optician R. Smith advertised his connection to 'The York Eye Institution', as well as his use of the 'optometer' in The York Herald. ${ }^{219}$ Between 1888 and 1891 Charles Winter, a 'Watchmaker, Jeweller, Silversmith \& Optician', advertised as an 'Ophthalmic Optician' and 'Maker to the Royal Infirmary' in the Preston Guardian. ${ }^{20}$ Traders also advertised that they had passed the examinations set up by the BOA and SMC in the late 1890s. Between 1899 and 1900 C. Wallace, for example, described himself as a 'qualified Optician \& Watchmaker' and 'Member of the British Optician Association' in The Isle of Man Times and General Advertiser. ${ }^{221}$ In light of this, discussion of jewellers and watchmakers in The Optician could be favourable. In January 1899 the editors, for example, argued that the clock and watchmaker could legitimately construct and sell vision aids because they had a 'high order of intelligence, as well as manual skill... Every skilful Jeweller has in him the making of the most capable Optician'. ${ }^{222}$ Later on in the issue it was stated that The Optician welcomed jewellers and watchmakers, if qualified, because they could help fill the gap that would be lost from eliminating quackery through regulation. ${ }^{223}$ Moreover, to demonstrate their approval, the journal adopted an extended title for the volume that these issues were published in: The Optician and Photographic Trades Review: The Organ of the Jeweller, Watchmaker, Acetylene Dealer, Photo Trader and Chemist. ${ }^{224}$ The journal attempted to separate the jeweller and watchmaker, as well as the photography trade and chemist, from quacks and the unregulated fringes of spectacle retail.

Discussion of jewellers in The Optician, and the association of a variety of traders with medical institutions, raises questions about how far the fringes of the trade can be described as 'unscientific'. Account books for John Potter Dowell, an

\footnotetext{
${ }^{219}$ The York Herald, between 21 March 1877 and 2 June 1881.

${ }^{220}$ The Preston Guardian, etc, between 30 June 1888 and 1 September 1888; and later found on the 21 November 1891; 5 December 1891.

${ }^{221}$ The Isle of Man Times and General Advertiser, between 16 September 1899 and 29 December 1900.

${ }^{222}$ The Optician, 5 January 1899, p. 530.

${ }^{223}$ The Optician, 5 January 1899, pp. 559-560.

${ }^{224}$ The Optician and Photographic Trades Review, vol XVI (London: The Gutenberg Press Ltd, 1899).
} 
optician and jeweller from Carlisle, which have been consulted between 1885 and 1898, show the way that spectacle dispensing could have changed amongst a broad range of traders during this period. They suggest that a working relationship, which involved prescription work, sometimes existed between opticians or spectacle traders and the medical profession. Dowell's accounts show a marked shift from no mention of any lens strength and the occasional mention of arbitrary lens measurements, to the inclusion of spectacles being made to prescription. In the accounts between 1885 and 1894 , for example, only a limited number of lens measurements were recorded in the style of 'specs no. 14', 'specs no. 2' or 'specs no. 6'. ${ }^{225}$ However, there was a substantial increase in the number of prescriptions being recorded in the Cash Day Book between 1897 and 1898. Whilst there was one mention of spectacles at "no. 13 ', the customers' prescriptions were more standardised with the dioptric measurement. ${ }^{226}$ Advertisements from a variety of trades followed this trend by including the phrase 'oculists prescriptions prepared'. In 1889, for example, Lindsey and Sons, surgical instrument makers, cutlers, and opticians stated that 'Oculists Prescriptions' were 'Carefully Worked' in their advertisements. ${ }^{227}$ In 1895 the 'Chemist and Optician', Henry Milne, in the Aberdeen Weekly Journal also advertised: 'Oculist's prescriptions accurately prepared'. ${ }^{228}$ This adjustment suggests that changes in spectacle dispensing, which were reported in The Optician and British Medical Journal, were having an effect on the wider spectacle trade. 'Scientific' spectacle dispensing did not appear everywhere, but a variety of sellers could adopt the discourse or methodologies being called for by both opticians and medical practitioners.

Whilst traders dispensing vision aids did not need to specialise as an optician to be 'scientific', dispensing practices were not wholly standardised by the start of the twentieth century. Lens measurements in inches, for example, persisted in the later nineteenth century. This was perhaps to be expected in the $1880 \mathrm{~s}$, as can be seen in a prescription for spectacles to J. Ellis from A. Carter of 'High Street' in Exeter, which included a measurement of ' 36 ' inches. ${ }^{229}$ However, even in the early

\footnotetext{
${ }^{225}$ Carlisle Archive Centre, DB9/1-7: John Potter Dowell, Cash and Day Book (Sales), 1885-1894.

${ }^{226}$ See Ibid., DB9/7 1897-1898.

227 Jackson's Oxford Journal, between 19 January 1889 and 7 September 1889.

${ }_{228}^{22}$ Aberdeen Weekly Journal, appears weekly between 1 January 1895 and 27 December 1895.

${ }^{229}$ Devon Heritage Centre: 1695M/FP/10, Prescription for spectacles to J. Ellis from A. Carter, 1884.
} 
twentieth century, correspondence in the British Medical Journal suggested that inch measurements were still being prescribed. An account of a lady 'at a fashionable seaside town on the South Coast', reported how she had tried to purchase spectacles from an optician who 'insisted that the inch-system was in use', and that the dioptric system was 'wrong'. ${ }^{230}$ Besides lens measurement, the way that vision aids were dispensed was not universal by the 1890s. A spectacle case in the Science Museum's Ophthalmology collection detailed the image of a key and was inscribed with the 'Automatic Sight Testing Company'. The case of the Automatic Sight Testing Company can be used to explore how far new vision aid testing methodologies had become fully ingrained in wider practice. In 1895 the Automatic Sight Testing Company's 'celebrated 'Key Lenses in spectacles and folders' in 'cases complete for 2s $6 \mathrm{~d}$ per pair' were advertised in the North Eastern Daily Gazette. ${ }^{231}$ Whilst in this instance, the vision aid was supplied through an agent at 'Clevenhead Dispensary', the spectacles were also dispensed through automated machines. In $1891 \mathrm{Mr}$ Woolfson set up the Automatic Sight Testing Company and became the Company's managing director. ${ }^{232}$ In 1889 an article headed 'Every Man his Own Oculist' in The North-Eastern Daily Gazette described the installation of Mr Woolfson's automatic machines at railway stations and hospitals. The article summarised that 'essentially, the apparatus consists of twenty-two pairs of lenses of varying convexity and concavity all or any of which can, by turning a handle, be successively brought before the pair of eyes being tested'. ${ }^{233}$ Patents for other automated machines that allowed users to test their vision and purchase a pair of spectacles appeared in patent records for 'B. Green' in 1888 and $1892 .{ }^{234}$ However, the very concept of automated vision testing was roundly criticised across the 1890 s.

The Automatic Sight Testing Company becomes a useful example for showing how far, and also how little, the advances in vision aid testing dispensing had come in broader practice. In the first instance, it highlights that the need for a

\footnotetext{
${ }^{230}$ The British Medical Journal, 4 June 1904, p. 1345.

${ }^{231}$ The North-Eastern Daily Gazette, 13 September 1895; 18 September 1895; 21 September 1895; 28 September 1895; 30 September 1895.

${ }_{232}$ Mentioned in The Optician, 28 May 1891, p. 140; 26 May 1892, p. 164.

${ }^{233}$ The North-Eastern Daily Gazette, 15 July 1889,

${ }^{234}$ B. Green, 1888, Patent Number 16,090 found in Patents for Inventions: Abridgements of Specifications, Class 97 Philosophical Instruments (London: Darling \& Son, 1896), p. 163; B. Green, 1892, Patent Number 3967 in Patents for Inventions: Abridgements of Specifications, Class 97 Philosophical Instruments (London: Darling \& Son, 1898), p. 131.
} 
precise and controlled eye examination was not yet fully acknowledged by all retailers or members of the public. The use of automatic sight testing machines is difficult to ascertain. However, The Optician commented on the advertising of the company in other publications. ${ }^{235}$ Whilst in 1894 the journal declared that there were a 'decreasing number of machines in operation at Metropolitan Railway Stations', a correspondent in 1895 stated that in the last twelve months 70,000 'spectacles and folders' were sold, and the demand had increased 'daily'. ${ }^{236}$ The automatic sight testing machines were undoubtedly used. Responses to the use of automatic sight testing machines reveal how the expected and approved methods of vision aid dispensing had changed. In contrast to the ideas discussed in chapter three, the dispensing of vision aids by trial and error, and with the autonomy of the customer, was no longer considered the most accurate methodology.

In 1892 The Optician acknowledged that, mechanically, the sight-testing mechanisms were 'ingenious', but that the circulars distributed by the Automatic Sight Testing Company were 'clap trap'. ${ }^{237}$ Medical practitioners and opticians in their respective journals drew upon knowledge of the eye and vision testing to criticise the Automatic Sight Testing Company. An article in The Optician in April 1894, for example, stated that 'the attempt to substitute a machine worked by a penny-in-the-slot runs counter to modern ophthalmic teaching, and reduces the whole matter to the level of an absurdity'. ${ }^{238}$ In 1895 the Company was also considered part of the 'scientific monstrosities' of modernity and reinvigorated demands for a 'Chartered Institute of Optician'. ${ }^{239}$ The Company threatened The Optician with 'penalties for libel' in response to these comments. ${ }^{240}$ However, correspondence suggests that the journal's concerns were shared by medical practitioners and published in the Medical Press. ${ }^{241}$ Criticisms were directed at the acknowledged delicacy of the eye and the need for precision that was no longer considered achievable through a customer's trial and error. A letter to The Optician in 1895, for example, argued that 'penny-in-the-slot-machines' should not be used

\footnotetext{
${ }^{235}$ The Optician, 21 February 1895, p. 322.

${ }^{236}$ The Optician, 20 December 1894, p. 198; 31 January 1895, p. 282.

${ }^{237}$ The Optician, 29 September 1892, p. 3.

${ }^{238}$ The Optician, 6 April 1894, p. 13.

${ }^{239}$ The Optician, 10 January 1895, p. 234.

${ }^{240}$ The Optician, 20 December 1894, p. 198.

${ }^{241}$ The Optician,, 6 April 1894, p. 13.
} 
for the dispensing of vision aids. ${ }^{242}$ To support this argument they highlighted the complexity of ascertaining the refraction of the eye and doubted the ability of members of the public to obtain 'suitable spectacles' through a mechanised machine. $^{243}$

Despite this criticism, attitudes towards how vision aids were meant to be dispensed remained complex at the close of the nineteenth century. It is too simplistic to presume that a jeweller dispensed vision aids more 'unscientifically' than the optician, and those who wished to reform the optical trade could approve of the dispensing practices used by a wide range of retailers. Yet, alongside this, both opticians and miscellaneous traders continued to dispense vision aids similar to any other item. Testing through postal correspondence, for example, was still advertised as a possible option throughout the remainder of the century. Opticians would often adopt this technique for potential customers that resided outside of cities or towns. In 1890, for example, Aitchison, who had claimed to be a 'thoroughly qualified as an oculist optician', still stated that sight could be 'tested by post'. ${ }^{244}$ Five years later the chemist and optician, Henry Milne, claimed that oculists' prescriptions were 'accurately prepared', and still advertised that spectacles could be 'sent to any address on application'. ${ }^{245}$

The trade literature and advertisements of vision aid dispensers raises questions about how sight testing methods would have been experienced by the majority. Criticism from the elite, in both the British Medical Journal and The Optician was often directed towards members of the public as much as the retailer. The second chapter showed how medical opinion did not always correlate with, or influence, public action. Similarly, individuals could ignore advice, and maintain autonomy over their vision testing. There was some awareness that knowledge was improving through 'many intelligently written articles about the eyes' that 'have attracted the attention of the reading public', but most comments were critical. In 1892 a correspondent who signed himself 'optician', for example, referred to a

\footnotetext{
${ }^{242}$ The Optician, 31 January 1895, p. 282.

243 Ibid.

${ }^{244}$ The Standard, 1 May 1890, p. 6

${ }^{245}$ Aberdeen Weekly Journal, advertised weekly throughout 1895.
} 
general lack of understanding amongst the public. ${ }^{246}$ Similarly, in 1896 an article titled 'Cheap Spectacles' in The Optician argued that the public 'created the imposter' and encouraged the practices of the 'quack' because of their preference for cheap and inappropriately sold products. ${ }^{247}$ This general lack of public understanding was thought by opticians to have reached extreme proportions in 1898:

The ordinary individual (or at least 90 per cent of the public, as I am able to glean from my experience in the trade) at the present time proceeds to buy a pair of glasses much in the same manner as he would do a pound of tea; and he is seen more concerned as to the quality of the tea than the suitability of the glasses he may select. His chief endeavour is to buy glasses as cheaply as he possibly can, while he will buy good tea and recognise the necessity of paying a decent price for it. ${ }^{248}$

However, lack of surviving information from the customer-perspective is problematic for gaining any definitive answer on this. The discourse of advertisements was changing, and traders could have adopted dispensing methods to align themselves with the arguments made in The Optician and British Medical Journal. However, criticism of public conduct challenges the extent to which these changes would have affected the experience of the majority in the nineteenth century. The medical and optical elite were pushing for change, but it was not universally met in wider vision aid retail. The public may not have necessarily acknowledged any change or shift in the need to have their eyes properly tested, or wear a good quality lens and frame.

\section{Conclusion}

This chapter has shown that the medicalisation of vision aids and vision testing was an uneven and incomplete process. It has explored how a broad range of retailers increasingly aligned themselves to the medical profession across the century. This alignment helped to generate a number of debates in the British Medical Journal and The Optician. It has also assessed how the relationship between the medical profession and opticians influenced the expectations and practice of vision aid dispensing. The change in vision aid dispensing could reflect the growing specialisation of medicine more widely. It also shows the effect of specialised institutions and anatomical knowledge on advertising in the nineteenth century.

\footnotetext{
246 The Optician, 26 May 1892, p. 164.

${ }^{247}$ The Optician, 20 August 1896, p. 310, italics my own.

${ }^{248}$ The Optician, 7 April 1898, p. 144.
} 
Advertisements consistently claimed lengthy anatomical study or an association with either medical practitioners or a medical institution across the period. By the later nineteenth century the dispensing of vision aids required a combined skillset, which included knowledge of optics and anatomy and the ability to use equipment. The expected degree of accuracy for testing vision and supplying vision aids altered significantly in the second half of the century; testing technologies became more complex and objective techniques shifted autonomy away from the patient.

Advertisements focused on these vision-testing technologies and sight-testing rooms in the closing decades of the century. The selling of vision aids went beyond the manufacture of the product and understanding of commercial business. It encompassed a wide variety of knowledge, which was increasingly controlled and dictated by the medical profession.

Opticians and the medical profession tried to co-operate in the nineteenth century. The Optician showed that a growing, cohesive, body of traders were striving for a professional identity. These opticians sought examination, certification and control. Enhanced education and standardised knowledge were part of their attempts to achieve integrity and a more favourable relationship with medical practitioners. The desire to distance themselves from the unqualified illustrates a shift in vision aid dispensing practices. Whilst not all opticians claimed to be 'refractionists', or wished to test vision, they had begun to acknowledge the importance of vision tests in the dispensing of vision aids. As suggested in the 1890s, the advance in ophthalmology had caused vision testing to 'acquire new meaning'; the nature of vision testing and the level of skill it now required went 'beyond a tradesman'. ${ }^{249}$ Whilst professional autonomy was important in medical and optical debates, the changing nature of dispensing practices was fundamental to their arguments.

However, whether spectacles can be seen as a medical object on the basis of this is questionable. Whilst vision aids appeared alongside other ophthalmic medical appliances in medical trade catalogues, they also continued to be advertised amongst a broad range of other items. Exploring the relationship between medical practitioners and opticians has highlighted the problems of ethics and

${ }^{249}$ British Medical Journal, 23 June 1904, p. 203. 
commercialism. It has also showed that both parties were required to co-operate because the medical profession did not have the capacity to provide everyone with spectacles, nor did they have the requisite skills. Similar to the retail of eighteenthcentury steel trusses, the provision of vision aids required a 'technological convergence' and a combination of different sorts of knowledge. Just as physicians had 'relied on businessmen who connected different trades', the medical profession were reliant on the trade networks and manufacturing capabilities of opticians. ${ }^{250}$ Opticians and medical practitioners were at the forefront of change, and the delineation of their respective roles was debated across the twentieth century. ${ }^{251} \mathrm{As}$ a result, the methodologies of vision aid dispensing did not necessarily extend to the fringes of the spectacle market by the end of the nineteenth century. Individuals could still earn a living by hawking spectacles, and quackery continued.

Opticians worried about encroachment because a diverse numbers of traders continued to dispense vision aids into the early twentieth century. Exploring these retailers highlighted how expectations of vision aid dispensing both succeeded, and failed, to filter down. Thomas Armstrong and Son's favourable relationship with the medical profession, as well as the use of medical titles and testing equipment by quacks, suggested that the new expectations of vision aid dispensing were not isolated to the publications of both opticians and medical practitioners. However, it was also clear that dispensing practices were not wholly standardised, or universal. The Automatic Sight Testing Company is a useful example. Criticism towards it showed how much vision aid dispensing had changed, and how these changes had failed to have any effect because it was used by a large number of people. As a result, The Optician criticised the general public as much as retailers. Members of the public were seen to encourage quackery due to their lack of understanding and desire for cheap products. Whilst the medical profession and opticians were pushing for change, this was not necessarily met by a significant proportion of the population who did not perceive spectacles as a 'medical object', but instead purchased and used them as they would any other product, such as a 'pound of tea' ${ }^{252}$ As highlighted by the Master of the SMC in March 1899, the public did not think to

\footnotetext{
${ }^{250}$ Hilaire-Perez and Rabier, p. 495.

${ }^{251}$ Larkin, pp. 15-28.

${ }^{252}$ The Optician, 7 April 1898, p. 144.
} 
visit a medical professional and 'only a very minute percentage ever find their way to properly qualified oculists'. ${ }^{253}$

Vision aids could be seen as a 'medical' object by the end of the nineteenth century. Both spectacles and eyeglasses were discussed in relation to the body with greater frequency, appeared in medical trade catalogues, and were increasingly expected to be dispensed as part of the ophthalmologist's, oculist's or medical practitioner's role. However, to say that they had become wholly medicalised in the nineteenth century would be to provide an incomplete picture of vision aid sale, which persisted in a variety of locations and could be dispensed in a variety of ways. Withey and Turner have argued that viewing corrective body technologies solely from a medical perspective is problematic because it would 'obfuscate' a variety of meanings that could be attached to them. ${ }^{254}$ Similarly, vision aids were part of the medical trade and also existed in the scientific, miscellaneous and toy trades. As part of this, they were imbued with a variety of social meanings and were not simply 'medical objects' that could be used to treat a 'medical problem'.

${ }^{253}$ British Medical Journal, 11 March 1899, p. 632.

${ }^{254}$ Turner and Withey, p. 786. 


\section{Chapter Five}

\section{The Design and Manufacture of Nineteenth-Century Vision Aids}

The design of vision aids changed considerably in the nineteenth century. Design is one of the most thoroughly researched areas in existing historical works. Written as guides for collectors, these studies have often taken an object-focused approach. In some instances, developments in design have been placed in a wider context by using additional sources. However, this research has often looked at nineteenthcentury developments as part of general histories of vision aids, which has limited their scope. Additionally, alternative sources facilitated their conclusions as opposed to being extensively researched to help formulate them. This chapter takes a different approach and focuses specifically on the nineteenth century to develop a greater understanding of how, and why, the design of vision aids changed in this period. It shows the value of researching objects alongside a variety of additional sources: the texts by opticians and medical practitioners, advertisements, business records, patents, and contemporary comment in newspapers and periodicals.

The chapter is split into three parts to assess the changing design and manufacture of vision aids, as well as the relationship between the expected function and use of a vision aid. Due to the scale and technical nature of nineteenth-century vision aid design, the first section uses the Science Museum's Ophthalmology and Dunscombe collections to outline how design evolved. It shows that the design and manufacture of vision aids altered across the century as part of attempts to achieve a better fit. The subsequent sections analyse why these changes in spectacle and eyeglass design occurred. The second section shows how developments in the manufacture of vision aids and materials created a lighter and more uniform frame. The final section expands this further and reveals how both function and appearance created a more elegant and better-fitting device. Joanne Gooding has argued that the design and manufacture of spectacles in the twentieth century was inextricably 
linked to wider developments in science and society. ${ }^{1}$ This chapter similarly argues that nineteenth-century design was driven by wider manufacturing and practical considerations, which, in turn, were ultimately influenced by the appearance and broadening function of eyewear.

\section{The Evolution of Design in the Nineteenth Century}

Due to the technical nature of the subject, it is necessary to understand how vision aid design changed in order to understand why. The Science Museum's Ophthalmology and Dunscombe collections contain a variety of spectacles and eyeglasses, which illustrate how the shape and size of both the frame and lens altered across the century. Indeed, tracking the development of vision aid design was one of the original purposes of these collections. The Ophthalmology collection, for example, was part of a wider collection amassed by Henry Wellcome, which sought to show how the history of medicine was built on 'evolutionary principles'. Likewise, the first Dunscombe collection, which was destroyed in a fire, was used to show progress in the 'Exhibit of Spectacles' at the Victorian Era Exhibition in 1897. In a description of the display, for example, Dunscombe juxtaposed 'Wig Spectacles' from the 'reign of George III' alongside a pair of 'Gold hook-side Bridge Spectacles' from 1893 as a means to 'illustrate the difference in style of work and the progress made in respect of spectacle frames in the present reign' ${ }^{3}$ Dunscombe also intended to use his second collection in a similar manner. The objects were used to illustrate the progress of nineteenth-century spectacle design in a paper delivered to the British Optical Society on 13 March $1913{ }^{4}$

\footnotetext{
${ }^{1}$ Joanne Gooding, 'Rather Unspectacular: Design choices in National Health Service Glasses', Science Museum Group Journal, 7 (2017) http://journal.sciencemuseum.ac.uk/browse/issue-07/ratherunspectacular/\#0 [accessed: 2 February 2018]

${ }^{2}$ See, for example, Ghislaine M. Skinner, 'Sir Henry Wellcome Museum for the Science of History', Medical History, 30 (1986) 383-418; Medicine Man: The Forgotten Museum of Henry Wellcome, ed. by Ken Arnold and Danielle Olsen (London: The British Museum Press, 2011), passim; Wellcome was not alone in this evolutionary thought process at the time, see for example, Arthur MacGregor, 'Exhibiting Evolutionism: Darwinism and pseudo-Darwinism in museum practice after 1859', Journal of the History of Collections, 21.1 (2009), 77-94.

${ }^{3}$ Science Museum Technical File T/1921-323: Catalogue of the 'Exhibit of Spectacles at the Victorian Era Exhibition', 1897, p. 4.

${ }^{4}$ Science Museum Technical File T/1921-323: Margaret Mitchell, 'Optics and the Science Museum', The Optician, 21 September 1979, pp. 22-4 (p. 23)
} 
The collections also highlight and emphasise the variety of nineteenthcentury frame designs. Alfred Chadburn of Chadburn \& Sons - Sheffield-based opticians and instrument manufacturers - reflected in 1894 that 'there are now an endless variety of spectacles manufactured' ${ }^{5}$ Chadburn did not see this range as an indication of progress, commenting 'many of which are by no means good'. 6 Despite this, Chadburn remarked on the number of frames that were available for different intended purposes and activities. This variety existed across the century. As early as 1819, Liverpool-based optical instrument maker, Egerton Smith, advertised the large number of frames and styles that were already available at the back of his text, Hints to the Wearers of Spectacles:

EGERTON SMITH \& CO. RESPECTFULLY SOLICIT THE ATTENTION OF THE PUBLIC TO THE FOLLOWING ARTICLES, Of the most approved Construction and Manufacture, which are CONSTANTLY ON SALE, AT THEIR OLD-ESTABLISHED SHOP, NO. 18, POOL LANE, Liverpool. OPTICAL INSTRUMENTS.

Best double and single jointed gold Spectacles, with pebbles or glasses.

Do. Double jointed stout silver Spectacles, with ditto, round and oval eyes.

Do. Do. Do. With ditto, and slip sprints.

Do. Do. Do. With ditto, and swivel joints.

Do. Particularly light for walking.

Do. Single jointed silver Do. Round and oval eyes, do.

Do. Double jointed tortoise shell Do. With silver joints, round and oval eyes, do.

Do. Single jointed Do. Do. Do.

Do. Tortoise shell Hand Spectacles, peculiarly convenient for occasional reading, do.

Spectacles for couched eyes.

Gogglets, or Shade Spectacles, for warm climates.

Best doubt jointed steel spectacles, round and oval eyes.

Do. Single jointed Do. Do. Do.

Spectacle Cases, mounted in Nourse skin and silver swages.

Do. Nourse and dog skin, plain mounted.

Do. Tortoise shell and silver swages.

Do. Tortoise shell, plain mounted.

Do. Fish skin, Do.

Do. Morocco, with snap springs.

Do. Do. With straps \&c.

Concave and Quizzing Glasses, mounted in gold and silver frames.

Do. Do. In tortoiseshell and horn boxes.

Reading and Burning Glasses, in various mountings.

Watchmakers' and Multiplying Glasses.

Gogglers, with white or green glasses, to guard the eyes from dust or wind.

Best achromatic Operas, elegantly mounted.

Common Do. In various mountings.

Brazil Pebbles, Periscopic, Green and best plate Glasses, ground into any frames at a few minutes' notice. ${ }^{7}$

\footnotetext{
${ }^{5}$ Sheffield City Archives, SY231: microfilm, Alfred Chadburn, Observations On The Choice And Use Of Spectacles, $11^{\text {th }}$ edn (1894), pp. 6-7.

${ }^{6}$ Ibid.

${ }^{7}$ Egerton Smith, Hints to the Wearers of Spectacles; or a Concise Statement of the Comparative Merits of Pebbles and Glasses, When Used as Spectacle Eyes (Liverpool, 1819), pp. 8-9.
} 
Smith's advertisement shows the various styles, the number of materials, and also the different types of activities that vision aids, or protective spectacles, were designed for. A number of advertisements in a variety of locations, including Birmingham, Nottingham, London, and Scotland, used phrases such as 'every variety', 'enormous variety', and 'infinite variety' across the century. ${ }^{8}$ However, the catalogues of Chadburn and Egerton reveal that the frames had changed substantially between 1819 and 1894. Historians have argued that the 'modern' shape of spectacles - a frame with the side-arm attachment resting behind the ear - can be traced to the middle of the nineteenth century. ${ }^{9}$ Their studies have also focused on the number of eyeglass designs that proliferated in the later nineteenth century. ${ }^{10}$

The Science Museum's collections, and contemporary texts, help to both illuminate and document the key changes in spectacle and eyeglass design. The Science Museum's collections show that the design of the bridge and side-arms of spectacles changed considerably in the nineteenth century. The side-arms of spectacle frames evolved continually across the period. As shown in Figure 5.1, they can be broken down into a number of different styles: transverse folding, extending, turn-pin, straight, and coil spring or hook-side frames.

\footnotetext{
${ }^{8}$ See, for example, Caledonian Mercury, 13 March 1859; Birmingham Daily Post, 21, 22 and 23 August 1872; Nottinghamshire Guardian, 4 February 1876; Daily News, 13 September 1890.

${ }^{9}$ Spectacles: H.W. Holtman, 'A Short History of Spectacles', in W. Poulet, Atlas on the History of Spectacles, trans. Professor Frederick C. Blodi (Godesberg: Wayenborgh, 1978), p. xviii; B. Michael Andressen, Spectacles: From Utility Article to Cult Object (Stuttgart: Arnoldsche, 1998), p. 20.

${ }^{10}$ Eyeglasses: William Rosenthal, Spectacles and Other Vision Aids: A History and Guide to Collecting (San Franscisco: Norman Publishing, 1996), p. 236; Derek C. Davidson, 'Nineteenth Century Metal Spectacles', Ophthalmic Antiques International Collectors Club Newsletter, No. 58 (1997), 9-10; R.J.S MacGregor, 'The Amazing Pince-Nez', Ophthalmic International Antiques Collectors Club Newsletter, No. 69 (1999), 5-7.
} 
Figure 5.1. Bar-chart of the kinds of side-arms utilised in 709 pairs of spectacles dating from between c. 1800 and c. 1900 in the Science Museum's collections.

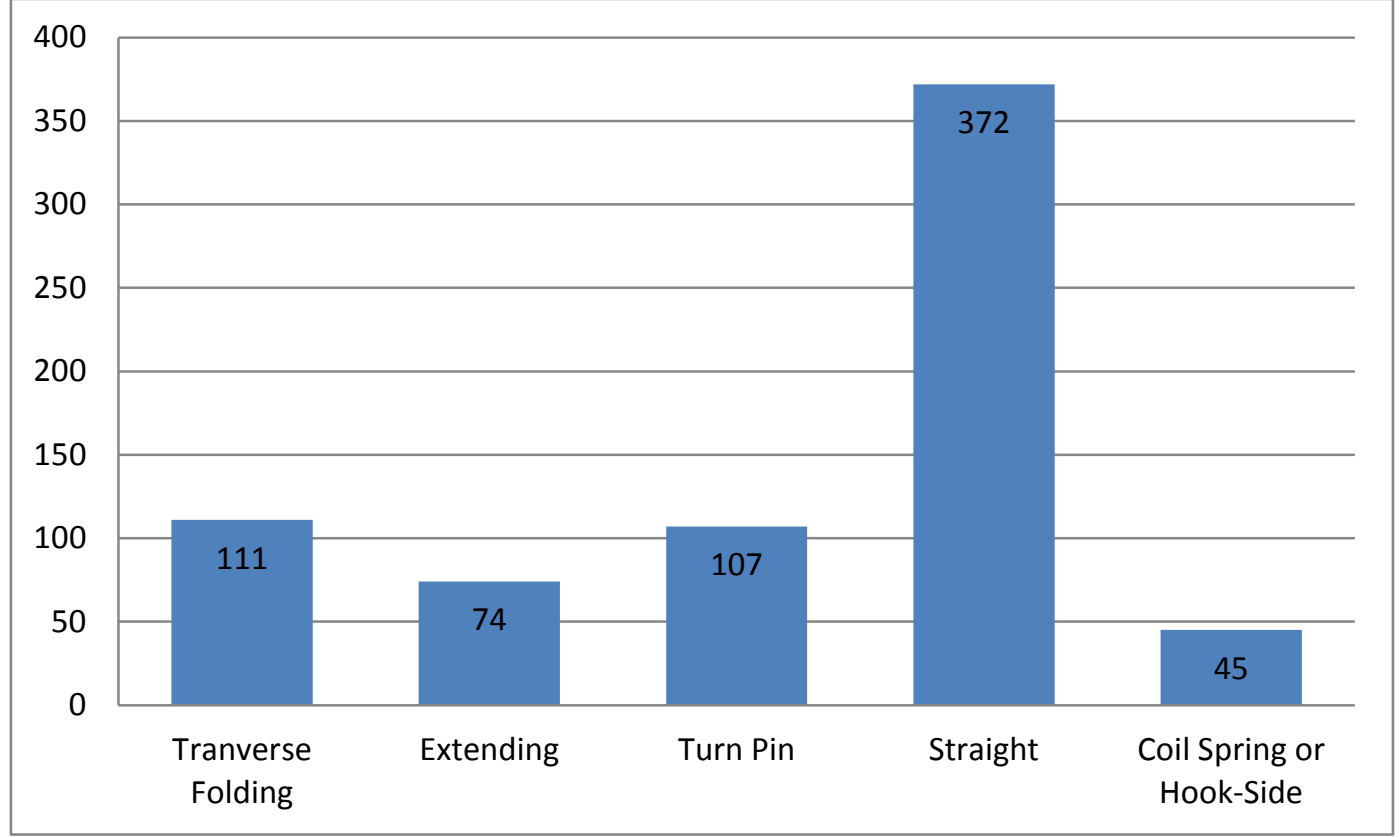

Previous research has shown how earlier frames, such as the 'sliding' and 'turnpin' side-arms, were slowly displaced by 'straight' and 'hookside' side-arms in the second half of the nineteenth century. ${ }^{11}$ The collections support these findings. As illustrated by the examples in figure 5.2 to 5.4, side-arms evolved from the thicker extending and transverse folding frames that dated from the eighteenth century, to the thinner turn pin arms of the early nineteenth century, the 'wire' straight frames in the mid-century, and eventually the light coil spring frames in the latter half of the nineteenth century.

\footnotetext{
${ }^{11}$ Derek C. Davidson, Spectacles, Lorgnettes and Monocles (Buckinghamshire: Shire, 2002), pp. 1617; Hugh Orr, Illustrated History of Early Antique Spectacles (London: The Author, 1985), p. 38; Rosenthal, p. 111.
} 
Figure 5.2. Science Museum Dunscombe collection 1921-323/137 and 1932$323 / 159$, an example of transverse folding and extending spectacles dated to c. 1800 .
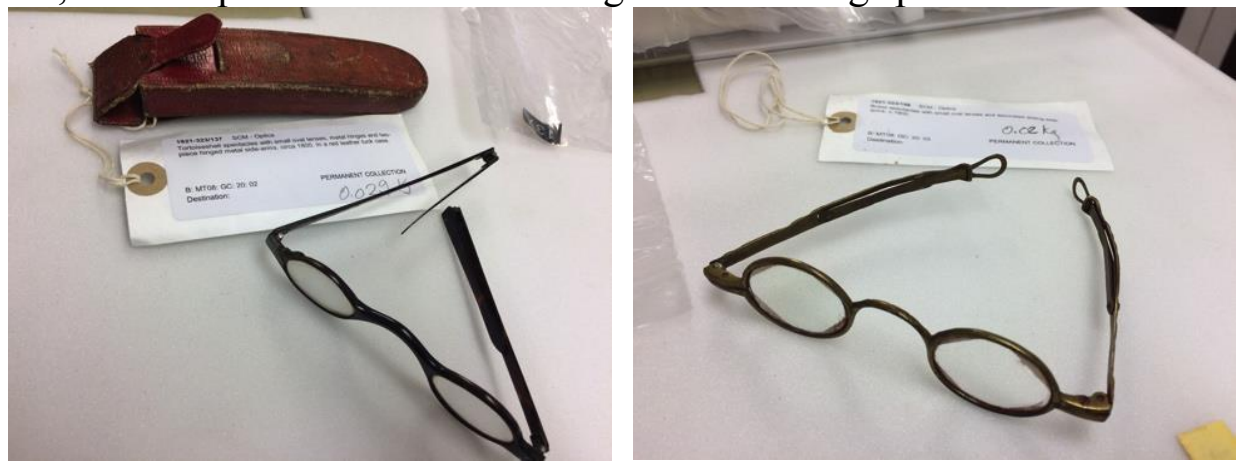

Figure 5.3. Science Museum's Dunscombe collection 1921-323/168 and 1921-323/200, examples of a turn-pin frame dated no later than 1820 and a straight frame dated between 1834 and 1913 .
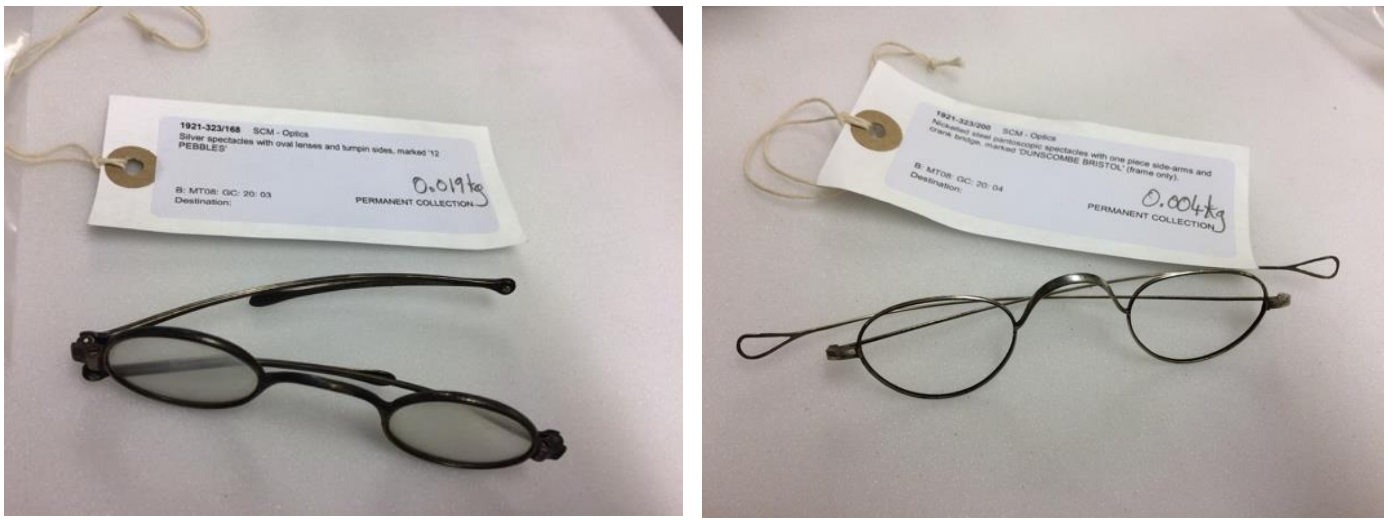

Figure 5.4. Science Museum's Dunscombe collection 1921-323/212, an example of coil-spring spectacles dated to 1893.

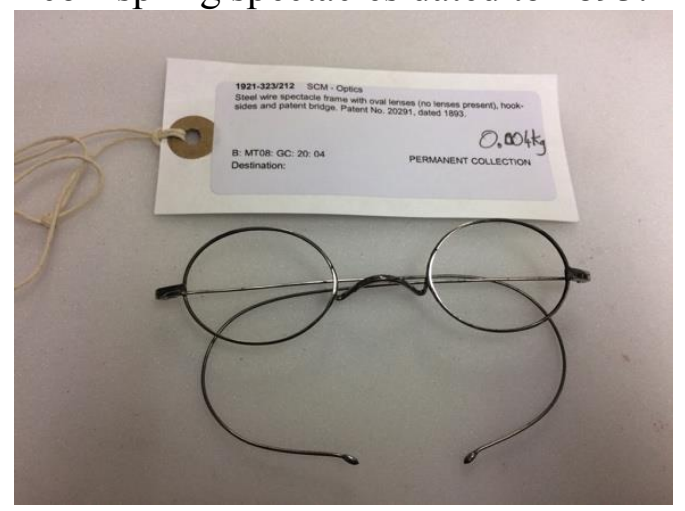

Contemporary advertisements illustrate developments in design. The language used to describe spectacles, for example, alters from 'double-joints' to 'curved sides'. ${ }^{12}$ However, comments or advice on frame design help to show how

\footnotetext{
12 'Double joints' see, for example, the Examiner: 27 January 1839, p. 62; 17 March 1839, p. 175; 2 June 1839, p. 351; 7 July 1839, p. 431; 28 July 1839, p. 479; 3 August 1839, p. 583; 13 October 1839,
} 
spectacle side-arms altered across the century. In 1881 an American Professor of Diseases of the Eye, C.H. Vilas, described 'Turn-pin' side-arms as 'old specs' in his text on Spectacles; and How to Choose Them. ${ }^{13}$ To explore these changes further, a mixture of optical and medical texts have been analysed to assess what styles were available. These were produced by firms and individuals including the Sheffield and Birmingham-based opticians G. and W. Proctor in 1815, London-based optician John Hudson in 1840, London-based optician and instrument maker Charles A. Long in 1855, an American ophthalmologist Christopher Fenner, whose work was published in London in 1875, Ophthalmologist and Hunterian Professor of Pathology and Surgery to the Royal College of Surgeons, Robert Brudenell Carter in 1880, and R.J. Phillips, whose work was published by The Optician in 1900.

These texts show that only the 'transverse folding' side-arms were available in Proctor's catalogue in 1815, and the drawings in Figure 5.5 resemble the older frames in the Museum's collections. ${ }^{14}$

Figure 5.5. Page from the catalogue of G.W. Proctor, showing the older straight and transverse folding spectacles styles, 1815 . $^{1}$

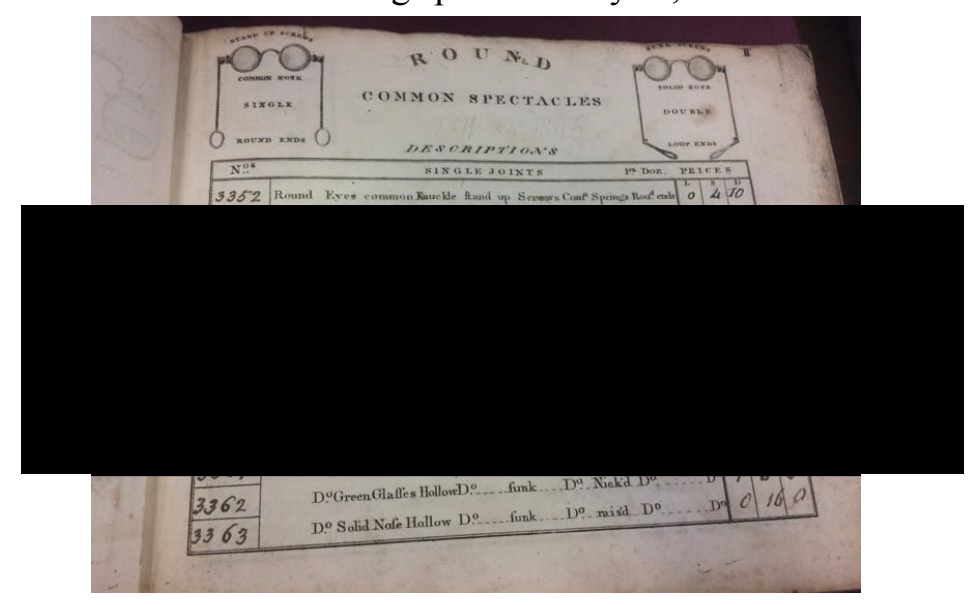

By 1840, however, Hudson mentioned the single-jointed (straight) spectacles, and alluded to the number of styles now available in his recommendation of the 'Turn

p. $655 ; 27$ October 1839 , p. 687; 17 November 1839, p. 735; 18 July 1840, p. 583. And mention of 'single or curved sides', later on in the century in, for example, The Wrexham Advertiser, and North Wales News, 26 March 1887 and 24 December 1887.

${ }^{13}$ C.H. Vilas, Spectacles; and How to Choose Them (Chicago: Duncan Brothers, 1881), p. 42.

${ }^{14}$ Sheffield City Archives, Bradbury Record 293: G.W. and Proctor, Opticians and Manufacturers (Sheffield: C.W. Thompson, 1815).

15 Ibid. 
pin' over both the transverse folding and extending spectacles. ${ }^{16}$ In 1855 Long continued to discuss these three styles across the mid-century, but his text revealed that metal manufacture had progressed further to make thinner wire metal frames available in both straight and turn-pin styles. An example of a straight frame can be seen in Figure 5.6. ${ }^{17}$

Figure 5.6. Science Museum's Wellcome collection A681342, an example of straight spectacles similar to those depicted in Charles A. Long's Spectacles (1855).

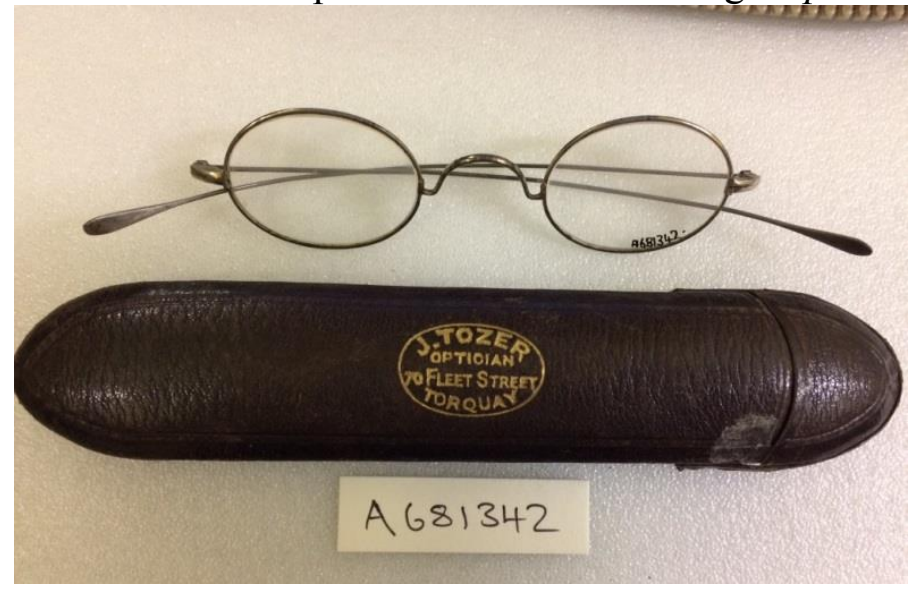

Whilst Fenner discussed hook-side frames in 1875 , they were considered flimsy and the turn-pin frames were preferable. ${ }^{18}$ By 1880 , however, the number of styles available had seemingly decreased, and Carter only mentioned the turn-pin, 'curled' - another term for the hook-side frame - and single-jointed spectacles; the transverse folding and extending spectacles were not discussed. ${ }^{19}$ By the start of the twentieth century, the recommended styles had narrowed further and Phillips considered the 'turn pin', extending and transverse folding frames 'antiquated', and the 'hook' and 'straight' sides 'to be preferred'. 20

\footnotetext{
${ }^{16}$ J.T. Hudson, Useful Remarks upon Spectacles, Lenses, and Opera-Glasses; with Hints to Spectacle Wearers and others; being an epitome of practical and useful knowledge upon this popular and important subject (London: Joseph Thomas, 1840), pp. 12-13.

${ }^{17}$ Charles A. Long, Spectacles: When to Wear and How to Use Them: Addressed to Those who Value Their Sight (London: Bland and Long, 1855), pp. 21-3.

${ }^{18}$ Fenner, p. 106.

${ }^{19}$ Christopher Smith Fenner, Vision: Its Optical Defects, and the Adaption of Spectacles (London: Lindsay \& Blakiston, 1875), pp. 104-6; Robert Brudenell Carter, Eyesight: Good and Bad: A Treatise on the Exercise and Preservation of Vision, $2^{\text {nd }}$ edn (London: Macmillan, 1880), pp. 244-246.

${ }^{20}$ R.J. Phillips, Spectacles and Eyeglasses, Their Forms, Mounting and Proper Adjustments, $2^{\text {nd }}$ edn (The Optician and Photographic Trades Review, 1900), pp. 40-49.
} 
Patents for spectacles across the century also reveal that the side-arms were one of the biggest areas of design innovation. However, patents show that this focus on the spectacle 'wings' was part of a broader attempt to try and fit the frame more securely to the wearer's face. ${ }^{21}$ Similar to other types of assistive devices, achieving a fit that was both secure and comfortable was a challenge that was particularly difficult to overcome - despite Edward Scarlett's invention of side-arms in the early eighteenth century - and placing the frame behind the ears was not necessarily the obvious solution. ${ }^{22}$ A patent from 1899, for example, detailed that the 'wing' or 'side' was made 'shorter than usual' so that it could 'press on the face in front of the ears'. ${ }^{23}$ The bridge itself presented a similar challenge and changes in design focused on achieving a better fit. The patents for bridges across the century established the finer details of how to construct the correct shape, and focused on the development of adjustable designs that could be moulded or suited to the wearer. ${ }^{24}$ These developments can be seen in the collections and Figure 5.7; older styles - such as the 'C-shaped' or X and K-bridged - were replaced by the development of newer 'crank' and 'W' bridge styles. ${ }^{25}$

\footnotetext{
${ }^{21}$ W.W. Popplewell, Patent Number 8621, 12 June 1888; H. Translev, Patent Number 125, 3 January 1889; T.A. Willson, Patent Number 8119, 12 May 1891; M. Vigers, Patent Number 1374, 23 January, 1892; W.P. Thompson, Patent Number 500, 7 January, 1898.

${ }^{22}$ See, for example, Katherine Ott, 'The Sum of Its Parts: An Introduction to Modern Histories of Prosthetics', in Artificial Parts and Practical Lives: Modern Histories of Prosthetics, ed. by Katherine Ott, David Serlin, and Stephen Mihm (New York: NYU Press, 2002), p. 18.

${ }^{23}$ W. Salt, Patent Number 98159 May, 1899.

${ }^{24}$ This trend in bridge shape is also documented in 'Development of Spectacles 1850-1900', pp. 4-5; Rosenthal, p. 46. For patents, see for example, L. Braham, Patent Number 2771, 7 November, 1863; R Purdom and H. Stokes, Patent Number 20,291, 4 November 1893; A. Brunner, Patent Number 23, 637, 5 December 1894; L.F. Committi, Patent Number 6592, 30 March 1895.

${ }^{25}$ For further information on different style of bridges in the nineteenth century, please refer to 'The Development of Spectacles 1850-1900', Ophthalmic Antiques International Collectors Club Newsletter, No. 17 (1986-7), 4-5; Rosenthal, p. 46.
} 
Figure 5.7. Science Museum's Well collection, A681355 and A681346 and Science Museum's Dunscombe Collection 1921-323/209, examples of the ' $\mathrm{C}$ ' and ' $\mathrm{K}$ ' Bridge, and the newer 'crank' bridge.
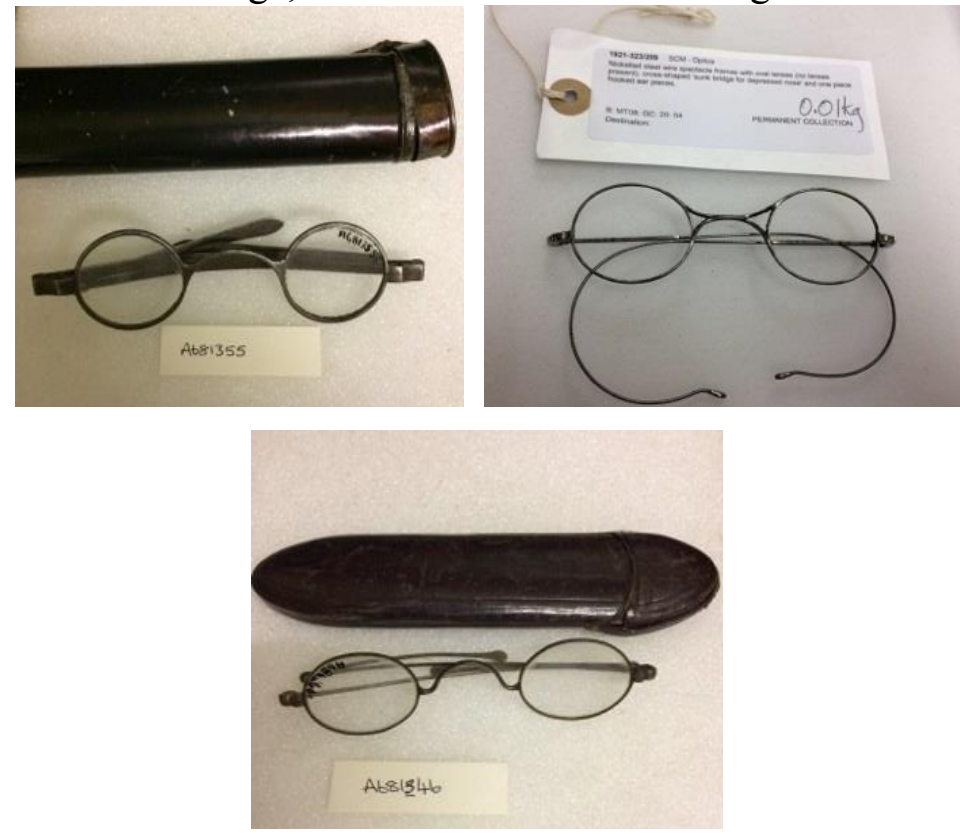

The shape of the lens was also considered in the overall fit of the frame. The catalogue of Proctor in 1815 revealed the availability of designs in both round and oval lenses. Besides tracking the development of spectacle side-arms, historians have often focused on the growth of oval lenses. ${ }^{26}$ This is supported both in the collections and contemporary texts. Comment in the mid-century found oval lenses preferable and by 1893 the round, 'octagon' and 'oblong' were described as 'antiquated' ${ }^{27}$ In the Science Museum's collection a similar pattern exists; the older frames had a rounded lens-shape while the thinner, later, metal or tortoiseshell styles, had lenses that were predominantly oval. The same pattern could be found in the straight and turn-pin arm spectacles, with the thicker styles being mostly round, and the later, thinner styles, mostly oval.

\footnotetext{
${ }^{26}$ Rosenthal, p. 103; Asa Briggs, Victorian Things (London: BT Batsford Ltd, 1998), p. 112; Richard Corson, Fashions in Eyeglasses, $3^{\text {rd }}$ edn (London: Peter Owen, 2011), p. 122; 'Development of Spectacles: $1^{\text {st }}$ half of the Nineteenth Century', Ophthalmic Antiques International Collectors Club Newsletter, No. 16 (1986), 4; 'Development of Spectacles, 1850-1900', p. 4.

${ }^{27}$ William Mackenzie, A Practical Treatise on the Diseases of the Eye, $4^{\text {th }}$ edn, revised and enlarged (London: A. and G.A. Spottiswoode, 1854), p. 843; John Phillips, Ophthalmic Surgery and Treatment: With Advice on the Use and Abuse of Spectacles (London: W.B. Keen \& Co., 1869), p. 36; The Optician, 29 June 1893, p. 674.
} 
Eyeglasses - a form of vision aid with no side-arms - developed alongside spectacles in the nineteenth century. In Proctor's 1815 catalogue in Figure 5.8, for example, nose spectacles were depicted.

Figure 5.8. Page from the catalogue of G.W. Proctor, showing nose spectacles. ${ }^{28}$

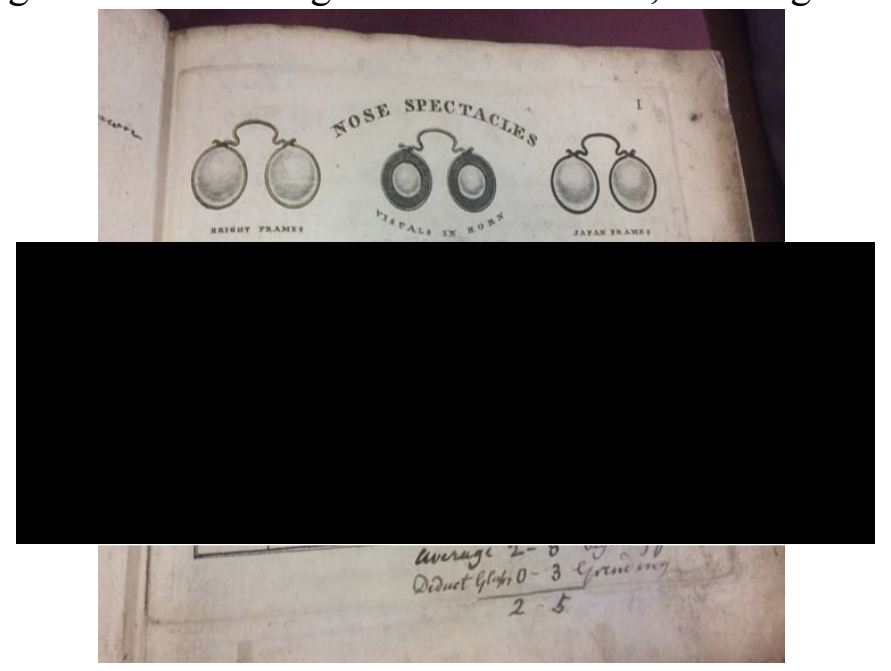

However, the 'pince nez', a style that was able to pinch the nose and stay gripped in position, was developed and became popular in the mid-century. Additionally, the texts reveal that advances in eyeglasses design occurred much later than advances in spectacle design. ${ }^{29}$ Long in 1855, for example, was still discussing 'hand folders', that were riveted and had no spring. ${ }^{30}$ However, they also show the speed of design innovation. In just over a decade, an American optician in 1866 described eyeglasses with both round and oval lenses and a bar spring bridge, which can be seen in Figure $5.9 .^{31}$

\footnotetext{
${ }^{28}$ Sheffield City Archives, Bradbury Record 293: G.W. and Proctor, Opticians and Manufacturers (Sheffield: C.W. Thompson, 1815).

${ }^{29}$ The same texts that were used to study the design of spectacles have been used.

${ }^{30}$ Long, p. 23.

${ }^{31}$ Walter Alden, The Human Eye; its Use and Abuse: A Popular Treatise on Near and Impaired Sight, and the Methods of Preservation by the Proper Use of Spectacles, etc (Cincinnati: The Author, 1866), pp. 125-6.
} 
Figure 5.9. Designs of pince-nez that were detailed in Walter Alden, The Human Eye; Its Use and Abuse (1866). ${ }^{32}$

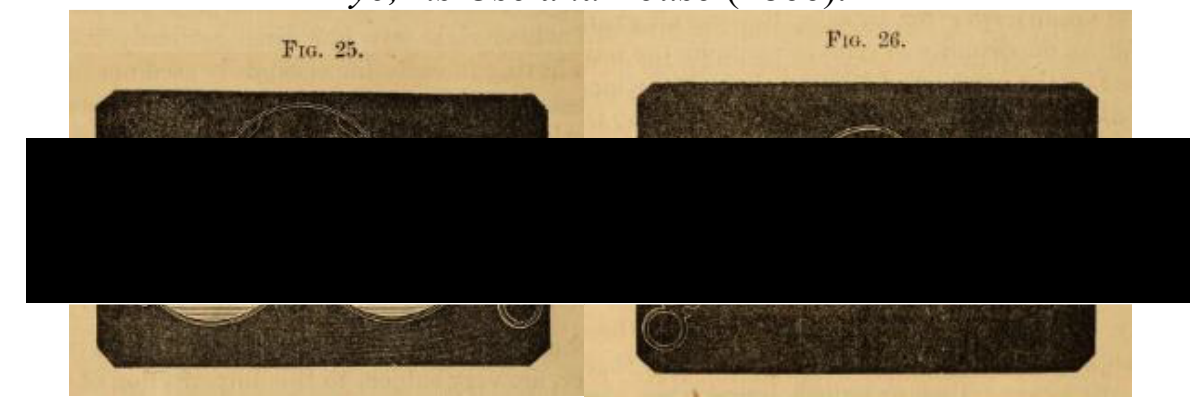

Fenner in 1875 and Carter in 1880 also discussed these designs. However, in the tenyear period the design had advanced again and some straighter styles had become available. Additionally, a number of different types of plaquets (nose-pieces) to allow for different shaped faces and noses, including those shown in Figure 5.10, had been developed. ${ }^{33}$

Figure 5.10. Designs of pince-nez detailed in Christopher Fenner, Vision: Its Optical Defects, and the Adaption of Spectacles (1875). ${ }^{34}$

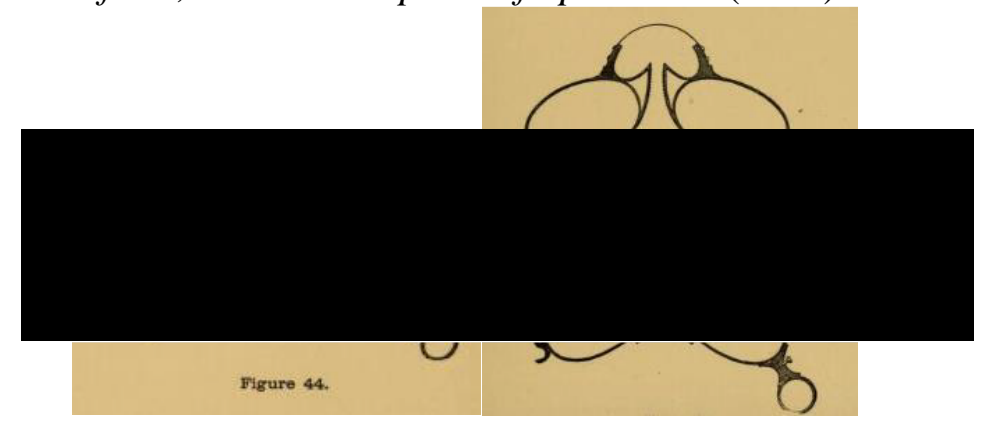

The variety of late nineteenth-century eyeglass designs is striking in both the collections and patent records. The objects in the Ophthalmology collection have a number of different kinds of springs and plaquet designs. The Dunscombe collection contains an even greater variety, such as the 'fairy clip', 'canadian', 'triple bar', and 'movilette type'. Patents show that design innovation primarily focused on the plaquets, with twenty-eight new plaquet designs being patented between the period 1884 and 1900 . These patents primarily claimed that the innovations they detailed sought to help increase comfort, allow for adjustment, reduce tension in certain

\footnotetext{
${ }^{32}$ Ibid.

${ }^{33}$ Fenner, pp. 108-9; Carter, p. 246.

${ }^{34}$ Fenner, pp. 108-9.
} 
areas, or improve the grip and sturdiness of the frame. ${ }^{35}$ Retailers in newspapers and periodicals also advertised a number of developments such as the 'helical spring', 'self-holding', and 'anti-pressure' eyeglasses. ${ }^{36}$ In 1900 R.J. Phillips discussed the variety of designs available and concluded that 'more or less ingenious frames' had been constructed for eyeglasses. ${ }^{37}$

Eyeglasses became popular in the second half of the century. Indeed, the number of newly-invented styles superseded those of any other form of vision aid, partly as a result of the manufacturers' attempts to increase their usability and comfort. In 1898 The Optician, in its discussion of a new German patent, stated that 'of late years so much activity has been displayed in the form and suspension of pince-nez nose pieces'. ${ }^{38}$ The journal also provided some favourable reviews of new designs across the 1890s. In 1895 a patent from London-based opticians and ophthalmic instrument makers, Curry and Paxton, was praised for the way that it could 'grasp the nose at the top as well, and with the same pressure, as at the bottom'. ${ }^{39}$ Yet the 'Revluc' pince-nez, which can be found in the Dunscombe collection, was favoured in the later 1890 s because of the simplicity of its design. In 1898 , the journal argued that the introduction of this design 'can be fairly described as having effected a revolution in the construction of pince-nez' ${ }^{40}$

R.J. Phillips, at the start of the twentieth century, concluded that 'much advance has been made in the art of constructing efficient, comfortable and handsome contrivances'. ${ }^{41}$ Phillips suggested that the 'clumsy' frames of bone, horn, and shell from the eighteenth century were replaced by the improved mechanical construction of 'light metal' later in the century. For Phillips, the material and

\footnotetext{
${ }^{35}$ See, for example, 1884 Patent Number 6377; 1889 Patent Numbers 1568, 7818, 11812, 20, 493; 1890 Patent Number 4280; 1891 Patent Numbers 7888, 9557; 1892 Patent Numbers 16,383, 20, 309; 1893 Patent Numbers, 7371, 8124, 10,371, 15,415; 1894 Patent Numbers 9193, 14,139, 15,997, 23,637; 1895 Patent Numbers 14,040, 17,862, 23,673; 1897 Patent Number 14,925; 1898 Patent Number 11,797; 1899 Patent Numbers 8707, 14, 796; 1900 Patent Numbers 17,366, 18,612.

36 'Helical spring' in The Bristol Mercury, 6 June 1863; 'Self-holding' in, The Era Almanack, January 1877, p. 117; January 1878, p. 117; in January 1879, p. 120; 'anti-pressure' The Scottish Review, April 1890, p. 13; April 1892, p. 10; October 1894, p. 6.

${ }^{37}$ Phillips, Spectacles and Eyeglasses, pp. 47-9.

${ }^{38}$ The Optician, 30 June 1898, p. 508.

${ }^{39}$ The Optician, 24 January 1895, p. 270.

40 The Optician, 31 March 1898, p. 76; for another favourable review of the 'Revluc' see also The Optician, 13 May 1897, p. 140.

${ }^{41}$ Phillips, Spectacles and Eyeglasses p. iv; This was also published much earlier in The Optician, 15 June 1893, p. 644.
} 
construction of the frame influenced how vision aid design changed. However, equally important in the discussion of the frame was its function and overall fit. This chapter explores how focus on the comfort and fit of the frame, as well as the overall change in manufacture and intended purpose, ultimately influenced the alterations in vision aid design across the century.

\section{The Material and Manufacture of Frames and Lenses}

The materials that were recommended and used for the frame and lens of vision aids altered significantly across the century. Whilst collectors have explored the materials that were available, they have not explored what materials were advocated by contemporaries. Materials and the changes in nineteenth-century manufacturing processes influenced the overall design and shape of vision aids. Across the century, spectacles and eyeglasses were constructed out of a range of different materials. In 1847 London ophthalmic surgeon Alfred Smee, for example, highlighted the number available, the importance of manufacturing them correctly, and suggested some of the relative differences between the heaviness and expense of frames that were 'usually composed' of: silver, German silver, brass, steel, or horn. ${ }^{42}$ These, along with tortoiseshell, are all present in the Science Museum's collection, and are shown in Figure 5.11.

\footnotetext{
${ }^{42}$ Alfred Smee, Mischief Caused by their Abuse: Being the Substance of Lectures Delivered at the Central London Ophthalmic Hospital (London: Horn, Thornwaite and Wood, 1847), p. 37.
} 
Figure 5.11. Bar-chart of the different kinds of materials utilised in 709 pairs of spectacles dating from between c.1800 and c.1900 in the Science Museum's collections. $^{43}$

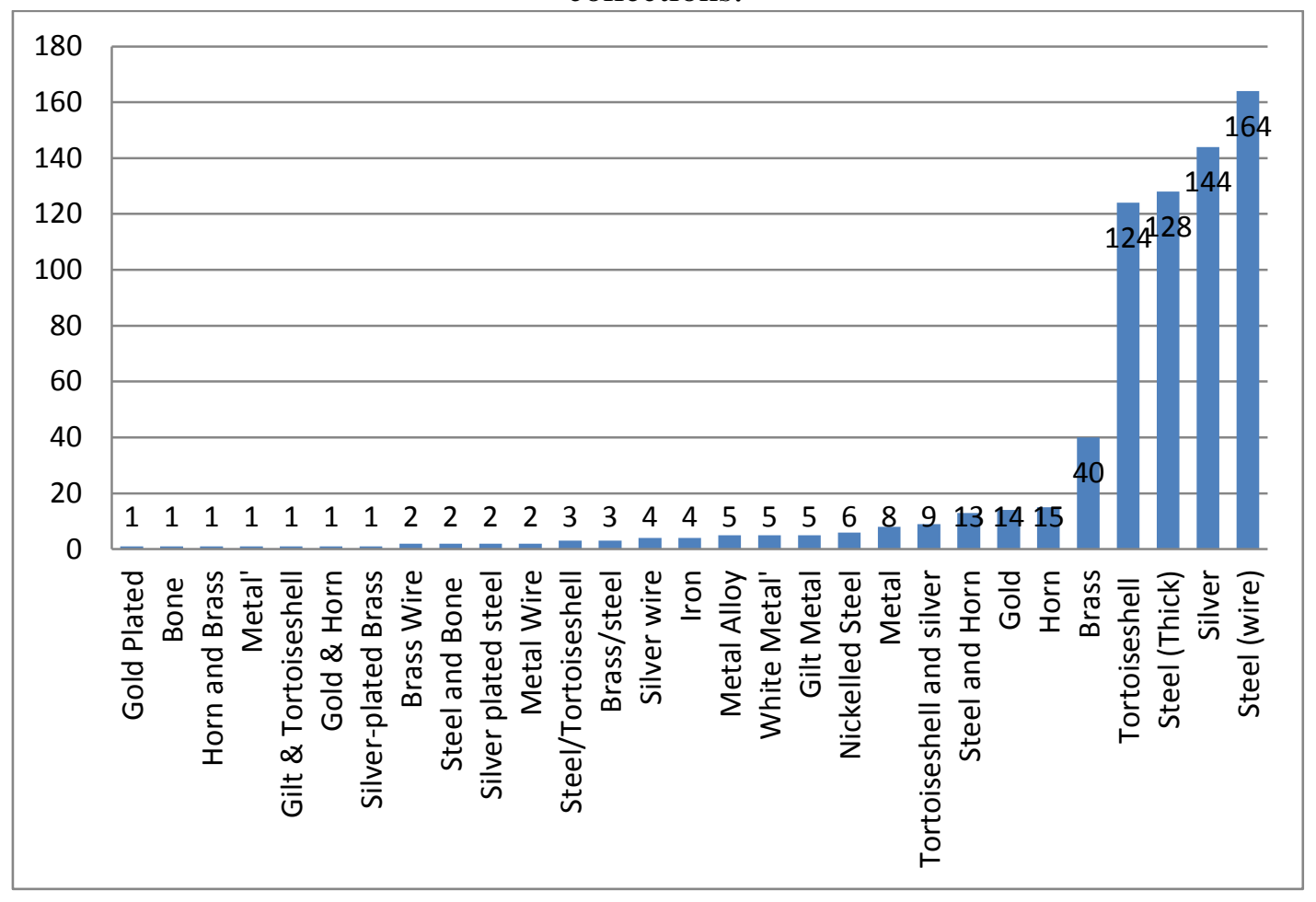

As Figure 5.11 reveals, steel, silver, tortoiseshell, and brass were the most commonly used materials for spectacle frames. Despite this, the advised materials changed over time. Tortoiseshell was one of the most popular early materials. In 1897 Dunscombe wrote in the catalogue of his first collection that tortoiseshell was considered 'for 150 or 200 years... a favourite material for the frames of the best spectacles, being soft and pleasant to the skin'. ${ }^{44}$ This is evident in the mid-century and William Mackenzie, one of the founding fathers of British ophthalmology, argued that tortoiseshell was 'to be preferred'. ${ }^{45}$ Despite this, a London based optician and instrument maker, William Ackland, discussed the popular materials of spectacle frames. In 1866 Ackland suggested that different materials were becoming prominent in the manufacture of spectacle frames in the second half of the century;

\footnotetext{
${ }^{43}$ Graph depicting the catalogued materials of 709 spectacles in the Science Museum's Ophthalmology and Dunscombe collections.

${ }^{44}$ Science Museum Technical File, T/1921-323: Catalogue of the 'Exhibit of Spectacles at the Victorian Era Exhibition', 1897, p. 3. However, tortoiseshell was not universally popular, and Kitchiner in 1818 argued that it was too easily broken and recommended 'silver frames': W Kitchiner, Practical Observations on Telescopes, Opera-Glasses and Spectacles, $3^{\text {rd }}$ edn (London: S. Bagster, 1818), p. 70.

${ }^{45}$ Mackenzie, p. 843; William Mackenzie Medal', British Journal of Ophthalmology, 12.12 (1928), 648-649.
} 
silver, tortoiseshell and horn were nearly out of use, with steel and gold being more commonly employed. ${ }^{46}$

The materials utilised in the nineteenth-century eyeglasses in the Science Museum's collections were, as shown in Figure 5.12, predominantly those favoured in the second half of the period. The bar-chart shows that tortoiseshell was still common. However, tortoiseshell was primarily used for earlier frames, and steel, white metal, and gold became more prominent as eyeglasses developed.

Figure 5.12. Bar-chart of the different kinds of materials utilised in the frames of 261 eyeglasses dating from between c.1800 and c.1900 in the Science Museum's collections. $^{47}$

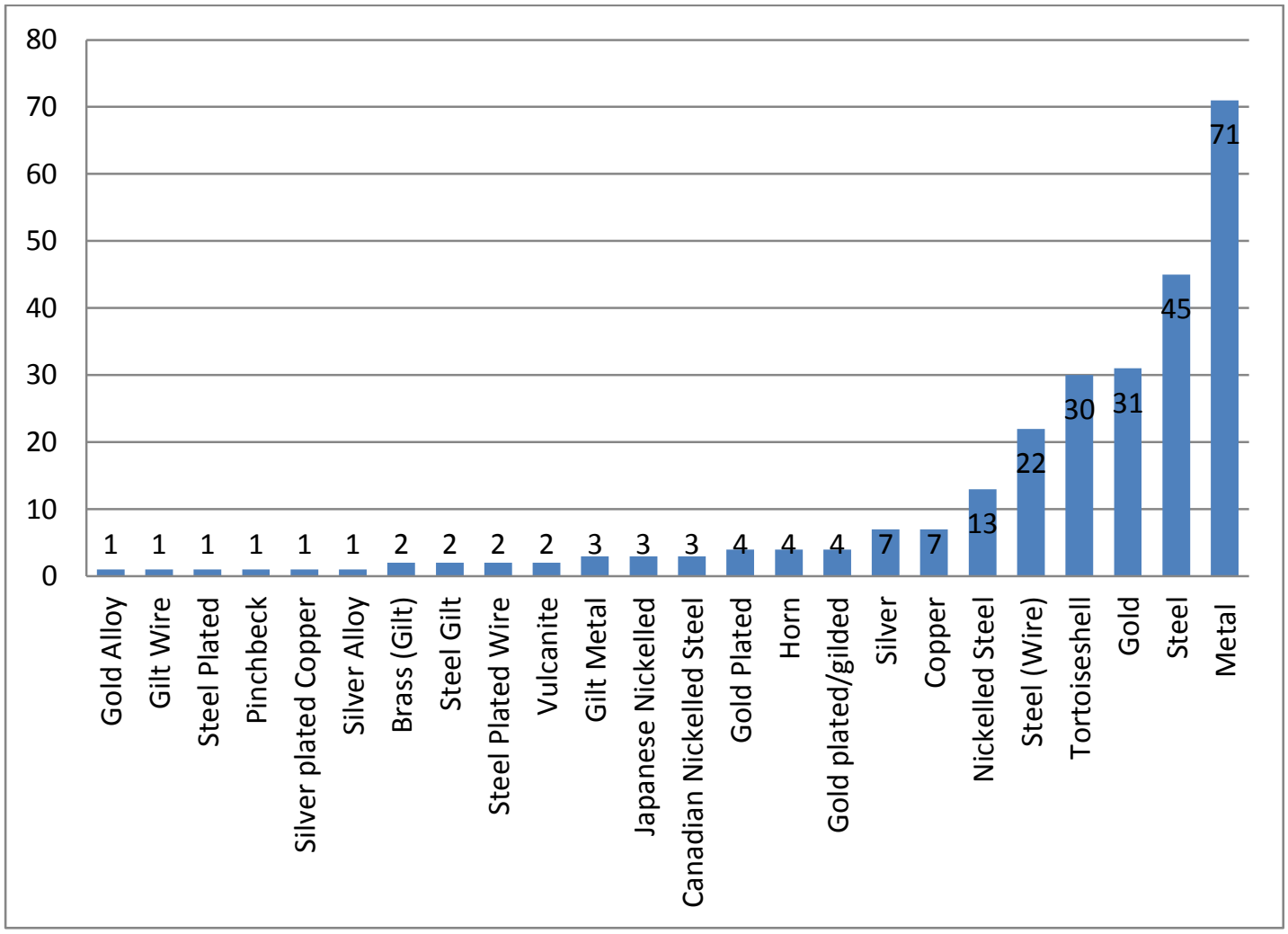

A number of optical and medical texts advised, from the late 1830s, on the use of steel and gold for both spectacles and eyeglasses. ${ }^{48}$ Moreover, whilst correspondence

\footnotetext{
${ }^{46}$ William Ackland, Hints on Spectacles. When to Wear and How to Select Them (London: Horne \& Thornthwaite, 1866), p. 10.

${ }^{47}$ Data derived from the 'materials' field of the object descriptions in the Science Museum's closed object database. The 'metal' category refers to frames whose material, beyond metal, has not been specified.

${ }^{48}$ Thos Harris \& Son, A Brief Treatise on the Eyes, Defects of Vision, and the Means of Remedying the Same by the Use of Proper Spectacles, Also Rules for judging when Spectacles are necessary, and Directions for selecting them (London: Onwhyn, 1839), p. 18; Hudson, p. 12; Alden, p. 103; Phillips,
} 
did question the accuracy of these reports, The Optician explored provincial manufacturing areas, such as Manchester, Sheffield and Birmingham to suggest that both steel and gold work were being employed in spectacle frame making in a variety of locations during the early $1890 \mathrm{~s} .{ }^{49}$ Additionally, frame design was influenced by modifications to traditional materials. The Science Museum's collections, for example, included plated, nickelled and gilt steel, and these processes were considered to help prevent rusting. ${ }^{50}$ By 1893 The Optician argued that 'alloys', often sold as aluminium or nickel, were the more 'usual' or typical materials being utilised for vision aid frames. ${ }^{51}$ By the start of the twentieth century, materials such as tortoiseshell and silver were no longer discussed. In contrast, the frames 'now in vogue' were made from steel, nickel and gold. ${ }^{52}$

The material of the lens also altered across the century. The catalogue for the second Dunscombe collection in the early twentieth century argued that much advance had been made in the use of spectacle lenses: lenses that were 'rare thirty years ago' were now commonly in use. ${ }^{53}$ Developments in manufacture changed the recommended lens material for use in vision aids. Two primary types of material were used in nineteenth-century spectacle and eyeglass lens manufacture: glass, of various forms, and Brazilian rock crystal, more commonly referred to as 'pebble'. There are a number of frames in the Science Museum's collections engraved with the word 'pebble', including the examples in figure 5.13. These frames suggest that pebble could be a marketable or desirable material. ${ }^{54}$

\footnotetext{
Ophthalmic Surgery, p. 35; D.B. Roosa, Defective Eyesight: The Principles of its Relief by Glasses (London: Macmillan, 1899), p. 163; although silver was sometimes referred to as well, such as in Carter p. 244, however, overall, Carter does recommend gold, p. 258.

${ }^{49}$ See, for example, The Optician, 8 October 1891, p. 46; 22 October 1891, p. 78; 24 December 1891, p. 222; 21 January 1892, p. 286; 31 March 1892, p. 30; 28 April 1892, p. 102. Also see the accuracy of these being questioned in correspondence from 25 June 1891, p. 207.

${ }^{50}$ Vilas, p. 42; Carter, p. 244.

${ }^{51}$ The Optician, 15 June 1893, p. 646.

${ }^{52}$ Carl Barck, The History of Spectacles, Originally Delivered as a Lecture Before the Academy of Science, St Louis (Reprinted from the Open Court for April, 1907), p. 12.

${ }^{53}$ Science Museum Technical File T/1921-323: Catalogue of the second Dunscombe collection, p. 2.

${ }^{54}$ See, for example, in the Dunscombe collection, object numbers 1921-323/167 and 1921-323/168 and in the Ophthalmology collection, object numbers A682615, A682440, A62378, A62335, A682342, A682343, A682360, A192695, A62351, A62368, A682430, A682427.
} 
Figure 5.13. Science Museum's Wellcome collection A68247 and A681402, examples of frames with 'pebbles' stamped onto the side.
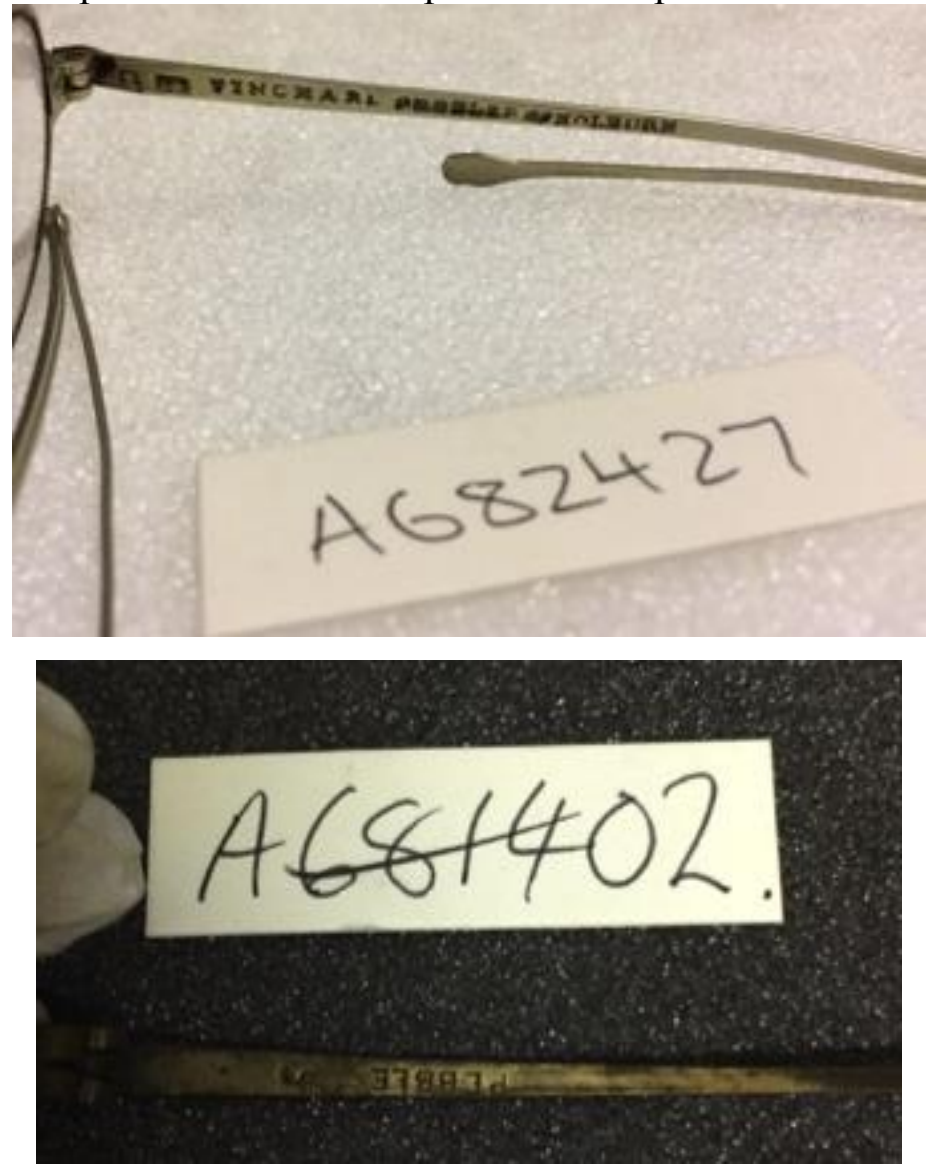

Pebble was advocated by a range of opticians and medical practitioners because of its relative hardness and resistance to scratching. ${ }^{55}$ Indeed, The Optician in the $1890 \mathrm{~s}$ advertised that new pebble grinding works were being established. ${ }^{56}$ However, both glass and pebble were advertised in newspapers and periodicals across the century. The recommended material for lenses does not appear to have formed a single consensus and was more a matter of individual opinion. Pebbles were favoured in texts from $1818,1839,1866$, and 1888 , just as much as they were out of favour in texts from $1819,1827,1840,1866,1869,1881$, and $1894 .{ }^{57}$

\footnotetext{
${ }^{55}$ Kitchiner, p. 69; Harris \& Son, pp. 27-8; Ackland, p. 18; Henry Laurance, The Eye in Health and Disease: With Hints on the Choice and Use of Spectacles, $3^{\text {rd }}$ edn (London: Love Brothers, 1888), $\mathrm{p}$. 29; Charles Bell Taylor, How to Select Spectacles in Cases of Long, Short and Weak Sight, $2^{\text {nd }}$ edn (London: Cassell, 1889), p. 28.

${ }^{56}$ See, for example, Newbold in Clerkenwell: The Optician, 3 March 1892, p. 380.

${ }^{57}$ In favour: Kitchiner, p. 69; Harris \& Son, pp. 27-8; Ackland, p. 18; Henry Laurance, The Eye in Health and Disease: With Hints on the Choice and Use of Spectacles, $3^{\text {rd }}$ edn (London: Love Brothers, 1888), p. 29; Charles Bell Taylor, How to Select Spectacles in Cases of Long, Short and Weak Sight, $2^{\text {nd }}$ edn (London: Cassell, 1889), p. 28; Out of favour: Smith, pp. 4-7; Francis West, A Familiar Treatise on the Human Eye: Containing Practical Rules that will Enable all to Judge what Spectacles are Best Calculated to Preserve their Eyes to Extreme Old Age (London: W. Ackrill,
} 
The arguments that were in favour of glass, and more critical of pebble, could be based on the potential flaws of pebble lenses, such as their imperfections and refractive index. ${ }^{58}$ However, by the later nineteenth century, commentators tended to focus on the improved manufacture of glass, rather than the possible disadvantages of pebble. In 1880 Carter argued how there was little difference between glass and pebble, except pebble's greater hardness, because glass manufacture had become more 'perfect'. ${ }^{59}$ In Britain, glass manufacture became mechanised in the early nineteenth century. ${ }^{60}$ In 1834 , for example, machinery for producing spectacle lenses was exhibited by Mr Samuel at the meeting of the Eclectic Society. ${ }^{61}$ In 1840 John Thomas Hudson, described how glass was obtained with less difficulty than in previous years. Hudson showed how the incorporation of machinery into the manufacturing process of lenses could be found in a variety of locations. Whilst Hudson highlighted that there was some initial reluctance, the mechanisation of lens manufacture had become increasingly accepted, and Hudson proposed that 'there are now comparatively few lenses that are not made by machinery'. ${ }^{62}$ Mechanisation influenced the scale and scope of manufacture. By 1851 opticians could advertise that their workshops were producing 12,000 lenses a week. ${ }^{63}$

From the mid-century, a number of patents focused on improving the shaping and bevelling machinery for both cylindrical and spherical lenses. ${ }^{64}$ In 1869 , for example, a description of how lenses were 'generally made' was recorded and involved: cutting the glass into proportionate thickness with a diamond, fixing it to a

1827), p. 29; Andrew Ross, On the Use and Abuse of Spectacles (London: R. Kinder, 1840), p. 4; Alden, pp. 95-9; Phillips, Ophthalmic Surgery, p. 42; Vilas, pp. 33-8; A. Fournet, Medical Spectacles and the Royal London Ophthalmic Hospital (London: A. Fournet, 1894), p. 19;.

${ }^{58}$ See, for example, The Optician, 15 June 1893, p. 646.

${ }^{59}$ Carter, p. 47.

${ }^{60}$ For further comment on how glass manufacture advanced see Rosenthal, pp. 29-32; or for more on the history of glass manufacture for optical instruments in general, see Anita McConnell, A Survey of the Networks Bringing Knowledge of Optical Glass to London Trade, 1500-1800 (Cambridge: Whipple Museum of the History of Science, 2016).

${ }^{61}$ The Literary Gazette: a Weekly Journal of Literature, Science and the Fine Arts, 29 November 1834 , p. 803.

${ }^{62}$ Hudson, pp. 19-20.

${ }^{63}$ Sheffield City Archives, SY231: Observations on the Choice and Use of Spectacles, backpage. ${ }^{64}$ See, for example, Salomon Strum, Patent Number 2608, 11 November 1853; W.H. Beck, Patent Number 3689, 11 March 1887; G. Prescott, Patent Number 19,683, 3 December 1890; J. E. Boyd, Patent Number 8287, 25 April 1893; and J. West and H.J.W. Raphael, Patent Number 13,357, 15 June 1898. 
metal tool to achieve the correct concavity or convexity, and then working the lens by hand or machinery on a 'smoothing tool'. ${ }^{65}$ Once ground and smoothed, the lenses were polished with oxide of tin, before the process was completed on the other side of the lens, 'perfectly polished', and cut to fit the shape of the spectacle frame. ${ }^{66}$ By 1905, R. M. Lockwood, a former Professor of Optometry and Physics at two American institutions, described a similar process. However, the overall production had become more efficient and mechanised; the duty of the labourer had been reduced to only keeping 'his set of machines properly supplied with the moist grinding material'. ${ }^{67}$ As highlighted by Carter, these developments in glass manufacture altered the choice of lens material. In 1891 an article on 'Spectacle Glasses' in a popular periodical recommended glass in direct relation to its improved manufacture, and argued:

The perfection to which glass-making has now attained has rendered the use of artificial glass for spectacles practicable, and, seeing the advantages attaching to its employment, which it is the object of this short paper to point out, it is probable that it will entirely supersede rock-crystal. ${ }^{68}$

Improvements in manufacture were inextricably linked to the choice of lens material. However, these improvements also highlight how manufacture had evolved in the nineteenth century. The mechanisation of manufacture in the nineteenth century altered the way that vision aids were produced and created a new type of frame that was both standardised and more suited to large scale production. Materials were an important part of this process. One of the greatest manufacturing transformations took place in steel, which had been used for spectacle frames since the eighteenth century. ${ }^{69}$ When looking at the materials that have been catalogued in the Science Museum collections, steel has been separated into 'steel', and 'steel wire'. These frames were manufactured in different ways and, as shown in Figure

\footnotetext{
${ }^{65}$ Phillips, Ophthalmic Surgery, p. 42.

${ }^{66}$ Ibid.

${ }^{67}$ R. M. Lockwood, Frames and Lenses: A Practical Treatise for Optometrists (New York: Frederick Boger Pub. Co., 1905), p. 8.

68 'Spectacle Glasses', Chamber's Journal of Popular Literature, Science and Arts 7 February 1891, pp. 92-3.

${ }^{69}$ For early use of steel in spectacle frames, see Alun Withey, Technology, Self-Fashioning and Politeness in Eighteenth-century Britain: Refined Bodies (Basingstoke: Palgrave Macmillan, 2016), pp. 3-5 and 98; For further information on the history of steel in spectacle manufacture see Rosenthal, p. 99; and Davidson, 'Nineteenth Century Metal Spectacles', pp. 9-10; For information on the manufacture of other materials see, for example, R.J.S. MacGregor, Hugh Orr, Derek C. Davidson, Stuart Eadon-Allen, 'Real Tortoiseshell', Ophthalmic Antiques International Collectors Club, No. 41 (1992), 3-8.
} 
5.14, produced frames of different thickness. As a result, the changing manufacture of steel vision aid frames illustrates the effect of both materials and mechanisation on overall vision aid design.

Figure 5.14. Science Museum's Wellcome collection A62297 and Science Museum Dunscombe Collection 1921-323/207, examples of 'steel' and 'steel wire' spectacles.

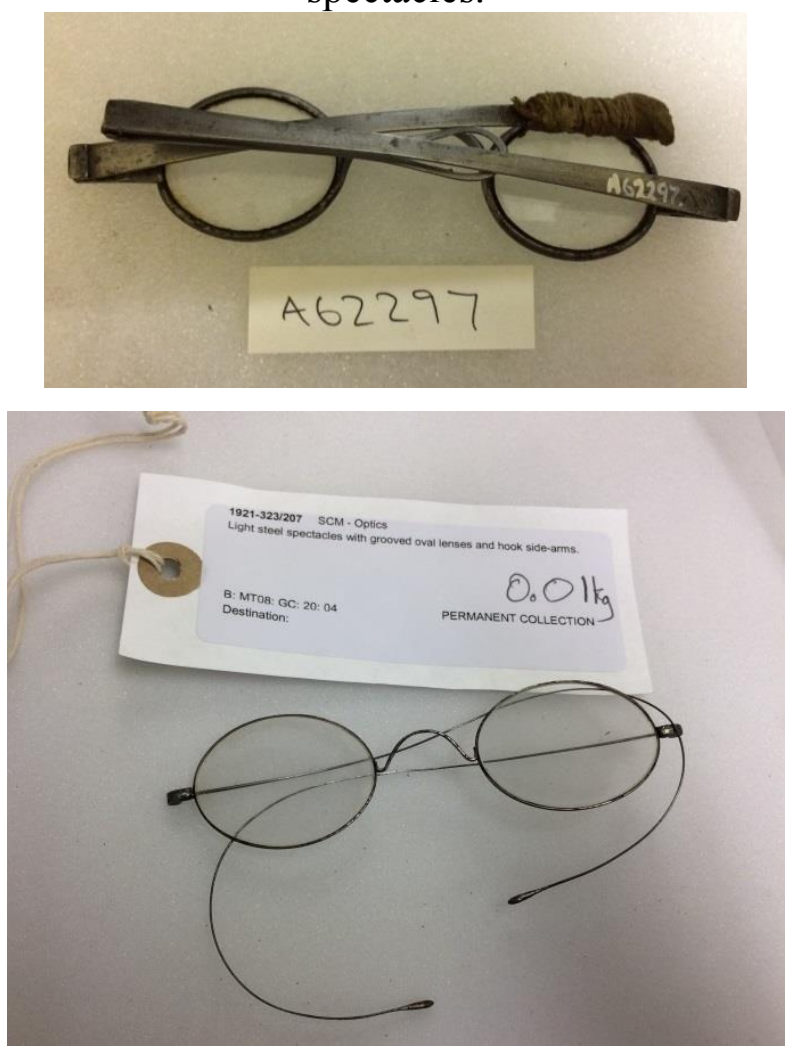

Similar to prostheses, the developments in spectacle design were influenced and intertwined with wider developments in science and technology. ${ }^{70}$ Patents show how broader changes in steel manufacture influenced vision aid frame design. From the mid-century patents primarily focused on a new technique of stamping or cutting out the necessary shapes from a piece of sheet metal. This was quickly applied to vision aid frames. In 1854, for example, a patent described a new process for producing vision aid frames that could replace older methods of casting and utilise 'dies or cutting tools and a stamp or press'. 71 In 1861 a variation of this process, which consisted 'of stamping or cutting out of the solid metal each several part

\footnotetext{
${ }^{70}$ See, for example, Alex Faulkner, 'Casing the Joint: The Material Development of Artificial Hips' in Artificial Parts and Practical Lives pp. 199-226, which explores how material technologies and wider developments in science and mechanical engineering influenced the overall development of hip technologies.

${ }^{71}$ John and Charles Greaves, Patent Number 1775, 15 August 1854.
} 
entire', was also patented. ${ }^{72}$ By the later nineteenth century, innovations in steel manufacture had helped to develop apparatus that was able to create thin wire. A patent from 1884, for example, described a process that would create spectacle frames out of a single piece of steel wire. ${ }^{73}$ A later patent sought to further strengthen the wire that was used in the manufacture of spectacles and eyeglasses. ${ }^{74}$ The actual process for forming steel wire for spectacle frames, which involved wrapping the metal around a cylinder, was discussed in a number of contemporary texts. The scale of manufacture is striking in these descriptions. In 1895 a visitor to the factory of Newbold and Bulford described the manufacture of vision aids in the factory's workshops, reporting in The Optician that:

To get the frames to assume the round wire-like form so much in vogue, the strips, as we have described them, are run through a series of perforations in metal plates on a draw bench, which is essentially a combination of a vice and a pair of very formidable pincers, which seizes the rough strip of metal, and being attached to a strong leathern band winding round a roller, which is actuated by a lever, it draws the length of metal through the series of graduated perforations till the required gauge is reached. ${ }^{75}$

Mass manufacture of thin-wire steel spectacles was part of wider changes in the construction of vision aids as whole, changes which sought to achieve a lighter and more standardised frame. In 1905 Lockwood described a process whereby 'several hundred turns' were made to create 'oval eye wires all of identically the same size'. ${ }^{76}$ Charles Booth's notebooks from the 1890 s also suggest that the manufacture of optical instruments was becoming increasingly mechanised. ${ }^{77}$ This mechanisation can be seen in a wider European context. In particular, German manufacture of vision aids expanded dramatically in the second half of the nineteenth century. B. Michael Andressen has listed the founding of a number of German optical factories, such as Nitsche \& Günther, Rodenstock and Zeiss, from 1846 onwards. $^{78}$ Additionally, H.W. Holtman has commented on the scale of

\footnotetext{
${ }^{72}$ Charles Eyland, Patent Number 451, 22 February 1861.

${ }^{73}$ S.Z. Ferranti, Patent Number 4584, 8 March 1884.

${ }^{74}$ F Ecaubert, Patent Number, 10, 576, 30 May 1893.

75 The Optician, 26 September 1895, p. 13.

${ }^{76}$ Lockwood, p. 30.

${ }^{77}$ This is discussed, for example, in an interview with Conrad Beck of R and J Beck in London School of Economics, Charles Booth's Notebooks: Booth/A/11, pp. 5-7. See also an overall discussion of the mechanisation of the optical industry in Charles Booth, Life and Labour of the London Poor, Second Series: Industry (London: Macmillan and Co., 1903), p. 41

${ }^{78}$ Andressen, p. 16.
} 
manufacture in Germany at this time, noting that 7.5 million spectacles were produced per year in Nuremberg and Furth in the mid-nineteenth century. ${ }^{79}$

In Britain itself, the manufacture of vision aids was increasingly being undertaken by wholesale companies. As early as 1831, an extract from the History of the County of York described the manufacture of lenses and spectacles in factories. It highlighted that 'about five gross per day of convex and concave lenses' were being ground in one shop. ${ }^{80}$ More recently, Catherine Gates has also explored Matthew Dunscombe's work for a Bristol firm in the mid-century, which supplied wholesale to Manchester, York, and London. ${ }^{81}$ Another optical business in the Science Museum's collections, Sheffield-based Chadburn and Son, is a useful example for assessing the advances that were being made in the manufacture of vision aids and lenses. Information about the firm's exhibit at the Great Exhibition of 1851 was displayed at the back of Alfred Chadburn's Observations on the Choice and Use of Spectacles. Here, they argued that spectacles were manufactured on a large scale, and their lenses were produced by steam power. ${ }^{82}$ Additionally, the information that they provided for the Children's Commission Committee supports the scale of manufacture in the mid-century. It details that they had a substantive workshop, machinery, overnight work and the employment of some children, usually above the age of thirteen. ${ }^{83}$

In 1893 Chadburn and Son's factory featured as part of a publication that documented a 'Century's Progress' of commerce in Sheffield, Rotherham, and Mexborough. ${ }^{84}$ In the 1890 s, other factories from individuals represented in the Science Museum's collection were described in The Optician. The factory of George Culver, the firm behind the 'revluc' eyeglass, for example, was first described in 1894. The Optician argued that Culver's factory would:

\footnotetext{
${ }^{79}$ Holtman, p. xx.

80 'Optical Instruments - Extracted from 'History of the County of York', Vol V by T. Allen in 1831', cited in Ophthalmic Antiques International Collectors Club Newsletter, No. 42 (1992), 9.

${ }^{81}$ Science Museum Technical File, T/1921-323: Catherine Gates, 'Matthew William Dunscombe: A Bristol Optician' (1997), p. 3.

${ }^{82}$ Sheffield City Archives, SY231: Observations on the Choice and Use of Spectacles, backpage.

${ }^{83}$ Sheffield City Archives, CA-VAC/119: Sheffield Town Council, Children's Commission Committee, From Manufacturers, Sheet 2.

${ }^{84}$ Sheffield City Archives, SYCRO 1731: Progress Commerce, 1893 - Sheffield, Rotherham, and Mexborough (The London Printing \& Engraving Company, 1893), p. 141.
} 
Make an Optician who quitted the world a hundred, fifty, or even twenty-five years ago, stare and rub his eyes could we revivify him and transplant him suddenly to an optical factory carried on in the most improved manner of to-day. ${ }^{85}$

A few years later the journal reported that a 'pair of 20 horse-power engines' operated the lens-making machinery in Culver's factory. ${ }^{86}$ Factories from other optical companies were also reviewed in favourable terms in The Optician across the 1890s. These suggest that other manufacturers had responded to wider advances in technological production. As also argued by Derek C. Davidson, in his short study on nineteenth-century metal spectacles, the manufacture and use of precise machinery had considerably advanced by the end of the period. ${ }^{87}$

Chadburn concluded in 1894 that 'amongst the improvements which time, experience and ingenuity have introduced into ordinary manufacture, few are more striking than those which affect the spectacle frame maker' ${ }^{88}$ Despite this, the development in manufacture did raise a number of concerns, most especially around the problem of skilled and unskilled labour. In 1905 Lockwood, for example, discussed how the machines being used were 'so perfect' that hand-craftsmanship was no longer required. ${ }^{89}$ In 1898 The Optician also worried that the manufacture, and repair, of frames in larger workshops and wholesale firms was reducing the 'handicraft work' required by opticians. ${ }^{90}$ In response to these changes, an employee of the Aitchison Optical Works in the 1890s suggested that Aitchison's company in the last decade of the century was run on the principle that the "personal equation should, as far as possible, be uppermost' and that a model whereby 'the machinery [was] subsidiary to the man had been carried out'. ${ }^{91}$ Chadburn and Son also employed 'a large number of highly skilled and experienced hands' in their extensive workrooms with 'elaborate and specially constructive machinery' at this time. ${ }^{92}$

\footnotetext{
${ }^{85}$ The Optician, 27 September 1894, p. 6.

${ }^{86}$ The Optician, 17 November 1898, p. 340.

${ }^{87}$ See, for example, The Optician, 31 March 1892, p. 3; 10 March 1892, p. 126; 26 September 1895, p. 13; 26 March 1896, p. 18; 25 March 1897, pp. 22-6; Davidson, 'Nineteenth Century Metal Spectacles', pp. 9-10.

${ }^{88}$ Sheffield City Archives, SY231: Observations on the Choice and Use of Spectacles, p. 8.

${ }^{89}$ Lockwood, p. 25.

${ }^{90}$ The Optician, 31 March 1898, p. 18.

${ }^{91}$ Boots Archives, DA16/8: An advance proof of an article titled 'Optics in the applications: Some workshop problems and processes’, 1890-1900s, p. 2; For more information on Aitchison, see chapter four, pp. 168-169.

92 Sheffield City Archives, SYCRO 1731: Progress Commerce, 1893 - Sheffield, Rotherham, and Mexborough (The London Printing \& Engraving Company, 1893), p. 141.
} 
Reference to the London firm, Curry \& Paxton, in Charles Booth's notebooks also indicates the number of people still employed in spectacle-frame manufacture. The questionnaire detailed a total of 129 employees from a range of occupations, including spectacle maker, folder maker, gold spectacle maker, gold folder maker, optical framer, glass grinder, glazier, engineer, carpenter and pointer. ${ }^{93}$ In 1895 the skill of these workmen was also commented on in a description of the firm's workshops in The Optician. ${ }^{94}$

However, regardless of whether optical manufacturers employed a 'large number of skilled workmen', changing manufacture had a lasting effect on the way that vision aids were constructed and designed. ${ }^{95}$ Davidson has suggested that the effectiveness of manufacturing machinery helped to promote the production and marketing of lenses and frames as 'interchangeable' in the late nineteenth century. ${ }^{96}$ Both the fact of mass-production and the use of the term 'interchangeable' to describe its outputs suggests that bespoke hand-made frames were being replaced by ready-made products. In 1899, the Anglo-American Optical Company sparked interest in The Optician because of their 'immense stock of interchangeable lenses' ${ }^{97}$ Across the $1890 \mathrm{~s}$, the journal suggested that most opticians were simply stockists. In 1891, for example, the editor claimed that 'we have no hesitation' in stating 'that not a single Optician manufactures his own glass'. ${ }^{98}$ An account in the journal of a thirteen-stone thirteen-year-old being prescribed spectacles further highlighted how individual frames were only made in certain instances; the boy had to have them specially made when 'the widest pair of frames in his [the optician's] large stock' were still too narrow. ${ }^{99}$ In fact, advertisements across the second half of

\footnotetext{
${ }^{93}$ London School of Economics, Booth/A/11: Charles Booth's notebook, pp. 78-8. Beyond this it is not easy to track the number of spectacle makers over a given period of time. In the Census Reports, for example, 'spectacle makers' were listed in 1844, but by 1861 they became 'spectacle makers, opticians' - causing numbers to increase dramatically - and then from 1871 onwards the category of 'spectacle maker' disappeared and only 'philosophical instrument makers, opticians' were individually listed.

94 The Optician, 24 January 1895, pp. 269-270.

${ }^{95}$ See footnote 99.

${ }^{96}$ Davidson, 'Nineteenth Century Metal Spectacles', p.10.

${ }^{97}$ The Optician, 30 March 1899, p. 48.

${ }^{98}$ The Optician, 7 March 1891, p. 91.

${ }^{99}$ The Optician, 20 July 1893, p. 718.
} 
the century frequently commented on the size of the stock that they housed. ${ }^{100} \mathrm{By}$ 1893 The Optician specifically advocated, in the event of unusual shaped faces, that the frames would need to be sent back to the 'spectacle maker'. ${ }^{101}$

The organisation of labour in the manufacture of vision aids was similar to the scientific instrument trade at this time, which had become increasingly subdivided and focused on piece-work. As part of this, retailers received a product that they need only stock or finish. ${ }^{102}$ The adoption of piece-work, and advance in manufacture, influenced the overall design and production of vision aids. Whilst Lockwood had suggested that spectacles were increasingly being constructed by piece-work, Charles Booth's notebooks showed at first-hand that the manufacture of optical instruments as a whole was becoming increasingly sub-divided. ${ }^{103} \mathrm{~A}$ breakdown of the employees of the prominent London firm, C.W. Dixey, in Charles Booth's notebooks, for example, showed that five employees were 'paid by piecework' and earned an average of 60/- per week. ${ }^{104}$ However, despite this, the effect of mass-manufacture on design was best revealed by a debate on 'ready-made' products. The debate was sparked in The Optician in the 1890s by one of C.W. Dixey's successors, W.A. Dixey. In 1898 W.A. Dixey responded to an article on 'Frames', which advised readers on how to select spectacles for a person out of a pre-bought stock and adjust them to the individual's face. ${ }^{105}$ W.A. Dixey argued that he would 'protest generally against the idea running through the paper that frames ought to be selected from a ready-made stock and 'adapted'. ${ }^{106}$ Whilst W.A. Dixey did not criticise the published advice on frame fitting, he advocated that a frame should be made to fit the person and not selected from a pre-bought stock. These comments received a number of responses, including the expense, technicality, and

\footnotetext{
${ }^{100}$ See, for example, Caledonian Mercury, 13 August 1859; Glasgow Herald, 14 March 1866; Birmingham Daily Post, 21 August 1872; The Blackburn Standard, 2 December 1882; Daily News, 1890.

${ }^{101}$ The Optician, 10 August 1893, p. 768; For advertisements see, for example, Hampshire Advertiser \& Salisbury guardian Royal Yacht Club Gazette, Southampton Town and Country Herald, Isle of Wight, Winchester Chronicle and General Reporter, 20 May 1837; 27 May 1837; 17 June 1837; 29 July 1837 and The Weekly Standard Express, 30 June 1900; 20 October 1900; 1 December 1900.

${ }^{102}$ Ben Russell, James Watt: Making the World Anew (London: Reaktion Books, 2014), pp. 13, 57-8, 65; However, as pointed out by A.D. Morrison-Low, the division of labour has only been hinted at by instrument historians because of lack of evidence: Making Scientific Instruments in the Industrial Revolution (Aldershot: Ashgate, 2007) p. 199.

${ }^{103}$ Lockwood, p. 30; London School of Economics, Booth/B/91: Charles Booth's notebook, p. 61.

104 Booth/A/11, p. 36.

105 The Optician, 31 March 1898, p. 26.

106 The Optician, 14 April 1898, p 172.
} 
number of workmen required to produce custom-made frames. ${ }^{107}$ The employee records of both Dixey and wholesale firms such as Curry and Paxton substantiate the claim that a number of workmen were required to produce vision aid frames. ${ }^{108}$ Both the records and debate in The Optician suggest that custom-made frames were increasingly becoming cost-intensive or unprofitable in comparison to the use of premade frames.

The manufacture of lenses or frames on the premises was still desirable in the latter half of the century. The desirability of self-manufacture can be seen in advertising claims, which detailed that initial manufacture or repair was being undertaken on the premises, or that they employed an 'efficient staff of workmen' in 'extensive workshops'. ${ }^{109}$ However, as early as 1847 , a London optician claimed that he was 'the only optician that manufactures spectacles on the premises'. ${ }^{110}$ Whilst this could have been an advertising ploy, there must have been some awareness that manufacture on the premises was becoming more unusual. Yet not all agreed with Dixey and thought that ready-made frames were an inferior alternative. In 1898 a 'student of optical handicraft' challenged Dixey in The Optician; the student questioned why an appropriately adjusted ready-made frame should be deemed 'unsatisfactory'. ${ }^{111}$ With the conclusion by some that 'a specially made frame is needed but rarely', there were growing calls in the latter half of the century for standardisation, and the availability of interchangeable lenses. ${ }^{112}$ By 1899 the use of 'interchangeable' lenses was mentioned by a number of companies. ${ }^{113}$ An advertisement for a new folder by a company in Hatton Garden stated that all of their frames were 'interchangeable' twice. ${ }^{114}$ Whether these lenses were ever truly 'interchangeable' by the end of century is open to question. However, spectacle and

\footnotetext{
${ }^{107}$ The Optician, 21 April 1898, pp. 221-2.

${ }^{108}$ Booth/A/11, p. 36; Booth/A/11, pp. 78-80.

${ }^{109}$ See, for example, Leeds Mercury, 1 August 1829; Examiner, 21 January 1838, p. 47; Lloyd's Weekly London Newspaper, 11 February 1844, 26 September 1847, 24 October 1847; The Bristol Mercury, 22 October 1853; The Hampshire Advertiser, weekly 7 January 1865 (for the whole year); Northern Echo, 30 July 1883; 29 August 1883; 10 September 1883; 24 September 1883; Longman's Magazine, May 1887, p. 8; 8 June 1887, p. 12; July 1887, p. 11; Macmillan's Magazine, May 1887, p. 24; June 1887, p. 25.

${ }^{110}$ Lloyd's Weekly London Newspaper, 11 February 1844, 26 September 1847, 24 October 1847.

${ }^{111}$ The Optician, 21 July 1898, p. 222.

${ }^{112}$ See, for example, comment on the 'Calibration of Spectacle Lenses', The Optician, 23 September, 1897, p. 104.

${ }^{113}$ See, for example, a new stock of lenses 'on the interchangeable plan' The Optician, 30 March 1899 , p. 116.

${ }^{114}$ The Optician, 16 March 1900, p. 919.
} 
eyeglass manufacture had grown in proportion. It had moved towards factory mechanisation, which favoured low-cost production and greater standardisation in both London and provincial areas. Derek C. Davidson has suggested that hand craftsmanship was rapidly disappearing by the start of the twentieth century. ${ }^{115}$ As this section has shown, this did not necessarily affect the employment of skilled men or the quality of the frame. However, it did create a frame design that was made of lighter materials, more uniform, and more suitable for larger-scale manufacture.

\section{The Functionality of Vision Aids in the Nineteenth Century}

Changes in design were linked to the broadening functionality of vision aids in the nineteenth century. Alun Withey has argued that alterations in the design of eighteenth-century spectacles influenced the way that the frames were used. ${ }^{116}$ For the nineteenth century, I argue that the changing function of vision aids influenced the way in which the frames and lenses were being designed. American optician Walter Alden in 1866, for example, argued that the preferred shape of a spectacle's frame or bridge depended on its intended purpose and what vision error it was 'correcting'. ${ }^{117}$ London-based opticians Charles A. Long and John Browning also explored the shape of the frame dependent on its purpose. ${ }^{118}$ In 1855 , for example, Long recommended a pantoscopic frame for 'long sight', and oval frames, as near to the eye as possible, for 'short sight'. ${ }^{119}$ Opticians' discussions raise a number of points for consideration: the expectation that spectacles might need to be worn continually, the importance of an accurate fit, and the varying positions of frames upon the face. When looking at the specific designs and materials of frames, authors discussed particular features. The key desirable selling points in both patents and advertisements of the period, for example, centred on lightness, convenience, fit of the frame, comfort and elasticity. In 1895 The Optician described a newly invented rigid bar eye-glass along these lines:

\footnotetext{
${ }^{115}$ Davidson, Spectacles, Lorgnettes and Monocles, p. 36.

${ }^{116}$ Withey, p. 94.

${ }^{117}$ Alden, pp. 104, 111-113.

${ }^{118}$ Long, pp. 21-3; John Browning, Our Eyes and How to Preserve Them from Infancy to Old Age. With Special Information About Spectacles, $7^{\text {th }}$ edn (London: Chatto \& Windus, 1887), pp. 65, 81, 83. ${ }^{119}$ Long, pp. 21-3.
} 
The pressure is easy, so that the eye-glass may be worn without discomfort. It can be put on with one hand only, as shown; is made with rimless or rimmed lenses; is very light; and is not liable to get out of order. ${ }^{120}$

Exploring these sources alongside the objects in the Science Museum's collections suggests that nineteenth-century design was driven by functional and practical considerations as well as manufacturing processes. This section explores three aspects to assess functional considerations in the nineteenth century: comfort; length of vision aid use; and the overall appearance of the frame. It argues that changes in design were not simply an outcome of improved manufacturing processes, but were also influenced by the overall importance of practical considerations and the appearance of the frame.

Alun Withey and Richard Corson have shown how spectacles were 'worn' on the face for the first time in the eighteenth century. ${ }^{121}$ Patents, material evidence, and advertisements in the nineteenth century suggest that wearing vision aids may have been uncomfortable. In 1891 a discussion of the newly patented 'cork bridge spectacles' in The Optician, for example, suggested that wearing spectacles could be a painful experience even at the end of the nineteenth century. The owner of the patent argued that it would 'prove a great boon to all wearers of spectacles' because:

\footnotetext{
Metal bridged spectacles... are a source of great pain and suffering to me, since by hurting and abraising the skin serious trouble has followed from their use, and [they] have been even known to have fatal results. ${ }^{122}$
}

Whilst this statement might be an exaggeration, it highlights, perhaps at the most extreme end, what changes in vision aid design were attempting to overcome.

Advancements in eyeglass design were frequently discussed in relation to weight and enhanced comfort. In 1897 a new eye-wire invention was published in The Optician because of its ability to 'alleviate pressure', for those 'who cannot bear the weight of spectacles on the bridge'. ${ }^{123}$ Preventing this discomfort became a primary motivation for new eyeglass designs. This is clear from newspaper and periodical advertisements from the second half of the century. Eyeglasses in the early 1880s, for example, were advertised as being able to stay 'firmly' upon the face 'without

\footnotetext{
${ }^{120}$ The Optician, 11 July 1895, p. 176.

${ }^{121}$ Withey, p. 92; Corson, p. 61.

${ }^{122}$ A. Davidson, Patent Number 15,928, 6 September 1891; The Optician, 8 November 1892, p. 112.

${ }^{123}$ The Optician, 8 April 1897, p. 76; J. Aitchsion, Patent Number 19, 864, 8 September 1896.
} 
marking' in the Liverpool Mercury. ${ }^{124}$ In 1890 'Anti-Pressure Eyeglasses' were also advertised in the Glasgow Herald and Scottish Review. ${ }^{125}$ Patents and new designs for eyeglasses towards the end of the century focused on adjusting the springs and pressure of the frame to prevent 'undue strain' or 'pinching'. ${ }^{126}$ These sources suggest that the experience of wearing certain vision aid frames may not have been comfortable in the nineteenth century. However, they also reveal how new designs attempted to alleviate this and provide improvements, which were based on two key considerations: the ability to be lightweight and the ability to be pleasant on the skin.

Weight was an important factor in nineteenth-century considerations of comfort and was closely linked to improvements in manufacture. Whilst a lightweight frame could be associated with flimsiness, early spectacles were heavy and reducing the weight of the frame became a primary concern. ${ }^{127}$ The ideal frame was summarised by Fenner in 1875: 'the material of which spectacle frames are made should be as light and as elastic as possible; but at the same time have the proper degree of strength'. ${ }^{128}$ An analysis of the average weight of 709 spectacle frames in the Science Museum's collections suggests that vision aids did get lighter across the century. As can be seen in Figure 5.15, older styles were about 10-20g heavier than newer designs.

\footnotetext{
${ }^{124}$ See, for example, Liverpool Mercury, 9 December 1881; 28 December 1881; 2 January 1882; 20 December 1883; 29 December 1883; 31 December 1883.

${ }_{125}^{125}$ Glasgow Herald, 17 October 1890; The Scottish Review, April 1890, p. 13.

${ }^{126}$ W.P. Thompson, Patent Number 9202, 28 June 1887; G.C. Bateman, Patent Number 15,300, 26 June 1897; See also discussion of new designs in The Optician, for example, 25 February 1892, p. 368; 17 May 1894, p. 81; 11 July 1895, p. 176; 17 September 1876, p. 361; 24 November 1899, p. 400; 30 March 1899, p. 48.

${ }^{127}$ Kitchiner, p. 108.

${ }^{128}$ Fenner, p. 106.
} 
Figure 5.15. Bar chart of the average weight (g) of 709 spectacles in the Science Museum's collections dating from between c.1800 and c.1900. They are arranged according to the design of their side-arms from the oldest (transverse folding) to the newest (coil spring) style of frame. ${ }^{129}$

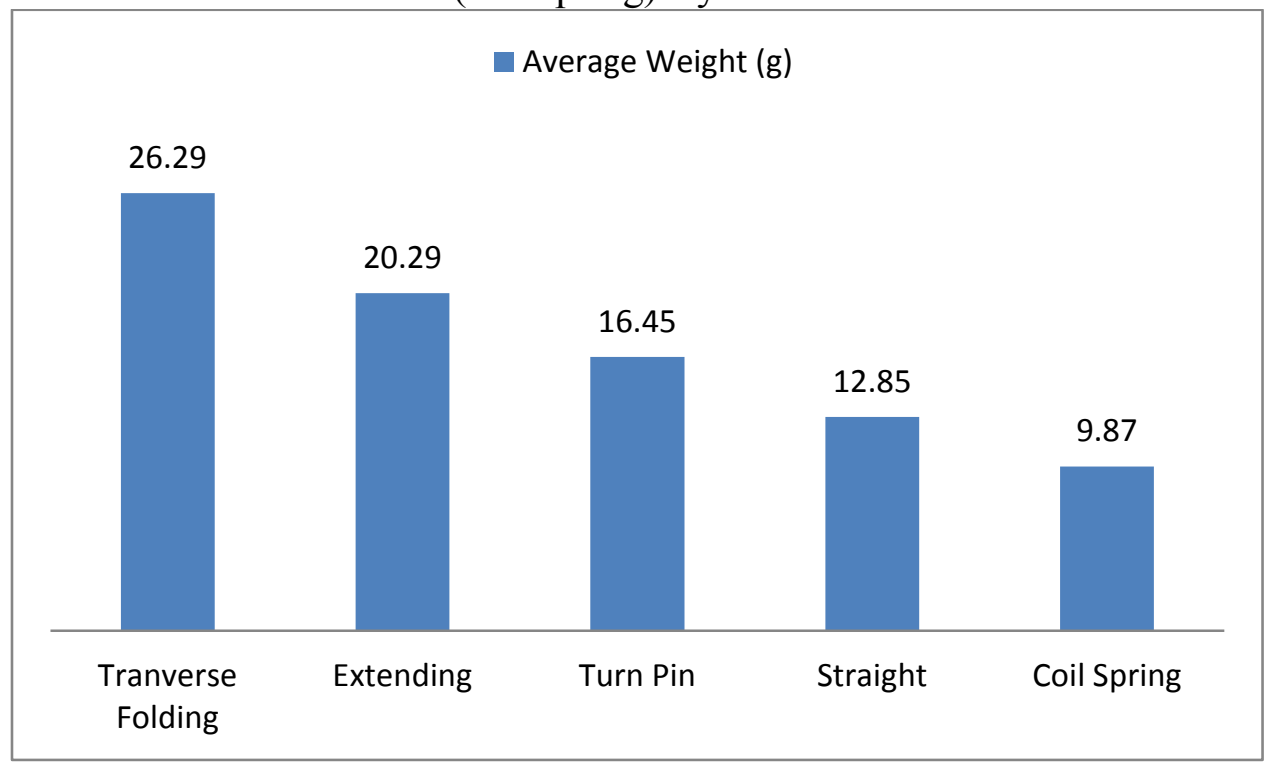

The effect of manufacturing changes on the weight of the frame can be clearly seen in the Museum's collections. As shown in figure 5.16, for example, the difference between the average weight of straight wire frames and the older sheet-cast metal or tortoiseshell designs was appreciable.

Figure 5.16. Bar chart of the average weight (g) of 201 older steel and tortoiseshell spectacles and 131 steel wire frames dating from between c.1800 and c.1900 in the Science Museum's Collections.

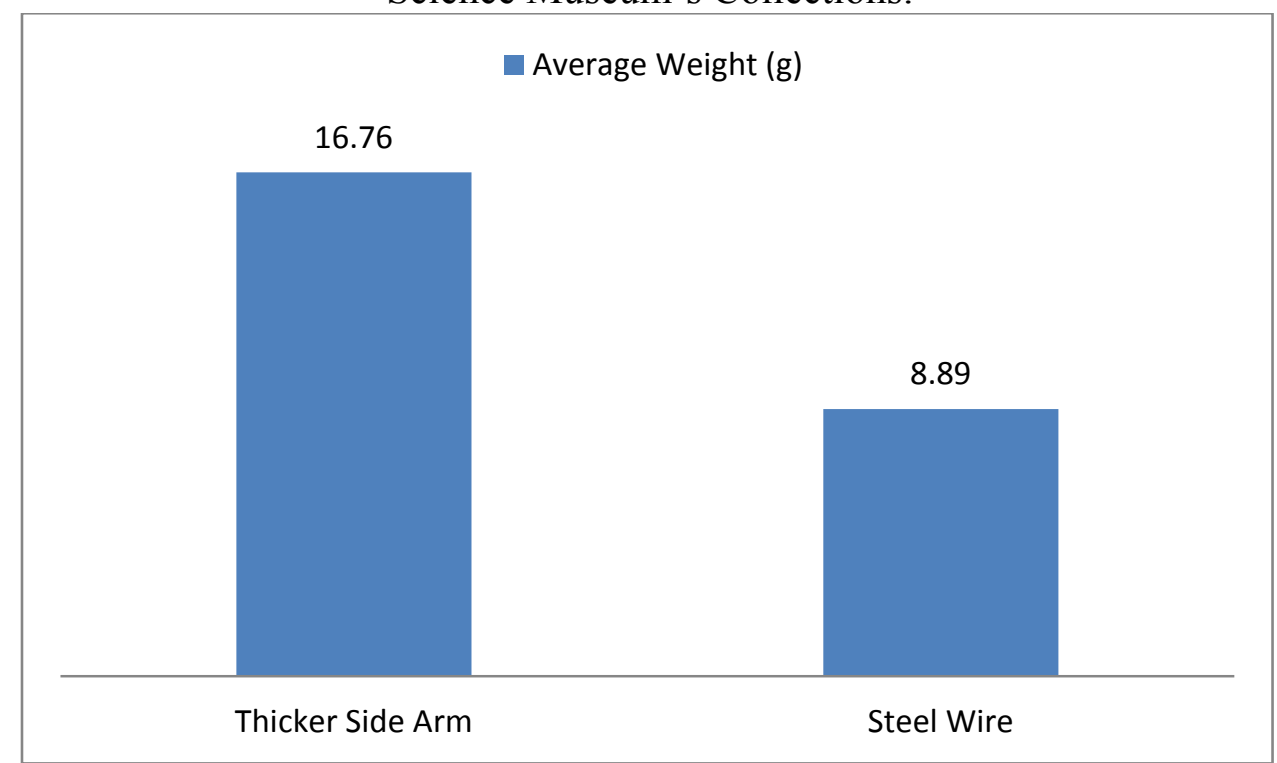

${ }^{129}$ Data derived from weighing the average weight of spectacle frames, in grams, in the Science Museum's ophthalmology and Dunscombe collections. 
Of course, this analysis of mean weights does not give a full account; straight spectacles could be as heavy as $38.33 \mathrm{~g}$ and the overall weight was affected by the weight or strength of the lens as well as the material of the frames. However, it does suggest that spectacle frames were becoming lighter. Moreover, contemporaries acknowledged the effects of manufacturing improvements on the weight of the frame. In 1894, for example, Chadburn discussed the advances in manufacture directly in the context of weight and considered light frames to be 'desirable'. ${ }^{130}$ Chadburn was not alone in this opinion, and in 1898 a lecture on the development of optics in The Optician concluded that:

It is only in this century that flexible and twisted wire side pieces have been introduced, and the advance in the handling of metal generally rendered it possible to make spectacle frames light and elegant. ${ }^{131}$

The emphasis on a light frame in advertisements and patents suggests that weight was not simply an outcome of improved manufacture but was a driving force behind new design innovations. The weight of the frame was consistently referred to in a regular column on new inventions in The Optician during the 1890s. In 1891, for example, the journal argued that a 'Useful Folder' had many 'desirable features', including its ability to combine 'lightness with strength'. ${ }^{132}$ Correspondingly, the heaviness of a frame could prevent the popularity of certain frames or be seen as a 'counteracting disadvantage'. ${ }^{133}$ The weight of the frame was a desirable selling point in advertisements across the century. In 1834, for example, an advertisement claimed that their spectacle frames were 'extremely light' and 'much-admired'. ${ }^{134}$ Newspapers in a variety of locations, including Hampshire, Ipswich and Liverpool, also discussed the 'peculiar lightness' or 'lightness and elegance of shape' of their various frames between 1837 and $1864 .^{135}$

The emphasis on weight was part of wider concerns surrounding the comfort of the frame and the expectation that vision aids would be worn on the face for both

\footnotetext{
${ }^{130}$ Sheffield City Archives, SY231: Observations on the Choice and Use of Spectacles, p. 8.

${ }^{131}$ The Optician, 21 April 1898, p. 201.

132 The Optician, 11 June 1891, p. 172.

${ }^{133}$ The Optician, 6 July 1893, p. 692; 31 March 1898, p. 30.

${ }_{134}$ Arnold's Magazine of the Fine Arts, and Journal of Literature and Science, May 1834, p. 10

${ }^{135}$ Hampshire Advertiser \& Salisbury Guardian Royal Yacht Club Gazette, Southampton Town and Country Herald, Isle of Wight, Winchester Chronicle, and General Reporter, 20 May 1837; 27 May 1837; 17 June 1837; 29 July 1837; Ipswich Journal, 3 June 1854; Liverpool Mercury, 9 July 1864.
} 
short and extended periods of time. The 1897 Exhibition Catalogue for the original Dunscombe collection discussed the reduced weight of the lenses, as well as the frame. ${ }^{136}$ Yet Dunscombe's descriptions of different styles of frame reveal additional features that were considered in nineteenth-century attempts to produce a comfortable device. Dunscombe proposed that a number of other design features, alongside weight, were being introduced to increase comfort and improve the wearing experience. The 'Twisted Wire Hook-side Zeffyr Spectacle' in the first Dunscombe collection, for example, was designed to 'prevent irritation of skin' by not resting upon the nose. ${ }^{137}$ Attempts to improve the comfort of a frame on the skin can also be seen in the catalogue of Dunscombe's second collection, which detailed new spectacle bridges designed 'to reduce pressure' and new 'comfort plaquets' for eyeglasses. $^{138}$

The use of additional materials to increase the comfort of the frame can be found in both the first and second collections. The number of vision aid frames with additional soft material on the side-arms is striking in the Museum's collections, and especially on straight frame designs. Rosenthal, in his volume on vision aids, has described how pads of a 'feltlike material' can be found on the inside of some straight side-arms. ${ }^{139}$ This can be seen on many tortoiseshell straight frames in the collections. The number of frames with additional materials suggests that it was a standardised practice, which was adopted to enhance the frame's comfort. Forty-one tortoiseshell spectacles, with straight arms, which date mostly from the late eighteenth to mid-nineteenth century, have material still attached to the ring ends or sides of the arms. On one frame, the material had only survived on one arm, and this frame revealed the type of serrated marks that could be left when the material had been worn away. These serrated marks can be found on a further thirty-five tortoiseshell frames, which likely had material attached that has since, through the passage of time or the receipt of damage, been removed. ${ }^{140}$

\footnotetext{
${ }^{136}$ See discussion of lenses, for example, in the Science Museum's Technical File T/1921-323: Catalogue of the 'Exhibit of Spectacles at the Victorian Era Exhibition', p. 7.

${ }^{137}$ Ibid., p. 9.

${ }^{138}$ See, for example, Science Museum's Dunscombe collection, object numbers 1921-323/223 and 1921-323/103.

${ }^{139}$ Rosenthal, p. 111. Rosenthal used alternative terminology for side-arms, including 'temples' and 'circular tips'.

${ }^{140}$ Science Museum's Ophthalmology collection, object number A62438 revealed this.
} 
Figure 5.17. Science Museum's Wellcome collection A62431 and A62416, examples of tortoiseshell spectacles with felt-like padding, and the serrated marks that can be found on the frames, most likely from previous material attachment.
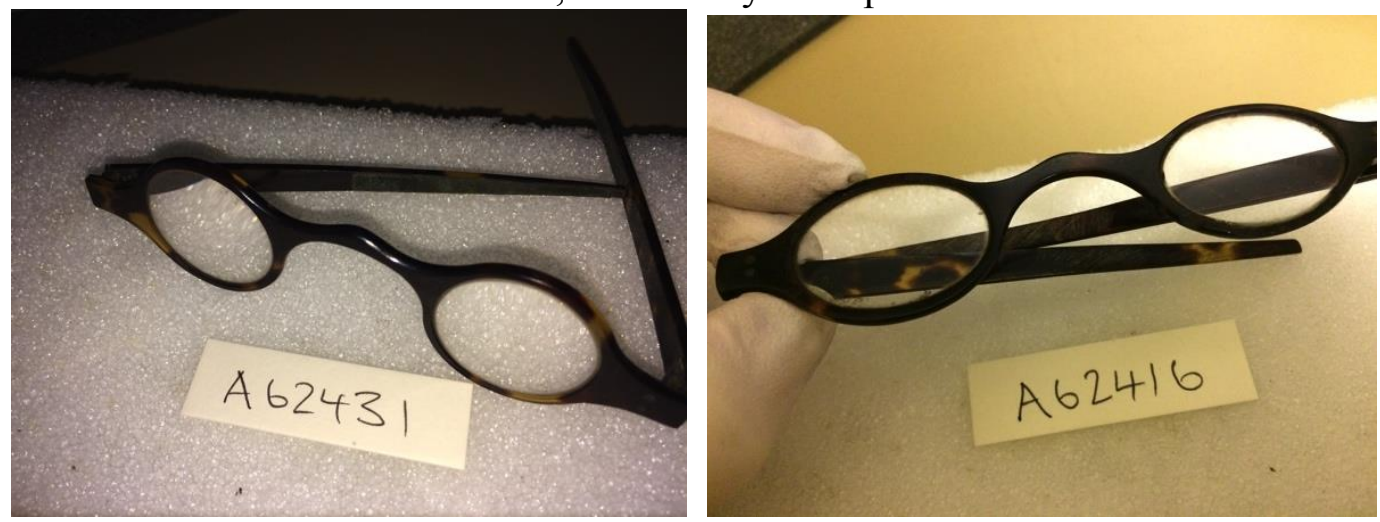

Whilst the number of spectacles with felt-like material on tortoiseshell frames suggests that there was a more standard approach to increasing the comfort of the frame, a variety of spectacles in the collection have material evidence remaining. These additional frames suggest that the frames could have been adapted or adorned on a more individual basis. Some of the loop ends of metal spectacles, for example, included material that was bound around the ends. Additionally, there were also instances of material appearing on the bridge, where there were no obvious signs of damage or a user's attempt at a makeshift repair. 
Figure 5.18. Science Museum's Wellcome collection A62550 and A681374, examples of objects with material on the bridge and ring ends in the Science Museum's collections.
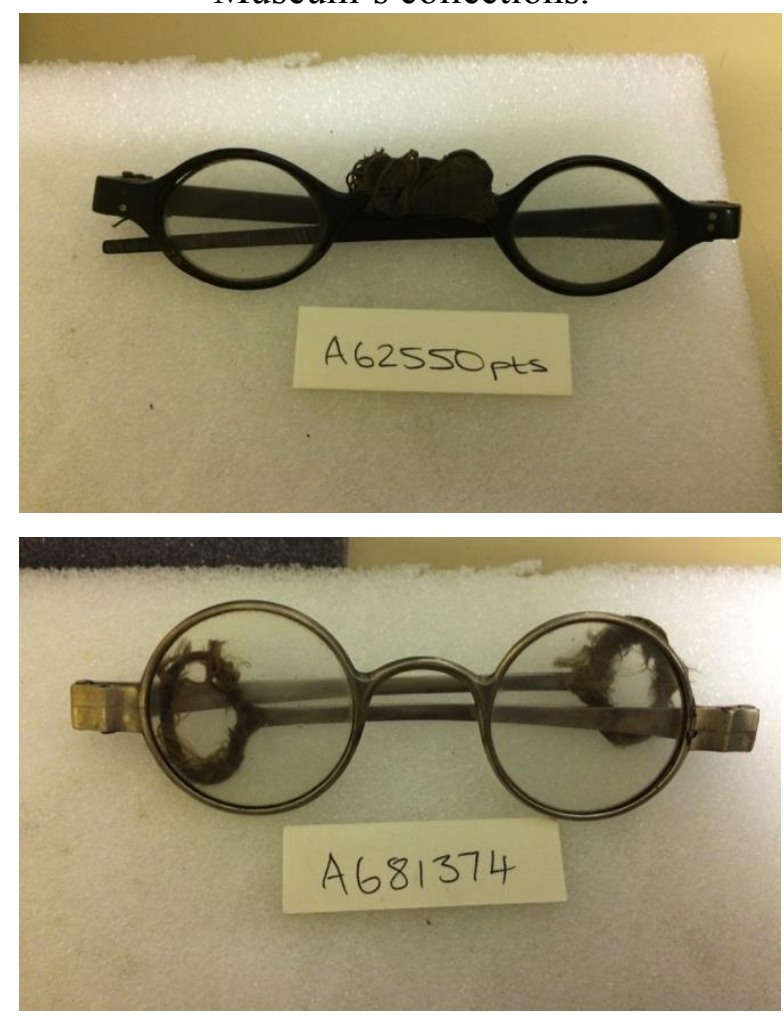

Both tortoiseshell and metal frames could include very thick material to improve the comfort and padding of the spectacles. This application of material was not restricted to older frames: and lighter steel wire frames had additional material added in some instances, such as the small end attachment that can be seen in Figure 5.19.

Figure 5.19. Science Museum's Wellcome Collection A681780, example of a straight wire frame with end attachment to increase comfort.

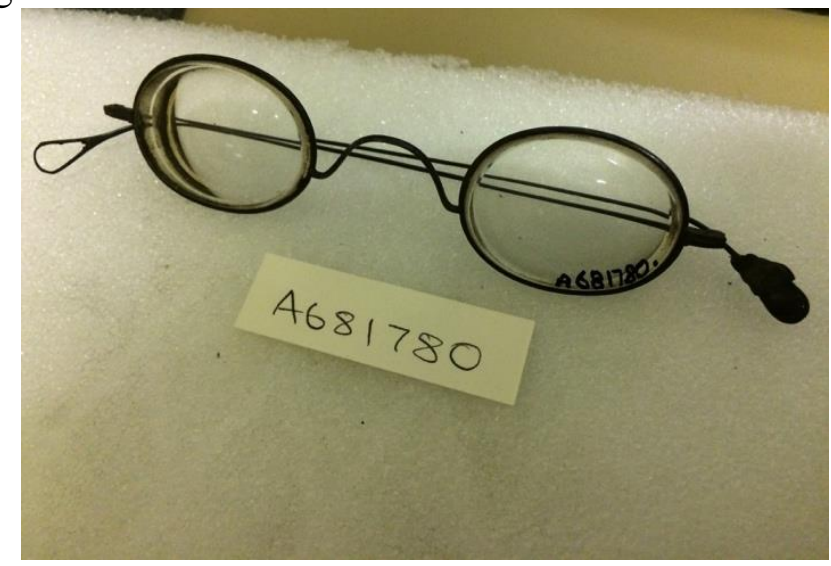


From the objects alone it is not possible to know whether these adjustments were undertaken by the maker or the wearer. However, patents from the period include the use of additional materials on spectacles and eyeglasses to alleviate discomfort. These patents suggest that the maker, as well as the wearer, added material to vision aid frames. In particular, the use of India-rubber and rubber tubing was discussed by contemporaries and attached to the bridge or side-arms to prevent irritation. ${ }^{141}$ Correspondingly, the catalogue of the first Dunscombe collection revealed that both newer and more traditional materials could be used. A couple of hook-side frames, for example, included a tortoiseshell plate on the bridge 'for tender skin', as well as celluloid on the spectacle sides 'to prevent contact of metal with the ear'. ${ }^{142}$

Patents for eyeglasses in the last two decades of the century also frequently discussed reducing the overall pressure of the frame through the addition of materials to the eyeglass plaquets. ${ }^{143}$ A number of materials, including cork, xylonite, and 'Indian-rubber', appeared on the plaquets of eyeglasses to improve comfort in the second half of the nineteenth century. Figure 5.20 shows that most of the 261 eyeglasses that were studied in the Science Museum's collections had cork plaquets.

\footnotetext{
${ }^{141}$ See for example, A.J. Boult, Patent Number 11,710, 27 August 1884; Patent Number 15,928, A. Davidson, 6 September 1891; J. Rintoul, Patent Number 6127, 24 March 1894; L.J. Flowerdew, Patent Number 14,458, 15 June 1893; D. Rugg, Patent Number 21,755, 13 August 1900.

${ }^{142}$ Science Museum's Technical File: T/1921-323: Catalogue of the 'Exhibit of Spectacles at the Victorian Era Exhibition', p. 9. An example of a frame with a 'shell-lined bridge' is also present in the current Dunscombe collection at the Science Museum, object number 1921-323/210.

${ }^{143}$ Curry and Paxton, Patent Number 22,304, 19 November 1894; See also, for example, A.J. Boult, Patent Number 11,710, 27 August 1884; W. Barr and D. McKay, Patent Number 10,344, 31 May 1891; W. Barr and D. McKay, Patent Number 15, 415, 14 August 1892; E. Brown, Patent Number 14, 025, 21 July 1894; H. J. Thatcher, Patent Number 22, 657, 28 October 1894.
} 
Figure 5.20. Bar chart of the kinds of plaquet materials utilised in 261 eyeglasses dating from between c.1800 and c.1900 in the Science Museum's collections. ${ }^{144}$

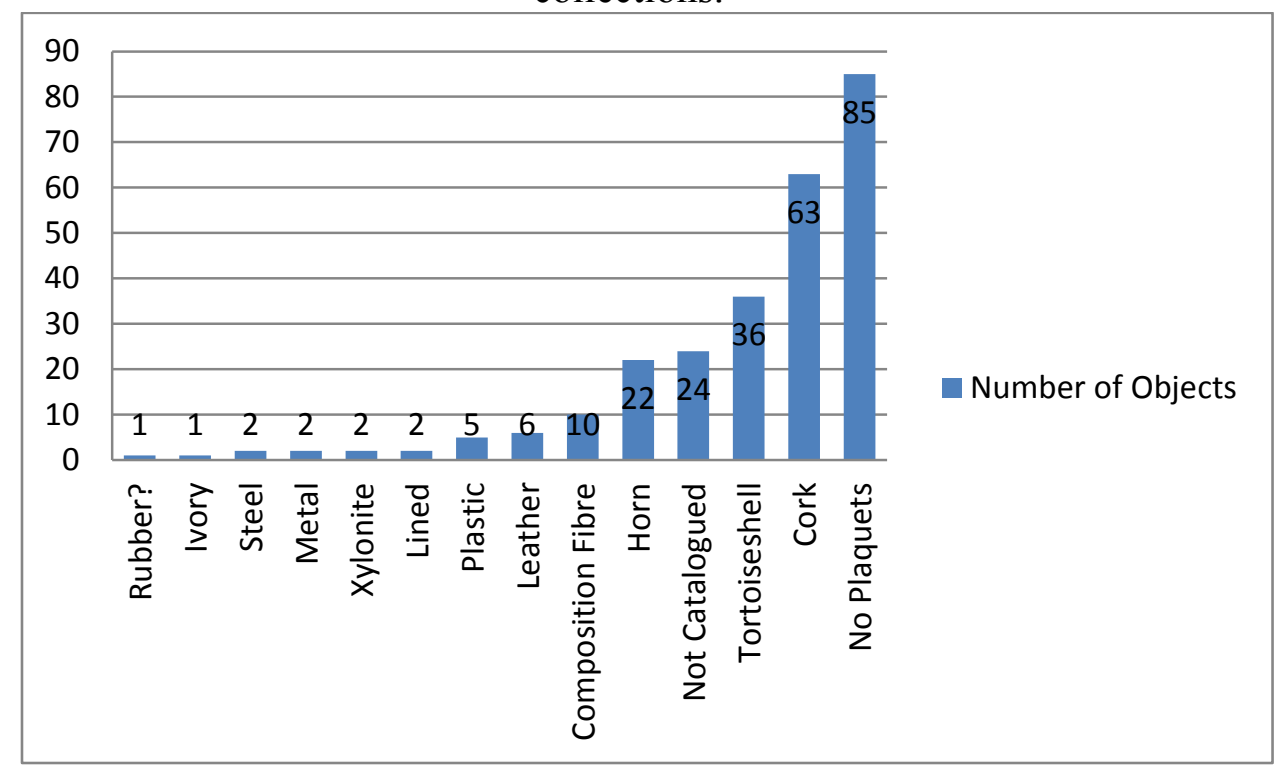

In 1897 The Optician also stated that cork was used on 'nearly all' eyeglass nosepieces. ${ }^{145}$ The use of additional materials on eyeglasses can be considered similar to the addition of materials on spectacle frames. However, Rosenthal concluded that cork became the most popular material because it served two primary functions, namely to improve comfort and also improve grip. ${ }^{146}$ Additional materials can be seen as an attempt to improve comfort as well the overall fit of the frame. These improvements were, in part, being driven by changing manufacturing processes and new material technologies. However, the language used to describe the key features of these designs also reveals that improvements were influenced by the expectation that vision aids should fit well and be comfortable, especially when worn for an extended period of time.

Opticians and medical practitioners expected new designs to be comfortable and suitable for more long-term use. Manchester opticians, Messrs Wood (late Abraham), for example, created in 1892 a pair of eyeglasses that were able 'to be used without intermission for a whole day, and not produce annoying or unpleasant

\footnotetext{
${ }^{144}$ Data derived from the 'materials' field of the object descriptions in the Science Museum's object database.

${ }^{145}$ The Optician, 15 April 1897, p. 84.

${ }^{146}$ Rosenthal, p. 243.
} 
effects'. ${ }^{147}$ Phillips argued that 'hook' and 'straight' side-arms for spectacles were 'to be preferred in all cases where the glasses are to be worn constantly'. ${ }^{48}$

Discussion of comfort was directly related to the expected function of these frames and their growing suitability for continuous use. How long vision aids were worn for is difficult to ascertain. Looking at the prescription and type of lens of spectacles and eyeglasses in the Science Museum's collections does reveal something about the potential purpose of these vision aids. Strikingly, although collected differently the collections reveal similar findings. The overwhelming majority of lenses were convex, and would have likely been used for long-sight or presbyopia, and aid with reading in later life. This is evident in Figure 5.21 below, which details the lens type for 709 spectacles and 261 eyeglasses in the Museum's collections.

Figure 5.21. Table of the type of lens utilised in 709 spectacles and 261 eyeglasses dating from between c. 1800 and c. 1900 in the Science Museum's Dunscombe and Ophthalmology collections. ${ }^{149}$

\begin{tabular}{|lcr|}
\hline Lens Type & Spectacles & Eyeglasses \\
\hline Convex & $75.46 \%$ & $57.09 \%$ \\
\hline Concave & $12.83 \%$ & $20.31 \%$ \\
\hline Other/Unknown & $11.71 \%$ & $22.60 \%$ \\
\hline
\end{tabular}

Across both collections convex lenses were the largest single type of lens fitted into spectacle frames, and roughly comprised three quarters of the total collection. However, Figure 5.21 also shows that there were a greater number of eyeglasses with concave lenses, which mostly dated from the latter half of the nineteenth century. The increase in concave lenses could suggest that vision aid usage was changing across the century.

Two opticians' account books support the findings in the Science Museum's collections. The accounts show that concave lenses were bought less frequently. ${ }^{150}$

\footnotetext{
${ }^{147}$ The Optician, 25 February 1892, p. 368.

${ }_{148}$ Phillips, Spectacles and Eyeglasses, pp. 40-49.

${ }^{149}$ Further analysis of the overall strength of the lens was prevented because of conservation concerns.

${ }^{150}$ Carlisle Archive Centre, DB9/1-77: John Potter Dowell, Cash and Day Book (Sales), 1885-1898; Cambridge University Library, GBR/0012/Ms Ad.5781-5783: Robert Sadd \& Co. Account Books 1837-1851 and Ledgers 1845-1889.
} 
Additionally, the account books of Robert Sadd of Cambridge in the mid-century and John Potter Dowell of Carlisle in the last two decades of the period suggest that people could own numerous pairs. Multiple transactions for an individual person are revealing and show that individuals could buy a range of vision aids, such as spectacles, folders, eyeglasses, and readers. In the ledgers of Robert Sadd, for example, Mr Owen of Clare College purchased spectacles, and eyeglasses between December 1863 and January $1865 .{ }^{151}$ Similarly, Mr French in the cash and day book sales of John Potter Dowell purchased and repaired numerous different types of frames, including spectacles, eyeglasses and folders between the 9 January 1888 and 15 April $1892 .{ }^{152}$ Lenses were frequently purchased but the type of lens was not recorded consistently to trace patterns of individual ownership. Despite this, Mr J. Hitzman, although a watchmaker and not necessarily representative of usual practice, visited Sadd between 1855 and 1867 and utilised vision aids for both near work through the purchase of convex and pantoscopic lenses - as well as for distant vision through the purchase of concave lenses. ${ }^{153}$ By the end of the century, John Potter Dowell had introduced the use of prescription lenses at his Opticians and Jewellers store in Carlisle and these were purchased, for example, by Mrs Wilson on $3^{\text {rd }}$ February $1897 .^{154}$

The accounts make it possible to track a growth in the variety of lenses and the use of vision aids for near and far work. Lenses with a dioptric prescription were part of wider advances in vision testing and the measurement of vision, which has been discussed in previous chapters. The development of the cylindrical and bifocal lens also reveals the changing nature of vision aid use. Previous work on the history of spectacles has tended to track the key developmental stages of these lenses from debates that surround their origin to the improvements at the end of the century. ${ }^{155}$

\footnotetext{
${ }^{151}$ Cambridge University Library, GBR/0012/Ms Ad.5781-5783: Robert Sadd \& Co. Ledger 1, p. 109.

${ }^{152}$ Carlisle Archive Centre, DB9/4 John Potter Dowell, Cash and Day Book (Sales), 1888-1890: dates 9 January 1888, 14 February 1888, 9 March 1888, 26 April 1888, 20 November 1888, 10 December 1888, 2 January 1890, 16 January 1890, 14 July 1891, 23 March 1892; 15 April 1892 [unpaginated] ${ }^{153}$ Cambridge University Library, GBR/0012/Ms Ad.5781-5783: Robert Sadd \& Co. Ledger 1, p. 17, and Ledger 2, sheet 75; also see comment on watchmakers and eyesight in chapter one, pp. 53, 54-5. ${ }^{154}$ Carlisle Archive Centre, DB9/7: John Potter Dowell, Cash Book (Sales), 1897-1898 and Day Book 1896: Day Book, 3 February 1897 [unpaginated].

${ }^{155}$ See, for example, Bi-focals Barck, p. 15; Rosenthal, pp. 258-261; Corson, pp. 31, 129-133; Bifocals: Rosenthal, pp. 246-55; Corson, pp. 132-3; Wolfgang H. Vogel and Andreas Berke, Brief History of Vision and Ocular Medicine (Amsterdam: Wayenborgh Publishers, 2009), pp. 209, 239;
} 
However, they have not considered how the introduction of more complex lenses could have influenced overall frame design. By the later nineteenth century, lenses were being developed for both continual and more complex use. Consequently, the fit of the frame needed to be secure because where the person looked through the frame was becoming increasingly more important for successfully enhancing a person's vision. Early bifocals, for example, appeared in advertisements during the first half of the century. Descriptions such as 'double spectacles to see at far and near distance', and the 'best glasses in silver frame for near and distant sight' can be found in London and provincial publications. ${ }^{156}$ By 1905 Lockwood argued that 'the finest and most expensive form of bifocal' was the 'Kryptok or invisible bifocal'. ${ }^{157}$ Dunscombe was one of the co-founders of the Kryptok Company. The catalogue for his surviving second collection, as shown in Figure 5.22, reveals how the company perceived its lens to be the culmination of a number of nineteenth-century advances.

Figure 5.22. Front cover of the catalogue for Dunscombe's second collection. ${ }^{158}$

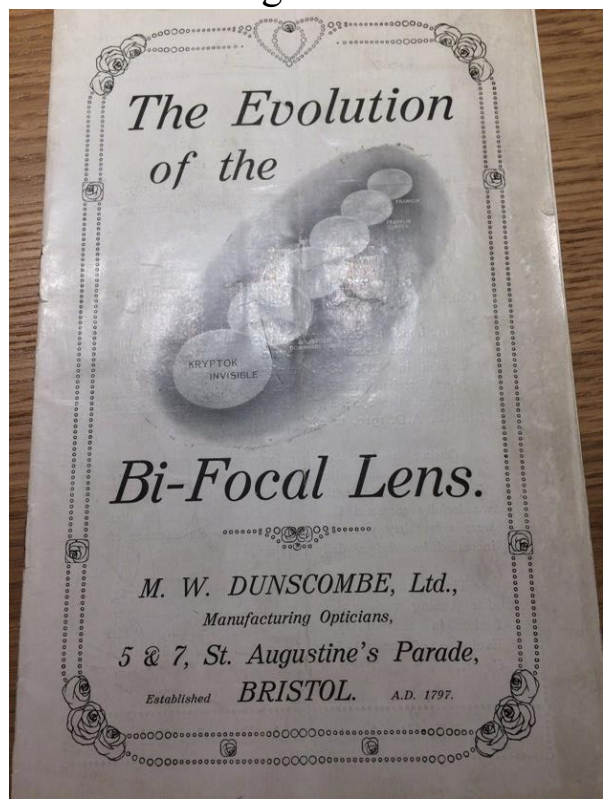

Dorothy M. Turner, 'Thomas Young and the Eye on Vision', in Science Medicine and History: Essays on the Evolution of Scientific Thought and Medical Practice Written in Honour of Charles Singer, ed. by E.A. Underwood (Oxford: Oxford University Press, 1954), pp. 243-55; Daniel M. Albert, 'Ocular Refraction and the Development of Spectacles', in The History of Ophthalmology, ed. by Daniel M. Albert and Diane D. Edwards (Oxford: Blackwell Press, 1996), p. 119.

${ }^{156}$ Hampshire Advertiser \& Salisbury Guardian Royal Yacht Club Gazette, Southampton Town and County Herald, Isle of Wight Journal, Winchester Chronicle, and General Reporter, 12 August 1837; The London Dispatch and People's Political and Social Reformer, 8 October 1837; 22 October 1837; 19 November 1837; 26 November 1837; 24 December 1837; 25 March 1838; July 1838; 9 December 1838.

${ }^{157}$ Lockwood, p. 21.

${ }^{158}$ Science Museum Technical File, T/1921-323. 
It is not possible to assess the demand for the bifocal or cylindrical lenses. However, in 1900 an American adjunct professor of Ophthalmology who published in London, James Thorington, recorded the use of the sphero-cylindrical lens and the newest advancements in the bifocal lens, including the 'Perfection' or 'Cement Bifocals'. ${ }^{159}$

Thorington also highlighted how cylindrical lenses had two focal planes and bifocals had two distinct fields of vision. Alongside the development of more precise measurements for simple refractive errors, different focal points on a single or bifocal lens needed to be accommodated. The complexity of these lenses meant that medical practitioners discussed, and opticians advertised, an unprecedented demand for accuracy when positioning the frame upon the face. Contemporary debates on the use of spectacles and eyeglasses show how important precision had become in the placement and wear of spectacles. A good fit arguably took on a greater degree of importance in the latter half of the century, and the advertisement of frames that did not 'slip from the face' can be found from the $1850 \mathrm{~s} .{ }^{160}$ Yet the debate between spectacles and eyeglasses in medical and contemporary texts can also highlight the varying function or purpose of nineteenth-century vision aids in terms of how they were worn, i.e. for short or long-term use. Eyeglasses were seen across the century as being capable of damaging the eyes because of their lack of security upon the face. Before the development of the pince-nez, criticism was directed towards the danger of using single eyeglasses, but this was more primarily focused on over-use of one eye rather than the position of the lens. ${ }^{161}$ By the second half of the nineteenth century, however, medical practitioners considered the ease with which eyeglasses could be displaced, or the difficulty of placing them consistently before the centre of the pupils, as a decided disadvantage. ${ }^{162}$ Spectacles, on the other hand, were

\footnotetext{
${ }^{159}$ James Thorington, Refraction and How to Refract, Including Sections on Optics, Retinoscopy, the Fitting of Spectacles and Eyeglasses, etc (London: Rebman Ltd, 1900), pp. 44, 131-5, 272-281.

${ }^{160}$ See, for example, The Critic, 15 July 1852, p. 386; 16 August 1852, p. 435; 15 January 1853, p. 54; 15 February 1853, p. 106; 15 March 1853, p. 159; 15 April 1853, p. 215; 16 May 1853, p. 251; 15 August 1853, p. 447; 15 February 1854, p. 109.

${ }^{161}$ See, for example, Georg Beer, The Art of Preserving the Sight Unimpaired to Extreme Old Age; and of Re-establishing and Strengthening it When it is Become Weak (London: Henry Colburn, 1815), pp. 80-81; West, pp. 14-15; Ross, p. 7; Smee, p. 49; Alden, p. 37

${ }^{162}$ See, for example, Phillips, Ophthalmic Surgery, p. 51; Fenner, pp. 108-9.
} 
described as 'sturdy' and 'sensible', in more popular newspapers in 1886 and $1892 .{ }^{163}$

Whilst the use of eyeglasses could be criticised, they could also be considered appropriate if they were not intended for 'continued use'. ${ }^{164}$ In 1875 Fenner concluded that 'they are very easily and quickly applied, and serve their purposes excellently when used only for a short time'. ${ }^{165}$ Similarly, in 1880 Carter described the convenience of a pince-nez as 'an accessory', but not as 'the chief reliance of its owner' ${ }^{166}$ In response to these discussions, practical considerations for both types of design were considered. Indeed, the function of eyeglasses for shortterm use meant that convenience became an important design feature. As early as 1825, London-based optician and instrument maker, Robert Bretell Bate, invented a spring mechanism that enabled hand folders to unfurl by means of a 'curved lever'. ${ }^{167}$ Moreover, by the end of the nineteenth century, convenience, in the form of being able to take eyeglasses on and off quickly and efficiently with one hand, was considered in both the patents and discussion of new inventions in The Optician. ${ }^{168}$ Patents to improve the spring mechanism or convenience of the frame, for example, can be found in the $1890 \mathrm{~s} .{ }^{169}$ This convenience was taken a step further by the end of the nineteenth century; two patents in 1898 and 1900 allowed the frames to be used without even taking them out of the case. ${ }^{170}$

British ophthalmologist, Robert Brudenell Carter, preferred spectacles for permanent wear because they were 'correctly centred' and enabled the wearer 'to run, ride, dance, or perform any other movements, without the glasses becoming

\footnotetext{
${ }^{163}$ The Sheffield \& Rotherham Independent, 8 April 1886, p. 8; The Yorkshire Herald, and the York Herald, 6 February 1892.

${ }^{164}$ See, for example, Alden, p. 103.

${ }^{165}$ Fenner, p. 108.

${ }^{166}$ Carter, pp. 252-3.

${ }^{167}$ Robert Bretell Bate, Patent Number 5124, 15 March 1825.

${ }^{168}$ See, for example, The Optician, 11 July 1895, p. 176; 21 May 1896, p. 138; 30 July 1896 p. 272; 17 December 1896, p. 176.

${ }^{169}$ See, for example, A.W. Newbold, Patent Number 23, 129, 2 December, 1893; J. Raphael, Patent Number 8366, 27 April 1894; G. Spiller, G.S. Martin and A.R. Toole, Patent Number 9598, 15 May 1895; C.E. Fitzgerald and G. Prescott, Patent Number 16, 214, 22 July 1896; W. Salt, Patent Number 8046, 4 April 1898; R.C. Hines and H.B. Waddey, Patent Number 16, 314, 10 August 1899.

${ }^{170}$ W. Jones, Patent Number 14, 663, 4 July 1898; A. Kahn, Patent Number 20,934, 20 November 1900.
} 
displaced'. ${ }^{171}$ Carter compared spectacles and eyeglasses to highlight how vision aids could be worn differently for different purposes. Whilst eyeglasses sought convenience and overall fit, spectacles needed to be adapted to an increasing number of activities, which ranged from reading a short document to dancing. Some retailers in newspapers and periodical advertisements discussed the use of their vision aids for more conventional activities, including drawing, writing, music, and needle-work. ${ }^{172}$ However, patents from the nineteenth century also suggest that there were a multitude of miscellaneous functions that spectacles could also serve. Patents, for example, included a number of frames that enabled users to see behind, or those that allowed an individual to attach a light to the frame to accommodate different occupations, including one for jewellers in 1883 and one for surgeons in $1888 .{ }^{173}$ Yet advertising retailers could also focus on perhaps more conventional, but broader, activities. In 1887, for example, a testimonial in an advertisement in The Wrexham Advertiser and North Wales News commented on having a pair of spectacles for reading, and a pair of spectacles for walking. ${ }^{174}$ In 1894 a new combined folder was also discussed in the The Optician, which came with 'detachable curlsides', and could be used on certain occasions 'such as horse-riding, playing cricket, tennis, music, cycling etc'. ${ }^{175}$

The demand for more precise prescriptions and the use of frames for more physical activities, heavily influenced frame design. Frames were expected to be secure on the face to ensure the greatest degree of accuracy for both short- or longterm usage. This is not to say that all frames had achieved a good fit by the end of the nineteenth century. The potential lack of improvement in either the overall angle of the lens or fit of the side-arms is evident in contemporary photographs. As shown

\footnotetext{
${ }^{171}$ Ibid. p. 253.

${ }^{172}$ See, for example, Hampshire Advertiser \& Salisbury Guardian Royal Yacht Club Gazette, Southampton Town and Country Herald, Isle of Wight, Winchester Chronicle, and General Reporter, 20 May 1837; 27 May 1837; 17 June 1837; 29 July 1837; North Wales Chronicle, 15 August 1837; 22 August 1837; Derby Mercury, 15 January 1840; 22 January 1840; 29 January 19; Arnold's Magazine of the Fine Arts, and Journal of Literature and Science, May 1834, p. 10; The Era Almanack, January 1877, p. 117; January 1878, p. 117; January 1879, p. 120.

${ }^{173}$ Patents for seeing behind: Alexander Allard De La Court, Patent Number 3359, 6 May 1826; P. Adie, Patent Number 4365, 7 October 1881; R. Galland-Mason, Patent Number 3701, 23 March 1885; J. Imray, Patent Number 2764, 25 February 1886; D Herman, Patent Number 549, 10 January 1899; C. Sharland, Patent Number 20,389, 13 November 1900. Patents for attachment of lighting to the frame: O.E. Woodhouse and F.L. Rawson, Patent Number 871, 16 February 1883; C. Smith, Patent Number 10,956, 28 July 1888.

${ }^{174}$ The Wrexham Advertiser, and North Wales News, 26 March 1887; 24 December 1887.

${ }^{175}$ The Optician, 20 December 1894, p. 199.
} 
in Figure 5.23, in order to achieve the right position some individuals were still attaching their frames to their hair, as opposed to placing them behind their ears, in the later nineteenth century.

Figure 5.23. Cartes de visite from Ron Cosen's collection, showing spectacle sidearms being attached into the wearer's hair. ${ }^{176}$
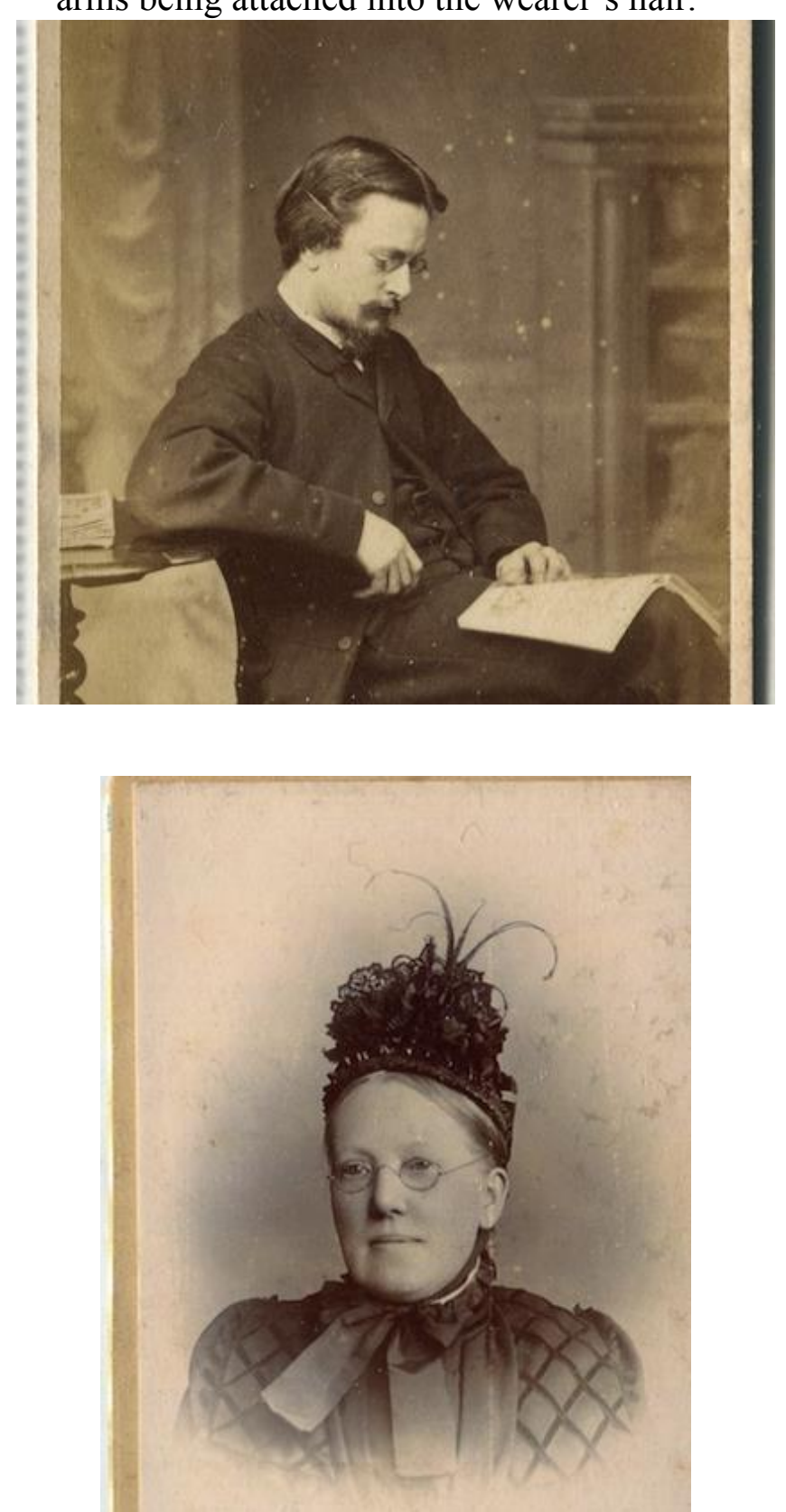

\footnotetext{
${ }^{176}$ I would like to thank Neil Handley, Curator at the College of Optometrists' Museum, for drawing my attention to Ron Cosens' collection of cartes de visite, and to Ron Cosens for his permission to use some examples from his extensive collection. Further information can be found at http://www.cartedevisite.co.uk [accessed: 27 July 2018].
} 
However, attempts to improve the fit of vision aids more broadly encouraged a number of design innovations, particularly in the manufacture of eyeglasses. Both Davidson and Rosenthal have briefly touched upon the increasing security of eyeglasses, including the invention of 'rigids' or 'astigmatic clip' frames. ${ }^{177}$

Comments on new inventions in The Optician suggest that frames, beyond the use of 'detachable curlsides', were being designed to 'grip perfectly', or reduce the 'tendency to shake' or 'rock'. ${ }^{178}$ Advertisements also claimed that their frames had this feature and emphasised how they were able to 'retain position... hold or fix on the nose'. ${ }^{179}$ Patents highlighted the importance of improving design to achieve a better fit. These patents can be split into two primary forms: improving stability on the nose through a more rigid joint or additional gripping device, and mechanisms that enabled the bridge to be adjustable to the shape of an individual's nose. ${ }^{180} \mathrm{In}$ 1894 a patent from Curry \& Paxton, for example, sought to provide a 'rigid' front to the frame. ${ }^{181}$ By the end of the century, the improved 'rigidity' of eyeglasses meant that they were less likely to be dismissed in medical and optical advice. In 1899 , for example, Emeritus Professor of Diseases of the Eye at the New York Post-Graduate Medical School, D.B. Roosa, suggested that:

It is not proper to insist that spectacles should be worn. Eyeglasses, if well chosen, may be worn by all adults or intelligent young people, even when a considerable degree of astigmatism exists. $^{182}$

As part of this advance, spectacles and eyeglasses were lighter, able to be worn for more long-term or continuous use, and more accurately fitted to accommodate a variety of complex lenses. Implicated in these changes was the broadening function of frames and lenses in the nineteenth century. Rather than providing a means to

\footnotetext{
${ }^{177}$ Davidson, Spectacles, Lorgnettes and Monocles, pp. 27-8; Rosenthal, pp. 243-9.

${ }^{178}$ See, for example, The Optician, 12 April 1894, p. 30; 3 May 1894, p. 61; 21 June 1894, p. 135; 29 August 1895, p. 246.

${ }^{179}$ The Dundee Courier \& Argus, weekly between 21 June 1890 and 8 November 1890.

${ }^{180}$ Patents to improve grip: J.P. Michaels, Patent Number 2586, 25 June 1880; P. Franck-Valery and E. Franck-Valery, Patent Number 11,207, 21 September 1885; J.E. Makins, Patent Number 19, 486, 4 December 1889; R. Lyons, Patent Number 7771, 19 April 1894; E. and S. Brown, Patent Number 14, 025, 21 July 1894; G. Bausch and S. Eastman, Patent Number 21, 503, 13 November 1895. Patents for an adjustable nose: S. Lubin, J.J. Frawley and A. Abraham, Patent Number 798, 18 January 1887; T. Bloor, Patent Number 12, 337, 12 September 1887; L.F. Comitti, Patent Number 6592, 30 March 1895; H.H. Lake, Patent Number 17, 785, 11 August 1896; O. Von Saal, Patent Number 16, 692, 21 August 1899.

${ }^{181}$ Curry \& Pickard, Patent Number 8953, 24 July 1885; Curry \& Paxton, Patent Number 22, 304,19 November 1894; for other examples of eyeglass springs for the bridge see 1885

${ }^{182}$ Roosa, p. 186.
} 
continue close-work, vision aids were expected to alleviate a variety of vision defects, and accommodate a number of activities.

B. Michael Andressen has argued that vision aids 'became purely functional' in the nineteenth century and 'only very rarely was the decorative potential of glasses taken into consideration'. ${ }^{183}$ However, the design of spectacles and eyeglasses was not wholly driven by practical considerations during this period. In particular, H.W. Holtman used the example of the pince-nez - and the discomfort it caused - to show how function alone did not influence the style of vision aid that became popular. ${ }^{184}$ Exploring the debate over the choice between spectacles and eyeglasses in greater detail is a good way to investigate the role of fashion, and the use of vision aids as both an accessory and functional device. In contrast, the use of rimless and invisible styles highlights how individuals could want to hide rather than display their vision aid. The development of both eyeglasses and rimless styles show how the appearance and social meanings of vision aids, as well as functional improvements, were equally important for the overall design of a frame in the nineteenth century.

When worn, vision aids become a central feature of the face. As previously highlighted, vision aids from the eighteenth century were increasingly being worn for a broader range of activities. This change in purpose ultimately influenced how spectacles and eyeglasses were used. Alun Withey has shown how wearing spectacles made the devices more public, after they had previously served a more private function, such as reading in the home. ${ }^{185}$ Besides practical considerations, this shift in the space and place for spectacle usage had an effect on the materials, styles, and function of vision aids. Certain materials or designs became popular, and it began to be possible for vision aids to be both fashionable and 'ugly'. Whether we can describe the popularity of certain materials or styles of vision aids as 'fashionable' is difficult to say. Although certain opticians were reputable - for example Dollond and Dixey - there are marked differences between this fact and, for example, the rise of commercial eyewear brands in the twentieth century that Neil

\footnotetext{
183 Andressen, p. 22.

${ }^{184}$ Holtman, p. xix.

${ }^{185}$ Withey, p. 98.
} 
Handley has discussed. ${ }^{186}$ Despite this, contemporaries used the term 'fashion' to describe the popularity of certain vision aid frames. In 1866 Ackland commented that it was 'curious how fashion alters even the material' of frames. ${ }^{187}$ Moreover, improvements in the elegance as well as the comfort or practicality of vision aids were discussed. In 1893, for example, The Optician commented that:

Of late years much advance has been made in the art of constructing efficient, comfortable, and handsome contrivances for holding glasses before the eyes. ${ }^{188}$

The appearance and 'fashions' of a vision aid frame were important to both the optician and the nineteenth-century wearer. Moreover, personal choice was considered to influence the choice of design by the end of the nineteenth century. In 1893 Chadburn and Son, for example, argued that the 'material, and to some extent the form of the frames are a matter of taste'. ${ }^{189}$ In 1905 Lockwood also argued that spectacles were required to 'fit' the face, be 'durable', and be 'attractive' in appearance. ${ }^{190}$ Indeed, in the 1890 s a review of a number of new designs in The Optician focused on the appearance of the frame as much as their practical comfort or convenience. ${ }^{191}$ In 1898 an article on the frames of vision aids also concluded that 'the finest finished and tempered frame' was 'worthless' when it did not fit or 'look well' ${ }^{192}$ The importance of appearance influenced how different designs were advertised across the century. Retailers, for example, used terms such as 'elegant' or 'handsome' in advertisements in the popular press in the 1830s, 1840s, 1850s, and 1880s. ${ }^{193}$ A 'handsome' frame did not improve a frame's functionality. In contrast, vision aids were 'displayed' in the nineteenth century because of their association with positive social markers such as status or intelligence. In 1886, for example, a satirical poem called 'Those Eyeglasses' included the following verse:

\footnotetext{
${ }^{186}$ Neil Handley, Cult Eyewear: The World's Enduring Classics (London: Merrell Publishers, 2011).

${ }^{187}$ Ackland, p. 10.

${ }^{188}$ The Optician, 15 June 1893, p. 644.

${ }^{189}$ Chadburn and Sons, Observations on the Choice and Use of Spectacles, p. 5.

${ }^{190}$ Lockwood, p. 24.

${ }^{191}$ See, for example, 6 July 1893, p. 692; 27 May 1897, p. 179.

192 The Optician, 31 March 1898, p. 30.

${ }^{193}$ See, for example, Arnold's Magazine of the Fine Arts, and Journal of Literature and Science, May 1834, p. 10; Examiner, 8 October 1837, p. 654; 19 November 1837, p. 750; 26 November 1837, p. 766; 3 December 1837, p. 783; 4 February 1838, p. 78; 25 February 1838, p. 126; 18 March 1838, p. 174; Lloyd's Weekly London Newspaper, 26 September 1847; 24 October 1847; Ipswich Journal, 3 June 1854; Gentleman's Magazine, April 1888, pp. 23-4; March 1888, pp. 317-8; June 1889, p. 622.
} 
What was't completed my attire,

Causing the ladies to admire.

My learning vast, and keen satire?

My eyeglass. ${ }^{194}$

A few years earlier, it was also stated that doctors and clergymen were 'especially partial to spectacles' because they were able 'to lend gravity to their looks, and enable them to pass for sages amongst the ignorant' ${ }^{195}$ However, this article took this a step further and suggested that vision aids could be worn to impart dignity even when they were not required. The article estimated that 'in ninety cases out of a hundred they don't require them'. ${ }^{196}$ A similar desire to wear vision aids for aesthetic reasons can be found across the century. In 1850 it was commented that 'plain glass is the most harmless contrivance for those who insist upon looking through a window to avoid the simplicity of ungarnished eyes'. ${ }^{197}$

Whether for the sake of appearance, or their ability to suggest sagacity, the desire to display vision aids had a marked effect on design. The debate over the choice between spectacles and eyeglasses is a useful example for exploring the importance of appearance on overall frame design. Whilst eyeglasses were considered appropriate for occasional use, they were continuously criticised when they were worn permanently. Despite this and some of the practical features that could make eyeglasses and pince-nez inconvenient - such as their inability to remain secure on the face - they became immensely popular in the latter half of the century. As previously shown, medical practitioners commented on the rise in the use of eyeglasses. However, comment in newspapers and periodicals highlights how these opinions filtered into contemporary culture. Two London periodicals quoted London ophthalmologist William White Cooper in the 1840s. The periodicals stated that eyeglasses were preferred 'in lieu of spectacles' because of their attractive appearance. ${ }^{198}$ By 1880 an article on 'Spectacles' in a Saturday periodical commented that 'the pince-nez has become wonderfully fashionable of late years'. ${ }^{199}$

\footnotetext{
194 'Those Eyeglasses', The Sheffield \& Rotherham Independent, 6 March 1886, p. 2.

195 The Hull Packet and East Riding Times, 18 June 1880.

${ }^{196}$ Ibid.

197 Trewman's Exeter Flying Post or Plymouth and Cornish Advertiser, 1 August 1850.

${ }^{198}$ The Athenaeum, 9 October 1847; The London Journal and weekly record of literature, science and general information, 29 January 1848, p. 351.

${ }^{199}$ Saturday Review of Politics, Literature, Science and Art, 21 August 1880, pp. 234-5.
} 
Eyeglasses could be used simply as an accessory for display. In photographs from Ron Cosens' collection of cartes de visite, for example, vision aids are shown as both worn and attached to the person's clothing. However, eyeglasses appear more prominent in photographs where they were attached to the person's clothing or held. The visibility of these eyeglasses raises a number of questions about why they were included in the photograph when they were not being used for functional purposes. Whether for their association with learning or fashion, or because of their importance to them personally, the people photographed in Figure 5.24 would have made an active choice to display and include them.

Figure 5.24. Display of vision aids by men and women in cartes de visite from Ron

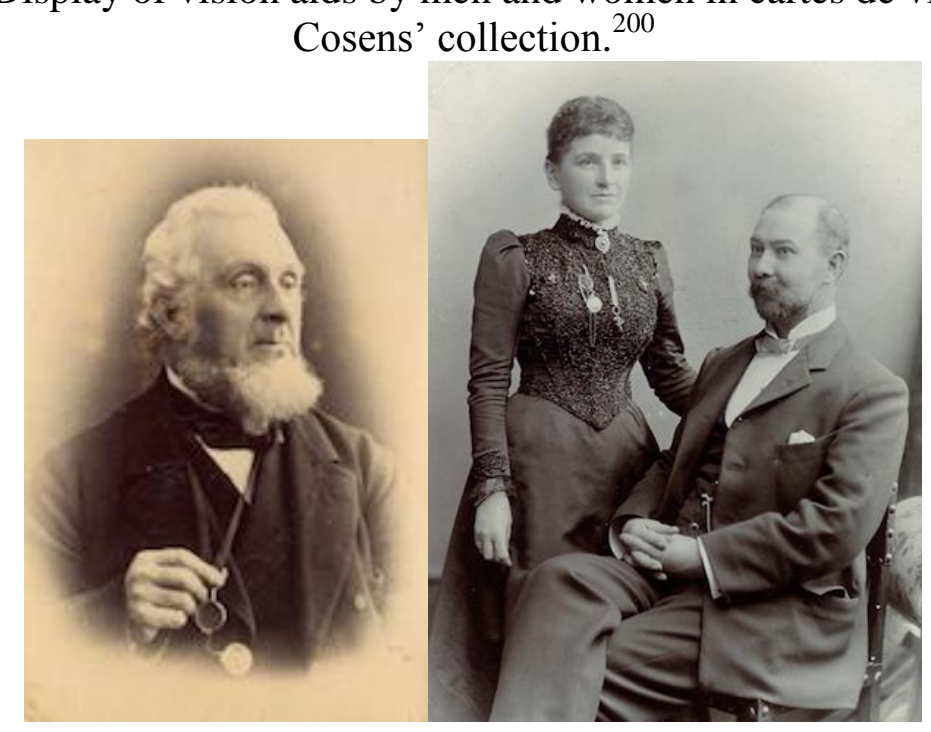

Besides in photographs, the display of eyeglasses can be found throughout the popular press. In La Belle Assemblee; or Court and Fashionable Magazine between 1818 and 1825, and the Kaleidoscope: or Literary and Scientific Mirror in October 1825, eyeglasses appear as part of the latest ladies' fashions. In 1823, for example, a description of a 'Walking Dress' from 'Fashions for November' stated that 'a gold chain, with a large perspective eyeglass, is generally adopted with this dress'; the accompanying illustration is shown in figure 5.25. ${ }^{201}$ Two years later in May 1825,

\footnotetext{
${ }^{200}$ Accessed from Ron Cosens' collection of cartes de visite, see footnote 179 above.

${ }^{201}$ La Belle Assemblee: or Court and Fashionable Magazine, November 1823, pp. 214-9
} 
white feathers, half-boots and a 'gold chain, with an eyeglass' were used to 'complete' the lady's outfit. ${ }^{202}$

Figure 5.25. Illustration of the latest 'Walking Dress' fashion, complete with an eyeglass, in La Belle Assemblee (1823). ${ }^{203}$

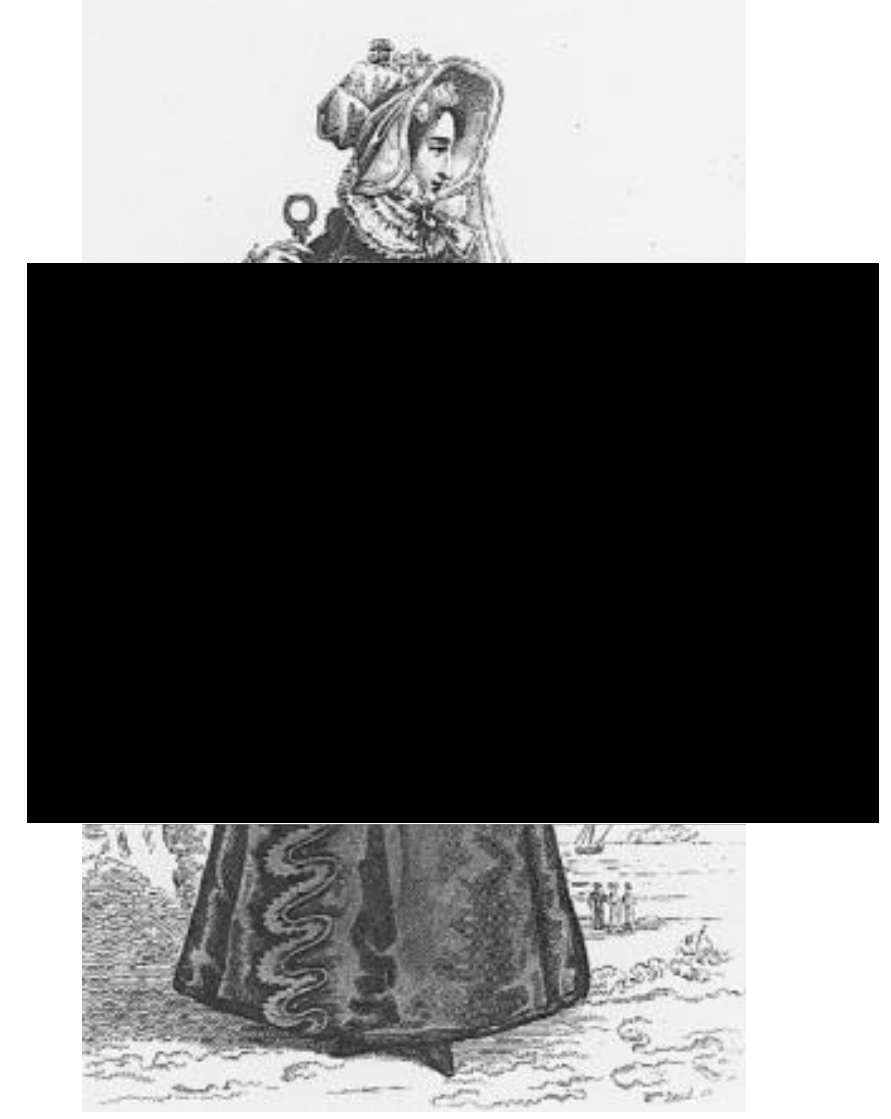

By the second half of the nineteenth century, a 'fashion' in eyeglasses was ascribed to both men - called 'dandies' and 'swells' - and women. In 1883, for example, a description of the London 'swell' in the Belfast News-Letter suggested that 'eyeglasses seemed to be a necessary appendage to complete their toilet'. ${ }^{204} \mathrm{~A}$ year later The Preston Guardian discussed the latest 'fashion' for ladies. It stated that eyeglasses were adopted because ladies 'imagine' that they impart 'an extra look of interest to them in the eyes of the opposite sex, who don the sight preservers with a similar idea'. ${ }^{205}$ However, popular, as well as medical, criticisms of the unpractical nature of these designs were prominent. In 1892 correspondence on the Dandy in a

\footnotetext{
${ }^{202}$ La Belle Assemblee: or Court and Fashionable Magazine, May 1825, pp. 210-212.

${ }^{203}$ La Belle Assemblee: or Court and Fashionable Magazine, November 1823, p. 214.

${ }^{204}$ Belfast News-Letter, 1 September 1883.

${ }^{205}$ The Preston Guardian, 30 August 1884.
} 
London periodical argued that "no sensible person will ever wear a single eyeglass... the straining is harmful'. ${ }^{206}$ Additionally, in 1893 people's preference for eyeglasses also became the subject of jokes, and the same periodical included under the column heading 'Facetiae':

'Jes' look at that!' he exclaimed to his wife, under his breath.

'What's the meanin' on it, do you think?' she inquired.

'I d'no - onless maybe he's buyin' his spectacles on the instalment plan. ${ }^{207}$

The choice of eyeglasses explicitly reveals how, regardless of practical benefit or advice, preference and taste were just as important in influencing the choice and popularity, and ultimately the demand and style, of certain vision aids. The overall effect of taste on all forms of vision aid design was acknowledged in medical and optical texts across the century. ${ }^{208}$ Materially, this is also evident on the frames of some of the vision aids in the Science Museum's collections. As shown in Figure 5.26, a number of brass and gold frames have elaborate etchings that would have not served a functional purpose. The use of pearl and luxurious materials shows that vision aid frames, even if worn for the enhancement of vision, could act as an accessory.

Figure 5.26. Science Museum's Dunscombe collection 2000-831/39 and Science Museum's Wellcome collection A682442, examples of a gold handfolder and brass spectacles with decorative features.

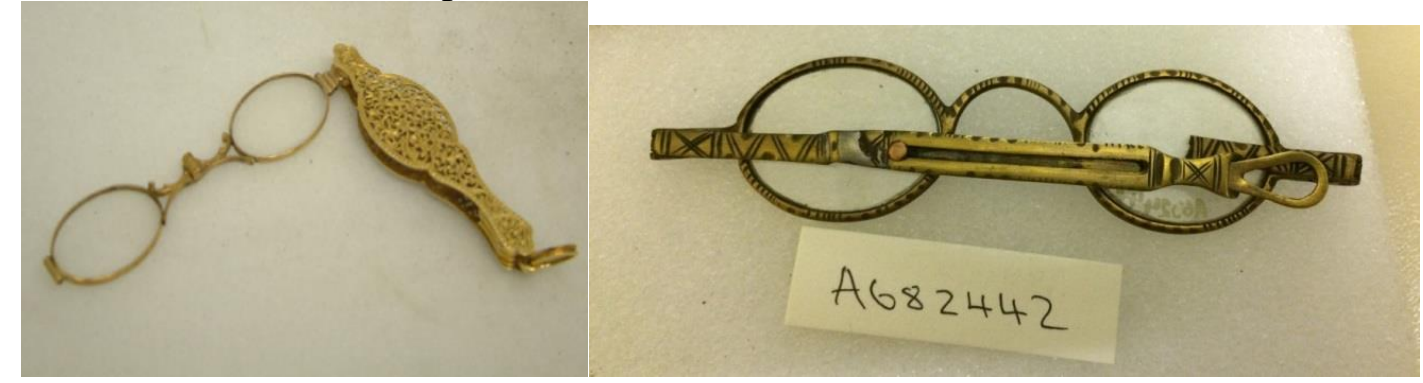

\footnotetext{
${ }^{206}$ The London Reader: of literature, science, art and general information, 29 October 1892, p. 48.

${ }^{207}$ The London Reader: of literature, science, art and general information, 16 December 1893, $\mathrm{p}$. 214.

${ }^{208}$ See, for example, Ackland, pp. 10-12; Vilas, p. 42; George Black, Eyesight and How to Care for It (London: Ward, Lock, 1888), p. 102; William Smith Baxter, Facts About Eyesight, Eyestrain and Spectacles (Leeds, J. Lonsdale, 1898), p. 8.
} 
Indeed, correspondence from 1830 on the 'improvement in the construction of spectacles' in The Lancet considered how a frame was at present 'unhandsome' but would by 'time, and its utility, be reconcilable to our ideas of beauty in figure'. ${ }^{209}$

Utility and appearance by the end of the nineteenth century took on the same level of importance in both medical and optical texts. In 1898 William Smith Baxter, an Optician, Chemist and Member of the British Optical Association, stated that his 'comfortable' spectacles and eyeglasses were chosen to suit 'personal appearance and to adorn the face', even for those with the 'most fastidious tastes'. ${ }^{210}$ Roosa also gave the following advice in his text on Defective Eyesight:

To some persons they [spectacles] are very unbecoming - much may be left to the patient in regard to the choice of frames for the glasses... Patients may consult their own notions of comfort and appearance. ${ }^{211}$

As highlighted by Roosa, the design and choice of vision aids in the nineteenth century was driven as much by a desire for elegance as it was for comfort and lightness. Moreover, the 'public' nature of spectacles heavily influenced people's decision of what frame they would choose to wear. In 1893 an article in The Optician, headed 'Spectacles for Cosmetic Effect', argued that spectacles would help make a person appear 'less lugubrious', and improve the appearance of those with epicanthus or a range of eye conditions. ${ }^{212}$ By 1893 , whether for show, to correct vision, or to hide what was deemed 'unsightly', spectacles were considered to improve the appearance, and the elegant or socially acceptable frames were available.

Despite this, the decision to wear spectacles or eyeglasses was also influenced by the stigma that was associated with spectacle wear. Whilst they might be associated with positive social markers in the nineteenth century, vision aids could also be considered 'a badge of infirmity' or 'a badge of disgrace'. ${ }^{213}$ Eyeglasses, for example, could be chosen over spectacles to 'conceal' an

\footnotetext{
${ }^{209}$ Martin Evans, 'Proposed Improvement in the Construction of Spectacles', The Lancet, 4 December 1830 , p. 346.

${ }^{210}$ Baxter, p. 8 .

${ }^{211}$ Roosa, pp. 161-3.

${ }^{212}$ The Optician, 6 July 1893, p. 692.

${ }^{213}$ Trewman's Exeter Flying Post or Plymouth and Cornish Advertiser, 1 August 1850.
} 
'imperfection' that was thought to 'wound' a person's 'self-love'. ${ }^{214}$ A description of a person using a pair of double eyeglasses in The Athenaeum argued that they carried them 'so gaily, you would have hardly known it was spectacles in disguise'. ${ }^{215}$ This desire to 'disguise' or 'conceal' the use of vision aids is made explicit in contemporary commentary, which discussed how the style of frame differed for public and private use. Vision aids could be used to hide other forms of physical difference, since they could facilitate, for example, the attachment of artificial noses or conceal early forms of assistive hearing devices. ${ }^{216}$ However, spectacles themselves could be stigmatised and only worn privately. Withey has argued that perceptions of spectacles were already becoming more positive, and had started to move away from an association with deficiency, in the eighteenth century. ${ }^{217}$

However, comments on spectacles and eyeglasses in nineteenth-century periodicals raises questions about how far this was the case in the longer-term. In 1880 it was argued that ladies wore spectacles 'exclusively in the company of their own sex' and would adopt an eye-glass or pince-nez 'in general society'. ${ }^{218}$ In 1891 a

miscellaneous column headed 'Over the Teacups' also commented that the 'optician is happy to prescribe them with eyeglasses for use before the public, and spectacles for their hours of privacy, ${ }^{219}$

Vision aids could embody a range of meanings in the nineteenth century and could even become a visible marker of defective eyesight. ${ }^{220}$ As discussed in chapter one, the number of vision errors being diagnosed caused alarm and was tracked across the period. In particular, short sight or myopia was often associated with feebleness and weakness because the condition was perceived to affect the overall health of the individual or permanently disfigure them by creating curvatures of the spine and stooping. Prosthetics have often been discussed in the context of workers'

\footnotetext{
${ }^{214}$ The Athenaeum, 9 October 1847; The London Journal and weekly record of literature, science and general information, 29 January 1848, p. 351.

${ }^{215}$ The Athenaeum, 4 November 1848, pp. 1099-1101.

${ }^{216}$ See, for example, Arthur S. Underwood, 'An Artificial Nose Affixed Without Spectacles', The Lancet, 2 May 1896, p. 1232.

${ }^{217}$ Withey, pp. viii, 6, 109.

218 Saturday Review of Politics, Literature, Science and Art, 21 August 1880, pp. 234-5

${ }^{219}$ The Academy, 10 January 1891.

${ }^{220}$ For further comment on stigma and its effect on spectacle wear, please see chapter six on users, pp. 285-291.
} 
efficiency and improving a person's capacity for work. ${ }^{221}$ Vision aids were an assistive technology that could similarly lengthen a person's working life. However, medical practitioners discussed how vision aids could also impinge on, rather than broaden, individual opportunities. In 1881 C.H. Vilas, for example, argued that it was 'not infrequent to find employers declining to engage an applicant wearing glasses or those needing them going without them, because of a silly (and generally incorrect) idea that they impart a tinge of age or foolishness' ${ }^{222}$ In 1887 Priestley Smith, an ophthalmic surgeon at Birmingham Eye Infirmary, also discussed the 'ignorant prejudice against spectacles'. Smith exposed the difficulty of the situation for people in these circumstances because they were 'able and skilled men', who could not 'do their work without glasses, and could not get employment if they wore them'. ${ }^{223}$ Smith, as a result, acknowledged both the practical benefits of vision aids and the potential social disadvantages. Members of the public were also aware of the disadvantages and, in correspondence between two women in a popular magazine in 1896, it was stated that, for children now wearing glasses, 'defective vision will go against them in the world'. ${ }^{224}$ Indeed, the stigma of spectacles could extend beyond the workplace and ultimately affect overall usage, which is discussed in the following chapter on spectacle users. ${ }^{225}$

The stigma associated with vision aids influenced innovations in nineteenthcentury design. Patent applicants towards the end of the nineteenth century, for example, sought to disguise spectacles in a variety of everyday items for public use, including the handle of an umbrella, parasol, walking-stick, whip, or fan. ${ }^{226}$ However, it also led to the development of rimless or 'invisible' styles. Whilst 'invisible' styles were reflective of improved manufacture and the ability to create thin wire, they could also reflect a person's wish to 'pass' and hide the use of a corrective or assistive device. 'Passing', is a term used to describe an attempt to

\footnotetext{
${ }^{221}$ For association with prosthetics and work efficiency see, for example, Heather R. Perry, 'ReArming the Disabled Veterans: Artificially Rebuilding State and Society in World War One Germany', Artificial Lives and Practical Lives, pp. 75-102.

${ }^{222}$ Vilas, p. 21.

${ }^{223}$ Freeman's Journal and Daily Commercial Advertiser, 19 March 1887.

224 'A Lady's Letter', Bow Bells: a magazine of general literature and art for family reading, 17 April 1896, p. 408.

${ }^{225}$ See chapter six, pp. 285-291.

${ }^{226}$ See, for example, G.G. Bussey, Patent Number 3031, 20 February 1889; F. Merriman, Patent Number 4470, 14 March 1889; H. Supthut, Patent Number 20,623, 14 October 1889.
} 
conceal social markers of impairment or avoid the stigma of disability. ${ }^{227}$ As argued by Claire L. Jones, users of prosthetics increasingly wanted to hide or mask their impairment. The use of rimless styles can be explained by the focus on achieving more 'natural' prosthetics in the nineteenth century. ${ }^{228}$ In a practical sense, they were flimsy and liable to breaking. However, rimless designs were considered desirable for their particular ability to appear non-existent to the wearer and this is apparent in contemporary photographs from the period, such as those in Figure 5.27 below.

Figure 5.27. Use of rimless spectacles and eyeglasses in cartes de visite from Ron Cosens' collection. ${ }^{229}$
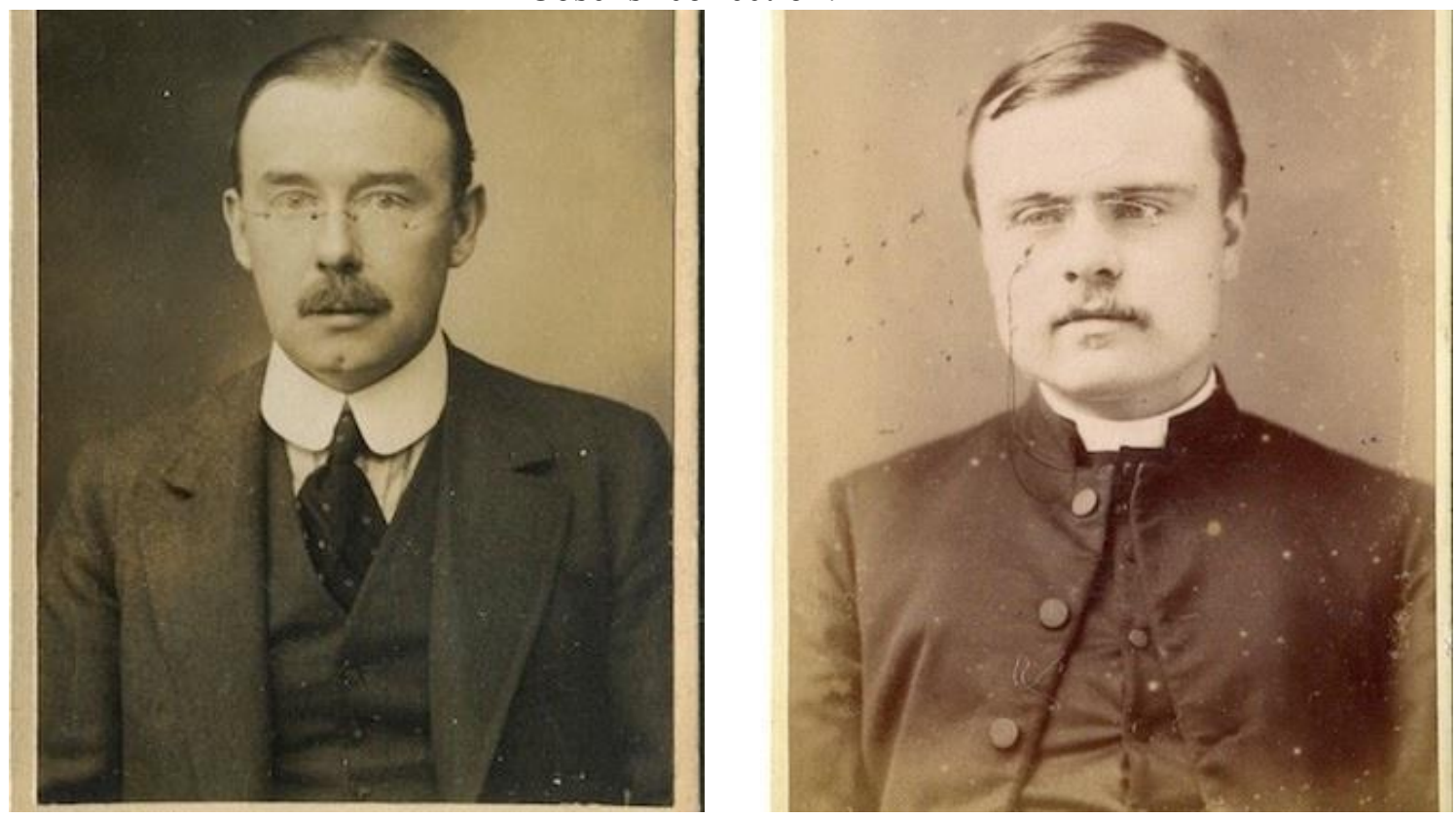

Descriptions of other styles of vision aid also highlighted how invisibility was a desirable feature. Alden in 1866, for example, discussed how the 'crotchet or riding spectacles' were considered favourable because they were 'very light and delicate' and 'almost invisible'. ${ }^{230}$ Whilst corrective or assistive devices aid a person's ability to conform to the idealised 'normal', spectacles may have done the opposite. In fact, eyewear was an obvious adornment to a person's face, and could

\footnotetext{
${ }^{227}$ Jeffrey A. Brune and Daniel J. Wilson, 'Introduction', in Disability and Passing: Blurring the Lines of Identity, ed. by Jeffrey A. Brune and Daniel J. Wilson (Philadelphia: Temple University Press, 2013), p. 1.

${ }^{228}$ Claire L. Jones, 'Introduction', in Rethinking Modern Prostheses in Anglo-American Commodity Cultures, 1820-1939, ed. by Claire L. Jones (Manchester: Manchester University Press, 2017), pp. 123. This could also be class-based, see for example, Stephen Mihm, 'A Limb Which Shall be Presentable in Polite Society: Prosthetic Technologies in the Nineteenth Century' in Artificial Parts and Practical Lives, pp. 282-299.

${ }^{229}$ Ron Cosens' collection of cartes de visite; see footnote 179 above.

${ }^{230}$ Alden, p. 113.
} 
highlight vision defects that were often associated with weakness or old age. As this chapter has shown, these associations could evoke stigma both socially and in the work place. The effect of stigma towards vision aids on overall design can also help to explain the development of the contact lens in the twentieth century. ${ }^{231}$ However, it is imperative to note that fashion and elegance was as important as invisibility in the nineteenth century. Indeed, the use of vision aids to conceal facial disfigurements or the use of other assistive devices highlights how complex perceptions were; it suggests that vision aid frames were becoming increasingly normalised across the century. This in turn enabled two markedly different forms of design to develop and become popular, one that was bold and intended for display and one that was more delicate and intended to be unobtrusive.

\section{Conclusion}

At the outset of this chapter, a study of the Science Museum's collections illustrated the variety of spectacle and eyeglass designs in the nineteenth century. However, the collections also suggested that many of these changes in design - such as the use of bar springs for eyeglasses or the changing side-arms of spectacles - were part of wider advances in manufacture, as well as the desire to improve the fit and comfort of the frame. Similar to prostheses, the overall development of vision aids was influenced by wider advancements in science and technology. The preferred material of the frame and lens, for example, altered in response to wider changes in manufacture and steam power across the century. Moreover, large scale manufacture changed the overall production of spectacle and eyeglass frames and encouraged the distribution of ready-made products. The improved manufacture of certain materials allowed the development of a frame that was not only lightweight but also standardised and designed for large scale production.

However, this chapter has also argued that the design of vision aids was not simply an outcome of improved manufacture. Indeed, practical considerations and the overall appearance of the frame were equally important. The development of

\footnotetext{
${ }^{231}$ See, for example, Eric P. Muth, 'Kevin Michael Tuohy: The Father of the Modern Contact Lenses', Indian Optician, Nov-Dec (1987), 14-17.
} 
wire manufacture and new materials such as Indian rubber helped to improve the overall comfort of the frame: the desire to alleviate the discomfort and pressure of frames was a driving force behind applying these technologies to spectacles and eyeglasses. Concerns about comfort were influenced by the acknowledgement that vision aids were being worn for an extended period of time and lenses could have more than one focal point. Consequently, the evolution of spectacle side-arms and the improved rigidity of all forms of vision aids can be seen as part of the need for a more secure fit. Yet, regardless of these considerations, it has also been shown that personal preference and taste could supersede the practical function of a frame. The public nature of vision aids meant that they had to accommodate either the desire to display or conceal, which drove two key innovations in nineteenth-century design. Collectively, manufacture, function and the appearance of the frame were inextricably linked to changes in vision aid design. Whether from a desire for a more comfortable or elegant frame, or simply a desire for a better fit, nineteenth-century design evolved alongside wider developments in manufacture and responded to the broadening public function that vision aids were expected to serve. 


\section{Chapter Six}

\section{Vision Aid Users in the Nineteenth Century}

Three spectacles in the Science Museum's collections had the names of their likely owners engraved into the side-arms of the frame. A pair of extending silver spectacles, hallmarked from 1834, were engraved with 'Mrs Hunter'; a pair of transverse folding silver spectacles, dated between 1790-1820, were engraved with 'John Ridler Esq, Bell \& Crown, Holborn'; and a further pair of transverse folding spectacles, hallmarked between 1824 and 1826, had 'C. Brown' engraved into the outside right arm, by the outer hinge. ${ }^{1}$ However, the remaining spectacles and eyeglasses reveal little about their users despite how personal or how well they might have been adapted to an individual's face. Indeed, ascertaining who wore vision aids in the nineteenth century is challenging. Historians have tracked a steady growth in spectacle wear since their invention at the end of the thirteenth century. These works have considered why the demand and use of vision aids changed. The invention of printing and the subsequent availability of cheaper reading material in the fifteenth century, for example, have received significant attention. ${ }^{2}$ Other key trends have also included the growing affordability of vision aids. The lack of quality control, which was highlighted in chapter three, has been used by historians to argue that a number of vision aid styles had not only become affordable, but 'common' by the nineteenth century. ${ }^{3}$

Despite this, ascertaining how many, and who, wore vision aids has proven problematic in previous research. In 1907 Carl Barck in his History of Spectacles commented that spectacles were incredibly valuable because without them

\footnotetext{
${ }^{1}$ Science Museum Ophthalmology collection, object numbers (in order cited): A682624; A682169; A682196.

${ }^{2}$ Richard Corson, Fashions in Eyeglasses, $3^{\text {rd }}$ edn (London: Peter Owen, 2011), p. 28; Hugh Orr, Illustrated History of Early Antique Spectacles (London: The Author, 1985), p. 7.

${ }^{3}$ Asa Briggs, Victorian Things (London: B.T. Batsford Ltd, 1988), p. 104; D.C. Davidson and R.J.S. MacGregor, Spectacles, Lorgnettes and Monocles (Buckinghamshire: Shire, 2002), pp. 12 and 22; Richard Champness, A Short History of the Worshipful Company of Spectacle Makers up to the Beginning of the Twentieth Century (London: Apothecaries Hall, 1952), pp. 8-9; Thomas H. Court and Mortiz von Rohr, 'On the Development of Spectacles in London from the End of the Seventeenth Century', Transactions of the Optical Society, 30.1 (1928-9), 1-21 (pp. 19-20).
} 
'thousands, or rather millions of elderly people would no longer be able to enjoy reading, and just as many millions of near-sighted individuals would be deprived throughout their lifetime'. ${ }^{4}$ Barck's comment illustrates the different themes that are discussed throughout this chapter: the association of vision aids with age, the broadening functionality of vision aids, and the growth in vision aid usage. Alun Withey has argued that spectacles were likely affordable to a large cross-section of society in the eighteenth century because of the range of designs and prices that were available. ${ }^{5}$ Yet both Withey and Asa Briggs for the nineteenth century have highlighted the lack of quantitative evidence to substantiate any claims for the increase in spectacle or eyeglass use. ${ }^{6}$ This chapter utilises a range of sources to explore vision aid users in the nineteenth century, including: contemporary comment; medical case accounts and opticians' registers that record people's experience; prices in surviving advertisements and catalogues; and material evidence from the Science Museum's collections.

Chapter one argued that a number of vision errors became exposed in the nineteenth century. The number of vision errors being diagnosed and the use of vision aids were reported in both the popular and medical press as an increasing national concern. Historians studying earlier periods have argued that printing could have increased the demand for vision aids. This chapter explores whether nineteenthcentury medical and technological changes influenced the number of vision aid wearers. However, it does so cautiously. John Dreyfus argued that, whilst both the environment and wider cultural context could influence spectacle use, historians have been liable to exaggerating their effect without fully exploring the costs or practical usability of spectacles. ${ }^{7}$ This chapter explores how contemporary perceptions, cost, and the benefits of vision aids - alongside improved design, materials and medical knowledge that have been discussed in previous chapters influenced both the number and type of users of vision aids. Additionally, historical studies of prosthetics have increasingly begun to explore a range of social

\footnotetext{
${ }^{4}$ Carl Barck, The History of Spectacles, Originally Delivered as a Lecture Before the Academy of Science, St Louis (Reprinted from the Open Court for April, 1907), p. 1.

${ }^{5}$ Alun Withey, Technology, Self-Fashioning and Politeness in Eighteenth-century Britain: Refined Bodies (Basingstoke: Palgrave Macmillan, 2016), p. 102.

${ }^{6}$ Ibid and Briggs, p. 106.

${ }^{7}$ John Dreyfus, 'The Invention of Spectacles and the Advent of Printing', The Library, 6.2 (1988), 93-106 (pp. 104-5).
} 
categories. ${ }^{8}$ In line with this trend, this chapter also explores whether spectacle usage was particularly gendered or class-based. The chapter has been split into three parts. The first section argues that the use of vision aids was affected by class in the nineteenth century. It shows that vision aids did not necessarily become more affordable, but were re-conceptualised and transformed from being objects associated with wealth to ones whose possession was considered a basic right of the poor. The second section shows that, whilst the relationship between utility and usability was not straightforward, improvements in the design and measurement of vision benefited vision aid users. Finally, the last section explores how vision aid usage altered. I argue that, in the absence of any statistics, it is still possible to explore how the number, age and gender of the typical users changed across the century. I show that, in response to changes that have previously been discussed in this thesis, vision aids were increasingly seen or expected to be accessible and functional for a broader cross-section of society by the end of the century, even if this was not entirely the case in reality.

\section{The Affordability of Vision Aids}

In 1859 an article on 'The Economy of Sight' in the Chambers 's Journal of Popular Literature, Science and Arts commented that:

All that is needed besides [a correctly fitting frame and lens], is health to wear the spectacles and money to pay for them. ${ }^{9}$

Here, spectacles were presented as high-cost items that were possibly, for some, out of reach. Chris Otter and Martin Willis have argued, in their studies on nineteenthcentury vision, that lower visual acuity was associated with the lower classes and poorer living conditions. ${ }^{10}$ However, on a practical level, nineteenth-century

\footnotetext{
${ }^{8}$ Claire L. Jones, 'Introduction' in Rethinking Modern Prostheses in Anglo-American Commodity Cultures, 1820-1939, ed. by Claire L. Jones (Manchester: Manchester University Press, 2017), pp. 123.

${ }^{9}$ Chambers's Journal of Popular Literature, Science and Arts, 21 May 1859, p. 329.

${ }^{10}$ Chris Otter, The Victorian Eye: A Political History of Light and Vision in Britain, 1800-1910 (Chicago; London: Chicago University Press, 2008), pp. 39-40; Martin Willis, Vision, Science and Literature, 1870-1920: ocular horizons (London: Pickering \& Chatto, 2011), pp. 166, 180. See also contemporary discussion of the relationship between nutrition and the environment of the lower classes and vision defects: extract from Francis West's Treatise on the Human Eye in the Operative, 27 January 1839; this is also commented on later in the century in John Phillips, Ophthalmic Surgery and Treatment: With Advice on the Use and Abuse of Spectacles (London: W.B. Keen \& Co., 1869),
} 
ophthalmologists considered the upper classes more susceptible to vision defects because of their tendency to occupy themselves with activities that involved indoor close-work. ${ }^{11}$ Partly for this reason, vision aids could be imbued with meanings of social status. Eyeglasses were often described as being used by the 'aristocracy' to observe 'the working men', or 'hold themselves as creatures apart' in popular comment from the 1870 s. $^{12}$ The status of vision aids as an object, can also be seen in an article on 'Spectacles' from 1877, which argued that spectacles and eyeglasses were regarded 'much in the same light as diamond rings, and patent-leather boots'. ${ }^{13}$ In ascertaining the relationship between class and the use of vision aids, F.C. Donders concluded: 'position in society has a great influence'. ${ }^{14}$ Donders argued this on the basis of need, and concluded that the living conditions of the upper classes increased their demand. However, position in society could also have an influence on the accessibility of vision aids in the nineteenth century.

Heather R. Perry, in her study of prosthetics in early twentieth-century Germany, has argued that prosthetics were 'tools of class' ${ }^{15}$ Perry has shown how a

p. 23; The Standard, 21 December 1881; Leeds Mercury, 5 October 1883; Bow Bells: A magazine of general literature and art for family reading, 18 November 1892, p. 490; Saturday Review of Politics, Literature, Science and Art, 18 July 1896, pp. 57-8.

${ }^{11}$ In contrast to Otter and Willis' argument, the upper classes were commented on much more frequently from as early as 1815 and continued across the century: James Ware, 'Observations Relative to the Near and Distance Sight of Different Persons', The Literary Panorama, January 1814, pp. 985-993; Saturday Review of Politics, Literature, Science and Art, 24 September 1870, pp. 38990; Richard Hengist Horne 'Eyes and Eyeglasses: A Friendly Treatise', Fraser's Magazine, December 1876, pp. 689-72; The Morning Post, 12 October 1883; Leciester Chronicle and the Leicestershire Mercury, 11 November 1899; and also more specialized texts: Georg Beer, The Art of Preserving the Sight Unimpaired to an Extreme Old Age; and of Re-establishing and Strengthening it When it is Become Weak (London: Henry Colburn, 1815), pp. 202-5; Francis West, A Familiar Treatise on the Human Eye: Containing Practical Rules that will Enable all to Judge what Spectacles are Best Calculated to Preserve their Eyes to Extreme Old Age, $2^{\text {nd }}$ edn (London: W. Ackrill, 1827), pp. 35-6; William Mackenzie, A Practical Treatise on the Diseases of the Eye, $4^{\text {th }}$ edn, revised and enlarged (London: A. and G.A. Spottiswoode, 1854), p. 911; F.C. Donders, On the Accommodation and Refraction of the Eye, with a Preliminary Essay on Physiological Dioptrics, trans William Daniel Moore (London: New Sydenham Society, 1864), p. 154; Walter Alden, The Human Eye; its Use and Abuse: A Popular Treatise on Near and Impaired Sight, and the Methods of Preservation by the Proper Use of Spectacles, etc (Cincinnati: The Author, 1866), p. 32; Christopher Smith Fenner, Vision: Its Optical Defects, and the Adaption of Spectacles (London: Lindsay \& Blakiston, 1875), pp. 220-2; C.H. Vilas, Spectacles; and How to Choose Them (Chicago: Duncan Brothers, 1881), p. 115; Sydeny Stephenson, Eye strain in everyday practice (London: The Ophthalmoscope Press, 1913), p. 1 .

${ }^{12}$ See, for example, Reynold's Newspaper, 8 June 1873; Nottinghamshire Guardian, 3 September 1875.

${ }^{13}$ Dublin University Magazine, June 1877, pp. 781-2.

${ }^{14}$ Donders, p. 154.

${ }^{15}$ Heather R. Perry 'Re-Arming the Disabled Veterans: Artificially Rebuilding State and Society in World War One Germany', in Artificial Parts and Practical Lives: Modern Histories of Prosthetics 
range of prosthetics were produced, designed, and worn depending on the wearer's social standing and what they could afford. Ledgers from opticians' account books do give some insight into the social standing of vision aid users. The ledgers of Robert Sadd from the mid-century, for example, recorded customers from a range of occupations, including professions as diverse as the Dean of Bristol, members of Cambridge University's colleges, a boot and shoemaker, a bookseller, a painter and a stonemason. ${ }^{16}$ The cash daybook sales of John Potter Dowell in the late nineteenth century included a similar range of occupations, such as reverends, ironmongers, drapers, grocers, and a dentist. ${ }^{17}$ However, there are no statistics on the class and occupational status of spectacle and eyeglass users. Despite this, the design and marketing of vision aids can be used to explore the intended users of nineteenthcentury vision aids. The materials, design, and advertisements of vision aids ranged substantially in relation to the cost and quality of the product, and its intended user. This section firstly draws upon the material evidence of vision aid frames and the prices recorded in advertisements and account books. It argues that vision aids did not necessarily reduce in price, but two distinct markets were established and increased the affordability of vision aids in the nineteenth century. Secondly, the language in advertisements and charity records reveal that, even if it was not achieved in practice, expectations of vision aid usage changed. By the second half of the nineteenth century access to vision aids was perceived as a 'basic right' for the lower-classes. This section considers these conclusions in light of the complexity of vision aid cost, and highlight that expenditure was not usually a single transaction, but could also incorporate a range of repairs and alterations. Ultimately, I argue that a range of different qualities of vision aids existed and the category of expected users expanded in this period.

The objects that can be found in the Science Museum's collections highlight the variety of materials, styles, and quality of vision aid design in the nineteenth

ed. by Katherine Ott, David Serlin and Stephen Mihm (New York: NYU Press, 2002), pp. 75-102; See also, David M. Turner, Alun Withey 'Technologies of the Body: Polite Consumption and the Correction of Deformity in Eighteenth Century England', History, 99.338 (2014), 775-796; Stephen Mihm, 'A Limb Which Shall be Presentable in Polite Society: Prosthetic Technologies in the Nineteenth Century' in Artifical Parts and Practical Lives: Modern Histories of Prosthetics, pp. 282300 .

${ }^{16}$ Cambridge University Library, GBR/0012/Ms Ad.5781-5783: Robert Sadd \& Co. Account Books 1837-1851 and Ledgers 1845-1889.

${ }^{17}$ Carlisle Archive Centre, DB9/1-7: John Potter Dowell, Cash and Day Book (Sales), 1885-1898. 
century. As a result, they are a visual reminder of the complexity of ascertaining the accessibility or affordability of these items; there were clearly different types of frames intended for different types of individuals, according to what they could afford. The way the Dunscombe and Wellcome collections were acquired reflects this at first-hand. Wellcome's collection of spectacles and eyeglasses highlights the lower-end spectacle market that existed in the nineteenth century. The collection acquisition records, for example, reveal that many items were bought as part of cheap job lots at auctions, which included a range of everyday objects collated under terms such as 'sundries'. ${ }^{18}$ Dunscombe's collection, on the other hand, was collected more carefully and focused on more 'choice' or upper-market items. Whilst a range of materials can be found, there was a much larger proportion of gold and patent frames, or objects of finer workmanship. ${ }^{19}$

The range in both the quality and material of vision aid frames has been explored in previous research. These works have considered the relative value of different materials or looked at some choice examples of nineteenth-century catalogues. ${ }^{20}$ Spectacles could be either expensive or cheap. Richard Corson has highlighted how both the style and cost of the vision aids were linked to the class of the intended user. ${ }^{21}$ Jonathan S. Pointer has also shown how the price of spectacles remained similar to the average daily wage between 1276 and $1996 .{ }^{22}$ However, the scope of Pointer's analysis limited the amount of data used for the nineteenth century. Additionally, other studies have only drawn on singular examples when assessing the cost of spectacles in the nineteenth century. Briggs and Davidson, for example, have shown that spectacles were sold for 18 pence in the 1830 s, or that a

\footnotetext{
${ }^{18}$ These are currently uncatalogued but are available at the Wellcome Library. Catalogues for Stevens auction house were viewed for 2 March 1915; 13 April 1920; 2 September 1924; 21 and 22 August 1928; 21 September 1928; 14 October 1928; 23 October 1928; 26 and 27 March1930; 16 and 17 September 1930; 7 November 1930; 5 August 1931; 20 and 21 October 1931; 20 and 21 September 1921; 20 and 21 October 1932; 16 April 1935; and catalogues for Glendining auction house for 29 July 1932; 29 October 1934; 14 January 1935.

${ }^{19}$ See, for example,: a pair of gold eyeglasses 1921-323/299; patent eyeglasses 1921-323/377; patent invisibly cemented bi-focal spectacles 1921-323/193; rimless gold spectacles 1921-323/215 in the Science Museum's Dunscombe collection.

${ }^{20}$ Michael Solomon, Spectacles (London: Thames and Hudson, 1994), p. 18; William Rosenthal, Spectacles and Other Vision Aids: A History and Guide to Collecting (San Francisco, Norman Publishing, 1996), p. 111; Orr, p. 38; Elson, p. 13.

${ }^{21}$ Corson, p. 41.

22 Jonathan S. Pointer, 'The found in Your Pocket and the Glasses on Your Nose -700 years of reading spectacle prices', Ophthalmic Antiques International Collectors Club Newsletter, No. 59 (1997), 4-5.
} 
pair of silver spectacles could be purchased for 16 shillings between 1850 and $1870 .^{23}$ Key-word searching the digitised popular press has made it possible to obtain advertisements and data on pricing that, although still limited in scope, was previously unobtainable. When placed alongside data collected from previously unresearched opticians' accounts, these prices can be used to assess the cost of vision aids, the effect of materials on prices, and also the range of the vision aid market in the nineteenth century, something which was reflected at first-sight in the Science Museum's collections.

The overall value of spectacles and eyeglasses in this period can be seen in the number of thefts of them reported between 1844 and 1895 in contemporary newspapers and periodicals. ${ }^{24}$ In 1821 eyeglasses were considered an accessory that could make gentlemen vulnerable to theft because these items 'daily exhibited' implied that their 'purse was well-stored'. ${ }^{25}$ Similarly, receipts show that spectacles and vision aids could be costly. A receipt for spectacles from William Henry, $4^{\text {th }}$ Duke of Portland in 1819, for example, revealed the expense of a pair of pearl and silver hand spectacles, which amounted to $£ 3 / 3 / 6 .{ }^{26}$ A number of other receipts from across the century record the purchase of spectacles that were made out of shell,

\footnotetext{
${ }^{23}$ Briggs, p. 114; Derek C. Davidson, 'Nineteenth Century Metal Spectacles', Ophthalmic Antiques International Collectors Club Newsletter, No. 58 (1997), 9-10

${ }^{24}$ See, the Examiner, 14 September 1844; Examiner, 13 November 1847; Lloyds Weekly London Newspaper, 3 July 1853; The Morning Chronicle, 1 August1855; Daily News, 25 May 1863; Glasgow Herald, 11 September 1863; Nottinghamshire Guardian, 18 September 1863; Birmingham Daily Post, 28 April 1864; The Dundee Courier \& Argus, 8 June 1865; Daily News, 12 June 1867; The Morning Post, 12 June 1867; Hampshire Telegraph and Sussex Chronicle, 9 January 1869; The Illustrated Police News, 30 September 1871; The Royal Cornwall Gazette, Falmouth Packet, and General Advertiser, 12 April 1873; Birmingham Daily Post, 26 May 1875; The Bradford Observer, 26 May 1875; The Daily Gazette, 26 May 1875; The Wrexham Advertiser, Denbighshire, Flintshire, Cheshire, Shropshire, Merionethshire and North Wales Register, 29 May 1875; Liverpool Mercury, 2 July 1875; Manchester Times, 3 July 1875; Nottinghamshire Guardian, 9 July 1875; The Lancaster Gazette, 10 July 1875; Nottinghamshire Guardian, 29 June 1877; Lloyd's Weekly Newspaper, 8 July 1878; The Standard, 20 July 1878; Leeds Mercury, 19 October 1878; The Dundee Courier \& Argus and Northern Warder, 10 February 1880; The York Herald, 10 June 1880; Jackson's Oxford Journal, 12 June 1880; Nottinghamshire Guardian, 3 September 1880; The Dundee Courier \& Argus, 22 September 1881; Liverpool Mercury, 29 October 1886; Belfast News-Letter, 10 April 1888; Freeman's Journal and Daily Commercial Advertiser, 10 April 1888; Birmingham Daily Post, 14 March 1889; Birmingham Daily Post, 22 July 1890; The Blackburn Standard and Weekly Express, 11 April 1891; Western Mail, 18 July 1891; Aberdeen Weekly Journal, 12 November 1891; The Newcastle Weekly Courant, 13 August 1892; Jackson's Oxford Journal, 15 October 1892; Glasgow Herald, 28 December 1893; The Lancaster Gazette and General Advertiser for Lancashire, Westmorland and Yorkshire, 6 January 1894; Derby Mercury, 11 July 1894; Liverpool Mercury, 26 January 1895; Derby Mercury, 5 June 1895.

${ }^{25}$ The Gentleman's Magazine: and Historical Chronicle, December 1821, p. 616.

${ }^{26}$ Nottinghamshire Archives, DD/P6/8/10/5/46: Spectacles for the Duke, 1819.
} 
silver or nickelled metal for over £1. An invoice from P \& G Dollond, for example, in 1806 detailed silver spectacles for $£ 1 / 17 /-.{ }^{27}$ Similarly, a pair of 'best quality curl side nickelled spectacles' with 'pebble lenses' were bought from Aitchison \& Co. for $£ 1 / 5 /$ - in $1899 .^{28}$ The clientele could also reveal the potential luxuriousness of an item. Letters of correspondence between Dollond and his customers, for example, included the Bishop of Gloucester, Lord Salisbury, and Lord Palmerston. ${ }^{29}$ By looking at the receipts and accounts of one individual we can ascertain the reputation of certain firms as well as the high cost. The receipts that survive from the $3^{\text {rd }}$ Earl of Egremont reveal the use of prominent London firms, including Dollond and Bradberry \& Co., and these bills could range between $£ 1 / 16 / 6$ and $£ 3 / 18 /-$ in 1821 and $1832 .^{30}$

Opticians' catalogues across the late eighteenth and nineteenth centuries reveal the range in price that is absent in the surviving receipts. Collectively, they suggest that the material of the frame had a strong effect on the price. This relationship has been acknowledged by historians who have briefly commented on the range in both cheaper and more expensive materials and styles. ${ }^{31}$ A catalogue from Dollond from the end of the eighteenth century, for example, showed a clear difference in price dependent on the frame and lens material, as well as the varying qualities of workmanship. As show below, their 'Best' frames were considerably more expensive:

BEST double joint Silver Spectacles

With Glasses 1/1/0

Ditto with Brazil Pebbles 1/16/0

\footnotetext{
${ }^{27}$ Boots Archives, DA14/3: Invoice from P \& G Dollond for silver spectacles, 1806.

${ }^{28}$ Boots Archives, DA23/1/18: Aitchison receipt written out to a Master Edwards for some spectacles, 1899.

${ }^{29}$ Boots Archives, DA23/1/53/1: Letter from the Bishop of Gloucester to George Huggins (George Dollond), 1836; Boots Archives, DA/23/1/53/2: Letter from Lord Salisbury to Dollonds, 1824; Boots Archives, DA/23/1/53/5: Letter from Lord Palmerston to Dollonds, 1823; Information on acquisition of these letters can also be found at the Boots Archives, DA/21/1/53/6: A collection of letters from Lord Salisbury, Bishop of Gloucester, and Lord Palmerston to Dollond, 1955; The overall reputation of the Dollond firm has been discussed by Hugh Barty-King, Eyes Right: The Story of Dollond and Aitchison, Opticians, 1750-1985 (London: Quiller P., 1985), p. 92 and Neil Handley, Cult Eyewear: The World's Enduring Classics (London: Merrell Publishers Ltd, 2011), pp. 17-20.

${ }^{30}$ West Sussex Record Office, PHA 13086: Bills from London Tradesmen receipted bills for goods and services by London tradesman, to account B, 1821; West Sussex Record Office, PHA 13096: Bills from London Tradesmen receipted bills from London tradesmen for goods and services supplied to the London house bills to account B, 1832.

${ }^{31}$ R.J.S MacGregor, 'Pebbles', Ophthalmic Antiques Collectors Club, No. 73, (2000), 5-9 (p. 6); Rosenthal, p. 46; Corson, pp. 41, 63-6, 120; Withey, pp. 99-100.
} 


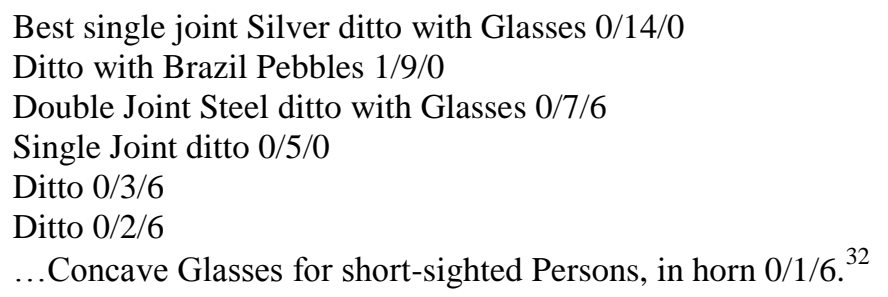

The catalogue of G.W. Proctor in the early nineteenth century also showed that the scale of manufacture could reduce the price of the frame. The manufacturing costs of frames, for example, were affected when frames were purchased by the dozen. ${ }^{33}$ However, the material of the frame also affected the price that Proctor advertised. This phenomenon persisted across the century, and the catalogue of the Sheffield firm, Chadburn \& Son, in the 1890s revealed a wide range of prices that were both dependent on the material of the frame and lens. ${ }^{34}$ However, the catalogues also reveal that the overall price was changing. Whilst 'fine gold spectacles' could still be bought from Chadburn $\&$ Son in the 1890 s, there were a number of cheaper steel frames for 1 shilling that did not exist in the earlier catalogues of Dollond and Proctor.

Variation in the price of vision aids is evident across a sample of nineteenthcentury newspaper and periodical advertisements. These advertisements and the surviving case accounts of two opticians in Cambridge and Carlisle further substantiate the trends that were revealed in opticians' catalogues. Seventy-nine advertisements included either a range of prices and materials that were available or an upper and lower price range between the period 1829 and 1900. The retail price index has been used to take into account inflation, which meant that the prices in each different year were comparable and the real price change could be calculated. ${ }^{35}$ At first sight, this method showed that the price of vision aids did not decrease or become more affordable in a straightforward manner. However, it did make it

\footnotetext{
${ }^{32}$ Boots Archives DA15/10, Page from catalogue of P \& J Dollond, this is undated but P. \& J. Dollond were active between 1766 and 1804, Gloria Clifton, Directory of British Scientific Instrument Makers 1550-1851 (London: Zwemmer, 1995), p. 87.

${ }^{33}$ Sheffield City Archives, Bradbury Record 293: G.W. and Proctor, Opticians and Manufacturers (Sheffield: C.W. Thompson, 1815).

${ }_{35}^{34}$ Sheffield City Archives, SY231: Observations on the Choice and Use of Spectacles, backpage.

${ }^{35}$ Retail Price Index obtained from https://www.ons.gov.uk/economy/inflationandpriceindices/datasets/consumerpriceinflation [accessed: 6 February 2017]. 1889 was set as the base year to calculate the real price change because it appeared in all of the data sets.
} 
possible to explore two general trends that influenced both the users and affordability of vision aids across the century: the price of the material of the frame and lens, and the subsequent existence of two distinct upper and lower end markets both in and outside of London.

At first sight, Figure 6.1 reveals that the price of vision aids could fluctuate across the nineteenth century, and that there was a considerable difference between the advertised upper and lower-end prices. It suggests that a cheaper range - which was suggested in the catalogue evidence and the work of previous historians - did exist alongside more expensive products between the period 1829 and 1900.

Figure 6.1. Line graph plotting the upper and lower end prices (in pence and normalised to 1889 value) that were advertised by nineteenth-century London and provincial retailers between 1829 and $1900 .^{36}$

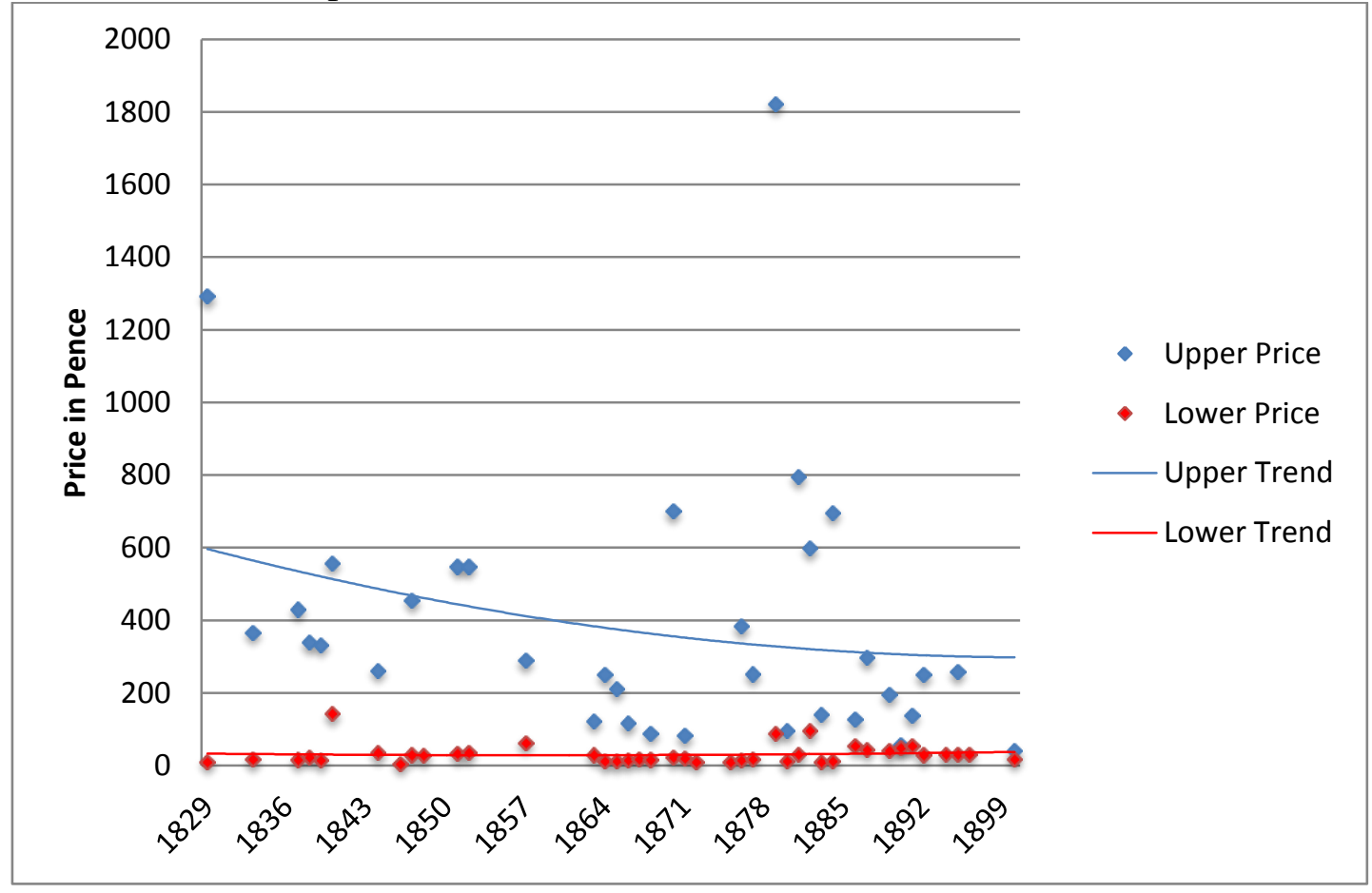

Taking into account the effect of inflation and plotting the price in this way is informative, because it allows the price to be compared across the century. However, it does not take into account additional factors that would have likely had an effect on the overall price, including the location of purchase and the material of the frame. Although the data became more limited when separated into these categories, it

${ }^{36}$ Data drawn from 79 advertisements from a range of locations between the period 1829 and 1900. 
shows both the effect of location on price and the role of materials in broadening the market range of vision aids.

Dreyfus argued that the material of the frame would have been an important factor in reducing the overall retail price of spectacles in the fifteenth century. ${ }^{37}$ Yet ascertaining the overall cost of nineteenth-century vision aid frames has not been attempted in previous research. A range of materials can be found in the Science Museum's collections of spectacles and eyeglasses. ${ }^{38}$ However, gold, silver, steel, tortoiseshell and horn were the most frequently advertised materials in the nineteenth-century popular press. By exploring price in relation to material, you can see a definite relationship between overall price and frame material. Figure 6.2, for example, shows that gold and silver frames with glass lenses were consistently more expensive, whilst horn, tortoiseshell, and steel were consistently cheaper.

Figure 6.2. Line graph of the overall price in relation to frame material (in pence and normalised to the 1889 value) in nineteenth-century London and provincial advertisements from between 1829 and $1894 .{ }^{39}$

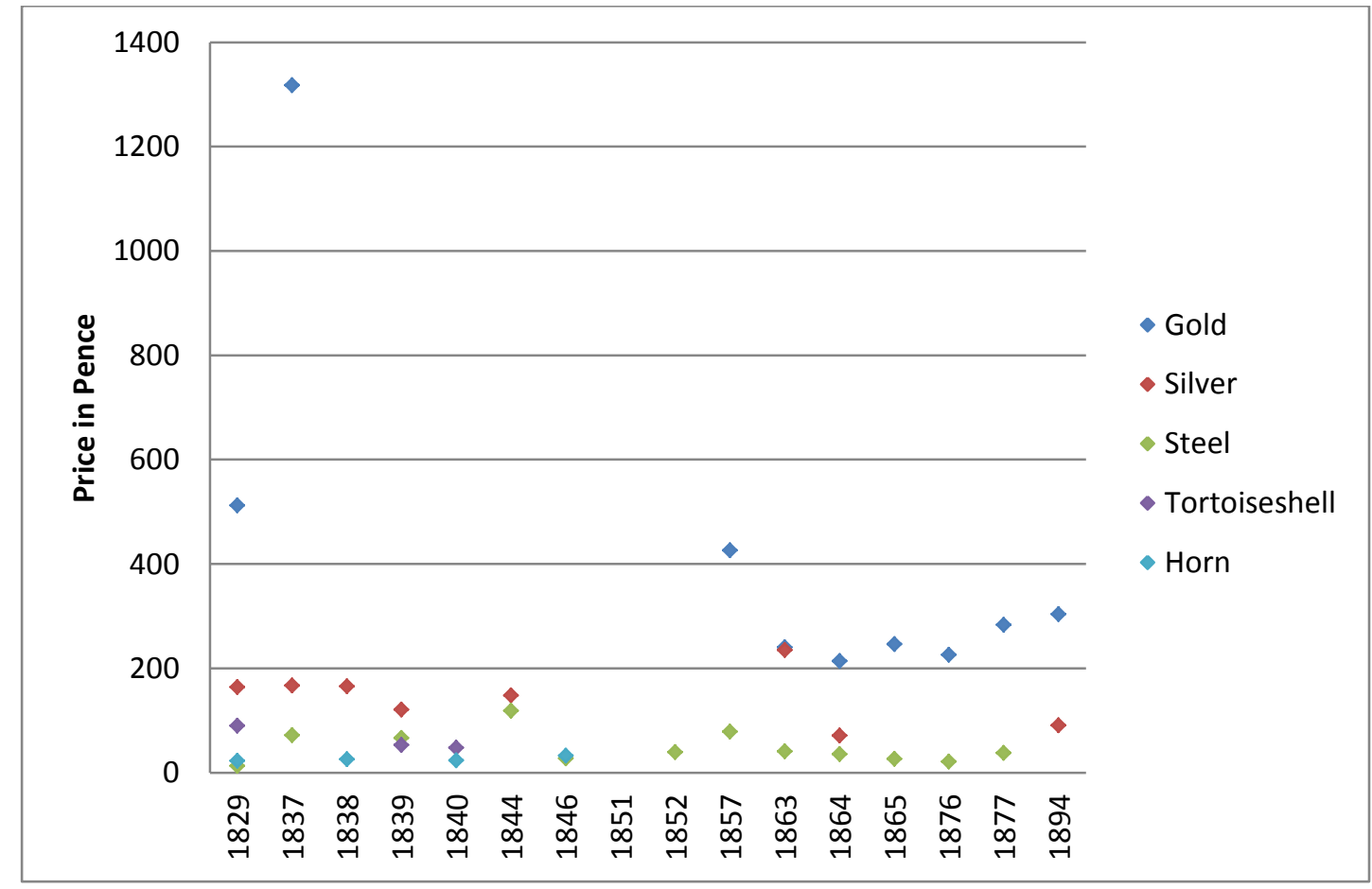

\footnotetext{
${ }^{37}$ Dreyfus considered this in his discussion about the introduction of leather, pp. 105-6.

${ }^{38}$ See chapter five, Figures 5.11 and 5.12 on pp. 200-201.

${ }^{39}$ Data drawn from 79 advertisements from a range of locations between the period 1829 and 1900.
} 
Both the advertisements and cashbooks suggest that there was a relationship between the material of the frame and lens, and the overall price. Consequently, materials enabled the price to vary from less than twenty pence, to multiple pounds. Figure 6.3 shows the relationship between the material of the frame and lens and the overall price in the nineteenth century. Here, both gold and pebble were significantly more expensive, and there was a clear distinction in the prices charged for the different materials.

Figure 6.3. Bar chart of the average price of different frame and lens materials (in pence and normalised to the 1889 value) in nineteenth-century London and provincial advertisements from between 1829 and $1900 .^{40}$

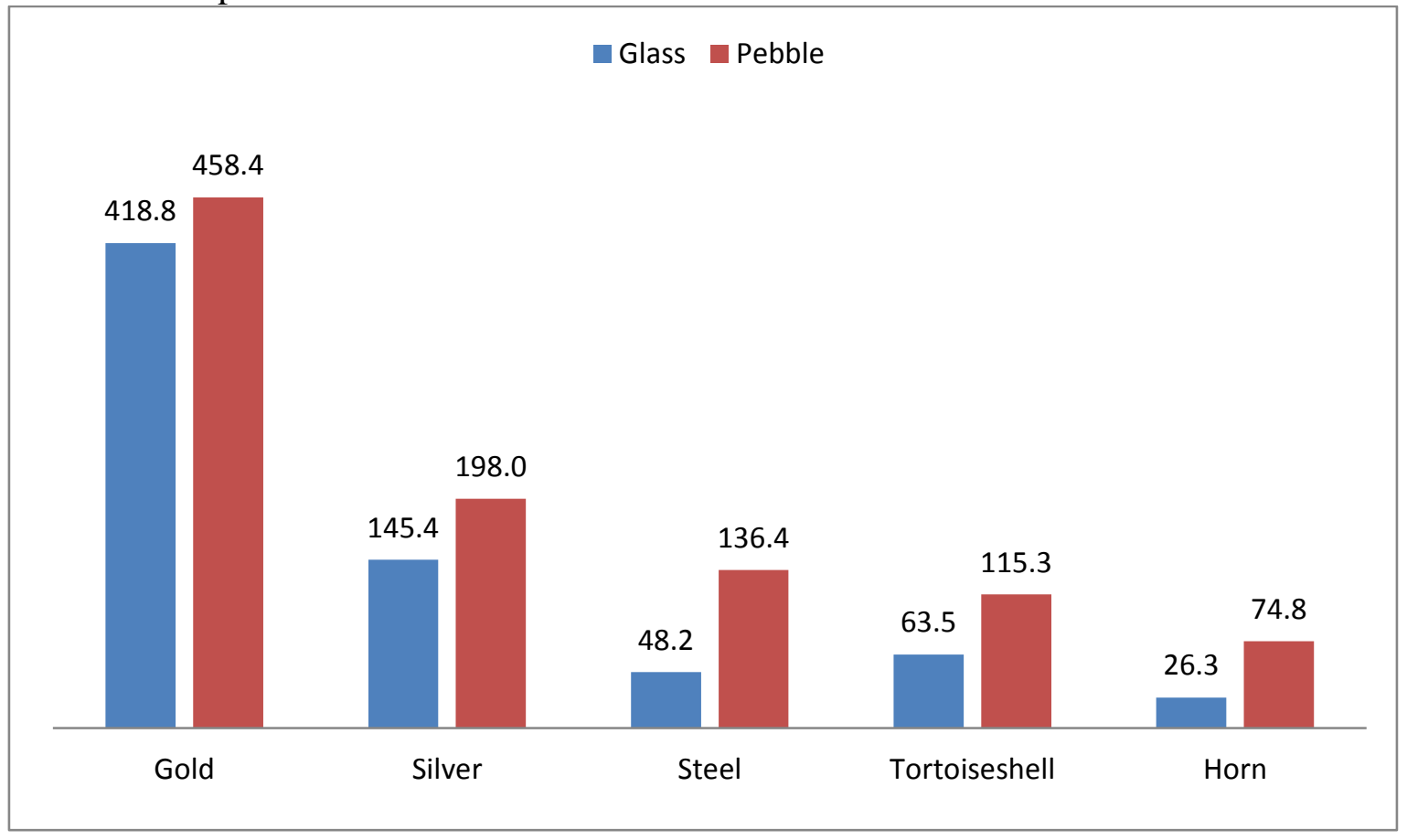

Figure 6.3 also highlights the influence of the material of the lens on the overall price. Pebble has often been acknowledged as an expensive material in historical work. However, previous research has not explored the price of vision aids across the nineteenth century in order to substantiate this claim. ${ }^{41}$ Figure 6.4 displays the overall price of spectacles recorded in that subset of nineteenth-century advertisements, identified by key-word search when both pebble and glass were mentioned in the same advertisement. For each year recorded, the same material of

\footnotetext{
${ }^{40}$ Data drawn from 79 advertisements from a range of locations between the period 1829 and 1900. ${ }^{41}$ See, for example, R.J.S. MacGregor, 'Pebbles', Ophthalmic Antiques International Collectors Club Newsletter, No. 73 (2000), 5-9, where pebbles are considered to be 'about twice the price of corresponding glass'.
} 
the frame has been used to explore this relationship, but due to the data available, different materials, such as steel and silver, appear across the data-set. Whilst it is therefore not possible to plot change in trends for the cost of a single frame and lens material over time, it is possible to explore the effect of lens material on the overall price of a certain type of frame for any given retailer in a particular year.

Figure 6.4. Line graph of the price of spectacles by material of the lens (in pence and normalised to the 1889 value) in nineteenth-century London and provincial advertisements in nineteenth-century London and provincial advertisements from between 1837 and $1892 .{ }^{42}$

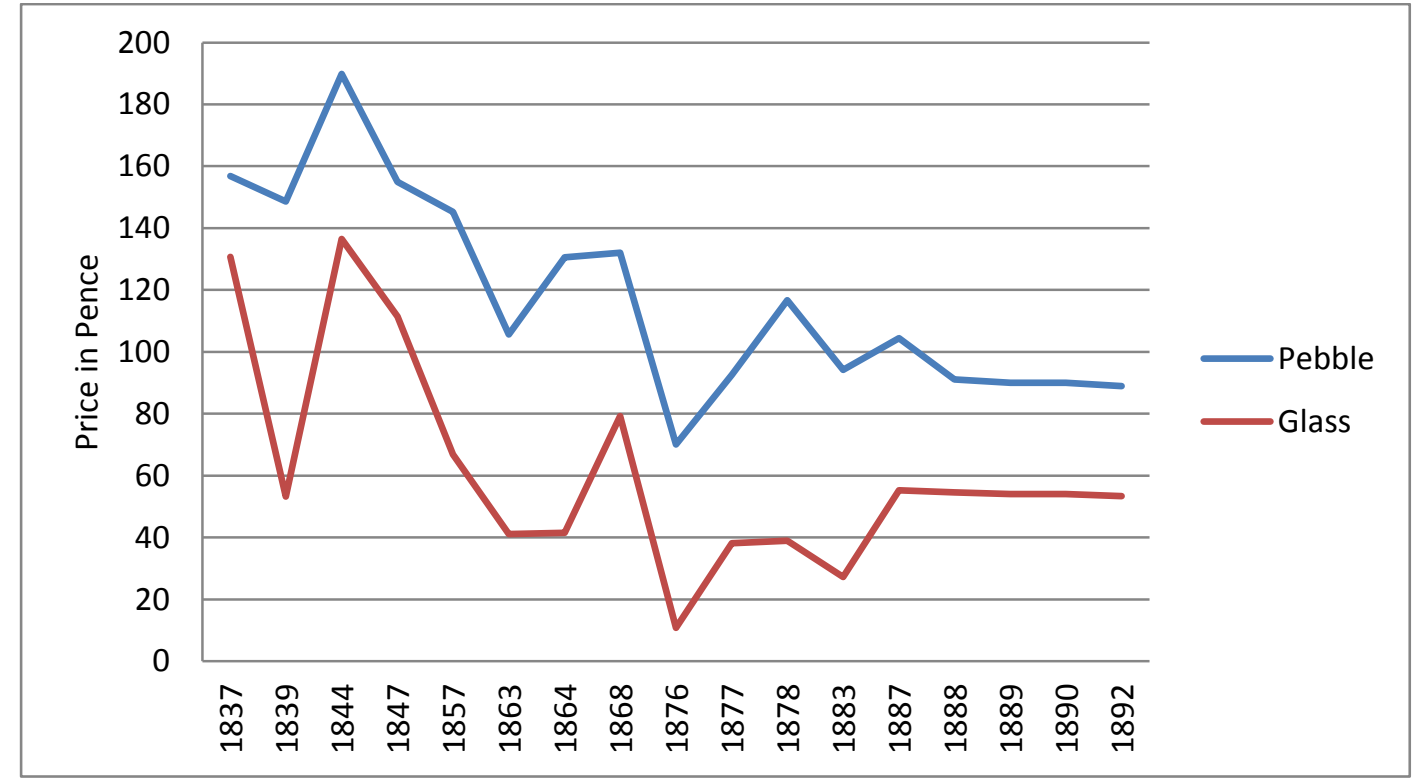

As can be seen here, the influence of the lens material on the price of the vision aid is appreciable. Moreover, the cashbooks of John Potter Dowell also document the effect of pebble on overall expense. Throughout, pebble vision aids were consistently more expensive than glass across each of the years recorded between 1885 and 1898. Additionally, pebble would later be surpassed by the expense of lenses to prescription, which appeared in the year $1897-8 .^{43}$

Both Withey and Briggs have suggested that spectacles became more affordable in the nineteenth century. ${ }^{44}$ The analysis of frame and lens materials certainly shows a broader range in price than those advertised by Dollond and Proctor in their late eighteenth and early nineteenth-century catalogues. However,

\footnotetext{
${ }^{42}$ Data drawn from 79 advertisements from a range of locations between the period 1829 and 1900.

${ }^{43}$ Carlisle Archive Centre, DB9/1-7: John Potter Dowell, Cash and Day Book (Sales), 1885-1898.

${ }^{44}$ Briggs, p. 12; Withey, p. 105.
} 
assessing the market range, and the effect of lens and frame material, does not necessarily show that the overall price of vision aids decreased in the nineteenth century. Exploring the data recorded in opticians' account books highlights how erroneous conclusions could be formed from simply comparing the prices that spectacles were either bought or advertised for at different points across the century. Trends in price are evident when the opticians' accounts are compared collectively. Figure 6.5 reveals that John Potter Dowell's sales between 1885 and 1898 were considerably cheaper than Robert Sadd's accounts recorded in the mid-century.

Figure 6.5. Bar chart of the difference in price of spectacles (in pence) in the account books of Robert Sadd and John Potter Dowell. ${ }^{45}$

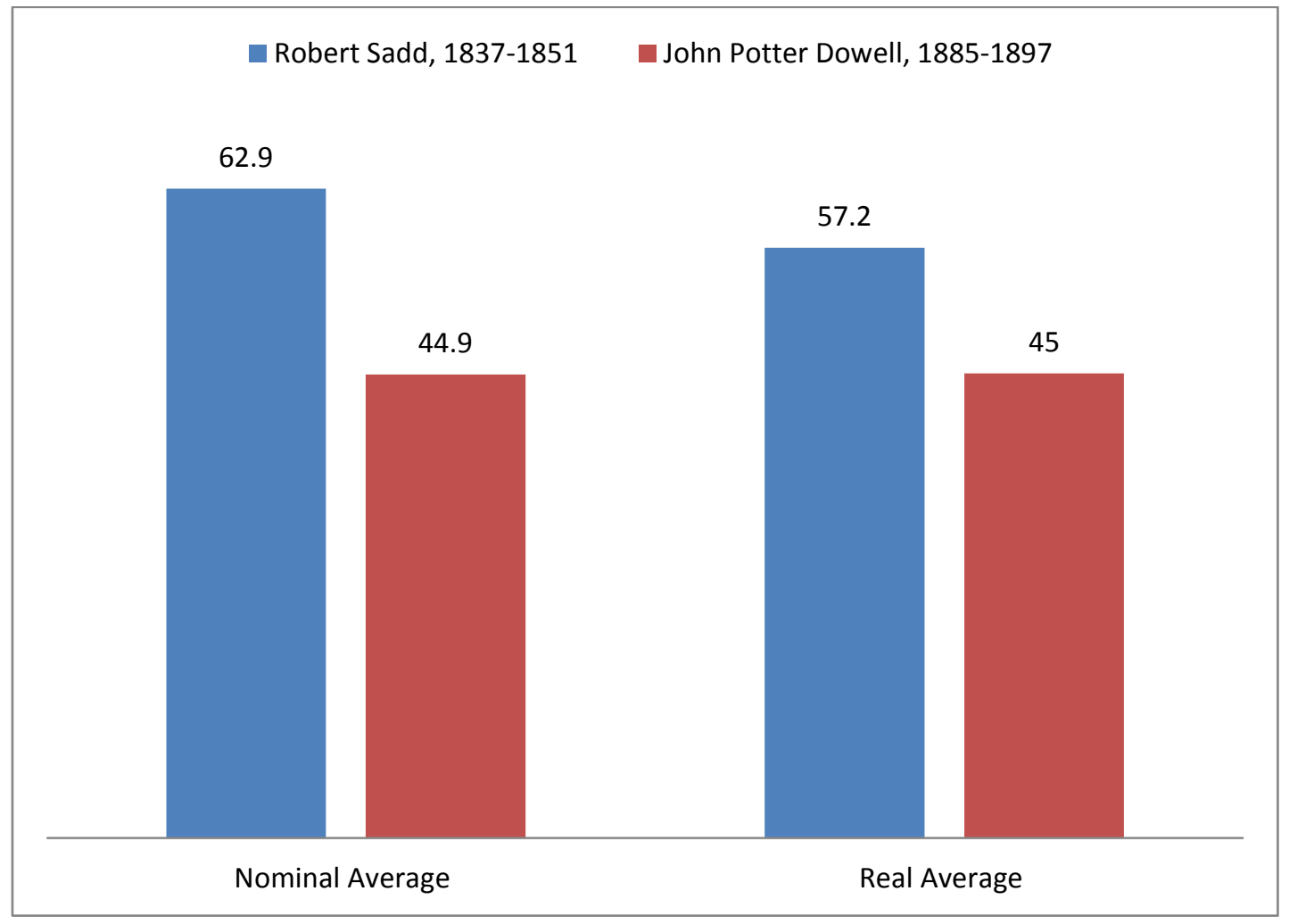

Both John Potter Dowell, in Carlisle, and Robert Sadd, in Cambridge, were opticians and jewellers and therefore comparable suppliers of vision aids. However, there is no overlap in the dates recorded to assess whether they sold a similar quality of product, and nor does a straightforward comparison of pricing take into account their different locations. Despite this, Figure 6.5 is helpful for highlighting the importance of

\footnotetext{
${ }^{45}$ Data drawn from the accounts books of John Potter Dowell and Robert Sadd \& Co: Carlisle Archive Centre, DB9/1-7: John Potter Dowell, Cash and Day Book (Sales), 1885-1898; Cambridge University Library, GBR/0012/Ms Ad.5781-5783: Robert Sadd \& Co. Account Books 1837-1851 and Ledgers 1845-1889.
} 
factoring in real price change. Here, both the nominal and the real price - which took into account inflation - do show a reduction in overall cost. However, just looking at the nominal price would have suggested that the change was more significant, at -18 pence, than the real price change at -12.2 pence.

Separating the London and provincial data from nineteenth-century advertisements highlights that overall price change was not as simple as opticians' account books and catalogues might suggest. Location could have a considerable effect on overall price. Indeed, exploring London in relation to the provincial towns provides greater insight into both the variation in the spectacle market, and the overall trends. Prices recorded in nineteenth-century advertisements suggest that the discrepancy in cost between the upper and lower end was shrinking over time, but that they were not necessarily becoming cheaper, or affordable, in the way that has been previously supposed. Figure 6.6, for example, shows that the low-end prices in nineteenth-century advertisements could differ depending on the retailer's location. Whilst the provincial price increased to a greater extent over time, the London prices - if we omit the outlier - remains fairly consistent across the century 
Figure 6.6. Line graph of the low end prices in nineteenth-century advertisements by location (in pence and normalised to the 1889 value) in nineteenth-century London and provincial advertisements from between 1829 and $1894 .{ }^{46}$

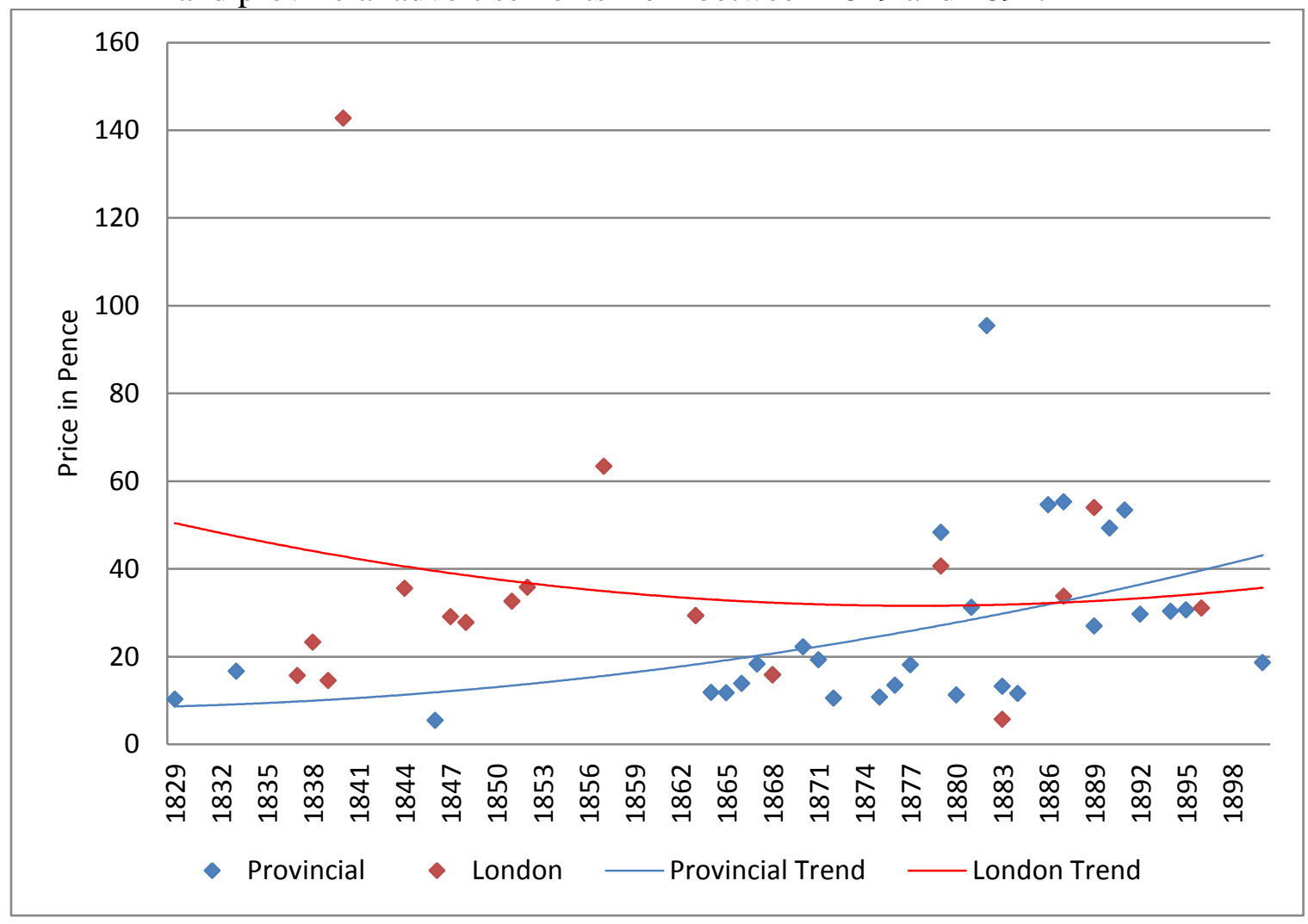

In contrast, as shown in figure 6.7, the upper-end prices were falling in both provincial and London newspapers in the first half of the century. Whilst the provincial prices began to increase again from the 1880s, the London prices continued to fall at an increasing rate.

${ }^{46}$ Data drawn from 79 advertisements from a range of locations between the period 1829 and 1900. 
Figure 6.7. Upper end prices in nineteenth-century advertisements by (in pence and normalised to the 1889 value) in nineteenth-century London and provincial advertisements from between 1829 and $1894 .^{47}$

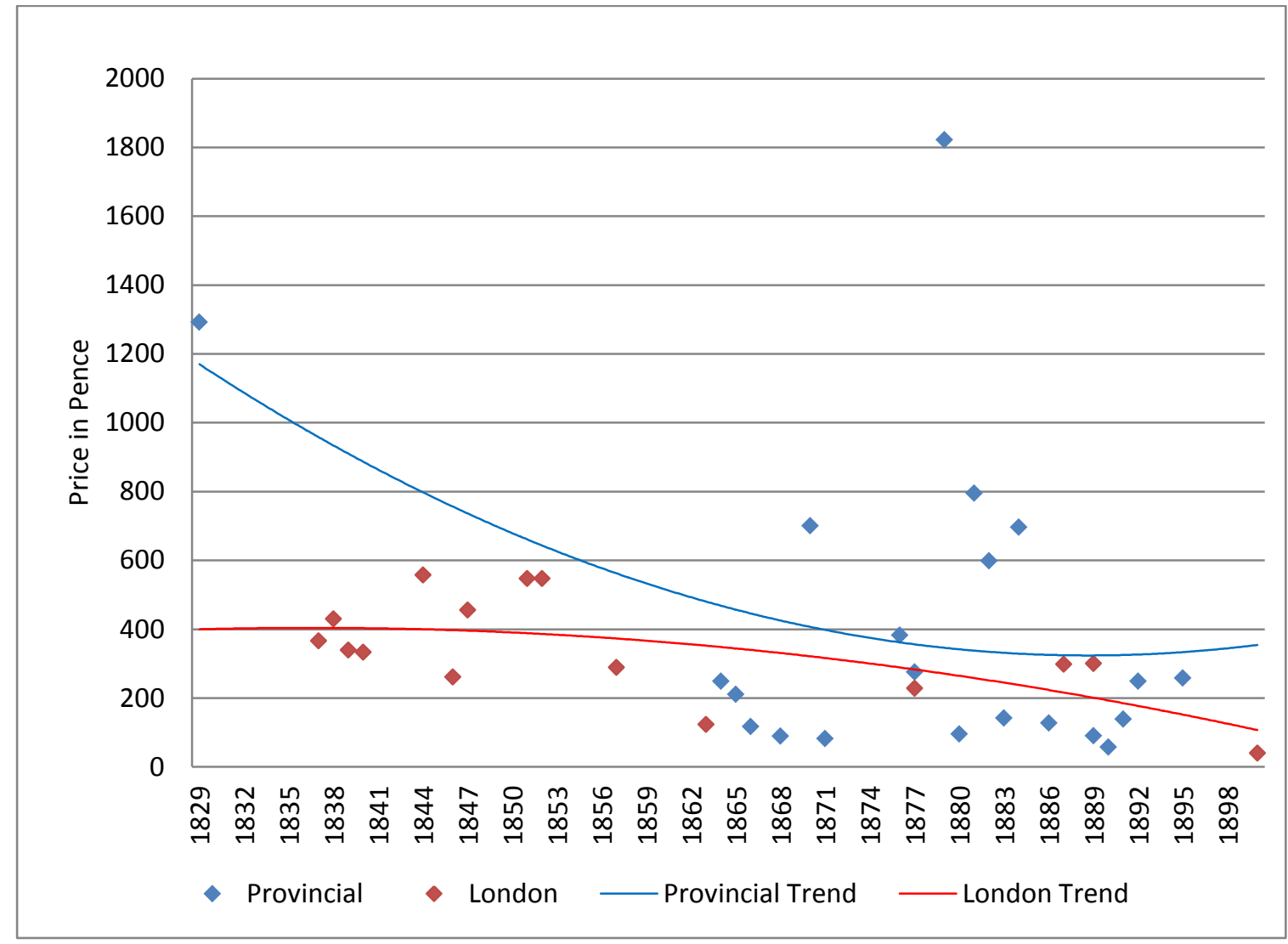

Overall, figures 6.6 and 6.7 highlight that opticians advertised a lower and upper price in both locations. They show that there were two distinctive markets, but that the absolute discrepancy in price was greater in provincial areas. By separating the data in this way it is possible to see a downward trend in upper end products, which was most significant in London, and a contrasting upward trend in lower end products, which was most significant in the provinces. Consequently, while two distinctive markets always existed, this data reveals the complexity of assessing whether vision aids became more 'affordable' or cheaper in the nineteenth century. Indeed, comparing the account books of two opticians alongside a broader range of advertisement data, and taking into account real price change, shows how misconceptions about the overall price of vision aids may have been formed. Although the mean price did not shrink as such, vision aids were available at the same, or slightly lower price, than the late-eighteenth century catalogue of Dollond.

\footnotetext{
${ }^{47}$ Data drawn from 79 advertisements from a range of locations between the period 1829 and 1900.
} 
They were not necessarily 'unaffordable' and a low-end market below 20 pence was consistently available across the century.

Changing manufacturing methods and the use of different materials were important factors in the production of cheaper vision aids. In 1877 Friedrich Horner, Swiss Ophthalmologist and Professor at the University of Zurich, argued that manufacturing developments directly correlated with affordability:

now-a-days- the processes of the manufacture of spectacles have been so greatly improved that they can be sold at a price that all can afford. ${ }^{48}$

The language used to describe products in opticians' account books highlights the existence of the cheaper range of vision aids that also appeared in retailers' advertisements. In the cashbook of Robert Sadd, for example, a sale of 'common spectacles' in 1837 was recorded, while entries from 1839 show how the price was affected by the material of the frame: a gold eyeglass was purchased for 20 shillings, steel spectacles for 10/6 shillings, and horn spectacles for as little as 2 shillings. As noted in Sadd's ledgers, customers also bought pairs of 'second hand specs', as well as 'fine' or 'best' frames, which varied substantially in price. ${ }^{49}$ By the latter half of the nineteenth century an article could discuss the advent of a range of products that might now be purchased for the price of one shilling, and spectacles were among them. ${ }^{50}$

It is difficult to determine that there was an overall reduction in the cost of spectacles and therefore the role of manufacture in the creation of cheaper products. However, it is possible to explore how contemporary expectations of who could or should be able to afford and use vision aids altered. The use of vision aids by a broadening proportion of society was reflected in the language of nineteenth-century advertisements. Cheap spectacles were mentioned in some advertisements in the first half of the century, but the specific targeting of the lower classes occurred more frequently in the latter half. This shows that, by the end of the period, spectacles and eyeglasses were either required, or expected to be used, by the lower classes. From

\footnotetext{
${ }^{48}$ Friedrich Horner, On Spectacles: Their History and Uses (London: Balliere, Tindall \& Cox, 1887), p. 5.

${ }^{49}$ Cambridge University Library, GBR/0012/Ms Ad.5781-5783: Robert Sadd \& Co. Account Books 1837-1851 and Ledgers 1845-1889.

${ }^{50}$ Chambers's Journal of Popular Literature, Science and Arts, 24 February 1877, pp. 120-22
} 
as early as 1838 , perhaps unsurprisingly, many retailers advertised the affordability of their products through prices that were 'very reduced', 'moderate', 'unusually low' or the 'lowest charged'. ${ }^{51}$ However, just as Perry argued that prosthetics were marketed and designed depending on the user's social status, advertisements for vision aids specifically targeted the lower classes, or advertised a cheaper range. ${ }^{52}$ Abraham \& Co in 1868, for example, advertised a range of vision aids but included at the bottom of this, as an adjunct, '*** Spectacles for the Humbler Classes, 1s $6 \mathrm{~d}$ and $2 \mathrm{~s} 6 \mathrm{~d}$ per pair'. ${ }^{53}$ Likewise, 'The working man's spectacle' was added to the bottom of an advertisement in The Wrexham Advertiser in $1887 .{ }^{54}$ This overall desire to appeal to a broad cross-section of society can also be found in phrases used in multiple advertisements between 1887 and 1888, such as 'suitable to all CLASSES' and the inclusion of 'Special Terms for Working Classes' in an advertisement for $\mathrm{Mr}$ R.W. Mason, Ophthalmic Optician, in The Leicester Chronicle. ${ }^{55}$ These advertisements highlighted a cheaper range, which was commonly referred to as 'second quality', or 'common spectacles' ${ }^{56}$ However, advertisements also attempted to make these cheaper items appear desirable by commenting on their utility. Similar to other prosthetics, this suggests that vision aids became a primarily functional tool at the lower end of the market. ${ }^{57}$ Less expensive or utilitarian steel spectacles, for

\footnotetext{
${ }^{51}$ See, for example, Newspapers: Examiner, 21 January 1838; The Morning Chronicle, 7 July 1840; 8 July 1840; The Bristol Mercury, 22 October 1853; Ipswich Journal, 3 June 1854; Caledonian Mercury, 30 April 1855; Belfast News-Letter, 10 October 1865; Cheshire Observer and Chester, Birkenhead, Crewe and North Wales Times, 22 December 1866; Belfast News-Letter, 18 October 1875; The Bristol Mercury, weekly between 16 June 1877 and 21 July 1877; Freeman's Journal and Daily Commercial Advertiser, 22 October 1879; 29 October 1879; 30 October 1879; 4 November 1879; 5 November 1879; Nottinghamshire Guardian, 7 November 1879; Glasgow Herald, 23 January 1883; The Dundee Courier \& Argus, 15 September 1883; 22 September 1883; 29 September 1883; 1 December 1883; 8 December 1883; Leicester Chronicle and Leicestershire Mercury, 22 March 1884; 12 April 1884; 26 April 1884; 3 May 1884; 10 May 1884; 17 May 1884; 24 May 1884; 31 May 1884; 7 June 1884; The Sheffield \& Rotherham Independent, 11 October 1887; 25 October 1887; Glasgow Herald, 26 February 1889; Periodicals: The Athenaeum, weekly between 4 January 1851, p. 1 and 29 October 1853, p. 1302; Longman's Magazine, April 1893, p. 655; December 1893, p. 221; Ipswich Journal, 7 December 1895; 14 December 1895; 21 December 1895.

${ }_{53}^{52}$ Perry, pp. 75-102.

${ }^{53}$ The London Reader: of Literature, Science, Art and General Information, regularly between 28 November 1868, p. 121 and 27 August 1870, p. 409.

${ }^{54}$ The Wrexham Advertiser, and North Wales News, 26 March 1887; 24 December 1887.

${ }^{55}$ The Leicester Chronicle and Leicestershire Mercury, 7 January 1888, p. 4; and weekly between 18 February and 7 April 1888; The Sheffield \& Rotherham Independent, 11 October 1887; 25 October 1887. A similar advertisement can also be found in The Sheffield \& Rotherham Independent, 1 January 1890.

${ }^{56}$ Lloyd's Weekly London Newspaper, 11 February 1844; The Athenaeum, regularly between 28 February 1857, p. 262, and 9 May 1857, p. 610; Leader and Saturday Analyst, 28 February 1857, p. 213; Reynold's Newspaper, 29 March 1857; 12 April 1857; The Sheffield \& Rotherham Independent, 11 October 1887; 25 October 1887.

${ }^{57}$ Perry, pp. $75-102$.
} 
example, could be marketed with phrases such as 'good serviceable spectacles' or a 'thoroughly good' pair for 1 shilling, or $1 \mathrm{~s} 9 \mathrm{~d}$ when a case was included. ${ }^{58}$

Advertisements that included a cheaper price were not limited to a single location and could be found in the metropolis, as well as a range of southern and northern cities, including Ipswich, Sheffield, and Glasgow. ${ }^{59}$ In both Bristol and Dundee spectacles were advertised for as little as $6 \mathrm{~d} .{ }^{60}$ Such advertisements targeted the lower classes with prices between $6 \mathrm{~d}$ and $1 \mathrm{~s} 6 \mathrm{~d}$ or $2 \mathrm{~s} 6 \mathrm{~d}$. They suggest that the low-end price recorded consistently across the nineteenth century would have been affordable or accessible to those at the far end of the social scale. ${ }^{61}$ However, whilst Horner argued in 1877 that spectacles were 'sold at a price that all can afford', there were concerns about the quality of these and especially the preying of fraudsters upon the 'working man'. ${ }^{62}$ Lower classes were frequently victims of fraud. One article in 1838 argued that knowledge and awareness of the practice would allow 'the poorest person to be defended against the tender mercies of the spectacle speculators'. ${ }^{63}$ In 1893 a number of cases of fraud associated with 'Electric Spectacles' appeared in the correspondence of The Standard. These cases, which detailed vision aids being sold under false pretences, were published in order to highlight the 'rascality that is practised on poor people'. ${ }^{64}$

Prior to advertisements targeting the lower classes appearing, and perhaps as a result of persistent concerns over fraud, a number of early appeals to charity can be found. Calls for charity highlight how the expected users of vision aids were changing; they argued that the lower classes required vision aids that they could not afford. In 1815 one of the founding fathers of ophthalmology, Georg Beer, suggested that a charitable service was a 'matter of serious import' and needed to be set up in order to 'distribute good spectacles to the poor that were absolutely in want of

\footnotetext{
${ }^{58}$ Belfast News-Letter, 10 October 1865; Glasgow Herald, 26 July 1871; 3 August 1871.

${ }^{59}$ See, for example, Lloyd's Weekly London Newspaper, 11 February 1844; The Sheffield \& Rotherham Independent, 14 May 1867; Glasgow Herald, 27 November 1872; Ipswich Journal, 26 February 1881.

${ }^{60}$ The Bristol Mercury, 21 March 1846; The Dundee Courier \& Argus, weekly between 30 June 1883 and 15 March 1884.

${ }^{61}$ See Figure 6.6.

${ }^{62}$ Beer, p. 247; John Grimshaw, Eyestrain and Eyesight; How to Help the Eye and Save the Sight (London: J. \& A. Churchill, 1907), p. 40.

${ }^{63}$ Tait's Edinburgh Magazine, December 1838, pp. 803-804.

${ }^{64}$ The Standard, 23 August 1893, p. 2
} 
them'. ${ }^{65}$ Additionally, Beer argued that, besides the poor, a broader range of people needed access to a 'cheap rate'. ${ }^{66}$ Similarly, in 1824 it was argued that 'there could not be a more Useful Charity than that of providing proper SPECTACLES FOR THE POOR' ${ }^{67}$ The text argued that the distribution of spectacles should be seen as part of the district societies and eye infirmaries' responsibilities. It concluded that 'in no way can so much good be done with so little money! ${ }^{68}$ A decade later in 1835, similar calls for attention were still being published, and the Ch ambers's Edinburgh Journal included an extract from a prominent British ophthalmologist, William Mackenzie, which stated that there 'could not be a more useful appropriation of part of the funds of charitable institutions than that providing spectacles for the poor' ${ }^{69}$

By the mid-century, vision aids were perceived as a 'basic right', and the provision of spectacles - albeit only for the elderly - was considered important in the reports of a poor law inspector. ${ }^{70}$ This was not an isolated phenomenon, and persistent need for charity existed in the second half of the century. This does highlight that the low-end market and the prices that were used by retailers to target the lower classes were not always affordable. In fact, whilst historians and Horner in 1887 have stated that spectacles had become affordable, correspondence in The Standard in December 1888 highlighted that they had 'not over-looked the fact that Spectacles are beyond the reach of many parents'. ${ }^{71}$ Similarly, J.D. Hirst, in his study of late nineteenth-century vision testing in schools, has argued that attendance at hospitals for vision tests was affected by class and the overall accessibility of vision aids at the lower end of the social spectrum. ${ }^{72}$ However, discussion of charity and the need for vision aids amongst the lower classes also shows that vision aids were considered necessary and a device that should be accessible to all. In January 1891, for example, The Review of Reviews noted that 'all the old inmates of Kingston

\footnotetext{
${ }^{65}$ Beer, p. 138.

${ }^{66}$ Ibid.

${ }^{67}$ W. Kitchiner, The Economy of the Eyes: Precepts for the Improvement and Preservation of Sight (London: Hurst Robinson \& Co., 1824), p. 10.

${ }^{68}$ Ibid., p. 11.

${ }^{69}$ Chambers's Edinburgh Journal, 10 January 1835, pp. 394-5.

70 The National Archives, MH 12/11000/19: Spectacles for aged inmates, 4 April 1853, folio 47; The National Archives MH 12/9534/77: From the Harry Farnall, Poor Law Inspector of Southwell workhouse, 30 October 1867, folios 105-7.

${ }^{71}$ The Standard, 22 December 1888.

72 J.D. Hirst, 'Vision testing in London: a rehearsal for the School Medical Service', Journal of Education Administration \& History, 14.2 (1982), 23-9 (p. 25).
} 
Workhouse' had been supplied with spectacles 'by the kindness of a local optician'. $^{73}$

Exploring the interaction of a customer with the retailer on an individual level is useful for ascertaining the overall accessibility of vision aids in the second half of the nineteenth century. Cost was considered important in the case accounts of the 'Optical Queries and Answers' column in The Optician. The queries highlight that the price of the vision aid in some cases was only part of the overall expenditure. A number of individuals, for example, were recorded as having been unable to afford treatment, oculist fees, or the need to travel a considerable distance to a hospital when either they, or their parents, were 'not all well off' ${ }^{74}$ Alongside this additional expense, there were a number of other hidden costs for owners of spectacles and eyeglasses in the nineteenth century. These additions only become apparent when looking at the records or receipts in the accounts of individuals and opticians. Receipts from George, $3^{\text {rd }}$ Earl of Egremont, in 1820 and 1822 detailed the initial purchase of a vision aid. However, they also show the repair of a vision aid for 5 shillings and the purchase of a new 'shell front to glasses' for 7 shillings. ${ }^{75}$ A range of vision aid frames in the Science Museum's collections highlight the need for repairs in the nineteenth century. The condition of the frames was not recorded at the time of acquisition to determine when the frames or lenses were broken or repaired. However, evidence of repair can be visibly found on the frames and include: the lens, plaquet, side-arms, hinge or the bridge being fixed or re-enforced. An example of a bridge repair can be seen in Figure 6.8.

\footnotetext{
${ }^{73}$ The Review of Reviews, January 1891, p. 10.

${ }^{74}$ See, for example, The Optician, 15 July 1897, pp. 298-9; 9 December 1897, p. 320; 6 October 1898, p. 188.

${ }^{75}$ West Sussex Record Office, PHA 10638: Bills supplied to George $3^{\text {rd }}$ Earl of Egremont, 1821 1822, 22 May 1820; West Sussex Record Office, PHA 8846: Receipted bills for goods and services supplied by London tradesmen, paid by William Knapman on behalf of George, 3rd Earl of Egremont, 19 January 1822.
} 
Figure 6.8. Science Museum Ophthalmology collection A62365, an example of a frame that has the bridge repaired.

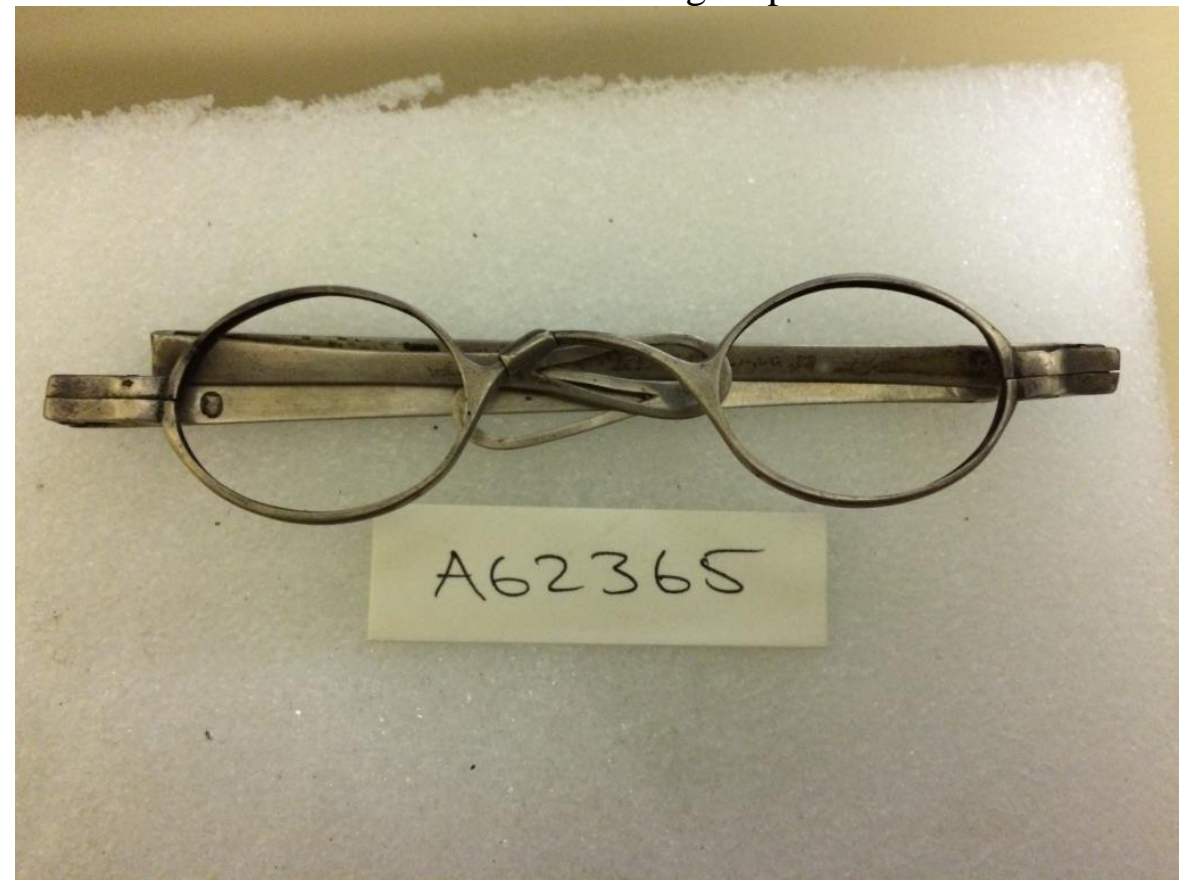

Alongside the material evidence of the Science Museum's collections, opticians' ledgers provide a unique record of customers' interaction with the seller. These include a large number of repairs, to suggest that vision aids were both bought and repaired regularly by a range of individuals. Repairs in opticians' ledgers and account books were referred to both generically as a 'spec job', or broken down into specific repairs for the side, frame, lens, plaquet, spring, and screw. In the account books and ledgers, people could make a single trip to either buy or alter their vision aids, and costs appeared relatively low. In the account books of John Potter Dowell, for example, Mr Borthwick paid 6d to have his spectacles repaired on the $25^{\text {th }}$ June 1891. ${ }^{76}$ Later, in June 1897 , Mr Hazell spent $3 / 6$ on a pair of spectacles. ${ }^{77}$ Similarly, in the ledgers of Robert Sadd Reverend A. Small had eyeglasses repaired for $6 \mathrm{~d}{ }^{78}$ Moreover, the entries in the account books of Robert Sadd and John Potter Dowell, summarised in Figure 6.9, show that the average costs of repairs varied from 37 pence for a new frame to 3 pence for a new screw.

\footnotetext{
${ }^{76}$ Carlisle Archive Centre, DB9/5: John Potter Dowell, Cash Day Book Sales 1891-1892; Day Book at the back, 25 June 1891 [unpaginated].

${ }_{77}^{7}$ DB9/7: Cashbook Day Sales 1897-1898, Day Book at the back, 8 June 1897 [unpaginated].

${ }^{78}$ Cambridge University Library, GBR/0012/Ms Ad. 5783: Robert Sadd \& Co. Ledger 2., p. 27.
} 
Figure 6.9. Table of the average cost of different types of repair (in pence) from John Potter Dowell and Robert Sadd's account books. ${ }^{79}$

\begin{tabular}{|c|c|c|}
\hline Type of Repair & $\begin{array}{l}\text { Robert Sadd, 1837-1851 } \\
\text { (Price in Pence) }\end{array}$ & $\begin{array}{l}\text { John Potter Dowell, 1885- } \\
1898 \text { (Price in Pence) }\end{array}$ \\
\hline New Lens & 18.6 & 14.5 \\
\hline Repair Spectacles & 16.7 & 5.8 \\
\hline New Sides to Spectacles & 28.2 & 10.1 \\
\hline Rep Eyeglasses & 12.0 & 9.8 \\
\hline New Spring & 6.0 & 14.3 \\
\hline New Screw & 6.0 & 3.6 \\
\hline New Frame & 37.0 & 17.0 \\
\hline New Bridge & 22.5 & 10.5 \\
\hline Glasses Repair & 12.0 & 17.0 \\
\hline Gold Repair & 23.5 & 6.2 \\
\hline Repairing Folders & & 5.5 \\
\hline New Plaquets & & 9.0 \\
\hline New Piece & & 14.0 \\
\hline Reader Repair & 12.0 & \\
\hline
\end{tabular}

Whilst the individual cost of repair or purchase could therefore be small, cumulatively, as a result of multiple visits, the cost of eyeglass and spectacle wear in the nineteenth century might be substantial. For many, it went beyond the purchase of a single item. In some instances, customers' interaction with the seller involved repeated visits over a period of years; records of these help to build up a fuller picture of vision aid expenditure. The transactions of Mr Rooper of Trim Street in Cambridge, for example, were recorded by Robert Sadd between 1868 and 1871. These transactions amounted to $£ 2 / 10 / 6$, and included the purchase of 'powerful convex' spectacles, tinted spectacles, reading glasses, cases, and the repair of the frames. ${ }^{80}$ L. Joley, of Kings College, also spent $£ 2 / 8 /$ - between 1859 and 1864, and visited Robert Sadd three or four times a year to purchase numerous pairs of

\footnotetext{
${ }^{79}$ Data collected from Carlisle Archive Centre, DB9/1-77: John Potter Dowell, Cash and Day Book (Sales), 1885-1898 and Cambridge University Library, GBR/0012/Ms Ad.5781-5783: Robert Sadd \& Co. Account Books 1837-1851 and Ledgers 1845-1889.

${ }^{80}$ Cambridge University Library, GBR/0012/Ms Ad. 5783: Robert Sadd \& Co. Ledger 2., p. 111.
} 
spectacles. ${ }^{81}$ This was not an isolated incident, and C.J. Roe of St John's College, spent $£ 1 / 15 / 3$ on regular purchases of eyeglasses, ranging in price between $1 / 6$ and 10/6, between 1863 and $1867 .{ }^{82}$ Correspondingly, in the cashbooks of John Potter Dowell a number of individuals were recorded numerous times over a period of years. Reverend A. Wrigley, for example, visited between 1886 and 1892 and spent a total of $£ 1 / 7 /-$ on a range of eyeglasses, folders, and spectacles, as well as having his folders repaired, a new spring to his eyeglass, and a new curl side and glass for his spectacles. ${ }^{83}$ Again, this was not unusual and a number of visits were paid by a range of customers, including a draper and ironmonger, for the purchase and repair of their spectacles and eyeglasses. ${ }^{84}$

An account of a visit to a hospital in The Leisure Hour in 1890 further challenges Horner's comment that spectacles had become affordable in the 1870s. It described the number of working class people that suffered from poor vision and required spectacles either 'free of cost' or at a 'very low price'. ${ }^{85}$ Descriptions such as this suggest that, by the 1890s, hospitals were providing a charitable service not dissimilar to the proposal made in 1824 . The scale of hospital charity can be seen in a complaint towards the Royal London Ophthalmic Hospital in 1900. This complaint argued that the provision of spectacles and artificial eyes, which amounted to $£ 135 / 3 / 6$ per annum, had negatively impacted the overall financial stability of the institution. Indeed, this enterprise was considered to be one of the primary reasons why it was not becoming a self-supporting charity. ${ }^{86}$ The correspondence of another late nineteenth-century charity is a good example for exploring both the affordability of, and expected need for, vision aids amongst the lower classes by the end of the nineteenth century. The London Spectacle mission was founded by Dr Waring in

\footnotetext{
${ }^{81}$ Ibid., p. 85.

${ }^{82}$ Ibid., p. 107.

${ }^{83}$ Carlisle Archive Centre, John Potter Dowell, DB9/2: Cash day book (sales) 1885-1886, Day book at the back: 20 March 1886; DB9/4 Cash day book (sales) 1888-1890: 11 July 1888; 17 April 1888; 18 October 1888; DB9/5 Cash day book (sales) 1891-1892, Day book at the back: 11 June 1891; 26 April 1892; 5 May 1892; DB9/6 Cash day book (sales) 1893-1894: 16 November 1893; 2 July 1894; 24 November 1894 [unpaginated].

${ }^{84}$ See, for example, Draper Mr J. Irving Bell: DB9/5 Cash day book (sales) 1891-1892, Day book at the back: 9 July 1891; DB9/6 Cash day book (sales) 1893-1894: 4 April 1894. Ironmonger Mr J.G. Parker, DB9/2 Cash day book (sales) 1885-1886, Day book at the back: 6 July 1885; 16 January 1886; 6 February 1886 [unpaginated].

${ }^{85}$ The Leisure Hour, February 1890, pp. 277-281

${ }^{86}$ London Metropolitan Archives, A/KE/B/01/04/004: Royal London Ophthalmic Hospitals, Complaint that there was little profit in supplying spectacles, letter dated 18 October 1900.
} 
1886, and sought to supply spectacles 'to those of the poorer classes who stand in need of them' ${ }^{87}$ In early newspaper clippings it was stated that over five hundred people were 'relieved' each year, and these were primarily 'sempstresses, laundresses, cobblers, and other workers of very limited means, who may be deprived of their means of livelihood by failing eyesight' ${ }^{88}$ The charity was carried on by Dr Waring's daughter following his death, and a response to a letter of enquiry provided an overview of how the charity functioned:

Receiving subscriptions \& issuing 'Spectacle Cards' to subscribers... Miss Waring has a large box with compartments containing various kinds of spectacles. She is the judge of what kind of spectacles are required, and whether the failure of sight is due to old age... She asks the patient if they have attended any Hospital for their eyes, and if so, she gives them an order for spectacles to take to an optician... She also gives each one a spectacle case, a Testament and a book of prayers compiled by her father. The 'Mission' seems to consist in the giving of these two books. 89

On receiving a signature from the subscriber on one of the distributed cards, the individual had the option to bring their signed card to four different locations dependant on the day of the week. As seen in Figure 6.10 below, they would not be charged for their first pair of spectacles unless they were 'specially made'.

\footnotetext{
${ }^{87}$ London Metropolitan Archives, A/FWA/C/D/223/001: London Spectacle Mission Correspondence and Papers, two Newspaper Clippings, undated.

${ }^{88}$ Ibid.

${ }^{89}$ London Metropolitan Archives, A/FWA/C/D/223/001: London Spectacle Mission Correspondence and Papers, Private and Confidential Report, 1 January 1896.
} 
Figure 6.10. Example of the cards that were distributed by the London Spectacle Mission Society. ${ }^{90}$

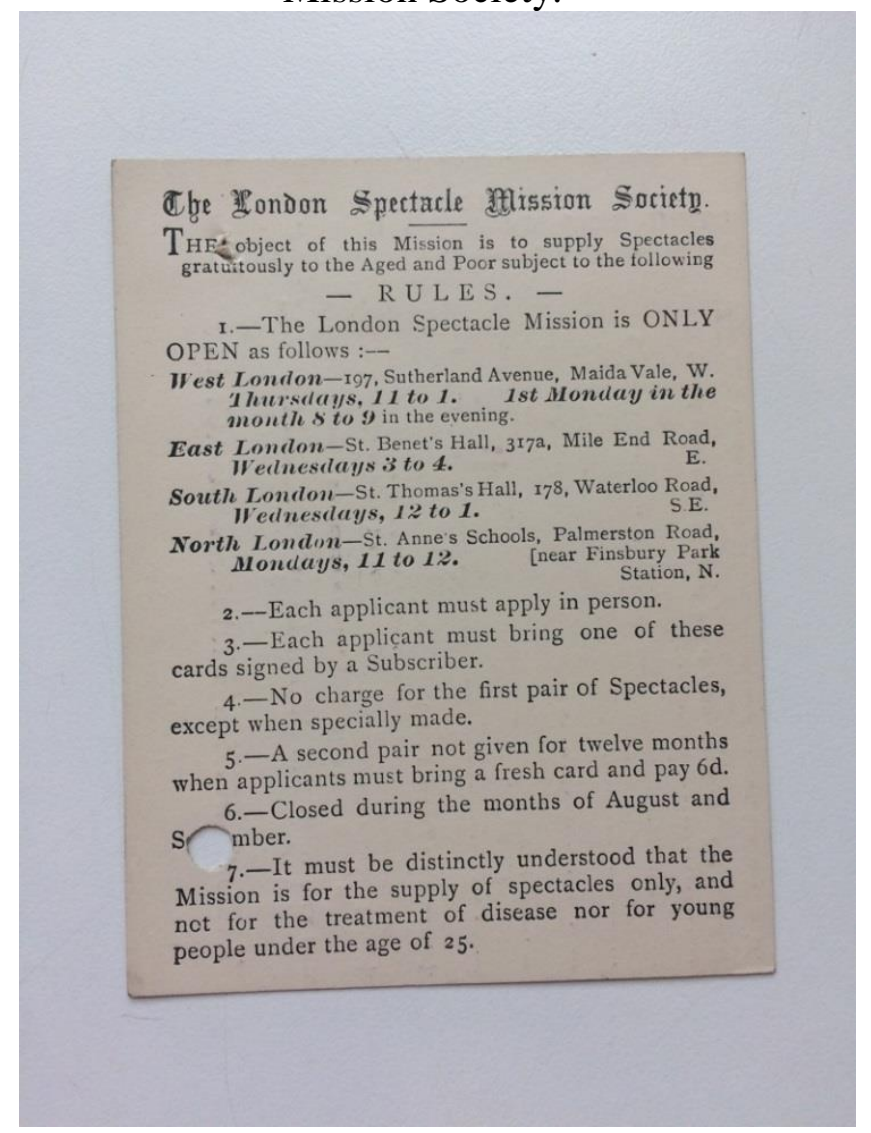

This charitable practice continued into the twentieth century. A pamphlet titled 'Spectacles for the Needy, and How to Get Them' provided an account of a visit to Miss Waring's house during one of the consultation hours in the early twentieth century. This recorded the provision of 'nickel or steel frames', which had been 'properly tested' to ensure that they were 'new, strong and well-made'. Additionally, a number of ledgers and books 'dealing with past cases' were described and they suggest that the charity was operating on a sizeable scale. The pamphlet concluded that the charity was 'yearly increasing in the sphere of its usefulness' and 37,000 people had applied between 1886 and 1912. ${ }^{91}$

The 'Spectacles for the Needy' pamphlet detailed that any 'peculiarity of vision' was quickly referred to a hospital or consulting physician. However, despite

\footnotetext{
${ }^{90}$ London Metropolitan Archives, A/FWA/C/D/223/001: London Spectacle Mission Correspondence and Papers.

${ }^{91}$ London Metropolitan Archives, A/FWA/C/D/223/001: London Spectacle Mission Correspondence and Papers, pamphlet Spectacles for the Needy, and How to Get Them, by Sibyl Bristowe, undated [but possibly 1912].
} 
this, responses to enquiries about the Mission from the London Charity Organisation Society suggest that there were wider concerns over its conduct in a range of letters from $1897 .^{92}$ The continued scale of hospital charity in the twentieth century is apparent in a letter from June 1923, which questioned the need for the Mission 'in view of the provision made by the Hospitals and otherwise' ${ }^{93}$ The London Spectacle Mission highlights not only the need for charity for those that could not afford spectacles, but also the ways in which this had been implemented by the early twentieth century. There were two distinct markets for vision aids in the nineteenth century. In particular, the advent of vision aids for a shilling or less would have likely broadened their accessibility in comparison to earlier periods. Yet the London Spectacle Mission highlights that cheaper vision aids may still have been inaccessible for some. Moreover, the number of those who were in need of spectacles was highlighted in 1890 when it was reported that over 1,500 'poor persons' had been supplied with a free pair of spectacles from a hospital to return to work. ${ }^{94}$ A letter that was written in 1898 also feared that there were 'many sufferers from inability to earn their livelihood, who might be cured by proper treatment but who have not the means to pay for it'. ${ }^{95}$ These statements do challenge the affordability of spectacles and eyeglasses in the later nineteenth century. However, the statements also highlight that there was a perceived need for vision aids amongst a broad cross-section of society. The value of vision aids for their users was apparent in the London Spectacle Mission correspondence. They were expected to be accessible, of a good quality, and dispensed in the medically appropriate manner to allow people to maintain work. Vision aids were expected to be worn amongst the lower classes. Far from being an ornament for the rich, vision aids by the end of the nineteenth century could be conceived as a solely utilitarian device and a basic right for the poor.

\footnotetext{
${ }^{92}$ See, for example, London Metropolitan Archives, A/FWA/C/D/223/001: London Spectacle Mission Correspondence and Papers, Private and Confidential Report, letters dated 4 January 1897; 8 November 1899; 26 May 1900; 16 May 1902; 20 August 1902; 10 July 1903; 24 May 1907; 6 April 1910; 14 April 1910.

${ }^{93}$ London Metropolitan Archives, A/FWA/C/D/223/001: London Spectacle Mission Correspondence and Papers, Private and Confidential Report, letter dated 29 June 1923.

94 The Leisure Hour, February 1890, pp. 277-281

${ }^{95}$ London Metropolitan Archive, A/KE/B/01/04/004: Royal London Ophthalmic Hospitals, Complaint that there was little profit in supplying spectacles, letters dated 23 and 26 October 1900.
} 


\section{User Experience}

The pamphlet, 'Spectacles for the Needy', described the 'gratitude so often displayed by the applicants' as one of the most 'touching' features of the London Spectacle Mission. ${ }^{96}$ Yet accessing the experiences of spectacle users, and ascertaining what it would have been like to wear vision aids in the nineteenth century, or the effect that they had on other people's lives, is challenging. A few anecdotal accounts can be found. A letter written by Lady Marianne Malet between 1846 and 1847, for example, gives a fleeting glimpse of how spectacles were used, through the comment that she 'habitually wears them'. ${ }^{97}$ A letter from Henry Bickersteth Mayor to his sister, Flora McDonald Mayor, contains the remark that:

\footnotetext{
I have noticed with regard to spectacles that father has eight pairs \& mother three; father invariably leaves his about on corners of mantel-pieces \& tables \& book shelves - anywhere that comes handy, \& as he does not know any of them by sight, a certain confusion follows. ${ }^{98}$
}

Whilst this letter reveals that spectacles could be a topic of conversation, or that individuals could own many, it does not give any real insight into the experiences of wearers. This section assesses users' interaction with their vision aids in more detail through case studies of individuals in opticians' ledgers and medical accounts. The section is split into two parts: an analysis of opticians' ledgers, which provides an insight into people's interactions with the seller and the types of vision aids that they bought; and an exploration of the medical case accounts, which reflect on the experience of treatment, and on the value or benefit of vision aids that was prophesised in the accounts discussed in chapters one and two. Dreyfus argued that the practical usability of vision aids is an important factor when considering overall usage. ${ }^{99}$ This section shows how improvements in the comfort of vision aids and vision testing enhanced the ability of vision aids to be used as an assistive device. However, it also argues that medical ideas were not necessarily immediately adopted, and the relationship between utility and usage is not straightforward.

\footnotetext{
${ }^{96}$ London Metropolitan Archives, A/FWA/C/D/223/001: London Spectacle Mission Correspondence and Papers, pamphlet Spectacles for the Needy, and How to Get Them, by Sibyl Bristowe, undated [but possibly 1912].

${ }^{97}$ Somerset Heritage Centre, DD/MAL/337: Lady Marianne Malet miscellaneous correspondence, 1846-1847.

${ }^{98}$ Trinity College Library Archives Cambridge, B25/23: Letter from Henry Bickersteth Mayor to his sister Flora McDonald Mayor, this letter is undated but Mayor's father died in 1916 so it can be dated before this.

${ }^{99}$ Dreyfus, p. 105.
} 
Despite this, both types of source can be analysed to assess ownership of vision-aids in the nineteenth century and the extent to which the increased utility of lenses transformed the lives of users.

As previously highlighted, the account books and ledgers of John Potter Dowell and Robert Sadd provide information on the cost of repairs and purchases from a number of people. In these instances, multiple visits from the same individual allow broader trends in the cost of repair and purchases to be tracked. However, the user's interaction with the seller also provides a more personal account of the use of vision aids in the nineteenth century. In the cash day books of John Potter Dowell as whole, multiple transactions from individual people can be found. Below, the records of Mr R.R. Buck of Norfolk Road in Carlisle show that he frequently visited for repairs between 1891 and 1896:

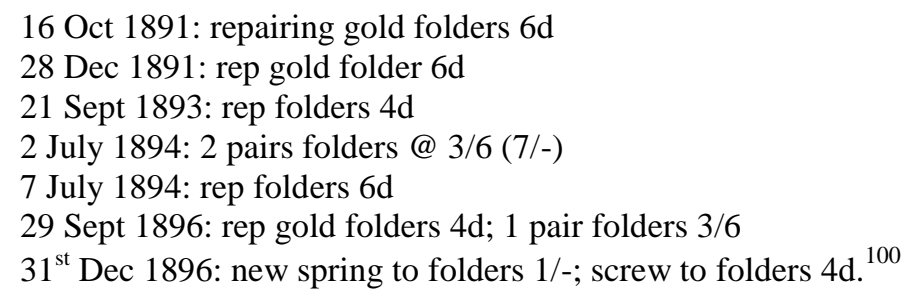

At first sight, these accounts seemingly only list the costs of spectacle repair and sale that have been previously discussed. However, they also allow a glimpse of the wearing experience of spectacles. Through the purchase of only two folders, and a number of transactions that detail the need for repair, the accounts of R.R. Buck suggest both signs of use from the frequency of breakages and a person's willingness to repair as opposed to replace their vision aid. Moreover, the existence of ad-hoc repairs in the Science Museum's collection, alongside accounts such as this, raises questions about why people chose to have their frame repaired, and whether people could also adapt their own frame on an individual basis. The frame in Figure 6.11 below, from the Science Museum's Ophthalmology collection, shows the use of thread for a make-shift repair to a broken side-arm, which has become unravelled.

\footnotetext{
${ }^{100}$ Carlisle Archive Centre, John Potter Dowell, DB9/5: Cash day book (sales) 1881-1892, Day book at the back: 16 October 1891; 28 December 1891; DB9/6 Cash day book (sales) 1893-1894 21 September 1893; 2 July 1894; 7 July 1894; DB9/7 Cash Day book (sales) 1897-1898, Day book at the back: 29 September 1896; $31^{\text {st }}$ December 1896 [unpaginated].
} 
Figure 6.11. Science Museum's Ophthalmology collection A62422, an example of a frame with a makeshift repair. ${ }^{101}$

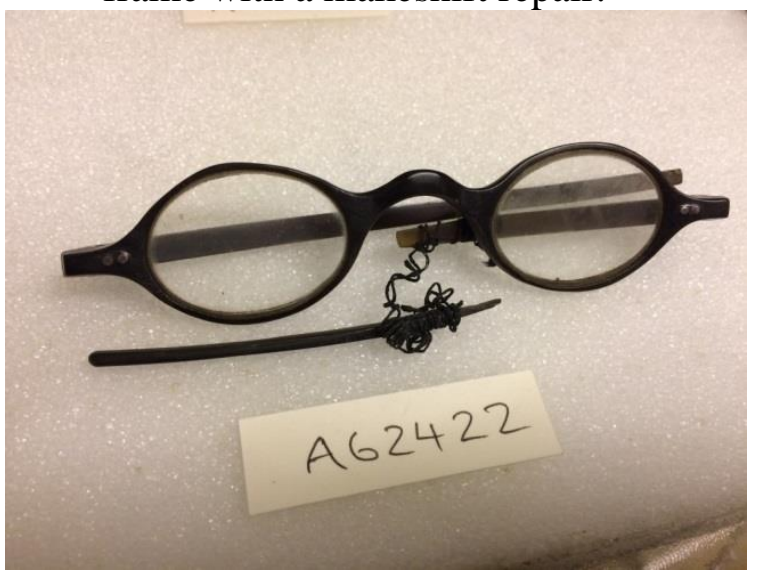

These repairs could reveal a person's attempt to avoid the costs of repair. However, repair could also show their attempt to keep or maintain a frame that they found particularly comfortable or had grown accustomed to. Indeed, modifications to other prosthetic devices highlight how the owner was active and not passive in adapting their device to suit their individual needs. ${ }^{102}$

A Draper, Mr J. Irving Bell, was another regular customer of John Potter Dowell between 1888 and 1898. The accounts show that Bell frequently purchased spectacles and tinted lenses and paid for repairs in 1890, 1892, 1894, and 1897. These repairs could include jobs such as a 'new leg to spectacles' or a new 'side'. Additionally, the accounts record intervals between the purchase of spectacles, and the potential for being dissatisfied or needing to try out pairs of spectacles that were bought:

20 Nov 1888: 1 pair specs@ 2/6 (6 crossed out)

25 Nov 1888: 1 pair spectacles $2 / 6$

14 April 1890: new leg to spectacles 6d

9 July 1891: repairing specs $4 \mathrm{~d}$

22 Dec 1891: 1 pair specs, plain lenses 2/6

28 Dec 1891: spec case 6d

4 April 1894: rep specs 4d

15 May 1894: specs case 1/-

15 May 1894: 3 pairs tinted specs @ 3/6, 4 @ 2/6 returned

22 April 1897: side to specs 6d

3 March 1898: gold filled cable specs $12 / 6$ returned. $^{103}$

\footnotetext{
${ }^{101}$ Science Museum's Ophthalmology collection, object number A62422.

${ }^{102}$ See, for example, Jones, p. 11.

${ }^{103}$ Carlisle Archive Centre, John Potter Dowell, DB9/4 Cash day book (sales) 1888-1890: 20

November 1888; 25 November; 188814 April; 1890 DB9/5 Cash day book (sales) 1891-1892, Day book at the back: 9 July 1891, 22 December 1891; 28 December 1891; DB9/6 Cash day book (sales)
} 
As can be seen in the above, Bell bought a number of spectacles between 1888 and 1898. However, he also returned them. Opticians' accounts, alongside showing the sale and repair of items, also document the intervals at which customers purchased spectacles, the ability to return frames when dissatisfied, and the ability to trial numerous pairs to pick the frame or lens that fitted best. On the 20 November 1888 , for example, he obtained six pairs, and only eventually purchased the one pair. Similarly, in 1894 he bought 7 pairs of tinted lenses, at different prices, and returned them all. Moreover, the return of spectacles is common across the whole of John Potter Dowell's accounts between 1885 and 1897. In particular, there is evidence that individuals 'purchased' anywhere between 2 and 14 pairs of vision aids, but would only eventually keep and pay for a single pair.

The replacement of lenses in opticians' account books also show the intervals that a lens needed to be changed, the liability of the lens to break, and the difficulties that individuals could have had in obtaining a lens that comfortably suited the sight. A letter written by Miss F. Perry in November 1900, who describes herself as a 'useful maid', reveals the difficulties of enhancing vision with lenses in this period. The letter detailed her treatment and interaction with a London optician, A. Fournet, in the late 1890s. Attached to Miss Perry's letter were a number of receipts, which documented 8 visits to the optician between June 1896 and April 1900. Whilst the receipts detailed repairs and new frames to spectacles in February 1898 and January 1899,7 out of the 8 visits involved 'alterations' or the 're-work' of lenses. In a one year period between 1897 and 1898, for example, Perry's lenses were altered five times in February, June, July, October, and the following February. ${ }^{104}$ Yet Perry also detailed in this letter that she began to see Fournet on account of her 'health getting worse and of getting to see double vision'. For Perry, the condition of her vision was having a negative impact on both her health and also her ability to 'keep in work'. Following successive consultations with Fournet, and a number of different lenses, Perry described how she re-gained 'single vision at once' and was able to continue her employment. Case accounts such as this can be used to reveal the difficulties of

1893-1894: 4 April 1894; 15 May 1894; DB9/7 Cash day book (sales) 1897-1888, Day book at the back: 22 April 1897; 3 March 1898 [unpaginated].

${ }^{104}$ London Metropolitan Archives, A/KE/B/01/04/004: Royal London Ophthalmic Hospitals, Complaint that there was little profit in supplying spectacles, letter dated 20 November 1900. 
enhancing vision in the nineteenth century as well as the health and financial implications that could be overcome by the appropriate use of vision aids.

The value of vision aids in the nineteenth century rested on the rejuvenating effects of lenses and their increasing ability to transform a person's life. ${ }^{105}$ The experience of people before their vision was enhanced with appropriate lenses could vary. At the most extreme end, James Ayscough in the mid-eighteenth century described the 'debilitating' effects of poor vision, prior to the use of spectacles, as an 'infirmity'. ${ }^{106}$ Moreover, in 1782 George Bew reflected on the hierarchy of impairment that was discussed in the first chapter, and concluded that blindness excited the most compassion in the 'human species' out of all the 'various accidents and calamities'. ${ }^{107}$ Yet a direct insight into how people experienced conditions such as short-sightedness was rarely documented. In 1824 William Kitchiner, a popular author of a number of advice manuals, provided a personal account of wearing and buying spectacles, as well as the selection of lenses with different focal lengths. He revealed that he first 'discovered' that he could not see at a distance 'so distinctly as people who have common eyes' at about fifteen years old. Kitchiner also described his experience of choosing lenses, and discussed how after his ' $40^{\text {th }}$ year' he adopted a different power, depending on how far he wished to see. ${ }^{108}$ Despite this account being informative, it does not reveal much about how he, as a user, felt. In contrast, a book by Francisque Sarcey, entitled Mind your eyes! and printed in London in 1886, gave a more personal response to refractive vision errors and his adoption of spectacles. Sarcey reflected on his first experience of wearing spectacles in detail and stated that:

My father was master of a boarding-school... one day, for fun, I got hold of the large silver spectacles my father used to wear, and put them on my nose as children will do in play. That was fifty years ago; the sensation I experienced is still vivid in my memory. I uttered a cry of astonishment and delight. Before that day I had never seen the vault of foliage which arched over my head, except as a large green compact sheet, through which no light penetrated. All at once I saw with surprise, stupefaction and rapture that there were openings in this dome through which light penetrated... what astonished me most and caused an enchantment

\footnotetext{
${ }^{105}$ See discussion of the increasing utility of lenses and the measurement of vision in chapter two, pp. 76-79.

${ }^{106}$ James Ayscough, A Short Account of the Eye and the Nature of Vision. Chiefly Designed to Illustrate the Use and Advantage of Spectacles, Wherein are Laid Down Rules for Chusing Glasses Properly, for Remedying all the Different Defects of Sight, as Also some Reasons for preferring a particular Kind of Glass, fitter than any other made Use of for that Purpose, $4^{\text {th }}$ edn (1755), pp. 1-2. ${ }^{107}$ George Bew, Observations on Blindness, and on the Employment of other Senses to Supply the Loss of Sight (Manchester, 1782), pp. 159-160.

${ }^{108}$ Kitchiner, pp. 96-7.
} 
which I cannot even now speak of without emotion was that through some holes in the foliage I suddenly perceived far away little bits of the blue sky. I clapped my hands and was in ecstasy. I was mad with admiration and joy. I could not rest until they gave me a pair of spectacles. $^{109}$

Sarcey provided a vivid account of someone's experience of being able to see fully for the first time and revealed the benefits that spectacles could bring to a nineteenthcentury user. However, equally insightful was his purpose for writing the book in the first place: to warn people against over-straining and damaging their eyes. Here, Sarcey hoped that his story would encourage people to 'tremble' and commented:

My myopic fellow sufferers, may this veracious story be of service to you! Know that every case of extreme myopia is almost certain to end in cataract, and that every myopia may become extreme by over-taxing the eyes. ${ }^{110}$

Similar to Ayscough in 1755, Sarcey described his condition as an 'infirmity'. The disadvantages associated with short-sightedness were discussed in medical texts of the time. London ophthalmologist Robert Brudenell Carter, for example, considered the negative state of 'a person who has grown up to manhood or womanhood with an uncorrected myopia'. ${ }^{111}$ Yet, like Sarcey, Carter also explored the benefits of spectacles for improving the quality of life of people affected, and allowing them to maintain work or access education.

The growing improvements in design or comfort, and the enhanced ability to 'correct' refractive vision errors increased the benefit of nineteenth-century vision aids. Indeed, improvements in vision testing show how improved medical knowledge of the eye helped increase the usability of vision aids in the nineteenth century. Medical practitioners frequently discussed the benefits of lenses for increasing both the quality of life and opportunities of the person affected. An article in Fraser's Magazine in 1876 by contemporary literary critic Richard Hengist Horne concluded:

The real second sight of modern man is a good pair of spectacles. They are at once the rejuvenescence of the eye, the preservative of the most important organ. ${ }^{112}$

\footnotetext{
${ }^{109}$ Francisque Sarcey, Mind your eyes! Advice to the short-sighted, by their fellow sufferers, trans. R.E. Dudgeon (London: Baillier, Tindall \& Cox, 1886), pp. 3-5.

${ }^{110}$ Ibid., p. xii.

${ }^{111}$ Robert Brudenell Carter, On Defects of Vision which are Remediable by Optical Appliances (London: Macmillan and Co, 1877), pp. 90-1.

${ }^{112}$ Richard Hengist Horne, 'Eyes and Eyeglasses: A Friendly Treatise', Fraser's Magazine, December 1876, pp. 689-722.
} 
In celebrating their value, people often reflected on how difficult it must have previously been. A column called 'Table Talk' in a weekly periodical, for example, suggested that 'spectacles are worn by so many people nowadays that we are inclined to wonder how former generations managed to get on without them'. ${ }^{113}$ The benefit of spectacles had long been acknowledged. James Ayscough in 1755, for example, concluded that 'he should think the advantage that Mankind receives thereby, inferior to no other benefit whatsoever, no absolutely requisite to the support of Life'. ${ }^{114}$ However, recognition of the ability of lenses to treat a wide range of eye conditions predominantly appeared in medical texts, and not until the later nineteenth century.

Medical texts in the second half of the nineteenth century discuss the physical condition of people with untreated refractive vision errors. The texts also show how increased medical knowledge encouraged the adoption of spectacles by the end of the period. Alongside the belief that many individuals were 'blind' or 'incurable', the physical symptoms that failing to wear vision aids or over-straining the eyes could cause were frequently discussed. These 'asthenopic' symptoms were most typically broken down into redness of the eyes, difficulty reading, severe headaches, migraines, sickness or dizziness. Mackenzie, in 1854, detailed the case of a 'young lady', aged 16, who experienced 'pain in her eyes' when painting or doing close work. ${ }^{115}$ In 1865 a surgeon of the Ophthalmic Hospital at Southwark, John Zachariah Laurence, also discussed how vision aids could be used to 'correct' a range of eye conditions, including hypermetropia, myopia, and astigmatism. Laurence described the case of 'Hannah M', aged 24, a tailoress who, on account of astigmatism, suffered 'a sensation of 'burning' in the eye-balls, congestion and lachrymation, all of which came on after reading \&c for a quarter of an hour or five minutes'. ${ }^{116}$ The use of spectacles to treat these cases was comparatively new. Laurence, for example, reflected on the case of Marcella D. Marcella, 43 years old, who had suffered asthenopic symptoms since childhood, and had received no previous treatment with lenses despite the fact that the symptoms had so intensified over the 'last eight or

\footnotetext{
113 Once a Week, 20 May 1871, p. 504.

${ }^{114}$ Ayscough, p. 25.

${ }^{115}$ Mackenzie, p. 910

116 John Zachariah Laurence Optical Defects of the Eye and their Consequences, Asthenopia and Strabismus (London: Robert Hardewicke, 1865), p. 70.
} 
nine years... as to utterly incapacitate her for all occupations that demanded close work of any description'. ${ }^{117}$ Although Laurence diagnosed Marcella with myopia and his treatment with 'corrective' lenses was effective, she had previously consulted sixteen or seventeen oculists. In 1875 Christopher Smith Fenner also discussed how a number of people with myopia were often 'subjected to harsh treatment' that could have been 'corrected' by spectacles. In one instance Fenner described the case of a gentlemen, aged twenty-six, who owing to asthenopic difficulties and pain was advised to abandon his studies and go to the country. ${ }^{118}$ This case in particular highlights the effect that medical knowledge of the eye could have on the usage of vision aids as a form of treatment.

Dreyfus argued that the overall number of vision aid users would be affected by the overall utility of vision aids. ${ }^{119}$ However, the cases above highlight that this was not a straightforward process. Vision aids may have been increasingly accepted by medical practitioners but were not always adopted immediately into medical practice. Chapters three and four have shown that vision aids were not solely controlled and acquired through the medical profession. However, as chapters two and four have argued, medical ideas were increasingly important in the dispensing, sale and distribution of knowledge in the second half of the century. As a result, the relationship between the discussion of vision aids by the medical profession and their use is important for assessing the overall usability. By the end of the nineteenth century, the association of vision defects with a range of physical symptoms became a topic of discussion amongst the medical profession. These works are significant because they collate the negative impact that not wearing vision aids had on individuals. Additionally, they also show that the use of lenses for a broad range of conditions was only just in the process of being implemented.

At the close of the century, the relationship between headaches or ocular discomforts and a range of refractive vision errors was being acknowledged. ${ }^{120}$

\footnotetext{
117 Ibid., 93.

${ }^{118}$ Fenner, pp. 208-9.

${ }^{119}$ Drefyus, p. 105.

${ }^{120}$ James Thorington, for example, in his text Refraction and How to Refract, Including Sections on Optics, Retinoscopy, the Fitting of Spectacles and Eye-glasses, etc (London: Rebman Ltd, 1900), frequently references headaches in his case studies. However, he also highlighted how headache was a symptom that could be assessed in diagnosing hyperopia/hypermetropia, p. 111.
} 
Investigation of this relationship was taken a step further by ophthalmologist and former President of the British Medical Association, Simeon Snell, in 1904 and the Ophthalmic Surgeon to the Queen's Hospital for Children in London, Sydney Stephenson, in 1913. Both Snell and Stephenson used a range of case studies to determine the utility of lenses in alleviating a range of symptoms, especially the headache. ${ }^{121}$ A headache could perhaps be seen as a minor affliction. However, Snell argued that it could cause 'constant or recurring suffering' and 'frequently so disables its victims that life becomes a burden'. ${ }^{122}$ Whilst a number of works in the mid-century acknowledged the benefits of lenses, Stephenson explored how discussion of the negative effects of eyestrain by the medical profession was a late nineteenth- and early twentieth-century phenomenon. ${ }^{123}$ Exploring the users of vision aids allows us to question the speed at which usage grew, and whether the medical ideas discussed in chapter two were adopted in practice. Stephenson, for example, described the case of 'Miss Alice B', aged 35. Stephenson discussed how Alice had previously been subjected to 'medical treatment of the most varied kind and failed to afford relief' before he examined her at the start of the twentieth century. ${ }^{124}$ The use of spectacles by this patient improved her condition in a similar manner to the cases that have been discussed. Indeed, Stephenson argued that spectacles enabled Alice to lead a normal life, for whenever she would 'leave off her glasses', her physical symptoms would return with 'former violence'. ${ }^{125}$

Although the use of vision aids for the treatment of more complex vision errors was still being established in practice, a number of case accounts from the mid-century highlight the benefits of vision aids that were being discussed in both popular and more specialised contemporary literature. ${ }^{126}$ As suggested by Dreyfus, greater awareness of the benefits of vision aids would have encouraged spectacle usage. However, besides detailing the effect of vision errors on a person's physical condition, the case accounts also provide a more direct insight into the personal

\footnotetext{
${ }^{121}$ Simeon Snell, Eye-strain as a cause of headache and neuroses (London: Simpkin, Marshall, Hamilton, Kent \& Co., 1904); Sydeny Stephenson, Eye strain in everyday practice (London: The Ophthalmoscope Press, 1913)

${ }^{122}$ Snell, Eye-strain as a cause of headache and neuroses, p. 1.

${ }^{123}$ Stephenson, pp. 87-91.

${ }^{124}$ Ibid., p. 31.

125 Ibid.

${ }^{126}$ See chapter two, which explores how medical knowledge filtered into popular literature, pp. 81-95.
} 
experience of vision aid users. William White Cooper, for example, described the personal experience of a patient who consulted him in January of 1851. In this case, Cooper described a 'professional friend' who was aged forty and was suffering from a range of physical symptoms as a result of straining his eyes. Cooper described the patient as being 'extremely depressed in spirits' because his inability to study or use his eyes was of 'serious consequence to him'. ${ }^{127}$ In 1877 a case discussed by Robert Brudenell Carter also revealed that misdiagnosis or ineffective treatment could have had a considerable effect on the well-being of an individual. In another case it was thought that the patient had a brain disease and, as a consequence, their 'whole life' had been 'blighted'. ${ }^{128}$ Examples such as these demonstrate that the effect on a person's wellbeing of partial sight was considered by British ophthalmologists of the mid-nineteenth century to be substantial. At the same time, however, they also show that many patients with such conditions were successfully treated through the provision of spectacles.

A series of letters from the 1890s were collated as part of a complaint that was sent to Moorfields Eye Hospital. The letters highlight how the benefits of vision aids were not necessarily being acknowledged for all cases by the end of the nineteenth century. However, the case accounts also reveal the personal benefit that users could receive from the adoption of accurately suited lenses. In 1899 a patient, W. Rudland, wrote about his previous treatment under two practitioners who eventually told him 'not to come anymore as they could do nothing'. The practitioners considered glasses to be of 'no use'. However, Rudland acquired a pair of spectacles that were able to restore his vision to the extent that he could 'read and write' and 'drive a horse and van in the thickest of traffic'. This could show that the adoption of vision aids was not standardised in practice. Additionally, it gives an insight into how a vision aid user felt. The use of vision aids enabled Rudland to leave the house with 'pleasure... whereas, it was a misery for me to get about before'. ${ }^{129}$ In 1899 J. Maddocks, also described how he had previously required 'a

\footnotetext{
${ }^{127}$ Ibid., p. 73.

${ }^{128}$ Robert Brudenell Carter, Eyesight Good and Bad: A Treatise on the Exercise and Preservation of Vision, $2^{\text {nd }}$ edn (London: Macmillan, 1880), p. 144.

${ }^{129}$ London Metropolitan Archives, A/KE/B/01/04/004: Royal London Ophthalmic Hospitals, Complaint that there was little profit in supplying spectacles, letter dated 8 June 1899.
} 
stick to guide myself in walking' and 'could not read even large print'. ${ }^{130}$ In both of these instances, the correspondents commented on the 'relief' that they had received from the use of spectacles despite having previously been 'given up' as 'incurable'. ${ }^{131}$

However, J. Maddocks also reflected on how he was unable to complete his term of office in the public service, and retire with a full pension because of the late adoption of appropriate vision aids. Maddocks made this claim because his deteriorating vision and physical symptoms prevented him from work. ${ }^{132}$ Prosthetics have often been discussed in the context of work efficiency. ${ }^{133}$ Similarly, vision aids provide insight into how assistive devices could maintain, access, or improve an individuals' capacity to work. As discussed in the previous chapter, certain stigmas towards vision aids could affect a person's employability. However, on a practical level they could extend a person's working life or allow them to regain employment. Maddocks' letter reveals the personal implications that could have arisen from not using a vision aid. Before the adoption of lenses, vision errors could have limited the careers and education of both children and adults alike. In 1896 the prescription of Mary Gray, aged six, advised that she should be taught 'orally' as much as possible. ${ }^{134}$ Likewise, in 1898 the 'Optical Queries and Answers' column of The Optician detailed the case of a boy who was advised to not be put to the trade of a tailor because of his myopic astigmatism. ${ }^{135}$ As suggested in Maddock's inability to complete his term of office, this reasoning could be well-founded. 'Uncorrected' vision errors could affect an individual's ability to continue work. Indeed, the negative financial situation of people suffering from a range of 'asthenopic' symptoms prior to the use of spectacle wear could be severe. In 1898 Miss Alice B,

\footnotetext{
${ }^{130}$ London Metropolitan Archives, A/KE/B/01/04/004: Royal London Ophthalmic Hospitals, Complaint that there was little profit in supplying spectacles, letter dated 12 May 1899.

131 Ibid.

${ }^{132}$ London Metropolitan Archives, A/KE/B/01/04/004: Royal London Ophthalmic Hospitals, Complaint that there was little profit in supplying spectacles, letter dated 12 May 1899.

${ }^{133}$ See Artificial Parts, Practical Lives, passim. For association with prosthetics and work efficiency see, for example, Perry, pp. 75-102.

${ }^{134}$ London Metropolitan Archive, A/KE/B/01/04/004: Royal London Ophthalmic Hospitals, Complaint that there was little profit in supplying spectacles, prescription dated $1^{\text {st }}$ November 1889.

135 The Optician, 7 July 1898, p. 542.
} 
for example, suffered day-long headaches 'about four times a week', which 'practically incapacitated her from work'. ${ }^{136}$

The experience of individuals in the nineteenth century show that vision aids allowed a person to overcome 'infirmity', maintain work, or even just engage in the outside world with 'pleasure'. George Kirby, in an account of his treatment during the 1890 s, commented that his eyes were causing him to become 'more disabled from work as time went on' ${ }^{137}$ The use of the word 'disabled' is poignant. The term in this context highlights the value of a vision aid to the user as well as the disadvantages faced by those who may not have had access to them. Moreover, the ability of spectacles to allow Kirby to resume work shows how their timely adoption could transform both a person's wellbeing and financial prospects. An individual who had been promoted in the service 'since wearing glasses', no longer feared 'not completing my term of service for a pension on account of my eyes' ${ }^{138}$ Similarly, the patient whose life was 'blighted' was able to take up 'the career which he had fancied closed to him for ever'. ${ }^{139}$ The benefits that users could receive from increased knowledge of the eye and utility of spectacles were not isolated to extreme cases of refractive vision errors. On the contrary, minor refractive vision errors could leave a patient with more severe symptoms. ${ }^{140}$ These case studies reveal how improvements in vision testing changed the lives of their users. They suggest that the use of vision aids may have increased alongside the publication of a number of case studies that revealed their utility as an assistive device. However, they also highlight that the of adoption vision aids in practice was neither quick nor standardised. The benefits of vision aids for a range of conditions were still being evaluated at the start of the twentieth century. Vision aids were celebrated in a range of medical and popular texts, and by those that wore them, but the relationship between utility and usage is not as straightforward as Dreyfus had suggested.

\footnotetext{
${ }^{136}$ Stephenson, p. 31.

${ }^{137}$ London Metropolitan Archives, A/KE/B/01/04/004: Royal London Ophthalmic Hospitals, Complaint that there was little profit in supplying spectacles, letter dated 20 May 1899.

${ }^{138}$ London Metropolitan Archives, A/KE/B/01/04/004: Royal London Ophthalmic Hospitals, Complaint that there was little profit in supplying spectacles, letter dated 23 May 1899.

${ }^{139}$ Carter, Eyesight: Good and Bad, pp. 143-5.

${ }^{140}$ See, for example, Stephenson, p. 114; Snell, Eye-strain as a cause of headache and neuroses, pp. $35-41$.
} 


\section{The Number, Age and Perceptions of Users}

An article in the Aberdeen Weekly Journal in 1885, headed 'Evils of Our School System', commented that the users of vision aids had changed. It stated that:

It is not many years ago... - even within my own memory - that spectacles were supposed to be necessary only to those of mature years, and indeed were looked upon as the first warning of declining age. A few also were compelled to wear them, chiefly those who were very short-sighted, but their numbers were so small that they were marked as peculiar, and attracted in our attention as a person afflicted with a deformity of body or limb. ${ }^{141}$

The commentator proposed that vision aids were worn by a broader proportion of society and not just those of 'mature years'. However, equally important was the normalising of spectacle wear. It suggested that the number of spectacle users had grown to the extent that they were no longer considered 'peculiar' or akin to a 'deformity of body or limb'. In the absence of any statistics it is difficult to substantiate this claim. However, this section assesses how the changing usership of vision aids can be explored in the nineteenth century. It also argues that the perceptions of vision aids, and perceptions of who should use vision aids, was just as important as their functional utility when assessing overall usage. By exploring contemporary comments in newspapers, periodicals, photographs, satirical images, and medical case accounts it shows that the users of vision aids diversified. Chapter five showed that vision aids were not solely a functional device. This chapter similarly argues that the total number of vision aid users was not just based on functional need; the perceptions of vision aids were able to have both a positive and negative effect on overall usage.

Vision aids have often been associated with age, because one of their primary purposes has been to enhance the vision of those with presbyopia, a condition that arises in later life and affects the ability to continue close-work or reading. The near universality of spectacle wear in old age is something that sets vision aids apart from other assistive devices. Alun Withey has argued that not requiring spectacles in old age was 'exceptional' in the eighteenth century. ${ }^{142}$ Good eyesight in old age was also considered unusual in the nineteenth century, and was often celebrated in newspaper

\footnotetext{
${ }^{141}$ Aberdeen Weekly Journal, 18 February 1885, emphasis my own.

${ }^{142}$ Withey, p. 97.
} 
and periodical obituaries. ${ }^{143}$ Not surprisingly then, an association of vision aids with the elderly can be found persistently across the nineteenth century. In descriptions of people in popular accounts, for example, the use of spectacles made a person seem 'at least ten years older' or 'appear to be older than is really the case'. ${ }^{144}$ Moreover, people disliked spectacles because of their 'aging' ability. In 1824, for example, it was observed that people held off the use of spectacles because it was assumed that they were 'unequivocal evidence of Age and infirmity'. ${ }^{145}$ This was also acknowledged by the London opticians, Thomas Harris \& Son, in 1839, when they commented that people 'dislike even the bare thought of using glasses, because, as it is said, they make them look so old! ${ }^{146}$

The association of vision aids with age, or as an accessory predominantly for the elderly, is also apparent in nineteenth-century photographs that depict children dressed up as their elder relatives.

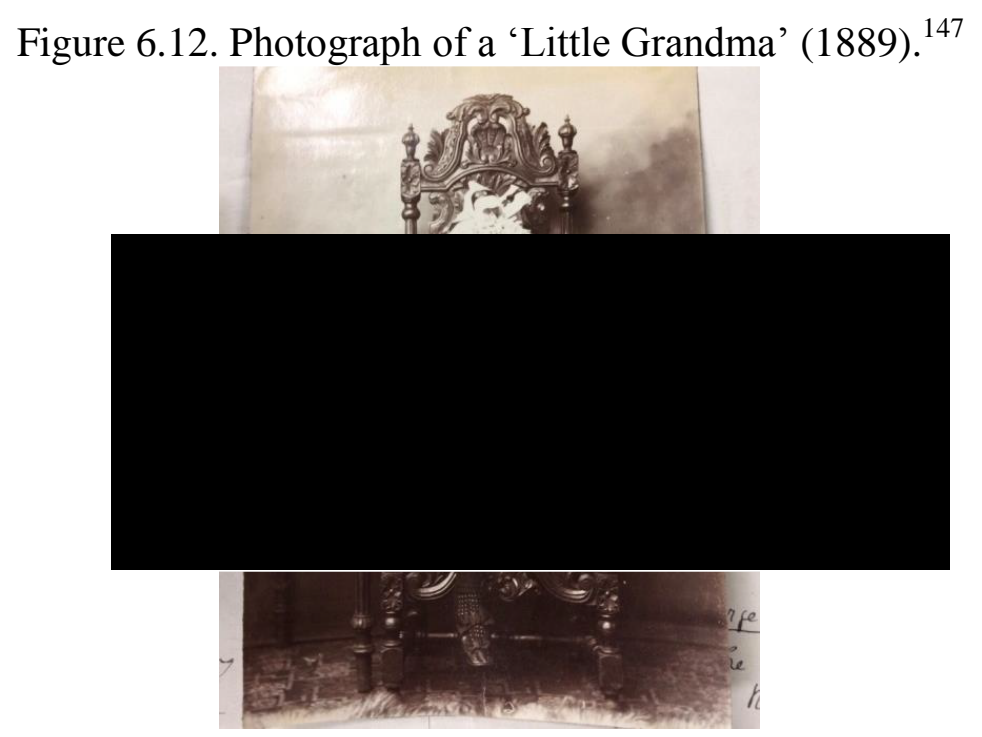

\footnotetext{
${ }^{143}$ See, for example, The Athenaeum: A Magazine of Literary and Miscellaneous Information, September 1808, pp. 270-1; The New Monthly Magazine, and Universal Register, September 1814, p. 190; The Gentleman's Magazine: and Historical Chronicle, February 1820, p. 186; The Blackburn Standard and Weekly Express, 16 November 1889, p. 7.

${ }^{144}$ See, for example, The Graphic, 5 September 1891; Leicester Chronicle and the Leicestershire Mercury, 2 July 1892; The Sheffield \& Rotherham Independent, 2 July 1892.

${ }^{145}$ See, for example, The Graphic, 5 September 1891; Leicester Chronicle and the Leicestershire Mercury, 2 July 1892; The Sheffield \& Rotherham Independent, 2 July 1892.

146 Thos Harris \& Son, A Brief Treatise on the Eyes, Defects of Vision, and the Means of Remedying the Same by the Use of Proper Spectacles, Also Rules for judging when Spectacles are necessary, and Directions for selecting them (London: Onwhyn, 1839), p. 17.

${ }^{147}$ The National Archives: COPY 1/397/35, 6 July 1889.
} 
As can be seen in Figure 6.12, a photograph captioned 'Little Grandma' from July 1889 shows a girl wearing both spectacles and a bonnet, whilst seated and holding knitting needles. ${ }^{148}$ In Figure 6.13 below, another girl was pictured in June 1874 wearing a 'cap and spectacles, seated by a table with knitting needles'. ${ }^{149}$ Other photographs that included girls in the same attire were taken across the latter half of the century, and furnished with accompanying captions such as: 'Now I'm Grandmamma' (1872), 'I'm Auntie Now' (1883), and 'Miss Giles Dressed as an Old Lady'(1893). ${ }^{150}$

Figure 6.13. Photograph of a little girl wearing 'a cap and spectacles... with knitting needles' (1874). ${ }^{151}$

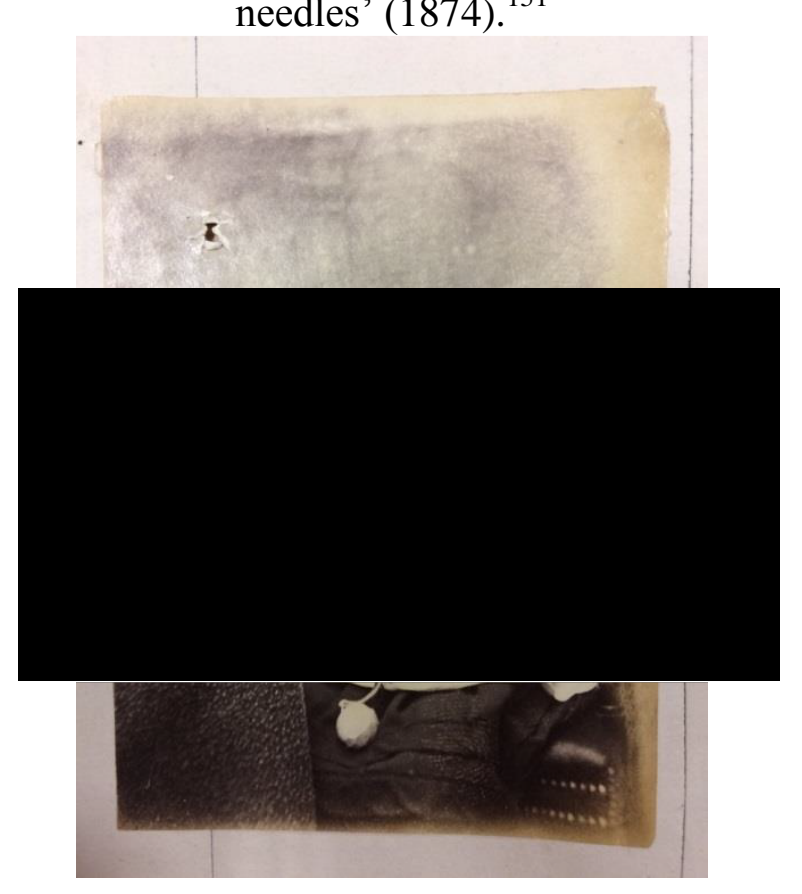

However, spectacles for the elderly were considered in a more practical sense as well. In Poor Law records from the mid-century, for example, it was only considered necessary to supply spectacles 'for aged', or 'the aged' inmates of workhouses in 1853 and $1867 .^{152}$

\footnotetext{
${ }^{148}$ The National Archives: COPY 1/397/35, 6 July 1889.

${ }^{149}$ The National Archives: COPY 1/25/88, 16 June 1874.

${ }^{150}$ The National Archives: COPY 1/19/110, 13 July 1872; COPY 1/366/247, 26 November 1883; COPY 1/414/928, 23 December 1893.

${ }^{151}$ The National Archives: COPY 1/25/88, 16 June 1874.

152 The National Archives, MH12/11000/19: Spectacles for Aged Inmates, 4 April 1853, Folio 47; The National Archives, MH12/9534/77: From Harry Farnall, the Poor Law Inspector of Southwell workhouse, 30 October 1867, Folios 105-107.
} 
Despite the persistent association of vision aids with age, the article at the outset of this section stated that usage had expanded beyond those of mature years. A number of contemporaries supported this opinion and noted a rise in spectacle wear. Correspondence in The York Herald and General Advertiser from 1843 commented that 'the use of spectacles by persons of various age has become so general... and the assistance rendered by them to many thousands of our fellow creatures so beneficial'. ${ }^{153}$ An article in a London periodical also observed the rise in eyeglasses in both 'men and women', as well as children in $1865 .{ }^{154}$ Chapter one discussed how vision defects were presumed to have reached the proportions of 'an epidemic'. ${ }^{155}$ Similarly, the number of spectacle wearers was feared to have dramatically increased by the last few decades of the nineteenth century. Indeed, one article contrasted the many benefits of modern society, including lighting in streets and houses, or large shops in public thoroughfares, against an 'increase of spectacle-wearers and other indications of a decidedly lower sight average'. ${ }^{156}$ Throughout these discussions, the number of children wearing vision aids was of particular concern. In 1898 an article headed 'Care of the Eyes' considered the 'many children' now wearing spectacles as 'a serious subject of remark'. ${ }^{157}$ Exploring why a number of people, of all age ranges, were wearing spectacles continued across the 1890s under headings such as 'Victims of Industry'. 158

Comment in the popular press suggests that some changes were occurring. However, whether they can be taken at face-value and substantiate the claims in the Aberdeen Weekly Journal, cannot be ascertained through exploration of comments in periodicals and newspapers alone. The development of mass-production, which was discussed in the previous chapter, suggests that there was a considerable demand for vision aids in the second half of the nineteenth century. ${ }^{159}$ Similarly, letters, case accounts, and photographs propose that a range of vision aid users existed. In the 1890s the cases discussed in letters of complaint to the London Ophthalmic

\footnotetext{
${ }^{153}$ The York Herald and General Advertiser, 21 October 1843, emphasis my own.

${ }^{154}$ The London Review of Politics, Society, Literature, Art and Science, 14 October 1865, pp. 404-5.

${ }^{155}$ The Morning Post, 12 February 1880; see also Leeds Mercury 4 October 1884 and The Pall Mall Gazette, 16 July 1889.

${ }^{156}$ The Nineteenth Century: A Monthly Review, March 1892, p. 465.

${ }^{157}$ The London Reader: of Literature, Science, Art and General Information, 29 June 1889, p. 228.

${ }^{158}$ See, for example, Bow Bells: A magazine of general literature and art for family reading, 18 November 1892, p. 490 and the Westminster Review, January 1894, pp. 425-6.

${ }^{159}$ See chapter five on mass manufacture, pp. 206-212.
} 
Hospitals, for example, included those of a number of children who had experienced treatment with lenses or therapeutic methods. ${ }^{160}$ Medical case accounts across the century also included the details of a number of children below the age of 18 . These included boys between the age of 7 and 15 , and girls between the ages of 8 and $18 .^{161}$ The age range amongst both men and women in these case accounts was revealing and included men, between the ages of 20 and 81, and women between the ages of 22 and $69 .{ }^{162}$ Cartes de visite, a popular type of photograph from the mid-century, reflect this range and illustrate the broad nature of spectacle use in the latter half of the century. ${ }^{163}$ A number of individuals were photographed wearing vision aids from the mid-nineteenth to early twentieth centuries. Photographs of vision aid users can be found in the large collection that has been amassed by Ron Cosens. As Figure 6.14 reveals below, these include children as genuine spectacle-users, rather than as wearers of a costume.

\footnotetext{
${ }^{160}$ London Metropolitan Archives, A/KE/B/01/04/004: Royal London Ophthalmic Hospitals, Complaint that there was little profit in supplying spectacles, letters dated 29 November 1898, 22 May 1899, 23 May 1899, 18 May 1900 and printed in 'A Petition on the Subject of the use of Appropriate Lenses in Certain Diseases of the Eye'.

${ }^{161}$ See, for example, Laurence, pp. 55, 71, 95; Fenner, p. 209; Kitchiner, pp. 95-6; Sir William White Cooper, On Near Sight, Aged Sight, Impaired Vision and the Means of Assisting Sight, $2^{\text {nd }}$ edn (London: John Churchill, 1853), p. 99; Alden, pp. 56, 59; Sarcey, pp. 1-7; Charles Bell Taylor, How to Select Spectacles in Cases of Long, Short, and Weak Sight, $2^{\text {nd }}$ edn (London: Cassell, 1889), p. 9; A. Fournet, Medical Spectacles and the Royal London Ophthalmic Hospital: Bloomfield Street, Moorfields, E.C. (London: A. Fournet, 1894), pp. 11-12; Stephenson, pp. 61, 102.

162 Cooper, pp. 42, 101; Mackenzie, p. 910; Laurence, p. 55; Anderson Critchett, 'On the employment of atropine in correcting errors of refraction,' British Medical Journal, 9 December 1882, p. 1146; Henry Juler, 'On the Best Methods of Diagnosing and Correcting the Errors of Refraction', British Medical Journal, 27 December 1884, pp. 1274-1275; Taylor, p. 11; Thorington, pp. 243-4, 254-5; Stephenson, pp. 27-8, 101.

${ }^{163}$ For more information on cartes de visite see, Ron Cosens,'Cartomania: Collecting Cartes de Visite and Cabinet Cards', Photographic World, 2 (2003), 34-37; Ron Cosens, 'Victorian Marketing Techniques: What do the Cartes reveal?', Photographic World, 1 (2004), 34; Ron Cosens, 'Cartomania: When was the old picture taken?', Photographic World, 3 (2005), 37-9; Ron Cosens, 'Cartomania: Victorian studios the background', Photographic World, 3 (2006), 29-32, which can be accessed: http://www.cartedevisite.co.uk/more-info/downloads/ [accessed: 27 July 2018].
} 
Figure 6.14. Children photographed in Ron Cosens' collection of cartes de visite. ${ }^{164}$

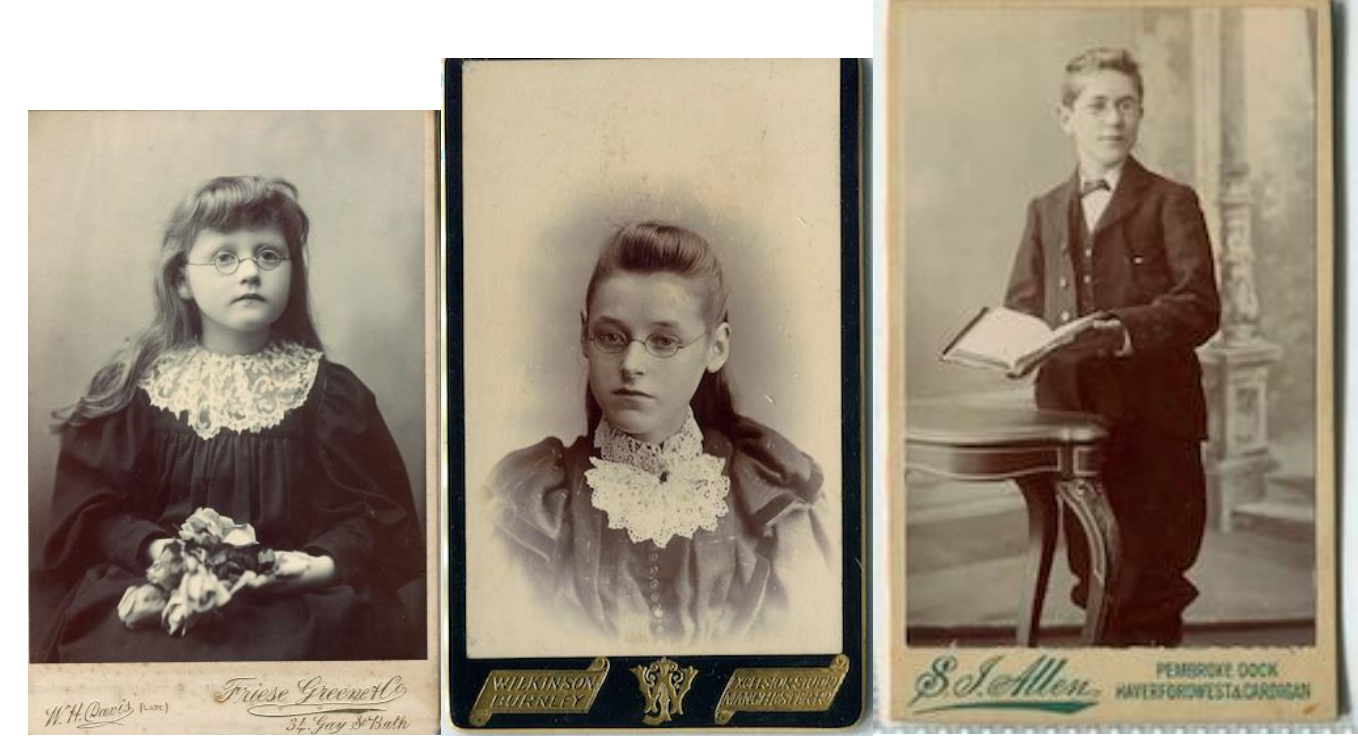

As shown in Figure 6.15, they also show adults, as well as the more elderly, wearing spectacles and eyeglasses.

Figure 6.15. Adults, of a wide age range, photographed in Ron Cosens' collection of cartes de visite. $^{165}$
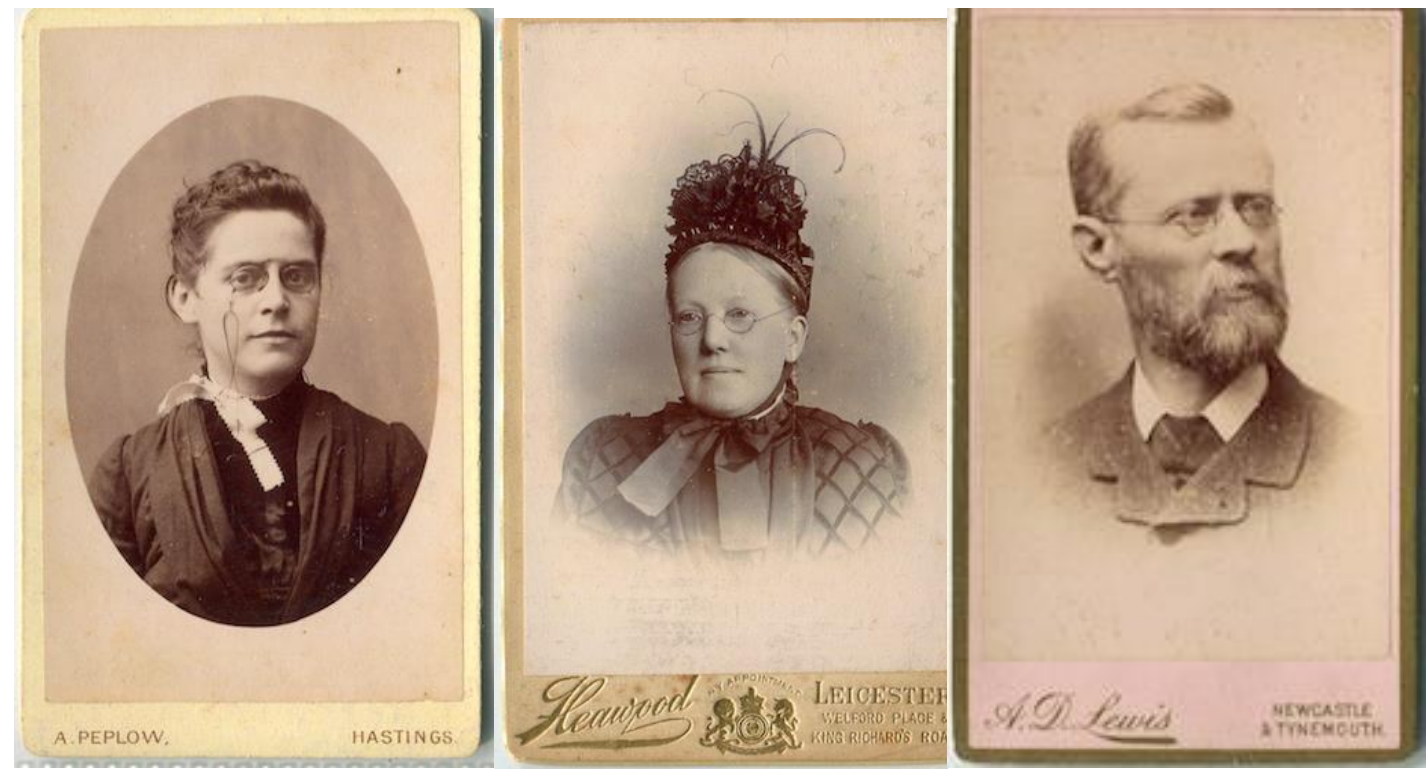

Both men and women can be seen in the collection of Cartes de Visite and the medical case accounts. Men and women also appear in reports of vision aids that

\footnotetext{
${ }^{164}$ I would like to thank Neil Handley, Curator at the College of Optometrist's Museum, for drawing my attention to Ron Cosens' collection of cartes de visite, and to Ron Cosens for his permission to use some examples from his extensive collection. Further information can be found at http://www.cartedevisite.co.uk [accessed: 27 July 2018]. ${ }^{165}$ Ibid.
} 
were stolen in the popular press. In the digitised periodicals consulted for this study, women's vision aids were reported stolen between 1847 and $1894 .{ }^{166}$ Whilst the age was sometimes noted, for example women could be described as 'elderly' or a 'grandmother', not all of these reports included enough detail about their owners to ascertain much beyond their gender. ${ }^{167}$ Men's vision aids were reported stolen between 1863 and $1894 .{ }^{168}$ For men, a few reports suggest that they were still of working age because they were described as a 'jeweller', 'leather merchant', 'engineer in the Royal Navy', or 'publican'. ${ }^{169}$ Although men and women appear evenly in medical case accounts and newspaper reports, women were noticeably less common in the accounts detailed in opticians' registers. In the account books and ledgers of both Robert Sadd between 1837 and 1887 and John Potter Dowell between 1885 and 1898, for example, men were recorded and covered a range of working occupations. In contrast, women were strikingly less frequent and were recorded only by their marital status. ${ }^{170}$

The relationship between gender and vision aid usage in the nineteenth century is not straightforward. Whilst contemporaries did not document the gender of spectacle users in the nineteenth century, they did discuss whether men or women were more susceptible to vision loss. In 1888, for example, a study of members from the Anthropological Section of the British Association for the Advancement of Science was reported in The Pall Mall Gazette. This study involved a number of

\footnotetext{
${ }^{166}$ Examiner, 13 November 1847, p. 731; Daily News, 25 May 1863; Daily News, 12 June 1867; The Morning Post, 12 June 1867, p. 7; The Morning Post, 25 September 1871, p. 7; Illustrated Police News, 30 September 1871; Nottinghamshire Guardian, 29 June 1877, p. 5; The York Herald, 10 June 1880, p. 7; Birmingham Daily Post, 22 July 1890; The Newcastle Weekly Courant, 13 August 1892; Derby Mercury, 11 July 1894.

${ }^{167}$ See, for example, Examiner, 13 November 1847, p. 731; Daily News, 25 May 1863.

${ }^{168}$ Glasgow Herald, 11 September 1863; Nottinghamshire Guardian, 18 September 1863, p. 7; The Dundee Courier \& Argus, 8 June 1865; The Royal Cornwall Gazette, Falmouth Packet, and General Advertiser, 12 April 1873, p. 8; Jackson's Oxford Journal, 12 June 1880; Nottinghamshire Guardian, 3 September 1880, p. 3; The Dundee Courier \& Argus, 22 September 1881; Liverpool Mercury, 29 October 1886; Hampshire Telegraph and Sussex Chronicle, between 12 November and 7 December 1887; Belfast News-Letter, 10 April 1888 and Freeman's Journal and Daily Commercial Advertiser, (more elaborate) 10 April 1888; Birmingham Daily Post, 14 March 1889; Aberdeen Weekly Journal, 12 November 1891; The Lancaster Gazette and General Advertiser for Lancashire, Westmorland and Yorkshire, 6 January 1894.

${ }^{169}$ See, for example, Glasgow Herald, 11 September 1863 and Nottinghamshire Guardian, 18 September 1863; The Dundee Courier \& Argus, 22 September 1881; Liverpool Mercury, 29 October 1886; Hampshire Telegraph and Sussex Chronicle, Sometime between 12 November and 7 December 1887; Aberdeen Weekly Journal, 12 November 1891.

${ }^{170}$ Cambridge University Library, GBR/0012/Ms Ad.5781-5783: Robert Sadd \& Co. Account Books 1837-1851 and Ledgers 1845-1889; Carlisle Archive Centre, DB9/1-7: John Potter Dowell, Cash and Day Book (Sales), 1885-1898.
} 
tests to assess members' 'keenness of sight'; the results were then broken down into the 'two sexes' and expressed as percentages. In this study it was concluded that 'women have very slightly the best of it'. The authors postulated that women's vision was 'sharpened' through threading needles, whereas men 'tried' their eyes more. ${ }^{171}$ However, in both nineteenth- and early twentieth-century medical texts women's eyes were frequently considered weaker. Indeed, women were thought to be more susceptible to the 'imaginary neuralgia' or 'chronic headache' that were symptomatic of vision defects. ${ }^{172}$

In terms of statistical evidence, there is little else to suggest that spectacle use was particularly gendered. Similarly, the design of vision aids in the Science Museum's Ophthalmology and Dunscombe collections was not overtly gendered. Despite this, advertisements in the popular press did include spectacles for 'ladies' and spectacles for 'gentlemen'. Strikingly, examples of these in the first half of the century show that women could obtain vision aids at a cheaper price or favoured a different style. In an advertisement for Chamberlain's 'Eye-Preserving Spectacles' from the late 1830 s, for example, the price offered to women was consistently lower. However, design also differed according to gender. Frames such as the 'finest blue steel', for example, appeared at 15 shillings for 'ladies', and then in a double joint style for an extra shilling for 'gentlemen'. ${ }^{173}$ Other advertisements in the later century also targeted particular designs for women. In 1854 the Ipswich Journal advertised new patented 'Spectacles for Ladies', whose key features were their convenience and the fact that they could be worn without coming into contact with the hair:

[This design] does not, in any way, incommode the wearer by catching in or disarranging the hair, which has hitherto been so great a source of annoyance in all Spectacles. They are light and elegantly made, and keep on any length of time without the slightest effort on the part of the wearer. ${ }^{174}$

Whilst the lightness of the frame was a common feature of most late nineteenthcentury vision aids, C. West repeatedly advertised a particular pair of 'Light Gold

\footnotetext{
${ }^{171}$ The Pall Mall Gazette, 13 September 1888.

${ }^{172}$ The Bristol Mercury and Daily Post, 7 February 1890; The Blackburn Standard and Weekly Express, 15 February 1890; For medical texts, see for example, Simeon Snell, Eye-strain as a cause of headache and neuroses, pp. 31-5; Stephenson, pp. 1, 109-112.

${ }^{173}$ This advertisement appeared frequently in the Examiner between 1838 and 1840. See, for example, 15 April 1838, p. 239; 3 August 1839, p. 583; 13 June 1840, p. 487.

${ }^{174}$ Ipswich Journal, 3 June 1854.
} 
Single Spectacles, for Ladies', in $1864 .{ }^{175}$ Additionally, fitting services for both 'ladies and gentlemen' were advertised by retailers in 1827 and $1855 .{ }^{176}$

Reliance on small-scale studies or advertisements, in the absence of any statistics, is problematic for ascertaining whether vision aid usage was gendered. However, both fashion and stigma could have influenced the use or adoption of vision aids. As discussed in the previous chapter, stigma and fashion affected the way in which vision aids were designed in the nineteenth century. However, the variety of meanings associated with spectacles and eyeglasses in the nineteenth century also influenced their use. As highlighted in the previous chapter, vision aids were not a solely functional device and, therefore, overall usage should not be seen in solely functional terms. At the most extreme end, stigma was thought to discourage people from wearing vision aids. Spectacles in particular were often considered masculine when worn by women. A number of jokes in the latter half of the nineteenth century included women wearing eyewear and discussing either their 'rights', social freedom, or education. ${ }^{177}$ Indeed, in 1872 the association of vision aids with masculinity and a potentially threatening intelligence can be seen in a British satirical description of an American 'Boston girl' who wore 'a double eyeglass'. It detailed that: 'her lightest small talk is of palaeontology; and her highest idea of relaxation is to attend a course of lectures on the polarisation of light' ${ }^{178}$ This can be placed in the broader context of the male and female gaze. Daryl Ogden, for example, has discussed how illustrations of women in overtly masculinised roles can be seen as a representation of male social anxiety towards the advancement of women's position. ${ }^{179}$ Vision aids could be used as a tool to represent this in popular literature and imagery. In 1880 the contemporary relationship between eyewear and masculinity, as well as study or intelligence, is summarised in an article from the Aberdeen Weekly Journal, which quoted the following from the Saturday Review under the heading 'Ladies and Spectacles':

\footnotetext{
${ }^{175}$ Liverpool Mercury, regularly between 10 March 1864 and 6 August 1864.

${ }^{176}$ See, for example, The York Herald and General Advertiser, 3 March 1827; The Essex Standard, and General Advertiser for the Eastern Counties, 30 May 1855.

${ }^{177}$ See, for example, The North-Eastern Daily Gazette, 25 July 1894; Aberdeen Weekly Journal, 10 April 1895.

${ }^{178}$ The Orchestra, 12 July 1872, p. 320.

${ }^{179}$ Daryl Ogden The Language of the Eyes: Science, Sexuality, and Female Vision in English Literature and Culture, 1690-1927 (New York: State University New York Press, 2005), pp. 133-154.
} 
We have known charming woman (says the Saturday Review) who wore spectacles, but as a rule, we do not consider glasses becoming to ladies. They are apt to give a semi-masculine, semi-scholastic, semi-clerical appearance to female wearers, which is not particularly prepossessing. A stern look is unpleasant in a woman, and glasses generally give this look more or less to the wearer... Glasses rarely increase the benignity of the countenance, but women can look through spectacles with a disagreeable expression, which is beyond the power of the male sex. ${ }^{180}$

Moreover, the ability of vision aids to affect a woman's appearance, and make them appear impudent, was commented upon earlier in the century in an article on 'feminine aggression'. The article described the use of an eyeglass by a woman, who was not short-sighted, but used their eyeglass as a means to portray 'sublime contempt' ${ }^{181}$ Rather than being presented as passive, women's use of eyewear in these instances supports Ogden's argument that women were as much a spectator as spectated in nineteenth-century society. ${ }^{182}$

The use of eyewear to convey a certain expression or feeling is revealing and suggests that the social meanings of vision aids had on effect on overall usage.

Nineteenth-century discussion often centred more on women's unwillingness to wear vision aids. The article headed 'Ladies and Spectacles', for example, concluded that spectacles were not 'becoming'. ${ }^{183}$ Women's failure to wear vision aids is perhaps not surprising in light of contemporary perceptions. Whether as a result of their association with masculinity or intelligence, or not, eyewear was often considered to negatively affect the appearance of the user. In 1866 contemporary literary critic, Richard Hengist Horne, concluded that a number of women were failing to wear vision aids because it was 'not considered graceful and becoming, and they certainly add something to the apparent age of the wearer'. ${ }^{184}$ In 1860 an account of an individual also stated that:

If there was anything with regard to the use of spectacles in the street which Viewcourt disliked more than the idea of wearing them himself, it was seeing young ladies 'carrying gig-lamps', as he elegantly phrased it. ${ }^{185}$

This is not to say that men did not face similar criticism or prejudice, or that they did not care about the overall appearance of vision aids upon their face. A statement in

\footnotetext{
${ }^{180}$ Aberdeen Weekly Journal, 25 August 1880.

${ }^{181}$ Saturday Review of Politics, Literature, Science and Arts, 5 December 1868, pp. 743-4.

${ }^{182}$ Ogden, p. 209.

${ }^{183}$ Aberdeen Weekly Journal, 25 August 1880.

${ }^{184}$ Bow Bells: a magazine of general literature and art for family reading, 14 November 1866, p. 368.

${ }^{185}$ Taken from 'Blind As a Bat; or, How Mr Viewcourt Came to Wear Spectacles' in The Leisure

Hour: A Family Journal of Instruction and Recreation, 16 August 1860, pp. 523-5.
} 
The School Board Chronicle in August 1889 argued that medical practitioners and opticians could be 'particularly severe on the men and women who suffer the inconvenience and danger of semi-blindness and sacrifice their eye-sight to the vanity which regards spectacles as unsightly'. ${ }^{186}$ However, medical and optical texts tended to identify women in their criticisms of those that put off the use of eyewear when it was required. ${ }^{187}$ Some medical commentators, on the other hand, excused women from wearing spectacles because of their concerns about the effect of vision aids on appearance. The prominent mid-century ophthalmologist Fransiscus Cornelis Donders, for example, stated that in some cases concave glasses did not need to be used even when they were required and 'women particularly have a right to be allowed some liberty in the matter'. ${ }^{188}$ In a similar manner, an early twentieth century text that suggested alternative treatments to spectacle-use considered this to be of 'interest to all' but of 'especial importance to women' because:

Spectacles destroy the beauty and expression of the eyes. Imagine Helen of Troy with glasses. Put spectacles on the Venus of Milo or the Apollo Belvedere! What could be more ridiculous ${ }^{189}$

Advice such as this reflects, perhaps at the most extreme end, the complexity and gendered nature of attitudes to the wearing of vision aids in the nineteenth century. It also suggests that the associated meaning and stigma of vision aids could encourage people to avoid using them.

References to appearance in medical discussion of vision aid usage highlights that overall use should not be explored in solely functional terms. In 1875 an American ophthalmologist, for example, concluded that 'many are prejudiced against glasses and decline to wear them when their use is imperatively demanded'. ${ }^{190}$ In 1860 an article in a British periodical also argued that 'vanity' caused people to abstain from the use of spectacles and 'walk about the world purblind' because they cared more about their appearance. ${ }^{191}$ This unwillingness is evidenced in case accounts in the mid-century. Of one patient, for example, it was

\footnotetext{
${ }^{186}$ Fournet, p. 21, emphasis my own.

${ }^{187}$ See, for example, Beer, p. 202; Alden, p. 36; John Browning, Our Eyes and How to Preserve Them From Infancy to Old Age, $7^{\text {th }}$ edn (London: Chatto \& Windus, 1887), p. 36

${ }^{188}$ Donders, p. 190; similar thoughts are also considered by Beer in 1815, p. 130.

${ }^{189}$ Bernarr Adolphus MacFadden, Strong Eyes: How Weak Eyes May Be Strengthened and Spectacles

Discarded (New York: Physical Culture Publishing Co., 1903), p. 44

${ }^{190}$ Fenner, p. 185.

${ }^{191}$ The Leisure Hour: A Family Journal of Instruction and Recreation, 16 August 1860, pp. 523-5.
} 
reported that 'spectacles had never been recommended, as he had a strong prejudice against them'. ${ }^{192}$ Another case detailed a lady, aged 48, who 'disliking to commence the use of spectacles... had delayed their purchase for four years'. ${ }^{193}$ An American optician included these cases in his 1866 text, a decade after their first publication by British ophthalmologist William White Cooper. Alongside the gendered nature of stigma that has been discussed, Alden argued that one of the primary reasons for avoiding the use of spectacles was the 'desire to conceal from friends and acquaintances an imperfection denoting the approach of old age' ${ }^{194}$ Publications by those such as Cooper and Alden directly correlated stigma, whether it be gendered or associated with age, with a negative influence on vision aid usage. In the American context, ophthalmologist Edward G. Loring argued that prejudice towards vision aids could have a severe effect on usage in 1878:

And it has for this reason been maintained, that if the people of this country overcame their prejudice to wearing glasses, that the evil would be found to be as great and as conspicuous as it is in Germany. ${ }^{195}$

Loring proposed that stigma might have been significantly dampening demand because Germany was considered to have had the largest proportion of vision aid users in both Europe and America in the nineteenth century. ${ }^{196}$ As a result, Loring highlighted that a person's decision to wear or abstain from the use of spectacles was just as important as functional need for determining overall usage.

Men and women's fashions in eyewear also influenced overall vision aid usage. Professor Emeritus of Diseases of the Eye at the New York Post-Graduate Medical School, D.B. Roosa, observed that the number who wore glasses 'unnecessarily' in America was 'relatively small'. ${ }^{197}$ Despite this, the use of vision aids when not required featured in international popular and medical texts across the century. The Austrian ophthalmologist Georg Beer in 1815, for example, highlighted

\footnotetext{
192 Alden, p. 42.

${ }^{193}$ Ibid., p. 55.

${ }^{194}$ Ibid., p. 13.

${ }^{195}$ Edward G. Loring, Is the Human Eye Changing its Form Under the Influence of Modern Education? (Publisher not identified, 1878), p. 13.

${ }^{196}$ See, for example, Simeon Snell, Influences of School Life on Eyesight (Wyman \& Sons, 1884), p. 5 and Charles Roberts, The Detection of Colour-Blindness and Imperfect Eyesight (London: J \& A Churchill, 1884), p. 6; Carter, Eyesight Good and Bad, p. 100.

${ }^{197}$ D.B. Roosa, Defective Eyesight: The Principles of its Relief by Glasses (London: Macmillan, 1899), p. 80.
} 
the 'great number of fools' who wore glasses when they had good vision. ${ }^{198}$ In British popular literature, an article headed 'Social Statistics' also correlated the use of vision aids for non-functional purposes to the overall number of users. It argued that:

It has been ascertained, by personal confession, that out of a thousand very elegant young gentleman afflicted with the monomania of wearing an eyeglass, only five were in reality afflicted with an actual infirmity of sight. ${ }^{199}$

The eyeglass became a popular accessory of politicians and gentlemen at various points across the century. Whilst eyewear could be perceived negatively for making woman appear masculine, groups of men who chose to wear an eyeglass could be considered effeminate. These men, referred to as 'dandies' or 'cockatoos', were often criticised for their foppishness and the eyeglass became a prominent part of their attire. ${ }^{200}$ In 1890, for example, an article in The Dundee Courier and Argus discussed the 'Lieutenant's Corset', which satirised the eyeglasses, tights, and slim waists of those in the German army. ${ }^{201}$ This effeminacy could also be associated with overall physical weakness, as can be seen in Figure 6.16 below.

\footnotetext{
${ }^{198}$ Beer, pp. 143-4.

${ }^{199}$ The London Reader: of literature, science, art and general information, 20 December 1873, p. 187.

${ }^{200}$ See, for example, Glasgow Herald, 30 May 1864; The Hull Packet and East Riding Times, 14 October 1881; The London Reader: of literature, science, art and general information, 29 October 1892, p. 48; Bow Bells: a magazine of general literature and art for family reading, 1 September 1893 , p. 226.

${ }^{201}$ The Dundee Courier \& Argus, 14 August 1890.
} 
Figure 6.16. Satirical image, 'A Man of Standing', from Fun (1879). ${ }^{202}$

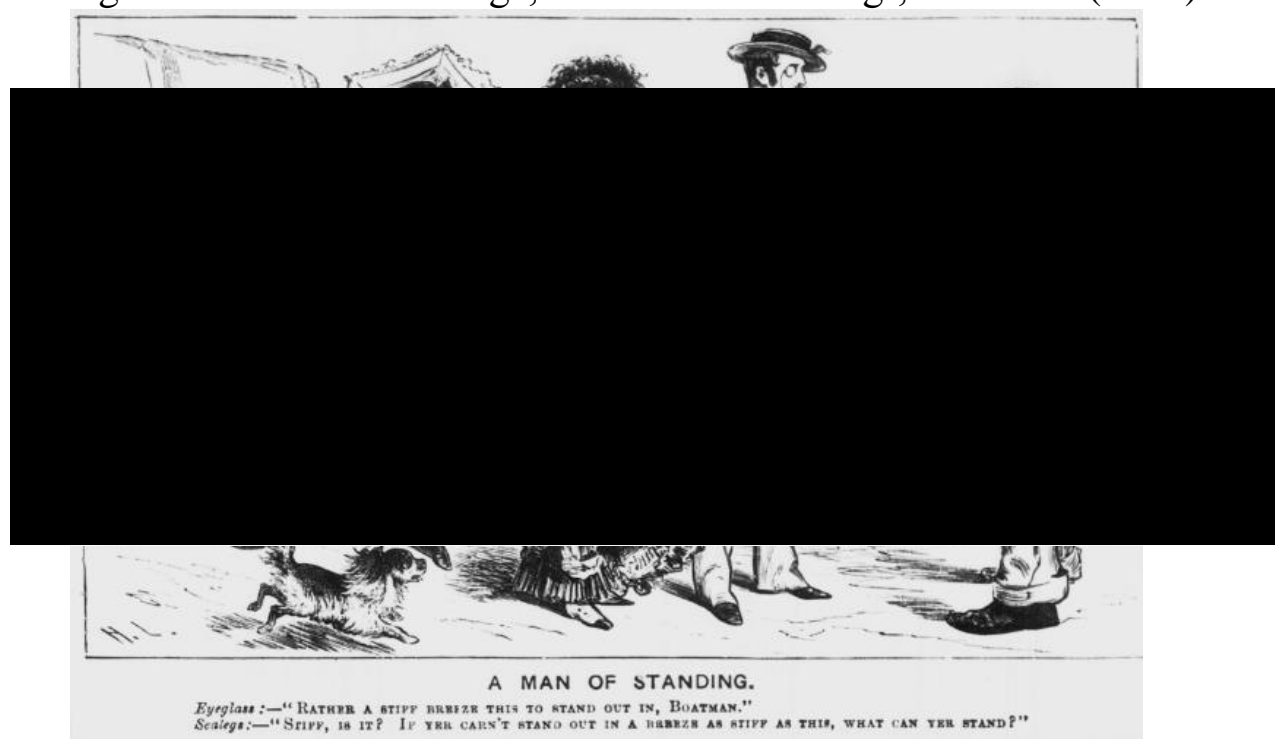

In the image above, the gentleman wearing the vision aid is simply referred to as 'Eyeglass'. The satire alludes to the contrasting association of an eyeglass with status or 'standing', by its user, and the perceived delicacy or effeminacy of eyeglass wearers.

Eyeglass: - 'Rather a stiff breeze this to stand out in, Boatman.'

Sealegs: - 'Stiff, is it? If yer can't stand out in a breeze as stiff as this, what can you stand?'

Prejudice towards those who were seemingly wearing glasses for show highlights the overall complexity of perceptions of vision aids at this time: they could be worn for fashionable purposes, stigmatised by those who did require them, and further stigmatised by those who did not. At the more extreme end, an account from 1877 in the Dublin University Magazine reported that people who were shortsighted could be judged as imposters or pretenders. In this, the man who dubbed himself 'The London Hermit', discussed a variety of situations where he had either been dismissed or ridiculed by individuals who had presumed his spectacles were being worn for show. ${ }^{203}$ Whilst the estimate that one-fifth of users wore vision aids when they did not require them was likely exaggerated, popular comment on the numbers and types of vision aid users highlight how the number of users could have been influenced both positively and negatively depending on the social context and perceptions of the time.

\footnotetext{
${ }^{202}$ Fun, 13 August 1879, p. 61.

${ }^{203}$ Dublin University Magazine, June 1877, pp. 780-786.
} 
In the nineteenth century, vision aids were worn by men, women, and children. Additionally, associations with age, stigma, and fashion, could both encourage and prevent their use. The remark quoted at the outset of this section argued how the users of vision aids had changed during a single lifetime. ${ }^{204}$ Whether usage actually increased or broadened, and whether contemporary comments can be taken at face value, is difficult to ascertain from an analysis of these sources alone. Demand could be evident in the scale of vision aid production by the nineteenth century. However, contemporary perceptions also suggest that change was occurring. Indeed, the complexity of stigma towards eyewear is revealing. Young people wearing spectacles were considered old, women were considered scholastic, masculine or clerical, and men could be considered effeminate. This suggests that vision aids users were not stigmatised if they were elderly, academics or clergymen. It shows who was expected to wear vision aids in the nineteenth century and how this was heavily influenced by a long historical association between spectacles and age and learning. ${ }^{205}$ However, at the same time, it also suggests that vision aid use had begun to expand beyond these groups. In the absence of any statistics and whilst individuals could be faced with a range of stigma, the broadening of vision aid users is evident in contemporary perceptions that commented on and responded to visible change.

\section{Conclusion}

A column from 1890 headed 'Chats with Housekeepers' in The Newcastle Weekly Courant argued that the 'true explanation' for the rise in spectacle wear was because 'we know more than we used to of the needs of the eye'. ${ }^{206}$ As a purely functional device, the use of vision aids could have been affected by improved manufacture and medical knowledge that has been discussed in both this chapter and the rest of this thesis. However, this chapter has shown that the relationship between manufacture and improved utility is not straightforward. Despite this, the chapter has looked at the users, costs, and benefits of vision aids in order to explore how they were adopted by a range of people across the century. Medical case accounts,

\footnotetext{
${ }^{204}$ Aberdeen Weekly Journal, 18 February 1885.

${ }^{205}$ See, for example, a discussion of this in the eighteenth century by Withey, pp. 6, 93, 96 .

${ }^{206}$ The Newcastle Weekly Courant, 5 July 1890.
} 
photographs, popular literature, and opticians' registers create a fuller picture of the number of women, men, and children who both utilised and adopted a vision aid in the nineteenth century. As has been shown, a number of case accounts increasingly acknowledged the benefits of spectacle wear. It has also been argued that vision aids were increasingly seen as a device that should be accessible regardless of a person's position in society. These discussions highlighted how the correct use of vision aids enabled a person to maintain employment or overcome a range of physical symptoms that were often associated with eye-strain.

Usability, cost, fashion, stigma and the benefits of vision aids have been explored to ascertain whether there has been a change in overall usage. It has shown that the need for vision aids amongst the lower classes became particularly prominent. The growing demand for vision amongst the lower classes was influenced by advances in medical and technological knowledge, which improved the utility of vision aid lenses. Quantitatively, it is difficult to say whether overall use increased in light of these findings; medical knowledge was not necessarily adopted in practice by the end of the nineteenth century. However, the expectation of who should wear and have access to vision aids did change and encompassed a broader range of society. Contemporary perceptions revealed that vision aid users expanded beyond the aged, or those in the learned professions. The claims in popular literature were substantiated by a range of additional sources, including case accounts and photographs. Moreover, vision aids, for those that wore them, had an increasing ability to 'cure' those who previously considered themselves to be 'blind' By the end of the nineteenth century, vision aids were not the preserve of the aged or the rich; they were a device that they thought should be accessible to all and were increasingly better adapted to the functions that they were expected to serve. 


\section{Conclusion}

This thesis has explored the place of vision in nineteenth-century society, the role of medical practitioners and medical knowledge in the retail and dispensing of vision aids, the design of vision aids, and the use of vision aids. It set out to answer five principal questions. Firstly, was vision important in the nineteenth century, and how and why did understandings of vision errors change? Secondly, what were the implications of this for vision aid use, and did they become a viable treatment method? Thirdly, how were vision aids sold, and was this affected by changes in medical thought across the century? Fourthly, how were vision aids designed, and to what extent was this influenced by function, as well as appearance? Finally, how did these changes affect the users of vision aids in the nineteenth century, and how accessible would they have been?

In answering these five questions its argument has been threefold. Firstly, the advancement and professionalisation of medical knowledge of the eye led to the reconceptualization of how vision aids were used, tested, and sold in the second half of the century. Secondly, changes in the manufacture and sale of vision aids led to greater numbers being produced and these devices were better suited to serve their function for long-term wear. Thirdly, these two changes affected the users of vision aids through improvements in utility, and also accessibility, in terms of cost and availability. Whilst it is difficult to generate statistics on spectacle wear, the use of vision aids was influenced by price, effectiveness, and overall comfort. The thesis provides a significant contribution to our understanding of vision aids in the nineteenth century. However, the value of this thesis does not come from these basic answers. Each chapter has demonstrated that answering the research questions was not straightforward. Doing so has generated new insights into the processes of medicalisation, professionalisation and normalisation that, although pervasive, were incomplete and complex. Additionally, the work shows that the study of the measurement of vision and the use of vision aids is informed by, and also significantly contributes to, our wider understanding of Victorian society, as well as the manufacture, retail, and perceptions of an assistive technology. 
In answering the first research question, chapters one and two explored whether vision was important in the nineteenth century and how and why understandings of vision errors changed. Chapter one drew upon newspapers, periodicals and medical texts to explore the value attributed to vision in the nineteenth century. As this chapter showed, increased medical understanding of the eye exposed the eye's fallibility. Awareness of the fallibility of the eye, alongside the value being attributed to vision, led to growing concerns about ocular capacity, as well as fears about an overall deterioration in the nation's vision. Through an analysis of the school and workplace environments, chapter one also highlighted how vision was being measured against newly formulated norms in response to these concerns. It showed firstly that the eye was increasingly medicalised in the nineteenth century. It further argued that the nineteenth-century environment placed new demands on vision and the need for vision testing. Chapter two built upon the findings of chapter one by exploring contemporary medical texts and popular literature to ascertain how the opinions of medical practitioners and opticians were distributed more widely. This chapter showed how the invention of the ophthalmoscope enabled the refractive condition of a person's eye to be fully understood. In doing so, chapter two answered the second research question, by showing how vision aids became more viable as a method for treating problems of vision and associated symptoms. Therapeutic methods were replaced by the use of lenses, which, for the first time, could be suited to a person's vision based on observable evidence of the refractive state of a person's eye, which could be viewed by a dispenser or ophthalmologist. Importantly, lenses allowed individuals to overcome what they perceived to be 'blindness'. However, chapter two did not wholly attribute this change to the ideas of medical practitioners. It also argued that medical monopoly was not absolute. Medical practitioners competed against two other groups of people, opticians and the general public, both of whose publications could differ from, and challenge, medical ideas.

Chapter two focused on the dissemination of knowledge about problems of vision, and the place of medical practitioners and opticians within this process. Chapters three and four then explored the extent to which this was acted on in practice. Together, chapters three and four answer the third research question by 
analysing the effects of changes in medical thought on the sale and dispensing of vision aids. Firstly, chapter three highlights how vision aids were sold prior to the involvement of medical practitioners in vision aid dispensing. Its analysis of vision aid sale between 1800 and 1850 contributes significantly to our understanding of shop and 'beyond the shop' retail in this period. Through study of advertisements, newspapers, and periodicals, as well as popular medical texts, objects, and trade literature, it showed how the number of different types of retailers involved in vision aid dispensing followed broader trends and developments in the wider retail sector. Vision aids, it demonstrates, existed in a variety of retail locations in the first half of the century, as scientific instruments, 'fancy goods', and miscellaneous items. Vision aids could be retailed in all of these locations because they were dispensed by trial and error. This chapter also showed that trial and error should not be understood as implying a lack of concern with accuracy in this period; the method was one that gave the customer ultimate authority over their choice of vision aid and therefore the notion of accuracy that mattered was that of the user of the device, rather than that of any kind of medical professional or manufacturer of spectacles.

Chapter four then explicitly answered the third research question by showing how the advertising and sale of vision aids changed between 1850 and 1900 because of new medical ideas and the involvement of medical practitioners. It analysed the same material that was used in chapter three, alongside the debates that appeared in two publications serving members of different occupational and professional groups: The Optician and the British Medical Journal. Analysing the discussions and correspondence in these publications provided new insights about the importance of professionalism and reputation in the nineteenth century. It highlighted how debates over co-operation and professional boundaries proliferated in the 1890s. Whilst the medicalisation of vision aid retail was not complete by the end of the century, the analysis showed that the fringes of the market were responding to this process, and beginning to advertise an association with a medical institution or eyesight testing rooms. Though medicalisation was not yet fully realised in practice, chapter four argued that medical ideas had transformed expectations of how vision aids should be sold. By the end of the nineteenth century, the sale of vision aids often included a vision test. Moreover, changing medical knowledge of the eye did not just affect the retail of vision aids in this period; optometry and the use of lenses as a treatment 
method for refractive vision errors were being considered part of medical practice for the first time.

The final two chapters developed previous historical work on the design and users of vision aids by studying a broader range of textual and visual evidence than other scholars have considered. Chapter five drew upon objects, patents, medical texts, opticians' texts, and The Optician in order to assess how and why vision-aid design changed in the nineteenth century. It answered the fifth research question by arguing that design was not simply driven by advances in manufacture. Instead, through an analysis of the comfort, length, and appearance of the frame, it proposed that design was driven by considerations of the frame's functionality and the desire for it to appear elegant or invisible. By the end of the period, vision aids were a more usable, even desirable, item and were better designed for permanent wear. As part of this analysis, the chapter showed how vision aids can provide new insights on the increasingly sub-divided nature of manufacture in the scientific instrument trade by the end of the period. The final chapter built upon the findings of all of the previous chapters to explore the characteristics of vision aid users. The chapter answered the final research question by assessing how changes in medical thought, design, accessibility, comfort and the perceptions or social meanings of vision aids influenced vision aid use. Through study of nineteenth-century advertisements, the chapter analysed the price of vision aids across the century to assess their affordability in detail for the first time. This analysis was supplemented with evidence from the objects themselves, opticians' account books, catalogues, and charity correspondence, to argue that vision aids were increasingly democratised across the century. In addition to continuing to hold their former social connotations of status, wealth or intellectual capacity, vision aids also came to be considered a basic utilitarian device that should be available even to the poor. The remainder of the chapter explored users' experiences of vision aids and popular comment on such devices to show that increased comfort, accessibility, and utility would have increased the number and range of vision aids users in this period.

Overall, this thesis has argued that there were key changes in vision enhancement and the use of vision aids in the nineteenth century. The demands of the nineteenth-century environment were met by advancements in medicine, 
manufacture, and an increased awareness of the need to measure the eye to characterise problems of vision, and to use lenses to 'correct' any defects detected. However, this analysis also has implications for broader trends in historical research. In particular, the case of vision aids provides a unique example of the processes of medicalisation and normalisation in the nineteenth century. In many ways the study of vision aids and the measurement of vision can be seen as a good example of medicalisation. Vision errors, particularly presbyopia, which was recognised as a near-universal complaint, were transformed from being a 'natural' problem, to something that was increasingly measured, considered deviant, and required intervention. As discussed in the Introduction, definitions and medical diagnosis are central to the process of medicalisation. ${ }^{1}$ During the nineteenth century, the refractive capacity of the eye was increasingly scrutinised, with vision 'errors' being diagnosed for the first time against the newly categorised emmetropic or 'normal' eye. New conditions such as myopia or shortsightedness, for example, were frequently considered a 'disease'. This development can be understood as part of a broader pattern of change in the nineteenth century, whereby the body was increasingly medicalised in response to state concerns about national health and inefficiency of populations. ${ }^{2}$ As shown in chapter one, medical practitioners were increasingly involved in using the vision test to 'gate-keep' the entrance to certain professions. However, medical practitioners also featured prominently in discussions of vision deterioration, and how to combat it, in newspapers, periodicals and a range of popular medical texts. Robert A. Nye has argued that the relationship between medicalisation and the professionalisation of medicine is not straightforward. ${ }^{3}$ Despite this, both Nye and Conrad have considered the prestige of scientific medicine and medical authority to be 'prime movers' in the growth of medicalisation. ${ }^{4}$ This finding is supported by this thesis. The specialisation of ophthalmology and the growing authority of medical practitioners in optometry were integral to defining and medicalising the refractive and accommodative condition of the eye.

\footnotetext{
${ }^{1}$ See p. 7 of the Introduction for an overview of the concept of medicalisation.

${ }^{2}$ Robert A. Nye, 'The Evolution of the Concept of Medicalization in the Late Twentieth Century', Journal of History of the Behavioural Sciences, 39.2 (2003), 115-129 (p. 122).

${ }^{3}$ Ibid., p. 121.

${ }^{4}$ Peter Conrad, The Medicalisation of Society: On the Transformations of Human Conditions into Treatable Disorders (Baltimore: The John Hopkins University Press, 2007), p. 9; Nye, p. 122.
} 
However, the case of vision aids can also be seen to challenge the narrative of medicalisation. Spectacles and eyeglasses developed alongside the identification of a 'problem'. As shown in chapter two, treatment methods transformed from therapeutic remedies to the use of vision aids, a technological intervention that forced medical practitioners to rely on skillsets that they did not possess. The tensions between medical practitioners and opticians, which were discussed in chapters three and four, can be seen to challenge the idea that the enhancement of vision became fully medicalised in the nineteenth century. Chapters two and four highlighted that medical practitioners were unable to dominate discourse and the dissemination of knowledge about the eye and its refractive capacities. However, chapter four revealed that vision aids increasingly appeared in medical trade catalogues. Additionally, a range of retailers began to incorporate medical language and institutions into their advertisements and trade literature.

Nye has argued that 'soft' and 'hard' definitions of medicalisation have appeared in scholarly literature since the 1970s. ${ }^{5}$ Similarly, Conrad argued that there could be different degrees of medicalisation and it need not be total or complete. ${ }^{6}$ Conrad highlighted that he was not interested in whether the 'problem' was really medical, but was interested in the process and social underpinnings of expanding medical jurisdiction. ${ }^{7}$ Vision errors were increasingly treated by technological intervention and medical practitioners did not monopolise the dispensing of vision aids. However, the refractive condition of the eye, and the use of lenses, were increasingly discussed in a medical context. Vision aids constitute a particular example of medicalisation and the role of technologies or competing groups and professions in this process. Conrad assessed how medicalisation created a new demand for 'medical products' in a number of chapters in his 2007 work, as well as the subsequent roles of the pharmaceutical industry and insurance companies in sustaining and meeting this demand. ${ }^{8}$ Popularisation of medical knowledge about the eye and vision testing in schools and the workplace influenced the demand for vision aids. However, professional boundaries, the difficulty of defining vision errors in a medical context, and the reliance on different skillsets were persistent problems

\footnotetext{
${ }^{5}$ Nye, p. 117.

${ }^{6}$ Conrad, p. 6.

${ }^{7}$ Ibid., p. 3.

${ }^{8}$ Ibid., p. $x$.
} 
for medical professionals throughout the early twentieth century. Extending this analysis to explore the relationship between medical practitioners and opticians, and the dispensing of vision aids, between 1900 and 1950 would be beneficial. It would help to further assess the roles of medicalisation and professionalisation in the treatment of vision errors and retail of vision aids by developing the findings of chapter four and determining when, or if, the process of medicalising vision was completed.

In contrast, vision aids do not fit into the wider history of prosthetics and assistive devices very easily. However, they do provide an interesting example of the process of normalisation and a different perspective on how we might understand historical experiences of disability. As assistive devices, vision aids are central to the face and could certainly be stigmatised in the nineteenth century. Chapters five and six explored the stigma wearers could face, and how, at its most extreme, this could affect a persons' employability. It was this stigma that led to the desire for rimless frames and lenses, something which can be considered similar to the desire for more 'natural' prosthetics in the nineteenth century. However, vision aids are markedly different in the extent to which they could be displayed or adopted as a fashionable accessory in the nineteenth century. The use of spectacles and eyeglasses in this way is unique. Whilst prosthetics have often appeared as something 'deviant', spectacles and eyeglasses quickly became regarded as a 'normal' response to vision loss in the nineteenth century. No longer a bespoke device, they were a high street product that could be bought from a variety of retailers and in a variety of locations. Moreover, the use of vision aids by those who did not require them in the nineteenth century further highlights their ability to act as a 'normal' accessory, as well as a device that was intended for the 'treatment' of 'abnormality'.

Consideration of the very large numbers of vision aid users is integral to any analysis of the difference between spectacles and eyeglasses and other assistive or prosthetic devices. As discussed in the Introduction, the social categories of 'normal' and 'deviant' emerged in relation to the gathering of statistical data about the body and observations of commonality. ${ }^{9}$ The diagnosis of vision errors and use

\footnotetext{
${ }^{9}$ Introduction, pp. 9-11.
} 
of vision aids in the nineteenth century offers scope for exploring how 'deviance' can itself become normalised through the numbers affected. In particular, the proportion of people who required vision aids or had a vision defect was becoming apparent in the nineteenth century. This, and the fact that vision aids could be purchased on the high street, helps to explain why short-sightedness and other visual impairments are not necessarily seen as a 'disabilities' that need to be treated by a prosthetic/assistive device/orthotic. ${ }^{10}$ As highlighted in chapter two, the definitions of 'blindness' were changing in the nineteenth century in response to the increased ability of lenses to improve a person's vision. This demonstrates the value of exploring an assistive device to assess the role of technology in helping to define a broad spectrum of impairments and what constitutes a 'disability'. The status of individuals in the nineteenth century altered from a disabling condition of 'blindness', to restored or enhanced vision through the use of lenses. As highlighted in chapter six, the democratisation of vision aids in the nineteenth century improved accessibility and enabled them to become devices for all, as opposed to ones utilised only within minority populations, such as the aged. Both the definition of visual impairments and the ability to treat it changed in this period. This finding could be developed further through a focused study on the stigma and cultural perceptions of vision aids in greater depth. Whilst they do not entirely fit within it, placing vision aids in the broader history of prosthetics highlights scope for further study of minor impairments and how they are assisted and perceived. Individuals were 'abnormal' if they did not pass the vision test, but they were treated with a device that was increasingly 'normalised'. However, equally important is how these categories of 'normal' and 'abnormal' are created in the first place. Contemporaries were alarmed at the extent to which the 'emmetropic' eye was not possessed by a large proportion of the population. The very use of the terms 'emmetropic' or 'normal' when, as highlighted by a contemporary, 'normal is a variety', raises questions about how these definitions are developed and formulated. ${ }^{11}$

\footnotetext{
${ }^{10}$ See Katherine Ott's discussion of the various different categorisations of body technologies in, 'The Sum of Its Parts: An Introduction to Modern Histories of Prosthetics', in Artificial Parts and Practical Lives: Modern Histories of Prosthetics, ed. by Katherine Ott, David Serlin, and Stephen Mihm (New York: NYU Press, 2002), p. 7.

${ }^{11}$ D. Love, 'The Vision of School Children', British Medical Journal, 25 March 1899, p. 763.
} 
Ultimately, this thesis shows how objects can be used by historians. The Science Museum's collections have been integral to my analysis and illustrate the value of material evidence for historical work. The collections have been used to formulate questions, inform, shape and structure, five out of the six chapters. Chapter one used the collections' mesh and tinted lenses to explore how the use of vision aids diversified to serve a protective as well as restorative purpose. However, chapter one was less focused on objects, and chapter two did not include them. As argued in the Introduction, chapters one and two demonstrate the importance of exploring the objects' wider context - in this instance medical and cultural - and this research helped increase the usefulness of the objects in the remainder of the thesis. In the last four chapters the objects have been incorporated in three primary ways: to introduce a key question; as a case-study into associated or named individuals on the frame or case; and also as material evidence through close study of the frame or lens. The importance of objects for creating new historical questions is evident in the number formulated: why did the design of spectacle side-arms change? Why were there a diverse number of trades on the spectacle and eyeglasses cases? How breakable were frames? Why was 'pebble' inscribed on the frames of spectacles? Did the frames become lighter? Who were the individuals on the frames and cases, were they the makers, suppliers or owners? What was the strength of the lenses and were they able to improve a person's vision? These questions emerged during the course of my study, helped me to answer my five main research questions, and shaped the final form of the thesis.

However, beyond promoting questions, objects have acted as an invaluable source of evidence. The names on the frames and the cases allowed for a diverse number of areas to be explored. In chapter three, the study of eighty-eight instrument makers in the collection alongside a range of textual sources provided evidence of the retail of vision aids. These showed who typically traded vision aids and where they were located, and demonstrated that sale was both London and provincial; vision aids existed as part of the scientific instrument, fancy good and sundry trades. Names on the frames also highlighted how the sale and dispensing of vision aids changed over the course of the century. The cases in the Science Museum's collections, and subsequent study of trade directory records, enabled the evolution of individuals' trade names to be explored. By the end of the century, many retailers 
included terms such as 'ophthalmic' and 'oculistic', and this finding shaped the analysis of chapter four. In particular, a case of trial lenses, which was made by London opticians C.W. Dixey and owned by the ophthalmologist Sir Anderson Critchett, encouraged research into the relationship between opticians and medical practitioners and how they delineated their roles and differing skillsets. Moreover, researching individuals to form case studies provided a unique perspective on how vision aids were sold in chapters three and four. Investigations of John Hudson Taylor, Thomas Armstrong and Brother, and the Automatic Sight Testing Company all showed the value of exploring a wide range of evidence, where available, on individuals associated with objects in Museum collections. These cases highlighted how concerns over accuracy did exist in the first half of the nineteenth century; jewellers could have a working relationship with medical practitioners as dispensers of vision aids, and trial and error could continue to persist against the backdrop of increased medical regulation and reform. Collectively, objects and textual sources were able to provide detailed insight into an area of history - how vision aids were dispensed in the nineteenth century - where there is very little remaining evidence.

The material evidence of the collections has also been important throughout this thesis. In chapter four, the materiality of the sight-testing equipment highlighted how these diagnostic tools were becoming less portable. The growing size and weight of the sight-testing equipment led to an exploration of how vision testing was increasingly taking place in designated sight-testing rooms. Similarly, chapter five drew heavily on the material evidence in the collections to track how design changed, including exploring the changing styles of the bridge, the design of the side-arms, and the materials of the frames and lenses. These design features showed how manufacture was itself changing in the nineteenth century. Weighing the frames in light of these findings highlighted how the comfort and usability of the device was increasing in the nineteenth century. Additionally, close-study of the objects alongside textual sources highlighted how design was driven by concerns over appearance as well as practical function. Findings from newspapers, periodicals, advertising, and medical literature were important, but the elaborate detail on the frame, and the existence of rimless lenses, were pieces of evidence integral to this analysis. The different materials in the collection, and the range of quality, also informed the final chapter on users. Studying the range of materials alongside 
advertised prices allowed the affordability of vision aids to be tracked across the nineteenth century. Evidence of repair and material added to frames for comfort also allowed the user's experience of vision aid wear to be explored; it showed that the cost of possessing vision aids extended beyond a single transaction. Here, however, the way the frames were collected was also important and highlighted how vision aids could vary from 'choice' to 'everyday' items.

The collecting context, associated names and the objects themselves reveal the value of using objects as evidence in historical research. However, objects also present challenges and studying them requires a considerable amount of additional work to maximise a collection's potential for raising and answering broad historical questions. In particular, working with an 'anonymous collection' - where the majority of objects have no recorded provenance or associated name - presents a number of time-consuming methodological issues. A considerable amount of background work was required to obtain information on the object itself, and then additional research to place it in its wider context. The use of objects alone would have not allowed this thesis to have been written. Indeed, a diverse range of written and visual evidence developed the findings from the material evidence in order to fully explore and understand how vision aids were made, sold, and worn. Additionally, onsistent and long-term access to collections is necessary, as well as a considerable block of time for research. Setting these practical and methodological challenges aside, objects, when closely studied and placed in context, allow a diverse range of historical areas to be explored in greater depth, including retail, manufacture, and design. To develop this work further, more time could be devoted to object-work, including measuring the strength of the lenses and providing a more in-depth study of the manufacture of materials, beyond steel. Coupled with the findings from this thesis, such research would help show the value of using anonymous and domestic objects or collections, as well as the more notable objects and instruments, in historical work.

This thesis has explored vision aids and the enhancement of vision in the nineteenth century. It has analysed the design, dispensing, and use of vision aids through a variety of material, textual and visual evidence. However, it has also informed a number of broader historical themes: medicalisation; medical authority, 
professionalisation and specialisation; normalisation; history of retail; and the value of material culture in historical research. The nineteenth century was a key period of change in the measurement of vision and use of vision aids. The refractive conditions of the eye were diagnosed and understood for the first time, mass-manufacture of frames and lenses grew to create a more uniform and accessible range of products, and the dispensing of vision aids came to be increasingly discussed by medical practitioners and informed by medical ideas. This thesis adds to the pre-existing literature on the history of vision aids in the nineteenth century. It highlights the importance of researching and understanding the medical context in order to understand the influence of medical knowledge on how vision aids were used and sold. However, it also illustrates the value of the Science Museum's collections in shaping the investigation of this topic and informing its findings. Objects, when placed in their medical and cultural context, have enabled the use and adoption of vision aids to be explored in much greater depth. Whether intended as decorative items for display or basic devices for the poor, the emergence of vision testing, changes in dispensing, and alterations in the design of the frames and lenses, meant that vision aids became better suited to the function that they were intended to serve. Placing this process of change in the wider context of the nineteenth century, this thesis has shown the importance of studying the measurement of vision in this period for the history of vision aids, as well as the history of medicine, assistive technology and the cultural perceptions that surround vision and its impairment. 


\section{Bibliography}

\section{Primary Sources}

\section{Science Museum's Library and Collections}

\section{$\underline{\text { Collections }}$}

Art Collection

Ophthalmology Collection

Optics Collection

$\underline{\text { Notable Technical Files }}$

T/1921-323: Dunscombe Collection, 'File for 289 Spectacles and 93 Lenses'

T/2000-831-839: C.W. Dixey \& Son

\section{$\underline{\text { Patents }}$}

Patents for Inventions. Abridgements or Specificiations relating to Optical, Mathematical and other Philosophical Instruments; including Nautical,

Astronomical and Meterological Instruments A.D. 1636-1866 (London George E. Eyre and William Spottiswoode, 1875)

Patents for Inventions: Abridgements of Specifications, Class 97 Philosophical Instruments, [Including OPTICAL NAUTICAL, SURVEYING, MATHEMATICAL and METEOROLOGICAL INSTRUMENTS] 1877-1883 (London: Patent Office Sale Branch, 1893)

Patents for Inventions: Abridgements of Specifications, Class 97 Philosophical Instruments, [Including OPTICAL NAUTICAL, SURVEYING, MATHEMATICAL and METEOROLOGICAL INSTRUMENTS] 1884-1888 (London: Darling \& Son, 1896)

Patents for Inventions: Abridgements of Specifications, Class 97 Philosophical Instruments, [Including OPTICAL NAUTICAL, SURVEYING, MATHEMATICAL and METEOROLOGICAL INSTRUMENTS] 1889-92 (London: Darling \& Son, 1898) 
Patents for Inventions: Abridgements of Specifications, Class 97 Philosophical Instruments, [Including OPTICAL NAUTICAL, SURVEYING, MATHEMATICAL and METEOROLOGICAL INSTRUMENTS] 1893-1986 (London: Darling \& Son, 1900)

Patents for Inventions: Abridgements of Specifications, Class 97 Philosophical Instruments, [Including OPTICAL NAUTICAL, SURVEYING, MATHEMATICAL and METEOROLOGICAL INSTRUMENTS] 1897-1900 (London: Darling \& Son, 1903)

Patents for Inventions: Abridgements of Specifications, Class 97 Philosophical Instruments, [Including OPTICAL NAUTICAL, SURVEYING, MATHEMATICAL and METEOROLOGICAL INSTRUMENTS] 1867-76 (London: Darling \& Son Ltd., 1904)

Patents for Inventions: Abridgements of Specifications, Class 97 Philosophical Instruments, [Including OPTICAL NAUTICAL, SURVEYING, MATHEMATICAL and METEOROLOGICAL INSTRUMENTS] 1855-1866 (London: Love \& Malcomson Ltd., 1905)

\section{Archival Sources}

$\underline{\text { Boots Archives }}$

DA14/3: Invoice from P \& G Dollond for silver spectacles, 1806

DA15/10: Page from catalogue of P \& J Dollond, undated

DA15/43: Collection of Letters from Lindsay Johnson to James Aitchison, 18981906

DA16/8: An advance proof of an article titled 'Optics in the applications: Some workshop problems and processes’ (1890-1900s)

DA/21/1/53/6: A collection of letters from Lord Salisbury, Bishop of Gloucester, and Lord Palmerston to Dollond

DA23/1/18: Aitchison receipt written out to a Master Edwards for some spectacles, 1899

DA25/8 - 1898e: Photograph of Thomas Armstrong and Brother store, Manchester

\section{Cambridgeshire Archives}

K1350/1/892: Wilhelm Bauman aged 51, moulder. Requests stock of spectacles for hawking. Passage paid to return to Germany, 1884-1886 


\section{Cambridge University Library}

GBR/0012/Ms Add.5781-5783: Account books of Robert Sadd, Optician and Jeweller, for the years 1837, 1839, 1847, 1849, and 1851

\section{$\underline{\text { Carlisle Archive Centre }}$}

DB9/1-7: John Potter Dowell, Cash and Day Book (Sales), 1885-1898

Devon Heritage Centre

1299F/0/HA/19: West of England Eye Infirmary, Cashbook of Subscriptions, 18851895

\section{$\underline{\text { London Metropolitan Archives }}$}

London Metropolitan Archives, A/FWA/C/D/223/001: London Spectacle Mission Correspondence and Papers, 1894-1938

London Metropolitan Archives, A/KE/B/01/04/004: Royal London Ophthalmic Hospitals, Complaint that there was little profit in supplying spectacles, 1900

\section{London School of Economics}

Booth/A/11: Charles Booth's Notebooks, 1893

Booth/B/91: Charles Booth's Notebooks, 1893

\section{$\underline{\text { Sheffield City Archives }}$}

Bradbury Record 293: G.W. and Proctor, Opticians and Manufacturers (Sheffield: C.W. Thompson, 1815)

CA-VAC/119: Sheffield Town Council, Children's Commission Committee, From Manufacturers

SYCRO 1731: Progress Commerce, 1893 - Sheffield, Rotherham, and Mexborough (The London Printing \& Engraving Company, 1893)

SY231, Alfred Chadburn, Observations On The Choice And Use Of Spectacles, $11^{\text {th }}$ edn (1894)

\section{$\underline{\text { Somerset Heritage Centre }}$}

DD/MAL/337: Lady Marianne Malet miscellaneous correspondence, 1846-1847 
DD/X/RCH/1: Tradesmans's Account and Memoranda Book' of Samuel Brookes, Cutler and Stationer, 1797

The National Archives

COPY 1/19/110, 13 July 1872

COPY 1/25/88, 16 June 1874

COPY 1/366/247, 26 November 1883

COPY 1/397/35, 6 July 1889

COPY 1/414/928, 23 December 1893

J/90/834: Catalogue of the 'late' William Strange, Watch and Clock-Maker

MH 12/11000/19: Spectacles for aged inmates, 4 April 1853

MH 12/9534/77: From the Harry Farnall, Poor Law Inspector of Southwell workhouse, 30 October 1867

Thackray Museum Leeds: Medical Trade Catalogues

Arnold \& Sons, Catalogue of Surgical Instruments and Appliances, 1904

Brady \& Martin, Catalogue of Surgical, Physical \& Physiological Instruments, Microscopes, Medical Appliances and Sundries, 1882

Brady \& Martin, Illustrated Catalogue of Instruments, Appliances, and Fittings used in Surgery \& Medicine, 1897

Brady \& Martin, Catalogue of Scientific Apparatus including Chemistry, Bacteriology, Mechanics, Meteorology, Microscopy, Physics \&c, 1906

Brady \& Martin, Catalogue of Surgical Instruments and Appliances Aseptic Surgical Furniture \& Dressings, Chemical \& Bacteriological Apparatus, 1908

Down Bros, A Catalogue of Surgical Instruments and Appliances, 1885

Down Bros, A Catalogue of Surgical Instruments and Appliances, 1887

Down Bros, A Catalogue of Surgical Instruments and Appliances, 1889

Down Bros, A Catalogue of Surgical Instruments and Appliances, 1892

Down Bros, A Catalogue of Surgical Instruments and Appliances, 1894 
Down Bros, A Catalogue of Surgical Instruments and Appliances, 1896

Down Bros, A Catalogue of Surgical Instruments, 1897

Down Bros, A Catalogue of Surgical Instruments and Appliances, 1900

Down Bros, A Catalogue of Surgical Instruments and Appliances, also of Aseptic Hospital Furniture, 1901

Mappin \& Co, Illustrated Catalogue of Surgical Instruments and Appliances, Manufactured and Imported, 1885

Mappin \& Co, Illustrated Catalogue of Surgical Instruments and Appliances, 1891

Maw \& Son, S, A Quarterly Price Current of Surgeon's Instruments and Appliances, 1870

Maw \& Son, S, A Quarterly Price Current of Surgeon's Instruments and Appliances, 1881

Maw \& Son, S, A Quarterly Price Current of Surgeon's Instruments and Appliances, 1882

Maw \& Son, S, A Quarterly Price Current of Surgeon's Instruments and Appliances, 1891

Maw Son \& Thompson, S, A Quarterly Price Current of Surgeon's Instruments and Appliances, 1897

Mayer, Meltzer \& Jackson, A Catalogue of Surgical Instruments and Appliances, 1885

Mayer, Meltzer \& Jackson, A Catalogue of Surgical Instruments and Appliances, 1890

Mayer, Meltzer \& Jackson, Illustrated Catalogue of Surgical Instruments, 1900

Reynolds \& Branson, Handy Guide to Surgical Instruments and Medical Appliances, Physical and Physiological Apparatus, Microscopes, Spectacles, Artificial Eyes, 1887

Woolley Sons \& Co, James, Catalogue of Surgeons' Instruments and Medical Appliances, 1894

Woolley Sons \& Co, James, Catalogue of Surgeons' Instruments and Medical Appliances, 1896

Woolley Sons \& Co, James, Catalogue of Surgeons' Instruments and Medical Appliances, 1898 
Woolley Sons \& Co, James, Catalogue of Surgeons' Instruments and Medical Appliances, 1903

Weiss \& Son, James, A Catalogue of Surgical Instruments, Apparatus, Appliances etc, 1863

Weiss \& Son, James, Illustrated Catalogue and Price List of Surgical Instruments, 1889

Weiss \& Son, James, A Catalogue of Ophthalmic Instruments and Appliances, 1898

Trinity College Library, Cambridge

B25/23: Letter from Henry Bickersteth Mayor to his sister Flora McDonald Mayor

\section{$\underline{\text { University of Nottingham Archives Manuscripts \& Special Collections }}$}

HT/7/1/30: Letter from Emma Botham Alderson to her sister Mary Howitt, 26 October 1931

Wr/D/28: Diaries of Edward M. Wrench, 1856-1912, 1883

$\mathrm{Wr} / \mathrm{D} / 28 / 4$ : Notes. Originally found enclosed in Wr D 28, inside front cover

\section{$\underline{\text { Wellcome Library }}$}

Wellcome's auction catalogues are available at the Wellcome Library, but are currently uncatalogued:

Catalogues for Stevens auction house were viewed for 2 March 1915; 13 April 1920; 2 September 1924; 21 and 22 August 1928; 21 September 1928; 14 October 1928; 23 October 1928; 26 and 27 March 1930; 16 and 17 September 1930; 7 November 1930; 5 August 1931; 20 and 21 October 1931; 20 and 21 September 1921; 20 and 21 October 1932; 16 April 1935

Catalogues for Glendining auction house for 29 July 1932; 29 October 1934; 14 January 1935

\section{$\underline{\text { West Sussex Record Office }}$}

PHA 8846: Receipted bills for goods and services supplied by London tradesmen, paid by William Knapman on behalf of George, 3rd Earl of Egremont, 19 January 1822

PHA 10638: Bills supplied to George $3^{\text {rd }}$ Earl of Egremont, 1821-1822, 22 May 1820 
PHA 13086: Bills from London Tradesmen receipted bills for goods and services by London tradesman, to account B, 1821

PHA 13096: Bills from London Tradesmen receipted bills from London tradesmen for goods and services supplied to the London house bills to account B, 1832

\section{Printed Primary Sources}

Ackland, William, Hints on Spectacles. When to Wear and How to Select Them (London: Horne \& Thornthwaite, 1866)

Alden, Walter, The Human Eye; its Use and Abuse: A popular Treatise on Near and Impaired Sight, and the Methods of Preservation by the Proper Use of Spectacles (Cincinnati: The Author, 1866)

Arlidge, J.T., The Hygiene Diseases and Mortality of Occupations (London: Perceval, 1892)

Ayscough, James, A Short Account of the Eye and the Nature of Vision. Chiefly Designed to Illustrate the Use and Advantage of Spectacles, Wherein are Laid Down Rules for Chusing Glasses Properly, for Remedying all the Different Defects of Sight, as Also some Reasons for preferring a particular Kind of Glass, fitter than any other made Use of for that Purpose, $4^{\text {th }}$ edn (1755)

Baxter, William Smith, Facts About Eyesight, Eyestrain and Spectacles (Leeds: J. Lonsdale, 1898)

Beer, Georg, The Art of Preserving the Sight Unimpaired to an Extreme Old Age; and of Re-establishing and Strengthening it When it Becomes Weak (London: Henry Colburn, 1815)

Bew, George, Observations on Blindness, and on the Employment of other Senses to Supply the Loss of Sight (Manchester, 1782)

Bickerton, Thomas H., Colour Blindness and Defective Eyesight in Officers and Sailors of the Mercantile Marine: A Criticism of the Board of Trade Tests (Edinburgh: James Thin, 1890)

Black, George, Eyesight and How to Care for It (London: Ward, Lock, 1888)

Booth, Charles, Life and Labour of the London Poor, Second Series: Industry (London: Macmillan and Co., 1903)

Browning, John, Our Eyes and How to Preserve Them from Infancy to Old Age. With Special Information About Spectacles, $7^{\text {th }}$ edn (London: Chatto \& Windus, 1887) 
Carter, Robert Brudenell, F.R.C.S., On Defects of Vision which are Remediable by Optical Appliances (London: Macmillan and Co, 1877)

Carter, Robert Brudenell, Eyesight: Good and Bad: A Treatise on the Exercise and Preservation of Vision, $2^{\text {nd }}$ edn (London: Macmillan, 1880)

Carter, Robert Brudenell, Eyesight in Schools: A Paper Read Before the Association of Medical Officers of Schools on April 15 ${ }^{\text {th }}, 1885$ (London: Harrison and Sons, 1885)

Cooper, William White, On Near Sight, Aged Sight, Impaired Vision and the Means of Assisting Sight, $2^{\text {nd }}$ edn (London: John Churchill, 1853)

Donders, F.C., On the Accommodation and Refraction of the Eye, with a Preliminary Essay on Phusiological Dioptrics, trans William Daniel Moore (London: New Sydenham Society, 1864)

Dudgeon, R.E., The Human Eye; Its Optical Construction Popularly Explained (London: Harwicke \& Bogue, 1878)

Emerson, William, The Elements of Optics. In Four Books (London: J. Nourse, 1768)

The Family Guide to Health, or a General Practice of Physic (London, 1767) Farquharson, Robert, School Hygiene and Diseases Incidental to School Life (London: Smith, Elder, 1885)

Fenner, Christopher Smith, Vision: Its Optical Defects, and the Adaption of Spectacles (London: Lindsay \& Blakiston, 1875)

Flemyng, Malcolm, An Introduction to Physiology, being a course of lectures upon the most important Parts of the Animal Oeconomy (London, 1759)

Fournet, A., Medical Spectacles and the Royal London Hospital: Bloomfield Street, Moorfields, E.C. (London: A. Fournet, 1894)

Grimshaw, John, Eyestrain and Eyesight; How to Help the Eye and Save the Sight (London: J. \& A. Churchill, 1907)

Harris, Joseph, A Treatise of Optics: Containing Elements of the Science, In Two Books (London, 1775)

Harris \& Son, Thos, A Brief Treatise on the Eyes, Defects of Vision, and the Means of Remedying the Same by the Use of Proper Spectacles, Also Rules for judging when Spectacles are necessary, and Directions for selecting them (London: Onwhyn, 1839)

Horner, Friedrich, On Spectacles: Their History and Uses (London: Balliere, Tindall \& Cox, 1887) 
Hudson, J.T., Spectalaenia; or the sight restored, assisted and preserved by the use of spectacles (London: Simpkin and Marshall, 1833)

Hudson, J.T., Useful Remarks upon Spectacles, Lenses, and Opera-Glasses; with Hints to Spectacle Wearers and others; being an epitome of practical and useful knowledge upon this popular and important subject (London: Joseph Thomas, 1840)

James, Robert, A Medicinal Dictionary, including physic, surgery, anatomy, chymistry and botany (London: T. Osborne, 1743-5)

Keith, J. Gray, Facts Relating to Spectacles: How, When, Where and Why to Wear Them, with Rules for the Preservation of the Sight, and Cautions as to how Thousands Ruin their Sight, or are Rendered Blind, also Several Important Discoveries (Glasgow: David Bryce \& Son, 1889)

Kitchiner, W., Practical Observations on Telescopes, Opera-Glasses and Spectacles, $3^{\text {rd }}$ edn (London: S. Bagster, 1818)

Kitchiner, W., The Economy of the Eyes: Precepts for the Improvement and Preservation of Sight (London: Hurst Robinson \& Co., 1824)

Landolt, E., A Manual Examination of the Eyes (London: Tindall \& Cox, 1879)

Laurance, Henry, The Eye in Health and Disease: With Hints on the Choice and Use of Spectacles, $3^{\text {rd }}$ edn (London: Love Brothers, 1888)

Laurence, John Zachariah, Optical Defects of the Eye and their Consequences, Asthenopia and Strabismus (London: Robert Hardewicke, 1865)

Lewis, William, Medical Essays and Observations, published by a society in Edinburgh, containing meterology, mineral waters, material medica and pharmacy, animal oeconomy, vol I (London, 1746)

Liebreich, Richard, School Life in Its Influence on Sight and Figure: Two Lectures (London: J. \& A. Churchill, 1878)

Lincoln, David F., School and Industrial Hygiene (Philadelphia: P. Blakiston, 1885)

Lockwood, R. M., Frames and Lenses. A Practical Treatise for Optometrists (New York: Frederick Boger Pub. Co., 1905)

Long, Charles A., Spectacles: When to Wear and How to Use Them: Addressed to Those who Value Their Sight, $2^{\text {nd }}$ edn (London: Bland and Long, 1855)

Longmore, T., The Optical Manual: or, Handbook of Instructions for the Guidance of Surgeons in Testing the Range and Quality of Vision of Recruits and Others Seeking Employment in the Military Services of Great Britain (London: HMSO, 1885) 
Loring, Edward G., Is the Human Eye Changing its Form Under the Influence of Modern Education (Publisher not identified, 1878)

MacFadden, Bernarr Adolphus, Strong Eyes: How Weak Eyes May Be Strengthened and Spectacles Discarded (New York: Physical Culture Publishing Co., 1903)

Mackenzie, William, A Practical Treatise on the Diseases of the Eye, $4^{\text {th }}$ edn (London: A. and G.A. Spottiswoode, 1854)

Martin, Benjamin, Essay on Visual Glasses (London: The Author, 1756)

Mayhew, Henry, London Labour and the London Poor, A Cyclopaedia of the Condition and Earnings or Those that Will Work, Those that Cannot Work, and Those that Will Not Work, vol 1 (London: Griffin, Bohn and Company, 1851)

Middlemore, Richard, Introductory Lecture on the Anatomy, Physiology and Diseases of the Eye, Delivered at the Birmingham Royal School of Medicine and Surgery, 4 October 1839 (London: S. Longman, Orme, Brown, Green and Longmans, undated)

Middleton, Erasmus, The New Complete Dictionary of Arts and Sciences (London, 1778)

Morton, A. Stanford, Refraction of the Eye: It's Diagnosis and the Correction of its Errors (London: H.K. Lewis, 1881)

Morton, A. Stanford, Refraction of the Eye: It's Diagnosis and the Correction of its Errors: with Chapter on Keratoscopy, $3^{\text {rd }}$ edn (London: H.K. Lewis, 1886)

Motherby, George, A New Medical Dictionary; Or, General Repository of Physic (London: J.Johnson, 1791)

Newsholme, Arthur, School Hygiene: The Laws of Health in Relation to School Life (London: Swan Sonnenschein, Lowrey, 1887)

Nicholson, William, An Introduction to Natural Philosophy, vol I (London: J. Johnson, 1790)

The Optician: The Organ of the Mathematical, Philosophical, Electrical, Nautical, and Photographic Instrument Industries, And Review of the Jewellery and Allied Trades, vol I (Hyatt-Woolf \& Hayman, Offices: London,1891)

The Optician: The Organ of the Optical, Mathematical, Philosophical, Electrical, Nautical and Photographic Instrument Industries, vol II (Hyatt-Woolf \& Hayman, Offices: London, 1892)

The Optician and Photographic Trades Review: The Weekly Organ of the Optical, Photographic, Electrical, Nautical, Philosophical and Mathematical Instrument Industries, vol III (Hyatt-Woolf \& Hayman, Offices: London, 1892) 
The Optician and Photographic Trades Review: The Weekly Organ of the Optical, Photographic, Electrical, Nautical, Philosophical, and Mathematical Instrument Industries, vol IV (London: The Gutenberg Press Ltd., 1893)

The Optician and Photographic Trades Review: The Weekly Organ of the Optical, Photographic, Electrical, Nautical, Philosophical, and Mathematical Instrument Industries, vol V (London: The Gutenberg Press Ltd., 1893)

The Optician and Photographic Trades Review. The Weekly Organ of the Optical, Photographic, Electrical, Nautical, Philosophical \& Mathematical Instrument Industries, vol VI (London: The Gutenberg Press, 1894)

The Optician and Photographic Trades Review: The Weekly Organ of the Optical, Photographic, Electrical, Nautical, Philosophical \& Mathematical Instrument Industries (London: The Gutenberg Press Ltd., 1894)

The Optician and Photographic Trades Review: The Weekly Organ of the Optical, Photographic, Electrical, Nautical, Philosophical and Mathematical Instrument Industries, vol VIII (London: The Gutenberg Press, Ltd, 1895)

The Optician and Photographic Trades Review: The Weekly Organ of the Optical, Photographic, Electrical, Nautical, Philosophical, \& Mathematical Instrument Industries, vol IX (London: The Gutenburg Press, 1895)

The Optician and Photographic Trades Review: The Weekly Organ of the Optical, Photographic, Electrical, Nautical, Philosophical, \& Mathematical Instrument Industries, vol X (London: The Gutenburg Press, 1896)

The Optician and Photographic Trades Review: The Weekly Organ of the Optical, Photographic, Electrical, Nautical, Philosophical, \& Mathematical Instrument Industries, vol XI (London: The Gutenberg Press Ltd, 1896)

The Optician and Photographic Trades Review: The Weekly Organ of the Optical, Photographic, Electrical, Nautical, Philosophical, \& Mathematical Instrument Industries, vol XII (London: The Gutenberg Press Ltd, 1897)

The Optician and Photographic Trades Review: The Weekly Organ of the Optical, Photographic, Electrical, Nautical, Philosophical, and Mathematical Instrument Industries, vol XIII (London: The Gutenberg Press, 1897)

The Optician and Photographic Trades Review: The Weekly Organ of the Optical, Photographic, Electrical, Nautical, Philosophical, \& Mathematical Instrument Industries, vol XIV (London: The Gutenberg Press Ltd, 1898)

The Optician and Photographic Trades Review: The Weekly Organ of the Optical, Photographic, Electrical, Nautical, Philosophical, \& Mathematical Instrument Industries, vol XV (London: The Gutenberg Press Ltd., 1898) 
The Optician and Photographic Trades Review: The Organ of the Jeweller, Watchmaker, Acetylene Dealer, Photo Trader and Chemist, vol XVI (London: The Gutenberg Press Ltd, 1899)

The Optician and Photographic Trades Review, vol XVII (London: The Gutenberg Press Ltd, 1899)

The Optician and Photographic Trades Review, vol XVIII (London: The Gutenberg Press Ltd, 1900)

Phillips, John, Ophthalmic Surgery and Treatment: With Advice on the Use and Abuse of Spectacles (London: W.B. Keen \& Co., 1869)

Phillips, R.J., Spectacles and Eyeglasses, Their Forms, Mounting and Proper Adjustments, $2^{\text {nd }}$ edn (The Optician and Photographic Trades Review, 1900)

Ramsey, A. Maitland, On the Rise of Modern Ophthalmology (Privately Printed: Ballantyne Press, 1900)

Roosa, D.B., Defective Eyesight: The Principles of its Relief by Glasses (London: Macmillan, 1899)

Ross, Andrew, On the Use and Abuse of Spectacles (London: R. Kinder, 1840)

Rowley, William, A Treatise on one hundred and eighteen principal diseases of the eyes and eyelids (London: J Wingrave, 1790)

Rowley, William, Dr Rowley's Rational Practice of Physic, in Four Volumes, vol III (London, 1793)

Smee, Alfred, Vision in Health and Disease: the Value of Glasses for its Restoration and the Mischief Caused by their Abuse: Being the Substance of Lectures Delivered at the Central London Ophthalmic Hospital (London: Horn, Thornwaite and Wood, 1847)

Smith, Addison, Visus Illustratus; or, the sight rendered clear and indistinct (London, 1783)

Smith, Egerton, Hints to the Wearers of Spectacles; or a Concise Statement of the Comparative Merits of Pebbles and Glasses, When Used as Spectacle Eyes (Liverpool, 1819)

Smith, Priestley, Short Sight in Relation to Education (Birmingham: The Midland Educational Company, 1880)

Snell, Simeon, Influences of School Life on Eyesight (London: Wyman \& Sons, 1884)

Snell, Simeon, On the Prevention of Eye Accidents Occurring in Trades: An Address Delivered at the Opening of the Section of Ophthalmology at the Annual Meeting of 
the British Medical Association at Portsmouth, August, 1899 (London: John Bale, 1899)

Snell, Simeon, Eye-strain as a cause of headache and neuroses (London: Simpkin, Marshall, Hamilton, Kent \& Co., 1904)

Stephenson, Sydeny, Eye strain in everyday practice (London: The Ophthalmoscope Press, 1913)

Taylor, Charles Bell, How to Select Spectacles in Cases of Long, Short, and Weak Sight, $2^{\text {nd }}$ edn (London: Cassell, 1889)

Thorington, James, Refraction and How to Refract. Including Sections on Optics, Retinoscopy, the Fitting of Spectacles and Eye-glasses, etc (London: Rebman Ltd, 1900)

Vilas, C.H., Spectacles; and How to Choose Them (Chicago: Duncan Brothers, 1881)

Wallace, William Clay, Wonders of Vision: A Treatise on the Eye (New York:

Samuel Colman, 1839)

Wells, Joel Soelberg, Short and Weak Sight and Their Treatment by the Scientific Use of Spectacles (London: J.A. Churchill, 1862)

West, Francis, A Familiar Treatise on the Human Eye: Containing Practical Rules that will Enable all to Judge what Spectacles are Best Calculated to Preserve their Eyes to Extreme Old Age, $2^{\text {nd }}$ edn (London: W. Ackrill, 1827)

Wharton-Jones, T., Defects of Sight and Hearing, Their Nature, Causes, prevention and General Management (London: John Churchill and Sons, 1866)

Willich, F.M., Lectures on Diet and Regimen: Being a systematic inquiry into the most rational means of preserving health and prolonging life (London: A. Strahan, 1800)

\section{Online Repositories}

British Medical Journal Archive

https://www.bmj.com/archive

British Medical Journal

Provincial Medical Surgical Journal

The Glasgow Medical Journal 
British Periodicals

https://search-proquest-com.openathens-

proxy.swan.ac.uk/britishperiodicals/advanced

The Academy

After Work

Arnold's Magazine of the Fine Arts, and Journal of Literature and Science

The Athenaeum

Bentley's Miscellany

Blackwood's Edinburgh Magazine

Book-Lore

Bow Bells: A Magazine of General Literature and Art for Family Reading

Bradshaw's Manchester Journal

British Architect

Chambers's Edinburgh Journal

Chambers's Journal of Popular Literature, Science and Arts,

The City Jackdaw

The Critic

The Critical Review, or Annals of Literature

Dublin University Magazine

The Edinburgh Review

The Examiner

Figaro in London

Fraser's Magazine

Fun

The Gentleman's Magazine

The Gentleman's Magazine and Historical Chronicle 
La Belle Assemblee: or Court and Fashionable Magazine

Leader and Saturday Analyst

The Leisure Hour

The Leisure Hour: A Family Journal of Instruction and Recreation

The Literary Gazette: A Weekly Journal of Literature, Science and the Fine Arts

The Literary Panorama

Longman's Magazine

The London Reader: of Literature, Science, Art, and General Information

The London Review of Politics, Society, Literature, Art and Science

The London Saturday Journal

Macmillan's Magazine

The Metropolitan Magazine

Monthly Magazine, or British Register

The Monthly Review

Monthly Review, or, Literary Journal

Musical Standard

The Musical World

The New Monthly Magazine and Literary Journal

The New Monthly Magazine, and Universal Register

The Nineteenth Century: A Monthly Review

The North British Review

Once a Week

The Orchestra

The Practical Teacher

The Quarterly Review 
The Review of Reviews

Reynold's Miscellany of Romance, General Literature, Science and Art

The Saturday Magazine

Saturday Review of Politics, Literature, Science and Art, Sunday Review of Politics, Literature, Science and Art

The Scottish Review

Tait's Edinburgh Magazine

Theatrical Journal

The Wesleyan-Methodist Magazine

Westminster Review

$19^{\text {th }}$ Century British Library Newspapers:

http://find.galegroup.com/bncn/start.do?prodId=BNCN\&userGroupName=uows

Aberdeen Weekly Journal

Belfast News-Letter

Berrow's Worcester Journal

Birmingham Daily Post

The Blackburn Standard

The Blackburn Standard and Weekly Express

The Bradford Observer

The Bristol Mercury

The Bristol Mercury and Daily Post

The Bury and Norwich Post, and East Anglican

The Bury and Norwich Post and Suffolk Herald

Caledonian Mercury

Cheshire Observer 
Cheshire Observer and Chester, Birkenhead, Crewe and North Wales Times

Daily News

Derby Mercury

The Dundee Courier \& Argus

The Dundee Courier \& Argus and Northern Warder

The Essex Standard and General Advertiser for the Eastern Counties

The Essex County Standard, West Suffolk Gazette, and Eastern Counties Advertiser

Examiner

Freeman's Journal and Daily Commercial Advertiser

Glasgow Herald

Graphic

The Hampshire Advertiser

Hampshire Advertiser \& Salisbury Guardian Royal Yacht Club Gazette,

Southampton Town and Country Herald, Isle of Wight, Winchester Chronicle, and General Reporter

Hampshire Telegraph and Sussex Chronicle

The Huddersfield Chronicle and West Yorkshire Advertiser

The Huddersfield Daily Chronicle

Illustrated Police News

Ipswich Journal

Isle of Wight Observer

Jackson's Oxford Journal

The Lancaster Gazette and General Advertiser for Lancashire, Westmorland, Yorkshire, \&c.

Leeds Mercury

The Leicester Chronicle and Leicestershire Mercury

Liverpool Mercury 
Lloyd's Weekly Newspaper

Lloyds Weekly London Newspaper

The London Dispatch and People's Political and Social Reformer

Manchester Times

The Morning Post

Newcastle Courant

The Newcastle Weekly Courant

The North-Eastern Daily Gazette

North Wales Chronicle

Northern Echo

Nottinghamshire Guardian

Operative

Pall Mall Gazette

Preston Chronicle

The Preston Guardian Etc

Reynold's Newspaper

The Royal Cornwall Gazette, Falmouth Packet, Cornish Weekly News \& General Advertiser Standard, West Suffolk Gazette, and Eastern Counties' Advertiser

The Sheffield \& Rotherham Independent

Southampton Herald

The Standard

The Star

Trewman's Exeter Flying Post or Plymouth and Cornish Advertiser

The Weekly Standard and Express

Western Mail 
The Wrexham Advertiser, Denbighshire, Flintshire, Cheshire, Shropshire, Merionethshire and North Wales Register

The Wrexham Advertiser, and North Wales News

The Yorkshire Herald, and the York Herald

The York Herald and General Advertiser

$\underline{\text { Additional Newspapers and Journals }}$

The Illustrated London News Historical Archives, 1842-2003

[Electronic Resource] by Gale and accessed through the Science Museum Group network:

http://find.galegroup.com/iln/start.do?prodId=ILN\&userGroupName=scimus\&final

Auth=true

The Lancet

https://www.sciencedirect.com/journal/the-lancet

$\underline{\text { Ron Cosens' Collections of Cartes de Visite }}$

http://www.cartedevisite.co.uk/

Trade Directories: University of Leicestershire, Special Collections (Arranged Chronologically by Area)

http://specialcollections.le.ac.uk/cdm/landingpage/collection/p16445coll4

History and General Directory of the Borough of Sheffield with Rotherham,

Chesterfield, and all The Villages and Hamlets (1833)

General Directory of Sheffield (1849)

Gazetteer and General Directory of Sheffield (1852)

General and Commercial Directory and Topography of the Borough of Sheffield (1862)

White's General and Commercial Directory of Sheffield (1879)

Kelly's Directory of West Riding of Yorkshire (1881)

Kelly's Directory of West Riding of Yorkshire (1881)

Kelly's Directory of Devon (1889)

Deacon's Leicestershire, Rutland \& Northamptonshire (1890) 
Post Office London Directory [part 3: Commerical and Professional Directory] (1895)

Post Office London Directory [Part 3: Commercial and Professional Directory] (1899)

Slater's Directory of Manchester \& Salford (1879)

Slater's Directory of Manchester \& Salford (1883)

Slater's Directory of Manchester \& Salford (1895)

\section{Secondary Sources}

\section{Books, Book Chapters and Journal Articles}

Albert, D.M., F.C. Blodi, 'George Joseph Beer: A Review of His Life and Contributions', in H.E. Henkes and Cl. Zrenner, eds., History of Ophthalmology 1. Academiae Ophthalmologicae Internationalis, vol 1 (Dordrecht: Springer, 1988), pp. 79-103

Albert, Daniel M., and Diane D. Edwards, eds., The History of Ophthlamology (Oxford: Blackwell Science, 1996)

Alberti, Samuel J., 'Objects and the Museum', Isis, 96.4 (2005), 559-571

Alexander, David, Retailing in England During the Industrial Revolution (London: The Athlone Press, 1970)

Ames, Kenneth L., Death in the Dining Room and Other Tales of Victorian Culture (Philadelphia: Temple University Press, 1992)

Anderson, Benedict, Imagined Communities Reflections on the Origin and Spread of Nationalism (London: Verso, 2006)

Andressen, B. Michael, Spectacles From Utility Article to Cult Object (Stuttgart: Arnoldsche, 1998)

Appadurai, Arjun,ed., The Social Life of Things: Commodities in Cultural Perspectives (Cambridge: Cambridge University Press, 1995)

Arnold, Ken, and Danielle Olsen, eds., Medicine Man: The Forgotten Museum of Henry Wellcome (London: The British Museum Press, 2011)

Auslandar, Leora, 'Beyond Words', The American Historical Review, 110.4 (2005), $1015-45$ 
Bailey, Joanne, Parenting in England, 1760-1830 (Oxford: Oxford University Press, 2012)

Baker, William, Kenneth Womack, eds., A Companion to the Victorian Novel (Westport: Greenwood Press, 2002)

Barber, Sarah, and Corinna M. Peniston-Bird, eds., History Beyond the Text: A Student's Guide to Approaching Alternative Sources (London: Routlege, 2009)

Barck, Carl, The History of Spectacles, Originally Delivered as a Lecture Before the Academy of Science (Reprinted from the Open Court for April, 1907)

Barker, Hannah, 'Medical Advertising and Trust in Late Georgian England', Urban History, 36.3 (2009), 379-98

Barty-King, Hugh, Eyes Right: The Story of Dollond and Aitchison, Opticians, 1750 1985 (London: Quiller P, 1985)

Bates, Denise, Historical Research Using British Newspapers (Barnsley: Pen and Sword History, 2016)

Bennett, Jim, 'Museums and the History of Science: Practitioner's Postscript', Isis, 96.4 (2005), 602-608

Bennett, Jim, 'Presidential address: Knowing and Doing in the Sixteenth Century: what were instruments for?', British Journal for the History of Science, 36.2 (2003), $129-150$

Benson, John, 'Drink, Death and Bankruptcy: Retailing and Respectability in Late Victorian and Edwardian England', Midland History, 32.1 (2007), 128-140

Berry, Helen, 'Polite Consumption: Shopping in Eighteenth-Century England', Transactions of the Royal Historical Society, 12 (2002), 375-394

Bingham, Adrian, 'Review Article: The Digitisation of Newspaper Archives: Opportunities and Challenges for Historians', Twentieth Century British History, 21.2 (2010), 225-231

Bourrier, Karen, The Measure of Manliness: Disability and Masculinity in the MidVictorian Novel (Ann Arbor: University of Michigan Press, 2015)

Briggs, Asa, Victorian Things (London: B.T. Batsford Ltd, 1998)

Bronstein, Jamie L., Caught in the Machinery: Workplace Accidents and Injured Workers in Nineteenth-Century Britain (Stanford: Stanford University Press, 2008)

Brown, Michael, 'Medicine, Reform, and the 'End' of Charity in Early NineteenthCentury England', The English Historical Review, 124.511 (2009), 1353-1388 
Brown, Michael, Performing Medicine: Medical Culture and Identity in Provincial England, c. 1760-1850 (Manchester: Manchester University Press, 2010)

Burns, Arthur, and Joanna Innes, eds., Rethinking the Age of Reform: Britain 17801850 (Cambridge: Cambridge University Press, 2003)

Carpenter, Mary, Health, medicine and society in Victorian England (Santa Barbara CA: Praeger, 2009)

Champness, Richard, A Short History of the Worshipful Company of Spectacle Makers up to the Beginning of the Twentieth Century (London: Apothecaries Hall, 1952)

Clifton, Gloria, Directory of British Scientific Instrument Makers 1550-1851 (London: Zwemmer, 1995)

Cody, Lisa Forman, 'No Cure, No Money', or the Invisible Hand of Quackery: the Language of Commerce, Credit and Cash in Eighteenth-Century Advertisements', Studies in Eighteenth-Century Culture, 28 (1999), 103-30

Conrad, Peter, The Medicalisation of Society: On the Transformation of Human Conditions into Treatable Disorders (Baltimore: John Hopkins University Press, 2007)

Corson, Richard, Fashions in Eyeglasses, $3^{\text {rd }}$ edn (London: Peter Owen, 2011)

Court, Thomas H., and Moritz Von Rohr, 'On the Development of Spectacles in London from the End of the Seventeenth Century', Transactions of the Optical Society, 30.1 (1928-9), 1-21

Crawforth, Michael A., 'Evidence from Trade Cards for the Scientific Instrument Industry', Annals of Science, 42.5 (1985), 453-544

Daston Lorraine, ed., Things That Talk: Object Lessons From Art and Science, ed. by Lorraine Daston (New York: Zone Books, 2004)

Davidson, Derek C., 'Nineteenth Century Metal Spectacles', Ophthalmic Antiques International Collectors Club Newsletter, No. 58 (1997), 9-10

Davidson, Derek C., Spectacles, Lorgnettes and Monocles (Buckinghamshire: Shire, 2002)

Davidson, Luke, “"Identities Ascertained": British Ophthalmology in the First Half of the Nineteenth Century', Social History of Medicine, 9.3 (1996) 313-33

Davis, Lennard J., Enforcing Normalcy: disability, deafness and the body (London; New York: Verso, 1995)

Davis, Lennard J., The Disability Studies Reader, $4^{\text {th }}$ edn (London: Routledge, 2013) 
Digby, Anne, The Evolution of British General Practice, 1850-1948 (Oxford: Oxford University Press, 1999)

'Development of Spectacles: $1^{\text {st }}$ half of the Nineteenth Century', Ophthalmic Antiques International Collectors Club Newsletter, No. 16 (1986), 4

Dixey \& Son, C.W., A Short History, 1777-1977 (Newport: Mullock \& Sons, 1977) Dreyfus, John, 'The Invention of Spectacles and the Advent of Printing', The Library, 6.2 (1988), 93-106

Dupre, Sven, and Christoph Luthy, eds., Silent Messengers: The Circulation of Material Objects of Knowledge in the Early Modern Low Countries (Berlin: Lit Verlag, 2011)

Elson, C.W., Origin and Development of Spectacles (Worthing: Worthing Archaeological Society, 1935)

Flint, Kate, The Victorians and the Visual Imagination (Cambridge: Cambridge University Press, 2000)

Foucault, Michel, The Birth of the Clinic: An Archaeology of Medical Perception (New York: Vintage Books, 1975)

Foucault, Michel, The History of Sexuality, vol 1 (London: Penguin Books, 1990),

Garland-Thomson, Rosemarie, Staring: How We Look (Oxford: Oxford University Press, 2009)

Gerritsen, Anne, and Giorgio Riello, eds., Writing Material Culture History (London: Bloomsbury Academic, 2015)

Glassie, Henry, Material Culture (Indianapolis: Indiana University Press, 1999)

Goggins, Sophie, Tacye Phillipson, Samuel J. M.M. Alberti, 'Prosthetic Limbs on Display: from maker to user', Science Museum Group Journal, 8 (2017) http://journal.sciencemuseum.ac.uk/browse/issue-08/prosthetic-limbs-ondisplay/\#reference-16 [accessed 28 March 2019]

Gooday, Graeme, and Karen Sayer, Managing the Experiences of Hearing Loss in Britain, 1830-1930 (Basingstoke: Palgrave Macmillan, 2017)

Gooding, Joanne, 'Rather Unspectacular: Design choices in National Health Service Glasses', Science Museum Group Journal, 7 (2017) http://journal.sciencemuseum.ac.uk/browse/issue-07/rather-unspectacular/\#0 [accessed: 2 February 2018]

Granshaw, Lindsay, 'Fame and fortune by means of bricks and mortar': the Medical Profession and Specialist Hospitals in Britain, 1800-1948', in Lindsay Granshaw and Roy Porter, eds., The Hospital in History (London: Routledge, 1989), pp. 199-220 
Grier, Katherine C., Culture and Comfort: People, Parlors and Upholstery, 18501930 (Rochester: Strong Museum, 1992)

'Guest Editorial: Hypermetropia or Hyperopia?', Ophthalmic \& Physiological Optics, 35 (2015), 2-7

Haley, Bruce, The Healthy Body and Victorian Culture (London: Harvard University Press, 1978)

Handley, Neil, Cult Eyewear: The World's Enduring Classics (London: Merrell Publishers Ltd, 2011)

Harvey, Karen, 'Men of Parts: Masculine Embodiment and the Male Leg in Eighteenth-Century England', Journal of British Studies, 54.4 (2015), 797-821

Harvey, Karen, ed., Material Culture: A Student's Guide to Approaching Alternative Sources (London: Routledge, 2009)

Herman, Bernard L., The Stolen House (London: University Press of Virginia, 1992)

Hess, Alison, Hilary Geoghegan, 'Object-love at the Science Museum: Cultural Geographies of Museum Storerooms', Cultural Geographies, 22.3 (2015), 445-465

Hilaire-Perez, Liliane, and Christelle Rabier, 'Self-Machinery?' Steel Trusses and the Management of Ruptures in eighteenth-century Europe', Technology and Change, 54 (2013), 460-502

Hill, Louise Curth, 'Medical Advertising in the Popular Press: Almanacs and the Growth of Proprietary Medicines', in Louise Hill Curth, ed., From Physick to Pharmacology: Five Hundred Years of British Drug Retailing (Aldershot: Ashgate, 2006), 29-48

Hirst, J.D., 'Vision testing in London: a rehearsal for the School Medical Service', Journal of Education Administration \& History, 14.2 (1982), 23-9

'History of the County of York', Vol V by T. Allen in 1831', Ophthalmic Antiques International Collectors Club Newsletter, No. 42 (1992), 9

Hitchcock, Tim, 'Confronting the Digital, or how Academic History Writing Lost the Plot', Cultural and Social History, 10.1 (2013), 9-23

Holtman, H.W., 'A Short History of Spectacles', in W. Poulet, Atlas on the History of Spectacles, trans. Professor Frederick C. Blodi (Godesberg: Wayenborgh, 1978), pp. vii-xxi

Ilardi, Vincent, Renaissance Vision from Spectacles to Telescopes (Philadelphia: American Philosophical Society, 2007)

Jay, Martin, 'The Rise of Hermeneutics and the Crisis of Ocularcentrism', Poetics Today, 9.2 (1988), 307-326 
Jenner, Mark S.R., and Patrick Wallis, eds., Medicine and the Market in England and its Colonies, c.1450-c.1850 (London: Palgrave Macmillan, 2007)

Jones, Claire L., ed., Rethinking Modern Prostheses in Anglo-American Commodity Cultures (Manchester: Manchester University Press, 2017)

Jones, Claire L., The Medical Trade Catalogue in Britain, 1870-1914 (London: Pickering and Chatto, 2013)

Kiliç, Mine Özyurt, Maggie Gee: Writing the Condition-of-England Novel (London: Bloomsbury, 2013)

Kingery, W. David, ed., Learning from Things: Method and Theory of Material Culture Studies (Washington and London: Smithsonian Institution Press, 1996)

Larkin, G.V., 'Professional Autonomy and the Ophthalmic Optician', Sociology of Health and Illness, 3.1 (1981), 15-30

Larson, Frances, 'The Things About Henry Wellcome', Journal of Material Culture, 15 (2010), 83-104

Lawrence, Christopher, Medicine in the Making of Modern Britain (London: Routledge, 1994)

Levin, Michael, The Condition of England Question: Carlyle, Mill, Engels (Basingstoke: Macmillan Press, 1998)

Levine, Philippa, The Amateur and the Professional: Antiquarians, Historians and Archaeologists in Victorian England, 1838-1886 (Cambridge: Cambridge University Press, 2002)

MacGregor, Arthur, 'Exhibiting Evolutionism: Darwinism and pseudo-Darwinism in museum practice after 1859', Journal of the History of Collections, 21.1 (2009), 7794

MacGregor, R.J.S, 'Pebbles', Ophthalmic Antiques Collectors Club, No. 73 (2000), $5-9$

MacGregor, R.J.S. Hugh Orr, Derek C. Davidson, Stuart Eadon-Allen, 'Real Tortoiseshell', Ophthalmic Antiques International Collectors Club, No. 41 (1992), 38

MacGregor, R.J.S., 'The Amazing Pince-Nez', Ophthalmic International Antiques Collectors Club Newsletter, No. 69 (1999), 5-7

Martin, Ann Smart, and J. Ritchie Garrison, eds., American Material Culture: The Shape of the Field (Winterthur: Winterthur Museum, 1997) 
McConnell, Anita, A Survey of the Networks Bringing Knowledge of Optical Glass to London Trade, 1500-1800 (Cambridge: Whipple Museum of the History of Science, 2016)

McCormack, Matthew, 'Boots, Material Culture and Georgian Masculinities', Social History, 42.4 (2017), 461-479

McMahon, Darrin M., Happiness: A History (New York: Grove Press, 2006)

Meckel, Richard A., Classroom and Clinic: Urban Schools and the Protection and Promotion of Child Health, 1870-1930 (New Brunswick: Rutgers University Press, 2013)

Mitchell, Margaret, History of the British Optical Association, 1895-1978 (London: British Optical Association, 1982)

Mitchell, Sally, ed., Victorian Britain: An Encyclopaedia (Oxon: Routledge, 2011)

Morgan, M., Molyneux's Question: Vision, Touch and the Philosophy of Perception (Cambridge: Cambridge University Press, 1977)

Morrison-Low, A.D., Making Scientific Instruments in the Industrial Revolution (Aldershot: Ashgate, 2007)

Morrison-Low, Alison D., Sara J Sechner, Paolo Brenni, eds., How Scientific Instruments Changed Hands (Leiden: Brill, 2016)

Morrow, John, Thomas Carlyle (London: Hambledon Continuum, 2006)

Mosley, Adam, 'Introduction [to Special Issue "Objects, texts and images in the history of science"]', Studies in the History \& Philosophy of Science, 38 (2007), 289-301

Murnane, Barry, Darragh Murnane, Mark Sanders, Noel Snell, 'Great Ease and Simplicity of Action': Dr Nelson's Inhaler and the Origins of Modern Inhalation Therapy', Science Museum Group Journal, 8 (2017) http://journal.sciencemuseum.org.uk/browse/issue-08/dr-nelson-s-inhaler/ [accessed 28 March 2019].

Mussell, James, The Nineteenth-Century Press in the Digital Age (Basingstoke: Palgrave Macmillan, 2012)

Muth, Eric P., 'Kevin Michael Tuohy: The Father of the Modern Contact Lenses', Indian Optician, Nov-Dec (1987), 14-17

Neaman, Judith S., 'The Mystery of the Ghent Bird and the Invention of Spectacles', Viator, 24 (1993), 189-214 
Ogden, Daryl, The Language of the Eyes: Science, Sexuality, and Female Vision in English Literature and Culture, 1690-1927 (New York: State University New York Press, 2005)

Oliver, Michael, and Colin Barnes, The New Politics of Disablement (Basingstoke: Palgrave Macmillan, 2012)

Orr, Hugh, Illustrated History of Early Antique Spectacles (London: The Author, 1985)

Ott, Katherine, David Serlin and Stephen Mihm, eds., Artificial Parts and Practical Lives: Modern Histories of Prosthetics (New York: NYU Press, 2002)

Otter, Chris, The Victorian Eye: A Political History of Light and Vision in Britain, 1800-1910 (Chicago; London: Chicago University Press, 2008)

Pearce, Susan M., 'Thinking about things', in Interpreting Objects and Collections (London: Routledge, 1994), pp. 125-132

Perkin, Harold, The Rise of Professional Society (London: Routledge, 2002)

Pointer, Jonathan S., 'The £ound in Your Pocket and the Glasses on Your Nose 700 years of reading spectacle prices', Ophthalmic Antiques International Collectors Club Newsletter, No. 59 (1997), 4-5

Porter, Roy, Health for Sale: Quackery in England, 1660-1850 (Manchester: Manchester University Press, 1989)

Rhodes, Michael, 'A Pair of Fifteenth-Century Spectacle Frames from the City of London', Antiquaries Journal, 62 (1982), 57-73

Richardson, Catherine, Tara Hamling and David Gaimster, eds., The Routledge Handbook of Material Culture in Early Modern Europe (London: Routledge, 2017)

Roach, J.P.C., Public Examinations in England, 1850-1900 (Cambridge: Cambridge University Press, 1971)

Robert A. Nye, 'The Evolution of the Concept of Medicalization in the Late Twentieth Century', Journal of History of the Behavioural Sciences, 39.2 (2003), $115-129$

Rose, Sarah F., No Right to be Idle: The Invention of Disability, 1840s-1930s (Chapel Hill: The University of North Carolina Press, 2017)

Rosen, E., 'The Invention of Eyeglasses', Journal of the History of Medicine and Allied Sciences, 11.1 (1956), 13-46

Rosen, George, The Specialisation of Medicine with Particular Reference to Ophthalmology (New York: Froben Press, 1944) 
Rosenthal, William, Spectacles and Other Vision Aids: A History and Guide to Collecting (San Francisco, CA, Norman, 1996)

Russell, Ben, James Watt: Making the World Anew (London: Reaktion Books, 2014)

Schaffer, Simon, 'Easily Cracked: Scientific Instruments in States of Disrepair', Isis, 102 (2011), 707-717

Schickore, Jutta, 'Misperception, Illusion and Epistemological Optimism: Vision Studies in Early Nineteenth-Century Britain and Germany', British Journal for the History of Science, 39.3 (2006), 383-405

Schlereth, Thomas J., Material Culture Studies in America (Nashville: Rowman Altamira, 1982)

Segrave, Kerry, Vision Aids in America: A Social History of Eyewear and Sight Correction since 1900 (London: McFarland \& Company Inc., 2011)

Shuttleworth, Sally, and Geoffrey Cantor, eds., Science Serialized: Representations of the Sciences in Nineteenth-Century Periodicals (London: The MIT Press, 2004)

Skinner, Ghislaine M., 'Sir Henry Wellcome's Museum for the Science of History', Medical History, 30 (1986), 383-418

Soderfeldt, V. R. Verstraete, 'From Comparison to Indices: A Disabling Perspective on the History of Happiness', Health, Culture and Society, 5.1 (2013), 249-264

Solomon, Michael, Spectacles (London: Thames and Hudson, 1994)

Stevens, Rosemary, Medicine and the Public Interest: A History of Specialisation (Berkley; Los Angeles; London: University of California Press, 1998)

Stobart, Jon, 'Selling (Through) Politeness: Advertising Provincial Shops in Eighteenth-Century England', Cultural and Social History, 5.3 (2008), 309-328

Stobart, Jon, Andrew Hann, Victoria Morgan, Spaces of Consumption: Leisure and Shopping in the English Town, c.1680-1830 (London: Routledge, 2007)

Stoddard-Holmes, Martha, Fictions of Affliction: Physical Disability in Victorian Culture (Ann Arbor: University of Michigan Press, 2004)

Sturdy, Steve, 'The Industrial Body', in Roger Cooter and John Pickstone, eds., Companion to Medicine in the Twentieth Century (London: Routledge, 2003), pp. 217-34

Styles, John, and Amanda Vickery, eds., Gender, Taste and Material Culture in Britain and North America 1700-1830 (New Haven and London: Yale University Press, 2006) 
Tate, Gregory, 'Researching Science and Periodicals: Satire and Scientific Jargon in Punch', in Alexis Easley, Andrew King, John Morton, eds., Researching the Nineteenth-Century Periodical Press: Case Studies (London: Routledge, 2018), pp. 161-174

Taub, Lisa, 'Reengaging with Instruments', Isis, 102.4 (2011), 689-696

Taylor, Geoffrey Stuart, and Malcolm Nicolson, 'The Emergence of Orthodontics as a Speciality in Britain: The Role of the British Society for the Study of Orthodontics', Medical History, 51 (2007), 379-398

Temple, Mick, The British Press (Maidenhead: Open University Press, 2008)

'The Development of Spectacles 1850-1900', Ophthalmic Antiques International Collectors Club Newsletter, No.17 (1986-7), 4-5

Turner, David M., 'Disability History and the History of Emotions: Reflections on Eighteenth-Century Britain', Asclepio, 68.2, http://dx.doi.org/10.3989/asclepio.2016.18 [accessed 2 June 2018]

Turner, David M., and Daniel Blackie, Disability in the Industrial Revolution: Physical Impairment in British Coalmining, 1780-1880 (Manchester: Manchester University Press, 2018)

Turner, David M., Disability in Eighteenth Century England (London: Routledge, 2012)

Turner, David, and Alun Withey, 'Technologies of the Body: Polite Consumption and the Correction of Deformity in Eighteenth-Century England', The Journal of the Historical Association, 99.338 (2014), 775-796

Turner, Dorothy M., 'Thomas Young and the Eye on Vision', in E.A. Underwood, ed., Science Medicine and History: Essays on the Evolution of Scientific Thought and Medical Practice Written in Honour of Charles Singer (Oxford: Oxford University Press, 1954), pp. 243-55

Ugolini, Laura, and John Benson, eds., Retailing Beyond the Shop, c. 1400-1900 (Bradford: Emerald Group Publishing Ltd, 2010)

Underwood, E.A., ed., Honour of Charles Singer (Oxford: Oxford University Press, 1954)

Vella, Stephen, 'Newspapers', in Miriam Dobson and Benjamin Ziemann, eds., Reading Primary Sources: The interpretation of texts from nineteenth- and twentieth-century history, (London: Routledge, 2009), pp. 192-208 Virdi, Jaipreet, and Coreen McGuire, 'Phyllis M. Tookey Kerridge and the Science of Audiometric Standardisation in Britain', British Journal for the History of Science, 51.1 (2018), 123-146 
Vogel, Wolfgang H., and Andreas Berke, Brief History of Vision and Ocular Medicine (Amsterdam: Wayenborgh Publishers, 2009)

Waddington, Ivan, 'The Movement Towards the Professionalisation of Medicine', British Medical Journal, 301.6754 (1990), 690

Waddington, Keir, 'Mayhem and Medical Students: Image, Conduct, and Control in the Victorian and Edwardian London Teaching Hospital', Social History of Medicine, 15.1 (2002), 45-64

Wear, Andrew, Medicine in Society, ed., (Cambridge: Cambridge University Press, 1992)

Weisz, George, Divide and Conquer: A Comparative History of Medical Specialisation (New York: Oxford University Press, 2006)

Weller, Toni, ed., History in the Digital Age (London: Routledge, 2013)

Whipple, Robert S., 'John Yarwell, or the Story of a Trade Card', Annals of Science, 7 (1951), 62-69

Williams, Kevin, Read All About It!: A History of the British Newspaper (London: Routledge, 2010)

'William Mackenzie Medal', British Journal of Ophthalmology, 12.12 (1928), 648649

Willis, Martin, Vision, Science and Literature, 1870-1920: Ocular Horizons (London: Pickering \& Chatto, 2011)

Winkler, Wolf, ed., A Spectacle of Spectacles: Exhibition Catalogue (Leipzig: Edition Leipzig, 1988)

Withey, Alun, Self-Fashioning and Politeness in Eighteenth-century Britain: Refined Bodies (Basingstoke: Palgrave Macmillan, 2016)

Woolgar, Christopher Michael, The Senses in Late Medieval England (London: Yale University Press, 2006)

\section{Online Resources and Websites}

Cosens, Ron, Collection of Cartes de Visite: http://www.cartedevisite.co.uk/moreinfo/downloads/ [accessed: 27 July 2018]

Handley, Neil, curator of the College of Optometrit's Museum: https://www.collegeoptometrists.org/the-college/museum/online-exhibitions/virtual-ophthalmicinstrument-gallery.html [accessed: 22 June 2018] 
Lloyd-Owen, D.C., 'British masters of Ophthalmology Series: II - Richard Middlemore (1804-1891), The British Journal of Ophthalmology, February 1920, 49-53 http://bjo.bmj.com/content/bjophthalmol/4/2/48.full.pdf [accessed: 18 April 2018]

McConnell, Anita, 'William Kitchiner', Oxford Dictionary of National Biography https://doi.org/10.1093/ref:odnb/15690 [accessed: 15/03/2018]

'Nineteenth Century Spectacles' but only in the context of design: https://www.college-optometrists.org/the-college/museum/online-exhibitions/virtualspectacles-gallery/nineteenth-century-spectacles.html [accessed: 22 June 2018]

'Ophthalmoscopes', https://www.college-optometrists.org/thecollege/museum/online-exhibitions/virtual-ophthalmic-instrumentgallery/ophthalmoscopes.html [accessed: 6 May 2018]

\section{Reviews}

Review of John M. Eyler, Sir Arthur Newsholme and State Medicine, 1885-1935 (Cambridge: Cambridge University Press, 1997), by Christopher Hamlin, Bulletin of the History of Medicine, 72.3 (1998), 564-566

Review of Bernard L. Herman, The Stolen House (London: University Press of Virginia, 1992), by Kim E. Wallace, Winterthur Portfolio, 27.4 (1992), 297-301 